\title{
Juventud y desigualdades en América Latina y el Caribe
}

Presentación: Pablo Vommaro

Florlenis Chévez Ponce | Iván Francisco Porraz Gómez | Luisina Castelli Rodríguez | María de los Ángeles Peña | Marialina García Ramos | Marvin Rodríguez Vargas | Melissa Villegas Quispe | Paola Viera Córdova | Vanina van Raap | Vivian Boza

Chacón | Yannet López Verdecia | Creación Colectiva/Tejidos del Viento | Bruna Rossi Koerich | Cecilia Millán La Rivera | Gianne Neves Oliveira | Arquímides Romero | Gonzalo Assusa 



\section{JUVENTUD Y DESIGUALDADES EN AMÉRICA LATINA Y EL CARIBE}


Juventud y desigualdades en América Latina y Caribe / Tejidos del Viento ... [et al.] ; prefacio de Pablo Vommaro. 1a ed. Ciudad Autónoma de Buenos Aires : CLACSO, 2016.

Libro digital, PDF (Estudios sobre desigualdades)

Archivo Digital: descarga y online

ISBN 9789877221893

1. Ciencias Sociales y Humanidades. 2. Juventud. 3. Desigualdad Social. I. Viento, Tejidos del II. Vommaro, Pablo, pref.

CDD 305.23

Otros descriptores asignados por la Biblioteca virtual de CLACSO: Juventud / Desigualdad / América Latina / Caribe / Estudiantes / Políticas públicas 
COLECCIÓN ESTUDIOS SOBRE LAS DESIGUALDADES

\section{JUVENTUD Y DESIGUALDADES EN AMÉRICA LATINA Y EL CARIBE}

Presentación : Pablo Vommaro

Florlenis Chévez Ponce | Iván Francisco Porraz Gómez | Luisina Castelli Rodríguez | María de los Ángeles Peña | Marialina García Ramos | Marvin Rodríguez Vargas | Melissa Villegas Quispe | Paola Viera Córdova | Vanina van Raap | Vivian Boza Chacón | Yannet López Verdecia | Creación Colectiva/ Tejidos del Viento | Bruna Rossi Koerich | Cecilia Millán La Rivera | Gianne Neves Oliveira | Arquímides Romero | Gonzalo Assusa

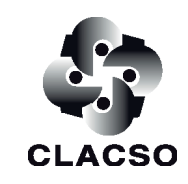




\section{CLACSO 50 AÑOS}

Consejo Latinoamericano de Ciencias Sociales

Estudios sobre desigualdades

Director de la Colección: Pablo Gentili

\section{CLACSO - Secretaría Ejecutiva}

Pablo Gentili - Secretario Ejecutivo

Nicolás Arata - Director de Formación y Producción Editorial

Núcleo de producción editorial y biblioteca virtual:

Lucas Sablich - Coordinador Editorial

Núcleo de diseño y producción web:

Marcelo Giardino - Coordinador de Arte

Sebastián Higa - Coordinador de Programación Informática

Jimena Zazas - Asistente de Arte

Rosario Conde - Asistente de Programación Informática

Creemos que el conocimiento es un bien público y común. Por eso, los libros de CLACSO están disponibles en acceso abierto y gratuito. Si usted quiere comprar ejemplares de nuestras publicaciones en versión impresa, puede hacerlo en nuestra Librería Latinoamericana de Ciencias Sociales.

Biblioteca Virtual de CLACSO www.biblioteca.clacso.edu.ar

Librería Latinoamericana de Ciencias Sociales www.clacso.org.ar/libreria-latinoamericana

\section{CONOCIMIENTO ABIERTO, CONOCIMIENTO LIBRE.}

\section{Primera edición}

Juventud y desigualdades en América Latina y el Caribe (Buenos Aires: CLACSO, junio de 2017)

ISBN 978-987-722-189-3

(c) Consejo Latinoamericano de Ciencias Sociales I Queda hecho el depósito que establece la Ley 11723.

\section{CLACSO}

Consejo Latinoamericano de Ciencias Sociales - Conselho Latino-americano de Ciências Sociais

Estados Unidos 1168 I C1023AAB Ciudad de Buenos Aires I Argentina

Tel [54 11] 43049145 I Fax [54 11] 43050875 I <clacso@clacsoinst.edu.ar> I <www.clacso.org>

No se permite la reproducción total o parcial de este libro, ni su almacenamiento en un sistema informático, ni su transmisión en cualquier forma o por cualquier medio electrónico, mecánico, fotocopia u otros métodos, sin el permiso previo del editor.

Patrocinado por la Agencia Noruega de Cooperación para el Desarrollo Norad 


\section{ÍNDICE}

Presentación : Pablo Vommaro

La producción y reproducción de desigualdades sociales en las prácticas de aulas costarricenses mediante el currículo oculto Florlenis Chévez Ponce

En los márgenes de la securitización. Ser joven migrante del sur en el siglo XXI

Iván Francisco Porraz Gómez

Producción de desigualdades entre jóvenes rurales: relaciones intergeneracionales, normativa y desarrollo agroindustrial Luisina Castelli Rodríguez

Reflexiones sobre experiencia investigativa Jóvenes estudiantes de la Universidad Indígena de Venezuela María de los Ángeles Peña

La tribu en peso: rastafari por fuera ¿y por dentro?

Intereses diversos, una meta común: el diálogo político colaborativo en Costa Rica Marvin Rodríguez Vargas

Jóvenes rurales y sus tránsitos postsecundarios: un estudio de caso en Perú Melissa Villegas Quispe

El caso de las y los jóvenes aspirantes a la educación superior pública como reflejo de la estructura social de desigualdad en Ecuador 
Juventudes y desigualdades en la Argentina: Notas para el debate en torno a la construcción de la problemática juvenil

Vanina van Raap

Tensiones juveniles como respuesta a la desigualdad social

Vivian Boza Chacón

Apuntes teóricos para el análisis de la desigualdad social en América Latina y su efecto en la juventud

Yannet López Verdecia

Jóvenes en CreAcción, aprendizajes desde

el acompañamiento psicosocial

Creación Colectiva/Tejidos del Viento

Ampliação no campo de possibilidades de jovens em vulnerabilidade social: a experiência da casa das juventudes

Bruna Rossi Koerich

Segmentación escolar: posiciones de profesores de escuelas secundarias en Chile*

Cecilia Millán La Rivera

Jovens no Brasil: a interface vídeo, juventude e projetos socias Gianne Neves Oliveira

Transición hacia el Estado comunal y políticas públicas de juventud en la Venezuela del siglo XXI: apuntes críticos desde la filosofía política de Simón Rodríguez Arquímides Romero

Jóvenes y clases sociales en el post-neoliberalismo

Gonzalo Assusa 


\title{
INTRODUCCIÓN ${ }^{1}$
}

\author{
Pablo Vommaro²
}

Este libro reúne los trabajos elaborados a partir de la experiencia que las autoras y los autores compartieron en la Escuela Internacional "Juventud y desigualdad en América Latina y el Caribe" que se realizó en el marco del Programa de Estudios sobre la Pobreza y la Desigualdad de CLACSO en Tegucigalpa, Honduras, entre el 22 y el 26 de junio de 2015, coorganizada por la Universidad Nacional Autónoma de Honduras (UNAH), con apoyo de la Agencia Noruega de Cooperación para el Desarrollo (NORAD).

El Programa de Estudios sobre la Pobreza y las Desigualdades, como parte del cual se realizó la Escuela y se publica este libro, es desarrollado por CLACSO y apoyado por NORAD. Las y los participantes de la Escuela -autoras y autores de los diversos capítulos de esta obra- fueron seleccionados a través de un concurso público e internacional luego de pasar por un riguroso proceso de evaluación. De los 35 participantes que tuvo la Escuela ( 23 mujeres y 12 varones provenientes de 14 países), 20 presentaron trabajos finales en condiciones de ser publicados. Es de destacar que estos participantes articularon en un mismo encuentro al menos tres espacios que no suelen coincidir y trabajar multilateralmente: tesistas de posgrado (maestría y doctora-

1 Agradezco la colaboración de Lucas Sablich e Isidora González en la elaboración de estas páginas.

2 Posdoctor en Ciencias Sociales, Niñez y Juventud (CINDE-Universidad de Manizales, COLEF, PUCSP y CLACSO); Doctor en Ciencias Sociales (UBA); Profesor de Historia (UBA). Director de Investigación de CLACSO. 
do), decisores de políticas públicas e integrantes y referentes de organizaciones sociales. Esta es una de las singularidades de las Escuelas que organizamos desde CLACSO. Reunir personas de espacios diversos que están trabajando temas similares para producir conocimientos de manera colectiva y participativa, desde las experiencias y las prácticas concretas, reconociendo diferentes saberes y propuestas y generando impactos e incidencias directas y situadas.

Este fue el marco en el que se produjo este libro que reúne 20 rigurosos artículos de investigaciones y experiencias elaborados por las y los participantes de la Escuela que abordan las múltiples dimensiones en las que se expresan las desigualdades sociales en América Latina y el Caribe enfatizando en la generacional.

\section{ACERCAMIENTO A LAS DESIGUALDADES GENERACIONALES}

En América Latina las juventudes se encuentran atravesadas por dos características fundamentales: desigualdades y diversidades. Por ejemplo, los cambios producidos en las últimas décadas las presentan como generación cada vez más educada y participativa, a la vez que no siempre considerada adecuadamente por las políticas públicas. Asimismo, ganan espacios en el mercado laboral, pero sus condiciones de trabajo están más degradadas y precarizadas. Según diversos informes, situaciones como el desempleo o la pobreza se duplican o triplican en este segmento, que no solo atraviesan desigualdades materiales, sino también étnicas, sexuales y de género, territoriales, culturales, educativas, laborales, políticas y religiosas, entre otras.

La desigualdad es una noción que permite reflexionar acerca de procesos relacionales, sobre todo en dos sentidos. Por un lado, aquellos donde los colectivos juveniles hacen hincapié en el derecho a la diferencia ó dan cuenta de cuando ésta se convierte en desigualdad y parece legitimarla. Por el otro, las dinámicas generacionales de producción y reproducción de las desigualdades y de construcción de igualdades de la diferencia. Pensamos que estos son dos de los aspectos más significativos de los procesos actuales de cambio social en la región, con inflexiones generacionales (Vommaro, 2017).

Pensar las desigualdades en clave generacional implica considerar las diversidades juveniles. Entonces, promover políticas hacia la igualdad conlleva incluir la diferencia y avanzar hacia la construcción de lo común en ese contexto. Proponemos como necesario indagar en el despliegue de estrategias repensando la noción de política pública (hacia lo público no estatal) y explorar procesos de producción universales, no unívocos ni homogéneos.

Para avanzar en el abordaje de las desigualdades sociales a partir de intersecciones generacionales y otras que tienen que ver con géne- 
ro, migraciones, cuestiones étnicas, culturales, educativas, laborales, territoriales, entre otras podríamos afirmar que aquellas son multidimensionales. De ese modo ha sido trabajado por diversos autores en la actualidad (Reygadas, 2004; Kessler, 2014; Pérez Sainz, 2014; Dubet, 2015 y Therborn, 2015). No podríamos hablar de una desigualdad unidireccional o unidimensional, solamente socioeconómica, por ingresos, que es la más clásicamente estudiada, o una vinculada solo con posiciones de clase.

Sin duda, a nivel estructural vemos posiciones de clase que signan las desigualdades, las estructuran y de cierta forma las determinan. Pero, sin dudas, también hoy es necesario asumir su multidimensionalidad.

Es indudable también que en los últimos años se ha instalado este problema en la agenda pública, tanto a nivel mediático, como político y académico. Lo interesante es hacer un ejercicio para pensar cómo se construye un problema social, a fin de que ingrese en la agenda pública, tanto en la de los medios, en la de la investigación, en la de las políticas , como en la de los colectivos, movimientos y organizaciones sociales ${ }^{3}$.

En este sentido, partiendo de análisis como los de Gentili (2015) o Dubet (2015), podemos pensar en los dispositivos de producción pública de los pares conceptuales desigualdad/pobreza y desigualdad/exclusión. Así, mientras la noción de pobreza es más estática, la de desigualdad permite un abordaje más relacional porque siempre está hablando en su vínculo con otro. No es un estado fijo. Algo similar sucede con el par desigualdad/exclusión. En los últimos años se ha debilitado el paradigma inclusión/exclusión, que predominó en décadas pasadas para guiar tanto estudios sociales como políticas públicas.

El avance del paradigma de las desigualdades sociales generó, a su vez, muchos estudios sobre procesos de "inclusión excluyente" o "exclusión excluyente", nociones utilizadas para caracterizar las expresiones sociales de la ampliación de derechos impulsada a partir de programas estatales. Estos fueron particularmente identificables en los orientados por las llamadas transferencias condicionadas, especialmente significativos en países como Argentina, Brasil, Ecuador o Boli$v a^{4}$. Por razones de espacio, no profundizaremos en estas cuestiones.

3 Para ampliar estos análisis se puede consultar a autores como Bourdieu (1990 y 2007) o Lenoir (1979 y 2000), quien en parte sigue y profundiza sus propuestas.

4 Nos referimos a los programas de transferencias condicionadas (PTC, según CEPAL) o los programas de transferencias monetarias condicionadas (PTMC, según el BID-BM) que adoptaron formas singulares en cada uno de los países mencionados. Entre los principales en cada caso, destacamos la Asignación Universal por Hijo, creado en 2009 en la Argentina; el Bono Juancito Pinto, implementado en 2006 en Bolivia; la Bolsa Familia, impulsada desde 2003 en Brasil; el Bono de Desarrollo Humano, que se aplica desde 2003 en Ecuador. 
Pensamos las desigualdades como dinámicas, situadas, productos sociohistóricos que se configuran en una territorialidad, con procesos sociales y relacionales, no autocentradas o autodefinidas.

Es posible ampliar este enfoque desde las propuestas formuladas por Dubet (2015), quien plantea que existen tres tipos de desigualdades: por acceso (por acceso a un bien, a un servicio, a la salud, al ocio, a la recreación); por oportunidades (relacionadas con el punto de partida de un individuo o grupo) y las de posiciones (que serían más estructurales, porque se vinculan justamente con la situación socioeconómica de los individuos y los grupos sociales).

Desde enfoques materialistas como el que aquí seguimos podríamos pensar que las desigualdades de posiciones son las más significativas. Sin embargo, es interesante incorporar las dimensiones múltiples que surgen a partir del enfoque de las oportunidades. Podríamos, con Dubet, pensar la intersección entre estos tres tipos para construir, si acordamos que las desigualdades son multidimensionales, un abordaje complejo que dé cuenta de ese carácter multidimensional.

Varios autores latinoamericanos como Kessler (2014), Reygadas (2004), Gentili (2015) y Pérez Sainz (2014), plantean estas cuestiones como paradojas o tendencias contrapuestas. Es decir, al pensarlas de modo relacional, proponen abordarlas también en sus ambivalencias, tensiones. Ellos sostienen, en coincidencia con cifras de la CEPAL (2012) o el BID-BM (2013), que en América Latina en los últimos quince o veinte años se produjo un fuerte crecimiento económico con diversidades o desigualdades entre los diferentes países y al interior de los mismos.

Es decir que la mejora de los indicadores sociales no fue igualmente beneficiosa para todos los Estados y grupos sociales. En muchos aspectos, América Latina sigue mostrando desigualdades sociales que no tienen que ver exclusivamente con los niveles de ingreso y que afectan a poblaciones en condiciones particularmente críticas, destacándose la situación de las mujeres -que mejoran sus niveles de vida, pero en menor medida que los varones-, los jóvenes -que lo hacen menos que los adultos- $\mathrm{y}$ los diversos grupos étnicos (indígenas y afrodescendientes o negros, en particular) que, aunque tienen mejores condiciones relativas que antes, muestran indicadores considerablemente más bajos que los de la población blanca y mestiza (Vommaro, 2017a).

Este libro pone el foco en la situación de los jóvenes, que no en todos los aspectos supera la registrada en las décadas pasadas. Los estudios relevados siguen mostrando un conjunto complejo y preocupante de paradojas y contrastes, junto con un profundo malestar social, evidente en las irrupciones de movimientos juveniles que hasta no hace mucho tiempo permanecían poco visibles en el espacio público y que en los últimos años han ocupado calles y plazas en lucha por diversos 
temas, no siempre considerados específicamente juveniles como, por ejemplo, educación pública, gratuita, democrática y de calidad.

Se configura así una coyuntura en la cual, a pesar de las mejoras descritas, de la baja de los índices de pobreza y de los avances en otros indicadores, las desigualdades sociales persisten. Por ejemplo, si bien la posición social relativa de las mujeres es mejor que la de hace cincuenta años, las desigualdades de género persisten. Es decir, no alcanza sólo con la mejoría de los índices, sino que muchas veces es necesario cambiar el enfoque para explicar el proceso por el cual, aunque muchos indicadores han mejorado, las desigualdades continúan.

Algo similar sucede con los jóvenes, que han aumentado su presencia social y su posición en el sistema educativo, en la fuerza de trabajo, en los espacios de participación. Sin embargo, las desigualdades generacionales son de las más agudas y persistentes en la región (CEPAL, 2014).

Queda claro que solo desde los enfoques basados en la inclusión y el combate a la pobreza no alcanza para contrarrestarlas .

Pensamos que ante estas limitaciones conceptuales y políticas y considerando las evidencias empíricas expuestas, hace falta complejizar los enfoques y abordar las desigualdades desde sus paradojas, desde sus tendencias contrapuestas y ambivalentes (Kessler, 2014).

Para continuar esta perspectiva, los autores que aquí trabajamos contribuyen a pensar en los mecanismos de producción y reproducción social de las desigualdades, en los dispositivos de perpetuación de estas. Más que abordar las expresiones o los índices, es necesario poner el foco en las formas de producción y reproducción social (Reygadas, 2004) y en los diversos modos en que las personas experimentan las desigualdades, en este caso desde la configuración generacional (Dubet, 2015; Chaves, Fuentes y Vecino, 2016).

Las cifras disponibles muestran que América Latina es el subcontinente más desigual del mundo. Si tomamos el índice de Gini (que, aunque tiene muchas limitaciones porque solo mide ingresos y distribución de renta, es reconocido por diferentes organismos internacionales), vemos que en el período 2003-2013 ha habido una mejora relativa general, que se produjo en algunos países más que en otros ${ }^{5}$. Sin embargo, esta mejora, como dijimos, no revierte las desigualdades. Inclusive, se agudizan si realizamos algunos cruces como el generacional.

Entre los jóvenes los índices sociales empeoran. Por ejemplo, el desempleo juvenil es el doble o el triple que el general, la pobreza juvenil duplica en muchos casos la general, en salud y en vivienda se produce una situación similar. Una vez más vemos que las desigualdades son

5 Para ampliar, consultar los Panoramas sociales producidos por CEPAL en 2014 y 2015. 
mucho más profundas entre los jóvenes que en otros grupos sociales.

Estos dos problemas -los modos de producción y reproducción social y las distintas formas de experimentar las desigualdades- se han planteado muchas veces desde la capacidad individual de superación de determinadas situaciones o la igualdad de oportunidades desde una mirada individualista. Nuestra perspectiva es relacional, holística, colectiva y propone considerar las estructuras sociales y partir de la multidimensionalidad, las tendencias contrapuestas, las paradojas y las ambivalencias que signan las desigualdades sociales.

Siguiendo con nuestro enfoque multidimensional e interseccional, si abordamos la situación -y las experiencias- de las mujeres jóvenes, el panorama empeora relativamente. Si dijimos que los jóvenes son los más afectados del subcontinente más desigual del mundo, las mujeres son las más desiguales entre los más olvidados del subcontinente. Sucede algo similar con las mujeres negras, indígenas, campesinas.

A partir de lo planteado, podríamos decir que las desigualdades en América Latina son generales, pero sobre todo, femeninas y jóvenes ${ }^{6}$.

Partiendo de estas multiplicidades, la noción de "experiencias de la desigualdad" que propone Dubet (2015) sostiene que no solo hay que pensar en las dimensiones relacional y estructural, sino también en la subjetiva; en los modos en que los individuos experimentan las desigualdades, en las maneras en las que los acontecimientos están incorporando la desigualdad a una experiencia de vida, a una subjetividad y a una construcción de individuación y subjetivación social. Serían subjetividades juveniles configuradas en la desigualdad.

Por otra parte, el protagonismo que han cobrado las juventudes en las dinámicas sociales y políticas de América Latina hizo más visible el despliegue de las propuestas y las movilizaciones de diversos colectivos juveniles en distintos países de la región. Esta acción contenciosa con marcas generacionales contribuyó al proceso de ampliación de derechos y consideración de las diversidades que vivió el subcontinente en los últimos años. Esto fue especialmente notorio en el ámbito educativo, aunque abarcó también otras esferas como la del género y las sexualidades o la étnica.

En definitiva, pensamos que es necesario producir trabajos que aporten a la comprensión de las actuales cartografías de las desigualdades sociales que atraviesan a las juventudes latinoamericanas, considerando sus diversidades como configuradoras de potencias hacia la igualdad. Esta es parte de la intención de la voluminosa obra que aquí presentamos.

6 Algo similar podríamos plantear con las violencias y las inseguridades, aunque no profundizaremos esta cuestión aquí. 


\section{EL LIBRO}

Avanzando en los contenidos de la obra, presentaremos a continuación los capítulos que la componen.

En primer lugar, Florencia Chévez Ponce enfatiza en la necesidad que existe en el ámbito educativo costarricense de reflexionar acerca de la práctica cotidiana en las aulas. Así, analizael denominado currículum oculto como una forma de producción y reproducción de desigualdades sociales entre los estudiantes. En su trabajo, las entrevistas en profundidad realizadas a docentes, los grupos de discusión con estudiantes y las observaciones de clases permitieron establecer que elementos como el lenguaje, el poder desplegado en el aula, el temor de los estudiantes, la interacción y comunicación docente-alumno y la imposición de pautas de trato y comportamiento son aspectos centrales que permiten analizar los dispositivos de reproducción de desigualdades sociales en el ámbito educativo.

El segundo capítulo corresponde a Iván Francisco Porraz Gómez. En él, el autor abre un abanico de campos temáticos y problemáticos sobre la migración internacional de los jóvenes desde el sur hacia el norte. Según su planteo, el fenómeno migratorio, vinculado a las dinámicas de auge y crisis de la economía de Estados Unidos, está instituyendo relaciones individuales y colectivas que exteriorizan problemas estructurales latentes y formas inéditas de respuestas ante los desafíos abiertos por la globalización. En estos procesos se condensan, además de violencias fácticas, mecanismos de producción y reproducción de las violencias. El análisis enfatiza el carácter sistémico de la violencia simbólica que sedimenta e internaliza, bajo el manto de la "libertad", las imágenes del mundo global.

Encontramos en tercer lugar el trabajo de Luisina Castelli Rodríguez, que explora la producción de desigualdades que afectan a las y los jóvenes de una localidad rural de Uruguay en base a un minucioso trabajo etnográfico. Analiza cómo incide en las trayectorias de vida de estos sujetos la trama construida en las últimas décadas por el desarrollo de las agroindustrias citrícola y forestal, la incorporación de normativa sobre empleo juvenil -con sus particularidades en el medio rural-y los cambios generacionales en los valores y los modos de vida.

Por su parte, María de los Ángeles Peña reflexiona acerca de la experiencia de jóvenes estudiantes de la Universidad Indígena de Venezuela a través de la deconstrucción de la noción hegemónica de juventud. Partiendo de la indagación en las formas en las que las y los jóvenes se definen así mismos en contextos de exclusión social y fuertes prejuicios hacia la pertenecía étnica, se analizan experiencias de mujeres indígenas jóvenes. Este artículo aporta una mirada vinculada a las dimensiones de género y al cruce entre género y generación, temas 
que necesitan ser abordados más profundamente en los estudios de juventudes en América Latina.

El cuarto trabajo corresponde a Marialina García Ramos quien estudia las prácticas del rastafarismo en La Habana, Cuba, a partir de la noción de "tribu", muy discutida en los estudios del campo. El movimiento rastafari es concebido como una agrupación juvenil surgida como espacio aglutinador que devuelve protagonismo y sentido de representatividad o distinción a los jóvenes que lo integran. La autora enfatiza en las dimensiones tribales y mediante los elementos simbólicos que los jóvenes apropian y reinventan, protagonizan prácticas cotidianas que reúnen, solidarizan y colectivizan sus experiencias como forma de resistencia a los procesos de segmentación social. La adscripción al imaginario "rasta", su correlato estético, sus significados, representaciones y valores asociados, refuerzan la autoestima de una juventud negra y mestiza enconcomitancia con las distinciones y oposiciones que, en la superposición raza-clase, emergen en la sociedad cubana actual en una coyuntura signada por procesos de diferenciación.

Marvin Rodríguez Vargas aborda la experiencia de la Asamblea de Trabajadores y Trabajadoras del Conglomerado Financiero Banco Popular y de Desarrollo Comunal de Costa Rica, enfocando en el diálogo político colaborativo como instrumento que, mediante el involucramiento de diversos sectores socioeconómicos con intereses interdependientes, promueve la construcción de consensos y la cooperación en torno a la formulación de políticas públicas. En el trabajo se resalta la situación de fragmentación del sistema de partidos políticos, la erosión de las lealtades partidarias y el deterioro de su rol decanalizadores de las demandas juveniles -y ciudadanas- hacia el Estado.

El trabajo de Melissa Villegas Quispe se basa en una investigación acerca de jóvenes rurales del Perú y sus transiciones en la educación postsecundaria. En los hallazgos se da cuenta de un contexto rural cambiante, donde la aparición de nuevas instituciones educativas configura un panorama de oportunidades para las recientes generaciones. En esta situación, resulta importante conocer las múltiples relaciones que se entablan entre juventudes y ámbitos educativos, específicamente en cuanto a oportunidades de acceso y terminalidad de la educación secundaria así como posibilidades y limitaciones en el tránsito hacia la instanciaspostsecundarias. Este trabajo aborda una cuestión poco trabajada para contextos rurales como es el tránsito a ámbitos educativos superiores en las juventudes rurales. Estudiar estos procesos es fundamental a la hora de abordar sus estrategias de vida y las posibilidades de desarrollo de estos jóvenes en sus comunidades locales.

En el capítulo siete se ubica el texto de Paola Viera Córdova que se propone explicar los mecanismos de reproducción de las desigual- 
dades en el Ecuador tomando el caso de las y los jóvenes que rinden el Examen Nacional para la Educación Superior (ENES) para ingresar a la universidad. La investigación analiza la relación sociológica entre condiciones sociales de origen de los aspirantes, acumulación de capitales y oportunidades, éxito educativo, expectativas de futuro, movilidad social y estrategias emocionales para enfrentarse al proceso de ingreso a las universidades como experiencia productora de desigualdades.

El trabajo de Vanina Van Raap cuestiona, a partir del caso argentino, el rol que asumen las políticas sociales para jóvenes en cuanto a las posibilidades que tienen para operar sobre las desigualdades sociales y promover genuinos mecanismos de inclusión social. En este marco, se plantean interrogantes y reflexiones sobre la orientación de las políticas públicas para jóvenes en la Argentina de los últimos años problematizando el carácter cuestionador e innovador de las mismas. Por otra parte, el texto analiza críticamente la emergencia de la cuestión juvenil y los diagnósticos hegemónicos sobre los cuales se construye la juventud como un problema social que requiere ser gobernado desde las políticas públicas.

Viviana Boza Chacón, por su parte, aborda las prácticas de las y los jóvenes de unazona rural-costera de Costa Rica y se enfoca en las situaciones cotidianas en las que se construyen estigmas, etiquetas, estereotipos e imaginarios sociales que reproducen las formas hegemónicas y heteronormativas de vida. Este análisis abre sugestivos cuestionamiento acerca de las manetas en las que se construyen las trayectorias de vida de las y los jóvenes de zonas rurales-costeras, enfatizando en las tensiones que se producen en estos procesos. De esta manera, el texto aborda las realidades cotidianas que son invisibilizadas por la opresión del patriarcado y el adultocentrismo.

El décimo trabajo que compone esta obra es el de Yannet López Verdecia, quien da cuenta de las experiencias vividas en la propia Escuela que dio origen a estos textos, enfocándose en la desigualdad social vista como producto de una hibridación entre su tematización teórica y las percepciones actuales configuradas desde diversas miradas. Así, la academia, los centros generadores de políticas y las diversas instituciones y organizaciones sociales son analizados para desentrañar los sentidos que atribuyen a las desigualdades y que configuran el modo de construcción social del problema. Al abordar las contribuciones teóricas para la comprensión de la desigualdad social en América Latina considerando la gestación del problema en el campo académico, la autora también se ocupa de las resonancias que esto genera en las juventudes. Así, en este trabajo la desigualdad social resulta expresión de la diversidad social que vive hoy las contracciones de la sociedad actual; lo cual desde las juventudes es sentida en diversas dimensiones 
como la desigualdad racial, de género, territorial, además de económica, política y social.

El colectivo Tejidos del Viento expone el proyecto generado para dar cumplimiento a la política gubernamental colombiana formulada desde la Secretaría de Cooperación y Enlace Institucional. Esta comenzó como una estrategia de intervención psicosocial directa que se desplegó en la comunidad víctima del conflicto armado de los municipios de Viotá y La Palma (Cundinamarca), debido a las secuelas e impactos causados por la guerra en la sociedad colombiana. Con apoyo de las alcaldías municipales de los mencionados poblados, Tejidos del Viento diseñó, planificó y llevó a cabo el proyecto de acompañamiento psicosocial Telares de vida: construcciones itinerantes. La propuesta se proyectó en cuatro fases con diferentes grupos poblacionales; entre las cuales en este texto se enfoca en el trabajo desarrollado con jóvenes rurales para visibilizar el impacto psicosocial de la guerra prolongada.

El trabajo de Bruna Rossi Koerich reflexiona acerca de la aplicación reciente de políticas públicas destinadas a generar planes para la prevención de la criminalidad y la mortalidad juvenil en el sur de Brasil. Se enfoca en las juventudes que habitan las periferias urbanas, a las que caracteriza como vulnerables, para interpretar una propuesta de intervención directa que se propuso ampliar las posibilidades de vida de estos jóvenes. En el artículo se consideran las trayectorias juveniles producidas en un marco de vulnerabilidad y enfocadas desde la noción de "campo de posibilidades" para dar cuenta de sus cambios y movimientos a partir de la participación en un programa de política pública específico.

En su trabajo, Cecilia Millán La Rivera aborda la problemática de la segregación escolar en los colegios secundarios de Chile y sus grados de complejidad reflejados en las tensiones y limitaciones institucionales que tiene la escuela y las dificultades de los profesores para enfrentar las diversidades que caracteriza la vida en las aulas en la actualidad. El trabajo se centra en los aspectos cultural y simbólico como factores que producen o contrarrestan las desigualdades educativas. El análisis se centra en las posiciones de los docentes de escuelas secundarias en tanto productores de vivencias de segregaciones y segmentaciones educativas que son interpretadas como parte de las dinámicas desiguales que caracterizan la sociedad chilena.

El texto de Gianne Neves Oliveira se propone promover una reflexión sobre las formas en las que los jóvenes brasileños egresados de proyectos sociales de comunicación audiovisual ingresan a la vida adulta. A través del análisis de proyectos desarrollados por la ONG Centro de Creación de Imagen Popular se reconstruye el relato de vida de los jóvenes egresados de estos proyectos en la denominada Baixada Flumi- 
nense, con datos que contribuyen a la reflexión sobre las posibilidades del accionar de las ONGs en estas trayectorias, teniendo en cuenta sus limitaciones en cuanto a duración, alcances y posibilidades de dar continuidad a los trabajos que emprenden en contextos adversos.

Arquímedes Romero indaga en el anteúltimo capítulo acerca de las políticas públicas venezolanas y la transición que el autor caracteriza como inconclusa hacia la conformación de un Estado comunal desde una perspectiva vinculada a la filosofía política de Simón Rodríguez. $\mathrm{El}$ autor sostiene que entender estas dimensiones es vital para abordar los procesos de creación de políticas públicas con perspectiva generacional y protagonismo juvenil. Asimismo, enfatiza en el protagonismo que ha tenido la juventud en el proceso político venezolano reciente y su potencial transformador desde la innovación.

Gonzalo Assusa cierra el libro abordando las problemáticas juveniles desde la perspectiva de las desigualdades de clase en América Latina y el Caribe. Para ello, analiza la distribución desigual de recursos de poder social entre jóvenes de los suburbios de la provincia de Córdoba, Argentina, y sus dificultades para incorporarse al mercado laboral. De esta manera, estudia el impacto de esta situación en sus familias, así como también los avances y limitaciones que se encuentran en las políticas públicas de juventud en el plano laboral, tanto para la identificación de problemáticas como para la intervención concreta.

Finalizamos esta introducción agradeciendo especialmente a Julieta Castellanos, Leticia Salomón y el equipo de la UNAH que recibió la Escuela y contribuyó a su desarrollo, creando siempre un clima de trabajo productivo y confortable. Asimismo, queremos reconocer también a Fabiana Espíndola (Uruguay), Carlos Ramos (El Salvador) y María Isabel Domínguez (Cuba), quienes coordinaron los talleres que funcionaron en la Escuela, orientaron y evaluaron los trabajos que componen esta obra.

Los dejamos entonces con los autores y sus trabajos, seguros de que encontrarán en la trama de este extenso libro aportes, preguntas y pistas para seguir trabajando acerca de las condiciones de vida, las formas de producción y las maneras en las que las juventudes despliegan sus propuestas en una situación de desigualdad multidimensional que las atraviesa.

\section{BIBLIOGRAFÍA}

BID-BM 2013 La movilidad económica y el crecimiento de la clase media en América Latina (Washington: Banco Mundial,).

Bourdieu, P. 2007 “Espíritus de Estado. Génesis y estructura del campo 
burocrático" en Razones prácticas. Sobre la teoría de la acción (Barcelona: Anagrama).

Bourdieu, P. 1990 “La 'juventud' no es más que una palabra” en Sociología y cultura (México: Grijalbo).

CEPAL 2012 Balance preliminar de la economía en América Latina y el Caribe 2012 (Santiago de Chile).

CEPAL 2014 Panorama Social de América Latina (Santiago de Chile).

CEPAL 2015 Jóvenes que no estudian ni están empleados en América Latina y el Caribe (Santiago de Chile). Disponible en: http://www.cepal. org/es/infografias/jovenes-que-no-estudian-ni-estan-empleados-enamerica-latina-y-el-caribe

Dubet, F. 2015 ¿Por qué preferimos la desigualdad? (aunque digamos lo contrario) (Buenos Aires: Siglo XXI).

Gentili, P. 2015 América Latina, entre la desigualdad y la esperanza. Crónicas sobre educación, infancia y discriminación (Buenos Aires: Siglo XXI).

Kessler, G. 2014 Controversias sobre la desigualdad: Argentina, 2003-2013 (Buenos Aires: Fondo de Cultura Económica).

Lenoir, R. 1979 «L'invention du «troisièmeâge»» en Actes de la recherche en sciences sociales. Vol. 26-27, mars-avril, pp. 57-82.

Lenoir, R., (2000) «Savoirs et sciences d'État: généalogie et démographie» en Actes de la recherche en sciences sociales, $\mathrm{N}^{\circ} 133$. Pp. 96-97.

Pérez S., Juan P. 2014 Mercados y bárbaros. La persistencia de las desigualdades de excedente en América Latina (Costa Rica: FLACSO).

Reygadas, L. 2004 Las redes de la desigualdad: un enfoque multidimensional (México: UAM).

Segura, R. 2015 Vivir afuera. Antropología de la experiencia urbana (Buenos Aires: UNSAM).

Vommaro, P. 2017 “Territorios y resistencias: configuraciones generacionales y procesos de politización en Argentina con perspectiva latinoamericana" en Iztapalapa. Revista de Ciencias Sociales y Humanidades (México: UAM-I).

Vommaro, P. 2017a "Hacia los enfoques generacionales e intergeneracionales: tensiones y perspectivas en las políticas públicas de juventud en América Latina" en Revista Latinoamericana de Estudios de Familia (Manizales: U. de Caldas). 


\title{
LA PRODUCCIÓN Y REPRODUCCIÓN DE DESIGUALDADES SOCIALES EN LAS PRÁCTICAS DE AULAS COSTARRICENSES MEDIANTE EL CURRÍCULO OCULTO
}

\author{
Florlenis Chévez Ponce*
}

\section{INTRODUCCIÓN}

En Costa Rica, el Tercer Informe del Estado de la Educación (2011) propone que se debe asegurar el derecho a la educación, al plantear principios fundamentales como la necesidad de una educación con equidad y sin exclusiones para la población joven. Sin embargo, en el sistema educativo costarricense, se identifican problemas como la desigualdad social, la inequidad, la segregación, la vulnerabilidad, la violencia, la deserción y la repitencia. En esta investigación se consideran aspectos que convergen en las relaciones que se generan entre el cuerpo docente y estudiantes, durante el desarrollo del currículo explícito y lo que ocurre ocultamente en la práctica de aula.

En el ámbito educativo costarricense, se puede indicar que "la escolaridad de las personas pobres está creciendo, pero la brecha entre su logro educativo y el de los no pobres se ha ampliado" (Estado de la Nación en Desarrollo Humano Sostenible, 2012: 119). También se ha demostrado que la escolaridad para estudiantes en situación de pobreza no es suficiente para salir de esta condición. Al referirse a la educación

\footnotetext{
* Master en Planificación Curricular, estudiante del Programa Latinoamericano de Doctorado en Educación de la Universidad de Costa Rica, asesora nacional de Estudios Sociales en el Ministerio de Educación Pública de Costa Rica. florlenis@gmail.com
} 
secundaria, en relación con el tema de la exclusión y el abandono escolar, se han identificado factores como "problemas con los docentes, temor a los exámenes, fallas pedagógicas y falta de una transición adecuada a sétimo" año. (Gaete y Jiménez, 2013: 113).

En todos los niveles educativos del sistema educativo costarricense se desarrolla un currículo oficial y explícito mediante los objetivos, los contenidos, las actividades y la evaluación que se lleva a cabo en las aulas. Con esta práctica se pretende alcanzar los fines de la educación costarricense e impactar los procesos de enseñanza y aprendizaje desarrollados en las prácticas de aula. Además, en la interacción que surge durante las lecciones aparecen también otras prácticas que influyen en la población estudiantil. Estas se manifiestan mediante el currículo oculto. Al respecto, Torres (1991) indica que este tipo de currículo hace referencia a enseñanzas que se imparten en la escuela, sin que estén registradas o reflejadas en ningún documento, ni formen parte de algún plan o asignatura en particular pero que sirven para perpetuar las relaciones desiguales entre las personas.

De acuerdo con Torres, ejemplos de currículo oculto, se presentan en la asignación de roles de género que se establecen en las aulas, al tratar de forma diferenciada a hombres y mujeres; esperar más de unos alumnos que de otros y otro tipo de prácticas mediante las cuales sin intención explícita por parte del educador se reproduce el status quo. Por su parte, el autor Van (2006) señala que las interacciones entre docentes y estudiantes en las prácticas de aula se cargan cada día de prejuicios que cierran los espacios para la aceptación, la tolerancia, la diversidad y la inclusión.

Por su parte Jackson (2010) señala que los centros educativos -en especial el aula- se convierten en un espacio donde el estudiantado aprueba o reprueba exámenes, pasa un tiempo divertido, tropieza con nuevas perspectivas y adquiere destrezas; pero, a la vez, se sientan, escuchan, aguardan, alzan la mano, entregan un papel y hacen fila; en fin, se vivencia una serie de relaciones con quienes forman su grupo de clase.

La problemática de las desigualdades sociales en relación con el currículo oculto desarrollado en las prácticas de aula es un tema que merece especial atención, ya que el sistema educativo y específicamente el educador "se encarga de transformar las diferencias y desigualdades extraescolares en desigualdades reales de aprendizaje o de capital cultural" (Nieves, 2000: 190). De manera que la escuela ha sostenido las desiguales reales mediante la cultura enseñada y exigida. 


\subsection{REFERENTES CONTEXTUALES DE LA INVESTIGACIÓN}

El sistema educativo costarricense, se propone favorecer el eficaz y dinámico cumplimiento de los objetivos del proceso educativo coordinando los distintos niveles que lo integran: educación preescolar, educación general básica y educación diversificada. Para orientar en estos niveles educativos, se aprobó la Política Educativa Hacia el Siglo XXI en 1994, la cual enfatiza que la educación, entre otros propósitos, debe buscar la movilidad social que caracterizó al sistema educativo en períodos anteriores. También subraya como fin educativo disminuir las brechas que existen entre áreas rurales y urbanas, entre instituciones marginales y no marginales, y entre quienes asisten a instituciones de educación pública o privada.

En Costa Rica, "en secundaria, los años críticos para la reprobación (al igual que en el caso de la exclusión) siguen siendo el sétimo y el décimo, es decir, los que marcan la transición entre ciclos" (Segundo Informe del Estado de la Educación, 2008: 56). El sétimo año se convierte en un espacio clave para investigar la reproducción de las desigualdades a partir del currículo oculto pues no solamente marca la transición entre ciclos sino también un fuerte cambio en las prácticas educativas de las instituciones al pasar del II al III Ciclo, o, de la primaria a la secundaria.

Con respecto a la estructura curricular en secundaria esta "no cambia desde los años setenta y tiene notables desequilibrios entre contenidos y actividades, poca articulación entre ciclos y materias, y una aplicación homogénea y descontextualizada" (Tercer Informe del Estado de la Educación, 2011, : 45). Asimismo, Garnier, Wachong y Mora (2010) plantean que, en Costa Rica, el 56\% de la población estudiantil que deserta en la educación secundaria corresponde a sétimo año. Los aspectos anteriores evidencian una situación problemática que requiere de mayor análisis para identificar sus consecuencias en relación con la producción y reproducción de desigualdades sociales en las prácticas de aula en la juventud costarricense y extranjeros que asisten a este año escolar.

\subsection{PROBLEMA DE INVESTIGACIÓN}

En educación, los diversos países de América Latina orientan las políticas educativas a que toda la población con edad escolar tenga acceso y permanezca en los centros educativos. No obstante, aspectos como la pobreza, la exclusión, el trabajo infantil o situación de riesgo en que se encuentra la juventud, se convierten en elementos generadores de limitaciones para su permanencia en el sistema educativo (Gutiérrez y Puentes, 2009).

En Costa Rica, el Tercer Informe del Estado de la Educación 2011 muestra que, en el sistema educativo, se torna conflictiva la permanen- 
cia del estudiantado en los centros de enseñanza e indica que, entre los aspectos que tienen influencia en esta problemática, están los siguientes: relación con personal docente y otros actores de la comunidad educativa, la metodología de enseñanza que se utiliza en las lecciones y el acceso o no a programas de apoyo como becas estudiantiles.

El Informe Regional sobre Desarrollo Humano para América Latina y el Caribe (2010) señala que, en Costa Rica, en la educación secundaria, la problemática de las desigualdades sociales es grave, ya que solamente un 49,3\% de jóvenes que ingresan a este nivel educativo logra graduarse.

En el contexto costarricense, se identifica la omisión de exploraciones que ahonden en el estudio del desarrollo del currículo en las instituciones educativas, para entender qué sucede en las prácticas de aula, por lo que ha quedado fuera de la investigación la cotidianidad de las interacciones que se generan en el aula. Así, el discurso subyacente a las medidas globales adoptadas en el país ha invisibilizado la práctica de aula como eje de investigaciones.

Fernández (2003) recomienda que sea necesario que en las investigaciones, para el estudio de las desigualdades sociales en el campo educativo; se incorporen las dimensiones curriculares, didácticas y pedagógicas. Por ello, se debe buscar la integración del proceso pedagógico de cada centro educativo y, más específicamente, en cada aula, donde el personal docente tiene la máxima responsabilidad.

Por consiguiente, estos elementos son relevantes para enfatizar estas prácticas como eje central para el estudio de las desigualdades sociales en educación en el ámbito educativo costarricense.

Respecto a ahondar en los procesos de investigación en que se llevan a cabo en el contexto del aula:

Ha estado ausente de la mayoría de las investigaciones sobre la interacción educativa hasta prácticamente la segunda mitad del siglo $\mathrm{XX}$. Como ya hemos mencionado, tradicionalmente el interés de estas investigaciones se ha centrado de forma mayoritaria en los rasgos o características del profesor, en su comportamiento o en el comportamiento de los alumnos, pero el aula en sí ha sido tratada casi siempre como un contenedor sin incidencia apreciable sobre lo que en ella sucede. (Coll y Sánchez, 2008: 20)

Por tanto, el tema del currículo oculto se constituye en un objeto para la investigación, ya que permite recoger evidencias empíricas de las interacciones de comunicación que se generan en las lecciones cuando se imparte el currículo oficial y explícito. Desde este posicionamiento, se plantea como objetivo general de la investigación: Explicar cómo se manifiesta la producción y reproducción de desigualdades sociales mediante el currículo oculto en las prácticas de aula. 


\section{METODOLOGÍA}

El planteamiento metodológico facilitó la construcción de la teoría a partir de los datos recogidos en el trabajo de campo y su relación con las otras etapas del diseño. De esta forma, se proyectó un diseño flexible y recursivo. Teniendo presente esta posición, se comenzó con el estudio: primeramente, se realizó el trabajo de campo, en segundo lugar, se llevó a cabo el análisis de los datos lo cual permitió la conformación del marco teórico, en el cual se generó un proceso: meditado, de análisis y síntesis durante las diferentes fases del estudio.

Así desde el paradigma constructivista, como investigadora, fue preciso posicionarse ante la realidad con la intención de comprenderla y reconstruirla mediante los datos obtenidos en el contexto donde se realizó la investigación. Al respecto Tello (2012: 48) manifiesta que las dificultades de la reflexión crítica no se encuentran solo al momento de desarrollar la investigación, sino que también se presenta en la difusión de los resultados de la investigación. En este estudio, fue fundamental, la intención de registrar todas las acciones que correspondieran a lo que ocurre en la práctica de aula durante el desarrollo del currículo oficial y qué manifestaciones, se produjeron, en el grupo de estudio, tras el currículo oculto generado en las clases. De acuerdo con Sandín (2003) en este posicionamiento el "significado emerge a partir de nuestra interacción con la realidad".

\subsection{DISEÑO METODOLÓGICO}

El diseño para esta investigación justifica la estrategia metodológica en el enfoque de Teoría Fundamentada. La selección de esta teoría fue establecida debido a la necesidad de realizar un estudio en el cual se pudiera explicar la producción y reproducción de las desigualdades sociales en educación, desde el nivel micro de la institución escolar: el aula. En el espacio recursivo, que se consigna en el estudio la creación de una fórmula teórica se basó en la realidad tal y como se generó en el campo, para ello, se usa la fidelidad de la propia expresión de los informantes y el mantenimiento del significado que tienen las palabras para sus propios protagonistas. Coherente con este planteamiento Corbin y Strauss (2002) muestran que se busca "patrones repetidos de acontecimientos, sucesos, o acciones/interacciones que representen lo que las personas dicen o hacen, solas o en compañía, en respuesta a los problemas y situaciones en los que se encuentran" (pp. 142).

Una razón más por la que se seleccionó la teoría fundamentada es por motivo de que en el aspecto práctico, una teoría puede ser necesaria para explicar cómo es la gente experimentando un fenómeno, de manera que se podrían generar evidencias de la producción y reproducción de desigualdades sociales en el aula en el proceso de puesta en 
práctica del currículo oficial. Creswell (2007) Así a partir de esta investigación, se puede establecer un marco general que busca esta teoría.

\subsection{PARTICIPANTES}

La realización de esta investigación, se llevó a cabo en un centro educativo del sistema educativo nacional costarricense y, en particular, en un grupo de estudiantes de sétimo año, para explicar cómo se producen y reproducen las desigualdades sociales en el aula, por medio del desarrollo del currículo oficial y las implicaciones ocultas que repercuten entre quienes forman parte del grupo de participantes de la investigación. El grupo se conformó por veinticinco estudiantes y una docente.

\subsection{TÉCNICAS UTILIZADAS}

En esta investigación, se utilizaron tres técnicas que permitieron recolectar la información: la observación participante, la entrevista en profundidad y el grupo de discusión. En conjunto la utilización de estas técnicas permitió recoger los datos desde la propia realidad en la que se llevó a cabo el desarrollo del currículo con los participantes directos del estudio en la práctica de aula. Cabe mencionar que los aspectos considerados para la elaboración de las guías de observación, entrevista y grupos de discusión, se establecieron nodos problemáticos que representan los aspectos necesarios para la recolección de información.

\subsection{NODOS PROBLEMÁTICOS}

Los nodos problemáticos establecidos para ser considerados en el desarrollo de las técnicas se presentan en la tabla 1. 
Tabla 1

Nodos problemáticos

\begin{tabular}{|c|c|}
\hline Técnicas & Nodos problemáticos \\
\hline Observación participante & $\begin{array}{l}\text { Lenguaje del docente } \\
\text { Interacciones entre docentes estudiante y estudiantes } \\
\text { entre sí } \\
\text { Normas, acciones y actividades } \\
\text { Códigos } \\
\text { Manifestaciones y reacciones } \\
\text { Gestualidades: docente y estudiantes }\end{array}$ \\
\hline Entrevista en profundidad & $\begin{array}{l}\text { Actividades que realizó la docente } \\
\text { Conocimiento sobre la realidad del estudiante } \\
\text { Expectativas sobre los estudiantes }\end{array}$ \\
\hline Grupo de discusión & $\begin{array}{l}\text { Percepción de los estudiantes sobre el lenguaje de la } \\
\text { docente } \\
\text { Opinión sobre la forma en que la docente se dirige al } \\
\text { grupo } \\
\text { Sentimientos con respecto a la comunicación e } \\
\text { interacción en el aula }\end{array}$ \\
\hline
\end{tabular}

Nota. Elaboración propia 2015.

\section{RESULTADOS}

La recolección y análisis de los datos, se estableció mediante un proceso de recursividad -relación del trabajo de campo-obtención de la información-el regreso al trabajo de campo-análisis, trabajo de campo, obtención de información con lo que se evidencia un proceso sistemático de análisis (figura 1). Para el análisis de los datos se utilizó las etapas que propone la Teoría Fundamentada.

La utilización de la teoría fundamentada permitió explicar lo que ocurrió en el contexto en el que se realizó la acción, las manifestaciones, los hechos y las expectativas de estudiantes y la docente, así se establecen las relaciones que se presentaron en el grupo de investigación. 
Figura 1. Recolección y análisis de los datos. Adaptado de Creswells, 2007

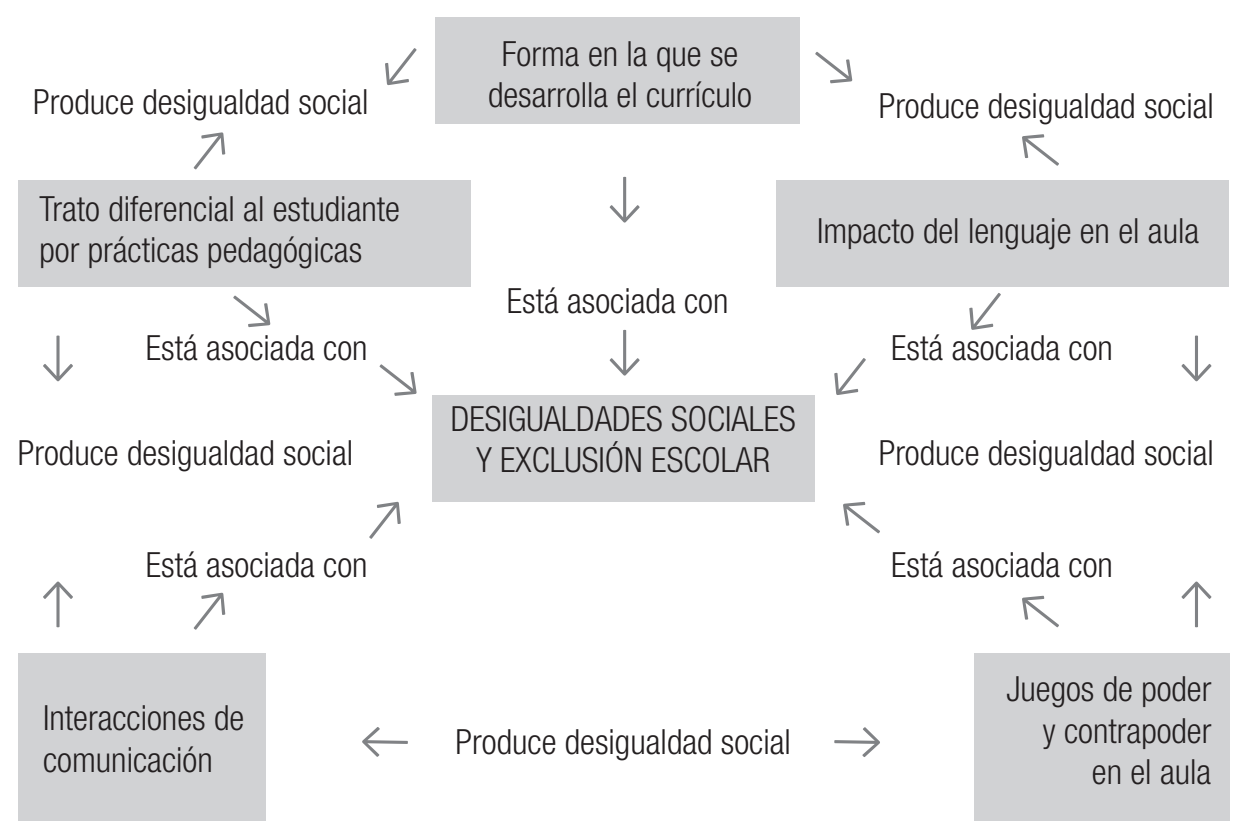

Elaboración propia 2015

En esta investigación, cabe resaltar que la forma en la que desarrolla el currículo oficial y tras este lo que surge de su puesta en práctica, se encuentra una estrecha relación con el impacto del lenguaje en el aula, el cual repercute en los juegos de poder y contrapoder en el aula, por lo cual existe una asociación directa con las interacciones de comunicación y estas con el trato diferencial que se muestra al estudiante por las prácticas pedagógicas, de esta manera existe asociación entre las diferentes categorías, las cuales son propiedad de la categoría central desigualdades sociales y exclusión escolar.

La influencia del lenguaje en las lecciones que se llevaron a cabo durante el período de observación, permitió identificar las relaciones de las categorías en relación con la categoría central, esta relación se establece desde el registro de datos expuestos por el estudiantado, la docente y el registro de notas de las observaciones. Desde esta categoría, se reconocieron propiedades que permiten tener evidencia empírica de cómo el lenguaje genera desigualdades sociales en el estudiante y posteriormente la exclusión escolar. 
En la investigación, se registraron las características de tres tipos de lenguajes que se utiliza en el aula al desarrollarse el currículo (verbal, no verbal y paralenguaje) a su vez, no solo se refleja la realidad, sino que se evidencia el papel crucial que jugó en la construcción de la categoría, al conjugarse elementos y conceptos desde la concepción de la realidad de cada persona que participó en este estudio. El lenguaje está en estrecha relación con los juegos de poderes que surgen entre los participantes del grupo, pues se identificaron palabras, gestos y acciones que manifiestan aspectos centrales que asientan el poder de la docente durante las lecciones, sin embargo, ante este accionar docente, los estudiantes contrarrestan este poder mediante acciones como escaparse de las clases, hacer actividades contradictorias al proceso que desarrolla la docente en el aula, como hacer ruidos, actividades que interrumpen durante las clases, aspectos que a la postre influyen negativamente hacia ellos mismos.

Asimismo, se evidencia la expresión oral en forma directiva hacia ciertos grupos de estudiantes; expresiones de silencios y pautas que atemorizan al estudiantado, así como gestos de represión cuando la docente se dirigía hacia algunos estudiantes, en particular, aquellos que presentan un comportamiento no esperado por la docente. Por otra parte, se desarrollaron gestos de simpatía por parte de la docente cuando se dirigía a estudiantes que terminaban antes sus trabajos y presentaban sus tareas e indiferencia ante determinados estudiantes, generalmente hacia aquellos que no lograban terminar sus trabajos y no realizaban sus tareas.

El tono de voz utilizado por la docente manifestó control, poder y autoridad por lo que los estudiantes sintieron el deseo de no continuar en el colegio, no por aspectos económicos, ni sociales, sino por el impacto que tiene la docente en su persona. Al respecto, algunos estudiantes, manifestaron que en muchas ocasiones han sentido que no son bien recibidos en las lecciones, por eso prefieren no entrar a clases. Por su parte la docente manifiesta la inconformidad con estudiantes que no acatan sus instrucciones y que estos estudiantes comienzan a faltar lo que conlleva a situaciones de abandono escolar.

Durante las observaciones los registros de lo ocurrido en las prácticas de aula, generan evidencias de comentarios de la docente en relación con la satisfacción de que algunos alumnos que no se presentan a las clases; ella enfatiza oralmente que es una dicha la ausencia de determinado estudiante pues es mejor su ausencia para poder desarrollar la clase.

Este accionar tiene un impacto en las desigualdades sociales que se producen y reproducen en las prácticas de aulas, ya que hay evidencias empíricas para el contexto inmediato en el que se realizó el 
estudio, en cuanto a la visualización y expresión del estudiantado en sentir que el estar en un centro educativo no contribuye con su superación personal, sienten que no aprenden a solucionar sus problemas y su situación se acrecienta, pues no reciben apoyo de docentes, lo que los hace desistir de seguir en un centro educativo, aspecto que se refleja en los datos de los excluidos del sistema escolar costarricense.

Las interacciones de comunicación en el aula permiten relacionarla con la categoría central, ya que se conciben como un patrón que repercute en las desigualdades sociales y el abandono escolar, en el sentido de que se mostró poca interacción de la docente con los estudiantes en la que la comunicación entre la docente y el estudiantado, fue directiva, con un predominio del trabajo de los contenidos, en este proceso de interacción comunicativa, se observó desinterés y una actitud pasiva por parte de algunos estudiantes.

En relación con los estudiantes, la interacción de comunicación que se presentó se mostró un comportamiento de actitudes agresivas, principalmente, se observaron gritos, manotazos y malas palabras. En este sentido, algunos estudiantes sintieron que ese comportamiento perjudicaba a las personas que querían estar atentos al trabajo de aula, no obstante, señalaron que la profesora seguía adelante con las actividades que se tenían que realizar.

Es fundamental que este tipo de patrón de comunicación que se desarrolle en las prácticas de aula, cobre relevancia, ya que por un lado, se puede fortalecer las relaciones interpersonales entre los miembros que conforman el grupo de trabajo, lo que permite conducir o acortar la distancia afectiva y hacer que el estudiante se mantenga en la institución de la mejor manera posible.

Por otro lado, las interacciones de comunicación en las cuales no se observan relaciones cordiales entre estudiantes y docentes, conllevan a situaciones de marginación en las aulas lo que acentúa las desigualdades sociales siendo este un aspecto que profundiza los problemas del estudiante, por lo que decide no continuar con sus estudios.

La práctica de aula registró la ausencia de actividades planeadas, en las cuales se presentaran actividades iniciales, de desarrollo y cierre de manera que el inicio de un tema, así como la continuidad del trabajo no siguieron un patrón que permitiera un ambiente en el cual el estudiante sintiera la necesidad de seguir una línea de labor en la que las pautas permitieran darle seguimiento al tema trabajado en las clases anteriores, por lo que los estudiantes indicaron que muchas veces no entendían lo que se estudiaba en las lecciones por lo que se sintieron desmotivados para seguir en el colegio.

La conformación de grupos sin criterios claros, según lo expresado por la profesora permitía la distribución de los estudiantes como 
ellos quisieran. Desde el punto de vista de la docente esto le podría proporcionar un trabajo de mayor armonía, ya que cada uno decidía con quien trabajar, sin embargo, en las actividades grupales los estudiantes tenían un comportamiento desordenado, por lo cual decidió desarrollar los trabajos de forma individual. Según lo registrado y lo que apuntaron los estudiantes el trabajo grupal les permitía un mejor avance en los temas y que era una mejor forma de trabajo, en vez de contestar preguntas en todas las clases.

Lo que ocurre en la práctica de aula tiene una incidencia particular en la producción y reproducción de desigualdades sociales, ya que en este caso en particular, la docente toma una decisión de llevar a cabo su labor de desarrollo del currículo en forma que no permitía aprovechar las fortalezas y debilidades de los estudiantes, en procura de lograr un ambiente de trabajo en el cual se obtuviera un mejor resultado para el grupo. En este planteamiento de trabajo, se observa que se interpusieron controles para el trabajo de aula, controles que desde la posición de los estudiantes son imposiciones que en el momento de no terminar una tarea asignada y las actividades de aula, se aplicaban según el logro alcanzado en la finalización de lo asignado. En esta situación experimentada por los estudiantes, estos indicaron que sentían temor y vergüenza ante los controles que ejercía la docente cuando ellos realizaban sus trabajos o tareas asignadas, pues al no terminarlos no alcanzaban un sello en el cuaderno, lo cual se reflejaba en la pérdida de puntos.

En las prácticas de aula, un aspecto que se debe resaltar son los datos que constantemente se relacionan con el trato diferencial que se da al estudiante, por el desempeño de la prácticas pedagógicas que realiza dentro del aula, así el trato de forma empática y afectiva se da a estudiantes que lograban terminar los trabajos y expresiones negativas mediante gestos por parte de la docente ante estudiantes de menor avance. En esta categoría es evidente que desde el desarrollo del currículo, así como las implicaciones del lenguaje, tienen una influencia directa con la posición de los estudiantes en abandonar sus estudios.

Las pautas a seguir en el aula fueron impuestas desde una imposición unidireccional que mantenía la docente en el aula, posicionamiento que genera descontento y un sentimiento de amenaza, lo cual se cumplía mediante boletas, firmas de cuadernos con tareas, trabajos de clase y extraclase asignados, la cantidad de sellos significaba rebajo de puntos, sin embargo, esto no consideraba si las actividades y el contenido desarrollado estaba bien logrado.

La relación que se presenta de esta categoría con la categoría central es que se identifica que en las prácticas del aula, de forma particular, al desarrollar el currículo, se generan acciones represivas y silencios 
durante el desarrollo de las lecciones, lo que influye en el accionar de los estudiantes que tienen un menor logro en el aula. Estos aspectos crean una diferenciación entre el trato a los estudiantes, lo cual conlleva a la producción y reproducción de las desigualdades y en su defecto a acrecentar el abandono del aula, por parte de estudiantes más vulnerables.

En el desarrollo del currículo y tras este las acciones que se derivan del currículo oculto, se identifica una relación con la categoría central y las otras categorías expuestas, ya que en el ambiente de aula una vez que se establece la puesta en práctica del currículo oficial y explicito surge una serie de elementos como las que se han expuesto en esta categoría central: tales derivaciones se identifican en el lenguaje que utiliza la docente cuando imparte las lecciones y el impacto que tiene este en el estudiante.

Las acciones evidentes del currículo oculto se manifiestan en las interacciones de comunicación en el aula, específicamente, se identifican las relaciones que se establecen entre quienes participan en las lecciones; las prácticas que se realizan en el aula a través de las actividades desarrolladas, generan elementos que influyen en el estudiante y en la docente y los juegos de poder y contrapoder identificados en la imposición docente y las acciones que manifiesta el estudiante en la lucha constante contra lo establecido por la docente. De manera que las desigualdades sociales y el abandono escolar en las prácticas de aula como producto del currículo oculto generador de esta situación, se identifica en la relación de las categorías que surgen del estudio, en donde se establece un panorama que repercute en el estudiantado, así para los actores las diferentes categorías con las que relacionan el tema de estudio las construyen desde sus experiencias con situaciones que se suscitan en el aula. En estas situaciones, el currículo oculto, se convierte en un aspecto fundamental que tiene un impacto principal en el estudiantado, el cual debido a diferentes circunstancias optan por manifestar actitudes como la no participación en el proceso educativo y rechazo a permanecer en las aulas. Las circunstancias que se experimentan en el grupo de estudio, refleja una serie de elementos que median las relaciones entre las personas que de una u otra forma se circunscriben en el desarrollo de la clase donde la docente encargada de la puesta en práctica del currículo y el estudiantado quien está en el proceso de formación en el aula son los entes principales en esta relación.

En consecuencia, se identifican diferentes acciones derivadas de la puesta en práctica del currículo oficial y explícito, y las incidencias del currículo oculto generado en el contexto de aula como son las desigualdades sociales y la exclusión escolar como producto del currículo oculto, esta se pueden definir como las condiciones que se originan en 
las prácticas de aulas y que generan una situación de intranquilidad en el estudiantado, es decir, existe insatisfacción con la vivencia en las aulas. De manera que los propios participantes señalaron que el trato hacia el estudiante es un factor determinante que influye en el sentir durante las clases, por esto, es necesario recalcar que la forma en que se ve a un estudiante en relación con otro, provoca una perturbación y sentimiento de desmotivación del estudiantado que es mal visto por la docente.

El siguiente aspecto para tomarlo en consideración en esta definición son las relaciones que se establecen en el aula desde las relaciones de poder que la docente quiere imponer (normas, registros, boletas e indiferencia). El estudiantado manifiestas acciones y reacciones que no tienen ningún aporte positivo para él, sino, que ese actuar de interrumpir, escaparse de la clase y no asistir a lecciones, le perjudica en su desempeño y finalmente lo puede hacer desistir por completo a abandonar el colegio.

\section{CONCLUSIONES}

En la actualidad existe un marcado interés por el análisis de las desigualdades sociales, pero no todos se dirigen a la búsqueda de la generación de una aproximación teórica desde el impacto que tienen las diferentes aristas que convergen en el currículo oculto, ante todo, en la producción y reproducción de desigualdades sociales y la exclusión escolar en el contexto educativo de la educación secundaria, interés fundamental de esta investigación.

El análisis de los datos se realizó de acuerdo con las categorías emergentes y dimensiones consideradas como instrumentos analíticos que sirvieron para ordenar y explicar que lleva a los participantes a conducirse como lo hacen. Por ende, los datos de cada categoría fueron explicados por separado para una mejor comprensión de la información, de manera que en cada una de ellas se manifestaron las particularidades y orientaciones específicas vinculadas con el objeto de estudio sobre las incidencias del currículo oculto como productor y reproductor de desigualdades sociales en las prácticas de aulas.

Los hallazgos de esta investigación brindan pautas para considerar el estudio de la vinculación entre la incidencia que tiene el currículo oculto en la producción y reproducción de desigualdades sociales, como un elemento que incide en la exclusión escolar. Así, las desigualdades sociales se develan en este contexto escolar desde las relaciones que median la práctica de aula en la cual tiene incidencia el comportamiento de la docente en cuanto a la diferenciación que hace en el trabajo de aula con respecto a algunos estudiantes. Por su parte, los estudiantes, repiten este patrón al tratar a sus compañeros 
de forma grotesca y a la docente con acciones que no permiten un desarrollo adecuado de las lecciones.

El impacto que tiene el lenguaje en el aula, se convierte en un aspecto que tiene incidencias negativas en el estudiante, pues toma como elemento las miradas, las palabras, principalmente, las orales como puntos que los hacen sentir fuera de un contexto de aula, fundamentalmente, como acciones que excluyen del trabajo a estudiantes que no muestran interés durante las lecciones.

Un elemento que se repite constantemente en las lecciones es el tipo de actividades que se realizan en las clases, en cuanto a la repetición de los mismos ejercicios (resolución de preguntas), esto provoca que algunos estudiantes trabajen y otros no realicen lo asignado, ya que como lo indicaron los estudiantes se sienten aburridos y muchas veces no logran avanzar porque ese trabajo no los motiva a continuar en las lecciones.

Las necesidades y expectativas de los estudiantes no son consideradas en la práctica de aula, hay un predominio a trabajar con los contenidos de forma homogénea, no se toma en cuenta el alcance ni el logro personal o grupal en cuanto a lo visto en clases. En esta forma de trabajo se pasa de un tema a otro sin la presencia de actividades, que por una parte, involucre al estudiante y por otra parte, la docente se siente a revisar de formas diferentes lo desarrollado por el estudiante. Es evidente que el sistema de revisión, está constatado por la asignación de sellos que indican la terminación del trabajo, sin ahondar en si está correcto lo realizado.

La producción y reproducción de desigualdades sociales en el aula, tiene impacto en la exclusión escolar, por lo que esta problemática, es conducente a que estudiantes abandonen el centro educativo por un tiempo, en algunos casos busquen otras alternativas de estudio y otros grupos abandonen de forma definitiva sus estudios, lo que constituye una situación que genera para estos estudiantes una limitada opción de trabajo, lo cual conlleva a situaciones de insatisfacción y resentimiento al proceso formativo que se realiza en los centros educativos.

Desde la aportaciones que se generan en el estudio se propone progresar en el tema de las desigualdades sociales en el ámbito educativo, ya que puede ser un apoyo fundamental para la explicitación de prácticas de aulas en las que se genere un espacio con mayor reconocimiento de quienes forman parte del contexto micro del centro educativo y se reconceptualice, se revalorice y se incorpore al estudiante como eje fundamental del ejercicio de formación educativa en mejores relaciones con los docentes y entre estudiantes.

Como investigadores del ámbito educativo, se debe reflexionar en torno al desarrollo de la red social en la que se está inmerso dentro de la 
labor que se desempeña, por lo que es necesario darle valor al estudiantado, que cobre cuantía su posición dentro del proceso de formación, de manera que pueda alcanzar el sentido de construcción y reconstrucción en su propio accionar. De manera que el valor positivo que tiene esta investigación con respecto a otros estudios sobre las desigualdades sociales en educación es que responde a la necesidad de estudiar lo que ocurre en la práctica de aula, pues es un tema poco explorado, desde la dimensión del impacto del currículo oculto.

\section{BIBLIOGRAFÍA}

Coll, C. Y Sánchez, E. 2008 El análisis de la interacción alumno-profesor (Colombia: Escribanía).

Corbin, J. y Strauss, A. 2002 Bases de la investigación cualitativa. Técnicas y procedimientos para desarrollar la teoría fundamentada (Colombia: Editorial Universidad de Antioquía).

Creswell, J. 2007 Qualitative Inquiry and Research Design: Choosing among Traditions (EEUU: Sage Publications).

Fernández, O. 2003 “Pierre Bourdieu, ¿Agente o Actor?” en Revista Tópicos del Humanismo.90 (1): 1-7.

Gaete, M. y Jiménez, W. 2013 "Estudio de la exclusión educativa y abandono en la enseñanza secundaria en algunas instituciones públicas de Costa Rica" en Revista Electrónica Educare (17) 1.

Garnier, L. Wachong, V. y Mora J. 2010 Un análisis descriptivo sobre el abandono estudiantil en secundaria durante el primer semestre del 2010 (José: Ministerio de Educación Pública).

Gutiérrez, M. y Puentes, G. 2009 Aceleración del aprendizaje de la población vulnerable con extraedad (Madrid: Fundación Iberoamericana para la Educación, la Ciencia y la Cultura).

Informe Regional sobre Desarrollo Humano para América Latina y el Caribe 2010 Actuar sobre el futuro: romper la transmisión intergeneracional de la desigualdad (Costa Rica: Editorama).

Jackson, P. 2010 La vida en las aulas (Madrid: Ediciones Morata).

Ministerio de Educación Pública 1994 Consejo Superior de Educación. Política Educativa: Hacia el Siglo XXI (San José de Costa Rica: Ministerio de Educación Pública). 
Nievez, C. 2000 "La escuela frente a las desigualdades sociales. Apuntes sociológicos sobre el pensamiento docente" en Revista Iberoamericana de Educación $\mathrm{N}^{\circ} 23$ Mayo - Agosto.

Programa Estado de la Nación en Desarrollo Humano Sostenible 2008 Segundo Informe del Estado de la Educación (San José de Costa Rica).

Programa Estado de la Nación en Desarrollo Humano Sostenible 2011 Tercer Informe del Estado de la Educación (San José de Costa Rica).

Programa Estado de la Nación en Desarrollo Humano Sostenible 2011 Tercer Informe del Estado de la Educación. San José, Costa Rica.

Programa Estado de la Nación en Desarrollo Humano Sostenible 2011 Estado de la Educación. (San José de Costa Rica: Consejo Nacional de Rectores).

Sandín, M. 2003 Investigación cualitativa en educación. Fundamentos y tradiciones (Madrid: McGraw-HILL).

Tello, C. 2012 "Las epistemologías de la política educativa: vigilancia y posicionamiento epistemológico del investigador en política" en Práxis Educativa, Ponta Grossa, 7(1), 53-68.

Torres, J. 1991 El currículum oculto (Madrid: Ediciones Morata).

Van, S. 2006 "El currículo en el entorno actual" en Revista Regional de investigación Educativa (s/d). Disponible en http://www.educatio. ugto.mx/PDFs/educatio3/curriculoenentornoactual.pdf

Vilas, C. 2007 "Desigualdad social y procesos políticos: una perspectiva interdisciplinaria" en Anuario de Filosofía Argentina y Americana, $\mathrm{N}^{\circ} 24$, pp. 9 a 33. 


\title{
EN LOS MARGENES DE LA SECURITIZACIÓN. SER JOVEN MIGRANTE DEL SUR EN EL SIGLO XXI
}

\author{
Iván Francisco Porraz Gómez*
}

"La inmigración es algo muy favorable. Imagine un obrero de origen senegalés: por un lado participa de la vida francesa; por otro, no forma parte de la antigua historia de la nacionalidad. Son europeos, europeos nuevos, un poco como los inmigrantes que hicieron los Estados Unidos o la Argentina" (Alain Badiou, 2003).

\section{INTRODUCCIÓN}

La propensión a migrar es la característica principal del comportamiento espacial de la juventud, y el sello distintivo de hoy lo es su inserción a los circuitos migratorios internacionales, un campo social tensado por la violencia y el desafío a ésta, con tan sólo las armas corporales e imaginarias del ser joven. La inserción laboral en el tiempo invoca una relación desnuda entre el capital y el trabajo, se registra sin mediación

\footnotetext{
* Antropólogo. Maestro en Ciencias Sociales por el CESMECA-UNICACH. Doctor en Ciencias Sociales y Humanísticas del Centro de Estudio Superiores de México y Centroamérica de la Universidad de Ciencias y Artes de Chiapas. Becario del Programa de Becas Posdoctorales en la UNAM, CIMSUR-UNAM. correo electrónico: pacon_83@hotmail.com
} 
alguna que proteja la vida y los derechos laborales mínimos. Paradójicamente, para los y las jóvenes que asumen ser dueños de "sí mismos" significa hacer uso de una libertad, que ahora tienen, para desafiar a una sociedad en la que aparentemente "todo se puede".

El siguiente artículo intenta abrir un abanico de campos temáticos y problemáticos sobre la migración internacional de los jóvenes del sur. El fenómeno migratorio, sujeto a las dinámicas de auge y crisis de la economía de Estados Unidos, está instituyendo relaciones individuales y colectivas que exteriorizan latentes problemas estructurales y formas inéditas de respuestas ante los desafíos abiertos por la globalización. En dicho fenómeno se condensan, además de sus violencias fácticas, la producción y reproducción de la violencia sistémica y sedimenta una violencia simbólica que, bajo el manto de la "libertad", internaliza imágenes del mundo global, que mandata la ordenación de los sistemas de significación con base a sus premisas (Zizek 2009; León, 2005), legitimando así viejas y nuevas formas de dominación global e imperial.

La presencia de los y las jóvenes migrantes de las periferias del Sur, a diferencia de un patrón migratorio en el que el migrante era el padre de familia en tanto los hijos estudiaban, ha trastocado el sentido "ordenado" de la gestión migratoria de los Estados receptores. Los jóvenes portan una identidad cultural que les es intrínseca, en la que el sentido de la experimentación, de la autonomía, de la transgresión y el desafío se torna colectivo; a ello, siguiendo la línea de pensamiento de Emma León, se suma el estimulo violento del mercado que hace del consumo un imperativo categórico, en la que el grito de la moda y sus aditamentos se tornan en "necesidad angustiosa", y sentimiento de "rezago y caducidad" por no tener acceso a éstos (León, 2005: 18). Los jóvenes, por ello, son "peligrosos" en los espacios de recepción así sean colectivos bajo estricta vigilancia sujetos a fines estrictamente laborales. En suma, el miedo lo generan sus prácticas y sensibilidades, en tanto irrumpen las regularidades espaciales y temporales, propias de las vivencias en movimiento, nucleadas por fracturas, discontinuidades y relaciones de disyunción que definen el mundo global, como un mundo de flujos. (Appadurai, 2006; Auge, 2008).

En esta tesitura, las prácticas y vivencias de los jóvenes migrantes en el sur de México y Centroamérica, se pueden leer como: i) indicadores de procesos sociales que tensan, desafían, y exigen interpretaciones y búsqueda de los sentidos de lo particular dentro de la generalidad; ii) experiencias desde donde asumen como propio los dispositivos de la globalización, pero los transforman, y desafían construyendo los suyos, alterando con ello las regularidades espacio-temporales y sus contenidos; iii) expresiones nítidas de las mutaciones que hoy viven los espacios 
sociales rurales y urbanos, cuya erosión de su universo de significados cuestionan su existencia como tal y, iv) expresiones de la huida radical del Estado de su compromiso con la población joven, y su conversión en estado policía a través de su "política de mano dura" (Peñaloza, 2010).

La incertidumbre, la particularización de sus destinos y la violencia abierta que los envuelve, nos lleva a la interrogante de por qué ocurre y qué es lo que lo hace posible. Economía y política se emparentan en su afán de hacer de los jóvenes átomos sociales, sujetos "sujetados" en la línea de Foucault; átomos sociales que alimenten esa sociedad del espectáculo definida por Guy Debord (2010) como el mal sueño de la sociedad moderna que no exprese más que su deseo de dormir. Sin embargo, esta ecuación estratégica del poder no es lineal ni homogéneo, es decir, el mercado y sus ofertas de consumo no hacen una sociedad "única", la exclusión no sólo persiste sino que se ve incrementada, y ésta desestructura la mítica sociedad global.

\section{PENSAR Y NOMBRAR LA VIOLENCIA DESDE LA SECURITIZACIÓN DE LAS FRONTERAS}

Según Abramovay es necesario ampliar y repensar el concepto de violencia, teniendo en cuenta las variadas manifestaciones sobre la cuestión, sus autores, sus víctimas, sus discursos, pensando que la violencia, además de destruir físicamente, destruye moralmente y toca la subjetividad de los involucrados (2014:2). Desde el prisma de las dinámicas internacionales globales y neoliberales, puede decirse que la migración de los jóvenes se hace en condiciones de violencia institucional que allana y atrae, además, a las violencias privadas. No es que la violencia sea un fenómeno nuevo o que se particularice a los jóvenes migrantes, pero hoy adquiere otro sentido que tiene que ver con la construcción deliberada de un marco simbólico que define las cuestiones de la inmigración como una <<guerra en casa >> (Butler, 2010: 47), y con un desplazamiento del Estado constitucional de derecho a un $<<$ Estado de la economía>>, abiertamente "global" y neoliberal. La "seguridad nacional" y su traducción en un presente y un horizonte propio de la guerra, construye y modula los "enemigos" entre los que incluye a los inmigrantes indocumentados, "ilegales" en la jerga jurídica.

Siguiendo el ejercicio de comprensión analítica que realiza García (2012) sobre la globalización, la aparente paradoja de ésta, es que si bien se le define como "las formas de relación y organización social que desbordan los espacios tradicionales y se expanden hasta abarcar el mundo todo" (Vallespín, 2000), también se le define como "aquello que por definición puede localizarse en cualquier parte, aunque tenga un origen local. Lo local no se opondría a lo global, sino que sería uno de sus elementos constitutivos (Santos, 50, citado por García, 2012), de- 
finición que se expresa en una realidad internacional en la que Estados Unidos, portador universal del mercado y la democracia parlamentaria, extiende su influencia a nivel planetario, cuyo despliegue coinciden en lo que Naïr define como Imperio, esto es, "un sistema mercantil hoy mundialmente dominante, que funciona particularmente en el ámbito económico y en el del consenso; un "imperio de nuevo tipo, que supera y abarca a Estados Unidos"; es "un imperio mercantil, oligopolístico, mundial y democrático" (Naïr, 2003: 3-4).

Esta línea de pensamiento, la relación entre globalización y Estado es igual de compleja, pues si bien el Estado pierde centralidad y presencia en las dimensiones sustantivas de la vida económica -sector financiero y tecnología de la información- y social -crisis del Estado de bienestar-, el sistema mundo imperial es "un imperio informal, no está institucionalizado, fundado y reconocido como tal" (Naïr, 2003: 2).

La dialéctica presencia-ausencia del Estado-nación en el concierto de la globalización, Santos (2004) la visibiliza en la configuración de un $<<$ Estado paralelo $>>$ que crea zonas salvajes y zonas civilizadas; un Estado que privatiza los bienes públicos y, digamos con Harvey (2000) que impulsa la acumulación por desposesión; un Estado desvinculado del riesgo cotidiano provocado por la precariedad laboral y la ausencia de capacidades individuales y colectivas para controlar las condiciones mínimas del mundo de vida cotidiana. [...] si hay una retirada del Estado-nación del concierto de la globalización ésta es selectiva, pero no es cosa menor, pues como señala Mercado (2005: 120), el proceso de globalización coloca al Estado y al Derecho en "un nuevo escenario en el que sus funciones, sus finalidades y sus actores resultan transformados de una manera significativa" (García, 2012: 3).

Particularizando este contexto internacional global y neoliberal al fenómeno migratorio internacional y a sus actores, los migrantes, mayoritariamente jóvenes, cabe destacar los "atentados del 11 de septiembre", como un punto de inflexión en el que se desparrama toda un serie de políticas y estrategias que vinculan los males que configuran la "globalización negativa" (Bauman, 2013; Kapuscinsky, 2012) y que se sintetizan en la centralidad de las fronteras como espacios de contención militarizada, violentando principios y valores propios de los derechos humanos, y en la construcción de un derecho penal del enemigo que ante el imperativo de la seguridad nacional deriva en acciones y prácticas que revelan la contigüidad entre el "estado de excepción" y la "soberanía" (García y Villafuerte, 2014).

Vale detenernos en este punto, por los impactos que el comportamiento del gobierno norteamericano en materia migratoria tiene sobre México y la población migrante latina, entre ellas los migrantes jóvenes. 
Después de esa fatídica fecha, la política internacional de ese país está nucleada por la seguridad nacional.

A la migración indocumentada de mexicanos, centroamericanos y de otros países del continente americano y de otros continentes, se le define como un riesgo de seguridad nacional y se correlaciona con toda la negatividad del crimen, el narcotráfico y el terrorismo. Las políticas antiinmigrantes ya impulsadas desde años atrás, cobran vida en estrategias y acciones bien definidas. La construcción de bardas y muros, la puesta en marcha de sistemas tecnológicos de vigilancia y la militarización de la frontera sur de los Estados Unidos, es su evidencia más visible. El otro factor a considerar es la crisis económica de ese país, referida a una crisis crediticia e hipotecaria que causó la quiebra de bancos y entidades financieras, arrastró a los valores bursátiles y minó drásticamente la capacidad de consumo y de ahorro de la población. Durante 2008 la crisis se agrava y el gobierno interviene, entre otras, en la compra de activos respaldados por hipotecas. En 2011 la nota periodística es que la crisis sacude "la deuda soberana del país, llevando a la crisis del techo de deuda".

Se trata pues de políticas deliberadamente antiinmigrantes, tampoco son nuevas, pero sus expresiones después de ambos eventos definen cambios de orden profundo en el tratamiento migratorio. El carácter ideológico y su politización conectada a coyunturas políticas y de crisis económicas, han definido las deportaciones. En relación al penúltimo ciclo de deportaciones que va de 1983 a 2006, las define como de "altas cifras, relativamente estables, girando alrededor de 1 millón de casos por años" (Guillén, 2012: 169). No obstante registra que después de los atentados del 11 de septiembre, y la recesión económica, se dan cambios en las deportaciones particularmente en el perfil de las personas deportadas.

“[...], en EE. UU., el mapa institucional de la política de migración y sobre las fronteras ha experimentado un giro conceptual y operativo de amplia escala, de efectos severos sobre su visión de los flujos migratorios y de los migrantes. De manera indirecta -en ocasiones, directa-, la migración no autorizada pasó a ser parte del desafío de la seguridad nacional, una potencial amenaza para ésta y, de manera eventual, un objeto susceptible de confrontación física".

Con estos cambios, se comprende que ya no estemos ante las tradicionales detenciones y repatriaciones de los años anteriores: ahora se trata de removais, expulsiones en un sentido fuerte, como reivindican los informes del ICE. Hasta el lenguaje debió adaptarse" (2012: 173) 
La securitización del país de destino, simplemente significa la destrucción de la única alternativa dada por el concierto económico nacional y global. Este es el contexto que hoy define a la migración de jóvenes. Desde el país de origen y de destino, pesan los intereses de los poderes económicos y políticos, y estos están más allá de las afectaciones humanitarias que traen consigo. Las deportaciones son la expresión más violenta del retorno: regresan porque los regresan.

\section{SER JOVEN MIGRANTE EN EL DISCURSO DE LA SECURITIZACIÓN}

Desde los discursos de los propios jóvenes migrantes la trayectoria migratoria no es homogénea. Inevitablemente dan cuenta del entorno que envuelve cada una las fases del circuito migratorio, un entorno que los confronta con vulnerabilidades y riesgos desconocidos. Desconcierta la actitud y el comportamiento desafiante de numerosos jóvenes mexicanos, centroamericanos y otras latitudes. Pareciera, recuperando las reflexiones de Appadurai, que la imaginación, que decimos es individual pero también social, es la facultad que les permite modular y dar sentido a las decisiones de emigrar y desde ahí configurar nuevas pautas de interacción y de disensión. Las formas de articulación material de los espacios locales al mundo que los globaliza, y la internalización y asunción de los jóvenes de las vertientes culturales y modos de ser global, tienden a transformar con celeridad la materialidad y la imagen del espacio local, esto es, la comunidad y la sociedad que la habita.

Hay que recordar que desde las sociedades democráticas, los jóvenes -en edad laboral-encarnan al ciudadano libre para ceder en el mercado una facultad personal como la fuerza de trabajo, en tanto expropiados de todo recurso económico ${ }^{1}$. Sin embargo, el funcionamiento actual del capital en su escala global, trastoca los términos y las exigencias de la independencia jurídica, al instituir en el campo de la migración laboral internacional, figuras ilegales que menguan el sentido de la libertad, no así el de la voracidad de la acumulación.

Pareciera un contrasentido pero la trasgresión a esta regla de oro del capitalismo, esto es, la conjunción de libertad y expropiación, se legitima con el propio discurso de la libertad, una libertad modulada por el juego libre y competitivo del mercado global, en donde la libertad, en palabras de Von Hayek, <<es un artefacto $>>$ (Citado por Vázquez: 92). Los y las jóvenes migrantes deciden, -haciendo uso de su libertad-, recorrer el desierto y arriesgar la vida para, también como

1 Siguiendo a Paolo Virno, sólo la intersección de estas dos condiciones, libertad y expropiación al mismo tiempo, hace que la potencia se afirme en el mundo de las apariencias como la concreta realización de un intercambio, llegando así a su parousia o revelación (2003: 169). 
una elección autónoma, situarse en un mercado laboral internacional que les demanda. Sin embargo, para quienes les contratan, la libertad manifiesta en la decisión de ceder su fuerza de trabajo, no tiene una traducción jurídica inmediata, esto es, no tienen derecho de estar situados en dicho mercado, pues son ilegales, no obstante, se les contrata en condiciones también ilegales, en tanto están ausentes, los salarios justos y los derechos que les corresponde como trabajadores.

Esta lógica imperial produce enormes dividendos al capital y a la sociedad, cuyos ciudadanos no están dispuestos a encara el trabajo peor y mal pagado, para eso están esos "otros". Sin embargo, el valor de uso que los jóvenes migrantes ofrecen, no existe por fuera de ellos, el capital se tropieza con un <<cuerpo viviente $>>$, esto es, en palabras de Virno (2003: 171), con el "insuperable tabernáculo de lo que ciertamente importa: "el trabajo como subjetividad". ${ }^{2}$

Y es ese "tropiezo", que se visibiliza con las migraciones masivas, lo que provoca la intolerancia y el rechazo abierto de la población nativa de los países del Norte, manifiesta en prácticas racistas y de persecución, a quienes trasgreden sus frontera y están dentro violentando el mundo de vida de la "buena sociedad". Los gobiernos, por su parte, instauran políticas encontradas, esto es, fomentan la permisibilidad para que en su mercado laboral se desarrolle una fuerza de trabajo en unas condiciones que serían imposibles en la lógica ideal del capital, pero, a la vez, se desentienden de esos <<cuerpos vivientes $>$; más aún, instauran dispositivos que intentan impedir los flujos migratorios en sus fronteras y emprenden, desde dentro, políticas de deportación y desprotección abierta con fines de higiene social.

Es el rostro de la biopolítica particularizada a una masa laboral de inmigrantes; una biopolítica que instaura y pone en práctica modos y formas de resarcir las tensiones entre la necesidad manifiesta de fuerza de trabajo y el costo social y político de alojar en sus territorios a esa masa corporal viviente inseparable de la potencia de producir. Pero, como señala Roberto Esposito, siguiendo la línea de George Simmel, es ese extranjero interno -porque está dentro- el que rompe la lógica binaria propia de la modernidad; es "el Tercero: el que disuelve con su misma presencia el orden del aut-aut, arrastrándolo al desorden del etet o del nec-nec" (Esposito, 1999:74).

Por eso da miedo, dice Esposito, da miedo también porque ese Tercero, lo forman principalmente los jóvenes del Sur en el Norte.

2 "El cuerpo viviente, desprovisto de cualquier dote que no sea la pura vitalidad, deviene el sustrato de la capacidad productiva, el signo tangible de la potencia, el simulacro objetivo del trabajo no objetivado. Si el dinero es el representante universal de los valores de cambio, la vida es el equivalente intrínseco del único valor de uso "no materializado en un producto"'”(Virno, 2003: 171-172). 
Y son éstos jóvenes los que con la imaginación y la edad, dislocan los muros externos e internos, e incluso las decisiones de deslegitimación absoluta como han sido las decisiones recientes de política migratoria de Estados Unidos para con los migrantes de México y de los países centroamericanos.

Estos jóvenes, potencia y fuerza de trabajo real, desde el Sur o en el mismo Norte, se vienen configurando con nuevos materiales que alteran las prácticas e identidades que les ha particularizado; se construyen desde la contingencia, por ello, la subjetividad juvenil es diversa y diferenciada, en tanto se engarzan de modos múltiples con la estructura social, de la que derivan pautas culturales y simbólicas igual de diversas (Reguillo, 2000; Valenzuela, 2003; Nateras, 2001; Alvarado, 2009).

Los define la desterritorialización pero también su capacidad para, más allá del espacio desde donde se hace uso de su fuerza de trabajo, apropiarse de esos otros espacios, centrales y periféricos de la globalización, desde donde configurar su subjetividad juvenil, visibles en el vestuario, los gustos, el lenguaje corporal, y los gestos, que articulados a las prácticas de sustentación material, configuran modos de vida individual y grupal. Desde ahí, desde sus capitales, se tornan agentes sociales, se movilizan, juegan son su capacidad de agencia y definen su disidencia y los términos de sus interacciones con esferas y actores del mundo global.

Los jóvenes migrantes del Sur, tienen de suyo, la edad y la imaginación, y en las tierras del Norte, como dice Audrey Singer, "son más jóvenes que los blancos, son más jóvenes que los negros [..]", y la demanda de su capacidad de trabajo es inevitable, por eso la inmigración tiene continuidad, aunque con el expediente abierto y puesto en práctica de mantenerlos a raya en el umbral que han cruzado, bajo amenazas de recurrentes de expulsiones, pero, como señala Esposito, sin posibilidades reales de hacerlo (1999: 74). Los jóvenes migrantes del Sur, hacen suyo el reto de ser globalizados, las sociedades del Norte tiene el reto de trastocar esa lógica binaria propio de la modernidad, de su modernidad. No hacerlo, dice nuestro autor, lleva al mecanismo sacrificial, un mecanismo "siempre preparado para entrar en funcionamiento" (ibíd: 74).

En esta tesitura, las prácticas y vivencias de los jóvenes migrantes que transitan por el sur se tornan procesos sociales que tensan, desafían, y exigen interpretaciones y búsqueda de los sentidos de lo particular dentro de la generalidad, modulados por la reconfiguración de relaciones de fuerzas (Marx) y relaciones de significado con dimensiones simbólicas (Durheim, Weber), en un campo social global descontrolado. 


\section{CONSIDERACIONES FINALES}

Las acciones de la securitización que decantan en la criminalización a migrantes, en este caso jóvenes, acarrean consecuencias que incrementan su vulnerabilidad. El cual pone a las personas migrantes en una situación extremadamente riesgosa fomentada en gran medida por el carácter restrictivo de estas políticas, así como del accionar de sujetos particulares con la anuencia del Estado.

Empíricamente demostrado por numerosos estudios, la condición de los jóvenes en tiempos de globalización neoliberal es la de vulnerabilidad y su correlato con el concepto de violencia (en tanto ejercicio y padecimiento del daño). Este planteamiento es el que mejor expresa la condición del joven migrante internacional irregular, una condición siempre colocada en el límite. El concepto de vulnerabilidad definida como la susceptibilidad "a ser herido o vulnerado, a recibir un daño o perjuicio, a ser afectado”, posee dos sentidos: una que tiende a su naturalización social, en tanto afectación propia de determinados individuos o sectores; el otro sentido, "reduce el significado general de afectación a aquel de daño" en el que el concepto de vulnerabilidad se relaciona con el de violencia. La dupla vulnerabilidad y violencia se presentan como una pareja que alude "al ejercicio y padecimiento del daño, respectivamente” (Rodríguez y Lindig, 2013: 360 y 361).

De manera desafortunada la tendencia frente a los retos que plantea la migración sigue siendo la selectividad y la generalizada exclusión, como dan muestra las masivas deportaciones en las administraciones del Presidente Obama, y de manera sorprendente lo acontecido en nuestro país durante el 2014, año en el que se deportaron casi el 50\% más de población centroamericana en relación al año 2013 (Porraz y Hernandez, 2015)

Desde esta perspectiva, la vulnerabilidad social es selectiva y está determinada por el poder. Siguiendo la línea de pensamiento de Butler (2010), la vulnerabilidad de los jóvenes es una vulnerabilidad creada: son vulnerables porque en su gran mayoría -del Sur y pobresson superfluos; es una vulnerabilidad construida porque el Estado y sus instituciones abandonan la protección, el cuidar y el desarrollo de su población joven mayoritaria en prácticamente todos los planos de su vida, particularmente en educación, salud y condiciones dignas de trabajo.

La evidencia es clara, a pesar de estas estrategias para reforzar la seguridad, controlar los flujos migratorios y desincentivar la migración, el fenómeno de la movilidad humana sigue siendo constante, se sigue innovando y reinventando, la mayor de las veces para sortear acciones como las aquí descritas. Lo que no parece tan claro, es la elaboración de estrategias que busquen el cambio de paradigma: de enfoques centrados 
en la seguridad nacional y en el temor hacia los otros, hacia enfoques que pongan el acento en la seguridad humana, los cuales incluyen el garantizar condiciones de vida en los lugares de origen, buscan alternativas frente a la pobreza y violencia que literalmente están forzando las migraciones; así como velar por ese mismo reconocimiento de derechos tanto en los lugares de tránsito como en los de destino.

La vulnerabilidad de los jóvenes migrantes cala aquí y cala allá. Aquí, porque todas las vulnerabilidades visibles en riesgo y daños infligidos deviene de la devaluación de éstos como personas con derecho a un desarrollo de vida digno y de calidad; allá, porque la globalización, en la figura del Estado norteamericano, erosionó todo principio ético de la llamada comunidad internacional e impuso como el principio de toda relación internacional el paradigma de la "seguridad nacional", cuya expresión extrema deviene en el despliegue práctico y real de los viejos conceptos de enemigo y de guerra, visibles hoy en el Derecho y los normalizados "estados de excepción" de las potencias del Norte (García y Villafuerte, 2014). A este respecto resulta importante recuperar el análisis complejo de los "marcos" de guerra de Butler (2010: 47), definidos como "las distintas maneras de repartir selectivamente la experiencia como algo esencial a la conducción de la guerra".

\section{BIBLIOGRAFÍA}

Badiou, Alain 2003 Condiciones (México: Siglo XXI).

Bauman, Zigmunt 2012 Mundo moderno. Ética del individuo en la aldea global (Buenos Aires: Paidós).

2013 Miedo Líquido. La sociedad contemporánea y sus temores (México: Paidós).

Butler, Judith 2010 Marcos de guerra. Las vidas lloradas (México: Paidós).

Comisión Económica para América Latina y el Caribe (CEPAL) 2006

Migración internacional, derechos humanos y desarrollo en América Latina y el Caribe (Montevideo).

Debord, Guy 2012 La sociedad del espectáculo (Valencia: Pre-Textos).

Donas, Burak 2001 Adolescencia y juventud en América Latina (Costa Rica: Libro Universitario Regional).

Durand, Jorge y Massey, Douglas 2003 Clandestinos: Migraciones MéxicoEstados Unidos en los albores del siglo XXI (México: Universidad Autónoma de Zacatecas-Porrúa). 
Durand, Jorge 2004 “Ensayo teórico sobre la migración de retorno. El principio del rendimiento decreciente" en Cuadernos Geográficos, 35 (2004-2). pp. 103-116.

Esposito, Roberto 1999 “Enemigo, extranjero, comunidad” en Manuel Cruz (comp.) Los filosofos y la política (Madrid: Fondo de Cultura Económica).

García Aguilar, María del Carmen y Daniel Villafuerte Solís 2014 Migración, derechos humanos y desarrollo, aproximaciones desde el sur de México y Centroamérica (México: UNICACH/Juan Pablos Editor).

-2012 "Migración y seguridad: del Estado Constitucional de derecho al Derecho Penal del enemigo" en Baltar, Enrique, María Da Gloria, Marroni, Daniel Villafuerte Solís (coordinadores) Viejas y nuevas migraciones forzadas en el sur de México, Centroamérica y el Caribe (México: Universidad de Quintana Roo/SITESA).

Guillén López, Tonatiuh 2012 "Entre la convergencia y la exclusión. La deportación de mexicanos desde Estados Unidos de América” en Realidad, datos y espacio. Revista Internacional de Estadística y Geografía. Vol. 3 N 3 septiembre-diciembre, México.

Harvey, David 2000 Espacios de esperanza (Madrid: Akal. Madrid).

Rodríguez, Circe y Erika Lindig 2013 "Vulnerabilidad (estudio de vocabulario)” en Martínez de la Escalera, Lorenzo y Erika Lindig Cisneros (coordinadoras) Alteridad y exclusiones. Vocabulario para el debate social y político (México, UNAM/Juan Pablos Editor).

Martín-Barbero, Jesús 2010 De los medios y las mediaciones. Comunicación, cultura y hegemonía (España: Anthropos/UAMIztapalapa).

Mercado, Pedro 2005 “El proceso de globalización, el Estado y el Derecho” en Guillermo Portilla Contreras (coord.) Mutaciones de leviatán. Legitimación de los nuevos modelos penales (Madrid: Universidad Internacional de Andalucía/Akal).

Naïr, Sami 2003 El imperio frente a la diversidad del mundo (Barcelona: Areté).

Porraz Gómez, Iván Francisco y María del Carmen García Aguilar 2015 "Entre el éxito y la incertidumbre: Formas de tránsito y adaptación de los jóvenes migrantes chiapanecos en Estados Unidos” en Anguiano Téllez María Eugenia y Daniel Villafuerte Cruces de 
fronteras. Movilidad humana y politicas migratorias (México: COLEF/CESMECA).

Valenzuela Arce, José Manuel 2012 Sed de mal. Feminicidios, jóvenes y exclusión social (México: El Colegio de la Frontera Norte/ Universidad Autónoma de Nuevo León).

Vallespin, Fernando 2000 El futuro de la política (Madrid: Taurus).

Villafuerte Solís, Daniel y María del Carmen García Aguilar 2009 "Crisis rural y contracción de las remesas en Chiapas, ponencia presentada en el VII Congreso de la Asociación Mexicana de Estudios Rurales, San Cristóbal de las Casas, Chiapas, México.

Virno, Paolo 2003 Gramática de la multitud. Para un análisis de las formas de vida contemporáneas (Madrid: Traficante de sueños).

Zizek, Slavoj 2009 Sobre la violencia. Seis reflexiones marginales (Barcelona: Paidós). 


\title{
PRODUCCIÓN DE DESIGUALDADES ENTRE JÓVENES RURALES: RELACIONES INTERGENERACIONALES, NORMATIVA Y DESARROLLO AGROINDUSTRIAL*
}

\author{
Luisina Castelli Rodríguez**
}

\section{INTRODUCCIÓN: SITUAR LAS DESIGUALDADES}

Cuando la dimensión económica o la diferencia de clase no es el rasgo más saliente de las desigualdades, estas pueden hallarse en un plano que no resulta evidente o inmediatamente accesible. Pueden incluso aparecer naturalizadas al mantener un vínculo estrecho con aspectos tales como la posición de género y la posición generacional de los sujetos, las características del territorio, entendido como espacio de desenvolvimiento de la vida, la matriz de valores que comparten y ponen en disputa los sujetos, que hacen a sus modos de relacionarse y representarse a sí mismos y a otros, determinantes de orden normativo y estructural, por mencionar algunos. Por ello, pueden no reconocerse en tanto desigualdades, sino como manifestaciones circunstanciales o, peor aún, devenir en estigma. En cualquier caso y procurando evitar caer en relativismos desmesurados, conviene tener presente que las desigualdades no son exclusivamente individuales o puramente es-

* Maestranda en Ciencias Humanas, opción Antropología de la Región de la Cuenca del Plata, Facultad de Humanidades y Ciencias de la Educación, Universidad de la República, Uruguay. 
tructurales -aunque bien estos elementos se sopesan diferencialmente-; constituyen, en suma, tramas relacionales, históricas, cambiantes.

Las relaciones entre sujetos que ocupan distintas posiciones generacionales en un momento dado, pueden analizarse desde una perspectiva que procure identificar tramas de desigualdad, tomando en cuenta que el estatus social también se define por el lugar que se tiene en la composición generacional, en estrecho vínculo con la valoración que, para dicho momento, se le atribuye a cada posición. Esto significa, como nos recuerda Bourdieu, que las generaciones están definidas de acuerdo a las leyes específicas de funcionamiento de un campo de relaciones dado (1990). En este sentido, en este texto referiremos a "posiciones generacionales" en el análisis de la construcción de las relaciones entre sujetos considerados jóvenes y sujetos considerados adultos, para denotar que en un mismo contexto conviven distintas generaciones entre las cuales se ponen en disputa los procesos de significación de la realidad social. Esta perspectiva retoma la conceptualización de la juventud en tanto "generación" señalada por Vommaro (2014) en diálogo con otros autores, la cual implica, además de la coexistencia en un tiempo histórico común, el "poner en juego de una u otra forma, criterios de identificación común entre sujetos que comparten un problema" (Ibídem:21).

Pensar las relaciones entre jóvenes y adultos (entre otros sujetos) en términos de posiciones generacionales permite, asimismo, incorporar la noción de "conciencia generacional" (Leccardi y Feixa, 2011) formulada, como apuntan estos autores, en base a dos componentes principales: "la historicidad y un vínculo estrecho con la dimensión de la experiencia" (Ibídem: 20). Producir una conciencia generacional posibilita
"situarse uno mismo dentro del marco histórico, en base a la conciencia de que existe un pasado y un futuro que se extien- den más allá de los límites de la propia existencia y de relacio- nar la propia vida con la vida de las generaciones previas y de las futuras generaciones." (Ibídem)

Como se intentará mostrar a propósito del objetivo esbozado para este texto, el hecho de "compartir un problema" -y, en tal sentido, producir una conciencia junto a otros sujetos- sea éste de orden material o simbólico, sentirse interpelado por determinados mandatos o moralidades o contar con ciertas oportunidades o impedimentos, resultan cuestiones decisivas para definir el "lugar común" de una generación, al igual que sus diferencias y relaciones con otras generaciones. Así, distintas generaciones pueden construir una situación social, pero los problemas envueltos en tal situación serán distintos para cada una, pues su perspectiva e involucramiento con el asunto difieren. 
Volviendo a la cuestión de las desigualdades y las juventudes rurales, dos cuestiones a tomar en cuenta: primero, que las desigualdades no entrañan pura negatividad; allí donde desde una mirada aparece subordinación y disciplinamiento, también es posible ver formas de cuidado y protección, o donde identificamos sanción de las prácticas, también se produce beneplácito. Así también, las desigualdades no son exclusivamente producto de las relaciones entre los distintos sujetos, sino que hay que reparar en qué otros elementos estructurales, políticos, económicos -como se aludió al comienzo- determinan las formas que adoptan tales relaciones. En clave metodológica, estudiar con detenimiento los distintos significados atribuidos a las prácticas es requisito para salvar el riesgo de identificar únicamente daño o violencias o, como en ocasiones sucede, que el/la investigador/a pase por alto, en su construcción del otro, el contexto de producción de éste, deslegitimando en consecuencia a sus interlocutores como sujetos cuyas actitudes carecen de una racionalidad.

Segundo, abordar las juventudes rurales implica reconocer, como punto de partida, la existencia de una matriz de alteridad que combina dos elementos: la condición de juventud y la de ruralidad. Ambas suponen posiciones subalternas para aquellos que las incorporan en un período de sus trayectorias vitales. Por un lado porque los jóvenes ocupan, entre las distintas posiciones generacionales, una posición subordinada a las normas definidas por otras generaciones; por otro, porque la juventud entendida como producción histórica y socio-cultural, emerge, primero, como un fenómeno relacionado a las circunstancias e institucionalidades de los entramados urbanos de los países del "primer mundo". Es lo que de algún modo deja entrever Feixa cuando apunta que la noción de adolescencia, en tanto forma de juventud, comenzó a popularizarse en torno al 1900,

"cuando diversas reformas en la escuela ${ }^{1}$, el mercado de trabajo, la familia, el servicio militar, las asociaciones juveniles

\footnotetext{
1 La educación ha sido señalada como uno de los rasgos principales en lo que respecta a la invención de la juventud y la subjetivación de los sujetos en tanto jóvenes. Bourdieu dice que con el acceso a la las instituciones educativas, "los estudiantes se encuentran, durante un periodo relativamente largo y a una edad en la que antes hubieran estado trabajando, en esas posiciones casi externas al universo social que definen la condición de adolescente. (...) De unos años para acá, casi todos los jóvenes han tenido acceso a alguna forma más o menos cabal -y sobre todo más o menos larga- de esta experiencia; por corta o superficial que haya sido, se trata de una experiencia decisiva." (1990: 121-122). Recordemos aquí que el desarrollo de las infraestructuras edilicias, al igual que los procesos de universalización de la enseñanza, han avanzado en las ciudades con anterioridad que en las áreas rurales, lo que determina un acceso más tardío para las y los jóvenes del medio rural o signado por la práctica migrar a la ciudad, la cual en la actualidad, a pesar de los esfuerzos apuntados a su disminución, continúa vigente.
} 
y el mundo del ocio, permitieron que surgiera una nueva generación consciente de crear una cultura propia y distintiva, diferente a la de los adultos" (Feixa, 2006:3)

noción que se afianzará en el contexto de la posguerra, en donde aquellos países alcanzaban nuevos estándares de vida y reivindicaban la existencia de niños y jóvenes como sujetos de derecho pero, fundamentalmente, como sujetos de consumo (Reguillo, 2003).

De este modo, ser joven rural implica tener un lugar subordinado en la estructura social, en un ámbito territorial que, al mismo tiempo, ocupa el lugar de lo alterno en el binomio campo-ciudad. Esto no significa, empero, que los vínculos entre las partes de este binomio deban entenderse exclusivamente en tanto oposición, o con una rigidez tal que impida comprender los tránsitos de los sujetos, en especial los de las y los jóvenes entre uno y otro espacio. Aunque bien aparecen tensiones, colocar al campo y la ciudad en términos de oposición resulta insuficiente para aproximarnos a conocer las situaciones contemporáneas (Clivati, Martins \& do Amaral, 2013).

Siguiendo a Joel Bevilaqua Marin (2009), la juventud rural aparece como una invención desencadenada por la expansión del capitalismo industrial en las zonas agrarias, en tanto el joven rural es un sujeto que ha sido puesto al servicio del desarrollo de este modelo de producción, al identificarse en él un potencial para el incremento de la producción con técnicas especializadas. Mientras que en Europa y Estados Unidos comienza a hablarse de juventud rural en las últimas décadas del siglo XIX, en América Latina, donde el fenómeno de la industrialización y modernización de la agricultura penetró con posterioridad.

"la idea de juventud rural se insertó en los discursos y prácticas de las instituciones desarrollistas, lo que no quiere decir que antes de la industrialización no hubiera jóvenes rurales, sino que la juventud en las sociedades campesinas no integraba un fase distinta y definida del ciclo de la vida de los individuos" (Ibídem: 622)

En el caso que aquí analizamos, puede apreciarse con claridad el proceso de incorporación de los sujetos jóvenes en las relaciones de producción agroindustrial, pero también, como veremos, éste está limitado a las pautas que establece la normativa sobre empleo juvenil con sus particularidades para el medio rural. Es interesante notar que tanto las juventudes rurales como construcción cultural, como la normativa sobre empleo juvenil en el contexto nacional, tienen un vínculo directo con la instalación a nivel internacional de un discurso sobre el reconocimiento 
de determinados sujetos y sus derechos específicos que produce efectos similares en los distintos países; esto ocurre a partir del empuje de organismos que se han legitimado como actores que intervienen, regulan y producen marcos de acción a nivel de los Estados-nación ${ }^{2}$.

La magnitud y rapidez con que acontecen los cambios en materia de relaciones económicas y de producción a escala global, con repercusiones específicas en lo local y en particular en los contextos rurales; la dilatación de las juventudes hegemónicas, asociada a la prolongación de las trayectorias educativas, la juvenilización de las prácticas de consumo de las nuevas tecnologías y la movilidad espacial -por mencionar algunos características-; y la consolidación de discursos y mecanismos jurídicos transnacionales en torno a las y los jóvenes como sujetos de derecho, vuelve pertinentes los esfuerzos por comprender las condiciones de vida de las generaciones de jóvenes en los contextos rurales actuales.

Incorporando este enfoque que sostiene que la construcción de los sujetos, como sus condiciones son relacionales y multidimensionales, y que la juventud implica una manera particular de estar en la vida (Margulis \& Urresti, 1998), el presente trabajo pretende contribuir a las discusiones sobre la producción de las desigualdades en la construcción de las juventudes, presentando el caso de las y los jóvenes de una localidad rural de Uruguay. El énfasis está puesto en comprender cómo inciden en sus trayectorias de vida las transformaciones en las dinámicas territoriales y laborales que han acarreado el desarrollo de las agroindustrias citrícola y forestal, presentes en la zona desde los ochenta y noventa respectivamente, la incorporación de normativa que regula el empleo juvenil con particularidades para el medio rural y, por último -pero no menos importante- los cambios generacionales en los valores y los modos de vida de los habitantes del centro poblado.

¿Por qué interesa discutir estos aspectos? Pues en lo profundizado en el trabajo de campo ocupan un lugar de relevancia para comprender la construcción de las identidades, oportunidades y limitaciones de los sujetos concretos y, al mismo tiempo, involucran prácticas, discursos y reglas que van más allá de las y los jóvenes, pero que los afectan de formas particulares. Cabe apuntar, además, que desde la investigación las juventudes rurales en Uruguay no han merecido la misma atención que las juventudes urbanas, estas sí abordadas desde múltiples enfo-

2 El sistema de Naciones Unidas, la Organización Internacional del Trabajo, la Organización Iberoamericana de la Juventud, la Organización de Estados Americanos, entre otros. Los mecanismos mediante los cuales estos dispositivos se incorporan en los contextos nacionales y los efectos que producen en las distintas tramas, merecen ser analizadas con detenimiento. 
ques. Esta desatención, si se quiere, tiene que ver con consideraciones que, aunque en la actualidad han caído en desuso, merecerían ser contrastadas con rigurosidad a partir de investigaciones empíricas. Entre tales consideraciones encontramos, por ejemplo, que el hecho de que "los estudios agrarios tradicionales, preveían que la modernización y la urbanización, al reducir el espacio rural destinaba a la mayoría de los jóvenes a la migración" (González Cangas 2003, citado por Kessler 2007:19)3. Por otra parte, se ha señalado que estos estudios mantienen un marcado énfasis urbanocéntrico, "al identificar a la cultura juvenil como una cultura eminentemente urbana" (Kessler, 2007:19). Los trabajos específicos sobre la temática comienzan a aparecer, tímidamente, durante los noventa (Kmaid, 1990; Rodríguez y Zamalvide, 1998) abordando de forma genérica la incidencia de los procesos sociales y económicos sobre las juventudes rurales en el país y, si bien han sido complementados con otros más recientes (Corbo, 1993; Caggiani, 2004; Gallo, Molinaro \& Osorio; Romero, 2012, 2008 y 2004), aún se puede sostener que, el conocimiento que se tiene sobre las juventudes rurales en Uruguay es escaso y fragmentario. Por último, se entiende como una aportación específica de los abordajes etnográficos, la posibilidad de arrojar luz sobre cómo se lían las prácticas, discursos y valores de los sujetos con cuestiones de orden estructural.

\section{ENFOQUE METODOLÓGICO}

Los aspectos abordados en este trabajo son producto de un estudio etnográfico en la localidad rural de Gallinal y sus alrededores (ubicada en el interior del Departamento de Paysandú, Uruguay), desde mayo de 2014 a julio de $2015^{4}$. Su objetivo ha sido dar cuenta de cómo se viven-

\footnotetext{
3 El punto amerita una breve problematización que sin duda requiere ser profundizada, puesto que no se ha confirmado completamente, pero tampoco puede descartarse. Por un lado, los datos demográficos confirman que la urbanización constituye un proceso incesante para todos los países de América Latina por lo menos desde mediados del siglo XX en adelante (Lattes, 2001), en donde además Uruguay aparece rankeando las estadísticas junto a Argentina y Chile; a su vez, los datos censales del Instituto Nacional de Estadística (INE) confirman que la evolución de la población rural en Uruguay ha ido en franco descenso. No obstante, la población rural no ha desaparecido y representa, de acuerdo a los datos del censo de 2011, el 5,34\% del total de la población (Tomado de: http:// www.ine.gub.uy/censos2011/index.html); al tiempo que la sanción de la Ley 14.101 de 1973 que dispone la obligatoriedad de la educación primaria y media básica (en la actualidad, con la sanción de la Ley 18.437 de 2008, comprende también la educación inicial y media superior), obliga también al Estado a ofrecer las posibilidades de acceso en los distintos escenarios, incluidos ahí los contextos rurales.
}

4 Por el período de un año el proyecto recibió el financiamiento de la Comisión Sectorial de Investigación Científica (CSIC-UdelaR) a través del Programa de Iniciación a la Investigación, adquiriendo continuidad con una beca de posgrado de la Comisión Académica de Posgrados de la Universidad de a República. 
cian y representan las juventudes rurales, cartografiando las relaciones sociales y territoriales del lugar.

La etnografía es el principal método de conocimiento desarrollado por la Antropología, basado en el "estar ahí" (participando, observando e involucrándose en extenso en las tramas sociales de un espacio determinado), y establecer un intercambio reflexivo con los sujetos de estudio. En esta inmersión en un campo relacional determinado, el/ la etnógrafo/a se convierte en la herramienta de investigación indispensable para llevar adelante un proceso etnográfico. Este proceso etnográfico supone conocer los discursos y prácticas de los sujetos, los sentidos que le atribuyen, las relaciones que establecen entre ellos y con el territorio.

En sus inicios la etnografía fue tributaria del paradigma positivista (Guber, 2005), y el propio Malinowski (1986), quien sentara las bases del método a partir de sus investigaciones en las Islas Trobriand (Papua Nueva Guinea), instaba a presentar los datos de forma "limpia y sincera". La reflexión en extenso sobre la etnografía en las décadas posteriores, condujo a reorientar el enfoque teórico del método, manteniendo del paradigma positivista aspectos como el trabajo empírico, pero incorporando de otros, como el interpretativista, la reflexión sobre la variabilidad de significados que puede tener una misma práctica, según en qué contexto y momento sea realizada, y una legítima preocupación por comprender los cambios y procesos socioculturales a lo largo del tiempo.

Malinowsky también definió las técnicas que se convirtieron en elementos medulares de la etnografía moderna: la observación participante, llevar el diario de campo de forma sistemática, establecer un rapport con los sujetos de estudio y mantener una alerta epistemológica sobre la introducción del sesgo etnocéntrico. En este trabajo fundacional, publicado originalmente en 1922, Malinowsky anotaba:

"considero que una fuente etnográfica tiene valor científico incuestionable siempre que podamos hacer una clara distinción entre, por una parte, lo que son los resultados de la observación directa y las exposiciones e interpretaciones del indígena y, por otra parte, las deducciones del autor basadas en su sentido común y capacidad de penetración psicológica" (1986:21)

De esta manera se colocaba la distinción entre las prácticas y discursos de los sujetos de estudio, y las interpretaciones formuladas por el etnógrafo. Cabe agregar, en vínculo con ello, que el campo de relaciones en el que se "sumerge" el/la investigador/a, así como el objeto de 
estudio que define, no son un espacio ni una realidad dada a priori. Por el contrario, el/la investigador/a participa de la conformación de dicho campo y objeto, interviniendo desde su posición social y en interacción con sus interlocutores.

El trabajo de campo organizado en base a las técnicas arriba mencionadas, continuó siendo la piedra de toque de la etnografía hasta la actualidad, al tiempo que fue colocándose como uno de los elementos centrales del método la reflexividad, entendida como una vigilancia epistemológica y en este sentido, una reflexión crítica, objetivante y "desde afuera" (Hammersley y Atkinson, 1994) de las prácticas del investigador y de su sentido común, tanto en el desarrollo del trabajo de campo como en el proceso de escritura.

Para este caso, llevar adelante un proceso etnográfico implicó desarrollar trabajo de campo en la localidad de Gallinal por el período de un año y algunos meses entre 2014 y 2015. También se realizó trabajo de campo en las empresas forestales y citrícolas que se encuentran rodeando la localidad, lugar de trabajo de buena parte de sus pobladores. En este lapso, se realizaron visitas quincenales al pueblo, conociendo las dinámicas espaciales y temporales del lugar. El trabajo de campo ha implicado observaciones, entrevistas a personal del centro educativo, charlas informales y entrevistas con adultos y jóvenes que viven en la localidad, llevando un registro sistemático en el diario de campo de estas actividades. También se han analizado las características de la política de vivienda (MEVIR) a través de la cual se construye Gallinal, documentos y normativa sobre desarrollo de las agroindustrias citrícola y forestal y sobre regulación del empleo juvenil.

En una instancia posterior a la de trabajo de campo se procedió a la desgravación de entrevistas, revisión de las notas de campo, análisis de los documentos e información aportados por las y los sujetos de estudio, de manera de ir conformando un mapeo de las relaciones sociales, de las prácticas y los discursos en torno a las cuales emergen tensiones que guardan relación con la construcción de las juventudes.

¿Quiénes son las y los jóvenes sobre los que trata este trabajo? Son los descendientes, hijos y nietos de quienes fueron los pobladores funcionales de Gallinal. Referiremos a las y los jóvenes en general y nos enfocaremos en particular en lo que acontece con anterioridad a los 18 años, puesto que se trata de un período en el cual se produce una forma de la desigualdad a partir de las intersecciones entre moralidades, normativa y enclave territorial. 


\section{RESULTADOS}

\section{GALLINAL}

En la historia rural del Uruguay Gallinal es un pueblo ${ }^{5}$ joven, 2015 es el año de su 25to aniversario. Su trayectoria responde a las transformaciones de las últimas décadas en el medio rural, en particular aquellas enlazadas al desarrollo de las agroindustrias de la citricultura y la forestación en el Departamento de Paysandú. En 1988, y mediante el sistema de ayuda mutua, a través de la intervención de MEVIR ${ }^{6}$ se comienza la construcción de la localidad, instalándose en 1990 los primeros pobladores. Ése será el primero de cuatro planes de viviendas que se sucederán durante la década de los noventa, a través de los cuales la población de la localidad aumentó de forma continuada ${ }^{7}$, pasando de ser un núcleo de unas 45 viviendas a uno de 220 en la actualidad. Este proceso se da a la par de las demandas de fuerza de trabajo de las

\footnotetext{
5 Pueblo es la categoría que utilizan sus pobladores de Gallinal, si bien formalmente sería categorizado como centro poblado. De acuerdo al texto aprobado (Repartido $\mathrm{N}^{\circ} 51$, Carpeta $\mathrm{N}^{\circ} 230$ de 1995), será categorizado como centro poblado aquel que cuente con a) más de 150 habitantes y b) posea: educación inicial y enseñanza primaria completa en la localidad o en su área de influencia; atención primaria de la salud pública por medio de un servicio regular de policlínica o población capacitada para efectuar tareas de socorro primario, de acuerdo con lo que establezca la reglamentación; destacamento policial; servicio regular de transporte colectivo, departamental o interdepartamental. Para ser pueblo, debe contar además con a) más de 1000 habitantes, y b) primer ciclo de enseñanza secundaria en la localidad o en su área de influencia, atención de la salud pública por medio de un servicio regular de policlínica y servicio de ambulancia y sub comisaría. Disponible on line: http://www.parlamento.gub.uy/textosaprobados/AccesoTextoAprobado.asp?Url=/textosaprobados/camara/d20061011-01405-0345.htm. El único aspecto que Gallinal no estaría cumpliendo en la actualidad para ser pueblo, es el de la cantidad de habitantes requerida.
}

6 MEVIR, o Movimiento para Erradicar la Vivienda Insalubre del Trabajador Rural, es una persona pública no estatal que persigue el objetivo de contribuir en la construcción de un hábitat sostenible para la población que vive y/o trabaja en el medio rural. Surge en 1967 a instancias de la figura del Partido Nacional Dr. Alberto Gallinal Heber. En sus inicios las acciones estuvieron orientadas al asalariado rural mediante la construcción de "viviendas nucleadas", pero con el paso del tiempo y de cara a las transformaciones que sufría el medio rural, fue adaptándose y diversificando sus líneas de acción, contemplando entonces las situaciones de los pobladores rurales dispersos a través de la incorporación de las "unidades productivas". Las viviendas del primer tipo -como es el caso de Gallinal- se construyen mediante ayuda mutua, y acceden a ellas "familias de escasos recursos que no tienen acceso a una solución habitacional"(Tomado de: http:// www.mevir.org.uy/index.php/institucion/que-es-mevir)

7 Hacia 1996 había en Gallinal una población de 472 personas, en 2004 ascendía a 655 y en 2011 a 700. (INE: http://www.ine.gub.uy/censos2011/resultadosfinales/paysandu.html). Para tener una idea de la población de niños adolescentes y jóvenes, según el Censo de 2004, en Gallinal habían 108 personas de entre 0 y 5 años, 164 de entre 6 y 14 años, 46 de entre 15 y 19,51 de entre 20 y 24 y 47 de entre 25 y 29 , cifra que en su totalidad supera ampliamente a la mitad de la población de la localidad (INE, 2004). 
empresas de producción de naranja (principalmente una, Azucitrus), que para entonces ya habían adquirido cierta trayectoria, además de la más incipiente agroindustria forestal que irá creciendo sin detenerse desde la década de los noventa.

El desarrollo de la industria citrícola en Paysandú y, en general, en la zona del litoral norte uruguayo, no es ajeno a transformaciones económicas de impronta neoliberalista que exceden al país, pero se vinculan al territorio nacional de manera particular mediante la incorporación de normativas específicas ${ }^{8}$. La producción citrícola se había instalado con bastante anterioridad a las décadas de 1980-1990; a comienzos del Siglo XX, el Río Uruguay ya constituía una vía de circulación de la producción citrícola proveniente de ambas márgenes (para el caso uruguayo, la producción provenía exclusivamente del Departamento de Salto), para su comercialización internacional, siendo la ciudad de Buenos Aires uno de los destinos principales. A partir de la década del ' 30 y debido a cambios en la estructura del mercado, Uruguay limitará su producción para el abastecimiento local (Ruffier, 2005). Décadas más tarde el marcado volverá a extenderse más allá de las fronteras nacionales, al amparo de las políticas basadas en la lógica del "estado de bienestar" (Ibídem). Con este marco, los procesos de desregulación y desprotección del mercado nacional implicarán el crecimiento de determinados rubros del sector agropecuario, entre ellos el citrus, el arroz y la cebada, rubros que registrarán un fuerte impulso exportador (Piñeiro, 2005).

Además de la citricultura, durante los 90 la forestación vino a dar un nuevo impulso al asentamiento de población en la zona donde se encuentra Gallinal. Cabe mencionar que Paysandú es uno de los departamentos que por sus características geográficas es considerado de "prioridad forestal", posicionándose entre los mayores productores forestales del país? ${ }^{9}$ La importancia económica que ha adquirido la fo-

8 No es casual la aprobación de la Ley $\mathrm{N}^{\circ} 13.930$ que reglamenta el Plan de Mejoramiento y Extensión Citrícola, del 31 de diciembre de 1970 (actualmente en revisión). Las pretensiones de extender la actividad del sector son claras y se manifestarán en actividades específicas. Dicho plan tendrá entre sus principales cometidos “a) Incremento de la producción de las plantaciones mediante la promoción de técnicas adecuadas de manejo, poda, sanidad, fertilización, riego, cosecha, empaque y comercialización de los productos cítricos; b) Introducción, selección y difusión de material genético de alta productividad; c) Preparación y ejecución de Planes decadariales para la expansión de nuestra área citrícola." (Ley N ${ }^{\circ}$ 13.930. Disponible en:http://www.parlamento.gub.uy/leyes/AccesoTextoLey. asp?Ley=13930\&Anchor $=$ )

9 En Uruguay la superficie ocupada por plantaciones forestales se multiplicó por nueve entre 1990 y 2000, fenómeno que se vincula con la Ley de Promoción Forestal Nº15.939 de 1987, pasándose de una situación histórica de producción para el abastecimiento de la 
restación en Uruguay, con grandes repercusiones en las dinámicas territoriales y sociales de los contextos rurales, también ha estado ligada a la implementación de disposiciones estatales como la exoneración de impuestos -medida vigente hasta 2005- y los incentivos establecidos por la primera ley de promoción forestal del año 1968 (Ley N ${ }^{\circ} 13.723$ ), reemplazada por en 1987 por la segunda ley de promoción del sector en Uruguay (Ley N $\mathrm{N}^{\circ}$ 15.939) (Riella \& Ramírez, 2008).

Gallinal fue pensado para radicar de manera permanente a la población que estas agroindustrias demandaban como mano de obra, en un lugar próximo al lugar de trabajo. De hecho, el predio donde se construye fue donado a MEVIR por uno de los directivos de la empresa Azucitrus y no existía allí de manera previa, como es común en las localidades rurales, un rancherío ${ }^{10}$. En Gallinal la centralidad que mantiene el trabajo es palpable en lo cotidiano; el trabajo en la naranja ${ }^{1}$ y en la forestación constituyen un locus simbólico y práctico medular en la trama social y en las dinámicas territoriales de la zona, puesto que las y los trabajadores se desplazan fuera del pueblo a diario para llegar a sus lugares de trabajo, sumado al hecho de que no se dispone de servicios de esparcimiento recreación. Así, el trabajo es la actividad en torno a la que se aglutina el conjunto de la población y el principio moral por el que se establecen las relaciones sociales y las representaciones de los distintos sujetos.

La promesa de "traer el desarrollo a la zona"11 que trajo la naranja durante los ochenta y noventa, reforzada luego el pujante negocio de la forestación, hizo eco en una población relativamente joven que buscaba emanciparse y que no había encontrado hasta entonces, en el medio rural, las vías para formar sus familias en condiciones dignas. Es así que Gallinal reunirá en sus comienzos a parejas de trabajadores con hijos pequeños del medio rural y de pueblos más antiguos como

demanda interna, a una de producción para exportación y para la elaboración de celulosa. (Carámbula y Piñeiro, 2006).

10 La expresión rancherío refiere a las viviendas de condiciones precarias que aparecían agrupadas o aisladas en el medio rural uruguayo. Promediando el siglo XIX y durante buena parte del siglo XX, los rancheríos eran llamados pueblos de ratas aludiendo a las condiciones de vida extrema que le tocó vivir a la población rural, -genéricamente conocidos como pobrerío rural- a partir de los cambios que introdujo el alambramiento de los campos, proceso que modificó no el medio, los vínculos entre empleados y patrones y disminuyó notablemente la demanda de fuerza de trabajo (Véase Barrán y Nahum, 1972).

11 La frase fue tomada de un video documental conmemorativo del aniversario número 20 de Gallinal, organizado por la empresa Azucitrus. En éste aparecía el hijo del mentado Don Carlos Fraschini dando cuenta de que la visión de su padre había sido justamente la de "traer el desarrollo a la zona". 
Cerro Chato, a población de ciudades cercanas como Paysandú ${ }^{12}$, y de entornos urbanos y rurales de otros Departamentos de la zona Norte del país, como Artigas y Rivera; población que vio en la incipiente agroindustria citrícola la oportunidad de un trabajo estable al cual no tenían acceso en sus lugares de origen. Las transformaciones que imprimieron en este escenario las agroindustrias mencionadas, con sus importantes demandas de fuerza de trabajo, propiciarán la reorganización de parte de la población rural de los Departamentos de la zona, pero también, en cierta medida, el desplazamiento poblacional de la ciudad al medio rural, proceso que había tenido -y aún tieneuna tendencia contraria, relacionada a la migración hacia las zonas urbanizadas de forma creciente desde mediados del siglo XX (Piñeiro y Moraes, 2008).

Hay que dejar en claro al lector que, en tanto localidad rural -es decir en tanto núcleo poblacional y habitacional que cuenta con la presencia de distintas instituciones estatales-, Gallinal tiene ciertas características que la diferencian de otras formas organizativas del medio rural, como unidades productivas familiares que aparecen más dispersas en el territorio; la incorporación de ciertos rasgos de urbanización no significa, empero, la pérdida del sentido de pertenencia de sus pobladores a este medio.

\section{GENERACIONES JÓVENES Y CICLO EDUCATIVO}

Como demanda planteada por la población se instala en la localidad, enseguida de su inauguración, una escuela rural que sobre los dos mil se convertirá en un Centro Educativo Integrado (CEI) ${ }^{13}$ alcanzando a partir de entonces hasta noveno grado del ciclo educativo de primaria y secundaria. Hoy concurren al CEI un total de 150 estudiantes entre niños y adolescentes de entre 5 y 15 años ${ }^{14}$; lo que significa, solo en esta franja de edad, poco más de la quinta parte de la población total. De la población de niños y jóvenes, los más pequeños concurren al CAIF ${ }^{15}$

12 La ciudad de Paysandú es la capital del Departamento que lleva el mismo nombre. Gallina se encuentra a una distancia aproximada de $80 \mathrm{~km}$ de esta ciudad.

13 Los Centros Educativos Integrados son una figura institucional en el sistema educativo uruguayo destinada a la población radicada en zonas rurales, que tiene el objetivo de promover la universalización de la educación secundaria básica al integrar en un mismo local los tres primeros años de este ciclo junto con el de primaria. Los CEI desarrollan el proceso educativo hasta noveno grado, evitando así que los adolescentes tengan que desplazarse a diario o migrar a las ciudades a edades más tempranas.

14 Datos proporcionados por la Directora del centro educativo.

15 El Plan CAIF es una política pública intersectorial, integrada por instituciones del Estado y Organizaciones de la Sociedad Civil, cuyo objetivo es contribuir a garantizar la protección y promoción de los derechos de los niños y las niñas desde la concepción hasta 
y los que se encuentran en edad escolar y liceal, al Centro Educativo Integrado. En contados casos, de acuerdo a lo mencionado por la directora y los docentes, se desvinculan antes de finalizar. Si no repiten ningún grado, a los 15 o 16 años han finalizado el ciclo educativo que se les ofrece en la localidad, lo que instala dos opciones: permanecer en el pueblo y esperar a cumplir la edad mínima para ingresar al mercado de trabajo, o migrar a la ciudad para continuar estudiando.

Por distintos motivos, esta situación se torna un escenario complejo. De acuerdo a lo mencionado por los pobladores de Gallinal, entre ellos los jóvenes consultados, cada vez más continuar estudiando es considerado como una opción para ellos; sin embargo no en todos los casos las familias disponen de recursos económicos suficientes para apoyar esta aspiración de sus hijos, aspecto que puede contemplarse en relación a las posibilidades de ascenso laboral limitadas y a las remuneraciones relativamente bajas que reciben ${ }^{16}$. Migrar a la ciudad implica, como mínimo, pagar un hogar estudiantil, pensión o apartamento y gastos de alimentación y de transporte; esto suma una cifra considerable, en algunos casos imposible de cubrir para familias que suelen tener más de un hijo/a. No obstante, en líneas generales la continuación de las trayectorias educativas por parte de la población juvenil es una característica presente. Se observa para localidades pequeñas y zonas rurales de todos el país, un aumento de $47,6 \%$ a 51,1\% entre 2006 y 2014, en el porcentaje de jóvenes de entre 14 y 17 años que completaron el ciclo básico de educación media. Con respecto a la finalización del ciclo de educación media se ha dado un aumento de $18,5 \%$ a 19,6\% entre 2006 y 2014, en el porcentaje de personas mayores de entre 18 y 20 años, en tanto para personas de 30 años y más, la evolución va de $8,6 \%$ a $12,0 \%$ en el mismo período (Observatorio de la Educación-Codicen, 2015). Estas cifras, si bien no son específicas del caso de Gallinal, muestran que la población juvenil del medio rural paulatinamente se inclina por continuar sus trayectorias educativas, característica que está menos presente entre las generaciones anteriores, en donde el ingreso al mercado de trabajo se daba en edades más tempranas y las posibilidades de estudiar en los contextos rurales eran menores; pero también revelan que

los 3 años, a través de un sistema de Centros de Atención a la Infancia y la Familia (CAIF) desplegado a nivel nacional. Tomado de: http://caif.org.uy/3671-2/

16 Vale la pena recordar que las soluciones habitacionales que ofrece MEVIR están destinadas a familias de escasos recursos que no cuentan con vivienda propia. En este marco, aparecen como relevantes los datos de que, para todo el país, el nivel educativo más alto alcanzado por los beneficiarios de MEVIR con 15 o más años es principalmente primaria, representando un 55\% del total. (Bertinat \& Bertullo, 2008), en tanto el 60\% de los jefes de hogar son asalariados, el $14 \%$ son trabajadores por cuenta propia, mientras tan solo un $1 \%$ son patrones (Bertullo \& Bertinat, 2009). 
existen distancias significativas entre quienes culminan ciclo básico y quienes culminan el ciclo de enseñanza media, en la actualidad. Como sea, estudiar en Paysandú implica un esfuerzo económico importante para las familias de los jóvenes y, es probable, como expresaba con preocupación Gustavo $^{17}$-uno de los pobladores fundacionales de Gallinal-, "que estos jóvenes no regresen al pueblo". Terminar el bachillerato abre la posibilidad de continuar realizando estudios terciarios o, en cualquier caso, aspirar a otros tipos de trabajos mejor pagos que aquellos que pueden obtener -básicamente en la naranja o la forestación- si regresan al pueblo. A propósito de la falta de incentivos para retornar, debemos mencionar las dificultades que pueden existir para acceder a una vivienda independiente ${ }^{18}$.

Pero no todos los jóvenes tienen un "tránsito exitoso" por el ciclo educativo, ni tampoco a todos les interesa continuar estudiando en la ciudad. Entre los discursos expresados por los distintos interlocutores que he tenido en Gallinal, los jóvenes que no culminan el ciclo básico de secundaria son situados en el foco de las preocupaciones, porque, seguía comentando Gustavo,

"hasta que no tienen la mayoría de edad [18 años] en las empresas no los toman para trabajar, ahora están mucho más estrictos coneso. Entonces andan acá en la vuelta, no tienen actividades, son juventudes perdidas y así empiezan con que toman un vino y después un porro, así se meten en 'la droga".

El discurso de Gustavo reúne los aspectos que hacen a la principal tensión entre las distintas generaciones, a saber, las limitaciones para acceder a mercado de trabajo y la estigmatización de las prácticas juveniles. Esto redunda en la configuración de una forma de desigualdad en donde convergen las disposiciones de la normativa, los valores adultocéntricos, las características de la oferta educativa y las "oportunidades" laborales que ofrecen la agroindustrias.

\section{NORMATIVA, VALORES Y POSICIONES GENERACIONALES}

El discurso de "la droga" instalado entre los adultos tiene una relación

17 Los nombres han sido modificados para preservar el anonimato.

18 En una entrevista personal, una Asistente Social de larga trayectoria en MEVIR señalaba que en el otorgamiento de viviendas se prioriza a mujeres jefas de familia, pero en caso de ser solteros y no tener hijos, tanto las mujeres como los varones no son considerados destinatarios con la misma facilidad, pues se entiende que son más propensos a mudarse. El acceso a su vez depende de la disponibilidad que pueda existir de viviendas que han sido expropiadas por falta de pago o dejadas en abandono, o de las demandas para construir nuevos planes en un lugar dado. 
estrecha con la circulación por el pueblo de jóvenes que no son de la localidad y que están alojados como trabajadores zafrales en las empresas citrícolas ${ }^{19}$. Aparecen en el pueblo eventualmente pero, según señalan sus habitantes, suelen alterar su tranquilidad, pues "vienen a emborracharse y arman peleas". De acuerdo a las narrativas construidas por los adultos, son ellos quienes "vienen a contaminar a los gurises de acá". Sin embargo, este discurso también se traslada a los jóvenes que viven en el pueblo -recae principalmente en los varones-, afianzando una perspectiva de la juventud entendida como un problema. En una charla informal, dos efectivos policiales comentaban:

"Acá lo que anda es el porro, el famoso porrito, nosotros si los vemos fumando se lo quitamos y lo rompemos o se lo llevamos." "El porro y el chasqui 20", agregó el otro oficial. "Ellos dicen que no tienen lugar, que no tienen un lugar donde chupar, porque eso es lo que quieren"

La principal problemática, aunque recibe distintos énfasis al ser enunciada por los sujetos que ocupan distintas posiciones generacionales y distintos lugares en la trama social, pareciera ser que los jóvenes no tienen un lugar propio, ni actividades destinadas a ellos. El salón comunal -el único espacio del pueblo destinado al uso común de la población que no es un espacio doméstico- no les es cedido a los jóvenes, quienes en repetidas ocasiones lo han solicitado con la finalidad de organizar actividades para ellos; mientras que en el espacio público no se les permite extender sus encuentros luego de la medianoche, argumentando los oficiales al respecto

"no sabés el ruido que meten con las motos, nosotros te invitamos a que te quedes un sábado de noche y a principio de mes cuando se haya cobrado la zafra para que veas lo que es". Si el problema son las motos, ¿por qué no se los insta a salir caminando?, -propuse-, "si no son las motos son los gritos y las carcajadas", respondieron.

\footnotetext{
19 Tan solo en los últimos meses han tenido lugar varios procesamientos por venta de estupefacientes por parte de trabajadores zafrales alojados en las empresas citrícolas en la zona de Gallinal. Los episodios son difundidos con un tono sensacionalista en el principal diario del Departamento, El Telégrafo:http://www.eltelegrafo.com/index.php?i $\mathrm{d}=102756 \&$ seccion $=$ policiales\&fechaedicion $=2015-08-16$ Sin dudas el asunto merece una exploración más detallada, pues involucra formas de desigualdad que afectan a los trabajadores zafrales tanto en lo relacionado a este tipo de trabajo como por las características de a sus trayectorias de vida.
}

20 Porro: cigarrillo de marihuana. Chasqui: dosis de pasta base de cocaína. 
Así, en tanto la policía asume su rol signado por el mandato de "hacer cumplir la ley", sustentado en los hechos por quejas de vecinos, no sólo no se buscan soluciones a los reclamos de las generaciones jóvenes de que no hay un lugar para ellos, sino que se practica una política de exclusión; esto ocurre a partir de formas de violencia en la que se ignoran sus derechos -por ejemplo a decidir qué tipo de sustancias desean consumir, práctica que en Uruguay no es penada por la ley, o a algo más sencillo como hacer uso del espacio público-y del afianzamiento de un discurso estigmatizante sobre las juventudes.

Por otra parte, en lo que respecta al acceso al mercado de trabajo, tanto las empresas vinculadas a la forestación como las de producción citrícola no contratan personal en edades anteriores a los 18 años, apoyándose en la normativa vigente. En este plano, se presenta el siguiente marco: La ley de empleo juvenil $\mathrm{N}^{\circ} 19.133$, sancionada en 2013, establece en su Artículo 7:

"podrán ser contratadas bajo las modalidades preceptuadas en la presente ley las personas jóvenes a partir de 15 años ( ) En caso de ser contratadas personas menores de 18 años de edad se las protegerá contra el desempeño de cualquier tipo de trabajo peligroso, nocivo para su salud o para su desarrollo físico, espiritual, moral o social, prohibiéndose todo trabajo que no le permita gozar de bienestar en compañía de su familia o responsables o que entorpezca su formación educativa, siendo de aplicación las demás disposiciones del Capítulo XII del Código de la Niñez y la Adolescencia"

Entre las formas de trabajo peligroso han sido incluidas la agricultura y la forestación, principales fuentes de trabajo en la zona, con lo cual las y los jóvenes quedan excluidos de toda actividad laboral hasta cumplir 18 años, mientras que la oferta educativa concluye con anterioridad.

Pero además, Estatuto del Trabajador Rural (Ley Nº14.785) sancionada en 2012, señala en su Artículo 25:

"La edad mínima para desempeñar un trabajo rural que por su naturaleza o las condiciones en que se ejecuta pudiera dañar la salud y la seguridad será de 18 años."

Con esto, pareciera ser que cualquier tipo de actividad laboral, peligrosa o no, queda vedada para las y los jóvenes de Gallinal hasta cumplir la "mayoría de edad", en un contexto donde el trabajo constituye un valor medular desde la perspectiva de los sujetos adultos, pero también desde 
lo experiencial dado que en los hechos este emerge como la principal práctica que regula las dinámicas sociales, territoriales e históricas.

Los sujetos jóvenes en edades que van entre los 18 y 29 años tienen prácticas que los diferencian de aquellos menores que ellos, básicamente por su inserción laboral. Es esta actividad, cuando se realiza formalmente ${ }^{21}$, la que se presenta como un punto bisagra en sus trayectorias, sobre todo entre los varones, quienes pasan de ser jóvenes "que no estudian ni trabajan", a "trabajadores" y, por tanto, proveedores, convirtiéndose rápidamente en "padres de familia". Entre las mujeres, los tránsitos llegan a ser relativamente más heterogéneos: si culminaron el ciclo escolar posiblemente continúen con el nivel de bachillerato en la ciudad de Paysandú, incluso tal vez prosigan con estudios terciarios en la capital del país; si eventualmente retornan al pueblo es posible que logren emplearse en alguna de sus instituciones (centro educativo, CAIF, policlínica, juzgado, Centro $\mathrm{MEC}^{22}$ ). Si terminaron ciclo básico, pero se quedaron en el pueblo, es posible que conformen una familia en no mucho tiempo, como observé entre varias de mis interlocutoras, aconteciendo de este modo su transición hacia la vida adulta y este aspecto facilita las posibilidades de acceso a una vivienda en el pueblo. Como se ve, las trayectorias que siguen mujeres y varones no dejan de estar atravesadas por las moralidades de género, de acuerdo a las cuales los varones tienen que cumplir con la obligación de proveer, mientras ellas deben ser buenas cuidadoras de sus hijos (Albano, Castelli, Martínez \& Rossal, 2015). También en conexión con ello, es común que la continuación de las trayectorias educativas entre las mujeres reciba una mayor aceptación social, en tanto de los varones se espera ingresen al mercado de trabajo.

\section{APUNTES FINALES}

A partir del abordaje de un caso concreto, lo expuesto en este texto ha tratado mostrar la multiplicidad de elementos que se ponen en relación para definir una situación social, en donde es posible identificar formas

21 Algunos jóvenes relataron haber conseguido changas con vecinos, es decir trabajos temporales e informales, pero esto no es la norma sino más bien la excepción.

22 Los Centros MEC son una política cultural del Ministerio de Educación y Cultura que surge en 2007. Es un espacio para el desarrollo de actividades culturales, educativas, de participación social y de acceso a las tecnologías de la información y comunicación (TIC). Está equipado con computadoras (entre 3 y 6 terminales, dependiendo de la cantidad de habitantes de cada localidad) con conexión adsl 1024 de Antel, una impresora láser, un escáner, un televisor de pantalla plana de 29 pulgadas (donado por la República Popular China), un lector de dvd y al menos una sala de reuniones o exhibiciones para veinte o treinta personas. Tomado de: http://archivo.presidencia.gub.uy/_Web/noticias/2007/07/ CENTROS_MEC.pdf 
particulares que adoptan las desigualdades que afectan a los sujetos jóvenes. Se ha intentado mostrar, a su vez, que el método etnográfico resulta una herramienta valiosa para introducirnos en las distintas tramas sociales y comprender por qué los comportamientos de los sujetos pueden parecernos inapropiados, por qué emergen diferencias entre lo que nuestros interlocutores dicen y hacen, e incluso proponer explicaciones acerca de por qué aún cuando las normas tienen por cometido proteger -como se ve aquí en relación a la normativa sobre trabajo juvenil-, producen vulnerabilidad y dejan expuestos a las y los jóvenes a la sanción social.

Las disposiciones de la legislación mencionada pueden considerarse como un punto de inflexión en la trayectoria laborales de las y los jóvenes en el medio rural en Uruguay y, en particular, para escenarios como el aquí abordado, donde grandes empresas regulan las dinámicas territoriales y no están dispuestas a correr el riesgo de ser sancionadas, como sí puede ocurrir en otros ámbitos rurales. Para el caso concreto de Gallinal, donde los pobladores más viejos testimonian que en otros tiempos "se trabajaba desde que eras gurí", estas normas son vistas con recelo, pues se tensionan con sus propias moralidades; de esta coyuntura deviene un conflicto intergeneracional atravesado por cambios introducidos desde el marco normativo.

Entendámonos: no se trata de que las generaciones más jóvenes no le otorguen valor al trabajo, sino que una serie de determinantes hacen que su inserción en el mercado de trabajo se de más tardíamente, al mismo tiempo que las instituciones del Estado presentes en la localidad no asumen el problema como un asunto procurando cambios. En tanto las escuelas rurales han sido identificados como espacios con potencial para promover el desarrollo territorial (Riella y Vitelli, 2005), se propone en este sentido que las instituciones educativas en articulación con otras instituciones cumplan un papel de mayor relevancia de cara a subsanar desigualdades específicas en el contexto rural.

Asimismo, la continuación de las trayectorias educativas fuera del pueblo, si bien es una actividad valorada, también marca diferencias con respecto a las oportunidades que tuvieron las generaciones anteriores. Si antes un padre tenía la convicción moral de que debía exigir a sus hijos que trabajasen desde la adolescencia, incluso desde la niñez, ahora no sólo la ley se lo prohíbe, sino que lo moralmente correcto pasa a ser que los padres apoyen a sus hijos en sus aspiraciones de continuar estudiando; entretanto, en la construcción de esta realidad social los obstáculos económicos tienen una presencia importante. En la articulación compleja de estos múltiples elementos las matrices de valores se van modificando 
y las generaciones se definen en relación a nuevos "problemas en común" (Vommaro, 2014).

Las y los jóvenes, por su parte, se han mostrado preocupados y activos por modificar la situación que les toca vivir y, en este sentido, compartiendo una "conciencia generacional" (Leccardi y Feixa, 2011). Lo que se vió, por el contrario, es que de forma incesante han buscado establecer vías que aporten a la resolución de ese "tiempo vacío" entre que terminan el ciclo educativo y pueden comenzar a buscar empleo, pero también incluso luego de que se insertan en el mercado laboral, pues sus expectativas e intereses son más amplios y no se limitan a este aspecto.

La articulación entre estudio y trabajo que propone la Ley de Empleo Juvenil (se prohíbe el trabajo que entorpezca la formación educativa), claramente encuentra mayores apoyaturas y posibilidades en los enclaves urbanos que en los rurales, donde las características territoriales y el tipo de actividades que se realizan complejizan las posibilidades de estudiar y trabajar al simultáneo, por ejemplo: dificultades para que se los contrate únicamente medio horario; necesidad de salir del pueblo para ir a trabajar tanto como para continuar estudiando, entre aquellos que finalizan el ciclo básico de secundaria; escasa circulación de autobuses que permitan el cumplimiento de los horarios de trabajo y/o estudio. Pero además, todo intento de solución se torna un proyecto estéril, puesto que más allá del tipo de trabajo, el Estatuto del Trabajador Rural señala que no está permitido trabajar en el medio rural antes de los 18 años. ¿No es posible, acaso, ofrecer algún tipo de alternativa laboral para las y los jóvenes que viven en contextos rurales y que reclaman actividades? Si la respuesta es no, ¿qué papel deben ocupar las instituciones estatales, en especial las vinculadas a lo educativo, para que las trayectorias de las y los jóvenes no se transformen en exclusión?

Por último, se ha podido observar cómo la forma en que se otorga sentido al territorio -en este caso al medio rural- a través de las normas, opera como limitante del desarrollo personal de las y los jóvenes, aún cuando en última instancia lo dispuesto en ellas tenga el objetivo de protegerlos. Se ve cómo los problemas del heterogéneo medio rural tienen un nexo estrecho con los centros urbanos (Pérez, 2005), en el caso de las generaciones más jóvenes vinculado a búsqueda de la emancipación; y cómo la construcción en términos de oposición del campo y la ciudad, atraviesa también el modo en que se estructuran las normas con un sesgo "urbanocéntrico" que desconoce la heterogeneidad de los escenarios rurales, al tiempo que simplifica las condiciones juveniles. 


\section{BIBLIOGRAFÍA}

Albano, Giancarlo; Castelli, Luisina; Martínez, Emmanuel \& Rossal, Marcelo 2015 "Legal, ilegal, ilegítimo. Usuarios de pasta base de cocaína en Montevideo" en Gazeta de Antropología, nro.31, vol.1 [on line]: http://www.gazeta-antropologia.es/?p=4725

Atkinson, Paul y Hammersley, Martyn 1994 Etnografía. Métodos de Investigación (Paidós: Barcelona).

Barrán, José y Nahum, Benjamín 1972 Historia rural del Uruguay moderno. Tomo IV. Historia social de las revoluciones de 1897 y 1904. (Montevideo: Ediciones de la Banda Oriental).

Bertullo, Jorge \& Bertinat, María 2008 Aproximación a la participación de los jóvenes en programas habitacionales de MERVIR.

(Montevideo: Unidad de evaluación, monitoreo, acompañamiento e investigación, MEVIR). Disponible en http://www.mevir.org.uy/ images/transparencia/Doc_estrategicos/juventud_rural.pdf -2009 Pobladores de MEVIR: una aproximación a sus condiciones de vida. Unidad de evaluación, monitoreo, acompañamiento e investigación (Montevideo: MEVIR).

Bevilaqua Marin, Joel 2009 “Juventud rural: una invención del capitalismo industrial” en Estudios Sociológicos, vol.27, N80, pp. 619-653 (México: El Colegio de México).

Bourdieu, Pierre 1990 "La juventud no es más que una palabra” en Sociología y Cultura, (México: Grijalbo).

Carámbula, Matías \& Piñeiro, Diego 2006 "La forestación en Uruguay: cambio demográfico y empleo en tres localidades" en Agrociencia Uruguay, Vol. X, N.2, pp.63-73.

Clivati Maria Regina; Martins Suely y do Amaral Wagner 2013 “Jovens do campo: a procura de visibilidade social” en Leila Sollberger Jeolás, Maria Ângela Silveira Paulilo, Maria Regina Clivati Capelo (orgs.) Juventudes, desigualdades e diversidades: estudos e pesquisas (Brasil: Eduel/Londrina). Disponible en: http://www.uel.br/editora/portal/ pages/livros-digitaisgratuítos.php

Caggiani, María 2004 Heterogeneidad en la condición juvenil rural: aportes para una definición sociológica de la juventud rural. Tesis Master en Sociología, FCS-UdelaR, Montevideo

Corbo, Daniel 1993 “El derecho de la juventud rural a la educación: la extensión de la Enseñanza Secundaria al medio rural” en Series Aportes a la Educación Nacional N5, MEC, Montevideo. 
Feixa, Carles 2006 “Generación XX. Teorías sobre la juventud en la era contemporánea”. Revista Latinoamericana de Ciencias Sociales, Niñez y Juventud, vol.4, $\mathrm{N}^{\circ} 2$, Manizales.

Feixa, Carles \& Leccardi, Carmen 2011 “El concepto de generación en las teorías sobre la juventud” en Última década, vol.19, №34, pp.11-32, [on line]: http://www.scielo.cl/scielo.php?pid=S071822362011000100002\&script=sci_arttext\&tlng=en

Gallo, Alejandra; Molinaro, Karina; Osorio, Natalia 2011 “Modelos heredados: continuidades y rupturas en proyectos laborales y profesionales de jóvenes rurales" en Mirada Joven, Revista de Divulgación Científica, $\mathrm{N}^{\circ} 1$, INJU-MIDES, Montevideo.

Guber, Rosana 2005 [1991] El salvaje metropolitano. Reconstrucción del conocimiento social en el trabajo de campo (Buenos Aires: Paidós).

Kessler, Gabriel 2007 “Juventud rural en América Latina. Panorama de las investigaciones actuales” en Bruniard, R. (coord.) Educación, desarrollo rural y juventud: la educación de los jóvenes de provincias del NEA y NOA en la Argentina. (Buenos Aires: UNESCO/IIPE/ Ministerio de Economía y Producción/ SAGPA/FIDA).

Kmaid, Gonzalo 1990 La juventud rural en el Uruguay: elementos para su discusión. (Montevideo: Ediciones de la Banda Oriental).

Lattes, Alfredo 2001 "Población urbana y urbanización en América Latina" en La ciudad construida. Urbanismo en América Latina (Quito: FLACSO Ecuador/Junta de Andalucía).

Malonowsky, Bronislaw 1986 [1922] Los Argonautas del Pacífico Occidental (Barcelona: Planeta Agostini).

Margulis, Mario y Urresti, Marcelo 1998 "La construcción social de la condición de juventud” en H. Cubides (ed.) Viviendo a toda. Jóvenes, territorios culturales y nuevas sensibilidades (Bogotá: Siglo del Hombre Editores).

Observatorio de la Educación 2015 Matrícula y cobertura. Educación técnica. ANEP-CODICEN. [On line]: http://www.anep.edu.uy/ observatorio/paginas/matricula/matricula_edtecnica.html

Pérez, Edelmira 2005 "Hacia una nueva visión de lo rural” en Giarracca, Norma (comp.) ¿Una nueva ruralidad en América Latina?, (Buenos Aires: CLACSO, Buenos Aires). 
Piñeiro, Diego 2005 "Población y trabajadores rurales en el contexto de transformaciones agrarias” en Giarracca, Norma (comp.) ¿Una nueva ruralidad en América Latina? (Buenos Aires: CLACSO).

Piñeiro, D. y Moraes, M. 2008 "Los cambios en la sociedad rural durante el siglo XX” en El Uruguay del siglo XX Montevideo (Montevideo: Departamento de Sociología/Facultad de Ciencias Sociales/UdelaR).

Reguillo, Rossana 2003 "Las culturas juveniles: un campo de estudio; breve agenda para la discusión” en Revista Brasileira de Educação, N²3, pp.103-118. Disponible en http://www.scielo.br/pdf/rbedu/ n23/n23a07.pdf

Riella, Alberto \& Ramírez, Jéssica 2008 “Población rural y forestación: estudio de la dinámica poblacional en los territorios forestales del Uruguay" en Agrociencia Uruguay, vol.12, N², pp.85-98. Disponible http://www.fagro.edu.uy/ agrociencia/index.php/ directorio/issue/view/13

Rodríguez, Juan y Zamalvide, José 1998 Juventud rural en el Uruguay de los 90 (Montevideo: Foro Juvenil /IICA).

Riella, Alberto \& Vitelli, Rossana 2005 “Escuelas rurales y desarrollo territorial: Revista Pampa, $\mathrm{N}^{\circ}$ 1, Santa Fe, Argentina

Romero, Juan 2012 "Población ocupada juvenil en el mercado de trabajo rural uruguayo, década 2000” en Ánfora, Vol. 19, N³3 (Colombia: Universidad Autónoma de Manizales).

2008 "La juventud rural: el caso uruguayo" en Marta Chiappe, Matías Carámbula y Emilio Fernández (comps.) El campo uruguayo: una mirada desde la sociología rural (Montevideo: Facultad de Agronomía).

2004 "La modernización agraria en el Uruguay. Los jóvenes rurales, una asignatura pendiente” en Norma Giarraca (comp.) Ruralidades latinoamericanas, identidades y luchas sociales (Buenos Aires: CLACSO).

Ruffier, Jean 2005 "La frontera como ventaja competitiva: la producción de naranjas en ambas márgenes del Río Uruguay” en Revista Galega de Economía, vol.14, $\mathrm{N}^{\circ} 1-2$, pp.1-20.

Vommaro, Pablo 2014 "Juventudes, políticas y generaciones en América Latina: acercamientos teórico-conceptuales para su abordaje” en Sara Alvarado y Pablo Vommaro (comp.) En busca de las condiciones juveniles latinoamericanas (Buenos Aires: CLACSO). 


\title{
REFLEXIONES SOBRE EXPERIENCIA INVESTIGATIVA JÓVENES ESTUDIANTES DE LA UNIVERSIDAD INDÍGENA DE VENEZUELA
}

\author{
María de los Ángeles Peña*
}

El presente artículo pretende contribuir al debate sobre los estudios de juventudes indígenas a partir de la reflexión de la experiencia de la investigación titulada Jóvenes estudiantes de la Universidad Indígena de Venezuela llevada en conjunción con reflexiones suscitadas en el marco de la Escuela Internacional de Posgrado "Juventud y Desigualdad en América Latina y el Caribe" que se llevó a cabo en la ciudad de Tegucigalpa en Honduras, del 22 al 26 de junio de 2015.

La intención, es delinear algunos criterios producto de la experiencia investigativa que pudieran orientar algunas futuras investigaciones y que a su vez, permitan visibilizar un sector demográfico que expone en sus múltiples realidades, circunstancias de marginalización preocupantes que ameritan ser atendidas por políticas públicas.

Se releva la deconstrucción hegemónica de lo que es ser joven, así como la importante consideración de indagar en las formas cómo

\footnotetext{
* Licenciada en Comunicación Social por la Facultad de Humanidades de la Universidad Central de Venezuela (UCV). Facilitadora en la Universidad Indígena de Venezuela. Becada por la Fundación Gran Mariscal de Ayacucho para Maestría en Gestión de ONGs en Hamline University, Minnesota. Tesista de la Maestría en Estudios de la Mujer de la UCV. Colabora como investigadora en Centro de Estudios para la Mujer UCV. E-mail: aliennto@yahoo.com.mx
} 
los jóvenes se definen así mismos en contextos de exclusión social y fuertes prejuicios hacia la pertenecía étnica. Las experiencias de mujeres indígenas jóvenes, permiten en esta investigación analizar las particularidades asociadas que género, las cuales, tienden a no ser objeto de estudio por parte de las tendencias académicas en estudios sobre juventudes latinoamericanas.

Las interrogantes formuladas por Ana Silvia Monzón constituyen en si misma una guía metodología para el estudio de juventudes. Al respecto la juventud o el ser joven es ¿sólo cuestión de edad o también es de identidad? ¿un hecho histórico, económico, social, cultural, simbólico y político o puede remitir a entramados de poder (interseccionalidades), a jerarquías de género, etnia, clase, edad, diversidad sexual, discapacidades? (Monzón, 2015).

\section{ASPECTOS METODOLÓGICOS EMPLEADOS EN LA INVESTIGACIÓN:}

El enfoque metodológico que emplee para esta investigación desarrollada en el año 2014 fue cualitativo enmarcado en la investigación acción. Con este enfoque se avanzó en conocer la realidad del objeto de estudio en movimiento con sus relaciones y sus contradicciones. Las voces de los estudiantes pertenecientes a los pueblos Wotuja, Pumé, Pemón, Yekuana, Eñepá, Yukpa, Jivi, Wayu y Warao son las protagonistas en esta investigación. El análisis estuvo centrado en la perspectiva de los actores mediante la escucha de su palabra, lo cual, fue sin duda, fuente inexpugnable de conocimiento. Las vivencias de estos, sus visiones del entorno, el recuerdo de sus trayectorias de vida cuyos datos biográficos aluden a instancias socio históricas y culturales, me permitieron irrumpir en el debate sobre las "juventudes indígenas" a partir de la perspectiva construida por los estudiantes. La decisión metodológica estuvo definida por la necesidad de vincular las voces de los entrevistados a ciertos aspectos teóricos referidos al tema juventudes, indígenas y educación universitaria. En analogía con el texto de Ana Lau Jaiven (1998), "Cuando hablan las mujeres", esta investigación se propuso visibilizar realidades objetivas y subjetivas de estos estudiantes, por tanto se revelan datos importantes a partir de cuando hablan los jóvenes estudiantes indígenas.

En cuanto a los instrumentos para la recolección de la información se acudió a la entrevista en profundidad dirigida la cual estuvo dirigida a 21 estudiantes indígenas, universo que se consideró representativo por pertenecer todos al total de los pueblos que para el periodo del estudio se encontraban presentes en la UIV: Pemón, Wotuja, Warao, Yekuana, Yukpa, Pumé,Eñapá. De igual modo, se incorporaron dos entrevistas de estudiantes Wayu y Pemón quienes cursan estudios 
en universidades criollas, esto con la intención de consolidar el objetivo relacionado al papel de la educación universitaria hegemónica y la intercultural. Las entrevistas fueron semiestructuradas, centradas en conversaciones intencionales con los estudiantes y que fueron de utilidad para organizar a partir de relatos testimoniales vivencias personales o sucesos significativos de los estudiantes. En algunos casos la narración se centró en la propia vida del informante, lo cual acerca algunas entrevistas a relatos de vida. Por otra parte, se procedió en el diseño de un cuestionario aplicado al total de la población de 72 estudiantes que se encontraban cursando estudios en el segundo periodo académico del año 2013. El propósito de este fue el de visibilizar tendencias en cuanto a espacios para la socialización, representaciones sociales, gustos musicales, motivaciones sobre el estudio y perspectivas a futuro. El cuestionario planteado fue de tipo combinado, es decir, en el que se encontraron presente preguntas abiertas no estructuradas, pregunta cerrada dicotómica y preguntas de tipo mixta, en las cuales se propuso la explicación o justificación de su respuesta.

A continuación algunos de los testimonios de jóvenes indígenas de la Universidad Indígena de Venezuela que evidencian la urgente tarea de incorporar otras "miradas conceptuales relevando etnia y género" (Monzon, 2015):

\section{ESPACIOS DE SOCIALIZACIÓN}

Los testimonios de los estudiantes permiten identificar espacios para la socialización los siguientes: las residencias estudiantiles, el infocentro, los juegos deportivos y en específico el terreno aplanado que se usa como cancha para jugar futbol. En cada una de estos espacios los estudiantes se agrupan para "escuchar música," echar broma" o "trabajar a gusto". La libertad se experimenta de forma más plena en virtud de que no hay presencia de figuras de autoridad. A la par de los mencionados, especial atención merece la música que aparece como un elemento simbólico presente a través de los dispositivos celulares. De igual forma el tiempo libre estipulado en el horario de actividades los sábados luego del medio día y los domingos.

Es importante resaltar que en la interacción de distintas culturas los jóvenes valoran el nacimiento de redes de amistad que se crean a partir de reconocerse a sí mismo en los otros. Uno de los aspectos que más hacen referencia los estudiantes es la oportunidad de poder conocer la diversidad de pueblos indígenas que existen en Venezuela. Javier, del pueblo yukpa comenta que antes de su experiencia en la UIV, él pensaba que sólo existían en Venezuela pueblos indígenas del estado Zulia. Por otra parte, sorprende las valoraciones que cada estudiante hace a partir de las apreciaciones de los otros en función del compartir 
que se genera en las residencias estudiantiles. Alberto, del pueblo Yekuana expresa que:

Lo que me ha impactado fue, como se llama, los chamos Eñepá, porque ellos son se ven como callados y a la hora de hacer cosas como son directos, van directo al tema y si tú cometiste un error ellos lo discuten en el momento o te llevan para la coordinación para que se pueda resolver. Yo viví un tiempo con ellos. Me di cuenta de que aunque son callados son muy directos, si son bravos, entonces no te dicen pero a la hora que tienen que decirlo te dicen y eso también me ha enseñado cosas.

José, del pueblo Pemón comenta que cuando ingresó a la UIV lo ubicaron en residencias estudiantiles distintas a las de su pueblo. Esta experiencia le permitió conocer a los demás jóvenes

Cuando vine por primera vez sentí que recibieron como en mi casa pues la mayoría de los jóvenes indígenas me aceptaron. Los primeros con los que me relacioné fue con los chirianas, Jivi y Sanema. Me dejaron alojar ahí en mi chinchorro. Aunque tenemos diferentes idiomas, el español me sirvió para comunicarme y no quedarme encerrado en mí mismo. Me quedé un semestre y luego en el otro también con otro pueblo. Los indígenas tenemos una forma de ser que nos hace parecidos. Empecé a tener más confianza y a echar broma, compartir cuentos. Empecé también a aprender palabras de otros idiomas.

Durante la convivencia en las residencias estudiantiles, existen espacios libres de las figuras de autoridad representadas por facilitadores, ancianos o por el coordinador general. Durante la semana están las horas de estudio personalizado, los encuentros que acontecen durante la hora de las tres comidas del día. En las residencias estudiantiles también se abren espacios para la resolución de conflictos que son abordados por todos los integrantes que viven en dicho espacio.

El tiempo libre es empleado para distintas actividades, pero la respuesta más concurrida fue la de buscar a las amistades para compartir, seguida por lavar la ropa en el río y la actividad de "ir a pescar con mis amigos". Por otra parte, la forma como la universidad indígena ha estructurad el horario surgió como un aspecto que llama la atención de Rafael, joven yukuana, por cuanto este explica que en su comunidad no existe ningún programador de las actividades para guiar lo que cada quien debe hace; sin embargo él admite que es necesario que en la UIV todos y todas se guíen por un horario. 
En la universidad indígena nosotros somos jóvenes estudiantes de diferentes pueblos, no solo Yekuana, nosotros somos 8 pueblos aquí. Entonces viendo la diferencia y la diversidad de todos los pueblos es necesario poner normas que nos puedan equilibrar el comportamiento. El Yekuana le gusta despertarse temprano, los adultos, se duerme tarde. El Warao es diferente, el Warao se duerme temprano, y se para temprano también. El Pemón se para, puede tener su diferencia también. Entonces para regular eso es necesario una norma, o sea un horario que es una hora donde todos se puedan despertar, donde todos puedan comer.

Respecto con el uso del tiempo libre, la mayoría de los estudiantes refieren como principal actividad la de buscar a mis amigos para compartir (24), seguida por la de lavar ropa e ir a pescar (Resultados Cuestionario Identidades Juveniles Indígenas en la UIV, 2013).

Durante la observación participante se constató la presencia de un acompañante ruidoso que se activa en medio de reuniones informales entre los estudiantes: el celular como dispositivo para escuchar música. Diferentes géneros musicales comparten la escena a diario, desde raspacanilla, paseándose por el reggaetón hasta el rock romántico, el vallenato y música llanera. El 53\% de los estudiantes afirmó tener celular. Para cada uno de los estudiantes entrevistados, la música constituye un referente identitario que lo distingue del otro. Por ejemplo, Alejandro, joven del pueblo Wotuja señala que en su comunidad lo mas que se escucha es "reggaetón y raspacanilla pa lante", él se ha inclinado por el rock mencionado a la agrupación The Killers y la canción "Here with me". Igualmente le gusta la música romántica pues se considera un "hombre triste por dentro pero por fuera demuestro alegría".

Por su parte, Damián, del pueblo Pemón no tuvo dudas al precisar sus gustos musicales agrupados en la música electrónica pues "me aburre mucho la música que escuchan en la comunidad, mucha viene de Brasil y no me gusta, prefiero DJ Tiesto, Simple Plan, Green Day". Tanto este joven Pemón, como el joven Wotuja comparten un estilo de peinado que también es usual en jóvenes urbanos consumidores de las mismas tendencias musicales. El uso del suéter negro, jeanes muy anchos, el corte de pelo Emo son también el reflejo de una parte de la identidad conectada en el consumo global musical. Todo esto indica la función simbólica de la música que funge como parte de "la socioestética", categoría empleada por Reguillo y que puede entenderse como "producto de mezclas, préstamos e intercambios que resignifican, en una solución de continuidad, la contradicción”(Reguillo,2012:119). Los géneros musicales consumidos por los estudiantes son en orden de pre- 
ferencia raspacanilla, vallenato, merengue, joropo, reggaetón, rock, y música romántica (Resultados Cuestionario Identidades Juveniles Indígenas en la UIV, 2013).

\section{AUTOVALORACIÓN SOBRE QUIÉN ES JOVEN- ESTUDIANTE INDÍGENA}

La condición de ser joven indígena varía según las experiencias de vida de cada estudiante entrevistado. Las definiciones revelan contextos y trayectorias de vida asociadas a la familia, la escuela, su relación con los abuelos y abuelas y la participación en actividades laborales, la mayoría informales. Sin embargo, surgió como categoría común la relacionada al estatus de estudiante, el cual fue considerado como un rasgo importante que mucho tiene que ver en la definición de ser joven indígena. La escuela como agente de socialización es también nombrada por todos los entrevistados como la institución responsable de muchos de los cambios que los jóvenes han experimentado, por cuanto la misma ha sustituido el tiempo que antes los padres, madres y abuelas les dedicaban a los niños. En la encuesta realizada, los estudiantes respondieron que son jóvenes indígenas porque "hago cosas que hacen los jóvenes criollos y los indígenas"; "porque tengo la edad de ser joven" y "porque estudio en la Universidad". El 64\% de los jóvenes reportaron haber estudiado en secundaria con jóvenes indígenas y criollos (Resultados Cuestionario Identidades Juveniles Indígenas en la UIV, 2013).

Juan, del pueblo Wotuja quien se considera así mismo "100\% joven indígena" explica lo siguiente:

Claro, los jóvenes de hoy han cambiado mucho a cómo eran antes. Los niños antes sabían cómo era el ritmo de la comunidad, lo respetaban. De niños pasaban a portarse bien como adultos de la comunidad, a trabajar en el conuco, a cuidar de la familia. Eso ya no está. Ahora la escuela los hace jóvenes después y quieren hacer otras cosas. Los padres que le dicen a sus hijos hoy?. Hijo vaya usted para la escuela que yo voy para el conuco, voy de cacería. Entonces el hijo se queda en la escuela y lo atiende una maestra que le habla puro en castellano y no le enseña cosas de la comunidad sino de libros que son criollos". -Porque los jóvenes indígenas de aquella época desde la niñez ya tenía su formación orientado avanzado comparado con los otros no indígenas el caso de los campesinos los criollos siendo el joven, ya desde niño tenia la orientación de sus padres claro eso no dificultaba si el enfrentaba todas sus cosas.

Su apreciación coincide con la de Isamel, Eñepá, quien manifiesta que algunos jóvenes "no hacen mucho trabajo en la comunidad sino que 
se preocupan de vivir por su propia cuenta. Eso ocurre sobre todo en los jóvenes que han estudiando más o menos desde sexto grado hasta el segundo año en escuelas criollas. Ellos estudian a veces con jóvenes criollos y aprenden a no participar en trabajos comunitarios. Les da pena si son mujeres dicen que no es trabajo de los jóvenes y que ellas no van a hacer lo que hacen los mayores".

Este comentario revela la influencia de las aspiraciones hegemónicas en las trayectorias de vida de los jóvenes indígenas. Los proyectos de vida individual, muy presente como metas en los jóvenes no indígenas, son asumidos también por los indígenas. Esto incide en el debilitamiento de los tejidos comunitarios y en la fragmentación de las prácticas colectivas de los pueblos indígenas.

El testimonio proveniente de Félix, Yekuana, vincula la juventud con el compromiso de defender su pueblo. Está conectado con la necesidad de manejar temas que las generaciones que le antecedieron no manejaban. Félix, es estudioso del tema de demarcación. Es padre de familia y fue el primer coordinador indígena que tuvo la universidad.

Yo me considero indígena Yekuana, o sea con mucha fuerza, con mucha claridad y eso es primero. Para mi ser joven indígena Yekuana es un orgullo pues, el fruto de la resistencia. Si nosotros los jóvenes no nos preparamos entonces como van a quedar nuestros pueblos? Van a quedar otra vez aplastados"

José, comenta que "nunca he perdido tiempo como joven. Desde mi juventud siempre he hecho cosas útiles. Hay siempre que aprovechar en la Gran Sabana, en la selva se pueden hacer cosas. Soy joven Pemón y tengo que aprovechar que tengo fuerza para hacer cosas".

Por su parte Rafael, precisa que es joven indígena porque "soy hijo de la comunidad de Tencua y soy hijo también de Yekuanas conocedores de la cultura y mi mamá también es Yekuana. Y eso me hace ser Yekuana, me siento orgulloso de ser Yekuana. Y eso me hace sentir como, como indígena". Resulta interesante saber que este joven tiene esposa pero aun no tiene hijos. Al ser interrogado sobre el por qué, él contesta que "aun no lo hemos decidido. Habrá tiempo de tener hijos, y eso será cuando no tenga muchas responsabilidades ya sea aquí o en otra parte". El ser joven estudiante le permite a Rafael, el poder de aplazar su rol de padre. El acto de estudiar en la UIV es tomado en cuenta por este joven como una de las responsabilidades que más pesa en este momento de su vida y que lo lleva a decidir que no es el momento de convertirse en padre de familia. Rafael hace uso de métodos anticonceptivos para evitar que su esposa quede embarazada. Desde la vivencia de jóvenes urbanos, el tener hijos no resulta compatible con el hecho 
de estar cursando alguna carrera universitaria. Es bien conocido el consejo de estudiar primero para luego poder tener los medios de mantener a la familia. Por ello, se puede afirmar que el ser joven indígena para este muchacho representa también la posibilidad de tomar desde lo juventud hegemónica, este arreglo que le permite tener tiempo para dedicarse a sus estudios. Por su parte, Alejandro, afirma que "Soy un joven que aprende todos los días en Universidad. Me gusta las fiestas también y como aun no estoy casado aprovecho del tiempo aquí para pintar, me gusta pintar, los indígenas somos muy buenos artistas". Wiliam, del mismo pueblo pero de otra comunidad se define como joven y a su vez "mestizo" porque "mi mama y mi familia es Piaroa y mi papa es colombiano. Por ahora siento orgullo de ser indígena y como joven rescatar la cultura, tener la experiencia de lo que vivieron mis abuelos, saber que hacían, cómo pasaban la vida".

Del pueblo Eñepá, Ricardo, manifiesta su concepción de joven indígena como "la edad para poder ayudar más a la comunidad" en virtud de que a partir de los 12 años "los Eñepá empezamos a trabajar de 15 o 16 años para arriba. El Eñepá comienza a trabajar pero no solo en la familia, o a los padres sino en el campo para todos". David Palmar', es del pueblo Wayú y explica que

Me defino un joven indígena que le apuesta a la pervivencia de los seres vivos y la ética planetaria. Desde la perspectiva occidental el ser joven implica ser una persona que tiene presiones por ser objeto de expectativas sociales. Y eso lo vivo también yo como indígena. Es un vaivén de desaprobaciones como por ejemplo "los wayú no hacen esto o aquello", "no pareces Wayú". Muchas de estas desaprobaciones vienen también de tu misma gente. Es una carga doble de expectativas. Hay romanticismo de que los ancianos son quienes tienen la verdad absoluta. Pero hay situaciones en las que hay que hacer una lectura muy compleja.

Lo narrado por David revela la doble carga que tienen los jóvenes indígenas en la construcción que otros hacen sobre ellos y ellas. Por ello "la forma de autonombrase en las diferentes adscripciones identitarias ( ) ha desempeñado un papel muy importante no solo en relación con las

\footnotetext{
1 David Palmar no es estudiante de la UIV. Sin embargo, se consideró importante su testimonio por considerarse joven indígena desde la cultura Wayú, pueblo de mayor presencia en el territorio nacional. Palmar cursó estudios en la Universidad del Zulia. Es documentalista y ha participado en encuentros nacionales e internacionales de realizadores audiovisuales indígenas. Es cofundador de la MICIV - Muestra Internacional de Cine Indígena de Venezuela
} 
formas de comunicación entre pares, sino con respecto a los diversos modos en que se posiciona ante la sociedad" (Reguillo, 2012: 99).

Es de singular importancia algunas valoraciones que estos estudiantes indígenas hacen de los jóvenes criollos. En todos los testimonios surgieron episodios de racismo y sentimientos de superioridad por parte de los criollos. El 89\% de los estudiantes indígenas considera que los jóvenes criollos y los indígenas son diferentes. Las reflexiones que se desprendieron a partir de las interrogantes si te consideras joven indígena y por qué, surgen también de precisar las diferencias en relación con el joven criollo. Así Eduardo, del pueblo Pumé relata que

Lo que yo he visto, no sé, los criollos siempre han sido, han visto, ven a los indígenas como muy inferiores, ellos creen así no, y dicen que los indígenas no saben nada pero viendo eso yo me he preguntado en mi personal, y los pumé somos iguales, pensamos iguales, lo que pasa. Los criollos utilizan una palabra. Que el indígena "pluma". Esa es la palabra que usan. Pero entonces en mi interpretación, he analizado así no, y pluma significaría que no vale, no. Ello sería carne y el indígena pluma que no vale.

Las experiencias de racismo han estado muy presentes en las escuelas primarias y secundarias donde las clases se comparten con estudiantes criollos. Esteban narra que "en el colegio la Guanota Fe y Alegría Apure. Porque allá los campesinos, los criollitos estaban acostumbrados a joder a los indígenas "mira, indio" los Yekuana siempre hemos sido talento en el futbol, jugamos más que los criollos, que aquellos entonces nos envidiaban y uno se sentía, bueno no sé porque uno no se burla sino que es la realidad y bueno cuando nosotros estábamos en la cancha jugábamos los mejores entonces nos envidiaban "indio come lombriz, come casabe, come mañoco" entonces una vez lo agarré. Peleamos ahí y hasta ahí pues"

Alberto, cuanta que existe mucha competencia entre los criollos e indígenas. Así narra que

En un liceo básicamente criollo donde él cursaba estudios junto con dos primos nos decían que esos indígenas no saben nada eso me ha arrechado mucho a mí me ponía molesto como éramos chamos paso una vez nos caímos a coñazos después, ellos se creían más y no era verdad porque nosotros decíamos vamos a estudiar a ver qué tal vamos a medirnos en el estudio y nos mediamos también en las matemáticas. 
Muchos de los estudiantes observan como principal diferencia entre los jóvenes criollos es que los indígenas "saben hacer más cosas", juegan mejor el futbol, tienen más habilidades y destrezas como por ejemplo correr en la selva, cazar, pescar. En este sentido, Rafael afirma que los jóvenes criollos de la secundaria

[...] primero no saben hacer su comida ( ) segundo, nosotros hacíamos una cosa como pequeña que es difícil para ellos que es peluquearnos, o sea simplemente con una tijera y ya se hace un corte. Y ahí es donde eso sorprendía. Bueno, son prácticas. Nosotros sabemos hacer eso. En el deporte también siempre ganábamos los indígenas. Entonces y se ha visto mucho eso la competencia también.

Los estudiantes yukpas consultados, son entre todos los de la universidad, quienes más cerca han experimentado el racismo, la discriminación y la injusticia. No solo en los términos de la lucha cuerpo a cuerpo contra los terratenientes, sino desde la escuela de "los curas" en donde estuvieron internados para aprender a leer y escribir bien. Javier recuerda que

Cuando yo estudié pues en la escuela de la misión del Tokuco que se llamaba Unidad Educativa Sagrada Familia, fundada desde muchos tiempos por los curas, entonces como mi papá Sabino pues ha luchado o ha tenido muchos tiempo de lucha entonces ya nos tenían señalados entre los ganaderos, entonces, bueno, nosotros como los hijos del cacique Sabino, all'i pues nos trataban mal, nos castigan mucho y que a barrer eso o limpiar cosas feas, podridas pues, como por ejemplos los excrementos de perros, a botar basura que tenía mucho tiempo. El padre Eduardo y el padre que es español y el padre Sandoval y que es de Caracas, y el padre español Víctor, este ellos decían siempre cuando yo estoy haciendo ya cuarto grado yo lo escuchaba cuando estaba diciendo que si mi papa seguía con la lucha nos iban a sacar; decían ellos, los curas decían ellos pues, que tenían que sacar a los hijos de Sabino, nos amenazaban con los estudios pues, nos amenazaban decían que tenían que cansarnos para que nos fuéramos de la escuela ( ) porque ellos nos decían que nuestro padre estaba haciendo malas cosas; también nos decían que teníamos que aprender mucho sobre la religión como hijo de Sabino ( ) y que nuestra cultura eso ya no valía pues porque ya hasta si hablamos así pues en nuestro idioma ellos decían que nuestro idioma no existía ( ) nos juntábamos con los muchachos de Toromo a 
echar cuentos en yukpa pero los curas querían siempre que uno este leyendo eso de lo que dicen biblia sino, nos decían que es importantísimo de estar diariamente rezando por el único dios que ellos tienen no sé donde.

Ismael narra que en la secundaria algunos estudiantes criollos provocaban a los jóvenes indígenas para "poner bravos a esos indios". Pero ese "indio" tiene nombre. Igualmente recuerda comentarios como "los indios no son de aquí venezolanos". Yo les decía que mira chamo ustedes tienen sangre indígena, y ellos se reían que va chamo yo no soy indio". Sin embargo, a pesar de esto, Najté con orgullo también recuerda que hizo equipo en algunos cursos con un estudiante Piaroa porque "era bueno en matemática y que "cuando el profesor me mandaba a sacar el problema de la física" los demás estudiante s criollos buscaban anotarse con ellos para hacer equipo. De hecho, $70 \%$ de los estudiantes afirmaron el haber sufrido alguna forma de racismo en sus vidas. Y en cuanto a las relaciones con los jóvenes criollos, el 53\% afirman que entre los indígenas y no indígenas "no se relacionan mucho" y un 23\% expresó que las peleas son porque los jóvenes criollos se creen más que los jóvenes indígenas (Resultados Cuestionario Identidades Juveniles Indígenas en la UIV, 2013).

Atendiendo a los testimonios citados, se considera que los estudiantes de la UIV, todos con experiencias diferentes, han construido simbólicamente un nosotros, que somos jóvenes indígenas estudiantes, como terreno de representaciones que les es común a todos y todas. Podría afirmarse que existe también una identidad colectiva a partir del encuentro de las diferentes identidades individuales, las historias colectivas de los pueblos y las vivencias de racismo y discriminación que le son comunes a todos los entrevistados. Se debe aclarar este aspecto porque no se trata de afirmar que sea una identidad colectiva que hace que todos sean iguales. Lo que acontece es que se afianza "el carácter relacional" de la identidad como proceso de "identificación- diferenciación" con relación a un Otro criollo que refleja en su relación con el Otro indígena su cognitivo de racismo.

\section{MUJER INDÍGENA, JOVEN Y ESTUDIANTE}

Las voces de las mujeres entrevistadas desafían la categoría de género universal elevada por el feminismo euronorcéntrico que excluye las especificidades de las mujeres de los pueblos indígenas, estigmatizadas no sólo por ser indígenas, sino por ser mujeres y portadoras de formas diferentes de concebir la vida y las relaciones con el mundo. Es necesario tomar en consideración que los modelos vigentes de ser mujer indígena son también el resultado del sistema de dominación colonial 
que se ocupó de naturalizar la violencia contra ellas, pero no únicamente ejercida desde los sujetos privilegiados, sino también por parte de "aquellos hombres que continúan siendo víctimas de la dominación racial" convirtiéndolos en partícipes de distintas formas de violencia (Lugones,2008: 75). Lucia, del pueblo Pemón revela la presencia de discriminación a la que es expuesta en la secundaria.

\begin{abstract}
$\mathrm{Si}$, fue en $8^{\circ} \mathrm{Grado}$, en el Colegio donde yo estudiaba, la población estudiantil era mixta, y en una oportunidad un compañero me dijo maldita india, en este momento no me acuerdo muy bien porque fue, pero fue una expresión que me dolió mucho, lloré de la impotencia; fue cuando mi Profesora Guía salió a mi defensiva y regañó a mi compañero, y ella me dijo que para la próxima le respondiera y le dijera a mucha honra, eso me ayudó a estabilizar mis emociones y sentimientos. Ahora que alguien me diga eso, creo que ni me dolería ni en mínimo.
\end{abstract}

Las entrevistadas hacen referencia a situaciones que sobre ellas ha ejercido presión, injusticia o prejuicios y que no solo provienen del mundo criollo sino también, en algunos casos, de compañeros indígenas. Las mujeres consultadas ponen en evidencia otros aspectos que median en la socialización a lo interno de la UIV, estos asociados a la necesidad de ganarse el respeto de sus compañeros así como lo difícil de enfrentar temas como el noviazgo a lo interno de la UIV pues "siempre, los muchachos le echan la culpa a las mujeres, como que si quien se enamora es una nada más y no el hombre", confirmó María del pueblo Wotuja.

Lucia fue la primera coordinadora mujer en la UIV. Desde esa experiencia comenta el haberse sentido juzgada en el momento en que salió embarazada y que a la par continuaba con sus funciones como coordinadora.

No estoy casada y eso me lo han criticado ( ) Lo más difícil de ser mujer es, ser señalada por la comunidad cuando la sociedad es machista y no ser comprendida y aceptada; Soy madre soltera. A mis 19 años de edad estuve en concubinato con un hombre indígena (Pemón - akawaio) a tan solo 8 meses de estar conviviendo juntos, él falleció. Después de 5 años acontecidos esto, quedé embarazada de una relación que mantuve con un voluntario (no indígena) de la UIV, le confieso que estuve asustada por la reacción que pudiera tener Ajishama (Fundador de la UIV); cuando le confesé que estaba en estado, su reacción fue tan serena y comprensible que nunca olvidaré sus palabras "Las madres no escogen a los hijos, ni los hijos escogen a las madres los hijos son un regalo del Creador, que hay que reci- 
birlos con alegría y como una Bendición “. la relación con el Padre de mi hijo no fluyó por lo que la relación tuvo que terminar; posteriormente me vi relacionada sentimentalmente con un estudiante de la UIV (de la etnia Pume) que desde la opinión de mis compañeros voluntarios indígenas lo desaprobaron, yo alegué diciendo que en mi condición de mujer soltera yo habría recibido algún halago o insinuación de ellos siendo compañeros, voluntarios, (con pareja allí con ellos ) pero no fueron correspondidos por respeto a ellos y a sus familias. Y si yo me vi relacionada con el estudiante fue porque él me apoyaba en las atenciones que yo carecía en ese momento, y nació como un sentimiento de admiración y agradecimiento. Los profesores aliados, en ese momento no le dieron mayor importancia u opinión a ésta situación, esa reacción influyó en el estudiante que se retiró de la Universidad sin culminar sus estudios, es un estudiante muy valioso. La relación tampoco se concretó.

Para las mujeres, pareciera haber una pauta diferente de socialización que se ve afectada cuando asumen la maternidad o ciertos roles del liderazgo colectivo. Miriam, Yukpa, fue estudiante de la UIV. No regresó desde que salió embarazada producto de una relación con un joven de una comunidad vecina.

Me hace falta la Universidad, lo que más me gustaba es lo que aprendí y que podía estar descalza, ir a clases, bañarme en el caño, estudiar. Ya tengo un niño. Estoy criándolo con mi mama, mis hermanas me ayudan ( ). Quiero preguntar a la coordinación indígena si puedo volver a la Universidad con mi hijo, no sé, tú crees?, yo creo que no me van a dejar, verdad.

En cuanto a la distribución del tiempo en la UIV, Lucía comenta que pudo ser capaz de asumir las responsabilidades de la coordinación junto con las de la crianza de su hijo pues

Siempre quise que mi hijo estuviera en contacto con lo que hago (mi trabajo) y mi hijo lo atendía personalmente en mi aldea, y siempre lo cargaba conmigo para que interactuara con los demás pueblos indígenas hermanos y aliados, para que conozca la realidad. Fue impresionante ver como mi bebé a tan solo tres añitos se había aprendido los nombres de los estudiantes. Me siento orgullosa de él.

Por otra parte explica que la Universidad le ofreció la oportunidad de relacionarse con muchas personas y así ir decidiendo de cual forma po- 
dría continuar sus estudios. Sin embargo, esto no fue fácil porque "me sentí juzgada por mis compañeros que no entendieron mis estudios en la UPEL ${ }^{2}$ paralelo al trabajo de la UIV; y también me juzgaron porque había sido becada por FUNDAYACUCHO "para estudios de pregrado". Ante todo esto, Ana comenta que a pesar de las críticas cuya razón de las mismas, ella atribuye el hecho de que la gente, mis paisanos, "pretendían que yo me quedara en mi comunidad sin hacer mas nada", procuró seguir adelante en virtud de que porque soy mujer Pemón, no quiere decir que no voy a seguir estudiando".

Vivencias como las de Lucia, también son referidas por otra de las entrevistadas. Para ellas, la UIV les posibilita "seguir siendo mujer Wotuja", "mujer Pemón sin tener que necesariamente que estar casada o tener hijos. El uso estratégico de la juventud como categoría que infiere búsqueda de libertad y autonomía es asumido por algunas de las mujeres estudiantes en un lugar de afirmarse en el marco de la apropiación de algunos derechos al mismo tiempo de no sentir que "traicionan" su cultura de origen por cuanto en la UIV, el proyecto a futuro no se desvincula con la posibilidad de aportar al impulso de su comunidad y pueblo. Así María argumenta que el ser joven es lo que ha hecho que no haya decidió aun por el matrimonio:

A una le cuesta decidir. Me caso o no me caso? Y bueno pienso en algo que me pueda servir ( ) uno ve la realidad de los familiares, a veces veo a mis primas y el hombre maltratándola y pegándole a los niños. Entonces para qué casarme ahorita? ( ) busco ser alguien en la vida para aportarle a otras personas, ayudarles y ese es el compromiso que a uno le dice iya va! Todavía no he cumplido con tu misión ( ) no quiero regresar con las manos vacía a mi comunidad

Tanto Lucia, como María, han estado a cargo de la coordinación general de la UIV; esto les ha servido como experiencia para "ganarse el respeto" de una comunidad estudiantil dominada por la presencia de hombres y que muchas veces algunos alegaban "que había competencia entre ellos y yo".

Lo difícil de la mujer aquí es que a veces no nos entendemos y a veces hay complicaciones que hay en la vida. Ha pasado que a veces las muchachas nos unos enamoramos pero los muchachos no nos ayudan (...) me he dado cuenta que no solamente

2 Siglas de Universidad Pedagógica Experimental Libertador

3 Siglas de Fundación Gran Mariscal de Ayacucho, institución que promueve becas para cursos de pregrado 
de los jóvenes criollos faltan el respeto la mujer, sino también los jóvenes ( ) no me gusta la manera como hablan con la persona y si es mujer a veces les gritan ( ) yo pongo limites con mis compañeros, si es de echar broma echamos broma pero con respeto y si es de trabajar se trabaja y busco me respeten si yo tengo que mandarles a hacer algo para que todo salga bien". Respuesta: es muy difícil dejarse respectar ya tengo mucho tiempo conociendo a los ser hacia los muchachos, profesores. Pues a mi gusta echar broma, reír, se cuando puedo portarme bien y cuando hablar seriamente, tener cada espacio para cada cosa eso me hace ganar el respecto de los muchachos. Por ejemplo para mantener el respeto con los muchachos hay que tener una limitación. Si me pongo a echar broma con ellos pero si se pasan ya me dejo de reír, como control para no pasar los limites.

En cuanto a las diferencias entre las mujeres indígenas y las criollas, las entrevistadas argumentan que las criollas suelen "ser tener más oportunidades para estudios universitarios"; "siempre están a la moda", "dominan la tecnología" mientras que las indígenas "son más sencillas en su forma de vestir", "caminan descalzas sin dificultad", "domina tanto el idioma materno como el español”.

Entre la mujer indígena y la mujer criolla, entre la mujer indígena esta ella tiene miedo a los muchachos, ya que cualquier cosa que le digan los muchachos que no sea su familia como corrígete tu estas mal, la mujer indígena a veces lo toma serio veces como se siente parte de su hermano lo toma en serio porque tienen que ver con su vida; en cambio se ve ese respeto se rompe se ve el respeto y no se meten, en cambio la mujer criolla como que eso es normal para ella, no hay mas respeto todo es igual se siente igual, no se siente que la mujer esta arriba y el hombre abajo es igual. En cambio nosotras alguien nos dice tu estas así ya me siento que ese es mayor que yo y lo respeto por lo que dice.

Tanto Miriam como María coinciden en la idea de que "la gente respeta más a la mujer criolla (...) a nosotros [los yukpas de la comunidad Chaktapa] pues cuando tomamos las haciendas los ganaderos nos decían perras váyanse, las vamos a matar a todas, ustedes paren como acures". Lo pronunciado por Miriam es parte de la violencia a la que son sometidas las mujeres indígenas sobre todo, si estas han sido protagonistas en procesos de recuperación de sus tierras como el 
caso de las mujeres yukpas. Pero la violencia también es ejercida a lo interno de sus comunidades. Todas entrevistadas también concuerdan en este aspecto.

En mis familiares más que todo si, vi un caso de mi prima ella tienen seis hijos, cinco varones y una niña. Por el maltrato que ha recibido por el marido ha perdido el ánimo de seguir en la vida se deprime, la ultima niña tiene siete años. La última vez le hicieron oración, su pareja es Wotuja pero se la pasa en la ciudad. Con la oración ha mejorado un poco. El la dejaba golpeada, morados en la cara, y los hijos también le pegaba. Estando embarazada en la maltrato y ella aborto. La segunda vez paso lo mismo. Y ella aborta y aborta. Y por esa reacción se llamaron los chamanes para que le haga la limpieza.

\section{REFLEXIONES FINALES}

La realidad constatada por el trabajo en campo con indígenas demuestra que los jóvenes indígenas no solo están presentes como un sector de la población diferenciado por rango de edad, sino que constituyen un sector trascendental que exponen aspectos cruciales de la realidad indígena nacional entre los cuales, la continuidad cultural, la exclusión, el consumo hegemónico y los conflictos identitarios, exigen una mirada alerta a lo que sus voces y sus sentidos expresan. Las políticas públicas en materia indígena son portadoras de una ceguera que no les permite apuntalar estrategias para reforzar el potencial de los jóvenes indígenas presentas en más de 40 pueblos del país (Instituto Nacional de Estadística).

Por otra parte, este trabajo consideró a la Universidad Indígena, no solo como institución de saberes, sino como un espacio que "produce juventudes" y "permite el despliegue del potencial juvenil" (Vommaro, Conferencia En busca de las condiciones juveniles latinoamericanas. UNAH 22 de junio 2015). En el sentido antes expuesto, se observó que dentro de la Universidad Indígena las diferentes identidades juveniles indígenas dialogan permanentemente e intercambia valores subjetivos, lo que permite sentar las premisas para una discusión de fondo sobre la educación universitaria y el futuro de los pueblos indígenas a partir de las miradas de sus jóvenes.

Toma en esta investigación un lugar protagónico la múltiple definición identitarias de lo que es ser indígena, joven, estudiante. Se demuestra que ninguna de estas hacen referencia a elaboraciones finitas, cerradas, estáticas, sino que por el contrario, muestran horizontes amplios como proyectos a futuro donde la resistencia, la transgresión a patrones fijos y procurarse un lugar en el mundo propio y colectivo es posible. 
Es relevante la reflexión cuidadosa tanto sobre los marcos teóricos que definen que es ser un joven, como las definiciones fijas que antropólogos han hecho sobre la identidad étnica de cada pueblo presente en la UIV. En gran medida, aun predomina tanto a nivel teórico como metodológico un discurso colonial al reproducir estereotipos acerca los marcadores étnicos que revelan el deber ser.

La experiencia de estos estudiantes transcurre en tres tiempos que se turnan en un constante proceso de re significación de aquellos aspectos que según la cultura dominante tienen que ver con el ser joven, espacio de vida marcado por la edad y al mismo tiempo la autodenominación y una heterodominación de origen colonial "cuyo uso implica connotaciones de asimetría, desigualdad y discriminación, que hace del sujeto étnico (del etnizado), un "otro", diferente del resto de los integrantes de la sociedad" (Pérez Ruiz, 2011:73).

Los espacios de socialización permiten evidenciar procesos permanentes de reapropiación identitaria. Y cuando estos están ligados al uso y consumo de información a través de las redes sociales, lejos de lo que algunos especialistas han avizorado, los jóvenes de UIV han demostrado estrategias para articular sentidos de pertenencia...mas de futuro

Sin embargo, en las trayectorias expresada por los jóvenes, hay también experiencias de racismo, exclusión extrema, tristezas profundas, confusión ante lo que debe ser asumido para "no estar siempre como el que recibe los golpes", de acuerdo al testimonio de un joven del pueblo yukpa. En algunos casos, surgen estrategias de mimetismo que ha servido para limitar de alguna manera el sentido de mal trato y poder al menos relacionarse con el otro como un semejante para contrarrestrar "las formas del Otro" ( Amodio,1993) del referente colonial que prepondera en la mayoría de los venezolanos al referirse al indígena.

Como resultado de los testimonios de los y las jóvenes indígenas, aboga este trabajo por la materialización de espacios académicos dentro de los cuales se materialicen estudios que reconozcan la identidad indígena en su complejidad y diversidad cultural. Al reconocer las relaciones interculturales inequitativas entre los indígenas y la sociedad criolla-mestiza, universidades como la UIV tiene el potencial de aportar a la construcción de otras formas de ciudadanías basadas en proyectos de vida de los pueblos y comunidades indígenas. La educación universitaria pensada para y por los pueblos indígenas, es necesaria para garantizar la sostenibilidad social, cultural a través de sus jóvenes, sujetos en cuyas experiencias se re significan claves identitarias, constituyentes a procesos de democracia que revitalizan América Latina. 


\section{BIBLIOGRAFÍA}

Amodio, Emanuele 1993 Formas de alteridad. Construcción y difusión de la imagen del indio americano en Europa durante el primer siglo de la conquista de América (Quito: Ediciones Abya-Yala).

Lugones, M. 2008 “Colonalidad y género” en Tabula Rasa, Nª, julio 2008. Universidad Colegio Mayor de Cundinamarca.

Monzon, Ana Silvia 2015 Conferencia "La dinámica de las juventudes hoy: perspectiva de género y etnia" ". UNAH 22 de junio.

Pérez Ruiz, Maya Lorena 2011 "Retos para la investigación de los jóvenes indígenas" en Alteridades (México) en ‘http://www.scielo.org.mx/ scielo.php?pid=S0188-70172011000200005\&script=sci_arttext s acceso 3 de octubre de 2013.

2012 Culturas Juveniles: formas politicas del desencanto

(México:Siglo veintiuno editores).

Reguillo Rossana 2012 Culturas Juveniles: formas políticas del desencanto (México: Siglo veintiuno editores)

Vommaro, Pablo 2015. Conferencia “Juventudes y políticas en la América Latina: participación política, políticas públicas y disputas por lo público". UNAH 22 de junio. 


\title{
LA TRIBU EN PESO: RASTAFARI POR FUERA iY POR DENTRO?*
}

\author{
Marialina García Ramos**
}

El siguiente texto ${ }^{1}$ tiene como objetivo ofrecer algunas reflexiones sobre los valores generados y fomentados al interior de un grupo juvenil habanero identificado como "rasta", tras una investigación realizada entre 2002 y 2010. Examinar, asimismo, los principales móviles (intereses, anhelos, motivaciones, necesidades, proyectos, objetivos o metas) de estos sujetos, en una tentativa de comprensión de las prácticas que protagonizan en su articulación con el contexto cubano de estos últimos años. Con respeto al grupo mencionado, en un acercamiento a sujetos que se autodenominan rastas y son portadores de atributos simbólicos que visualmente los identifican como tales, advertimos dos tendencias en el escenario sociocultural capitalino: por una

\footnotetext{
$1 \mathrm{El}$ artículo ofrece un resumen del Capìtulo $\mathrm{V}$ del libro De las reivindicaciones míticas a las tribus urbanas. Rastafarismo en La Habana, Editorial Ciencias Sociales, La Habana, 2013, 206 pp. Premios Dador 2010 y Pinos Nuevos 2012, Centro Dulce María Loynaz del Instituto Cubano del Libro, La Habana, Cuba. Mención Nacional Anual de Investigación Cultural 2013, Instituto cubano de Investigación Cultural Juan Marinello, Ministerio de Cultura, Cuba.
}

* Escuela Internacional de Posgrado "Juventudes y Desigualdades en América Latina y el Caribe", realizada en Honduras entre el 22 y el 26 de junio de 2015.

** Graduada de Licenciatura en Historia del Arte, Facultad de Artes y Letras, Universidad de La Habana (2003), Diplomado Intensivo de Antropología Cultural (2004), Fundación Fernando Ortiz (La Habana) y Master en Antropología Cultural, Facultad de Filosofía e Historia, Universidad de La Habana (2009). Estudiante de Doctorado de Antropología Social, Departamento de Ciencias Sociales y Políticas, Universidad Iberoamericana de México, D.F. marialina.ramos@gmail.com 
parte, un segmento minoritario en el que se constata una filiación al contenido de creencias rastafari y, por otra, un grupo juvenil, más numeroso y creciente, donde se observa la apropiación de atributos o símbolos identificados con los rastafaris (dreadlocks, uso de colores de la bandera de Etiopía, apariencia desaliñada y desenfadada, gusto o preferencia por el reggae) sin relación o compromiso ideológico o religioso con el Rastafarismo. Llama la atención el incremento de este fenómeno traducido en un verdadero apasionamiento hacia una estética o estereotipo "rasta" que se manifiesta en la asunción de atributos vinculados al movimiento, pero despojados de su significado religioso y hasta ético. Al mismo tiempo, dentro de este segmento se localizan sujetos que no clasifican como negros o mestizos. De tal modo, creemos que una mirada problematizadora del Rastafarismo en Cuba debe necesariamente comprender el análisis de estas expresiones, donde se verifica un desplazamiento hacia lo sociocultural que trasciende lo religioso y hasta lo racial. Una doble mirada que ha de considerar tanto la moda "rasta" y los estereotipos asociados, como las formulaciones ideológicas y religiosas más profundas.

De tal suerte, el presente trabajo ${ }^{2}$ está orientado hacia la consideración de la emergencia de una cultura juvenil urbana donde se verifican tendencias tribales en el escenario sociocultural capitalino de la primera década del actual siglo, desde la perspectiva específica de su dimensión simbólico-estética.

Si las tribus urbanas surgen con voluntad cohesionadora en su intento de reconstruir el tejido de solidaridades en las sociedades contemporáneas - enfrentadas al poder disgregador de los excesos consumistas y los aislamientos de la urbe-,${ }^{3}$ la emergencia de una tribu

2 Las intuiciones y derroteros de esta pesquisa se cimentaron en el transcurso de casi 10 años. Sus motivaciones iniciales surgen en los predios de la Facultad de Artes y Letras de la Universidad de La Habana, hacia 2002, cuando en el seminario "Problemáticas de la cultura afrocaribeña" impartido por la Dra. cubana Lázara Menéndez, la académica presentaba un corpus de interrogantes sobre el campo cultural cubano atravesado por los peliagudos ejes de raza y religión. Tras estos tanteos fueron realizadas las primeras aproximaciones al fenómeno en un informe que ofreció las reflexiones testimoniales aportadas por un grupo de sujetos autodenominados rastafaris durante un trabajo de campo realizado en la Ciudad de La Habana en el propio año 2002. El material se obtuvo a través de dos instrumentos: entrevista y observación etnográfica. Luego, el tema sería inscrito en el Diplomado de Antropología Cultural convocado por la Fundación Fernando Ortiz (2004), La Habana, donde la investigación resultó considerablemente ampliada en sus aspectos teórico-metodológicos, coyuntura que propició una nueva interpretación de los datos empíricos. En el programa de Posgrado de Maestría en Antropología Sociocultural (2006/2009) de la Facultad de Filosofía e Historia de la Universidad de La Habana, sería retomado y proseguido dicho estudio hasta el año 2010.

3 Cf. Félix Guattari: Cartografías del deseo, Francisco Zegers, Santiago de Chile, 1989. Cit. por Raúl Zarzuri Cortés: "Notas para una aproximación teórica a nuevas culturas 
rasta en La Habana aparece en concomitancia con las tendencias desintegradoras que atraviesan nuestra trama sociocultural tras el colapso de los años noventa. Irrumpe e interpela desde un lugar específico dentro de ella: un segmento integrado mayoritariamente por sujetos negros y mestizos, con endeble participación social efectiva. En sus discursos se expresan problemáticas vinculadas a variantes de desigualdad y discriminación, que trasuntan un evidente carácter marginal. ${ }^{4}$ Comportamientos susceptibles de ser analizados desde las lógicas de exclusión/ diferenciación, donde los factores clasista y racial constituyen ejes de obligado análisis.

Con tal propósito se propone una lectura que revele y exponga las conexiones e interacciones expresadas entre el grupo y el escenario social de la Isla, al procurar una generalización de los valores y motivaciones ${ }^{5}$ de lo convenido en llamar tribu rasta, desde una mirada dinámica que aborde el fenómeno en relación con los cambios por los que ha transitado el país durante las últimas décadas. Se trata de detectar - mediante un enfoque antropológico- sus determinaciones o causas, a través del sistema de normas, valores, conductas y hábitos desarrollados por estos actores.

Los resultados que ahora se ofrecen en el texto fueron obtenidos mediante las técnicas de entrevista en profundidad y observación participante, aplicadas entre los años 2007 y 2009. La muestra fue conformada según un criterio que contemplaba aquellos sujetos que se autodenominan "rastas", portaban los símbolos y atributos ras-

juveniles: Las tribus urbanas", en Última Década, Viña del Mar, Centro de Investigación y Difusión Poblacional de Achupallas, n. 13, sept. 2000, p. 8; Centro de Ética: "Tribus urbanas", Informe Ethos, Santiago de Chile, Universidad Alberto Hurtado, n. 31, 2003, p.2. http://etica.uahurtado.cl/html/informe_ethos_31.html

4 Cf. Roger Vekemans: La marginalidad en América Latina, un ensayo de conceptualización, DESAL, Santiago de Chile, 1967; Larissa Adler de Lomnitz: Cómo sobreviven los marginados, Siglo XXI Editores, México D. F., 1975, y Pablo Rodríguez Ruiz: Los marginales de las Alturas del Mirador. Un estudio de caso, Fundación Fernando Ortiz, La Habana, 2011.

5 Los conceptos de valores y motivaciones serán entendidos, respectivamente, en el sentido atribuido por la investigadora Carolina de la Torre, quien así los define: el primero, en tanto una "creencia relativamente estable acerca de que determinado modo de conducta o estado de existencia es personal y socialmente preferible a otros (...)"; el segundo, referido a "(...)los procesos relacionados con las intenciones, necesidades, aspiraciones, deseos, que impulsan la conducta humana hasta encontrar su satisfacción o realización". C $f$. Carolina de la Torre Molina: "Valores y motivaciones de los cubanos y cubanas de hoy. Un aporte al conocimiento del mercado cubano y sus segmentos", La Habana, may. 2007, pp. 8-9. (Material digital inédito.). Según coordenadas de la estudiosa, se contribuirá a su caracterización a través de una exploración sobre la manera en que estos jóvenes manifiestan cierta correspondencia entre determinado sistema de valores y el modo en que organizan su vida y satisfacen sus necesidades. 
tafaris al uso - desprovistos de auténticos significados religiosos-, ostentaban un significativo despliegue de sus acciones cotidianas en el espacio capitalino y comprendían hasta la edad de cuarenta y cinco años. Fue acogido el enfoque generacional de la especialista cubana Ma. Isabel Domínguez, para quien una generación es "el conjunto histórico-concreto de hombres próximos por la edad y socializados en un determinado momento del proceso histórico, es decir, copartícipes de una actividad social común en etapas claves de formación de la personalidad y poseedores de características objetivas y de rasgos subjetivos afines que dotan al grupo de una fisonomía propia". ${ }^{6}$ Dentro de las cinco generaciones coexistentes establecidas por la autora para el caso cubano, fueron tomadas las dos últimas (la cuarta, que comprende los nacidos entre 1962 y 1975 con edades entre treinta y dos y cuarenta y cinco años, y la quinta, que incluye los que nacieron después de 1976, donde clasifican los menores de treinta y dos años). Aquellas impactadas con mayor fuerza por los embates de la crisis de los noventa, según Domínguez, y caracterizadas por una heterogeneidad superior como consecuencia de la recomposición de la estructura socioclasista, el fortalecimiento de algunas diferencias territoriales asociadas al ritmo de recuperación económica y la presencia del sector emergente. ${ }^{7}$

La muestra estuvo integrada por ocho individuos (varones en su totalidad) y constituida en su mayoría por negros (un blanco y dos mestizos). Caracterizada por un deficiente acceso a los servicios de educación, trabajo y vivienda, en especial en el ámbito laboral, se destaca la inserción en la economía informal y algunas actividades ilícitas. En materia edueativa, solo uno de los jóvenes aparece vinculado a la enseñanza superior (en curso). Los grados de escolaridad fluctúan entre la secundaria y técnico medio, abundan los testimonios sobre deserción escolar sistemática en etapas tempranas y un promedio educacional descendente a medida que aumenta la edad. Exhiben un bajo nivel adquisitivo, privados en general del consumo de bienes ofertados por la sociedad, fundamentalmente de aquellos en CUC. ${ }^{8}$ Se aprecia, de manera acentuada, lo precario del proyecto de vida y un bajo nivel de

$6 C f$. Ma. Isabel Domínguez.: "Generaciones y procesos sociales en Cuba", Contracorriente, año I, no. 1, 1995, p. 58. (Cit. por Carolina de la Torre Molina: ob. cit., pp. 37-38).

7 Cf. también Germán Leva y Sergio Paz: "Jóvenes y Ciudad: Notas para una aproximación a los nuevos espacios urbanos juveniles", en Habitat Metrópolis, Departamento de Ciencias Sociales, Universidad Nacional de Quilmas, Buenos Aires, p. 12. (Documento de Internet) y M. Margulis y M. Urresti: "La juventud es más que una palabra”, en M. Margulis (coord.): La Juventud es más que una palabra. Ensayos sobre cultura y juventud, Biblos, Buenos Aires, 1998. (Cit. por Germán Leva y Sergio Paz: ob. cit., p. 13).

8 Moneda cubana paralela al peso, que funciona como divisa. Su cambio oficial es de 24 pesos por 1 CUC. 
participación social efectiva que los sitúa en los límites mismos de la exclusión y la marginación (donde se advierten algunos patrones como pobreza, desigualdad de oportunidades, consumo de drogas, prostitución, deprimidas tasas de escolaridad, etc.).

La psicóloga Carolina de la Torre ha destacado, en el conjunto de sus investigaciones sobre identidad, el estrecho vínculo entre valores, motivaciones y situaciones de crisis. ${ }^{9}$ Un criterio coincidente sostiene la especialista argentina María Silvina Souza, para quien la crisis será “(...) un momento privilegiado, que hace visible, permite la mediación reflexiva de las determinaciones de la estructura y genera las condiciones para el surgimiento de nuevas subjetividades colectivas o formas de percepción, apropiación simbólica y acción”. ${ }^{10}$ Se impone, pues, el reconocimiento de las secuelas acarreadas por el cisma cubano de los años noventa; la reflexión sobre los modos de socialización surgidos a partir del resquebrajamiento de los discursos homogeneizadores y las formas tradicionales de participación y representación social. ${ }^{11}$

Coyuntura derivada, grosso modo, de las disparidades económicas y de acceso al bienestar material — y espiritual-, cuya consecuencia más inmediata ha sido un aumento de la distancia entre segmentos, la aparición de sectores vulnerables, una acelerada y excluyente movilidad. Parámetros que indican el grado de desarticulación estructural de la sociedad cubana en las dos últimas décadas y la reciente emergencia de zonas marginales. Un debilitamiento que ha implicado no solo la profundización de diferencias de clases, sino también el fortalecimiento de otros nudos de conflictividad, entre ellos, el crecimiento de los prejuicios raciales, según ha alertado Mayra Espina en el conjunto de su obra.

Si, como asevera Carolina de la Torre, valores, motivaciones, logros y fracasos han de ser analizados desde el impacto de la subjetividad por las condiciones adversas resultantes de la crisis, ${ }^{12}$ el estrato juvenil que nos ocupa no escapa a tal generalización. En su caso, las

9 Carolina de la Torre Molina: ob. cit., p. 19.

10 María Silvina Souza: Nuevos actores, nuevas prácticas, Facultad de Periodismo y Comunicación Social, Universidad Nacional de La Plata, Buenos Aires, p. 1. (Documento de Internet).

$11 C f$. Mayra Espina: “Cuba: reforma económica y reestratificación social”, en J. Busquets (coord.): Cuba: Sociedad y Trabajo, Fundación Comaposada y Ajuntament del Valles, Barcelona, 1998; Mayra Espina et al.: "Impactos socioestructurales del reajuste económico", CIPS, La Habana, 1995. (Informe de investigación). Mayra Espina: "Panorama de los efectos de la reforma sobre la reestructuración social cubana: grupo tradicionales y emergentes", CIPS, La Habana, 1998. (Informe de investigación) y “Transición y dinámica de los procesos socioestructurales", en M. Monereo, M. Riera y J. Valdés (coords.): Cuba construyendo futuro, El Viejo Topo, Madrid, 2000.

12 Carolina de la Torre Molina: ob. cit., pp. 19-20, 60-61. 
variables mencionadas han de ser relacionadas con las dinámicas de estratificación y diferenciación surgidas, de cuyo análisis se desprenden indicadores estrechamente asociados a las prácticas culturales desplegadas por el grupo. En otras palabras, se procederá en lo que sigue a identificar las tensiones que afloran en el discurso de estos individuos; en especial, las definidas según criterios de clase, raza y, obviamente, generación.

Es sabido que en Cuba, al margen de las corrientes contraculturales que se han sucedido durante coyunturas diversas, con la llegada de los años noventa y el aumento de las desigualdades - y la marginalidad derivada-, se ha consolidado un área de relaciones conflictuales con la cultura dominante, ${ }^{13}$ que trasciende el ámbito etario. En el caso de los jóvenes alistados encontramos, en general, actitudes de contestación a las entidades del sistema (escuela, centro laboral, cuerpo policial, aparato judicial y político), cuando estas, al parecer, han dejado de ofrecer protección o un cabal sentido de pertenencia. Resulta presumible que los elementos tribales constituyan un vehículo para la provocación y el distanciamiento de la esfera institucional mediante mecanismos comportamientos irreverentes, parafernalia, enunciación crítica hacia la sociedad-que reclaman "distinción" — para decirlo en palabras de Bourdieu - ante la anomia entronizada en el tejido social circundante.

Para los sujetos interpelados, la cuestión de la exclusión racial es un fenómeno arraigado en el país. Declaran la reproducción de estereotipos y prejuicios sobre el negro, temas abordados en recientes estudios que reconocen la existencia de prácticas discriminatorias establecidas en la Isla. ${ }^{14}$ Estas expresiones contribuyen a la irrupción de conductas racistas que conllevan, como respuesta, la aparición de un campo discursivo contra toda postura segregacionista mediante la búsqueda, exaltación, reivindicación y sublimación de una identidad negra. Se constata la denuncia de atropellos y arbitrariedades; un repertorio de detenciones, acusaciones de extorsión o acoso que conforman las rutinas de algunos de estos individuos en sus relaciones cotidianas con los

13 Cf. Mayra Espina: "Reajuste económico y cambios socioestructurales", Revista Cuba Socialista, no. 21, La Habana, 2001; Pablo Rodríguez Ruiz: ob. cit., pp. 33-34.

14 Juan A. Alvarado: "Relaciones raciales en Cuba. Notas de investigación", Temas, no. 7 , La Habana, julio-septiembre de 1996; Esteban Morales Domínguez: Desafíos de la problemática racial en Cuba, Fundación Fernando Ortiz, La Habana, 2007. Para los autores mencionados, si bien estas no han sido fomentadas desde un discurso oficial que promulga la igualdad racial y social, son generadas desde la conciencia social y cultural cubanas, en las que se hallan fuertemente consolidadas como parte de nuestra herencia histórica, mientras se produce un efecto de "destape" en la actualidad. $C f$. también Colectivo de Autores: Las relaciones raciales en Cuba, Fundación Fernando Ortiz, La Habana, 2011. 
agentes del orden. ${ }^{15}$ La policía deviene figura emblemática de un poder que se ha de enfrentar simbólica y físicamente, como se observa con frecuencia a través de los relatos:

|Tal vez porque somos un sello, mi'ja. (...) Te voy a decir (...) antes de salir de cualquier lugar, de su estación [se refiere a la policía], te ponen así... "este es malo", "este es malo", "este es malo", pero a todo el que ponen son negros. (...) También no es solo ser negro sino también ser rasta, el sello del rasta es la marihuana, a mí me cogen y me revisan también completo, desde el pelo. (...) pero ¿qué voy a hacer yo?: dejar entonces que me toquen hasta el cielo. (...) yo puedo hasta discutir con ellos pero si discutes sacas bronca, y tengo deseos de llegar a mi casa, alguien me espera y llevo la comida aquí en el bolso. La última vez (...) fue por el cuchillo [de carnicero, el oficio del informante] y yo le dije entonces al policía: "mira, necesito de corazón irme, tengo una carne ahí en el bolso y se me va echar a perder", (...) después llamé al político y le dije "mira (...), llévatela para tu casa", era carnero (...), yo se la regalé, con todo eso me metieron tres días allí, por gusto. (...) Sí, yo sí creo que existe discriminación (...). Son muchas cosas mi’ja, ¿sabes lo que es jugar fútbol? (...) los contrarios quieren darte una patá' en el pie, pa' tumbarte, pa' quitarte el balón, así pasa aquí con los negros. (...) yo no quiero ser el balón, ni que me den una zancadilla, que no estén jugando fútbol con nosotros...

Se aprecia en los testimonios cómo la asunción de los atributos al uso - en tanto estrategias de distinción-rezuma el peso excluyente de acciones devaluatorias. Al sentirse minusvalorados, desplazados, estos jóvenes construyen en sus despliegues discursivos los procedimientos para afirmar su reputación mediante la dignificación de los valores de la raza propia. Significan, o mejor aún, "dramatizan" así la lucha contra los símbolos de desacralización de lo negro y mestizo; desafíos emprendidos para que la diferencia sea reconocida, legitimada. Pronunciamientos donde se advierte cómo los mismos estigmas desencadenan manifestaciones de resistencia que, al funcionar también dentro de la lógica del estereotipo, condicionan y refuerzan respuestas atravesadas por la cuestión racial. El siguiente relato ilustra algunos de los efectos sufridos a causa de prejuicios y actitudes excluyentes con motivo del

15 En el excelente estudio Los marginales de las Alturas del Mirador, el antropólogo Rodríguez Ruiz atribuye a las históricas desventajas de los negros, en tanto grupo social, un importante peso en la gestación de prejuicios que determinan su vulnerabilidad como sector proclive al delito y su represión. Cf. Pablo Rodríguez Ruiz: ob. cit., p. 292. 
color de la piel, convirtiéndose estos tópicos en importantes aspectos para el grupo:

Mira, sobre la discriminación racial, siempre la ha habido (...), eso el que no lo sepa es porque no lo quiere saber (...). Yo, por lo menos yo, vivo orgulloso de mi pelo, de mi cara, de mi negrura, de to', yo vivo orgulloso de mí... pero hay veces que tú te das cuenta de que uno no es aceptado (...), que uno no es aceptado en el ámbito de la sociedad, que tú quieres buscar un trabajo, un ejemplo, tú eres profesor, como un amigo mío que se fue para los Estados Unidos, profesor, el mejor profesor que había en su escuela, pero era negro y tenía drelos, no los tenía grande, los tenía chiquiticos... pero no lo querían dejar en la escuela porque era negro y tenía drelos...

Lo expuesto anteriormente, se relaciona con los criterios que sostienen sobre la sociedad cubana, en un sentido más general. Es sabido que la discriminación racial tiene su correlato en las desigualdades. Arguyen como limitaciones, grosso modo, además de la mencionada cuestión de raza, los problemas confrontados para solucionar necesidades materiales consideradas perentorias (alimentación, ropa y calzado, vivienda, transporte, equipos electrodomésticos esenciales), las diferencias surgidas hacia el disfrute de estos bienes según la pertenencia a los distintos estamentos sociales, ciertas restricciones que atribuyen a la esfera de la libre determinación y expresión, así como las pocas opciones para el esparcimiento y recreación (también para viajar). Por último, en uno de los casos, las escasas posibilidades para acceder a una carrera universitaria según la vocación profesional propia y la garantía de un sustento decoroso luego de graduados, donde sean reconciliables expectativas profesionales y lo que consideran viables proyectos de vida. ${ }^{16}$

Declaran abiertamente los obstáculos impuestos con respecto al bienestar de los jóvenes, pronunciamientos contentivos de una fuerte crítica e insatisfacción, de incertidumbre y desconfianza. Planteos que trasuntan un similar pesimismo están referidos al deterioro de los sistemas de salud y educación, campos de emblemáticos logros alcanzados por la gestión del gobierno. Para ellos, los valores altruistas de justicia y plena igualdad social operan de modo más efectivo como entelequia apuntalada en la utopía magnánima del proyecto revolucionario cu-

\footnotetext{
16 Carolina de la Torre glosa, en similar jerarquización, lo que define como las principales dificultades reconocidas por los jóvenes en el panorama cubano actual. $C f$. Carolina de la Torre Molina: ob. cit., p. 29. Cf. también Lázara Y. Carrazana Fuentes: "Movilidad social y filiación racial en la reestructuración económica en Cuba", en Colectivo de Autores: $L a$ relaciones raciales en Cuba, Fundación Fernando Ortiz, La Habana, 2011, p. 101.
} 
bano, que en el plano de la realidad palpable; anhelos traducidos en una desiderata de noble y humanista empeño sin otro asidero que un universo de contornos abstractos e ilusorios. De tal suerte, reconocen el alcance de las posibilidades de ascenso ofrecidas por la Revolución en estos rubros, pero el rasero con que miden los parámetros de equidad parece obviar los mencionados y carenar allí donde irrumpen los factores de desintegración que impactan la sociedad cubana actual.

Aparece en los relatos, de manera reiterada, la situación en extremo compleja y singular que vive la isla. Un país donde adoptan proporciones alarmantes el descalabro de la vida cotidiana y una economía precaria, colapsada. Las voces revelan las trazas del duro bregar en el convulso contexto signado por la crisis. Grafican la dimensión de la escasez, problemáticas como la depresión de los salarios en moneda nacional (devengados en peso en el sector estatal), las dinámicas de una doble economía y su repercusión en las mentalidades de los más jóvenes. Carencias todas traducidas en escepticismo, que denotan gran preocupación y desasosiego acerca del futuro. El tema de un presente y devenir inciertos surge cual leitmotiv, describe la clásica figura de la serpiente que se muerde la cola en torno a una existencia constreñida al difícil lidiar con necesidades siempre insatisfechas y la impotencia generada por dificultades concretas para revertir la situación. Mientras, se pone en solfa la credibilidad del sistema y se engrosa el distanciamiento respecto de las instituciones sociales, como es constatable en el siguiente testimonio:

Mi mirada hacia el futuro es que yo veo que el tiempo pasa y aún no tenemos nada (...) llevamos una vida (...) ni alta, ni media, ni baja (...) porque todo eso que dicen del sistema de salud...(...) ahora cuando ella [se refiere a su pareja] estuvo en el médico, normal, era la cochiná más grande el hospital (...)... lo que había era una gotica de agua ahí, un ratico nada más, y ya después te la quitaban y... eso es Salud. (...) mira, podemos tener como yo te digo una casa, que muchos no la tenemos (...) pero la alimentación de nosotros ¿qué es?... (...) el modo de vida... para adquirir un artículo, es demasiado caro (...) un televisor para comprarlo son 300 dólares, ¿cuándo un cubano aquí ha cobrado 300 dólares? Nunca. Ni siquiera en un año. La vida diaria de una persona en Cuba, mínimo, son 50 pesos, para poder comer diario (...) ¿de dónde? ¿cómo los vas a buscar?... el salario entonces no alcanza ni pa' tres días...

Las manifestaciones de frustración adquieren un significado mayor, se exacerban, a la luz de la diferenciación surgida, zona de gran sen- 
sibilidad para estos sujetos. La cuestión de la desigualdad creciente es recurrente en los relatos. Ha sido destacado por analistas de qué modo este fenómeno - y otros factores coadyuvantes (empobrecimiento, marginalidad y exclusión social) - irrumpe en el escenario cubano tras el cisma de los años noventa, mientras sus antecedentes se localizan en una herencia estructural donde se identifican procesos de segregación históricos que afloran y arraigan en la sociedad con la crisis. ${ }^{17}$ Algunas de sus expresiones actuales radican en la depreciación de los ingresos de ciertos segmentos y las limitaciones acaecidas en la satisfacción de sus necesidades básicas. Hecho determinado por la fuerte contracción en la relación producción/oferta de bienes y servicios iniciada en la década de 1990, así como los necesarios reajustes adoptados para salvar del naufragio el proyecto de nación. Una situación caracterizada, entre otros, por un retraimiento del alcance real de los salarios de estos estratos específicos —enfrentados a una doble moneda que tributa a mercados diferentes e incongruentes políticas de precios- y la consecuente devaluación de la fuerza de trabajo en el sector estatal, que ha tenido su contraparte en la aparición de fórmulas de laboreo alternativas, algunas ancladas en la economía informal y el mercado negro, de funesto impacto en la economía del país. ${ }^{18}$

En los relatos salen a relucir las dificultades que para entrar al mundo del consumo experimentan los jóvenes en cuestión. Corroboran cómo el disfrute en áreas de esta esfera está signado por desventajosas condiciones. ${ }^{19}$ En tales circunstancias, la igualdad es esgrimida como valor y reclamo, imperativo o demanda, un ideal que confrontan con la vislumbrada pérdida de indistintas oportunidades para todos. ${ }^{20}$

Según veremos, ante el distanciamiento de los márgenes entre grupos, rechazan los privilegios o discriminación en cualquiera de sus variantes, no solo racial, sino social o económica. Se perciben excluidos del consumo, como otros de los rasgos de mayor fragilidad que les distingue. La diferenciación referida, para decirlo con las palabras empleadas por Carolina de la Torre en el mencionado documento, parecen no proceder exactamente "del esfuerzo personal, la superación o el trabajo, sino de la recepción de divisas, la posibilidad de ingresar en

17 Cf. Pablo Rodríguez Ruiz: ob. cit. y el conjunto de los trabajos de Mayra Espina anteriormente citados.

18 Cf. Pablo Rodríguez Ruiz: ob. cit.

19 Pablo Rodríguez Ruiz: ob. cit., pp. 7-8, 50, 78-79, 83; Pablo Rodríguez Ruiz, Lázara Y. Carrazana Fuentes y Ana J. García: "Relaciones raciales en la esfera laboral”, en Colectivo de Autores: ob. cit., pp. 83-84.

20 Carolina de la Torre Molina: ob. cit., p. 44. 
sectores emergentes de la economía y la habilidad para 'inventar' vías alternativas de ingreso" . ${ }^{21}$ Dichas problemáticas aparecen ilustradas en este parlamento:

(...) yo con el pan diario me conformo... lo que yo no me conformo es que cuando tú ves tantas personas por ahí consumiendo bultos de cosa y que tú que estás trabajando, que estás estudiando, que lo mismo chapeas un patio, que cargas unas piedras (...) que por eso te están dando tres morrocotas, que tú camines tres cuadras y a las tres cuadras tú veas un policía que te diga a ti que por tu pelo y por tu apariencia no..., y eso lo hablo con base, no es que lo hable porque me lo hayan dicho, (...) lo hablo (...) porque lo estoy sufriendo yo ahora mismo... y tú ves tantas personas que están haciendo negocios, que están inventando no sé cuantas cosas por ahí pa'llá y nunca les pasa nada, y yo (...) trabajo, yo estudio, yo no tengo nada que ver con robar (...), no tengo nada que ver con nada de eso y sin embargo tengo la policía arriba de mí porque dicen que yo... rasta es droga y están arriba de mí...

Los testimonios grafican, pues, la desproporcionalidad en el acceso a los bienes, la existencia de dos segmentos de mercado - aquel atrayente que opera en divisas, a la par de otro regido por la restringida oferta en una devaluada moneda nacional-, y cómo las privaciones orientadas hacia el primero calan en la sensibilidad de los jóvenes con toda la fuerza del contraste generado. Reflejan, además, de qué modo el ámbito del consumo se configura a partir de escaños restrictivos donde el trabajo está cada vez más lejos de constituir un eje medular. El relato anterior resulta harto elocuente al sugerir la localización de los sujetos en uno u otro extremo del espectro de los ingresos devengados, mientras propicia una lectura en cuanto a estilos de vida y hábitos de consumo asociados.

Otros aspectos salen a relucir, entre estos, la devaluación del trabajo enfrentado a la economía no formal y el mercado negro - como fue apuntado-, la irrupción de los negocios ilícitos, la pérdida de prestigio del empleo estatal o el estudio, y la consecuente expansión de la informalidad, como opciones que ganan espacio en la vida cotidiana. Por último, se aprecia cómo estas voces son proyectadas desde lugares segregados, marginados, allí donde muerde la discriminación, la sensación de sentirse desplazados, relegados. Alegatos que rezuman cómo los procesos de diferenciación inciden de manera lacerante en las relaciones raciales hacia el interior de la trama social cubana. Cómo se siente

21 Ibídem, p. 20. 
"en carne propia" el rigor de las carencias o de qué modo la cuestión de raza - y los estigmas derivados_-atraviesan los rasgos más destacables que marcan las disparidades.

De manera concomitante, los valores y motivaciones se desplazan hacia otras zonas que se alejan del trabajo. Se asiste, en efecto, a una depreciación de este, específicamente del procedente del sector estatal. Para Rodríguez Ruiz tal problemática se explica, en esencia, mediante una reconfiguración del sistema de valores donde pautan las nuevas dinámicas de jerarquización, determinadas por lógicas estructurales de desigualdad y exclusión que van consolidándose paulatinamente. ${ }^{22}$ Una coyuntura donde incide de manera definitoria la participación poco equitativa respecto de las oportunidades de inserción en los distintos renglones emergentes de la economía, ${ }^{23}$ como otra de las agravantes de un panorama nacional donde las circunstancias económicas limitan ingresos y anulan la capacidad de los sujetos para vivir del salario y, de tal suerte, del trabajo. ${ }^{24}$ En los testimonios llama la atención el peso que adopta el deterioro de este último, cómo es subestimado a partir de su alcance real. Para algunos de ellos, veremos, este ha perdido su valor, mientras para otros es justamente el dinero empleado para pagar el esfuerzo del trabajo el componente diezmado. ${ }^{25}$ De cualquier modo, y en esto parece existir un consenso, el trabajo solo es considerado valioso cuando se traduce en entradas que garanticen el sustento, fuente de remuneración que retribuya y compense el sacrificio realizado, como sostiene uno de los jóvenes en la siguiente aseveración:

Lo que yo creo que se ha perdido no es el valor del trabajo sino el valor del dinero... porque la paga no es compensada con el trabajo que uno hace... No solamente el rastafari, sino cualquier joven o adulto no desean trabajar (...). (...) yo entiendo que ni yo tampoco lo haría si no me pagaran un salario bueno, igual no trabajara. Porque no me gustaría reventarme por una cosa que cuando llego a mi casa no tengo ni pa' comer, porque normalmente el dinero que se paga aquí en Cuba no alcanza para pagar ni para la comida diaria. Ahora estoy trabajando de

22 Pablo Rodríguez Ruiz: ob. cit.; Cf. Lázara Y. Carrazana Fuentes: ob. cit., pp. 92-96, 122.

23 Pablo Rodríguez Ruiz: ob. cit., pp. 91, 192-193; Pablo Rodríguez Ruiz, Lázara Y. Carrazana Fuentes y Ana J. García: ob. cit., pp. 45-84; Lázara Y. Carrazana Fuentes: ob. cit., pp. 85-124.

24 Pablo Rodríguez Ruiz: ob. cit., pp. 66-76, 87-89, 394-398, 412-413; Pablo Rodríguez Ruiz, Lázara Y. Carrazana Fuentes y Ana J. García: ob. cit., pp. 58-60, 66-67; Carolina de la Torre Molina: ob. cit., p. 65.

25 Cf. Carolina de la Torre Molina: ob. cit., pp. 40-41, 43. 
parqueador, y como un trabajo más... en la venta de pinturas en La Catedral. Pero me iría mejor si trabajara en mis esculturas (...). No, no... ahora no hago esculturas porque el jefe de sector dice que eso es ilegal. Que gano mucho dinero con eso. (...) Yo lo que no quiero discutir con ninguno, no sea que me vayan a meter preso... si ellos dicen que es así, vamos a hacerlo así, ya después vamos a ver qué pasa. (...) En el parqueo, formal, completamente... en lo otro, informal. El parqueo puedo hacerlo de noche... en lo otro no hay una formalidad como tal (...) más bien lo que estoy es de asistente para poder ayudar a vender algo... y así voy tirando... pero alcanza un poco más. (...) Yo he trabajado, trabajé parte de mi juventud para el gobierno, bastante. Al principio, mucha construcción (...) trabajé en la enfermería, trabajé en distintos lugares, pero cuando descubrí la escultura, no quise trabajar pa' más nadie, quise trabajar para mí. (...) las esculturas daban para eso [vivir]...

El argumento anterior, además de plasmar la asimétrica relación trabajo/salario/bienestar, grafica la incrementada presencia de la economía informal. Cómo las alternativas que tributan a este campo irrumpen en detrimento de los niveles de empleo orientados al ámbito estatal, en franca competencia con otros ramos emergentes - en este caso, el cuentapropista, muchas veces de enrevesado deslinde respecto de la actividad ilícita-, al representar vías de ingresos más llamativas. ${ }^{26}$ Opciones no reñidas entre sí, según vemos, cuando aquellas estrategias más legitimadas parecen radicar en las argucias puestas en práctica para articular ambas variantes. Destaca un repertorio de triquiñuelas desplegadas con el fin de conciliar el desempeño exitoso en los dos foros: el empleo informal como mecanismo asegurador del sustento, mientras su reverso (el estatal) deviene telón necesario para burlar la vigilancia y censura de los órganos de control de la sociedad.

Asistimos a un contexto precario que no solo precipita a la errancia entre el laboreo formal e informal, sino que compulsa a transgredir las reglas éticas y jurídicas instituidas por el discurso oficial de la nación. El colapso económico que afecta todas las facetas del país resiente los valores, la subjetividad y, en general, la jerarquía motivacional de los más jóvenes, ${ }^{27}$ convertidos en segmento de gran vulnerabilidad. En los discursos de estos jóvenes encontramos que grandes relatos como el

26 Cf. Pablo Rodríguez Ruiz: ob. cit., pp. 88-89, 127, 168-192, 272-282, 399, 412; Lázara Y. Carrazana Fuentes: ob. cit., pp. 89-90, 122. Cf. también Carolina de la Torre Molina: ob. cit., pp. 82-114.

27 Cf. Carolina de la Torre Molina: ob. cit., pp. 19-20, 22-24. 
estoicismo, la abnegación u honestidad, erigidos en paradigmas de los años ochenta y primera mitad de los noventa - situando al trabajo y a la superación técnico-profesional en la cúspide de la realización y ascenso social- sufren un fuerte debilitamiento. ${ }^{28}$ Los desvelos gravitan en torno a las necesidades para alimentarse, vestirse, transportarse, mientras el esparcimiento y el consumo en fiestas y otras actividades recreativas vinculadas al ocio suponen prioridad para el grupo en cuestión. En su mayoría, los sujetos abordados aceptan la ilegalidad como modo de subsistencia; manifiestan tolerancia hacia los negocios ilícitos y otras prácticas delictivas menores.

Una de las expresiones del fenómeno aludido alcanza su cristalización en la metáfora de "la lucha", noción alrededor de la cual se establecen los mecanismos de supervivencia para paliar el rigor de la escasez. ${ }^{29}$ El término abarca un dilatado universo semántico donde se legitiman las alternativas para entendérselas con la difícil contingencia. En el discurso de "la lucha", el trabajo surge como fuerza neurálgica, pero los escenarios donde opera se tornan más flexibles, plurales, permisivos. Como veremos, algunas de las estrategias más socorridas colindan con el delito menor, sin importar su proscripción por el sistema jurídico. En la "lucha" y el "invento" se redimensionan y normalizan los valores de la honradez, el sacrificio y la abnegación, convertidos ahora en aliados que rigen la épica del apurado vivir. Sostenidos sobre la idea de subsistencia, adquieren raigambre de principios en los avatares de la vida cotidiana. Las iniciativas para procurar el sustento o asegurar las divisas son disímiles. En las voces de los sujetos abordados aparecen prácticas de "acoso" al extranjero; incursiones en la economía informal donde el mercado negro deviene sostén benefactor de claras imbricaciones con un emporio "cuasilegal" cuentapropista-pues maniobra sin licencia, las más de las veces-en tanto variantes que incrementan el prestigio de la "lucha", según se aprecia en las declaraciones de este joven:

(...) pa' mí eso es luchar... un ejemplo, que yo venda tabaco o un ejemplo... (...) que lo lleve [a un extranjero] a una paladar o a un mojito y en vez de decirle que son tres pesos, son 4 pesos y eso... (...) hay personas que sí viven de eso... de que "vamo aquí", "vamo allá", un ejemplo, que la misma entrada de la actividad (...) no sé, vale 10 doláres o te sentaste aquí y le dijiste "no,

28 Ibídem, p. 26.; Cf. Lázara Y. Carrazana Fuentes: ob. cit., pp. 88-90.

29 Carolina de la Torre define una suerte de genealogía de "la lucha" como tópico que alcanza rango o estatus de valor. $C f$. Carolina de la Torre Molina: ob. cit., pp. 25-26, 42, 61, 64; Cf. Pablo Rodríguez Ruiz: ob. cit., pp. 356-364. 
aquí vamos a consumir un mojito, vale 4 dólares" y en realidad vale 2 y después van por atrás de eso y el dependiente le da su propina ¿entiendes?... y eso es una forma de luchar... de obtener dinero (...) Yo te digo a ti que mayormente las personas que hacen esas cosas son personas que no trabajan... que no tienen una entrada (...) y entonces... de alguna forma tiene que buscar el dinero para vivir, o para mantenerse ¿no? (...) Un ejemplo, yo mismo, si yo no trabajara... si no tuviera la entrada que tengo ahora haciendo mis trabajitos particulares y eso y estuviera en la calle sin hacer na'... de alguna forma tengo que buscarme el dinero y... entonces... pasan esas cosas ¿no?...

Vemos en los relatos, en definitiva, difuminarse los contornos negativos de los eventos delictivos y el mercado negro como espacios de ilegalidad. Circunstancias donde parece tener lugar un reacomodo de valores, mientras el discurso hegemónico se agrieta y asistimos, entre sus fisuras, a los necesarios trasvases que embisten la norma social para la estandarización de las actividades que tributan a la "lucha". En otras palabras, comportamientos arraigados en actitudes transgresoras de los cánones, legitimadas cuando los apremios por la supervivencia le relativizan y confieren contenidos diferentes a prácticas otrora desacralizadas; cuando los sujetos aparecen abocados a una mentalidad cifrada en una existencia vivida al límite. ${ }^{30}$

La problemática aludida prospera en estrecho vínculo con el recrudecimiento de otras patologías, entre ellas la prostitución. El “jineterismo" deviene opción en algunos casos y en los testimonios encontramos cómo es acogido sin conflicto, suerte de designio que participa, cuando más, de cierta condición fatalista. Se fundamenta sobre diversas motivaciones: el ingreso de divisas, la posibilidad de salida del país, la oportunidad de ayudar a la familia y un largo etcétera. Otras sintomatologías son apreciables, entre ellas un repertorio de truculentas estafas dirigidas al "yuma", ${ }^{31}$ que apelan al ingenio, picaresca o cualidad seductora del cubano enfrentado al turista ingenuo, impostoramente estereotipado. Afloran consideraciones sobre los quehaceres ilícitos y las nuevas gradaciones endilgadas, una suerte de "economía del delito” — a decir de Rodríguez Ruiz en un intento de resemantiza-

30 Rodríguez Ruiz se explica tales procesos a partir de un fenómeno que el estudioso J. L. Martín ha definido como “(...) maximación del inmediatismo y la lucha por la subsistencia (...)”. Cf. José Luis Martín: “Controversia: ¿Entendemos la marginalidad?”, Temas, no. 27, La Habana, octubre-diciembre de 2001, p. 71. (Cit. por Pablo Rodríguez Ruiz: ob. cit., p. 34).

31 Extranjero. 
ción del concepto del ensayista Enrique Cirules-, ${ }^{32}$ donde son acogidos como válidos aquellos tildados de "menores" (compraventa de drogas y productos en el mercado negro, prostitución, atraco o estafa, por ejemplo) y objetados los que suponen mayor gravedad (robo o asalto, en este caso). ${ }^{33}$ Conductas que clasifican entre las más establecidas para la "lucha" o el "invento" son corroborables en el próximo enunciado:

Yo pienso que cada cual que tenga su manera de luchar, ese es su maletín, que si él quiere jinetear que jinetee, yo normal, (...) si tú jinetea, tú mete tu lucha, tu forma lo tuyo, ese es tu maletín, tuyo, pero yo lo que sí veo feo es que roben, que roben, si quieren vender marihuana, que la vendan, eso es una forma de luchar ellos también...

(...) Sí, al gil, mira, al principio de que todos los yumas venían, tú te le tirabas pa' arriba: "un gil”, pum, y lo raspabas. ¿Tú sabes lo que es raspar? (...) Cambiaban, llegaban y les decías: esto vale tanto y era tanto. Gilberto, de verdad que eran gil, tú llegabas y les decías: "diez pesos", diez pesos; "cinco pesos", cinco pesos. Eso fue al principio (...) pero ya han aprendido mucho.

Asimismo, no existe una mirada cuestionadora sobre el consumo de drogas; de la marihuana, específicamente. No se asume la implicación delictiva de la práctica. Los relatos ilustran los encontronazos con las instituciones de control, cómo se articulan los mecanismos transgresores ante las acciones de las autoridades encargadas de la seguridad ciudadana y prevención del delito. Permiten aproximarnos a la operatoria de las rutinas desplegadas, muchas veces circunscritas al propio entorno barrial e inmediato del grupo, donde son presumibles las redes de solidaridad y entramados que garantizan su cohesión, sustentados en la confianza, la lealtad y la incondicionalidad a ultranza: estar dispuestos a no "fallar" o "flaquear" ni aun en los momentos de mayor peligro según sostiene, a continuación, uno de los sujetos entrevistados:

El DNA me ha citado una pila de veces a mí... por gusto (...) empezaron con una labor profiláctica los primeros días para conocer quién era la persona etcétera, etcétera... pero después venían ya como hincándome ahí... "no, tú vendes droga"... "no, yo no vendo droga" "no, tú haces esto" "no, yo no hago nada de esas cosas, yo no fumo, yo no bebo, yo no hago nada"... "no,

32 Ibídem, p. 187.

33 Cf. Pablo Rodríguez Ruiz: ob. cit., pp. 283-296; Cf. Lázara Y. Carrazana Fuentes: ob. cit., pp. 89-90, y Carolina de la Torre: ob. cit., pp. 45, 82-114. 
pero tú sabes quién lo hace” (...) porque querían realmente que trabajara para ellos (...) chivatear, mira, yo digo que no tengo nada que ver con eso... (...) “Bueno, [G], confío en ti”, "sí, sí, sí, confía en mí que aquí no hay problema”. "No, pero ¿tú piensas que tú puedas decirme algo, algo que tú...?” "yo no conozco a nadie que fume ¿qué tú quieres que te diga?” (...) una onda muy obstinadora por parte de ellos (...) pero pa'chivato no nací...

Como veremos, son desaprobadas las sanciones penales establecidas, los esfuerzos realizados por el gobierno en relación con las campañas emprendidas. Se objetan disposiciones legales y la reciedumbre de condenas impuestas. Se conforma un discurso de denuncia, mientras surgen las tensiones en torno a un Estado represor que margina mediante la reiterada privación de derechos y libertades, y les convierte en objeto de posturas coercitivas y excluyentes. Voces que impugnan, emplazan -y resisten - las instancias de poder que acometen sus faenas normativas sobre ellos:

(...) las consecuencias son muy graves ¿entiendes? mira (...) hay que tener en cuenta que cuando se habla de marihuana en este país hoy en día estamos hablando hasta de 30 años de privación de libertad... (...) no me hables de eso [se refiere a la Campaña Antidrogas], que eso pa'mí es gastar dinero por gusto, eso son miles de pomos de leche que se pueden tomar los niños en este país. Esa línea antidrogas, ese espacio en el televisor... (...) yo prefiero... ese presupuesto dárselo a los niños en caramelos... eso no sirve... eso no va a ningún lado. (...) Eso no respeta ¿tú me entiendes? (...) eso no me respeta a mí, eso que tú ves ahí en la televisión...yo me insulto cuando yo veo eso... (...).

La mirada crítica también subraya la necesidad de una flexibilización hacia ámbitos de participación más inclusivos, ante una política cultural que restringe la autonomía de los diversos imaginarios juveniles en los medios de comunicación oficiales, como se destaca en el próximo relato. Cierto reclamo orientado a una mayor pluralidad en la gestación de espacios de representación; el despliegue de iniciativas que favorezcan la diversidad de discursos culturales, sometidos al disenso por una proyección oficial monolítica que confina estas manifestaciones al guetto de lo underground y alternativo.

De tal suerte, se estructuran impetraciones de reconocimiento y legitimidad institucional, argumentos que trasuntan experiencias de exclusión desde las que se canalizan frustraciones, vejaciones y expec- 
tativas de vindicación. Observamos, una vez más, los estigmas o rótulos que acompañan el fenómeno; vemos a la figura del policía encarnar un rol que de modo frontal conflictiviza las relaciones con estos sujetos, quienes reafirman su otredad — su derecho a ser diferentes- en los constantes tejemanejes que rigen los encontronazos con las fuerzas del orden, tal como aparece registrado en el siguiente parlamento:
Sí, sí, sí, mira, el rock está mejor, (...) el rock tiene a Cuerda Viva en la Televisión ¿entiendes? (...) El reggae no tiene espacio en ningún lado (...) y es una música que llega, a la gente le gusta (...) Aquí en Cuba hay represión contra los rasta, (...) entonces [te] prestan un local, no puedes disfrutar del local ¿por qué? porque se meten otra gente que son los que malean al rasta, se mete la policía, el bábilon, y pone la cosa mala. Entonces des- pués dicen: “ino!”, “¡los peludos!”, “jlos negros peludos estos!”. Mira, se acaba eso como la fiesta del Guatao (...) les molesta el vestir de nosotros... que somos negros y somos pelú... y nos gusta el reggae.

De igual modo, se demandan alternativas recreativas y de esparcimiento para el empleo del tiempo libre. Medidas que ayuden a paliar las necesidades económicas, de adaptación o reajuste a las carencias existentes. Un discurso donde las responsabilidades se achacan con displicencia a "los de arriba", mientras estos actores parecen resentirse de cierta condición de "olvidados" por las instancias del gobierno, que descuidan atención y seguimiento a las opciones de divertimento exigidas a los aparatos administrativos. En algunos pronunciamientos, es evidente la mirada consciente sobre aspectos vinculados al universo delictivo juvenil —un repertorio de tipos, desde el hurto hasta las drogas - que ofrece un conjunto de apreciaciones sobre el tema, pero donde destacan, sobre todo, los clamores ante los escollos que limitan su desenvolvimiento como jóvenes. Veamos:

Mira (...) la juventud no tiene ningún lado donde ir, la juventud no tiene un espacio para dejar de pensar en las cosas malas que están haciendo (...), quieren ir a un lugar bueno, o quieren salir con su novia, entonces tienen que robar (...) están haciendo cosas malas que no deben de hacer ¿entiendes? entonces lo que tienen que hacer es tratar de buscar un espacio para que esos mismos jóvenes tengan algo en qué pensar (...) no estén pensando bobería (...) ni vendiendo drogas ni haciendo cosas fuera de lo normal. (...) yo pienso que lo mejor pa' eso es hacer, no sé, hacer (...) algún plan pa' ese tipo de ayuda (...) algo que sea... con una economía más barata, que tú puedas consumir 
algo más barato, que tengan ellos donde ir (...) que puedan ellos ir con sus novias... pero eso a ellos no les importa.

Las circunstancias parecen agravarse cuando los indicadores que regulan y miden el acceso al consumo no se corresponden exactamente a los lugares tradicionales asignados al estatus educacional, sino a las astucias asumidas para agenciarse las variadas e inciertas vías de subsistencia. Es de suponer que se produzcan entonces lógicas adaptaciones, (re)estructuradas sobre un nuevo orden de valores articulados entre lo permitido y los necesarios reacomodos que la sociedad y la agreste realidad imponen, ${ }^{34}$ según ya se ha expuesto.

Si los derroteros que apuntan a la movilidad han de cifrarse en la capacidad para la lucha, si los niveles de instrucción y el trabajo no garantizan el sustento, si emergen cambios de una reforma económica que legitima otros mecanismos encaminados al progreso social, irrumpen conjuntamente las condicionantes que restan interés hacia el estudio. ${ }^{35}$

En los testimonios adquiere gran peso la desmotivación hacia este rubro, sobre todo por la enseñanza universitaria. ${ }^{36}$ Como observamos, la superación técnico-profesional también parece dejar de ser un medio para ascender y alcanzar un futuro mejor. ${ }^{37}$ Predomina la incertidumbre en relación con las contradicciones acerca de las expectativas del éxito laboral, vocacional y económico. La precaria realidad del país se impone cuando se tornan irreconciliables bienestar material y desempeño profesional, atravesado este par por inmensas paradojas que determinan un progresivo desinterés hacia la inserción laboral estatal de egresados universitarios, un estado de insatisfacción y frustración evidenciado en el discurso de uno de los jóvenes abordados:

Bueno, yo, mi intención es trabajar en lo que yo me gradúe (...) porque yo pienso, no sé, pasar lo de periodismo y pasar

34 Cf. Pablo Rodríguez Ruiz: ob. cit., pp. 21, 50, 184-187, y Ovidio D’Angelo Hernández: Desarrollo de una cultura reflexiva para la transformación social en diferentes actores sociales, CIPS, La Habana, 2004, p. 98. (Informe de investigación). Cit. por Pablo Rodríguez Ruiz: ob. cit., p. 188.

35 Cf. Lázara Y. Carrazana Fuentes: ob. cit., pp. 87-90, 121-122; Pablo Rodríguez Ruiz: ob. cit., p. 136, y el conjunto de los trabajos citados de Mayra Espina.

36 En la muestra, solo un sujeto ha cursado la educación superior, presentando irregularidades que lo han alejado coyunturalmente de la carrera de Comunicación Social en la modalidad de Universidad a distancia.

37 La investigadora Carolina de la Torre Molina sitúa desde inicios de los años noventa la gradual pérdida de interés por el estudio y, en general, un paulatino deterioro de su tradicional prestigio. $C f$. Carolina de la Torre Molina: ob. cit., pp. 32, 45, 65-66. 
también lo de marketing (...) yo pienso de que si yo encuentro un trabajo que verdaderamente a mí me sea factible aquí, aunque eso yo lo dudo un poco (...) porque no creo, vaya, de que yo vaya a coger, de que me vayan a ubicar en un lugar que verdaderamente, no sé. (...) A mí me gustaría (...) hablar sobre los temas de racismo, el maltrato de la policía con las personas, no solo con los rastafari, raperos, sino con todas las personas, el porqué de la emigración (...), pero para todo eso es necesario de que lo que tú hagas te lo dejen hacer (...) yo sé que eso va ser imposible... y además está lo económico... ¡cómo me voy a mantener a mí y a mi familia si el salario que voy a percibir por eso no me va alcanzar ni pa' comer?

Aunque resulta difícil trazar una acabada jerarquía motivacional de estos sujetos - para emplear los ejes conceptuales de Carolina de la Torre- ${ }^{38}$ es posible aproximarnos a algunas metas, sueños, anhelos, ambiciones o deseos que traducen sus intereses. Encontramos, en el análisis, determinaciones socioeconómicas objetivas que les lanzan hacia un entramado de comportamientos específicos, con indiferencia de la capacidad demostrada para estructurar planes y maneras efectivas para su emprendimiento o concreción: en ocasiones estos asumen formas dispersas o difusas.

Sobre la precariedad de un proyecto de vida que no les satisface, gravitan los móviles fundamentales — dificultades confrontadas para tener una vivienda, un trabajo decoroso que les garantice el sostén o cubrir contingencias perentorias como vestuario, alimentación y transportación, así como otras necesidades asociadas al disfrute, entretenimiento y ansias por viajar- que parecen ser causales de que siete de ocho jóvenes abordados se planteen irse del país. ${ }^{39}$ Ante la imposibilidad de alcanzar tales aspiraciones - convertidas en algo casi apócrifo-, las soluciones se buscan en el exterior como lugar o destino deseado para el mejoramiento con vistas al futuro.

Esta problemática es reiterada en los relatos. Las estrategias para el logro de estos fines se antojan imprecisas, cuando no disolutas. En ocasiones adoptan tintes de evasión, subterfugios verdaderamente enajenantes hacia un panorama que no ofrece salidas — según opinan los entrevistados-. Como veremos, pueden ser disímiles: el matrimonio

38 Ibídem, pp. 19, 39, 63.

39 En su estudio sobre "los valores y motivaciones de los cubanos y cubanas de hoy", Carolina de la Torre advierte estas necesidades, aspiraciones y motivaciones en segmentos poblacionales más amplios, a través de un conjunto de investigaciones que se remontan a la década de 1990. Cf. Carolina de la Torre Molina: ob. cit., pp. 29-35, 39, 77-121. 
con un extranjero — se acuda o no a la prostitución-, la salida ilegal, el apelar a amigos o familiares mediante redes transnacionales generadas por la migración. En cualquier caso - aunque no siempre apreciable en el discurso-, no predominan vías consagradas a la vocación técnicoprofesional, el estudio, el trabajo o la superación, como asideros para emprender tales derroteros.

Destaca la abulia en el propósito mismo, proyectado las más de las veces desde la hiperbolización de expectativas sobre la resolución de carencias; una resultante de experiencias también etiquetadas, distorsionadas e idealizadas, cuyos retos se desconocen o se niegan. La emigración surge como alternativa plausible, en detrimento de otras variantes de "movilidad", como es dable constatar en la voz de este joven:

(...) te digo, hay personas que lo hacen [jinetear] y no están buscando la economía ¿no?, no están buscando dinero y lo que están buscando es para irse del país, por la situación económica en su casa, a lo mejor viven mal y quieren salir y hacer una nueva vida y así ¿entiendes?... (...) porque yo soy cubano y yo me siento cubano y a mí me gusta mi país y no sé, en mi caso, si yo conociera una chica y me dice "oye, vámonos" que-se-cuando y yo veo posibilidades de que pueda mejorar y mi economía puede mejorar, yo me voy también igual, ¿entiendes?... Como no podemos resolver los problemas, lo mejor es tratar de salir pa' ver si resolvemos los de nosotros ientiendes? porque normalmente aquí no hacemos nada. Yo sí, siempre he ambicionado irme de este país. Siempre. (...) Yo me casé al final con una extranjera, pensando que ella me sacaría, normal, al final nunca me llevó a ninguna parte. Eso fue hace como diez años. Yo con esta me casé por amor, de verdad, porque yo la quería. Porque yo tuve miles de jevitas extranjeras, normal, y a mí ninguna me gustaba, pero si me sacaban, yo contento (...). También mediante el trabajo, pero encontrar un turista que se enamore de lo que tú haces normalmente es muy difícil, tienes que buscarlo en un pajal, y eso está difícil. Y la otra sería tirarse para el mar, pero a mí no me gusta eso, prefiero ponerme a esperar aquí, normal, a que la muerte me llegue (...). Me gustaría ir a Inglaterra e iría normalmente a trabajar, no iría a ser un estúpido ahí, como mucha gente que piensa que se van del país... y van buscando, cómo decir, seguir jineteando por otros lugares, ese es el error de mucha gente. Si voy, voy a empezar a trabajar...

Otras veces hallamos que la principal motivación para ello aparece vinculada a la familia. Apoyarle en la búsqueda de opciones para enfrentar 
limitaciones materiales y procurar su mejoría o avance, deviene móvil fundamental e importante valor. ${ }^{40}$ Bajo este presupuesto, la salida del país adquiere para algunos un interés mayor, si contribuye al bienestar económico del grupo familiar. En el siguiente testimonio salen nuevamente a relucir sentimientos de frustración y desesperanza acerca de la realidad de la isla como escenario de oportunidades para los más jóvenes. Cuando la asfixia aprieta en la familia, la partida se convierte en imperativo para aliviar la dramática situación del núcleo, una fuerza que precipita a estos jóvenes a una difícil disyuntiva; conflicto cuya resolución, las más de las veces, les escinde entre las "dos orillas":

Mi proyecto... yo tengo ganas de irme del país, (...) tengo amigos que se han ido (...) y me han dicho "esto aquí está bueno (...) no es que esté bueno, esto está en candela, pero tú lo único que tienes es que trabajar", el que no manda 10, 20 dólares o 30 dólares pa' su casa es porque no quiere mandarlo (...). (...) mira... todos mis amigos, todos se han ido, pero no se han ido por la ley, todos se han ido en balsa, sin quererse ir (...) todos se han ido llorando (...) y ellos me han dicho "asere no, no, no es que yo quiera irme, es que esto me obliga" pero yo no he tenido el valor ese de irme así... (...). Pero sí (...) yo pienso que la manera mejor que yo puedo ayudar a mi familia es yéndome (...) no es que yo quiera, pero (...) una persona trabaja y trabaja aquí y es lo mismo con lo mismo... sin embargo, allá tú trabajas y tienes (...) no tendrás pa' ser rico, pero tienes pa' por lo menos mandar 10 pesos mensuales a tu casa, 10, 5, 20 o 30 (...) tienes pa' por lo menos decir (...) "abuela, mira, ven, para que te tomes un refresco por la noche", y me ha pasado aquí que mi abuela ha tenido ganas de tomarse un refresco y no he podido, no he tenido dinero pa' comprarle un refresco, entonces, aunque tú creas que no, eso a uno le duele y le molesta, una cosa insignificante... como tomar un refresco... (...) mi obsesión no es tanto irme del país, sino de ayudar a mi familia (...) lo más malo que hay es ver a... por lo menos yo a mi abuela... que tiene ochenta y tres años y mi abuela lucha que es una barbaridad, lo mismo te vende un tamal, que te hace comida, lo que sea, y hay veces que tú te quedas así mirando y dices una persona de ochenta y tres años todavía haciendo esto... por lo menos a mí eso me da un dolor enorme, (...) enorme, hay veces que yo no tengo un medio y mi abuela viene y me da dinero y a mí eso me da pena, una persona joven como yo que no tenga dinero ni para

40 Ibídem, pp. 41, 45, 62, 64. 
coger la guagua, (...) y eso a mí me me me... [casi llorando], y yo pienso que la mejor manera de yo ayudar a mi familia es yéndome del país (...)

La familia, esté donde esté, ocupa un lugar priorizado. Constituye un nodo fundamental en la articulación de planes y esfuerzos hacia la consecución de ciertos objetivos, donde también destaca el deseo depositado en la conformación de un hogar propio, como móvil importante. Las historias personales ilustran cómo se despliegan las redes de solidaridad que organizan los destinos y trayectos familiares. Apoyar a la familia y "luchar" por ella, ayudarla a echar "pa'lante", resulta un valor insoslayable en relatos como este:

Mira, ahora mismo, hace como dos años y pico que no voy [a Guantánamo]. Mi prioridad es ayudar a mi familia en lo que pueda y no sé... formar un hogar... una familia... (...) guiarla por el camino correcto, educarlos... ¿ ¿tú me entiendes? (...). De vez en cuando siempre le mando algo de dinero, o le hago unas cajitas con, por ejemplo, con arroz, frijoles, un ejemplo, latas, cosas así, yo, por ejemplo, se las mando por ahí por el expreso. Mira, por ejemplo... el aceite que falta, sí, cosas así ¿no?... el jabón... esas cosas así se las mando...Sí, la situación es difícil, pero hay que ayudar a echar pa'lante a tu gente.

Existen otras motivaciones de gran significación en las representaciones colectivas del grupo. El baile, la fiesta o bonche, la música reggae, el divertimento, adquieren altos niveles de preferencia; distracciones cardinales que estimulan a estos jóvenes. Dentro del sistema de valores establecido, resalta en el "rasta" su capacidad para ser solidario, sociable, honesto, bondadoso, cordial, amable y mostrar calidez en las relaciones interpersonales. La sensibilidad hacia la condición humana y la naturaleza, la humildad, la sencillez y, sobre todo, la lealtad a ultranza, fidelidad o el auxilio incondicional a los miembros del clan, engrosan un discurso de exaltado encomio, de enaltecido contenido. Sobre estos fundamentos se conforma una imagen positiva y halagüeña que sustenta la identidad rastafari, como vemos en la voz de este sujeto:

Veo el rastafari como una hermandad, un ejemplo, mira, yo tengo mis amistades y yo he tenido amigos que me han dicho "oye, no tengo zapatos" y si yo tengo posibilidades de darle un par de zapatos se los doy, o una camisa, o si tengo un plato de comida se lo doy, o si tengo 10 pesos, si le hacen falta d'eso les doy, porque sé, un ejemplo, que mañana yo estoy en ese mismo caso y... 
Es posible enumerar, a modo de resumen, las sintomatologías más evidentes en cuanto a los valores sostenidos por el grupo, en el orden siguiente: la pérdida de protagonismo del trabajo como eje vertebral de la sociedad (este aparece como dimensión cada vez más flexible e inestable, hasta convertirse en un referente poco estimado); un debilitamiento del lugar tradicionalmente otorgado a la superación técnicoprofesional, el estudio o la especialización; grandes motivaciones por las prácticas centradas en el ocio, el esparcimiento y las actividades festivas. Otros rasgos también aparecen como característicos: la demanda de igualdad racial y social en tanto aspiración, mientras la abulia, el consumo de marihuana, prácticas vinculadas a la prostitución y otros eventos ilícitos, también salen a relucir en los relatos.

Como se ha podido constatar, la adscripción al imaginario y estilo rasta constituye no solo una marca de disconformidad con las normativas establecidas, expresada en la adopción de una apariencia menos convencional, sino que aparece como signo diferenciador racial y clasista de este segmento juvenil. Recurso atávico, despliegue performático cuando el uso del cuerpo y la imagen externa representan, de modo más general, una forma de subversión y rebeldía contra los cánones hegemónicos.

Sus significados - y estética asociada-irrumpen como símbolo de pertenencia identitaria, modelo que refuerza la autoestima de una juventud negra y mestiza en concomitancia con las distinciones y oposiciones que, en la correlación raza/clase, emergen en la sociedad cubana en su tránsito por los actuales procesos de fragmentación y diferenciación.

Las formas de socialización analizadas surgen a la par que la pérdida de confianza en la esfera institucional y el discurso oficial del país. Aparecen con las transformaciones acarreadas por una crisis económica que ha impactado, entre otros, los ámbitos de la educación, la vivienda, la salud, la transportación, la recreación y el trabajo. Este grupo informal se presenta como una propuesta organizativa que favorece la búsqueda alternativa de espacios de pertenencia — de vuelta a los postulados de Carolina de la Torre- $-{ }^{41} \mathrm{Si}$ los conglomerados tradicionales han dejado de aportar compensación a las necesidades de estos jóvenes, la satisfacción de sus demandas (otras) de participación se convierte en motivación fundamental.

En medio de un contexto signado por la enunciada fragilidad, la agrupación tribal surge como instancia aglutinadora que devuelve el protagonismo al sujeto y le ofrece a la vez un sentido de represen-

41 Ibídem, p. 67. 
tatividad o distinción. En torno a las dimensiones tribales (códigos, representaciones, atributos y valores) se configuran los lazos rearticuladores que ofrecen cohesión, en detrimento de las entidades institucionales rechazadas. Mediante los elementos simbólicos apropiados y reinventados, estos jóvenes protagonizan las prácticas cotidianas con que se aglutinan, solidarizan y colectivizan sus experiencias frente a una sociedad abocada a la segmentación.

En los avatares que rigen los predios de la identificación juvenil se recurre, entonces, a la matriz del rastafarismo. La mirada — en busca de alivio ante rechazos y exclusiones- se vuelve hacia una cultura foránea, donde las preferencias por un repertorio importado tienden a compensar la autoestima lesionada. Marca identitaria que permite impugnar al sistema establecido desde una protesta simbólica y una enunciación crítica, al mismo tiempo que se erige en reclamo de seguridad, fortaleza espiritual, sentido de vida y significados. 



\title{
INTERESES DIVERSOS, UNA META COMÚN: EL DIÁLOGO POLÍTICO COLABORATIVO EN COSTA RICA
}

\author{
Marvin Rodríguez Vargas*
}

\begin{abstract}
A MODO DE RESEÑA HISTÓRICA
El Banco Popular y de Desarrollo Comunal de Costa Rica ${ }^{1}$ fue fundado el 15 de julio de 1969, ante la inexistencia de una opción financiera que pudiera satisfacer las necesidades de ahorro y crédito de la población trabajadora. Puede considerarse parte de la arquitectura del bienestar social costarricense, erigida entre las décadas de 1940 y 1970, y que se
\end{abstract}

\begin{abstract}
1 Es relevante aclarar que con el paso del tiempo, cambios en la normativa que regula los mercados de seguros, instrumentos de inversión y fondos de pensiones en Costa Rica, condujeron al banco a crear empresas para incursionar en estos mercados y diversificar su giro de negocio. De esta manera, en la actualidad el Conglomerado Financiero Banco Popular y de Desarrollo Comunal está conformado por el banco y cuatro sociedades anónimas: Popular Sociedad Comercializadora de Seguros, Popular Pensiones, Popular Sociedad Administradora de Fondos de Inversión y Popular Valores Puesto de Bolsa. De acuerdo a la Superintendencia General de Entidades Financieras (SUGEF), al cierre del 2015 el grupo financiero obtuvo una utilidad neta de aproximadamente 65 millones USD, y contabilizaba un patrimonio de más de 1.000 millones USD. Su participación de mercado en crédito ronda el $10 \%$ y el 15\% en captaciones a plazo, lo que le convierte en una de las entidades más vigorosas y estables del sistema financiero nacional (SUGEF, 2016).
\end{abstract}

* Licenciado en Sociología por la Universidad de Costa Rica. Labora en San José de Costa Rica para la Asamblea de Trabajadores y Trabajadoras del Banco Popular y de Desarrollo Comunal en calidad de gestor de los procesos de formulación de las políticas institucionales y encargado de articulación sectorial. Es también consultor en metodología de investigación social con el apoyo de ATLAS.ti e instructor profesional certificado por Scientific Software Development GmbH. Contacto: marvinrodriguez@bp.fi.cr 
expresa en la creación de un amplio conjunto de instituciones públi$\operatorname{cas}^{2}$ cimentadas en los principios de la solidaridad y la universalidad de la provisión de bienes y servicios públicos, y en la ampliación de los derechos sociales, políticos y económicos de la población, a través de instrumentos jurídicos como el Código de Trabajo (1943) y la Segunda Constituyente (1949).

De acuerdo a su Ley Orgánica, el Banco Popular es un ente de derecho público no estatal. Se define como público en tanto promueve la protección económica y bienestar de los trabajadores y las trabajadoras del país mediante el ahorro y la prevención de la usura, de allí que entrañe un interés colectivo. Asimismo, pretende incidir positivamente en los procesos de desarrollo comunal.

Por otra parte, no es estatal debido a que el banco es propiedad de los trabajadores y las trabajadoras. Según preceptúa el Artículo 1 de la Ley Orgánica:

[...]El Banco es propiedad de los trabajadores por partes iguales y el derecho a la co-propiedad estará sujeta a que hayan tenido una cuenta de ahorro obligatorio durante un año continuo o en períodos alternos. Los ahorrantes obligatorios participarán de las utilidades y por medio de sus organizaciones sociales en la designación de sus directores.

El fondo de trabajo se constituyó mediante el aporte obligatorio de la población trabajadora y la patronal. Cada trabajador costarricense aporta un $1 \%$ de su salario al Banco Popular; la patronal aporta una contrapartida del 0,5\% sobre las remuneraciones que paga.

En el espíritu del legislador, el Banco Popular no solo incidiría en la incorporación en el sistema financiero formal de sectores que hasta ese momento habían estado excluidos (trabajadores, pequeños productores agrícolas, pobladores de las zonas rurales), sino que mediante el ahorro obligatorio y la figura de co-propiedad, brindaba la posibilidad a la población trabajadora de acceder a la propiedad colectiva, por lo cual el banco, en última instancia, fue concebido como un instrumento de democratización económica.

No obstante los nobles propósitos con que fue creada la institución y el innovador mecanismo de ahorro obligatorio, esta atravesaría difíciles etapas para lograr consolidarse. Uno de los principales escollos

\footnotetext{
2 Entre las instituciones creadas durante el periodo del Estado de bienestar social en Costa Rica sobresalen la Universidad de Costa Rica (1940), Caja Costarricense de Seguro Social (1941), Instituto Nacional de Seguros (1948), Instituto Costarricense de Electricidad (1949), nacionalización de la banca privada (1948) y creación del Banco Central de Costa Rica -órgano central de la economía del país- (1950).
} 
que debió sortear se relaciona justamente con la figura de co-propiedad, y el reclamo recurrente por parte de los sectores de trabajadores ante la inexistencia de mecanismos para hacer efectiva su participación en el gobierno de la institución.

Fue en 1986, con la promulgación de la Ley $\mathrm{N}^{\circ}$ 7031, que se dio respuesta a las reticencias que la población trabajadora tenía sobre el banco. Esta ley creó la Asamblea de Trabajadores y Trabajadoras, y la situó como el órgano de máximo rango dentro de la gobernanza institucional. Adicionalmente, redujo de nueve a siete los integrantes de la Junta Directiva Nacional, de los cuales cuatro son nombrados del seno de los sectores de trabajadores, y tres por parte del Poder Ejecutivo, lo que permitió despolitizar en gran medida la gestión administrativa de la institución.

Las reformas introducidas atribuyeron a la Asamblea la responsabilidad de dictar las orientaciones políticas generales del banco, las cuales deben ser traducidas a políticas puntuales por parte de la Junta Directiva Nacional, e implementadas por la Administración.

\section{Cuadro 1}

Variaciones en la integración de la Junta Directiva Nacional del Banco Popular y de Desarrollo Comunal (1969-2002) ${ }^{3}$

\begin{tabular}{|c|c|}
\hline Ley & Composición Junta Directiva Nacional \\
\hline No 4351 (1969) & $\begin{array}{l}9 \text { miembros: } 2 \text { por Bancos Estatales; } 2 \text { por Asociaciones de Desarrollo de } \\
\text { la Comunidad; } 4 \text { por Confederaciones de Trabajadores Democráticos; } 1 \text { por } \\
\text { Municipalidades. }\end{array}$ \\
\hline № 5435 (1973) & $\begin{array}{l}\text { Se cambia el representante de Municipalidades por un representante de los } \\
\text { Trabajadores Artesanos. }\end{array}$ \\
\hline № $7031(1986)$ & $\begin{array}{l}7 \text { miembros: } 3 \text { representantes del Poder Ejecutivo; } 4 \text { representantes de los } \\
\text { sectores de trabajadores. Se crea la Asamblea de Trabajadores y Trabajadoras, } \\
\text { órgano máximo del gobierno institucional. }\end{array}$ \\
\hline $\mathrm{N}^{0} 8322(2002)$ & $\begin{array}{l}\text { Conformación paritaria de la Junta Directiva Nacional y la Asamblea de } \\
\text { Trabajadores y Trabajadoras, y sus órganos, por razón de sexo. }\end{array}$ \\
\hline
\end{tabular}

Fuente: Elaboración propia con base en Mora Alfaro (2002) y Ley № 8322.

\footnotetext{
3 El proyecto de ley $\mathrm{N}^{\circ} 19.227$, que a febrero 2016 se encuentra a espera de aprobación por la Asamblea Legislativa de Costa Rica, busca reformar la Ley Orgánica del Banco Popular y de Desarrollo Comunal para que los sectores de trabajadores nombren seis de los siete directores ante la Junta Directiva Nacional, de los cuales uno deberá provenir del sector comunal y otro de los sectores que solo alcancen un delegado o delegada en la conformación de la Asamblea. Además, tres de los directores deben ser mujeres, y se elimina el poder de veto que el Poder Ejecutivo puede ejercer a través de la figura de ratificación de los directores, estipulado actualmente en el Artículo 15 de la Ley Orgánica. Con ello se pretende dotar a la Asamblea de mayor autonomía.
} 


\section{CARACTERÍSTICAS Y CONFORMACIÓN DE LA ASAMBLEA DE TRABAJADORES Y TRABAJADORAS}

El Pleno de la Asamblea de Trabajadores y Trabajadoras se integra con doscientos noventa delegados y delegadas, y sus suplentes. Son nombrados por un periodo de cuatro años, con derecho a reelección en periodo consecutivo, y provienen de diez sectores sociales, a saber: asociaciones de desarrollo de la comunidad, asociaciones solidaristas, asociaciones magisteriales, cooperativas de autogestión, cooperativas tradicionales, sindicatos confederados, sindicatos no confederados, trabajadores artesanos, trabajadores independientes y trabajadores profesionales.

De los doscientos noventa escaños, el sector de asociaciones de desarrollo de la comunidad posee cuarenta escaños fijos. Los restantes doscientos cincuenta escaños se dividen entre los demás sectores siguiendo dos criterios: proporcionalidad y representatividad. En primer lugar, se realiza un censo de ahorrantes obligatorios, en el cual cada sector de trabajadores notifica a la Asamblea la cantidad de asociados y asociadas que posee una cuenta de ahorro obligatorio. El número de ahorrantes obligatorios se divide entre los doscientos cincuenta espacios de la Asamblea, lo que da como resultado la cantidad de ahorrantes obligatorios necesarios para obtener una delegación. Por otra parte, en el caso de que un sector de trabajadores no posea suficientes ahorrantes obligatorios para lograr un espacio en la Asamblea, la Ley Orgánica estipula que deberá brindársele un espacio, lo que garantiza la representatividad de todos los sectores ante el órgano colegiado.

Vale aclarar que la integración de la Asamblea siguiendo el criterio de proporcionalidad no siempre existió. Entre 1986 y 1998 la integración se realizó con base en cuotas fijas definidas por ley. Por considerar las cuotas fijas violatorias de varios principios constitucionales, en 1996 un dirigente del sector solidarista interpuso un recurso de amparo ante la Sala Constitucional de la Corte Suprema de Justicia, el cual fue acogido y declarado con lugar.

La resolución de la Sala Constitucional, emitida mediante el voto $\mathrm{N}^{\mathrm{o}}$ 1267-96 de 1996, obligó a la Asamblea a conformar el órgano en estricto apego a la cantidad de ahorrantes obligatorios de cada sector de trabajadores y a mantener un registro actualizado de la población copropietaria. El fallo modificó sustancialmente el peso de los distintos sectores a partir del periodo cuatrienal 1998-2002, reconfigurando las relaciones de poder entre estos. El cambio más significativo fue el desplome de los sindicatos, y el progresivo crecimiento de los sectores solidarista, de trabajadores profesionales y cooperativo tradicional. 
Cuadro 2

Integración de la Asamblea de Trabajadores y Trabajadoras por sector (1986-2018)

\begin{tabular}{|c|c|c|c|c|c|c|}
\hline Sector & 1986-1998 & 1998-2002 & $2002-2006$ & 2006-2010 & 2010-2014 & 2014-2018 \\
\hline $\begin{array}{l}\text { Asoc. desarrollo } \\
\text { comunal }\end{array}$ & 40 & 40 & 40 & 40 & 40 & 40 \\
\hline $\begin{array}{l}\text { Asoc. } \\
\text { Magisteriales }\end{array}$ & 40 & 19 & 17 & 18 & 11 & 12 \\
\hline Asoc. Solidaristas & 20 & 73 & 61 & 65 & 63 & 52 \\
\hline $\begin{array}{l}\text { Coop. de } \\
\text { autogestión }\end{array}$ & 10 & 1 & 1 & 1 & 1 & 1 \\
\hline $\begin{array}{l}\text { Coop. } \\
\text { tradicionales }\end{array}$ & 10 & 77 & 103 & 92 & 100 & 110 \\
\hline $\begin{array}{l}\text { Sindicatos } \\
\text { confederados }\end{array}$ & 120 & 32 & 21 & 26 & 21 & 15 \\
\hline $\begin{array}{l}\text { Sindicatos } \\
\text { no conf. }\end{array}$ & 20 & 18 & 10 & 7 & 6 & 14 \\
\hline Trab. Artesanos & 10 & 1 & 1 & 0 & 1 & 1 \\
\hline $\begin{array}{l}\text { Trab. } \\
\text { independientes }\end{array}$ & 10 & 1 & 1 & 1 & 1 & 1 \\
\hline $\begin{array}{l}\text { Trab. } \\
\text { profesionales }\end{array}$ & 10 & 28 & 35 & 39 & 46 & 44 \\
\hline
\end{tabular}

Fuente: Elaboración propia con base en registros de la Asamblea de Trabajadores y Trabajadoras.

\section{EL DIÁLOGO POLÍTICO COLABORATIVO: INSTRUMENTO PARA LA PROFUNDIZACIÓN DE LAS PRÁCTICAS DEMOCRÁTICAS}

De acuerdo a la Organización Internacional del Trabajo (OIT), se comprende por diálogo social todo tipo de negociaciones y consultas -incluso el mero intercambio de información- entre representantes de los gobiernos, los empleadores y los trabajadores sobre temas de interés común relativos a las políticas económicas y sociales (OIT, 2009, citado por Solari, 2011, p. 41).

En Costa Rica existen tres espacios dialógicos institucionalizados de carácter tripartito que caben dentro de la definición de OIT: Consejo Nacional de Salarios, Consejo de Salud Ocupacional y Consejo Superior de Trabajo. Las tres instancias están adscritas al Ministerio de Trabajo y Seguridad Social (MTSS).

Con relación a la Asamblea de Trabajadores y Trabajadoras, en virtud de su heterogénea composición y las atribuciones sustantivas en ella depositadas en lo que atañe a la emisión de políticas institucionales y la elección de representantes ante la Junta Directiva Nacional, el 
órgano se vio en la necesidad de desarrollar e instituir mecanismos de diálogo social para dirimir conflictos intra e inter-sectoriales y construir consensos con base en la cooperación. Con el tiempo, la Asamblea se ha consolidado como uno de los espacios dialógicos más importantes de Costa Rica, siendo el que cuenta con mayor pluralidad y representatividad de los sectores socio-laborales, lo que repercute en la legitimidad de sus planteamientos.

En la actualidad, los doscientos noventa delegados y delegadas de la Asamblea de Trabajadores y Trabajadoras representan a poco más de 1.100.000 ahorrantes obligatorios (Departamento de Ahorro Obligatorio del Banco Popular y de Desarrollo Comunal, 2015). A su vez, los ahorrantes obligatorios representan el 53,2\% del total de ocupados del país (Encuesta Continua de Empleo, Instituto Nacional de Estadística y Censos, II Trimestre-2015).

La dirigencia de los sectores sociales que históricamente han participado de la Asamblea ha sabido aprovechar al máximo el capital político que concentra esta instancia, de manera que su quehacer no ha quedado circunscrito al ámbito de las temáticas propias del banco, sino que incluye además el análisis y discusión permanente de la realidad nacional, lo que convierte a la Asamblea en una suerte de observatorio ciudadano ad hoc y en un importantísimo centro de formulación y cabildeo de políticas públicas sobre las más diversas temáticas.

Esto es cuanto más importante si analizamos que el afianzamiento de la Asamblea de Trabajadores y Trabajadoras coincide en la historia nacional con un proceso de signo inverso: la reforma neoliberal. A diferencia de otros países de la región, en los que la reforma neoliberal se concretó de manera abrupta, en Costa Rica este fue un proceso paulatino, implementado mediante tres programas de ajuste estructural ${ }^{4}$ y el tratado de libre comercio Estados Unidos, Centroamérica, República Dominicana (CAFTA, por sus siglas en inglés), aprobado vía referendo nacional en octubre de 2007, el cual posibilitó la apertura de los monopolios naturales de telecomunicaciones y seguros, los cuales continuaban bajo el resguardo del Estado. Si bien la reforma neoliberal no logró el desmantelamiento completo de las instituciones del Estado, esta ha significado un ataque frontal y permanente a las organizaciones de trabajadores, ambientalistas, estudiantes, pequeños productores, mujeres organizadas y todos aquellos grupos defensores

4 En Costa Rica, los tres programas de ajuste estructural, también llamados PAEs, fueron aprobados durante gobiernos del Partido Liberación Nacional. El PAE I se aprobó durante la administración de Luis Alberto Monge Álvarez (1982-1986); PAE II durante la gestión de Oscar Arias Sánchez (1986-1990); el PAE III, aunque impulsado durante el mandato del socialcristiano Rafael Ángel Calderón Fournier, no fue sino el liberacionista José María Figueres quien logró su aprobación (administración 1994-1998) (Jiménez Castro, 2000). 
de las conquistas históricas de la clase trabajadora. Durante el avance del neoliberalismo, la Asamblea se constituyó como un bastión para los y las trabajadoras de Costa Rica.

La multiplicidad de sectores sociales que integran la Asamblea y la interdependencia de intereses que representan, permiten analizar los procesos de construcción de consensos a la luz de los aportes de Innes y Booher (2003) sobre la elaboración colaborativa de políticas.

En el trabajo Collaborative policymaking: governance through dialogue, estos autores exponen su experiencia en la mediación de conflictos en torno a la gestión del recurso hídrico y en la elaboración de políticas públicas del sector transporte en California, Estados Unidos. Su argumento principal es que la emergencia de la sociedad de la información ha transformado la arena política y las prácticas democráticas, por lo cual se torna necesario el desarrollo de nuevas formas de relacionamiento entre los actores políticos.

Ciertamente, la revolución telemática en marcha ha posibilitado la masificación del acceso a la información y ha brindado la oportunidad a importantes sectores de la población -otrora excluidos de los medios de comunicación de masas-, de hacer visibles sus perspectivas y demandas. A la postre, esta relativa democratización de los procesos de comunicación puede consolidarse como un contrapeso de los monopolios mediáticos que históricamente han operado en América Latina, por lo que entraña un factor dinamizador de los escenarios políticos.

Adicionalmente, asistimos a un agotamiento de las prácticas democráticas tradicionales, que se expresa en el aumento del abstencionismo en los procesos electorales ${ }^{5}$, en la erosión de las lealtades partidarias y la disminución de la militancia en los partidos políticos, y su transformación en maquinarias electorales, soslayando su labor fundamental de canalización de las demandas ciudadanas hacia el Estado.

Por otra parte, proliferan en todo el mundo nuevas formas de resistencia e involucramiento en la política, y se intensifican las demandas de diversos colectivos que reclaman su participación en el poder ${ }^{6}$.

5 De acuerdo a las estadísticas electorales de Costa Rica, en la elección presidencial de 1998 el abstencionismo alcanzó el 30,0\%, casi 13 puntos porcentuales más que la elección de 1994. Esta elección marcó un clivaje en el sistema electoral, pues desde entonces el abstencionismo no ha bajado de una tercera parte del padrón de electores (Programa Estado de la Nación, 2014, p. 417).

6 En Costa Rica, el impulso por parte de los gobiernos neoliberales de propuestas con un elevado costo social como la privatización de las telecomunicaciones y la generación eléctrica propuesta por Miguel Ángel Rodríguez (1998-2002) o el CAFTA, aprobado durante el segundo mandato de Oscar Arias Sánchez (2006-2010), repercutieron en la emergencia de formas organizativas de la sociedad civil para hacer frente a lo que se consideraba 
Los diversos movimientos de indignados alrededor del mundo son una manifestación clara de este fenómeno, que en alguna medida implica un desplazamiento de lo político-partidario a lo político-social.

De manera concomitante a las tendencias antes descritas, en el contexto costarricense se suscita un agotamiento del sistema bipartidista que predominó durante medio siglo. En 2002 surgen dos nuevas fuerzas políticas -Acción Ciudadana y Movimiento Libertario-, partidos que en poco tiempo consiguen un significativo caudal electoral y presencia en la Asamblea Legislativa. Esta nueva configuración multipartidista ha dificultado aún más la consecución de acuerdos entre las distintas fracciones políticas que permitan dar respuesta a los grandes retos del país.

Si el sistema democrático representativo es incapaz de ofrecer respuesta a las grandes demandas de la sociedad civil, se torna necesaria la generación de nuevos espacios y prácticas que posibiliten su involucramiento en la elaboración e impulso de políticas públicas. Justamente, Innes y Booher plantean el diálogo político colaborativo como una práctica para dirimir conflictos y generar consensos, pero principalmente, para potenciar el desarrollo de formas de relacionamiento entre actores con intereses contrapuestos, y construir y distribuir aprendizajes con relación a cómo abordar colectivamente problemáticas sociales complejas. Ellos sostienen que:

(...) la construcción colaborativa de políticas no es solamente un método para solucionar problemas cuando surgen conflictos en el sistema político tradicional. Es, más importante aún, una manera para establecer redes entre los actores del sistema y propiciar la distribución de conocimiento de las necesidades y capacidades del otro, y sobre las dinámicas de los problemas sustantivos de la sociedad. (...) El planeamiento colaborativo ha emergido como una forma altamente flexible y creativa de formulación de políticas y acción en la Era de la Información. Es un modo emergente de gobernanza (Innes y Booher, 2012, p. 36; traducción propia).

¿Cuáles son las condiciones para un diálogo político fructífero? Para Otero, las libertades individuales y colectivas de los ciudadanos, garantizadas por un sistema democrático sólido, aparecen como condición sine qua non de cualquier proceso de diálogo social (2005, p. 106).

Complementariamente, Innes y Booher argumentan que lo primero que debe asegurarse es la autenticidad del diálogo. Cada partícipe

una profundización de las inequidades generadas por la reforma neoliberal. Los Comités Patrióticos surgidos en el marco de la lucha contra el CAFTA son quizá la expresión más acabada de estas nuevas formas de organización e incidencia política de la sociedad civil. 
debe representar legítimamente los intereses de su sector, debe hablar sinceramente, plantear argumentos inteligibles y precisos. Además, es importante que la dinámica del proceso de diálogo sea definida por los propios partícipes, y no impuesta por un actor exterN ${ }^{\circ}$ Los y las partícipes deben estar en capacidad de dotar al proceso de sus reglas, cuestionar supuestos y desafiar el statu quo (Innes y Booher, 2003, p. 38).

En segundo lugar, las personas partícipes del diálogo deben poseer dos características: diversidad e interdependencia de intereses. El impulso de un proceso de diálogo colaborativo demanda un amplio involucramiento de todos aquellos actores sociales -colectivos o individuales- que de alguna manera estén viéndose beneficiados o afectados por la coyuntura en cuestión. La exclusión de un actor, incluso si es pequeño, puede enviar una mala señal y deteriorar la legitimidad del proceso. De cualquier manera, la diversidad repercute en una mayor creatividad en la elaboración de cursos de acción para abordar las problemáticas.

La participación pluralista propicia, al mismo tiempo, comprender la interdependencia de intereses de los actores, así como las capacidades que cada uno posee para perfilar una solución al conflicto.

Al lado de la necesidad de propiciar diálogos auténticos, con actores diversos, cuyos intereses son interdependientes, en la argumentación de Innes y Booher es posible identificar dos supuestos implícitos de suma relevancia. Primero, las problemáticas de nuestras sociedades son tan complejas que su solución no depende de un único actor. Segundo, cada actor dispone de mecanismos para bloquear o entrabar un proyecto que estime inconveniente para sus intereses. Si la acción individual solo puede servir para el bloqueo de los cursos de acción de otros actores, se concluye que la cooperación es el camino para la solución de los conflictos y retos contemporáneos.

Situar la cooperación y el consenso como punto de partida de los procesos de construcción de políticas públicas implica un cambio de paradigma con relación a cómo se gestiona la cosa pública. Implica moverse de una concepción de la política como mecanismo para la consecución de fines particulares, a una concepción de la política como construcción del beneficio común.

Vale subrayar que los procesos de diálogo político colaborativo pueden ser costosos en razón de los recursos económicos, tiempo y talento humano necesarios para su sostenibilidad, pero casi en la totalidad de las coyunturas el costo de no solucionar los problemas resultará mayor (Innes y Booher, 2003, p. 54).

En el siguiente acápite se detalla una experiencia puntual de diálogo político colaborativo propiciada por la Asamblea de Trabajadores y Trabajadoras, sus alcances y limitaciones. 


\section{CONSTRUIR LA OTRA ECONOMÍA: DIÁLOGO POLÍTICO COLABORATIVO EN TORNO A LA ECONOMÍA SOCIAL SOLIDARIA}

Desde su creación en 1986, la Asamblea ha apoyado numerosas instancias de diálogo político. Las sistematizaciones de estos procesos han sido publicadas en su gran mayoría, con el fin de socializar los planteamientos de las agendas políticas construidas y preservar la memoria histórica del órgaN ${ }^{\circ}$

En este apartado se expone la experiencia de en un diálogo colaborativo iniciado alrededor del año 2000, y que entraña el proceso de más largo aliento impulsado por la Asamblea de Trabajadores y Trabajadoras. Este diálogo ha buscado la construcción de un agenda conjunta de los sectores sociales para el fortalecimiento de la economía social solidaria.

A modo de breve paréntesis, es pertinente aclarar que entendemos por economía social solidaria el conjunto de actividades empresariales desarrolladas en el ámbito privado por colectivos cuyos propósitos son el bienestar común, la satisfacción de necesidades colectivas, la distribución equitativa de la riqueza y el desarrollo territorial. Estas organizaciones se sustentan en la cooperación, la solidaridad, la gestión democrática y autónoma. En la economía social solidaria subyacen dos principios rectores interdependientes: el bienestar integral del ser humano y su relación sustentable con la naturaleza. Por tal motivo, Acosta (2013) sostiene que la economía social solidaria procura trascender el antropocentrismo de la economía tradicional, para fundar una nueva civilización basada en un socio-biocentrismo, pues reconoce que la sostenibilidad y perpetuación de la vida humana no puede explicarse al margen de su relación con la naturaleza. En palabras de Mora y Hinkelammert (2008), se trata de construir una economía para la vida, en oposición a aquella economía que espoleada exclusivamente por el lucro, niega la existencia digna a millones de personas en el mundo.

El diálogo en torno a este tópico inició con la celebración del I y II Simposios sobre Economía Social Solidaria en el año 2000 (Asamblea de Trabajadores y Trabajadoras, 2000a, 2000b). Entre los principales planteamientos emergidos de estos simposios, destaca la necesidad de convertir al Banco Popular en la institución financiera líder de la economía social solidaria y profundizar las estrategias de fortalecimiento recíproco entre el banco y los sectores sociales agrupados en la Asamblea.

En el año 2001 se dictan las políticas institucionales tituladas Pautas para la forja de la nueva historia, las cuales retoman muchas de las conclusiones emanadas de los simposios. En este documento la economía social se plantea como el eje vertebrador de la estrategia de negocio del Banco Popular (Pauta 1, Asamblea de Trabajadores y Tra- 
bajadoras, 2001). A raíz de las directrices emanadas de la Asamblea, el banco creó un innovador mecanismo de inclusión financiera denominado fondos especiales. Estos fondos se alimentan de un porcentaje de las utilidades anuales del grupo financiero, y dado que son recursos que no provienen de la captación del público no se encuentran sometidos a la regulación de la Superintendencia General de Entidades Financieras, lo que posibilita tener mayor flexibilidad en su administración. Los fondos creados son el Fondo para el Fomento de la Micro, Pequeña y Mediana Empresa (FODEMIPYME) ${ }^{7}$, al cual se transfiere no menos del $5 \%$ de las utilidades anuales del grupo financiero, Fondo Especial de Vivienda $(\mathrm{FEVI})^{8}$ y Fondo Especial de Desarrollo (FEDE) ${ }^{9}$, a los cuales se transfiere al menos un $15 \%$ de las utilidades anuales.

En el año 2010 la Asamblea emite una actualización de las Pautas y Orientaciones del año 2001, y nuevamente el fomento de la economía social solidaria se señala como el eje transversal del accionar de la institución (Asamblea de Trabajadores y Trabajadoras, 2010). No obstante, se enfatiza un elemento que puede considerarse una deuda histórica del banco para con los sectores de trabajadores: el desarrollo de una estrategia de negocio que permita dar una atención diferenciada a los sectores de trabajadores, en tanto estos representan a los copropietarios y las copropietarias de la institución. El mandato de la Asamblea apunta a que el Plan Estratégico Corporativo (PEC), del cual se desprenden los planes operativos de las distintas direcciones del grupo financiero, esté plenamente armonizado con las Pautas y Orientaciones de la Asamblea, y que su evaluación se realice en función de estas.

Cabe preguntarse ¿por qué después de los Simposios sobre Economía Social Solidaria, y las Pautas y Orientaciones del año 2001 y 2010, el banco fue incapaz de generar una estrategia de negocio que atendiera a cabalidad el mandato de sus copropietarios y copropietarias?

La reforma a la Ley Orgánica del Banco Popular introducida mediante la Ley $\mathrm{N}^{\circ} 7031$ de 1986 preceptúa que la Junta Directiva Nacional

7 El FODEMIPYME surge de las Pautas y Orientaciones dictadas en 2001 y se crea mediante la Ley $\mathrm{N}^{\circ} 8262$ de 2002. Este fondo posee tres componentes: crédito, otorgamiento de avales y garantías, y servicios de desarrollo empresarial. Entre 2002 y 2014 se transfirieron alrededor de 42.5 millones USD a este fondo.

8 El FEVI es un fondo para el financiamiento de vivienda para aquellas personas que por su condición socioeconómica no son sujetas al otorgamiento de un bono de vivienda (superan la línea de pobreza), pero tampoco poseen garantías para aplicar a la línea regular de crédito de vivienda. Este producto financia el 100\% para la adquisición de vivienda y favorece principalmente a sectores de clase media baja.

9 El FEDE es un fondo para el financiamiento de organizaciones y empresas de la economía social solidaria. Normalmente se ejecuta a través de banca de segundo piso, lo que permite a las organizaciones satisfacer las necesidades de crédito de sus agremiados. 
se conforma con cuatro miembros designados por la Asamblea de Trabajadores y Trabajadoras y tres miembros nombrados por el Poder Ejecutivo. Al tiempo que los sectores de trabajadores aglutinados en torno a la Asamblea trataban de impulsar figuras empresariales basadas en principios, valores y prácticas distintos para hacer frente a la embestida del neoliberalismo, los gobiernos de turno buscaban profundizar dicho modelo de desarrollo, lo que devino en una profundización de la conflictividad social y un distanciamiento entre la sociedad civil y los gobiernos. Aún cuando el Poder Ejecutivo no tiene mayoría ante la Junta Directiva Nacional, sus tres directivos son un contrapeso importante. Por otra parte, en vista de que el Poder Ejecutivo debe ratificar a los representantes de los sectores de trabajadores ante la Junta Directiva, esto opera como un poder de veto del gobierno hacia los copropietarios y copropietarias. De hecho, durante el gobierno liberacionista de Laura Chinchilla (2010-2014), se nombró una Junta Directiva pro tempore, cuyos siete miembros fueron designados por el gobierno, en un claro irrespeto hacia la Ley Orgánica y la estructura de gobernanza institucional.

Esta situación cambia sustancialmente en 2014, año en el que se marca un hito en la historia política contemporánea de Costa Rica. Por vez primera desde la fundación de la Segunda República un partido diferente a Liberación Nacional y Unidad Social Cristiana triunfa en los comicios presidenciales. Luis Guillermo Solís Rivera del partido de centro Acción Ciudadana logra la presidencia de la República por un amplio margen con relación al candidato de Liberación Nacional.

El gobierno de Acción Ciudadana, dentro del cual participan diversos líderes y lideresas que fungieron como delegados de la Asamblea de Trabajadores y Trabajadoras, ha permitido la dinamización de la Asamblea y la revitalización de los procesos de construcción y cabildeo de políticas públicas en torno a la economía social solidaria.

La primera acción importante fue devolver el control del banco a la Asamblea, mediante la ratificación de sus representantes ante la Junta Directiva Nacional. La adecuada coordinación entre la Asamblea y la Junta Directiva Nacional ha posibilitado impulsar iniciativas de profundo calado en muy corto tiempo, entre ellas:

1- Creación de la Banca Social de Desarrollo del Banco Popular (diciembre 2014), la cual viene a complementar a las existentes Banca de Personas y Banca Empresarial.

2- Trabajo articulado entre representantes de la Asamblea, la Junta Directiva Nacional y la Gerencia General Corporativa en la armonización de los instrumentos de planificación del banco con relación a las Pautas y Orientaciones de la Asamblea. 
3- Celebración del Ciclo de Foros de la Economía Social Solidaria (diciembre 2014 - julio 2015), el cual comprendió once foros regionales, un foro nacional y un foro internacional. En total, poco más de 1.500 líderes y lideresas de la economía social solidaria, representantes de la sociedad civil y de la institucionalidad pública participaron de este proceso de diálogo y co-construcción.

4- Impulso de políticas públicas, entre las que destacan el Decreto Ejecutivo 39.089-MP-MTSS, que declara de interés público la economía social solidaria; el Proyecto de reforma a la Ley Orgánica del Banco Popular para dotar de mayor autonomía a la Asamblea de Trabajadores y Trabajadoras (exp. $\mathrm{N}^{\circ} 19.227$ ) y el Proyecto de Ley Marco para la Economía Social Solidaria (exp. $\mathrm{N}^{\mathrm{o}}$ 19.654), el cual pretende robustecer el apoyo institucional para las organizaciones de este sector.

Como se puede apreciar, el proceso de diálogo colaborativo iniciado por los líderes y lideresas en torno a la economía social solidaria en el año 2000 tuvo sus altibajos debido a la propia estructura de gobernanza del Banco Popular. No obstante, dichas dificultades no impidieron concretar diversos proyectos que han ido sentando las bases para contar con un acompañamiento institucional y políticas públicas que permitan potenciar los impactos positivos de las organizaciones y empresas de la economía social solidaria. Han sido muchísimos los espacios de diálogo, como foros, simposios y mesas de trabajo en torno a temáticas puntuales celebradas durante estos años. Estos espacios permitieron madurar las formas de relacionamiento entre los actores políticos de los distintos sectores sociales, refinar la comprensión de las necesidades de cada sector y los factores contextuales que impedían la consecución de las metas planteadas.

Es claro que falta aún trabajo por hacer con el fin de que todos y cada uno de los sectores sociales se vean beneficiados de los distintos proyectos. Asimismo, es importante incorporar otras sensibilidades y puntos de vista dentro de este proceso. En razón de esta necesidad, en 2015 la Asamblea formalizó la instalación de tres mesas temáticas de trabajo: Mesa de Economía Social Solidaria, Mesa Comunicar la Otra Alternativa y Mesa de Diálogo Permanente sobre Juventudes.

Con relación a esta última, la Asamblea ha manifestado su profundo interés en que los y las jóvenes vinculados a las organizaciones sociales dispongan de un espacio para el análisis de sus intereses y necesidades, y en la cual se pueda construir una agenda política que atienda sus problemáticas. Esta mesa se ha propuesto analizar el papel de la juventud en el marco de la economía social solidaria, posibili- 
tar el intercambio de experiencias entre las estructuras de juventud de los sectores sociales, de manera que aquellos sectores con estructuras más débiles o inexistentes puedan beneficiarse de los aprendizajes de sectores que poseen más camino andado. Además, se busca elaborar lineamientos de acción para que el Banco Popular favorezca la inclusión financiera de este grupo poblacional.

Esta mesa, instalada en agosto 2015, ha gestionado vínculos con el Ministerio de Trabajo y Seguridad Social, el Viceministerio de la Juventud, el Consejo de la Persona Joven, Programa Agenda Joven de la Universidad Estatal a Distancia, Red de Economía Social Solidaria (REDESS), Confederación Sindical de Trabajadores y Trabajadoras de las Américas (CSA-TUCA), Fundación Friedrich Ebert, Instituto Nacional de Fomento Cooperativo (INFOCOOP), entre otros. Como promotor de este proceso, y con base en la experiencia de la metodología empleada por organismos como el Consejo Latinoamericano de Ciencias Sociales (CLACSO) en sus escuelas internacionales, estimo de vital importancia el que los procesos de diálogo político colaborativo poseen una naturaleza tripartita: sociedad civil, academia e institucionalidad pública.

Esta metodología de trabajo permite no solo conocer las necesidades de la sociedad civil, expresada en los distintos sectores sociales, sino además su fundamentación técnica y científica por parte de los y las académicas. Al mismo tiempo, el contar con representantes de la institucionalidad pública en la mesa de trabajo agiliza el proceso de cabildeo de las políticas públicas.

\section{CONCLUSIONES}

El diálogo político pluralista y colaborativo se perfila como un método fundamental para robustecer las relaciones Estado-sociedad civil, y conlleva un inestimable valor en tanto mecanismo de profundización de la democracia. En tiempos en que los partidos políticos han visto erosionado su papel de enlace entre las demandas ciudadanas y el Estado, se deben aprovechar las plataformas de articulación de la sociedad civil para establecer vías alternativas de interlocución y canalización de las demandas de la ciudadanía hacia el Estado, de manera que las políticas públicas respondan verdaderamente a sus intereses y necesidades, y repercutan en una mejora sustancial de sus condiciones de vida.

Los desafíos de nuestra época convocan a abandonar los múltiples e infructuosos soliloquios propios de la defensa de intereses particulares, para entablar un diálogo franco que posibilite trascender posturas inflexibles y egoístas, en pos de un objetivo mayor: la construcción de un proyecto de sociedad que garantice una existencia digna a todos y todas. En ese sentido, la experiencia de la Asamblea de Trabajadores y Trabajadoras es un valioso referente, pues representa 
un espacio social y político cuya pluralidad de actores e intereses no le ha impedido alcanzar objetivos comunes de gran trascendencia para la institución y la sociedad costarricense.

Entre los retos que las prácticas de diálogo político colaborativo poseen en el corto y mediano plazo se encuentra la asignación de recursos para dar sostenibilidad a los procesos. Una de las dificultades que Innes y Booher (2003) señalan para los procesos de diálogo es la inexistencia de plataformas de articulación política debidamente institucionalizadas. Los procesos de diálogo son largos, requieren apoyo técnico para la fundamentación de las propuestas, apoyo logístico, etc. Por tal motivo es importante gestionar los recursos necesarios para garantizar la sostenibilidad del espacio dialógico.

Por otra parte, es fundamental la sistematización de estos procesos y su divulgación, con el fin de que otros actores políticos se sensibilicen en formas alternativas de solución de conflictos y construcción de consensos. El diálogo político colaborativo implica un cambio en la cultura política: el asumir la responsabilidad de ser parte de la solución de los grandes retos contemporáneos, y no esperar a que las instituciones políticas tradicionales se encarguen de ellos.

\section{BIBLIOGRAFÍA}

Acosta, A. 2013 “Otra economía para otra civilización” en Temas: Cultura, ideología y sociedad, julio - setiembre 2013, pp. 21-27.

Asamblea de Trabajadores del Banco Popular y de Desarrollo Comunal (ATTBPDC) 2000a Economía Social: Experiencias y Estrategias. Ponencias y conclusiones del I Simposio de Economía Social, San José, 23 y 24 de marzo 2000 (Costa Rica: Asamblea de Trabajadores del Banco Popular y de Desarrollo Comunal).

Asamblea de Trabajadores del Banco Popular y de Desarrollo Comunal (ATTBPDC) 2000b Elementos para una agenda del sector de economía social (Memoria II Simposio nacional de Economía Social) (Costa Rica: Asamblea de Trabajadores del Banco Popular y de Desarrollo Comunal).

Asamblea de Trabajadores del Banco Popular y de Desarrollo Comunal (ATTBPDC) 2001 Pautas para la forja de la nueva historia. XVIII Asamblea Plenaria Extraordinaria. (Costa Rica: Asamblea de Trabajadores del Banco Popular y de Desarrollo Comunal). 15 de diciembre.

Asamblea de Trabajadores del Banco Popular y de Desarrollo Comunal (ATTBPDC) 2010 Pautas y Orientaciones Generales con sus Valores 
y Principios. LIX Sesión Plenaria Extraordinaria (Costa Rica: Asamblea de Trabajadores del Banco Popular y de Desarrollo Comunal) 27 de marzo.

Asamblea Legislativa de Costa Rica 1969 Ley No 4351: Ley Orgánica del Banco Populary de Desarrollo Comunal. Sistema Costarricense de Información Jurídica. Sistema de consulta en línea en: http://www. pgrweb.go.cr/scij/

Asamblea Legislativa de Costa Rica 1973 Ley No 5435: Reforma Integral a la Ley Orgánica del Banco Popular. Sistema Costarricense de Información Jurídica. Sistema de consulta en línea en: http://www. pgrweb.go.cr/scij/

Asamblea Legislativa de Costa Rica 1986 Ley $N^{o}$ 7031: Reforma Ley Orgánica del Banco Popular y de Desarrollo Comunal. Sistema Costarricense de Información Jurídica. Sistema de consulta en línea en: http://www.pgrweb.go.cr/scij/

Asamblea Legislativa de Costa Rica 2002 Ley No 8262: Ley de Fortalecimiento de las Pequeñas y Medianas Empresas. Sistema Costarricense de Información Jurídica. Sistema de consulta en línea en: http://www.pgrweb.go.cr/scij/

Asamblea Legislativa de Costa Rica 2002 Ley No 8322: Ley de Democratización de las Instancias del Decisión del Banco Popular y de Desarrollo Comunal (Reforma a la Ley Orgánica del Banco Popular, $N^{\circ}$ 4351). Sistema Costarricense de Información Jurídica. Sistema de consulta en línea en: http://www.pgrweb.go.cr/scij/

Asamblea Legislativa de Costa Rica 2014 Proyecto Reforma del artículo 14, 14 bis, artículo 15, 22 y 24 de la Ley Orgánica del Banco Popular y de Desarrollo Comunal $N^{o} 4351$ y sus reformas, Expediente $N^{o} 19.227$. Asamblea Legislativa de Costa Rica. Sistema de consulta en línea en: http://www.asamblea.go.cr

Asamblea Legislativa de Costa Rica 2015 Proyecto de Ley Marco de la Economía Social Solidaria, Expediente $N^{o}$ 19.654. Sistema de consulta en línea: http://www.asamblea.go.cr

Departamento de Ahorro Obligatorio del Banco Popular y de Desarrollo Comunal 2015). Estadísticas de ahorrantes obligatorios del Banco Popular y de Desarrollo Comunal. Comunicación personal.

Hinkelammert, F. y Mora, H. 2008 Hacia una economía para la vida. Preludio a una reconstrucción de la economía (Costa Rica: Editorial Tecnológica). 
Innes, J. \& Booher, D. 2003 "Collaborative policymaking: governance through dialogue” Ien Hajer, M. \& Wagenaar, H. (Eds.) 2003 Deliberative Policy Analysis. Understanding Governance in the Network Society (United Kingdom: Cambridge University Press).

Jiménez, W. 2000 Préstamos y programas de ajuste estructural (Costa Rica: EUNED).

Instituto Nacional de Estadística y Censos (INEC) 2015 Encuesta Continua de Empleo, II Trimestre-2015. Sistema de consulta en línea en: www. inec.go.cr

Mora Alfaro, J. 2002 El Banco Popular y la sociedad costarricense: una interpretación histórico social (Costa Rica: Asamblea Nacional de Trabajadores del Banco Popular y de Desarrollo Comunal).

Otero, R. 2005 “El diálogo social: fundamentos y alternativas" en Boletín Técnico Interamericano de Formación Profesional de la Organización Internacional del Trabajo (Boletín Cinterfor), $\mathrm{N}^{\circ} 156,105-124$.

Programa Estado de la Nación 2014 Vigésimo Informe Estado de la Nación en Desarrollo Humano Sostenible (Costa Rica: PEN).

Sala Constitucional de la Corte Suprema de Justicia de Costa Rica 1996 Voto No 1267-96 (Costa Rica: Sala Constitucional).

Solari, R. 2011 "Análisis de las experiencias de diálogo socio-laboral" en Weller, J. (Comp.) Mercado laboral y diálogo social en Costa Rica (Santiago de Chile: CEPAL).

Superintendencia General de Entidades Financieras (SUGEF) 2016 Estadísticas del Sistema Financiero Nacional. Sistema de consulta en línea en: www.sugef.fi.cr 



\title{
JÓVENES RURALES Y SUS TRÁNSITOS POSTSECUNDARIOS: UN ESTUDIO DE CASO EN PERÚ
}

\author{
Melissa Villegas Quispe*
}

\section{INTRODUCCIÓN}

Las diversas situaciones los jóvenes en América latina motivan a reflexionar sobre sus oportunidades y desafíos en contextos diferenciados. Es claro que durante las últimas décadas, Latinoamérica coincide en niveles de crecimiento poblacional juvenil, lo cual ha sido reconocido como un contexto de oportunidad para potenciar el capital humano en la región (CEPAL, 2010, 2012). Sin embargo, como ya es conocido, las juventudes son diversas y sus situaciones económicas, sociales y culturales también dependen del contexto en el cual se desarrollan.

Uno de campos para entender a los jóvenes es la educación y las condiciones de igualdad de oportunidades que a partir de ello se generan. Al respecto, la situación de los sistemas educativos latinoamericanos registra avances en las tasas de escolarización de jóvenes en el nivel medio o secundario, lo cual también es producto de la condición de obligatoriedad de la educación secundaria que se establece durante la década de los 90 (Reimers 2000, SITEAL ,2010).

\footnotetext{
* Licenciada en Antropología por la Pontificia universidad Católica del Perú y diplomada en Políticas y gestión de programas en infancia y adolescencia por la Universidad Antonio Ruiz de Montoya. Correo electrónico:melissa.villegas@pucp.pe
} 
Sobre ello, Perú es uno de los países latinoamericanos que tiene un mayor incremento de matrícula y culminación de la educación primaria y secundaria dentro de la edad oportuna (SITEAL, 2010). Sin embargo, haciendo una división entre población urbana y rural, se registra un mayor porcentaje de acceso y culminación en los sectores urbanos a diferencia de los rurales (Escale, 2014). Pese a estas diferencias, las condiciones de oportunidad en el acceso en la secundaria para los jóvenes rurales son crecientes, aunque limitadas, y más aún es poco conocida la situación de aquellos que logran culminar la secundaria en sus contextos rurales de origen y las nuevas expectativas de profesionalización para su futuro.

En este sentido, este estudio desarrollado en una zona andina de Perú expone la situación de jóvenes que viven contextos rurales de desarrollo económico y de expansión oportunidades educativas locales tanto en la secundaria como la educación superior. Sobre este contexto, intenta responder a los cambios que han afectado y modificado el marco de expectativas, oportunidades y limitaciones para los jóvenes rurales.

De acuerdo con ello, el texto se desarrolla en dos partes. Una primera parte aborda, por un lado, la situación educativa en la secundaria y los contextos rurales en transformación y, por otro lado, una aproximación a las juventudes donde se destacan los enfoques que han sido útiles para el estudio de caso. Esta primera parte, integra un marco conceptual que ayuda a comprender la situación de las juventudes rurales. En segundo lugar, de manera focalizada, se exponen las particularidades de las transiciones postsecundarias de un grupo de jóvenes en una zona andina de Perú donde se destacan sus estrategias y posibilidades de decisión sobre su futuro. Finalmente, se exponen reflexiones a tener en cuenta para el desarrollo de políticas públicas que atiendan a este sector de la población.

\section{PRIMERA PARTE}

\section{AVANCES EN LA COBERTURA DE LA EDUCACIÓN SECUNDARIA Y CONTEXTOS RURALES EN TRANSFORMACIÓN}

Pese a la complejidad latinoamericana, se encuentran ciertas similitudes entre países que muestran un mayor acceso en la secundaria y con trayectorias educativas más sólidas (Chile, Perú, Argentina, Colombia, Panamá, Brasil) y aquellos países que mantienen un acceso limitado en secundaria y con trayectorias más frágiles (Guatemala, Nicaragua y Honduras) (D’alessandre y Mattioli, 2015). Considerar estas tendencias en las trayectorias educativas es importante dado que implicaría una mayor inclusión de las juventudes en la educación y generación de nuevas oportunidades en sus proyectos de vida. 
El perfil latinoamericano en cuanto a cobertura de la secundaria asimismo muestra las particularidades de los territorios donde las poblaciones tienen diferentes brechas de oportunidad educativa según los niveles o "gradientes" de ruralidad que presentan (Itzcovich, 2010). Así, las desigualdades internas muestran que los contextos rurales ofrecen distintas condiciones de oportunidad en el acceso cuando hay un mayor o menor nivel de ruralidad.

No obstante, pese a las diferencias por los contextos más o menos rurales, las políticas de ampliación de cobertura en la educación responden a una necesidad de democratizar el servicio y brindar las mismas oportunidades a los grupos tradicionalmente excluidos. Es por ello, que el tránsito por la secundaria de los grupos de jóvenes que anteriormente no habrían tenido oportunidades, es importante en la medida que pueden ampliar su marco de expectativas educativas futuras. Así, la secundaria se considera un periodo de tránsito para el acceso a la educación superior, sobretodo universitario. Como algunos autores señalan, las demandas económicas de los países latinoamericanos han crecido sustancialmente y esto ha generado una mayor necesidad de desarrollar competencias tecnológicas, capacitación en procesos productivos y requerimiento de un mayor nivel de calificación para los jóvenes (Jacinto, 2013). El desarrollo de competencias más complejas requiere de mayores niveles de formación que ofrecería la educación superior, motivo por el cual, a medida que las nuevas generaciones acceden y culminan la educación secundaria, depositan mayores expectativas en su profesionalización futura.

Si bien continúa la tendencia de que las juventudes buscan alcanzar la profesionalización futura a fin de asegurarse mejores condiciones de vida para ellos y sus familias, la educación secundaria se convierte en un momento crucial para fortalecer sus capacidades y para potenciar sus vínculos con la educación superior en los años posteriores. Así, los jóvenes que actualmente aceden a la educación secundaria pueden tener mayores herramientas para pensar en un futuro profesional, factible de realizar según las posibilidades y limitaciones que ocurre en cada contexto.

En el caso peruano, la relación de la educación con la población juvenil puede entenderse por la expansión educativa, la alta valoración de las personas y los retornos asociados a mayores niveles educativos (Benavides, 2006). La expansión educativa en el nivel secundario es creciente, pero con una considerable tasa de deserción escolar que tiene principalmente un rostro rural. Desde el estado, actualmente se vienen implementando modelos de atención diversificados según los ámbitos rurales, como son la modalidad de educación presencial, semipresencial y a distancia para la población rural. Esta diversificación se 
hace oportuna y necesaria dadas las condiciones de alta dispersión que tiene nuestro territorio, lo cual también ha generado oportunidades en el acceso pero desigualdades en la calidad de los servicios educativos.

Por otro lado y en relación a lo anterior, los contextos rurales son diversos y en continua transformación, tal cual ocurre en Perú. Así, es importante destacar enfoques que complejizan los territorios rurales como la nueva ruralidad. Según Kessler (2005) la transformación de los espacios rurales influye en la definición de la juventud rural debido a la influencia de la cultural global en las identidades locales y las variaciones tipo económico-ocupacional. Asimismo se destaca la interconexión entre las actividades rurales y los mercados distantes y el desarrollo rural que no puede vincularse exclusivamente a las actividades agrícolas, de este modo, los espacios rurales se caracterizan por la creciente "multiactividad" que señala Cruz (citado en Kessler, 2005).

Como señala Kessler, la creciente interacción campo - ciudad genera dificultades para identificar lo rural con lo agropecuario y una fuerte interdependencia con centros urbanos próximos. En Perú, al contextualizar la ruralidad se parte de la caracterización según las cifras estadísticas ${ }^{1}$ que refieren a grupos de viviendas agrupadas y población indígena. Aquí, un primer detalle que vale la pena mencionar es que si bien, comúnmente, la determinación de indígena se manifiesta por la lengua materna, en el país existe población andina y quechahablante que no se auto determina como indígena, lo cual genera una mayor complejidad para el reconocimiento de derechos.

Asimismo, los espacios rurales sobrepasan la realización de actividades agrícolas y pecuarias tradicionales. Siguiendo esta premisa, se destaca la pluriactividad de las familias; sujetos a una multiplicidad de actividades y diferentes circuitos productivos. A este fenómeno se asocia la configuración de ciudades intermedias, la movilidad de la población rural y parte de dicha movilidad debido al acceso educativo de las nuevas generaciones (Monge 2011, Pérez-correa 2008, Barker 2005).

Sobre lo último, en este gran escenario rural y en relación con el panorama educativo actual, la transformación de los escenarios rurales ha generado una mayor movilidad asociada en gran medida a las demandas educativas y donde la migración ha sido variable importante a considerar. Históricamente, familias rurales enviaban a sus hijos a las ciudades para poder acceder a servicios educativos; hoy en día, esta dinámica cambia relativamente porque ocurre un hecho particular de-

\footnotetext{
1 Según datos del Instituto nacional de estadística e informática- INEI, la definición de rural se basa en cantidad de habitantes que sean población indígena. Esto puede ser en un centro poblado rural con menos de 100 viviendas contiguas o teniendo más de 100 viviendas, estas se encuentran dispersas, no agrupadas.
} 
bido a una mayor expansión en la oferta educativa sobretodo en el nivel superior en los escenarios rurales.

Partiendo de un consenso general en que los proyectos de vida de la gran mayoría de jóvenes, alude a lograr acceder a la educación superior y por ello que resulta importante su tránsito en la secundaria, en diversos contextos rurales del país se viene creando nuevos centros de educación superior tanto públicos como privados ${ }^{2}$, de formación universitaria y técnica, que atienden a una creciente demanda de jóvenes para quienes antes no habría sido posible acceder a la educación superior y en todo casso, hubiesen tenido que migrar a otras ciudades a fin de poder estudiar ${ }^{3}$. Así a medida que la población cursa la secundaria demanda una mayor oferta en la educación superior. La presencia de centros públicos y privados universitarios y técnicos es entonces una parte importante para comprender los escenarios rurales y la situación de los jóvenes en cuanto a sus estrategias de vida.

\section{APROXIMACIÓN A LAS JUVENTUDES}

Las juventudes como categoría social se circunscriben a un tiempo y contexto determinado. Siguiendo a Vommaro (2014: 2), al referirse a la juventud se trata de considerar una diversidad de prácticas, comportamientos y universos simbólicos de significación que convergen en ella, cruzada a su vez por variables como clase, género, etnia, cultura, región y contexto socio-histórico.

Partiendo de ello, resulta oportuno referirse al enfoque de la construcción social (Casal et. al, 2011, Moreno, 2012) para llegar al enfoque de las transiciones (Punch 2002, Thomson 2000, Otero 2010); importante a tomar en cuenta para analizar las transiciones postsecundarias. Desde la construcción social, la juventud es una categoría de análisis que depende no solo de estructuras sino también de procesos simbólicos que construyen los sujetos. Casal et al (2011) afirma que la construcción social retoma la importancia metodológica de la biografía para aproximarnos a los sujetos y establecer una triangulación de tres

2 En el contexto peruano, el sistema educativo en el nivel superior está compuesto por la educación técnica y educación universitaria. Según ello existen universidades e institutos privados y públicos. Respecto al tiempo de formación profesional, la universidad toma un promedio de cinco años de formación, mientras que los institutos tienen un promedio que varía desde un año, tres o cinco años.

3 Es importante mencionar que este contexto de oportunidades educativas en los escenarios rurales, también corresponde a una política de estado, durante 1996, para liberalizar el mercado educativo. Así, se permitió la inversión privada para atender la creciente demanda de servicios educativos y se masificó la oferta privada en detrimento de la calidad. Actualmente el país viene promoviendo reformas en la educación superior a fin de mejorar la calidad educativa en este nivel. 
ámbitos presentes de manera simultánea como son: 1) las estructuras sociales, 2) los jóvenes como actores y 3) las generaciones que son el resultado de procesos históricos de cambio. Por su parte, Moreno (2012) señala que entender la juventud como construcción social supone situar a los jóvenes en camino hacia la autonomía personal; entre la independencia y la necesidad de protección familiar.

Por su parte, las transiciones aluden a momentos específicos en el curso de vida entre las oportunidades del sujeto y sus limitaciones. Las transiciones, también son llamadas "momentos críticos"; aquellos periodos en la vida en los cuales los sujetos despliegan acciones guiadas por aspiraciones de futuros posibles (Thomson, 2002). Según Thomson, las transiciones se componen de momentos clave donde los sujetos buscan superar sus dificultades, pero siempre dentro de márgenes posibles; lo que también denomina como niveles de agencia. Por su parte, Otero (2010) señala que para reconocer el margen de agencia que tendrían los jóvenes en sus trayectorias, resulta imprescindible partir de sus propios discursos, ya que las historias de vida aluden a relaciones que establecen entre el pasado, el presente y futuro. Esto es importante porque también permite comprender el carácter de negociación que los jóvenes desarrollan con su entorno más cercano como es la familia. Al respecto, Punch (2002) sostiene que los niveles de agencia se ponen en juego en la toma de decisiones, que suponen acuerdos entre los intereses propios y familiares. Para Punch es sumamente importante contextualizar el papel de las decisiones en el marco de lo que denomina Interdependencias que se negocian continuamente entre padres e hijos.

Las juventudes como construcción social posibilitan identificar diversas dimensiones en las trayectorias de vida de los jóvenes desde lo que ellos piensan y hacen en su vida cotidiana. Es necesario prestar atención a la heterogeneidad de los grupos y los significados que los jóvenes atribuyen a las relaciones que establecen con diferentes entornos y actores. Así, la heterogeneidad de las juventudes muestra experiencias sociales y significados diversos que se construyen continuamente. Siguiendo a MacLeod (citado en Benavides et. al, 2010: 24) se entiende que las aspiraciones de los jóvenes son niveladas por las experiencias propias y del entorno. Esto significa que, en un contexto de igual nivel socioeconómico, lo que para un grupo de jóvenes puede significar persuadir en los estudios, para otro grupo puede no tener mayor interés en el logro educativo y por tanto, este último grupo desarrollará estrategias distintas al primer grupo.

Resaltar la importancia de los significados personales que los jóvenes atribuyen a sus experiencias es también analizar la dimensión cultural que está detrás de las heterogeneidades que existen en contex- 
tos de exclusión (Benavides 2006). Producto de ello, en el caso peruano, algunos de los estudios, evidencian heterogeneidades en los factores asociados a la toma de decisión sobre el estudio y el trabajo (León y Sigumaru, 2013) y el esfuerzo por persuadir en la educación postsecundaria (Rojas y Cussianovich, 2013). Los estudios analizan grupos juveniles que encuentran un alto significado en la educación, sobretodo la educación superior, y por ello se esfuerzan para cumplir el objetivo educativo; hecho que sin embargo, no necesariamente ocurre en todos los jóvenes y que tampoco supone que realicen las mismas estrategias.

Dicho esto, el estudio de las trayectorias de los jóvenes rurales, específicamente las transiciones postsecundarias, se entiende como una etapa de gran importancia donde los jóvenes desarrollan estrategias en relación al futuro. Las estrategias muestran los niveles de agencia posibles así como sus limitaciones que no necesariamente son propias del nivel económico. Por ello, es clave analizar el proceso transitorio sobretodo porque son pocos los estudios en relación al mismo y menor aún en contextos rurales. Así, las particularidades ayudan a identificar oportunidades y nuevos tipos de exclusión que podrían estar presentes.

\section{SEGUNDA PARTE}

\section{LAS TRANSICIONES POSTSECUNDARIAS DE JÓVENES EN UN CONTEXTO RURAL}

Luego de haber situado el panorama educativo, la complejidad de los contextos rurales y destacar algunas categorías relevantes para comprender a los jóvenes, en este acápite se desarrolla los hallazgos de un estudio de caso sobre las transiciones postsecundarias de un grupo de 20 jóvenes varones y mujeres en una zona andina de Perú. Estudio que se realiza al año posterior luego de culminar la secundaria.

La región donde se desarrolló el estudio tiene una población mayormente quechua hablante y tiene un gran desarrollo comercial dado que pertenece a un valle altamente productivo, el cual esta estratégicamente interconectado con otras ciudades de gran comercio en la región. En el contexto se puede encontrar comunidades campesinas más y menos alejadas de la capital provincial y alta movilidad de la población principalmente por motivos comerciales y educativos. A la expansión educativa en el nivel secundario y superior (universidades e institutos) $)^{4}$ se suma la oferta de instituciones fuera del sistema formal

4 En la educación superior existen dos modalidades; educación la universitaria y la educación técnica. La universidad tiene un periodo de estudio de aproximadamente 5 años, mientras que el instituto es de tres años. 
como son los centros de preparación preuniversitaria, que son claves para comprender las transiciones postsecundarias de muchos jóvenes.

La socialización de los jóvenes en este contexto se entiende desde la relación escuela- comunidad. Es necesario resaltar que la escolaridad debe entenderse en el marco de las responsabilidades que los jóvenes asumen con sus familias. Pese a ser estudiantes, los jóvenes comparten parte de su tiempo con otras responsabilidades fuera del estudio como por ejemplo, ayudar en cuidado de los hermanos menores, ayudar en la chacra (siembra y cosecha), hacer mandados, etc. Los padres, quienes se dedican principalmente a labores agrícolas, reconocen la importancia de que sus hijos estudien, pero también demandan tiempo para que les ayuden en las actividades del hogar. Siendo consecuentes a esta lógica, todos los jóvenes indicaron haber participado en diversas actividades tanto domésticas como productivas, donde se reitera lo que previos estudios señalan sobre la importancia de la participación desde temprana edad como una fuente de aprendizajes para la vida (Ames y Rojas 2010, Alarcón 2011). Asimismo, se encuentra diferencias en la denominación del tipo de participación; específicamente entre "ayuda" y "trabajo". Según reportan los jóvenes, trabajo es toda actividad dirigida al beneficio de terceros del cual se recibe un monto de pago determinado; por el contrario, "ayuda" es aquella actividad que realiza para la familia nuclear o extensa, donde no se recibe un monto de pago.

El nivel educativo de los padres es otro punto importante a considerar para comprender las motivaciones de los jóvenes. En el contexto de estudio, casi todos los padres de familia no llegaron a culminar incluso el nivel primario. Así, solo cinco personas del grupo total de padres y madres llegaron a culminar la secundaria. Los padres de familia señalaron que el motivo principal del temprano abandono de su escolaridad fue básicamente porque no recibieron apoyo de sus familiares asociado a las carentes oportunidades educativas en el contexto. Esta diferencia en los niveles educativos entre una generación y otra terminan siendo incentivos para los jóvenes ${ }^{5}$.

La trayectoria en la educación secundaria se entiende como un medio para acceder a la educación superior universitaria. Esto se plasma cuando se alude a la elaboración de los proyectos de vida que comienzan a manifestarse durante último año escolar y que se prolonga en la transición postsecundaria ${ }^{6}$. En ello, los proyectos de vida

5 En caso de que los jóvenes ingresaran a algún centro de educación superior, serían los primeros profesionales en la familia.

6 Esto significó que si bien durante el quinto año de secundaria los jóvenes fueron organizando sus intereses, aptitudes y posibilidades de manera más concreta, estas 
definen como objetivo central la profesionalización para lo cual identifican estrategias que potencien sus posibilidades en lograr sus objetivos.

\section{¿CÓMO HAN SIDO LAS TRANSICIONES?: FACTORES INVOLUCRADOS Y NIVELES DE SEGURIDAD IDENTIFICADOS}

Durante la transición postsecundaria se identifican dos dimensiones paralelas que son clave para comprender las expectativas y estrategias de los jóvenes rurales. Por un lado se identifican factores en las decisiones y por otro lado, estrategias a fin de alcanzar los objetivos. Respecto a los factores se encuentra:

\section{TIEMPO Y COSTO DE ESTUDIOS}

Los jóvenes reconocen que acceder a la educación superior supone previamente un tiempo de preparación para ampliar las posibilidades de ingreso. Para ello, es importante la preparación en centros preuniversitarios privados denominados academias, los cuales manejan periodos y costos monetarios considerables.

\section{APRENDIZAJES ESCOLARES}

Los jóvenes reconocen que sus preferencias personales por una carrera profesional u otra también dependen de cómo fueron sus aprendizajes en determinadas áreas de la currícula escolar. Por ejemplo, hay quienes tienen un mejor rendimiento en el área de ciencias y otros que tienen un mayor rendimiento en el área de letras. Esto es un factor de importancia para reconocer como fueron los aprendizajes escolares y según ello buscar una especialidad que convenga a sus posibilidades académicas.

\section{PREFERENCIA Y PRESTIGIO DE LAS INSTITUCIONES EDUCATIVAS}

Existen dos alternativas para insertarse en la educación superior; uno es el caso de los estudios universitarios y otro, el caso de los estudios técnicos. En cada caso existen instituciones públicas como privadas. La mayor preferencia de los jóvenes se encuentra en la educación universitaria por considerar que tiene mayor reconocimiento social a diferencia de los institutos. No obstante, entre las universidades se atribuye un mayor prestigio a la universidad pública por considerar que los requisitos académicos de ingreso son muchos más exigentes a comparación de las universidades privadas. De este modo, ingresar a la universidad pública generaría un mayor reconocimiento social para los jóvenes.

evaluaciones se prolongan hasta después de culminar la secundaria donde se encuentran otros elementos que reordenan las expectativas y las estrategias 


\section{APOYO ECONÓMICO}

La educación superior genera una serie de costos monetarios para lo cual los jóvenes y sus familias se organizan a fin de asumir responsabilidades compartidas. En este momento es de suma importancia saber si los jóvenes recibirán algún tipo de apoyo económico para evaluar sus posibilidades de estudiar en el corto plazo.

Cada uno de estos factores es identificado por los jóvenes al momento de evaluar sus posibilidades en sus tránsitos postsecundarios. Evaluar sobre estudiar y trabajar, solo estudiar o solo trabajar, evidencia sus modos de abrirse posibilidades en relación a sus objetivos educativos. Estos momentos se viven con una sensación de preocupación constante, tal como se evidencia en la siguiente cita:

"Sentíla presión por querer estudiar ósea cuando sales del colegio, ya estas fuera como en una sociedad diferente, tienes que lograr algo, porque como otras personas se van quedando sin estudios...tenía el pensamiento de que yo también podría quedar como esas personas sin ser profesional, sin tener una carrera, era terrible" (joven mujer, 18 años)

Posteriormente, también se identificaron dos grandes estrategias que caracterizan a este grupo de jóvenes en sus transiciones postsecundarias.

\section{INGRESAR A LA ACADEMIA:}

La academia preuniversitaria como un paso previo de suma importancia para facilitar el ingreso a la universidad. La academia, que no forma parte del sistema educativo formal, es un centro especializado de formación concreta y acelerada donde se priorizan cursos de aptitud verbal y matemática en función a las necesidades del examen de postulación para la universidad. Este paso por la academia supone destinar tiempo y costo determinados, que no todos los jóvenes pueden asumir inmediatamente y para lo cual deben apoyarse de otro tipo de estrategias laborales. Así, la expectativa de ingreso a la universidad que requiere de estudiar previamente en la academia, se convierte en una necesidad que puede generar problemas para los jóvenes, no solo por el acceso, sino porque incluso una vez que se logra acceder a estos centros de estudios, los jóvenes identifican problemas de aprendizaje y se sienten en mayor desventaja para lograr ingresar a la universidad.

\section{ESTUDIAR MIENTRAS TANTO}

El mientras tanto consiste en estudiar aquello que no había sido planeado inicialmente, ya sea porque desistieron mientras se preparaban en la academia, porque no tuvieron los suficientes recursos económicos 
para persuadir en la universidad o porque los padres los incentivaron a estudiar otras profesiones. El mientras tanto alude a una medida alternativa a la inserción universitaria y se concentra en el acceso en la educación técnica. Es decir, que si dentro de un tiempo corto no se logra ingresar a la universidad, se opta por estudiar en un instituto técnico y se posterga la idea de ir a la universidad. Ahora, la educación técnica no se reconoce como prestigiosa al lado de la educación universitaria y es por ello, que los jóvenes que acceden a una modalidad técnica tienen la expectativa de que en el largo plazo estudien en la universidad.

\section{LAS TRANSICIONES DE VARONES YMUJERES: LAS POSIBILIDADES DE DECIDIR Y LA AUTONOMÍA}

En las transiciones postsecundarias de los jóvenes se identifican diferencias sobre las posibilidades de decidir que mantienen una relación directa con los grados de autonomía desarrollados y reconocidos en el tiempo. Según ello, varones y mujeres pueden tener las mismas expectativas educativas, como se encuentra en este estudio, pero las trayectorias evidencian que las posibilidades reales son diferentes para varones y mujeres. Las decisiones y oportunidades de decidir sobre el futuro responden a márgenes de agencia diferentes entre varones y mujeres. Al respecto, en el estudio se identificaron tres grupos según sus posibilidades de decisión y modos de apoyo que recibirían de sus familias.

Grupo 1: Está conformado por jóvenes varones. Son aquellos quienes se mostraron con mayor seguridad respecto al plan de vida, pese a que reconocían que no recibirían apoyo económico familiar. Lo más resaltante en estos jóvenes es que tenían mayor confianza en poder valerse por sí mismos y por ello, la escasez de recursos y el consecuente escaso apoyo económico de sus familias, no alteró en gran medida sus seguridades en las decisiones tomadas.

Grupo 2: Está conformado por jóvenes varones y mujeres. Son aquellos quienes tenían una mayor seguridad respecto a sus planes elaborados, pero también reconocían sentirse respaldados económicamente por sus familias. Un dato a considerar es que en estos casos, varios tenían hermanos mayores que eran profesionales y de quienes recibían consejos para persuadir con los estudios.

Grupo 3: Está conformado por mujeres en su mayoría. Son aquellas quienes tenían poca seguridad sobre estudiar y tenían escasa posibilidad de recibir apoyo económico de sus familias. A diferencia de los varones, las mujeres se percibían 
muy limitadas a tomar decisiones, esto porque tenían mayores restricciones de sus padres.

Considerando lo anterior, las diferencias entre los tres grupos se caracterizan por las actitudes de seguridad y posibilidad de decisión que tienen los jóvenes. En el primer grupo, estos jóvenes, todos varones, tuvieron mayores dificultades económicas por la cuales su principal estrategia fue trabajar para ponerse a estudiar; hecho que conocían bastante bien porque era parte de lo que siempre acompañó su trayectoria escolar. El apoyo moral de sus familias estuvo acompañado del reconocimiento de una autonomía que se generó en el tiempo. Esto significó, otorgarles mayor libertad para tomar sus decisiones sobre lo que creían más conveniente hacer. Es así que la autonomía es una dimensión de suma importancia porque amplía los márgenes de agencia en términos de Thomson (2000).

El segundo grupo, a diferencia del primero, goza de cierto respaldo económico familiar y existen profesionales en la familia en su generación. Al parecer, las posibilidades de acceder a los estudios son más cercanas; es decir prepararse en la academia o matricularse en algún instituto técnico es casi una seguridad. Estos jóvenes y sus familias se organizaron para que las estrategias generaran resultados positivos.

Una situación diferente ocurre en el tercer grupo, dado que el soporte familiar no garantiza un desarrollo de mayor seguridad en las jóvenes. Cada uno de los casos de este grupo, presenta inseguridades y limitaciones no solo económicas. Las jóvenes buscan estudiar y trabajar al mismo tiempo, mientras que sus padres niegan esa posibilidad porque temen que al darles libertades, ellas puedan abandonar el proyecto educativo . La etapa postsecundaria para los padres de estas jóvenes es también un momento que les preocupa continuamente y frente a lo cual se toman medidas de protección contra posibles embarazos no deseados . Por ello, no es casualidad que este grupo desarrolle la estrategia de estudiar una carrera "mientras tanto" y casualmente todas las jóvenes ingresan a estudiar la especialidad de educación en un instituto pedagógico . El motivo detrás de esta estrategia es que los padres, temen

7 Las jóvenes mencionan que a diferencia de lo que ven con sus hermanos, ellas tienen mayores prohibiciones en salir a buscar un trabajo o permanecer tiempo fuera de la casa.

8 Para estas familias, el temor más grande es que sus hijas, producto de un embarazo, abandonen sus proyectos educativos. Los padres justifican este temor porque evidentemente existen casos en los cuales las hermanas mayores de estas jóvenes salieron embarazas poco antes de culminar la secundaria y otras poco después de egresar de la misma.

9 Una de las jóvenes entrevistadas mencionó que debido a no haber logrado ingresar a la universidad, se matriculó en un instituto técnico donde estudia educación. Indicó que 
que si no hacen el esfuerzo de colocar a sus hijos en un centro de estudio, estas puedan abandonar el interés de ser profesionales. Las posibilidades de agencia y negociación de las jóvenes se reducen, llevando a que estas estudien lo que sus padres desean a futuro.

Sobre esto último, las reflexiones de la estrategia del mientras tanto conduce también a identificar las percepciones sobre el ingreso a los institutos pedagógicos en relación a las exigencias académicas de la educación superior sobretodo universitaria. Así, pese a que existan nuevas oportunidades educativas, los jóvenes se sienten poco capaces de aprobar el examen de postulación en la universidad debido a que no encuentran una continuidad entre lo aprendido en la secundaria y lo que se requiere para ingresar a la universidad. Ahora, esto no quiere decir que desistan de estudiar, solo que las decisiones que tomen, con un mayor o menor margen de agencia, terminan siendo lo que creen que pueden y no lo que realmente desean. De esta manera, el mayor objetivo en los planes de vida se convierte en una oportunidad con limitaciones estructurales. El objetivo es llegar a ser profesionales a través de la universidad, para lo cual pueden tener los incentivos familiares, mayores márgenes de agencia y estrategias según sus niveles de autonomía logrados.

No obstante, existen limitaciones educativas que les impiden lograr sus objetivos universitarios. Es ahí donde volvemos a reflexionar sobre el paso por la academia, ya que los jóvenes identifican carencias sobre la calidad de sus aprendizajes. Este paso por la academia significa entonces, el reconocimiento de los pocos aprendizajes desarrollados durante la secundaria ${ }^{10}$ a lo cual se atribuyen como responsables generando mayores angustias. Es por ello que los tránsitos postsecundarios no solo involucran dedicación y acompañamiento de las familias, sino encuentros con las carencias estructurales del propio sistema educativo que no logra vincular la secundaria con la educación superior, más aún cuando se trata de la educación rural.

\section{BALANCE Y RECOMENDACIONES DE POLÍTICA}

Sumando los resultados de la investigación y las discusiones surgidas durante los talleres de la escuela Clacso, se identifican a los jóvenes como actores diferentes en el sentido inter e intrageneracionales, y contextos diferentes siendo más urbanos o más rurales. En todos los casos, el artículo expuesto muestra ciertas particularidades de jóvenes que

hubieses deseado seguir preparándose para postular a la universidad pero que sus padres no podía seguir apoyándole económicamente y decidieron que estudie en un instituto.

10 Hecho que es recurrente encontrar si consideramos las brechas de logros de aprendizajes entre losestudiantes urbanos y rurales (PISA 2012). 
demandan mayores niveles educativos y requieren un acompañamiento para que se fortalezcan sus tránsitos postsecundarios.

En este sentido ¿Cómo acompañar las transiciones de los jóvenes reconociendo sus oportunidades educativas, sus posibilidades de decidir y las estrategias que emplean para mejorar sus condiciones de vida? Es cierto que el estudio expuesto retrata una situación de jóvenes de un contexto rural particular, donde los varones y mujeres tienen diferentes oportunidades, sin embargo, resulta importante dar cuenta que esta etapa entre la salida de la secundaria y el acceso a la educación superior es un tramo de la vida considerable donde muchos jóvenes lidian con las preocupaciones y el optimismo que trae consigo esta etapa.

Desde las políticas públicas a las juventudes, siguiendo a Ernesto Rodríguez, en Perú se mantienen paradigmas de situar al joven como problema y algunas otras que abogan por situar a los jóvenes como actores estratégicos en el desarrollo. Para una mejor comprensión y acompañamiento a los jóvenes se debe priorizar este último paradigma atendiendo las diversas situaciones educativas que ocurren hacia el final de la secundaria.

Al pensar en cómo desarrollar una política para las juventudes, sobretodo rurales, en la transición postsecundaria, es necesario detenernos a mirar cual es el estado de las situaciones que ocurren en diversos contextos para que eso sirva de insumo para programar intervenciones.

Desde el sector educativo, el mayor problema identificado en la educación secundaria es que esta no incrementa los aprendizajes que aseguren un tránsito exitoso para el ingreso a los estudios superiores, sobretodo la universidad. Es por ello, que la existencia de centros preuniversitarios se hace indispensable para potenciar y asegurar el ingreso a las universidades. Las llamadas "academias" son escuelas privadas que nos forman parte del sistema educativo formal y que se crearon para fortalecer la demanda de quienes no ingresaban a la universidad luego de egresar de la secundaria. Las academias sin embargo, se focalizan en cursos intensivos de ciencias y letras con niveles mucho más acelerados de lo que aprende en secundaria y que genera un estrés constante en los jóvenes que no lograr adaptarse al ritmo de aprendizaje. Así, la academia rellena el vacío que deja la secundaria y se convierte es una escuela más; esto demanda un tiempo y costo adicional que no todos los jóvenes pueden asumir. Aquí el problema es entonces que la educación secundaria necesita tener una propuesta diversificada y enfocada en aprendizajes que vinculen a los jóvenes con la educación superior, sobre todo en los dos últimos años ${ }^{11}$, pero no solo en el hecho de fomentar el acceso a la universidad sino también el acceso a la educación técnica.

11 Esto en relación al tiempo donde van elaborando sus proyectos de vida. 
Asimismo, se necesita que desde las escuelas secundarias se incentive la presencia de las universidades e institutos para que ofrezcan charlas informativas sobre en qué consisten las especialidades profesionales que ofrecen y con ello, los jóvenes tengan mayor información sobre la oferta educativa.

Otro gran problema es el de los centros de educación superior en cuanto a tipo de institución al cual se puede acceder; si es pública o privada. Las universidades no se vinculan con los estudiantes de las escuelas secundarias, sobre todo las universidades públicas. Brevemente, existen alrededor de 140 universidades en el país, la gran mayoría es de gestión privada y con fines de lucro. Este tipo de universidad se ha masificado en los últimos años con la premisa de democratizar el acceso a todos los sectores de la población, pero en perjuicio de la calidad. Esta masificación de universidades está presente en todo el país y son las que tienen una mayor presencia en las aulas de los estudiantes de secundaria, ofreciendo becas de ingreso directo, facilidades de pago con tarifas de menor costo y una llamativa infraestructura. La competencia ha superado a las universidades públicas que también están en todos el país, pero las condiciones presupuestales y de gestión, en muchas de ellas, no hacen que sean atractivas para los jóvenes. Más aun, la universidad pública no se acerca a las escuelas y no muestra su oferta educativa a los estudiantes. En este escenario, que también es rural, los jóvenes buscan acceder a la universidad pública de la cual desconocen su oferta de especialidades, pero que es gratuita y, pese a los problemas, se considera prestigiosa porque demanda un mayor esfuerzo académico para poder ingresar antes que económico. Vale mencionar que este panorama universitario es motivo de recientes investigaciones en Perú a propósito de la reforma universitaria y reforma de la educación técnica que también tiene problemas en la calidad del servicio ${ }^{12}$. En este contexto entonces se necesita fortalecer la universidad pública que es la más accesible a las posibilidades de los jóvenes de menores recursos, pero estos jóvenes necesitan acceder a una universidad de calidad que les asegure una formación profesional con la cual puedan desarrollarse profesionalmente y tener mejores condiciones laborales. Al respecto, un aspecto positivo es la ya mencionada reforma en la educación superior para mejorar la calidad, mientras que por el lado del acceso, se rescatan experiencias de becas que actualmente ofrece el gobierno a estudiantes sobresalientes gracias a un programa llamado "Beca 18".

Por otro lado, también desde el sector educativo se necesita trabajar más en potenciar la educación superior técnica para que esta sea

12 Se intenta mejorar la calidad de la educación superior, para que los jóvenes accedan a una educación de calidad que asegure mayores retornos económicos en el futuro. 
una alternativa mucho más atractiva para los jóvenes. Al igual que la educación universitaria, se encuentra un sin número de institutos que carecen de una infraestructura adecuada y de carreras profesionales que poco se ajustan a las demandas del mercado. Es necesario para fortalecer la presencia de la educación superior técnica en la vida de los jóvenes como una alternativa de profesionalización válida que también les ofrezca posibilidades de desarrollo.

Como último aspecto a considerar en las políticas que atiendan las transiciones de los jóvenes, se debe diseñar estrategias diferenciadas según las potencialidades de los contextos para que las nuevas generaciones gocen de mayores oportunidades en sus propias localidades. La transformación de los escenarios rurales demanda una atención diferenciada a los jóvenes. Así, la profesionalización debe también orientarse a las potencialidades de los contextos para dinamizar los territorios. En el estudio de caso, no se mencionó la oferta de especialidades en la universidad, sin embargo, se puede decir que existe poca diversidad que no siempre se vincula con las demandas del mercado local.

Respecto a esta situación, se necesita promover un desarrollo territorial. Lo interesante aquí en relación a las juventudes es que ellos y ellas necesitan tener mayores insumos de información y capacitación sobre las potencialidades sobretodo agrícola de sus territorios para demandar una nueva generación de expertos locales técnicos que potencien las capacidades productivas de sus localidades.

En este sentido, las políticas de juventud en el Perú tienen grandes desafíos para las próximas décadas. La población actual de jóvenes que culminan la educación secundaria es creciente, pero define contextos escolares muy diferentes donde se podría decir que todos y todas buscan acceder a la educación superior. Sus estrategias de vida, sus aprendizajes educativos en la educación secundaria y los problemas en el acceso y calidad de la educación superior necesitan ser tema de debate público. Los problemas expuestos son al mismo tiempo una oportunidad de reflexión para reconocer experiencias y similitudes de problemas a nivel regional latinoamericano. La experiencia de Clacso es en este sentido valiosa para profundizar los debates.

\section{CONCLUSIONES}

Las características del contexto rural y la situación educativa amplían las oportunidades en los proyectos de vida de los jóvenes rurales. La transición postsecundaria es una etapa de suma importancia para contextualizar a los jóvenes, ya que es donde se concentran los mayores esfuerzos para el futuro y en función a ello, los jóvenes diseñan estrategias que están sujetas a sus márgenes de posibilidad. Un contexto de oportunidad educativa local motiva a que los jóvenes amplíen 
sus expectativas pero también los confronta con mayores retos que van encontrando en el camino.

El acceso a la educación superior está presente como la meta principal en los proyectos de vida. Así, prioridad de los jóvenes es adquirir mayores niveles educativos, postergando la idea de establecer un hogar propio. El sentido de la independencia se asocia a la autonomía donde se evidencian márgenes de posibilidad relativamente diferentes entre varones y mujeres. Estas diferencias sumadas a las trayectorias educativas secundarias en el contexto, hacen que las transiciones postsecundarias sean vulnerables para acceder a la educación superior. En este sentido, a medida que es creciente la inserción y la permanencia en la educación secundaria así como la culminación, es importante también fortalecer las oportunidades de acceso a la educación superior de los jóvenes contextos rurales para promover mayores condiciones de igualdad de oportunidades.

\section{BIBLIOGRAFÍA}

Ansion, Juan \& Iguiñiz, Javier 2004 Desarrollo humano entre el mundo rural y urbano (Lima: PUCP).

Ames, Patricia \& Rojas, Vanessa 2010 Cambios y oportunidades: la transición de la escuela primaria a la secundaria en el Perú. Documento de trabajo $\mathrm{N}^{\circ} 63$ (Lima: Niños del Milenio).

Alarcón, Walter 2011 Trabajo Infantil en los Andes (Lima: IEP).

Barker Carolyn 2005 "Desarrollo rural y migración en comunidades rurales en Huancavelica" en Economía y sociedad $\mathrm{N}^{\circ} 58$. Consorcio de investigación económica y social-CIES.

Benavides, Martin 2007 "Lejos (aun) de la equidad: la persistencia de las desigualdades educativas en el Perú" en Investigación, políticas y desarrollo en el Perú (Lima: Grade).

2006 Para acercarse a los que se alejan. Exclusión, jóvenes y políticas públicas (Lima: RES- BID/Grade).

Benavides, Martin (et al) 2010 Ser joven y excluido es algo relativo: dimensiones cuantitativas y Cualitativas de la heterogeneidad de los jóvenes pobres urbanos peruanos (Buenos Aires: CLACSO).

Bynner, John \& Chisholm, Lynne 1998 "Comparative Youth Transition Research: Methods, Meanings, and Research Relation" en European Sociological review. Vol. 14. № 2. Disponible en: http:// www.jstor.org/stable/522631 
Casal, Joaquim (et al) 1988 “Elementos para un análisis sociológico de la transición a la vida adulta” en Política y sociedad, pp. 97-104.

— 2011 "Pasado y futuro del estudio sobre la transición de los jóvenes" en Revista de sociología. $N^{\circ} 96$.

CEPAL 2000 “Adolescencia y juventud en América Latina y el Caribe: problemas, oportunidades y desafíos en el comienzo de un nuevo siglo" en Serie población y desarrollo. http://repositorio.cepal.org/ bitstream/handle/11362/7207/S2000941_es.pdf?sequence=1

2012 Informe regional de población en América Latina y el Caribe 2011: Invertir en juventud. 140pp.

Cotler, Julio y Cuenca, Ricardo (editores) 2011 Las desigualdades en el Perú: balances críticos (Lima: IEP).

ENAJUV 2011 Encuesta nacional de juventud. Disponible en: http:// juventud.gob.pe/libro-electronico- enajuv/ nPeru.pdf

Kessler, Gabriel 2005 Estado del arte de la investigación sobre juventud rural en américa latina.

Monge, Carlos 201 “La educación pública y el mundo rural Peruano”. Ponencia presentada en Conferencia nacional de educación y desarrollo rural: perspectivas en el contexto de descentralización. Foro educativo

Moreno, Almudena (Coord.) 2012 "La transición de los jóvenes a la vida adulta. Crisis económica y Emancipación Tardía” En Colección de estudios sociales. $\mathrm{N}^{\circ} 34$ (Barcelona).

León, José. \& Sugimaru, Claudia 2013 Entre el estudio y el trabajo: las decisiones de los jóvenes peruanos después de concluir la educación básica regular. Avances de investigación N¹1. 54 pp. Grupo de Análisis para el desarrollo.

Otero, Analía 2010 "Los avatares de la transición a la vida adulta, el papel de la educación y el trabajo en los recorridos juveniles" en Revista latinoamericana de ciencias sociales, niñez y juventud. Vol. 59, pp. 1-13.

Punch, Samantha 2002 "Youth transitions and interdependent adult-child relations in rural Bolivia” en Journal of rural studies $\mathrm{N}^{\circ} 18$. Pp, 1-13.

Reimers, Fernando 2000 “Educación, desigualdad y opciones de política en América Latina en el siglo XXI" en Revista Iberoamericana $\mathrm{N}^{\circ} 23$. Organización de estados iberoamericanos. 
Rojas Alejandra y Cussianovich Vanessa 2013 Le va bien en la vida: percepciones de bienestar de un grupo de adolescentes del Perú. Documento de trabajo - GRADE.

Sen, Amartya 2000 (1992) Nuevo examen de la desigualdad (Madrid: Alianza editorial).

Vommaro, Pablo 2014 "Movilizaciones juveniles en América Latina actual: hacia las configuraciones generacionales de la política". Disponible en http://www.academia.edu/23431522/Movilizaciones_juveniles_ en_Am\%C3\%A9rica_Latina_actual_hacia_las_configuraciones_ generacionales_de_la_pol\%C3\%ADtica 



\title{
¿IGUALDAD DE OPORTUNIDADES O REPRODUCCIÓN DE LA DESIGUALDAD SOCIAL?
}

\author{
EL CASO DE LAS Y LOS JÓVENES ASPIRANTES A LA \\ EDUCACIÓN SUPERIOR PÚBLICA COMO REFLEJO DE LA \\ ESTRUCTURA SOCIAL DE DESIGUALDAD EN ECUADOR
}

Paola Viera Córdova*

\section{INTRODUCCIÓN}

¿Son los exámenes de ingreso a la universidad un mecanismo meritocrático de selección o una forma de concentrar privilegios en los grupos que ya están bien posicionados socialmente? En contextos de promoción de oportunidades y meritocracia, ¿la reproducción de las desigualdades sociales debería tender a reducirse? Esta investigación (en desarrollo) busca explicar cómo operan las desigualdades sociales en el Ecuador, tomando como un reflejo de esto al estudio de jóvenes que quieren ingresar a la universidad pública y que rinden el Examen Nacional para la Educación Superior (ENES). ¿Quién (socialmente hablando) tiene éxito en esas pruebas?

Esta investigación en curso analiza la relación sociológica entre condiciones sociales de origen, acumulación de capitales y oportunidades y, por otro, el éxito educativo, las expectativas de futuro,

\footnotetext{
* Magíster en política social de la infancia y adolescencia por la Universidad Politécnica Salesiana y estudiante de la maestría de Sociología de la Facultad Latinoamericana de Ciencias Sociales, FLACSO Ecuador, en Quito, Ecuador. paoviera@yahoo.com
} 
la movilidad social y las estrategias de las y los jóvenes y sus familias para enfrentarse al proceso de ingreso y admisión a las Instituciones de Educación Superior Pública (IESP) como una forma de manejar las emociones que este proceso genera.

La pregunta que guía este proceso investigativo es: ¿Cuáles son y cómo operan los factores asociados a la desigualdad social en el campo educativo? La estrategia metodológica incluye un análisis cuantitativo de los perfiles sociales y los resultados que obtienen 65.000 jóvenes que rinden el examen a partir de una base de datos de la encuesta de contexto del segundo ENES del 2012, base levantada por el Sistema Nacional de Nivelación y Admisión (SNNA) durante el proceso de admisiones a las IESP, así como un análisis etnográfico de cómo las y los jóvenes experimentan el proceso de potencial ingreso a la universidad. La investigación se nutre además, de entrevistas semiestructuradas y relatos de vida de las y los aspirantes y sus familias para comprender y explicar cómo construyen para enfrentarse al proceso de ingreso a las IESP, de donde se espera conocer las especificaciones para la explicación de los mecanismos de reproducción de desigualdades.

Esta investigación está orientada a estudiar la relación entre las condiciones sociales de origen y los logros escolares, expectativas de futuro y movilidad social de jóvenes en Ecuador. El estudio se nutre del debate teórico sobre los mecanismos de la reproducción de la desigualdad, la desigualdad persistente y la desigualdad de posiciones, así como los efectos del origen y contexto social asociados a los logros educativos, expectativas de futuro y movilidad social. Busca estudiar la hipótesis de que quienes tienen un origen y una trayectoria social más favorable, tienen más probabilidades de ser admitidos en la universidad. Tal idea sopesaría los supuestos de que, ante igualdad de oportunidades, las y los aspirantes solo son evaluados en base a méritos y talentos. En este sentido, el reprobar el ENES implicaría una expresión de los factores asociados a la reproducción de la desigualdad social; y que el no obtener el puntaje mínimo y necesario en el ENES para ingresar al proceso de nivelación y obtener un cupo en la carrera elegida por la o el joven, conlleva a un cambio en sus expectativas de futuro y posterior movilidad social generando la necesidad de emplear estrategias para enfrentarse al proceso de ingreso a las IESP como una forma de canalizar las emociones que este proceso genera.

Aquí se presenta un avance de la fase exploratoria en la que se identifican algunos factores que asocian el origen y el contexto social del postulante, con sus posibilidades reales de ingreso. La pregunta que subyace es: ¿Cuáles son los factores que influyen en los resultados académicos en Ecuador? Se indaga la relación entre los orígenes sociales, los antecedentes institucionales, el género y los resultados académicos de jóvenes, mujeres y hombres, que se encuentran en tran- 
sición de estudios de bachillerato a superiores. Se argumenta que la desigualdad social y los resultados académicos están relacionados. El análisis confronta uno de los principios en los que se funda el actual sistema de nivelación y admisiones del país: la meritocracia, partiendo por la premisa de que la "igualdad de posiciones" está en detrimento a la "igualdad de oportunidades" tal como lo sostiene Dubet $(2010,2012)$.

Este ensayo se organiza en tres partes: en la primera sección se incluye una aproximación al caso de estudio; en segundo lugar, se presentan las ideas teóricas y esquema analítico que sustentan este trabajo; y finalmente el tercer acápite incluye algunos hallazgos de este proyecto en ejecución que opera, todavía, con una lógica exploratoria en tanto, una vez finalizado el trabajo de campo y el análisis de los datos cuantitativos se pueda explicar los mecanismos de reproducción de la desigualdad.

\section{SISTEMA NACIONAL DE NIVELACIÓN Y ADMISIONES, SNNA: UNA BREVE REVISIÓN}

A raíz de la nueva Constitución del 2008, en el Ecuador se han planteado nuevas reformas en educación superior tales como: la evaluación, acreditación y categorización de las Universidades y Escuelas Politécnicas; la implementación del SNNA para estudios superiores, entre otras. En este escenario, la instrumentalización del actual SNNA se da a través de la aplicación del ENES, implementado a inicios del 2012, el cual evalúa las habilidades de razonamiento abstracto, verbal y numérico desde una perspectiva de igualdad de oportunidades. La aplicación del examen se realiza en: septiembre el primer período; y marzo el segundo período. En primera instancia, lo aprueban quienes obtienen un puntaje mayor a 601/1000 puntos, a excepción de quienes optan por las carreras de medicina y educación, cuyo puntaje mínimo es de 800/1000.

Inicialmente, este examen tenía la finalidad de filtrar el ingreso a la universidad pública, sin embargo, a partir de marzo del 2014 fue implementado también como mecanismo de ingreso a los institutos técnicos y tecnológicos superiores -totalidad de IESP-y se estipuló como obligatorio y universal para quienes cursan el último año de bachillerato, en todo tipo de planteles educativos como requisito para la graduación de sus estudios. De este modo, rendir el ENES se convirtió en obligatorio y devino en un instrumento estatal de evaluación de los centros educativos del país. Esto trajo algunas repercusiones, entre otras, el aumento de la calificación promedio que se obtiene en el examen afectando a la hora de la distribución de los cupos en función de los puntajes obtenidos, en tanto, en gran medida las y los jóvenes ubicados en mejores situaciones socioeconómicas y mejores trayectorias educativas continuaban el proceso más allá de la obligatoriedad del requisito con la finalidad de alcanzar una beca del gobierno ecuatoriano para cursar sus estudios en cualquier universidad de 
prestigio del mundo, o para obtener un cupo en una universidad pública de prestigio académico implicando gratuidad en sus estudios superiores. A partir de estos efectos identificados por la Senescyt, a partir del 2015, el ENES regresa a ser un requisito específico para las instituciones públicas.

El proceso de ingreso a las instituciones de educación superior puede explicarse en cinco fases: 1) preparación; 2) elección, aspiración e inscripción; 3) primer filtro: aplicación, calificación y postulación de carreras; 4) segundo filtro: asignación de cupos, aceptación o rechazo de cupos asignados y la inscripción al respectivo curso nivelación; y 5) tercer filtro: aprobación del curso de nivelación y las consecuentes afectaciones en su futuro (para profundizar en estas fases vid. Infra, Gráfico 1). Estas fases influyen en las aspiraciones y expectativas de futuro, los logros o fracasos escolares y las afectaciones posteriores en la continuidad de estudios superiores, generación y manejo de emociones y posterior movilidad social.

De acuerdo con datos oficiales de la Secretaría Nacional de Educación Superior, Ciencia, Tecnología e Innovación (SENESCYT), en el ENES del segundo período de 2013, 157.217 aspirantes se inscribieron en el sistema para rendir el examen, 112.762 jóvenes lo rindieron, 91.662 obtuvieron un puntaje mayor a 600 puntos lo cual les permitía optar hasta por 5 carreras en orden de prioridad, sin embargo, solo 80.027 postularon a las 5 opciones de carrera; a 54.769 aspirantes se les asignó un cupo, de los cuales 42.525 aceptaron dicho cupo. En suma, del total de quienes se inscribieron en el sistema para rendir el ENES en el II período 2013, el 27\% tuvo y aceptó un cupo y el 0,11\% (170) obtuvieron los puntajes más altos a nivel nacional, lo cual los habilitó para ser parte del Grupo de Alto Rendimiento (GAR).

Los datos expuestos pueden ser llamativos pues el puntaje obtenido en el ENES podría determinar la movilidad social de las y los jóvenes en esta etapa vital, tanto a nivel económico (ya que se relaciona con la calidad de la posterior inserción laboral), así como el reconocimiento, el respeto y dignidad asignado a la o el joven en su círculo social. La pregunta que surge es: ¿Quién tiene más posibilidades de obtener un cupo?

Cabe señalar que una de las consecuencias no intencionales de la aplicación de esta política, es que las y los jóvenes pueden enfrentar la necesidad de prepararse para rendir dicho examen con la intención de ser parte del grupo que ingresa a la educación superior pública. Esto ha llevado a la proliferación del negocio de los centros que ofertan cursos preuniversitarios, los cuales se muestran como un paso intermedio en el proceso de ingreso a la educación superior y una respuesta aparentemente "efectiva" ante el nuevo escenario de transición del colegio a la universidad: "Ellos [la SENESCYT] crearon el problema, nosotros creamos la solución” (Roberto 
, director de un centro particular de cursos preuniversitarios, entrevista, septiembre 2014). Es así que quienes gozan de una situación socioeconómica favorable, se preparan en centros privados, lo que podría generar mayores probabilidades de acaparar oportunidades.

\section{FORMACIÓN DE LAS CLASES SOCIALES Y MECANISMOS DE REPRODUCCIÓN DE LA DESIGUALDAD SOCIAL A PARTIR DE LOS RESULTADOS DEL EXAMEN NACIONAL PARA LA EDUCACIÓN SUPERIOR}

De acuerdo a las últimas reformas en las políticas educativas ecuatorianas ¿la transición de la educación media a la superior podría estar vinculada con la igualdad de oportunidades para el ingreso y permanencia de las y los jóvenes en la educación superior pública? Parecería ser que no necesariamente en el proceso se tome en consideración los factores que generan la desigualdad en las posibilidades de: a) aspirar a estudiar una carrera de educación superior, b) prepararse adecuada y oportunamente; c) aprobar con éxito el proceso de evaluación; d) salvar los obstáculos sociales asociados a las carentes condiciones socioeconómicas. Estas situaciones más bien podrían reflejar las desigualdades persistentes a través del tiempo y durante el curso de la vida (Solís, 2012), lo que podrían afectar a las expectativas y opciones reales de movilidad social a través de la educación.

De acuerdo con Dubet (2010, 2012), la "igualdad de posiciones" y la "igualdad de oportunidades" -en tanto principios de justicia socialbuscan disminuir las desigualdades sociales. Sin embargo, la igualdad de oportunidades pone énfasis en la meritocracia al reducir las discriminaciones, mientras que la igualdad de posiciones se centra en la organización de los espacios ocupados en la estructura social, con lo que sostiene que la justicia social debe enfocarse en la reducción de la desigualdad de posiciones sociales, ajustar la estructura social y enfocarse en la movilidad social de los individuos.

Según Erik Olin Wright (2010), a la clase social y la estratificación social, se incluye como atributo fundamental la educación en las sociedades económicamente desarrolladas, en tanto las credenciales educativas constituyen un factor determinante al momento de pertenecer a una clase $\mathrm{u}$ otra, pues permite acceder a un estatus y mayores ingresos económicos a partir del acceso a trabajos mejor remunerados. Según Wright, las condiciones sociales de origen que se adquieren en el entorno familiar desde la infancia influyen en las habilidades, educación y motivaciones que determinarán las perspectivas económicas de un individuo. Sostiene además que las clases "se definen por el acceso a ciertas oportunidades económicas y por la exclusión de las mismas" (pág. 101); es decir, a la apropiación de oportunidades respecto al acce- 
so y exclusión de aquellas vinculadas a la educación y a la ocupación, lo que los ubica en una condición socioeconómica específica.

En esta misma línea, Bourdieu (2007 [1980]) contribuye a la construcción del marco analítico con sus aportes sobre la acumulación de capital cultural, que responde a la apropiación de los recursos simbólicos y la legitimidad del capital cultural que está determinada por credenciales que certifiquen su poder, títulos académicos, los que influyen al momento de ingresar al mercado laboral. Los títulos académicos constituyen uno de los instrumentos que viabilizan la acumulación del capital simbólico, pues expresan materialmente el "éxito" o "fracaso" y determinan el tránsito en el ciclo de vida al marcar el fin e inicio entre las diferentes etapas (Bourdieu y Passeron, 1996:180).

Al respecto, para Charles Tilly (2000 [1998]) las desigualdades socialmente reconocidas (desigualdad categorial) generan consecuencias que se plasman en la exclusión y las vuelven persistentes. Estas tienen que ver con desigualdades en las ventajas de las personas en relación a sus categorías, más allá de las diferencias de los atributos individuales o desempeños. Sostiene que los mecanismos de funcionamiento de la desigualdad son las "secuencias causales recurrentes de alcance general" (pág. 21), es decir, aquellas potenciales causas, socialmente forjadas, que son recurrentes y tienen claros efectos sobre las posiciones, oportunidades y condiciones de mejoramiento de la calidad de vida, así como en los resultados de eventos significativos de la transición a la adultez.

Tilly identifica dos mecanismos que causan la desigualdad persistente: "explotación y acaparamiento de oportunidades", y dos mecanismos que refuerzan lo anterior: "emulación y adaptación" (pág. 22). Para este caso, el acaparamiento de oportunidades opera cuando "los miembros de una red categorialmente circunscripta ganan acceso a un recurso que es valioso, renovable, está sujeto a monopolio, respalda las actividades de la red y se fortalece con el modus operandi de ésta" (Ibíd.: 23). Es decir, éste respondería a una causa de la desigualdad persistente, pues perdura a través del tiempo al incorporar las categorías pareadas en la organización social.

Jean-Paul Fitoussi y Pierre Rosanvallon (2006 [1997]) permiten ampliar la mirada respecto a las desigualdades basándose en el caso de la sociedad francesa. Proponen la noción de "desigualdades dinámicas" adicional a la de desigualdes estructruales. Sostienen que en nuestros días las desigualdades se han ampliado modificándose con ello la respectiva percepción en la sociedad; es decir, existen nuevas desigualdades al interior de las categorías en las trayectorias individulaes. Por ejemplo, aquellas relacionadas al desempleo o a la limitación en el acceso y permanencia en la educación, lo cual tendrá un efecto importante en lo correspondiente a ingresos y acumulación de patrimonio. Esto, según los autores, tendría 
una afectación directa en la identidad del individuo, la estructura de la sociedad y en las representaciones que tienen de la estructura social.

A partir de este punteo de ideas teóricas, se pueden definir tres factores que podrían ser determinantes al momento de decidir quién efectivamente obtiene un cupo en una IESP. Me refiero a: 1) las condiciones sociales de origen y la acumulación de capital, 2) la desigualdad categorial y el acaparamiento de oportunidades, y 3) desigualdades dinámicas al interior de las categorías en las trayectorias individulaes. Es sobre estos factores que esta investigación procura hallar evidencia y construir explicaciones.

Tomando el caso del proceso de ingreso y admisión a la educación superior pública como un reflejo de las estructuras sociales que generan desigualdad en el Ecuador, se puede observar en el actual Reglamento del SNNA, que el puntaje obtenido en el ENES posibilita al aspirante a postular por un cupo de carrera seleccionando entre una y cinco opciones en orden de su preferencia durante el proceso de postulación. Los cupos se distribuyen y asignan en relación ordinal según el puntaje obtenido en el ENES, el número de cupos reportados por las IESP y el orden de selección de las opciones de carrera. Es decir, la asignación de cupos se distribuye en orden a partir de la nota más alta hasta cubrir el número de cupos asignados por las IESP en cada carrera. La paradoja está en que en un proceso cuyos principios son la igualdad de oportunidades y la meritocracia, de manera no intencional, la calificación obtenida en el ENES podría devenir en una estratificación del destino académico y en una estratificación socioeconómica de las y los jóvenes. Parecería ser que las trayectorias y destinos de las y los postulantes se distribuyen en cuatro vías, lo que podría afectar su potencial movilidad social, (Vid. Gráfico 1):

En un primer estrato están las y los jóvenes que son parte del grupo GAR, quienes obtienen dos tipos de incentivos: económico y de oportunidades. Económico puesto que las y los aspirantes que aceptan el cupo GAR reciben el 50\% de una remuneración básica unificada mientras dura el curso de nivelación para asegurar dedicación exclusiva a este proceso preparatorio.

Los incentivos de oportunidades se observan en primera instancia en la posibilidad de cursar una nivelación de alto rendimiento con una duración máxima de 11 meses. Este curso de nivelación tiene el propósito de prepararlos para aprobar los procesos de admisión e ingresos propios de cada centro de excelencia a nivel mundial. En segundo lugar, esta preparación les abre la posibilidad de estudiar en el exterior con una beca completa del gobierno ecuatoriano. Finalmente, quienes cursen sus estudios en el extranjero tienen la obligación de retornar al país y permanecer por el doble del tiempo que duró su beca, lo que implica mayores posibilidades de acceder al mercado laboral con una oferta económica superior. 
1- En segundo lugar están las y los jóvenes cuyo puntaje les permite obtener un cupo en la IESP y carrera aspirada como primera opción, lo que les posibilita a ingresar a un curso de nivelación de carrera con una duración de 4 meses y medio o a la carrera deseada luego de aprobar el examen de exoneración (EXONERA), esta posibilidad implicaría una mayor probabilidad de ingresar, permanecer y culminar la carrera elegida por la o el joven, y posteriormente, acceder al mercado laboral con una mejor oferta económica.

2- En el tercero están las y los jóvenes cuyo puntaje los posibilita a obtener un cupo en una carrera diferente a la deseada, con lo cual tienen la opción de aceptar un cupo en la fase de postulación o repostulación o esperar hasta un máximo de dos ENES consecutivos para aplicar con el mismo puntaje obtenido. Caso contrario, deberán volver a postularse en el siguiente examen con la intención de obtener un puntaje superior que le permita ingresar a la carrera deseada. En el caso de aceptar el cupo de una carrera no deseada, y de pasar el proceso de nivelación vía EXONERA o nivelación de carrera, existe la probabilidad de que la o el joven: i) ajuste sus intereses hacia la carrera elegida para no postergar su ingreso a la educación superior, ii) ingrese a la carrera pero que no finalice sus estudios por deserción, o iii) intente cambiarse de carrera, siempre que sea a una que esté dentro de la misma área de conocimiento a la que obtuvo el cupo y que su puntaje esté dentro del mínimo indicado por el SNNA para esa carrera e IESP. En este caso, el ingreso al mercado laboral y el acceso a mejores ofertas salariales estarían asociados a la obtención o no del título académico.

3- En una cuarta posición están las y los jóvenes que no obtienen un cupo para continuar sus estudios superiores, con lo cual podrían: i) aceptar un curso de nivelación general con una duración de 2 meses, ii) rechazar el curso y esperar seis meses para rendir un nuevo ENES, iii) en el caso de tener recursos económicos, buscar una opción de IES privada, y en el caso de no tener recursos económicos, buscar un cambio de perspectivas de futuro inmediato y mediato. En este caso, el ingreso al mercado laboral y el acceso a mejores ofertas salariales están más limitadas pues la falta de credenciales educativas en la sociedad ecuatoriana influye en el acceso y/o precariedad laboral. 
Gráfico 1

Esquema analítico de la transición de la educación de bachillerato a la superior en Ecuador

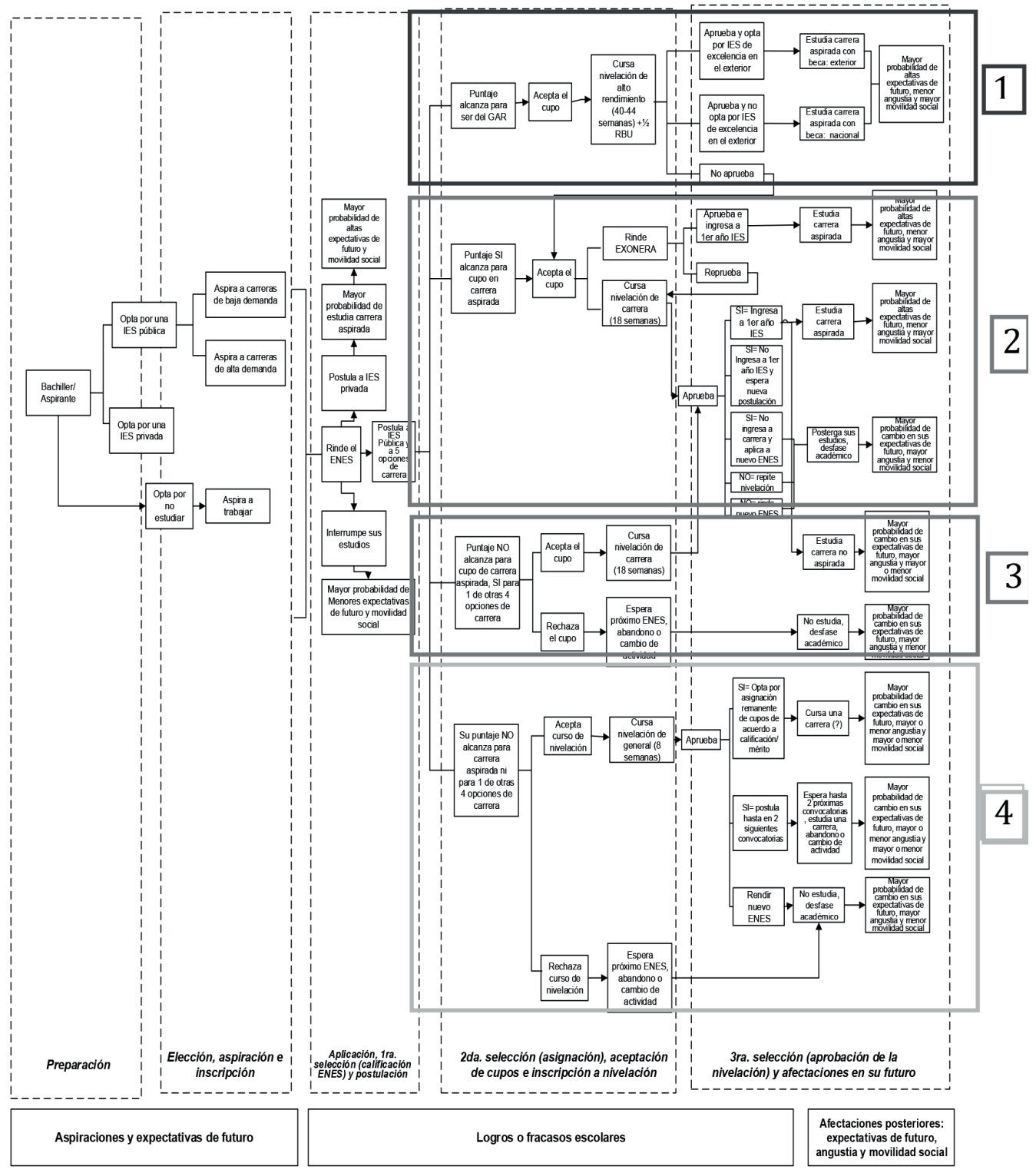

Fuente: Reglamento del Sistema Nacional de Nivelación y Admisión -SNNA-, 2013 Elaboración y adaptación: propia. 


\section{ESTRATEGIA METODOLÓGICA}

La estrategia empírica empleada en esta investigación es mixta, cualitativa y cuantitativa, con el propósito de producir y analizar datos sobre la relación entre desigualdades sociales y oportunidades educativas que aborden las experiencias de jóvenes que intentan ingresar a las IESP en el Ecuador. Constituye una forma de acceder a la comprensión y explicación de la reproducción de la desigualdad social en la sociedad ecuatoriana, los factores y los mecanismos que operan, los posibles efectos en los logros académicos, los cambios generados en las expectativas de futuro y movilidad social, y las acciones que realizan las y los jóvenes para canalizar sus emociones.

\section{Gráfico 2 Estrategia metodológica}

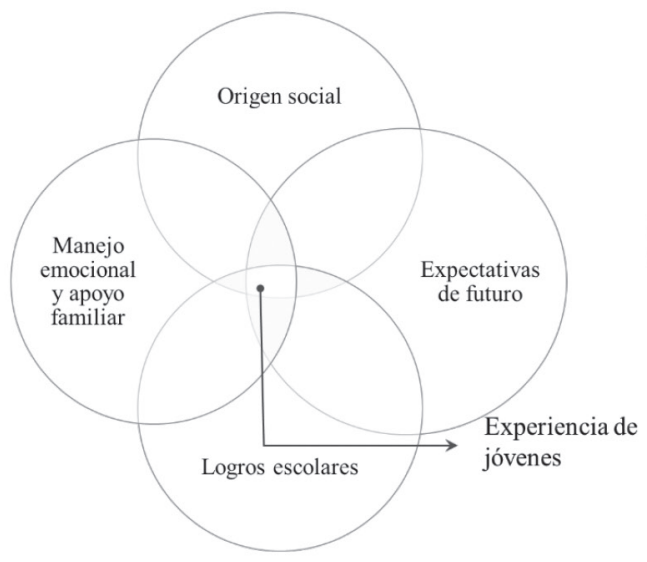

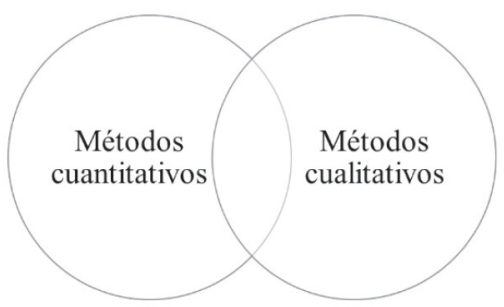

Estrategia empírica mixta

Para el análisis cuantitativo se contempla el análisis de la información de los perfiles sociales y resultados de 65.000 jóvenes que rinden el examen a partir de una base de datos de la encuesta de contexto del segundo ENES del 2012, base levantada por el SNNA durante el proceso de admisiones a las IESP. Además, se incluye la aplicación y análisis de 250 cuestionarios estructurados a una muestra no representativa, intencional y teóricamente informada que genere indicadores de las variables estudiadas. Además, esta es una estrategia para tener la autorización y los datos de contacto posterior para realizar el respectivo seguimiento a su proceso.

El análisis etnográfico se centra en abordar cómo las y los jóvenes experimentan el proceso de potencial ingreso a la universidad, cuáles fueron los resultados de su ENES y las estrategias posteriores para transitar este proceso. Para esto, se emplearon dos métodos de investigación: a) observación participante en cursos de nivelación (y 
otros espacios) que toman las y los aspirantes durante del proceso de inscripción, evaluación y nivelación,; y, b) entrevistas semiestructuradas y relatos de vida.

\section{ALGUNOS RESULTADOS PRELIMINARES: APROXIMACIONES A DETERMINANTES EN LA TRANSICIÓN DE ESTUDIOS DE BACHILLERATO A SUPERIORES EN ECUADOR}

Algunos resultados iniciales del análisis de los datos dan cuenta de que el SNNA podría reflejar la estructura social de desigualdades de la sociedad ecuatoriana y que una de las consecuencias no intencionales de su aplicación es que podría estar generando mecanismos de desigualdad social, específicamente a través del acaparamiento de oportunidades entre los grupos que han estado históricamente favorecidos en la sociedad ecuatoriana, haciendo evidente que en el proceso de ingreso y admisión toman fuerza las desigualdades sociales de posiciones y de oportunidades.

Los datos analizados hasta el momento parecerían mostrar que las desigualdades de los grupos históricamente excluidos persisten. En el caso de estudio, se puede observar que quienes están en una situación de mayor desventaja son mujeres, montubios, de estado civil viudo y quienes no dedican tiempo al estudio. El potencial perfil de un estudiante del grupo GAR es hombre, mestizo, de estado civil casado y que dedica entre 1 y 3 horas de estudio. En suma, tendrían mayores posibilidades de ser parte del grupo GAR los hombres, en tanto su puntaje máximo fue de 994, mientras que el de las mujeres fue de 978 puntos. Esto reforzaría la idea de la desigualdad categorial en tanto son desigualdades socialmente reconocidas cuyas consecuencias se plasman en la exclusión que deviene en una desigualdad persistente. En este caso, existe mayor probabilidad de que las mujeres sea una minoría dentro del grupo GAR y, en consecuencia, de tener menores posibilidades de movilidad social ascendente a través del mecanismo de la educación e inserción laboral con una mejor retribución económica. En suma, parecería ser que la diferencia de puntajes entre hombres y mujeres marcaría una diferencia sustancial en sus trayectorias de vida.

Otra de las consecuencias no intencionales de la reforma de las políticas de educación superior está el surgimiento de un nivel intermedio entre la finalización del bachillerato y el ingreso a las instituciones de educación superior, a saber: los cursos preuniversitarios, centros que están al margen de la regulación por parte de la institucionalidad estatal vinculada a la educación, del modo que no existe una regulación de los costos, características, acreditación o estándares de calidad.

En la misma línea, parece ser que existen fallas en la implementación que de no ser adecuadamente tratadas, pueden devenir 
en un impedimento a la hora de presentarse a rendir el examen y, sobre todo, de afianzar el acaparamiento de oportunidades en grupos socialmente privilegiados. Un ejemplo de ello es el acceso a internet en el hogar, puesto que debido a la afluencia de jóvenes que buscan rendir el examen, la actual plataforma tecnológica se satura, lo que ubica en mejores condiciones a quienes tienen internet en su hogar durante el día y noche.

Como se ha mencionado, el acaparamiento de oportunidades podría ubicar a ciertos aspirantes en ventajas que resultan determinantes al momento de trazar su futuro inmediato, mediato y de largo plazo. En este sentido, las emociones y su manejo están diversamente distribuidas en función de las condiciones socioeconómicas y relacionales, reproduciéndose la desigualdad y siendo un factor que influye en las decisiones y acciones que tendrán en sus trayectorias de vida. Es así que entre los efectos secundarios de las recientes reformas de las políticas de educación superior, estarían las asociadas a la generación de otras desigualdades y afectaciones en los trayectos de vida, que los ubica en distintas condiciones socioeconómicas, generándose una estratificación entre las y los jóvenes ecuatorianos.

Según lo antes analizado, a partir de los resultados obtenidos en el ENES y el proceso de ingreso y admisión a la educación superior, podrían surgir dos tipologías a partir del criterio obtención de cupo para cursar estudios superiores en una universidad pública. Surge una sub división al momento de incluir el criterio de las expectativas. A partir de aquí, se puede observar algunos posibles destinos de las y los postulantes lo que podría afectar su potencial movilidad social, sus condiciones socioeconómicas y su ubicación en un determinado estrato socioeconómico:

1- Quienes obtuvieron un cupo y que son parte del grupo GAR, superando las expectativas al momento de iniciar del proceso y ampliando sus aspiraciones a futuro.

2- Quienes obtuvieron un cupo en la IESP y carrera aspirada como primera opción, alcanzando las expectativas planteadas en un inicio y manteniendo las aspiraciones a futuro.

3- Quienes obtuvieron un cupo en una carrera diferente a la deseada, en cuyo caso no se alcanzaron las expectativas iniciales y que por diversas razones ajustan sus decisiones ante los resultados.

4- Quienes no obtuvieron un cupo para continuar sus estudios superiores, cuyas expectativas no se cumplen y, por consiguiente, deben buscar estrategias para enfrentar este escenario. 
Si bien cada una de las vías implica en sí misma trayectorias de vida diferentes, se puede observar cómo los resultados del proceso de ingreso y admisión a la educación superior tendría efectos inmediatos, mediatos y de largo plazo que generaría desigualdad entre las y los jóvenes.

En suma, y para terminar, se podría plantear como hipótesis que existen interdependencias entre distintos ejes de desigualdad que afectan al ingreso de los aspirantes a las IESP, estos son: la clase, quienes pertenecen a los sectores populares tendrían menos opciones; el lugar de residencia, los aspirantes que viven en espacios urbanos tendrían más opciones de ingresar a una IESP, en tanto la calidad de educación a la que acceden es mejor y además tendrían mayor posibilidad de acceder a cursos preuniversitarios; el género, pues en el caso ecuatoriano, habrían diferencias entre hombres y mujeres en los puntajes obtenidos.

\section{A MODO DE CONCLUSIÓN PRELIMINAR}

Se podría señalar como potencial conclusión que en la medida en que las desigualdades sociales se continúen reproduciendo, se puede generar una "clausura social" - en términos de Rosanvallon- en la que se impida la movilidad social de los grupos socialmente excluidos, siendo los grupos mejor posicionados quienes tengan mayor privilegio de concentrar oportunidades, lo cual podría ser paradójico en un sistema que se basa en la igualdad de oportunidades como principio de justicia social.

\section{BIBLIOGRAFÍA}

Bourdieu, Pierre 2001 “CCómo se hace una clase social? Sobre la existencia teórica y práctica del os grupos” en Poder, derecho y clase social (Madrid: Palimpsesto,).

Dubet, Francoise 2012 "Los límites de la igualdad de oportunidades" en Nueva Sociedad, N²39. Mayo- junio.

Dubet, Francoise 2011 [2010] Repensar la justicia social. Contra el mito de la igualdad de oportunidades (Buenos Aires: Siglo XXI).

Fitoussi, Jean-Paul y Pierre Rosanvallon 2006 [1997] La nueva era de las desigualdades (Buenos Aires: Ediciones Manantial).

Marx, Karl y Federico Engels 1998 [1848] El manifiesto comunista (Barcelona: Grijalbo/ Critica).

Olin Wright, Erik 2010 “Comprender la clase” en New Left Review N60, pp. 98-112. 
PNUD 2014 Resumen Informe sobre Desarrollo Humano 2014. Sostener el Progreso Humano: reducir vulnerabilidades y construir resiliencia (New York: PNUD).

Solís, Patricio 2012 "Desigualdad social y transición de la escuela al trabajo en la Ciudad de México". Estudios sociológicos XXX: 90, 641-680.

Solís, Patricio 2013 "Orígenes sociales, instituciones, y decisiones educativas en la transición a la educación media superior" en Revista mexicana de investigación educativa. Vol. 18, № 59, México.

SENESCYT 2013 Reglamento del Sistema Nacional de Nivelación y Admisión -SNNA-. Obtenido de: www.snna.gob.ec

SENESCYT 2014 Boletín de prensa, 6/5/2014. Disponible en: http:// www.institutobecas.gob.ec/264-estudiantes-conforman-la-sextapromocion-del-grupo-de-alto-rendimiento-gar/

SENESCYT 2014 Metodología de asignación y distribución de cupos. Disponible en: http://www.snna.gob.ec/wp-content/themes/ institucion/procesodeadmision.php\#

Tilly, Charles 2000 La desigualdad persistente (Buenos Aires: Manantial).

Weber, Max [1923] "Los tipos de dominación", "División del poder en la comunidad: clases, estamentos y partidos" y "La institución estatal racional y los partidos políticos y parlamentos modernos (Sociología del Estado)" en Economía y Sociedad (Fondo de Cultura Económica). 


\title{
JUVENTUDES Y DESIGUALDADES EN LA ARGENTINA: NOTAS PARA EL DEBATE EN TORNO A LA CONSTRUCCIÓN DE LA PROBLEMÁTICA JUVENIL
}

\author{
Vanina van Raap*
}

\section{PRESENTACIÓN}

El presente artículo se propone aportar al debate sobre juventud(es) y desigualdad(es) a partir de analizar críticamente la emergencia de la "cuestión juvenil" y los diagnósticos hegemónicos sobre los cuales se construye el "problema" que aqueja a los jóvenes.

En primer lugar, se presentarán algunas reflexiones en torno al concepto de juventud y se analizará la cuestión de los jóvenes como objeto de políticas públicas. Algunos de los interrogantes que guiarán este primer desarrollo son: ¿qué se entiende por colectivo juvenil? ¿Cuáles son las características "comunes" de la "juventud", para que puedan ser ubicados y nombrados como parte de un mismo colectivo? ¿Es posible pensar en una problemática juvenil que afecta a todos los jóvenes de la misma manera?

* Quiero agradecer muy especialmente a Fabiana Espíndola por sus valiosos aportes en los talleres de la Escuela, por su generoso intercambio y por sus comentarios/sugerencias al presente artículo. , y a mi querida compañera Sofía Inés Munárriz por la revisión final del documento.

** Universidad de Buenos Aires, Facultad de Ciencias Sociales. 
En segundo lugar, se intentarán reconstruir los diagnósticos sobre los cuales se construye el "problema" que aqueja a los jóvenes. De este modo, se propone analizar las discursividades que entran en juego a fin de "deconstruir" la problemática juvenil y los procesos de producción de dichos problemas sociales, revelando también cómo otros diagnósticos alternativos quedan excluidos de la lectura política del fenómeno y, en última instancia, de la construcción de la realidad misma.

Por último, se presentan algunas reflexiones finales que abren interrogantes sobre la orientación de las políticas públicas para jóvenes en la Argentina y se intenta aportar al debate respecto de la(s) función(es) -reales y potenciales- de la política social en la reproducción del orden social y en su capacidad para cuestionarlo y transformarlo.

\section{UN PUNTO DE PARTIDA: LA NOCIÓN DE JUVENTUD}

Con frecuencia, se piensa a la juventud como una etapa del ciclo de vida de las personas que media entre la infancia y la vida adulta, y se considera a los jóvenes como un colectivo o grupo definido por un determinado rango de edades. Sin embargo, distintos análisis coinciden en señalar el problema que se produce al entender a "los jóvenes" como un grupo socialmente definido por una mera identidad etaria y a la juventud como una categoría de tránsito (Bourdieu y Wacquant, 1995; Martín Criado, 2000; Reguillo, 2003; Chaves, 2009).

Siguiendo a Pierre Bourdieu y Louis Wacquant, numerosos objetos reconocidos de la ciencia -y entre ellos el propio concepto de juventud-han sido producidos socialmente dentro y mediante un "trabajo colectivo de construcción de la realidad social" (1995:179). Es entonces a través de la historia social de los objetos o problemas de investigación que se puede rastrear el origen de las categorías conceptuales utilizadas $^{1}$, para repensarlas y re-significarlas.

En esta misma línea, Bourdieu procura mostrar que el hecho de hablar de los jóvenes como si fuesen una unidad social con intereses

\footnotetext{
1 Martín Criado rastrea la matriz histórica de lo que posteriormente será la categorización social de "Juventud" en el Emilio de Rousseau a partir de la noción de "adolescencia" como espacio de paso de la irracionalidad infantil a la racionalidad adulta. Analiza, también, cómo la estructuración en clases de edad difiere enormemente de unas sociedades a otras (Martin Criado, 2000). Siguiendo a Reguillo (2003), la juventud, como la conocemos hoy, es una invención de la posguerra. Al tiempo que se cobraba forma el nuevo orden internacional, un discurso jurídico, un discurso escolar y la industria de posguerra reivindicaban la existencia de niños y jóvenes como sujeto de derecho y, de estos últimos asimismo como sujetos de consumo. Las sociedades del primer mundo alcanzaban una insospechada esperanza de vida, con impacto en el tiempo de vida socialmente productivo, lo cual implicaba que la inserción de las nuevas generaciones de relevo tendía a posponerse. Para un desarrollo sobre estas cuestiones, se recomienda ver G. Levi y J C Schmitt (1996), Historia de los jóvenes.
} 
comunes constituye en sí mismo una manipulación: sólo a través de un abuso tremendo del lenguaje pueden colocarse en un mismo concepto universos sociales que no tienen nada en común. Por tal motivo, señala que, "el lenguaje plantea un problema particularmente dramático al sociólogo: constituye, en efecto, un inmenso depósito de preconstrucciones naturalizadas $y$, por tanto, ignoradas en tanto tales, las cuales funcionan como instrumentos inconscientes de construcción" (Bourdieu y Wacquant, 1995: 180).

El concepto "juventud”, según Margulis (1996), es una palabra cargada con diferentes evocaciones y significados y puede conducir a laberintos del sentido si no se tienen en cuenta la heterogeneidad social y las diferentes modalidades con que se presenta en la sociedad y en la cultura la condición de joven. Ello no implica desconocer que el concepto es un objeto privilegiado de producción y consumo cultural (Margulis y Urresti, 1999) y, especialmente en este trabajo, también un objeto de política social. Desde esta perspectiva, la identificación de "los jóvenes" a partir del factor cronológico sin considerar las diferencias en las condiciones materiales, sociales, culturales y simbólicas que, a igual edad, se producen entre los jóvenes de distintos sectores sociales, géneros, etnias, regiones, culturas, genera la ilusión de la juventud como un grupo social homogéneo.

Complementando estos enfoques y siguiendo las propuestas de Mannheim (1928), Bourdieu (1990) y Lewkowicz (2004), Vommaro (2014) destaca la utilidad del enfoque generacional a partir de entender a la juventud como una producción socio-histórica y cultural, situada y relacional. En este sentido, desde una perspectiva socio-histórica, Martin Criado (2005) sostiene que para que se produzca un "relevo generacional" es necesario que se den cambios en las condiciones de existencia que provoquen que los individuos sean "generados" de una manera distinta, constituyendo de este modo "generaciones". A partir del enfoque generacional, Vommaro (2014a) señala cómo se logra correr la mirada del enfoque más clásico vinculado con el recorte etario, definido por criterios biológicos o demográficos, así como también se produce un desplazamiento del enfoque de la juventud como una etapa de moratoria social hacia el reconocimiento de aquello que las juventudes son en el presente.

Vinculado con la idea de moratoria, se suele definir a los jóvenes como aquellos que tienen porvenir, "son el futuro" y, desde este enfoque, la juventud es pensada como un estatus temporal, transitorio "medio niño-medio adulto", o bien "ni niño, ni adulto", definido fundamentalmente por aquello que no son. Pero entonces, cabe al menos preguntarse por aquello que sí son los jóvenes y, en este marco, siguiendo a Bourdieu (1990) podemos decir que son quienes definen el porvenir (Bourdieu, 
1990) y son, también, quienes están construyendo/forjando el presente.

De modo que se reconoce un consenso en relación con que "la juventud no es algo en sí, sino que se construye en el juego de relaciones sociales" (Chaves, 2009). En este sentido, no habría hechos que permitan afirmar que la juventud implica una homogeneidad de base. Los jóvenes son un grupo social heterogéneo con marcos de acción que se vinculan directamente con las condiciones materiales, sociales y culturales que fragmentan al conjunto de la sociedad (Przeworski, 1982).

Dentro de este marco, se sostiene que la diferenciación social es actualmente uno de los dispositivos centrales en la configuración de los modos de construcción y reconocimiento de las distintas juventudes. Ello implica debatir acerca del reconocimiento (y aceptación) de las diferencias, así como también reconocer cuándo estas diferencias cristalizan en profundas desigualdades. Es por ello que el estudio de las juventudes no puede dejar de lado las particulares condiciones materiales y simbólicas de existencia asociadas a los procesos que moldean la estructura social y la desigualdad económica.

\section{LA CONSTRUCCIÓN DE LA “CUESTIÓN JUVENIL”}

La problemática juvenil y la precariedad laboral ocupan el centro de gravedad de la cuestión social

(PREJAL OIT, 2007: 4)

La definición de los jóvenes como objeto de políticas sociales y laborales es un desafío relativamente reciente para los gobiernos del mundo. Debido a cuestiones tales como la extensión de los problemas de desempleo y desafiliación social, la "exclusión juvenil" ha logrado instalarse en las agendas públicas y se ha posicionado en los diversos ámbitos de la vida social.

Intentando esbozar una breve reconstrucción del surgimiento de políticas públicas orientadas a la juventud, se puede vincular este hecho, entre otras cuestiones, con la emergencia de determinadas "tribus urbanas" desafiliadas de la vida ciudadana, así como con una particular y supuesta relación existente entre los jóvenes y determinados riesgos sociales y epidemiológicos. Muy rápidamente, el HIV, la anorexia y la drogadicción, así como sus supuestos efectos negativos (delincuencia, violencia juvenil, etc.), se constituyeron en temas de agenda pública, pasando a ser en todos los casos los jóvenes las principales "víctimas" (y "causantes") de estos problemas (Salvia et al., 2006; van Raap, 2010).

La proclamación por parte de las Naciones Unidas del Año Internacional de la Juventud (1985) estimuló a los gobiernos a planificar diferentes 
actividades con motivo de su celebración. En el caso de la Argentina, el contexto nacional de la recuperación democrática permitió y fomentó la participación de grupos políticos con representación juvenil (Balardini et al., 2005). Es en ese momento cuando comenzaron a crearse áreas gubernamentales (en los niveles local, provincial y nacional) que se identifican una serie de necesidades específicas de este segmento poblacional y, en este contexto, cabe destacar la creación de la Dirección Nacional de Juventud ${ }^{2}$.

En ese marco, emerge el interés por dotar a la "juventud" -en tanto grupo social vulnerable- de derechos jurídicos especiales, así como de una formación educativa acorde a los cambios productivos, sociales y culturales que ocurrían a escala nacional y global, en función de facilitar su integración a la sociedad (Salvia et al., 2006). Cabe destacar que las preocupaciones centrales ligadas a la intervención del Estado sobre la cuestión juvenil fueron fundamentalmente la necesidad de formar "buenos" ciudadanos para la democracia, así como trabajadores capaces de asimilar los cambios tecnológicos. En síntesis, una juventud sana, productiva, útil y educada en aquellas formas de pensar funcionales a la vida en sociedad.

Un aspecto que resulta interesante problematizar es justamente la emergencia de la "cuestión juvenil" en la esfera pública, su apropiación, utilización e institucionalización desde el ámbito gubernamental. Más concretamente, ¿por qué la juventud se ha convertido en una cuestión? ¿cómo determinados problemas de grupos específicos se convierten en temas públicos, en cuestiones socialmente problematizadas?3.

Tal como señalaran Bourdieu y Wacquant (1995), ello implica que un determinado problema privado, particular y singular se convierta en un problema público, legítimo, digno de ser discutido -la "esfera pública" en términos de Habermas- y hasta en un problema "oficial", que es el campo particular que nos interesa analizar.

La hipótesis planteada sostiene que cuando las desiguales condiciones estructurales generadas por el sistema quedan invisibilizadas

2 En la Argentina, en 1986, se crea un área de juventud dependiente de la Secretaría de Desarrollo Humano y Familia, antecedente de la Subsecretaria de la Juventud (1987), donde funcionó la Comisión Interministerial de la Juventud. En 1989, la subsecretaría pasó a ser Dirección Nacional de Juventud (DINAJU). Para seguir el derrotero de la Dirección Nacional de Juventud, en la actualidad nuevamente con rango de Subsecretaría Nacional de Juventud (191/2014), ver el trabajo de Núñez, Vázquez y Vommaro (2015).

3 Es importante aclarar que este fenómeno no responde a una demanda específica de la población afectada, sino que la identificación del problema ha entrado en la agenda como una preocupación social (es decir, del conjunto de la sociedad frente a una perspectiva fatalista del futuro ante la realidad presente de las nuevas generaciones) sustentada por los analistas especializados (académicos y políticos), así como también por los medios de comunicación, que terminan por legitimar la intervención estatal y lograr el consenso del conjunto de la población. 
(o estratégicamente ignoradas), se crea un campo fértil para la emergencia de cuestiones particulares de grupos específicos que tienen sus propias problemáticas. Recuperando la expresión de Donzelot (2007), surge una sospecha: la "cuestión juvenil" también ha sido una "estratégica invención".

Entonces, ¿cuál es la problemática que afecta a los jóvenes que permite construir sobre este "colectivo" una "cuestión" que se encuentra en el centro de la cuestión social? ¿Está dado por la "condición juvenil" y los riesgos sociales asociados a la "juventud"? ¿O tal vez sean las desigualdades sociales que cristalizan en un segmento (los pobres, los más desaventajados) del heterogéneo colectivo que conforman los jóvenes?

Martin Criado plantea que la idea de juventud resulta fundamental porque "servirá para sustituir la clase social por la clase de edad tanto en (...) la definición de los "problemas sociales" como en los dispositivos de intervención. (...) De esta manera, se legitiman todas las políticas de intervención que propongan, como solución al "problema juvenil”, una serie de medidas de aculturación y formación de los sujetos a intervenir que, por supuesto, dejen intacta la estructura política y económica" (Martín Criado, 2005: 2).

De este modo se puede apreciar cómo, junto con la emergencia de la cuestión juvenil, la problemática de la desigualdad se fragmenta y deviene en una multiplicidad de cuestiones específicas (pobreza, exclusión, desempleo, precarización, etc.) que afectan a grupos/comunidades particulares (pobres, excluidos, desocupados, etc.), entre los que se encuentran los jóvenes y que se ubican, tal como se sostiene desde PREJAL OIT (2007), en el "centro de gravedad de la cuestión social".

Desde este esquema conceptual, se puede (re)pensar el surgimiento de la "cuestión juvenil" y la institucionalización de la problemática a partir de áreas gubernamentales específicas para jóvenes, la emergencia de expertos/especialistas técnicos y académicos (llamados en la jerga "juvenólogos” ${ }^{4}$ y la aparición de políticas públicas focalizadas en los jóvenes "que no estudian ni trabajan", "en situación de pobreza" o "en situación de vulnerabilidad social".

\section{POLÍTICAS, DIAGNÓSTICOS Y DISCURSOS EN TORNO A LA PROBLEMÁTICA JUVENIL}

Las preguntas sobre el objeto de la política social conducen a cuestionamientos acerca del modelo de política social dentro del cual estos sujetos, constituidos en objetos (objetivados), son intervenidos.

4 En esta misma línea, Eduardo Bustelo advertía acerca de los "niñólogos” y la construcción de campos profesionales y carreras personales en nombre de la defensa de los derechos de la infancia. 
Se parte de una comprensión de las políticas sociales como productoras y reproductoras de un orden social desigual (Oszlak y O' Donnell, 1984). Para evitar caer en ciertos reduccionismos ${ }^{5}$, cabe agregar: sobre el cual estas operan y al cual continuamente modifican.

De acuerdo con Danani (2005), se entiende a las políticas sociales como aquellas intervenciones del Estado que producen y moldean las condiciones de vida y reproducción de la vida de distintos sectores y grupos sociales. Para la autora, dado que las políticas sociales intervienen en el proceso de reproducción social, participan también en el proceso de constitución de las clases sociales, ya que generan cierto tipo de estratificación social (y no otro). Asimismo, deben ser consideradas en el centro mismo del orden social y, en consecuencia, el sentido y orientación de las mismas deben ser analizados en términos de los distintos proyectos socio-políticos en pugna. En este sentido, también cumplen una función específica en la producción de discursos referidos a la sociedad (Danani, 1996).

Entonces, nos interesa particularmente analizar la producción de discursos de las políticas focalizadas en los jóvenes y, para ello, consideramos central analizar los diagnósticos a partir de los cuales se construye el problema.

En la Argentina, desde mediados de la década de los 90 y en un contexto de aumento del desempleo, la pobreza y la ampliación de las brechas sociales, los jóvenes fueron un grupo particularmente afectado por estos procesos. De este modo, el reconocimiento de la problemática juvenil se instaló con fuerza en la agenda de las políticas sociales: el doble atributo de ser joven y ser pobre se conformó como un tema privilegiado de los discursos profesionales y gubernamentales en materia de política pública.

En este marco, cabe reflexionar sobre la noción de los "peligros" asociados a la juventud y, más específicamente, a la juventud en contextos de pobreza. Es decir, si "ser joven" representa en sí mismo una serie de riesgos, "ser joven y ser pobre" sería un riesgo aún mayor asociado a los jóvenes en situaciones de pobreza. Entonces, si los jóvenes pobres son la expresión/manifestación de

5 Soldano y Andrenacci (2005) nos advierten sobre ciertas visiones polares que vacían de complejidad a las políticas sociales. De una parte, un enfoque reduccionista de la política social se limita a comprenderla como un conjunto de herramientas técnicas de gestión compensatoria o reparadora del funcionamiento macroeconómico. Por otra parte, otra visión simplista de la política social como mecánicamente dependiente de las estrategias de legitimación socioeconómica del modo de producción capitalista. Según los autores, esta visión la reduce a un conjunto de herramientas de funcionalización económica de sujetos, disciplinamiento de grupos de riesgo y neutralización de conflictos sociales, limitando de este modo la discusión al modo en que esta responde a los imperativos de reproducción sistémica. 
estos peligros, ¿no es necesario regularlos y normalizarlos de alguna manera?

Esta población -definida a partir de una serie de parámetros operativos- pasó a constituirse en un segmento vulnerable sobre el cual el Estado debía emprender acciones de capacitación profesional y participación comunitaria, con el fin de facilitar su inclusión competitiva en un mercado laboral cada vez más exigente, lo cual se consideraba condición necesaria para salir de la pobreza (Salvia et al., 2006). En este marco, y en un contexto más amplio de transformaciones del Estado, comenzaron a desarrollarse programas focalizados de formación profesional y acciones especiales para la prevención y recuperación a la vida social de los jóvenes en situación de riesgo.

A partir de los diagnósticos presentes en las políticas sociales para jóvenes, financiados en su mayoría por organismos internacionales de crédito (BID, Banco Mundial, BIRF), se desprende que el problema que presenta el "colectivo juvenil" está ligado fundamentalmente a las dificultades de permanencia en el sistema educativo y a las trabas de acceso al mercado de trabajo, derivando en situaciones de vulnerabilidad y exclusión. De esta forma, emerge en la agenda pública, mediática y social la problemática de los jóvenes ni-ni: "ni estudia-ni trabaja".

Estos diagnósticos entienden que las principales causas del desempleo en los jóvenes son la falta de experiencia laboral previa y la falta de conocimientos requeridos por el mercado, por no haber concluido la educación básica obligatoria o porque estos conocimientos no son adecuados para ocupar un puesto de trabajo. En este sentido, se parte del supuesto de que el problema se debe a un desajuste entre la oferta y la demanda; los jóvenes no contarían con las competencias laborales necesarias para ocupar los nuevos puestos y perfiles que demandan las empresas, sumado a las dificultades que presentan para adaptarse al mundo del trabajo.

Esta lectura del fenómeno justificó el diseño de programas de formación, capacitación y entrenamiento laboral para jóvenes pobres centrados en el paradigma del capital humano ${ }^{7}$. En el campo de las

\footnotetext{
6 Recordemos que los jóvenes también habían sido definidos por aquello que no son "ni niños-ni adultos". El enfoque generacional viene a romper con esa mirada de la juventud, reconociendo aquello que son y las condiciones que hacen posible un relevo generacional.

7 Para la Argentina, se hace referencia a los programas "Jóvenes con Más y Mejor Trabajo" dependiente del Ministerio de Trabajo, Empleo y Seguridad Social y al Programa Nacional de Inclusión Juvenil (2004-2006), dependiente del Ministerio de Desarrollo Social de la Nación. En la década de los 90, diagnósticos similares se presentaron en una diversidad de programas como el Programa Nacional de Pasantías para la Reconversión (1994); el Programa Aprender (1995-1997), el Programa de Apoyo a la Reconversión Productiva (PARP) y el Programa de Apoyo a la Productividad y Empleabilidad de los Jóvenes (PA-
} 
políticas sociales y de empleo para jóvenes, el correlato de la teoría del capital humano cristaliza en la noción de "empleabilidad". Esta noción, impulsada por los organismos internacionales de crédito y utilizada por funcionarios, intelectuales y técnicos, surgió a mediados de los años 80 , si bien como señala Bourdieu (2002), se trata de vocablos aparentemente sin origen. Su uso extendido a través de un discurso que se presenta como un saber técnico, un lenguaje en apariencia "neutral" de quienes diseñan las políticas públicas, ha logrado posicionar este nuevo concepto en el centro de los programas de capacitación y empleo orientados hacia la población joven.

Desde estos diagnósticos, se sostiene que los sujetos activos deben encargarse y esforzarse para desarrollar ciertos conocimientos, habilidades y saberes que les posibilitarían ingresar y permanecer en el mercado de trabajo. Las técnicas y estrategias privilegiadas en el marco de estos programas son, como sostiene la teoría del capital humano, la educación y la formación profesional entendidas como una inversión (en tiempo y dinero) que deben realizar los sujetos para mantener(se) su condición de "empleables". Desde este diagnóstico, el capital humano es percibido como el modo de lograr la inclusión y este hecho refiere, desde el propio discurso ideológico de la teoría, a la decisión individual, voluntaria y racional de los sujetos de capacitarse o no capacitarse.

Morduchowicz (2004) advierte que esta visión del problema justifica y legitima teóricamente los diferenciales de ingresos en la sociedad, en la medida que ellos se originan en las decisiones individuales por adquirir determinado grado de instrucción. Es preciso detenerse en este punto porque aquello que está en juego es la lectura sobre el origen, las causas de la desigualdad. O, como bien señala Dubet (2011), aquello que se pone en juego es el modelo de justicia social según cuáles sean las desigualdades que se pretenden revertir.

De este modo, las desigualdades estructurales ligadas a posicionamientos socio-económicos diferenciales se enmascaran en la figura del "vago" que ha decidido de manera individual y más allá del contexto familiar, social, económico, regional y cultural en el cual se encuentre, alejarse de la escuela, abandonar su educación, no capacitarse en forma continua. Así, el mito de la igualdad de oportunidades (Dubet, 2011), el cual se apoya en el mérito personal y la responsabilidad individual, acaba por legitimar el pasaje de la responsabilidad del plano colectivo al plano individual, respecto de la situación social en la que cada sujeto se encuentra: un proceso de individualización de la culpa social.

Retomando los debates de la Escuela Juventud y Desigualdades, cabe al menos una reflexión sobre la conceptualización estigmatizante

PEJ), entre los cuales se destaca el Proyecto Joven. 
y con gran impacto mediático respecto de la problemática de los ni-ni. Existe consenso entre investigadores y analistas respecto de la "inflación" estadística en relación con este "colectivo" ya que muchas veces quienes no estudian ni trabajar tienen responsabilidades en el hogar (madres/padres y/o cuidadores de otros familiares), o bien se encuentran imposibilitados de trabajar o, incluso, lejos de ser los sectores más desaventajados, es posible encontrar dentro de este colectivo jóvenes de clases acomodadas gozando de un "año sabático" luego de finalizar la escuela media ${ }^{8}$. Y, por supuesto, también encontramos a los jóvenes más desfavorecidos que no encuentran oportunidades en el mercado de trabajo y que tampoco logran insertarse en un sistema educativo que los excluye. En este marco, y para este grupo en particular, dentro de los comúnmente llamados ni-ni, cabría pensar si no resulta más adecuado llamarlos jóvenes marginalizados, sin oportunidades educativas y laborales, la "masa marginal" en términos de Nun (1999). Es decir, si bien es necesario reconocer la problemática que afecta a estos jóvenes, es también fundamental entenderla adecuadamente: no es un atributo propio de las juventudes no tener educación o no tener trabajo. Sin embargo, este discurso estigmatizante cumple una funcionalidad política e ideológica bien interesante: de este modo, la responsabilidad recae en los sujetos. Tal como sostiene la teoría del capital humano, son los jóvenes quienes deben ocuparse por adquirir aquellos conocimientos y capacidades valorados en el mercado, re-direccionando la mirada hacia cuestiones individuales e ignorando aspectos que refieren a las causas más profundas y estructurales del problema.

Investigaciones recientes sobre la relación entre los jóvenes, la educación y el mercado de trabajo brindan evidencias acerca de que, si bien el problema del desempleo juvenil es de magnitud relevante, la causa de ello no es la condición de "ser joven" sino factores asociados a la desigual estructura social (Bonfiglio, Salvia, Tinoboras, van Raap, 2008; van Raap, 2010, Tinoboras y van Raap, 2014).

De esta manera, los problemas de desafiliación educativa, desempleo y precariedad laboral juvenil parecen ser el resultado combinado de una trama compleja de condiciones sociales estructurales. El acceso a una educación y a un empleo de calidad parece depender fundamentalmente de un sistema social que genera trayectorias desiguales para los jóvenes según sus recursos socioeducativos, origen familiar y otros factores de discriminación étnica, sexual o residencial. Si esto es así, el

8 Para un análisis de los distintos discursos sobre los "nini", véase la Tesis de Doctorado de Claudio Comari "Examen de validez teórica y empírica del concepto "jóvenes nini" o "generación nini" en la Argentina del Siglo XXI. Instituto Nacional de Estadísticas y Censos, 2015. 
mercado laboral no operaría de manera segmentada en desventaja de los jóvenes en general, sino sobre determinados grupos -así como en el interior de otros sectores-. A su vez, estas condiciones familiares y personales tienden a reproducir de manera ampliada la segmentación de la oferta laboral juvenil. No todos los jóvenes pueden continuar estudios secundarios o superiores, ni acceder -cuando logran mantenerse en el sistema educativo- a igual calidad de formación: por una parte debido a la falta de recursos para invertir en educación y, por la otra, debido a la mayor urgencia o necesidad de emancipación o de generar ingresos para el hogar.

Las oportunidades juveniles en materia educativa, laboral, social y cultural muestran en forma persistente un carácter segmentado, producto de una estructura socio-económica desigual y polarizada. Si bien la inserción social de los jóvenes presenta rasgos particulares, los progresos y retrocesos en materia de inclusión educativa y laboral responden en primera instancia a las condiciones generales de desarrollo e inclusión que presenta el sistema económico y social en su conjunto.

\section{REFLEXIONES SOBRE LA (¿RENOVADA?) ORIENTACIÓN DE LAS POLÍTICAS DE JUVENTUD}

Para finalizar, cabe introducir una reflexión sobre la conceptualización de la cuestión juvenil y las intervenciones sobre este "colectivo" durante la última década en la Argentina. Luego del estallido de la crisis social, política y económica de diciembre del 2001, se han puesto en evidencia los efectos de las políticas neoliberales implementadas durante los 90 sobre el conjunto social. A partir de entonces, pero fundamentalmente desde el 2003, se han producido cambios en la orientación de las políticas de Estado que llevan a algunos autores a hablar de contra-reformas y a sostener la tesis del resquebrajamiento de la hegemonía neoliberal (Danani y Hintze, 2010) 9 .

En este marco, es preciso interrogarse y abrir el debate acerca de los alcances, logros y limitaciones de este proceso de re-orientación de las políticas de Estado en lo que respecta a la cuestión juvenil: ¿En qué medida se puede hablar/pensar en una re-conceptualización de la problemática juvenil? ¿Cuáles han sido los cambios discursivos que se

\footnotetext{
9 Danani y Hintze (2010) introducen la denominación de contra reformas ya que sostienen que participan en un proceso de producción de sentido que se apoya en la atribución de significados negativos a las políticas neoliberales de la década de los 90. Por otra parte, las autoras se refieren a un resquebrajamiento de la hegemonía neoliberal al considerar que los grupos que se volvieron hegemónicos durante los años noventa han visto afectada su capacidad de imponer lo que se denomina sentido común, razón por la cual hablan de una "crisis de hegemonía", pero señalan que en cambio han conservado mucho más la capacidad de realización de sus intereses.
} 
plantean en las intervenciones sociales para jóvenes? Y, finalmente, ¿̇en qué medida el resquebrajamiento del discurso neoliberal y las consecuentes transformaciones en las políticas públicas han logrado (si es que lo han hecho) desplazar la mirada fuera del paradigma del capital humano que tiende a responsabilizar fundamentalmente a los jóvenes por la situación en la cual se encuentran?

Uno de los elementos destacados a la hora de re-significar el accionar de las políticas sociales está vinculado con las practicas discursivas, con los deslizamientos en el uso del lenguaje por parte de las autoridades gubernamentales. En este sentido, durante la última década se han implementado políticas de corte "universal" que responden a un paradigma totalizador orientado hacia el conjunto social y vinculado con la noción de derechos sociales. Este aspecto resulta central ya que se ha producido un desplazamiento desde un modelo de política social compensatorio y residual, donde prima el enfoque de las juventudes en riesgo y los jóvenes como potenciales peligros para el funcionamiento y el orden social, hacia un enfoque distinto donde el joven es un sujeto de Derecho. Desde esta perspectiva, la política no es un "beneficio" sino precisamente un derecho al cual el joven accede en su condición de ciudadano (aún cuando en la práctica se trate de programas de amplia cobertura pero que, en rigor, no alcanzan al conjunto de la ciudadanía) ${ }^{10}$.

En cuanto a las políticas que en épocas pasadas se hubieran denominado focalizadas, el lenguaje post (¿anti?) neoliberal prefiere nombrarlas utilizando expresiones como "políticas particulares para grupos con necesidades específicas". En las políticas de empleo y formación orientadas a los jóvenes se dejan de utilizar términos fuertemente vinculados con las políticas de flexibilización laboral, como por ejemplo las "pasantías", para hablar ahora de "prácticas calificantes en ambientes de trabajo"11.

10 El primero de estos programas que introduce la noción de derechos fue el Programa Jefes de Hogar hacia el año 2002. Asimismo, la Asignación Universal por Hijo para la Protección Social (AUH) y el recientemente creado Programa de Respaldo a Estudiantes Argentinos (PROG.RES.AR) también se plantean en términos de garantizar y ampliar el acceso a derechos sociales. Por su parte, la AUH exige un conjunto de requisitos para poder acceder al beneficio. Se argumenta su carácter "universal" en virtud de la complementariedad que esta asignación tiene con el Régimen de Asignaciones Familiares otorgadas a través del sistema contributivo. Incluso el PROG.RES.AR también plantea que se trata de una asignación económica "universal" aun cuando para poder acceder a ella es necesario cumplir una serie de condiciones en relación con la situación laboral del joven y la de su grupo familiar, más allá del rango de edad que delimita la población a la cual se orienta en programa. Según un estudio del CEIL-PIETTE, el 51\% de los jóvenes del país dentro de ese rango de edad están en condiciones de participar del Progresar. www.progresar.anses.gob.ar

11 El programa PROGRESAR cuyo objeto es el de generar oportunidades de inclusión social y laboral a través de acciones integradas que permitan capacitar a los jóvenes entre 18 y 24 años de edad, con el objeto de finalizar la escolaridad obligatoria, iniciar o 
En cuanto a los diagnósticos oficiales de las políticas para jóvenes, si bien se define el problema como en la década de los 90 vinculado con la "exclusión juvenil", las causas parecen estar menos "individualizadas" y el fenómeno se comprende en términos multi-causales, donde las condiciones sociales tienen un lugar preponderante en los diagnósticos acerca de la "cuestión juvenil". Por ejemplo, según el texto del decreto de creación del PROG.RES.AR: Que la problemática juvenil tiene múltiples facetas que deben ser contempladas a la hora de abordar la temática, evitando caer en categorizaciones simplificadas y estigmatizantes (...). ${ }^{12}$

Más allá de los deslizamientos discursivos y en consonancia con el enfoque que promueve la OIT para toda la región latinoamericana, aparece desde las autoridades gubernamentales el reconocimiento del carácter estructural del problema y el rol central que le cabe al Estado en el desarrollo de políticas adecuadas ${ }^{13}$. En este marco, resulta interesante recuperar unos breves pasajes del discurso presidencial en el cual Cristina F. de Kirchner anunció el lanzamiento del PROG.R.ES.AR:

La historia a la que hemos llegado aquí es una historia larga, empezó (...) con la Asignación Universal por Hijo, (...) estamos consolidando un sistema de seguridad social, en la República Argentina, sin precedentes en nuestra historia y que reconoce al sujeto de derecho humano, desde la panza de su madre hasta los 24 años.” (... “... estos chicos son los hijos del neoliberalismo, estos hijos son los chicos que sus padres no tenían trabajo o que lo perdieron, que no fueron educados en la cultura del trabajo y el esfuerzo y que necesitan de la presencia del Estado precisamente para salir adelante.

Discurso de Cristina F. de Kirchner, 22 de enero de $2014^{14}$

\footnotetext{
facilitar la continuidad de una educación superior y realizar experiencias de formación y/o prácticas calificantes en ambientes de trabajo (Decreto 84/2014 http://www.infojus. gov.ar/legislacion/decreto-nacional-84-2014-)
}

12 Decreto de creación 84/2014 del Programa PROGRESAR. http://www.progresar.anses. gob.ar/institucional/resolucion-decreto-9

13 Según el documento de la OIT (2012) "estamos frente a un problema estructural. El crecimiento económico es determinante pero no suficiente para resolverlo. El empleo juvenil requiere de medidas específicas para hacer frente a los retos que se plantean. Al Estado le corresponde el papel de generar las políticas adecuadas, y los interlocutores sociales, a los empleadores y trabajadores, apoyarlas con decisión." http://www.ilo.org/ americas/oficina-regional/direcci\%C3\%B3n-regional/WCMS_178354/lang--es/index.htm

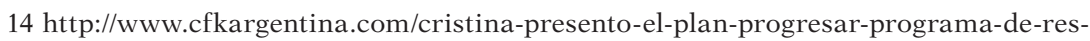
paldo-a-estudiantes-argentinos/ 
Como se puede observar en ese breve fragmento, resulta evidente el posicionamiento ante la racionalidad neoliberal y la tensión entre distintos proyectos sociopolíticos en pugna. Pareciera también haber un reencuentro entre la cuestión política y la cuestión social en el cual, a partir de un conjunto de intervenciones sociales, se plantea abiertamente una racionalidad que responde a un proyecto político y se opone a otro.

También ese pasaje nos habla del modelo de seguridad social que se promueve, con un Estado activo y presente en el reconocimiento de los derechos de los ciudadanos (no solo de los jóvenes sino del conjunto de la ciudadanía).

Sin embargo, hay indicios que parecen indicar que la noción de "empleabilidad", acuñada en el seno de la teoría del capital humano, sigue ocupando aun el centro del discurso de esta política, constituida en derecho para las juventudes. Como señalaba Bourdieu (2002), hay nociones que forman parte de aquella "vulgata planetaria" que se vuelven (y se pretenden posicionar como) a-temporales, a-políticas, aideológicas.

Una sospecha es que el "sentido común" que promueve el discurso del capital humano aún está arraigado en las racionalidades políticas y técnicas post neoliberales, que reniegan del mercado como el mejor asignador de recursos para restituir el rol del Estado en la redistribución del ingreso, pero que, al mismo tiempo, pregonan la mejora de la empleabilidad y la cultura del esfuerzo personal como estratégica solución para lograr la tan deseada inclusión social.

Una esperanza es que, tal como señalara Dubet (2011), el deseo de priorizar un modelo que tienda a disminuir las desigualdades entre sujetos que ocupan distintos posicionamientos sociales no implique negar o dejar de promover la igualdad de oportunidades y reconocer, en este contexto, los méritos y esfuerzos personales. Claro está, dentro de un enfoque solidario de justicia social que promueva, ante todo, la igualdad de posiciones.

\section{COMENTARIOS FINALES}

Considerando que la forma en la cual se define un problema o una cuestión - la cuestión juvenil en este caso - condiciona, determina y delimita las posibles estrategias para su abordaje y resolución, en estas páginas se procuró reflexionar acerca de la emergencia de la "cuestión juvenil" y la racionalidad presente en los principales diagnósticos gubernamentales que han dado lugar a la intervención sobre este "colectivo", en particular en materia de promoción de la inclusión social a través de dos canales privilegiados de integración: la educación y el empleo.

En cuanto a los diagnósticos que sirvieron de base para el diseño de políticas públicas de juventud, se ha destacado el lugar hegemónico 
ocupado por la teoría del capital humano y se ha reflexionado acerca de cómo a través de esta teoría se pretende, de modo engañoso, plantear una determinada "solución" cuya consecuencia real es invisibilizar el carácter estructural de la desigualdad, al considerar que los sujetos individuales tienen la capacidad, potencialidad y responsabilidad de mejorar sus condiciones de vida y posicionamiento en la estructura social.

El sistema de calificaciones y credenciales opera movilizando las oportunidades para un segmento de la población, sea esta joven o no. Pero no para todos. De este modo, aspectos o características intrínsecas del propio sistema son atribuidos (y en muchos casos percibidos por los propios sujetos) como déficits personales. El trasfondo es la sospecha del "engaño" presente en los diagnósticos. En esta sociedad globalizada, la adquisición de un mayor capital humano es considerada como un mecanismo potenciador de oportunidades. Sin embargo, en el marco de un sistema excluyente con oportunidades diferenciales según posicionamientos sociales, son justamente aquellos sujetos más necesitados los que no logran re-significar/capitalizar ese "capital humano" y movilizarlo en sus proyectos de vida (Sen, 1995).

Retomado el interrogante planteado acerca del rol que asumen las políticas de juventud en cuanto a las posibilidades que tienen para operar sobre las desigualdades sociales y promover mecanismos de inclusión social, creo firmemente en la capacidad transformadora de las políticas públicas para la construcción de una sociedad menos desigual y más justa, según sean los principios que las orienten.

Siguiendo a O'Donnell (1984), las políticas sociales son productoras y reproductoras de un orden social. La posibilidad de operar sobre las desigualdades está presente tanto en la reproducción del orden social como en los intentos por modificar, aunque sea en parte, el "estado de las cosas", las brechas sociales, las desigualdades persistentes. Si se considerara efectivamente que los problemas que afectan al heterogéneo colectivo que conforman los jóvenes no se encuentran en el espacio íntimo de las decisiones y elecciones individuales (más o menos acertadas) que realizan los sujetos y que, por el contrario, es necesario enmarcar estas problemáticas en una trama compleja de condiciones estructurales, ¿cuáles serían entonces los espacios que pueden (y deben) ocupar las políticas públicas considerando el origen estructural de estas desigualdades sociales? Definir y asumir esos espacios como propios del campo de la política social es un desafío urgente.

A modo de cierre -que posibilite y fomente la apertura de nuevos debates- se plantean unas reflexiones sobre algunos posibles (y sobre todo deseables) caminos para las políticas de juventud. En primer lugar, es fundamental una fuerte voluntad política orientada a reducir las brechas sociales entre los jóvenes (y el conjunto de los sujetos) que ocupan 
distintos posicionamientos en la estructura social. En segundo lugar, es preciso también comprender y pensar las políticas públicas de juventud de manera integral, desde una perspectiva de derechos, lo cual implica reconocer a los jóvenes no como beneficiarios de políticas sociales sino como sujetos con derechos que deben ser garantizados por el Estado. Asimismo, es clave reconocer la diversidad de la categoría juventud, que se expresa en todos los jóvenes que son susceptibles de habitarla (Guemureman, 2009). También, se requiere priorizar un enfoque solidario de justicia social que promueva la igualdad de posiciones (Dubet 2011). Y dentro de este enfoque como marco general, promover la redistribución real no sólo del ingreso sino también de las oportunidades, sean estas educativas, laborales, culturales, sociales, políticas, etc.

Estos enfoques se han hecho presentes, de diversas maneras y con variadas intensidades, en un conjunto de políticas dirigidas hacia la juventud en los últimos años ${ }^{15}$, a partir de lo cual se puede pensar que, efectivamente, ha tenido lugar un proceso de re-conceptualización de la problemática juvenil y de las intervenciones sociales orientadas hacia los jóvenes. En el actual contexto de un nuevo escenario político, si bien se pregona la continuidad de varios programas diseñados durante la gestión anterior, como por ejemplo el PROGRESAR, la orientación de las políticas de juventud, a priori, no resulta tan evidente.

Finalmente, resulta clave tener presente el mito que se esconde detrás de la igualdad de oportunidades cuando se presenta como único modelo de justicia social (entre tantos otros mitos y verdades construidas). Es una responsabilidad compartida no desconocer el carácter político, ideológico e histórico de las diferentes verdades, diagnósticos y conceptos que pretenden explicar y operar sobre la realidad. Más precisamente, en el marco de un nuevo contexto político y económico, parece ser fundamental que los investigadores, los hacedores de políticas, los propios jóvenes y todos los actores sociales involucrados sean capaces de discutir los diagnósticos y asumir el rol central de las políticas públicas en la construcción de una sociedad más justa e inclusiva.

15 Núñez, Vázquez y Vommaro (2015) marcan un cambio en la orientación de las políticas de juventud a principios del año 2007, coincidente con el cambio de autoridades en la DINAJU, tendientes a la promoción de un enfoque participativo e integral. También, señalan un nuevo cambio en el enfoque de la DINAJU, hacia el 2010 (año del fallecimiento del ex presidente Néstor Kirchner) que, desde entonces, pasó a ser leído fundamentalmente desde el Kirchnerismo, como la "vuelta" de la juventud a la política y a la militancia. Asimismo, el lanzamiento del PROGRESAR en el 2014, centrado en un enfoque de derechos y garantías sociales, plantea nuevos horizontes y oportunidades para las juventudes en la Argentina y establece un umbral desde donde pararse a pensar/discutir las futuras políticas de juventud. 


\section{BIBLIOGRAFÍA}

Andrenacci, L. y Soldano, D. 2005 “Aproximación a las teorías de la política social a partir del caso argentino” en Andrenacci (comp.) Problemas de política social en la Argentina contemporánea. (Buenos Aires: Editorial Prometeo9.

Balardini, Dávila León, Paciello, Souza, De Freitas 2005 Políticas locales de Juventud. Experiencias en el Cono Sur (Buenos Aires: Friedrich Ebert)

Bonfiglio, Salvia, Tinoboras, van Raap 2008 "Educación y trabajo: Un estudio sobre las oportunidades de inclusión de los jóvenes tras cuatro años de recuperación económica” en Salvia (comp.) Jóvenes promesas: Trabajo, educación y exclusión social de jóvenes pobres en la Argentina (Buenos Aires: Miño y Dávila).

Bourdieu, Pierre 1990 La juventud no es más que una palabra (México: CNCA/)Grijalbo).

Bourdieu, Pierre y Wacquant, Loïc 1995 Respuestas por una antropología reflexiva (México: Grijalbo).

Bourdieu, Pierre 2002 "La nueva vulgata planetaria” en Pensamiento y acción (Buenos Aires: Libros del Zorzal.

Castel, Robert 1991 "De la exclusión como estado a la vulnerabilidad como proceso" en J. Affichard y J. B. Foucault, Justice sociale et inegalites (s/d: Paris).

Chávez, M. 2009 “Investigaciones sobre juventudes en la Argentina: estado del arte en ciencias sociales 1983-2006” en Papeles de Trabajo. Revista electrónica del Instituto de Altos Estudios Sociales de la Universidad Nacional de General San Martin. Año 2. Numero 5, Buenos Aires.

Comari, C 2015 "Examen de validez teórica y empírica del concepto ‘jóvenes ni-ni’ o 'generación ni-ni’ en la Argentina del Siglo XXI. Tesis de Doctorado. Instituto Nacional de Estadísticas y Censos.

Danani C 1996 "Algunas precisiones sobre la política social como campo de estudio y la noción de población objeto” en Hintze S. (organizadora) Políticas Sociales. Contribución al debate teóricometodológico. Sec. De Cca. Y Tca. De la U.B.A.

Danani C. 2005“la construcción sociopolítica de la relación asalariada: obras sociales y sindicatos en América Latina, 1960 2000”. Tesis doctoral en Ciencias Sociales. Mimeo, Bs. As. 
Danani, C. 2008 “América Latina luego del mito del progreso neoliberal: las políticas sociales y el problema de la desigualdad” en Revista Ciências Sociais Unisinos, № 44.

Danani, C .y Hintze, S. 2010 "Reforma y contra-reformas de la protección social: la seguridad social en la Argentina en la primera década del Siglo" en Revista Reflexión Política, año 12, N²4, Colombia.

Donzelot, J. 2007 La invención de lo social: ensayos sobre la declinación de las pasiones politicas (Buenos Aires: Ediciones Nueva Visión).

Dubet, F. 2011 Repensar la Justicia Social (Buenos Aires: Siglo XXI Editores).

Foucault, M. 2005 "Naissance de la Biopolitique" en Annuaire du Collége de France, 79 année, Histoire des systémes de pensée, année, 19781979.

Margulis, M. 1996 La juventud es más que una palabra. Ensayos sobre cultura y juventud (Buenos Aires: Editorial Biblos).

Margulis, M. y Urresti, M. 1999) La segregación negada. Cultura y discriminación social (Buenos Aires: Biblos).

Martín Criado, E. 1993 "Estrategias de Juventud. Jóvenes, estudios, trabajos, clases sociales”. Tesis Doctoral, Facultad de Ciencias Políticas y Sociología, Universidad Complutense de Madrid.

Martín Criado, E. 2000 “Juventud” en Román Reyes (Dir): Diccionario Crítico de Ciencias Sociales. Publicación Electrónica de la Universidad Complutense. http://www.ucm.es/info/eurotheo/ diccionario/J/index.html.

Martin Criado, E. 2005 "La Construcción de los Problemas Juveniles” en Nómadas $\mathrm{N}^{\circ} 23$. Bogotá.

Morduchowicz, A. 2004 Discusiones en economía de la Educación. (Buenos Aires: Editorial Losada).

Nun, José 1999 "Nueva visita a la teoría de la masa marginal” en Revista Desarrollo Económico N 154IDES, vol. 30, Buenos Aires.

Núñez, P., Vázquez, M. y Vommaro, P. 2015 “Entre la inclusión y la participación. Una revisión de las políticas públicas de juventud en la Argentina Actual" en Juventudes Latinoamericanas. Prácticas socioculturales, políticas y políticas públicas (Buenos Aires: CLACSO). 
Organización Internacional del Trabajo (OIT) 2013 Trabajo decente y juventud en América Latina. Políticas para la acción (Lima: OIT).

Oszlak, O. y O’Donnell, G. 1984 “Estado y Políticas estatales en América Latina: Hacia una estrategia de investigación” en Kliksberg, B. y Sulbrandt, J. (comps.) Para investigar la Administración Pública (Madrid: Instituto Nacional de la Administración Pública).

Przeworski, A. 1982 “Teoría sociológica y el estudio de la población: reflexiones sobre el trabajo de la comisión de población y desarrollo en CLACSO" en Reflexiones teórico metodológicas sobre las investigaciones en población (México: CLACSO/El Colegio de México).

Reguillo, S. 2003 "Las culturas juveniles: un campo de estudio; breve agenda para la discusión” en Revista Brasileira de Educação $\mathrm{N}^{\circ} 23$ (Mayo-Agosto 2003). Tomado de G. M. Carrasco, Gabriel Medina (comp.) Aproximaciones a la diversidad juvenil (México: El Colegio de México/ Centro de Estudios Sociológicos).

Repetto, F. y Díaz Langou, G. 2014 "Recomendaciones integrales de política pública para las juventudes en la Argentina”. Documento de Políticas Públicas/Recomendación N 137. Buenos Aires: CIPPEC.

Rodríguez, E. 2011a “Jóvenes que no estudian ni trabajan en América Latina: entre la estigmatización y la ausencia de políticas públicas" Texto presentado en la XI ${ }^{\mathrm{a}}$ Asamblea General de COPA (Confederación Parlamentaria de las Américas) y en la X Reunión Anual de la Red de Mujeres Parlamentarias de las Américas, celebradas en Quebec, Canadá, del 6 al 9 de Setiembre de 2011.

Rodríguez, Ernesto 2011b "Políticas de juventud y desarrollo social en América Latina: bases para la construcción de respuestas integradas". Trabajo presentado en el Foro de Ministros de Desarrollo Social de América Latina, UNESCO, 11 y 12 de julio.

Rodríguez, E. 2012 "Políticas de Juventud en Centro América: Construyendo un paradigma para el desarrollo social". Organización Iberoamericana de Juventudes.

Tinoboras. C. y van Raap, V. 2014 Encuesta Joven. Principales Resultados. Observatorio de la Juventud, Dirección General de Políticas de Juventud - Gobierno de la Ciudad de Buenos Aires.

Salvia, A; de Souza, D.; Schmid, S.; Scofienza, M. A. y van Raap, V. 2006 "Los jóvenes pobres como objeto de políticas públicas ¿una oportunidad para la inclusión social o un derrotero de 
manipulación y frustraciones? Ponencia presentada en el Tercer Congreso de Políticas Sociales, Buenos Aires.

Salvia, A. 2008 "La cuestión juvenil bajo sospecha” en Salvia (comp.) Jóvenes promesas: Trabajo, educación y exclusión social de jóvenes pobres en la Argentina (Buenos Aires: Miño y Dávila).

Sen, A. 1995 Nuevo examen de la desigualdad (Madrid: Alianza).

van Raap, Vanina. 2010 “Educación, políticas sociales y acceso al mundo del trabajo: un estudio acerca de la desigualdad de oportunidades para los jóvenes en la Argentina”. Tesis de Maestría en Políticas Sociales. Facultad de Ciencias Sociales, Universidad de Buenos Aires.

Vommaro, Pablo 2014a "Movilizaciones juveniles en América Latina actual: hacia las configuraciones generacionales de la política”. Trabajo presentado en ALAS. Material de la Escuela CLACSO Juventudes y Desigualdades.

Vommaro, P. 2014b "Juventudes, políticas y generaciones en América Latina: acercamientos teórico-conceptuales para su abordaje” en Alvarado, S y Vommaro, P (comp.) En busca de las condiciones juveniles latinoamericanas (Buenos Aires: CLACSO). 


\title{
TENSIONES JUVENILES COMO RESPUESTA A LA DESIGUALDAD SOCIAL
}

\author{
Viviana Boza Chacón*
}

\section{INTRODUCCIÓN. PARA COMPRENDER MEJOR}

La presente investigación surgió como una necesidad de estudio sociológico, que responde al cuestionamiento de la influencia de factores sociales, culturales, políticos y económicos que determinan la construcción de juventudes en Costa Rica, por lo tanto, es importante plantear un aporte teórico sobre la comprensión de tensiones en la diversidad/dinamismo de la estructura social, producción/reproducción de las relaciones de poder y las trayectorias juveniles que sobrellevan a las rupturas o continuidades por medio del accionar a la construcción de los roles o estereotipos de género en particular para el caso de Isla Caballo, Costa Rica.

Tres procesos, fueron los que permitieron que la investigación se realizará, el primero y como una necesidad, la caracterización de las nociones de juventud, lo juvenil y jóvenes construidas en una comunidad costera, como segundo punto, se identificó cual es la construcción

\footnotetext{
* Licenciada en Sociología de la Universidad Nacional de Costa Rica. Investigadora en el Programa Desarrollo Integral de Comunidades Rurales Costeras del Golfo de Nicoya de la Universidad Nacional. Especializada en estudios sobre juventudes, colaboradora en la elaboración de la política pública para la juventud rural en San José, Costa Rica. vivi.boza.15@gmail.com
} 
de los roles de género que reproduce el sistema educativo formal dentro de la Isla, y por último pero no menos importante, se identificó cuál es la construcción de los roles de género desde las y los jóvenes a partir del ingreso al sistema educativo formal de Isla Caballo.

Ahora bien, es necesario retomar que en Costa Rica, es evidente la existencia de realidades demarcadas cada vez más por las condiciones políticas, sociales, educativas, económicas, culturales y territoriales, lo que permitió contrastar las tensiones, tendencias y trayectorias que se tejen en la cotidianidad de las y los jóvenes costarricenses.

Para una mejor comprensión de esas realidades y dinámicas cotidianas a las cuales se enfrenta la población joven, la II Encuesta Nacional de Juventud ${ }^{1}(E N J s)$, presenta datos importantes como: más de la mitad de la población joven se encuentran en un rango de edad que va desde los 15 a los 24 años, (momento etario construido socialmente para que las personas culminen su formación profesional a través del estudio secundario y universitario), el 30\% de la población joven se encuentran en zonas rurales y en relación al ámbito educativo, muestra que el 56\% de la población joven no se encuentran estudiando actualmente. (Consejo Nacional de Política Pública de la Persona Joven, 2013: 36).

Lo anterior, plasmó un panorama más claro por el cual se logró alcanzar un análisis crítico de la perspectiva de las realidades juveniles presente en el país, facilitando a la investigación un panorama amplio sobre posibles tensiones y trayectorias que viven las y los jóvenes en el diario vivir.

Además, al incursionar por medio de la búsqueda teórica del accionar juvenil en zonas rurales-costeras, se identificó un vacío teórico y epistemológico, constatando que la mayoría de los aportes sobre juventud responden a la caracterización propuesta por Casal, donde señala tres enfoques: "juventud como etapa de vida, juventud como radicalismo y juventud como tiempo biográfico de jóvenes.” (2014: 5).

Asimismo, Bajoit (2003) señala como desde la sociología se establecen abordajes teóricos, donde el énfasis de estudio responde al interés de la relación y formación de vínculos y rupturas en la cotidianidad de la persona joven, esto pone en evidencia, como se ha construido desde el ámbito sociológico un vació en relación a las transformaciones del proyecto de vida a través de acciones ejecutadas por jóvenes en contextos particulares como lo es el territorio rural costero.

1 "La Encuesta Nacional de Juventudes posee el propósito de actualizar información sobre las personas jóvenes a nivel nacional, llevando al campo de la investigación la temática de derechos humanos, con el fin de evaluar la situación desde la perspectiva de las personas jóvenes, contribuir al conocimiento, orientar políticas y promover acciones inclusivas de las personas jóvenes en Costa Rica" (Consejo Nacional de Política Pública de la Persona Joven, 2013) 
Al visualizarse dicho vacío en los estudios de juventud, se consideró necesario el análisis del accionar y las tendencias sociales que emergen como consecuencia al capitalismo informal en zonas de exclusión social, que influyen mayoritariamente en la población joven, es decir, aquellas acciones ligadas al contexto social que producen rupturas o continuidades en el dinamismo de la estructura social, en las relaciones de poder y en las trayectorias juveniles, reforzando así la idea de Weber donde menciona que en la construcción de investigaciones se deben de “...exponer todas las conexiones de sentido irracional y racional que se encuentren condicionadas al comportamiento que influyan en la acción..." (2002: 54).

Lo anterior, expone la importancia del análisis de una realidad conformada por oportunidades de elección que permiten el accionar y trascienden en la construcción de los roles de género conllevando a posibles transformaciones en la cotidianidad de las y los jóvenes desde la ruptura de determinadas estructuras sociales a partir del ingreso al sistema educativo formal (secundaria), por lo que fue necesario preguntarse: ¿Cuáles son las rupturas y continuidades construidas en roles de género de las y los jóvenes, a partir del ingreso al sistema educativo formal (secundaria) de Isla Caballo, Costa Rica?

\section{PASOS QUE FUERON NECESARIOS}

Para este análisis de las acciones, fue necesario una metodología cualitativa, además se planteó la investigación como un estudio de caso donde el enfoque generacional, facilitó identificar aquellas rupturas y continuidades de las acciones colectivas en la población joven con respecto a la construcción social de los roles de género, donde se determinó que en este accionar de las y los jóvenes se encontraba ligado al accionar de otras generaciones, como consecuencia de la (de) construcción cultural que se vive diariamente.

Este enfoque generacional, es necesario entenderlo como aquello que permite comprender relaciones que se encuentran más allá de lo que es la acción en tres tiempos: pasado, presente y futuro (Infantino, 2013), por consiguiente, lo generacional permitió atender el proceso de (de) construcción social del accionar de las generaciones, al evidenciar las realidades excluyentes en las cuales se encuentran inmersos las y los jóvenes, y además, comprender el cómo y por qué de la adscripción identitaria.

La delimitación en la investigación se vio dividida en dos aspectos el primero, lo geográfico considerando que Isla Caballo se encuentra en el Golfo de Nicoya, Costa Rica, aproximadamente a $12 \mathrm{~km}$ del puerto de Puntarenas, mide alrededor de $7 \mathrm{~km}$ de un extremo al otro (Elizondo, 2005). Posee alrededor de $4 \mathrm{Km} 2$ de superficie y en sus cerros más altos cuentan con una altura menor de 200 m.s.n.m. (Láscarez, 2012). 


\section{Figura 1.}

\section{Ubicación geográfica de Isla Caballo}

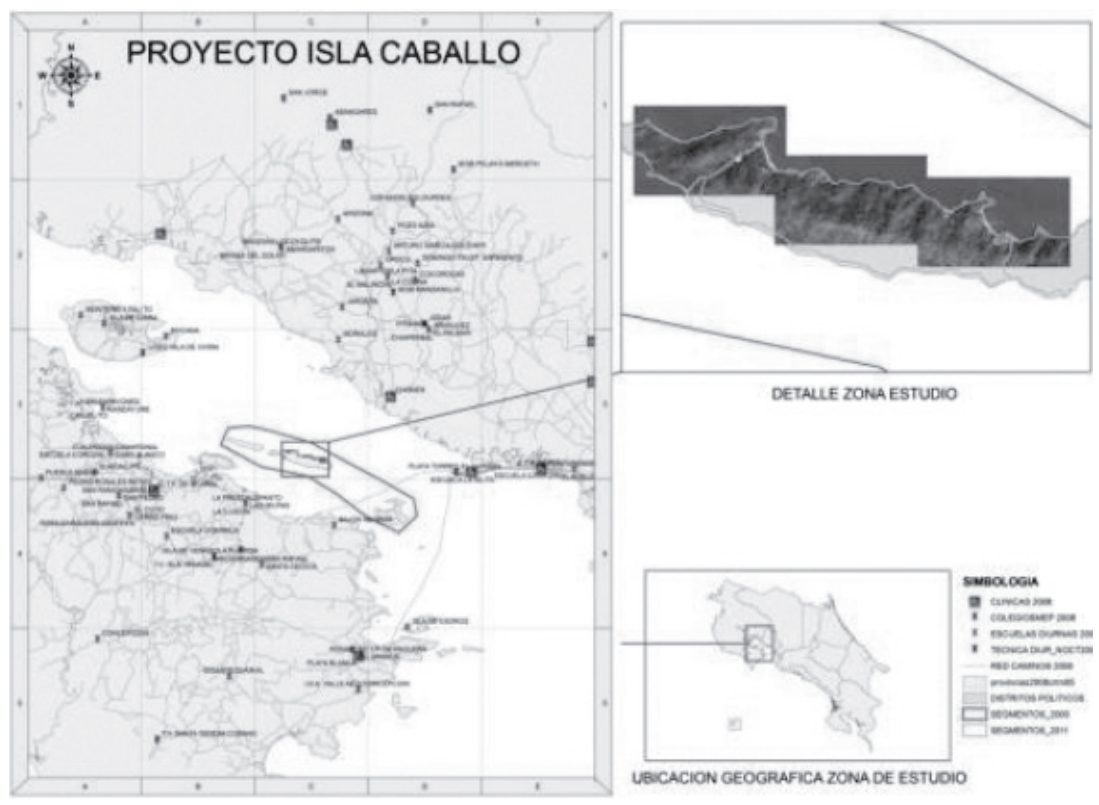

Fuente: Elaborado por John Boza Araya, año 2011.

La segunda delimitación es la poblacional, donde es importante rescatar que la población joven para el presente estudio, no parte de una caracterización ni delimitación etaria, por lo contrario, se consideró pertinente plantear una identificación sociocultural basada en el contexto socio-histórico de la Isla.

La población se organizó en dos grupos, uno de estudiantes y otro, no estudiantes, esta división se estableció con el fin de un mejor análisis de la información por medio de la comparación de las acciones, significados, códigos y símbolos, además se encontró fundamentada en la influencia de la apertura del sistema educativo formal secundario por parte del MEP a la comunidad de Isla Caballo.

Se consideró como suficiente la participación de un total de 12 jóvenes, seis hombres y seis mujeres lo que facilitó la caracterización por sexo a través de entrevistas a profundidad, además se realizaron entrevistas semi-estructuras a cuatro informantes claves de la comunidad y por último se utilizaron entrevistas a profundidad a tres docentes del centro educativo de secundaria, tanto para las y los jóvenes, informan- 
tes claves y docentes el número de entrevistas dependiendo del principio de saturación de la información.

\section{¿QUÉ SE ENCONTRÓ? PRINCIPALES HALLAZGOS CONTEXTUALIZACIÓN SOCIO-HISTÓRICA DE ISLA CABALLO}

Para comprender las realidades de las y los jóvenes en Isla Caballo actualmente, es necesario hacer un breve recorrido por la historia a nivel local (zona de Guanacaste y Puntarenas) y nacional, dado a que para el año de 1824, Nicoya y Guanacaste se incorporan a Costa Rica, producto de una anexión política (Peréz, 2010: 17) hecho que trajo consigo un aumento demográfico y territorial para Costa Rica, además de la apertura hacia nuevos sistemas de producción.

Estos nuevos sistemas de producción, surgieron gracias a la cercanía del puerto de Puntarenas y al aumento demográfico de la población en las primeras décadas del siglo XIX, específicamente en la zona de Guanacaste y Nicoya. Estas transiciones económicas y productivas a las cuales se vio obligada la población, evidencian transformaciones históricas que como bien alude Lascarez, surgen como necesidades al desarrollo de la región, demarcadas en el siglo XX por sistemas productivos como la ganadería -principal actividad económica- que luego fueron reemplazados de manera progresiva, por consecuencia de la decadencia del sector agro y la facilidad que presentaba la pesca como suplidor de las necesidades de manera rápida (Láscarez, 2012).

Al estar situada Isla Caballo dentro del Golfo de Nicoya, según Láscarez la hace parte de la dialéctica de la convivencia en la cual se encuentran las y los pescadores artesanales y las empresas industriales de pesca, en donde se forma un "...aumento del riesgo y un esfuerzo del trabajo producido por una tendencia a la disminución de la remuneración en la forma de la pesca conseguida" (Láscarez, 2012), siendo así los pescadores dedicados a la pesca artesanal los más afectados consecuencia a la destrucción de fuentes de riqueza del medio natural y a la exclusión y vulnerabilidad social consecuencia a las desigualdades impulsadas por la globalización.

Esa dialéctica de convivencia, sumado al aislamiento territorial en el cual se encuentra la comunidad, sin duda producto de su caracterización como territorio isleño, afecta de manera directa la brecha de desigualdad social, estableciendo un riesgo y vulnerabilidad social aún mayor dado a que no cuentan con un acceso real de servicios básicos como lo son: salud, agua potable, electricidad.

\section{CONSTRUCCIÓN DE LAS NOCIONES DE JUVENTUD Y JÓVENES EN UNA ZONA RURAL-COSTERA}

La construcción de las juventudes y jóvenes en una zona rural-costera, se ven determinadas por sistemas opresores como lo son el patriarcado 
y el adultocentrismo, estableciendo social y culturalmente desigualdades basadas respectivamente en el género y la edad. Estos sistemas opresores -naturalizados en muchos casos- demuestran trampas epistemológicas y empíricas al momento de concebir y realizar aportes referentes a lo que es juventud y jóvenes, con una mirada desde la academia.

Esas trampas son caracterizadas por Duarte (2006: 7) como: la universalización como homogenización, estigmas del grupo social juvenil, de sus prácticas y discursos como objetivación invisilizadora, parcialización de la complejidad social como mecanismo reflexivo y por último la idealización de la juventud como objetivación esencialista.

Esas trampas epistemológicas, una vez identificadas, permiten comprender desde una postura crítica y a la vez cuestionar, los aportes que hacen alusión a las construcciones o nociones de juventudes y del accionar de las personas jóvenes desde la academia.

De esta manera, al incursionar en el accionar de jóvenes en zonas rurales-costeras, se concibió el dinamismo continuo y colectivo del accionar, enmarcado por ciertos procesos históricos y culturales que determinan la construcción de la noción social de juventud y jóvenes en la comunidad.

Por lo tanto, con respecto a la construcción de juventudes el análisis fue el siguiente:

\section{CONSTRUCCIÓN DE JUVENTUDES}

Es necesario cuestionarse ¿Siempre han existido las juventudes en la sociedad? Si bien es cierto, juventud como categoría de análisis en el ámbito académico ha estado presente desde el siglo pasado, sin embargo, hablar de juventudes como una realidad cotidiana en las sociedades o comunidades, es lo que obliga a recorrer la historia en busca de acontecimientos que demarcarán un antes y un después en la formas de construcción de juventudes en la sociedad.

Hacer referencia a la colonización como un eje de partida, es necesario dado a que este hecho histórico demarcó construcciones e imposiciones de nuevas formas de dominación de los espacios, territorios y actores sociales de las comunidades ya existentes en la región. Algunas de las estructuras impuestas durante el período de la colonización responden al sistema educativo formal, lo religioso y el consumo.

Esas estructuras marcan hitos de transición y trayectoria entre niños y adultos, induciendo a una competición entre deseos, intereses individuales y acciones colectivas, para ser considerados "dignos" de privilegios que goza únicamente el sector adulto de la población, estableciendo así relaciones verticales de poder entre quienes alcanzan esos privilegios y quiénes no. 
En la búsqueda exhaustiva de la respuesta, es evidente, que la emergencia del sistema educativo formal una vez institucionalizado pasó a ser una estructura necesaria para la reconstrucción de juventud. Por consiguiente, se puede decir que es a partir de 1820 con la expansión y las oportunidades de ingreso al sistema educativo secundario en los principales asentamientos humanos de Costa Rica, que se resignifica juventud en la sociedad de manera cotidiana.

¿Porque decir que se resignifica juventud con el sistema educativo? Al observar la lógica del sistema educativo, es evidente que fundamente su necesidad e importancia en la medida que aporta nuevos conocimientos a través de la especialización profesional, con el fin de preparar de manera idónea a personas para la ocupación laboral.

Esta especialización profesional, demarca una tardía a la inserción del mundo laboral, económicamente remunerado, lo cual permitirá el gozo de los privilegios del sector económico. Es de esa manera, que juventud, surge en la sociedad como una respuesta al retraso de inserción ocasionado por la educación al mercado laboral.

Es ingenuo, considerar que sólo existe una forma de construcción de la juventud al día de hoy, donde las realidades y contextos se conforman de múltiples formas, por esa razón es necesario hacer referencia a otro sistema que se encarga de resignificar juventud, por medio de las constantes señales, símbolos, iconos y códigos, que impone el sistema capitalista para su reproducción en las sociedades.

Podría decirse que ese sistema de resignificación de la juventud, responde a la lógica de consumo, donde diariamente se establecen estrategias específicas dirigidas a las personas jóvenes, sin importar la realidad de la que forma parte cada persona, con el fin máximo de impulsar un consumo impulsivo, donde el ser joven se determina en la manera que se obtengan esos símbolos y códigos para formar parte de la población que conforma la juventud en un territorio específico.

$\mathrm{Al}$ analizar estos dos sistemas como los encargados de la resignificación de la juventud en nuestras sociedades, es perceptible, que juventudes no siempre han existido en la sociedad, y que existen diversas formas de ser joven en los contextos de cada comunidad.

Dar respuesta al primer cuestionamiento sobre juventudes, lleva a considera que la construcción de juventud a partir del ingreso al sistema educativo secundario existe desde hace casi dos siglos en Costa Rica (191 años), no obstante, en Isla Caballo es hasta el año 2012 que en la comunidad se establece la juventud como consecuencia a la apertura del sistema educativo formal secundario, lo cual permite estudiar que la forma de construir la noción de juventud en la Isla por más de 60 años, ha sido por medio de las estructuras de consumo y el sistema religioso de la comunidad. 


\section{¿QUÉ ES SER JOVEN EN ISLA CABALLO?}

Es necesario recordar que para el presente estudio, se consideraron dos grupos de jóvenes, estudiantes y no estudiantes de la Unidad Pedagógica Rural de Isla Caballo (UPIC), eso visualizo dos perspectivas diferentes de lo que implica ser joven en Isla Caballo.

Como puntos de encuentro entre ambos grupos, se describieron un conjunto de acciones individuales y colectivas que responden a cualidades de la personalidad con respecto a las relaciones interpersonales, descritas por jóvenes como necesarias para desenvolverse en la socialización y vida cotidiana, en especial cuando se intenta establecer relaciones horizontales con la población adulta, por consiguiente, ser joven implica:

"ser una persona madura, dinámica, respetuosa, obediente a los adultos, dispuestos ayudar a los padres de familia, divertidos, llenos de energías, trabajadores y conscientes que es una simple etapa de la vida para reflexionar sobre los errores" (Andrea ${ }^{2}$, 2014).

Con la definición anterior, se pueden observar como esas cualidades descritas por jóvenes, se han desarrollado como medios de respuesta a la opresión adultocéntrica (Duarte, 2006) dentro de la comunidad, donde el ser joven, se presenta como un castigo social, que se quedará atrás, una vez que pase el tiempo y alcance cualidades del mundo adulto.

Como respuesta a lo anterior, David ${ }^{3}$ afirma que:

"cuando alguna persona joven, se sale de las características anteriores, es expuesta por una persona adulta, o por los mismos jóvenes mayores, ante la sociedad como una persona inmadura, poco trabajadora, sin intereses en la educación, catalogada automáticamente como una persona sin proyecto de vida".

Ahora bien, como puntos distantes entre estudiantes y no estudiantes, en la construcción del ser joven, se identificaron elementos importantes y fundamentales que demuestran puntos de rupturas en las formas de pensar y sentirse, ejemplo a esto se demuestra con afirmaciones como las siguientes:

2 Andrea forma parte de la investigación caracterizada como una joven estudiante, que forma parte de un grupo reigioso.

3 David forma parte de la investigación caracterizado como un joven estudiante. 


\begin{abstract}
"la educación y la edad son características necesarias del ser joven dentro de la comunidad" (Joven estudiantes).

"la educación si es importante, pero no determina que una persona sea joven o no, tampoco es determinante si estar casados o tener hijos antes de los 20 años" (Jóvenes no estudiantes)
\end{abstract}

Es también necesario resaltar, las diferencias que se tienen en cuanto a la participación política dentro de la comunidad donde se señala la importancia y además necesidad de ser tomados en cuenta, por el sector adulto:

"ser joven es poder aprender y aprovechar el tiempo de nuestra juventud aportar a la ciudadanía y poder crecer, soñar y poder ejercer mis derechos como tal para ser escuchado" Julián"

"para mi ser joven es alcanzar muchas metas a pesar que piensan que no tienen liberta de expresarte, es vivir con la mente de alcanzar metas para el futuro como persona joven" Emma 5 .

Las expresiones anteriores, demuestran y evidencias, el sentimiento, deseo y ganas que poseen un sector de la población joven, en relación a la reconstrucción del proyecto de vida como personas jóvenes de la comunidad de Isla Caballo.

\title{
TENSIONES JUVENILES A RAÍZ DE LA EDUCACIÓN
}

Es en $1969^{6}, 22$ años después de ser habitada la isla, es que surge la primera escuela de educación básica unidocente ${ }^{7}$, localizada en el sector de Playa Coronado, obligando de esta manera a una movilización de estudiantes a la escuela Isla Caballo y es hasta 1988 que en Playa Torres se da la apertura de un segundo centro de educación básica, facilitando así el acceso a la educación del segundo asentamiento humano de Isla Caballo, Playa Torres.

4 Joven hombre estudiante.

5 Joven mujer estudiante.

6 Los documentos oficiales del MEP que demuestran la creación de los centros educativos en Isla Caballo, se perdieron consecuencia a un incendio que sufrió la dirección regional de Puntarenas años atrás, por lo tanto, datos y fechas históricas han sido posible recuperarlas por medio de entrevistas a personas claves que formaron parte de la primera generación que asistió a la escuela, cuando esta fue fundada.

7 Las escuelas unidocentes se caracterizan por estar constituidas por una población menor a los 15 estudiantes, donde existe un solo profesor (a) encargado de la dirección del centro educativo y la realización de las clases. Además las clases se dan a todos los estudiantes al mismo tiempo, por lo que estudiantes del grado más avanzado, se encuentran recibiendo clases con estudiantes del primer grado. (Ministerio de Educación Pública, 2014) 
Para el año 2014, se consolida un grupo de jóvenes interesados en la educación segundaria, por lo que se da la apertura de la UPIC, en la cual se contempla educación básica general y educación secundaria.

Al plantearse, la educación secundaria como una oportunidad palpable para la comunidad, trae consigo rupturas en la cotidianidad para esas personas que deciden incorporarse al sistema educativo formal de secundaria, rupturas en muchos casos, que implican acciones, debates y luchas por parte de las y los estudiantes en los ámbitos sociales, culturales, económicos y políticos dentro de la comunidad, que marcan esta transición de familia/educación.

\section{LO GENERACIONAL EN LA EDUCACIÓN}

$\mathrm{El}$ acontecimiento o hecho social que llega a ser determinante para consolidar las tensiones juveniles, es la apertura del sistema educativo formal secundario a la comunidad, surgiendo elementos que se conforman como fundamentales para el proceso de la construcción de nuevas cotidianidades, transformaciones en el proyecto de vida y desenvolvimiento de acciones colectivas que conllevan a la organización de ciertos grupos en relación a otros, estableciendo una relación recíproca entre generaciones.

Ese sistema educativo secundario llego a la comunidad a reforzar una línea divisora entre sectores sociales y generaciones en la comunidad, estos sectores se podrían caracterizar como: a) jóvenes que estudian b) jóvenes que no estudian c) la generación que tuvo la oportunidad de estudiar d) la generación que no tuvo la oportunidad de estudiar. Está caracterización facilita comprender como surgen y se van construyendo tensiones en las relaciones tanto individuales como colectivas entre las personas de la comunidad.

$\mathrm{Al}$ abrir la UPIC esa oportunidad de continuar los estudios, sin discriminación de edad, obliga a hablar de lo generacional en la educación, como se visualiza en el siguiente gráfico: 


\author{
Gráfico 1 \\ Porcentaje de la población en la Unidad Pedagógica Rural \\ de Isla Caballo \\ según grupo de edad. \\ Población de la UPIC, según grupo de edad
}

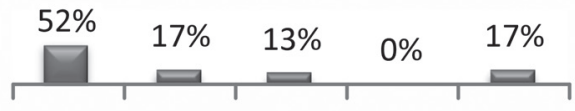

13-17 18-23 24-28 29-33 34-38
Población inscrita en la UPIC de Isla

Caballo

\title{
Edad
}

Fuente: Elaboración propia según datos suministrados por la Coordinación de la Unidad Pedagógica de Isla Caballo, año 2014

Lo anterior, si bien es cierto, demuestra que más de la mitad de la población en toda la UPIC, se encuentran en un rango de edad entre los 13 a los 17 años, no obstante, se puede observar como existe un alto porcentaje de personas que se encuentran por arriba de los 17 años estudiando al año 2014, lo cual evidencia como este centro educativo rompe con estereotipos reproducidos en la estructura educativa del sistema secundario, en el cual se supone que es a los 17 años que se debe de estar culminando con estudios secundarios.

Al no ser el sistema educativo secundario en Isla Caballo excluyente según la edad, se convierte, en un fenómeno que trae consigo, tensiones generacionales entre las y los estudiantes, consecuencia a la convivencia entre diferentes generaciones familiares, es decir, durante el desarrollo de las clases y en los recesos, deben de compartir hermanos mayores y hermanos menores, madres e hijos (as), tías y sobrinos (as) conllevando a inhibir comportamientos, sentimientos y acciones entre las generaciones familiares.

La variable del sexo según el grado académico en la UPIC, permitió una visualización más concreta de posibles rupturas que se fueran dando en la estructura social en relación a los roles de género, establecidos y naturalizados socialmente en la comunidad, por lo que se puede observar el siguiente gráfico: 


\section{Gráfico 2}

Porcentaje de la población de la Unidad Pedagógica Rural de Isla Caballo según grado académico y sexo

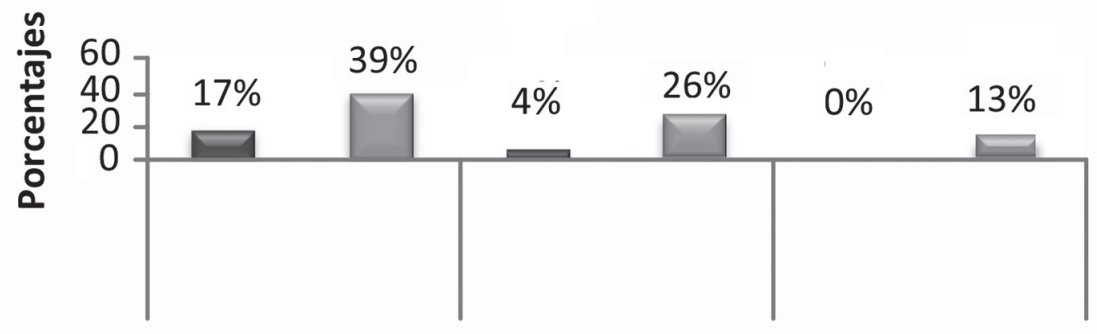

Fuente: Elaboración propia según datos suministrados por la Coordinación de la Unidad Pedagógica de Isla Caballo, año 2014

Dicho gráfico demuestra como efectivamente, más del 50\% de la población en la UPIC corresponde a mujeres, lo cual podría estudiarse como indicador de cambios y rupturas en los patrones sociales establecidos para las mujeres, sin embargo, también se podría decir, que se da en los hombres una continuidad en los roles sociales a pesar de instalarse el sistema educativo secundario en la comunidad, es decir, no se están produciendo cambios significativos a nivel colectivo en hombres, dado a que la población de hombres alcanza cerca del $20 \%$ del total de la población estudiantil.

EL SIGNIFICADO DE SER ESTUDIANTE.

El significado de ser estudiante para las y los jóvenes de la Isla, permitió observar como esta significación posee implicaciones en el accionar individual y colectivo.

"Para míla educación es una forma de vivir, tiene un gran valor para mí porque me ayudado para tener una buena educación en el colegio, en mi hogar y con el estudio puedo lograr muchas metas, me ha enseñado tantas cosas que no había entendido y me ayuda a desenvolverme" Clara ${ }^{8}$. "Vivir esa experiencia es única, ver las destrezas de la mente cuando puedes aprender, que puedes ejercer en el transcurso del que está estudiando, compartes con los compañeros, estudiar es algo importante porque le enseña a vivir un poco mejor" Pedro?.

8 Mujer estudiante.

9 Hombre estudiante. 
Lo anterior, son dos ejemplos de lo que significa para la población estudiante, tener la oportunidad de estudiar y de formar parte de ese acontecimiento histórico dentro de la comunidad de Isla Caballo, lo que a su vez demuestra el conjunto de responsabilidades individuales y colectivas que como grupo de estudiantes deben de asumir para garantizar la continuidad de la educación secundaria dentro de la isla.

También, se puede observar como el simple hecho de formar parte de la UPIC trae consigo un peso familiar, social, cultural y político en cada estudiante. Un peso que no fue elegido sino impuesto como consecuencia al anhelo individual, de que la educación es la esperanza de movilización social, una movilización que no es garantizada por la inclusión a la educación.

Igualmente, el estudio demostró que el ser estudiante ha implicado para la realidad de jóvenes estudiantes, adquirir una deuda familiar casi innegable, donde continuar con los estudios secundarios involucra la manutención económica y social de las madres y padres de familia una vez que se logre la incorporación al mercado laboral.

\section{PERCEPCIÓN ENTRE JÓVENES ESTUDIANTES Y NO ESTUDIANTES}

$\mathrm{Al}$ establecerse la educación secundaria en la comunidad de Isla Caballo, replanteó en las y los estudiantes, un cambio de rutina casi que de manera abrupta, donde debieron dejar de lado, acciones colectivas ejecutadas en conjunto con las y los no estudiantes, lo que plantea hoy día, acciones colectivas pero entre los mismos estudiantes y los no estudiantes, es decir, que establecen nuevas relaciones interpersonales.

Estas relaciones interpersonales, nacen como nuevas alternativas a la construcción de la identidad y condición juvenil, donde las costumbres y acciones colectivas, se instauran en la división de estudiantes y no estudiantes consecuencia del ingreso del sistema educativo formal en la comunidad.

\section{A) CONCEPCIÓN SOBRE LOS NO ESTUDIANTES}

$\mathrm{Al}$ construir nuevas acciones colectivas y reconstruirse la identidad juvenil sobre cierto grupo de jóvenes a raíz del ingreso al sistema educativo formal secundario, la noción sobre lo que significa la educación presenta un cambio determinante con respecto a las personas que no forman parte del sistema educativo.

Es necesario aclarar, que la mayoría de las y los estudiantes, al fundamentar las razones del por qué existen jóvenes en la comunidad que no asisten a la UPIC, fundamentas sus ideas en: 
I) "Los hombres no asisten a la UPIC, por la comodidad de manejar su propio dinero y porque ven el estudio como una pérdida de tiempo". (Ángela ${ }^{10}$ )

II) "Las mujeres no asisten a la UPIC, porque son vagas y no les interesa estudiar". (Roy $\left.{ }^{11}\right)$

Si bien es cierto, el concepto de "vagos" fue el concepto con el que mayor se atacó a la población no estudiantil, exponiendo que las acciones colectivas de este grupo de jóvenes, hombres y mujeres que no asisten a la UPIC, es consecuencia a la vivencia del día con día y a la falta de un proyecto de vida, por lo que no ven la educación como un elemento necesario para el sobrevivir cotidianamente, según la población estudiantil.

Sin embargo, cuando a este grupo de jóvenes no estudiantes se les consultó sobre el porqué no se incorporan al sistema educativo formal secundario, ahora que se tiene la oportunidad dentro de la comunidad, las respuestas generalizadas fueron:

I) "Porque debo de mantener a mis hijos y el trabajo de pescador nunca se sabe, cuando hay marea buena, por lo que tengo que ir así este en clases". Ricardo ${ }^{12}$

II) "El título de la escuela me lo regalaron, y yo no sé escribir ni leer, iría a perder mi tiempo". Leo ${ }^{13}$

III) "Tengo que cuidar a mis hijos(as) y hermanos, por lo que es imposible poder ir al colegio". Anabel ${ }^{14}$

Queda constatado, que la concepción sobre las y los no estudiantes, se encuentra posiblemente fundamentado en la repetición de discursos de la población adulta y en la falta de un real acercamiento a la realidad individual de cada persona.

B) CONCEPCIÓN SOBRE LAS Y LOS ESTUDIANTES

La percepción de la población no estudiante, con respecto a las y los estudiantes, al contrario de estos, construyen una concepción positiva

10 Estudiante de la UPIC

11 Estudiante de la UPIC

12 Joven no estudiante y pescador

13 Joven no estudiante y pescador

14 Mujer joven no estudiante 
que les caracteriza dentro de la comunidad. Al plantear esta noción se pudo generalizar en una sola propuesta:

I) "Dichos que pueden estudiar, ojala que aprovechen la oportunidad y sigan adelante porque somos muchos los que no podemos estudiar" Melissa ${ }^{15}$.

Demostrando así, una naturalización a la exclusión educativa que sufren, por el hecho de no contar con un sistema educativo que se adapte a las necesidades de la mayoría de jóvenes de la comunidad.

\section{CONCLUSIONES. NUEVOS DIÁLOGOS}

\section{LA JUVENTUD COMO REALIDAD COTIDIANA, NO SIEMPRE HA EXISTIDO.}

Es preciso recordar que el presente trabajo abordó el concepto de la construcción de juventud a partir de la educación, Alba señala que es en la extensión del sistema escolar secundario y la ampliación del tiempo de escolarización donde se encuentra la fuente histórica de la juventud como "etapa de vida" y como "categoría social" (Alba, 1975), en otras palabras, el sistema educativo a nivel de secundaria, se establece socialmente como el principal sistema institucional, encargado de constituir las pautas para la consolidación de la juventud, siempre y cuando se analice el mismo, como ese que produce un retraso o moratoria a la incorporación de las personas al mundo laboral.

Si volvemos la mira hacia el Estado, y analizamos cómo surgió la educación secundaria, entonces se podría decir que en Costa Rica, juventud existe a partir del acceso al sistema educativo formal de secundaria desde el año de 1820, momento histórico en el cual se da la expansión de centros educativos secundarios a través de la Constitución de Cádiz (Molina, 2008).

No obstante, cuando se realiza un acercamiento con la realidad de las comunidades excluidas y empobrecidas históricamente, en este caso el de Isla Caballo, se puede observar cómo se plasma una trayectoria marcada de la niñez al mundo laboral, es decir, no existe la transición social que marcaba Casal (2014), sino más bien, se culminan los estudios de educación general básica y se pasa inmediatamente al mundo laboral.

Por consiguiente, la continuidad de estudios secundarios no es prioridad y ha sido negado por más 50 años para este sector joven pesquero de Isla Caballo, dado a edades tempranas de 15 años, son considerados socialmente los varones por la población adulta, como hombres adultos, consecuencia al manejo autónomo de dinero, lo que

15 Mujer joven y ama de casa 
les facilita la independencia del principal proveedor económico de la familia, del mismo modo sucede con las mujeres jóvenes, quienes son consideradas socialmente en la comunidad como mujeres adultas a edades de 13 años, facilitando el cuido de otros familiares (niños y adultos mayores), así como la crianza de sus propios hijos.

Al no estar presente el sistema educativo formal en secundaria, facilita a que la trayectoria de la niñez a la adultez suceda casi de manera inmediata. Es aquí donde se establece que juventud en las realidades costeras de Isla Caballo, ha sido negada socialmente al no tener las y los jóvenes la opción de retrasar su inserción al mundo laboral a través de los estudios, por lo que se podría decir que juventud en Isla Caballo no siempre ha existido como un hecho real, sino que consolida por primera vez, a partir del año 2011, cuando se dan las oportunidades reales de asistir al sistema educativo formal secundario, es decir, la oportunidad de considerarse joven en Isla Caballo por medio de la secundaria, surge casi dos siglos después (191 años), de que se consolidará en Costa Rica.

Esta exclusión hace pensar de manera crítica que las juventudes han sido construidas como una necesidad para la reproducción de las opresiones que ejercen tanto el sistema patriarcal como el adultocéntrico. ¿Por qué decir que son una necesidad para la reproducción de las opresiones? Porque en la medida que estos sistemas y estructuras jueguen y construyan los procesos de transición, trayectorias y tensiones juveniles, la población joven se convierte, se podría decir, en esa necesidad para que esas opresiones funcionen en la medida que a las y los jóvenes se le es negada la educación, los derechos, la voz, las oportunidades laborales pasando a ser sujetos invisibilizados pero necesarios para la estructura social excluyente.

Con esto no quiero decir, que las y los jóvenes no cuestionen, no construyan rupturas, no crean, no sean capaces de establecer luchas, por el contrario, al momento que cuestionen, establezcan rupturas, construyan, son considerados los principales enemigos de quienes están en puestos de poder, criminalizando socialmente ellos mismos, el accionar colectivo.

\section{EXISTEN RUPTURAS EN EL PROYECTO DE VIDA, A RAÍZ DEL INGRESO AL SISTEMA EDUCATIVO FORMAL}

En la medida que hablo sobre las rupturas del proyecto de vida, para el caso de Isla Caballo, responden a esas nuevas formas de tejer las dinámicas de las estructuras y sistemas, a través de la construcción de lo cultural, social, político y económico desde una perspectiva diversa y diferente.

Estas rupturas del proyectos de vida suceden, según Bajoit, por las posibilidades reales de llegar a concretizar sus futuros proyectos, 
de acuerdo a la manera en que logren insertarse y traspasar las y los jóvenes los "canales" clásicos de integración social que viven en su comunidad, ya sea por caminos como lo son la educación, el empleo, conformación de la familia o su independencia (Bajoit, 2003).

Para la población estudiantil de Isla Caballo, se presentó de manera muy evidente, una consolidación de nuevas dinámicas en el accionar, toma de decisiones, esperanzas, deseos, anhelos y visiones de vida por las y los estudiantes tanto jóvenes como adultos, lo que implico cambios sociales y culturales en la cotidianidad de una comunidad rural- costera.

Por lo que se pudo visualizar que efectivamente, el formar parte del sistema educativo de secundaria, si conlleva y provoca cambios en el proyecto de vida de las y los jóvenes, al construir estos nuevos replanteamientos, acciones y nociones de la identidad individual y colectiva, es decir, formar parte del sistema educativo formal secundario ha sobrellevado a que se establezcan nuevas condiciones juveniles dentro de la comunidad de Isla Caballo. Esto anterior, lo refuerza Dávila al decir que "los efectos socioculturales más relevantes que acompañan la masiva incorporación y permanencia en la educación secundaria de sujetos, provoca nuevas condiciones juveniles (Davila, Ghiardo, \& Medrado, 2008: 31).

Ahora bien, no se puede decir que estas nuevas identidades y condiciones juveniles que surgen en la comunidad como consecuencia de ingresar al sistema educativo formal de secundaria, no han consolidados cambios en los roles de género de las y los estudiantes. Al estudiar el accionar de las y los estudiantes y de las y los no estudiantes, se pudo observar como si existe una influencia del sistema educativo, así como de las y los docentes de la UPIC, lo que ha provocado cambios en el accionar colectivo y las formas de pensar del sector estudiantil, con respecto a los estereotipos de género establecidos socialmente.

Además estos cambios o rupturas que se dan en la vida cotidiana de la población estudiantil, es posible que afecten no solamente a la población joven, sino también a las y los adultos, como consecuencia de ese efecto intergeneracional tan particular que se viven en Isla Caballo y que es producido por el sistema escolar.

De esta manera, cuestiono nuevamente ¿Cuál es el papel que posee la educación en las comunidades excluidas y empobrecidas históricamente por el Estado costarricense? 


\section{BIBLIOGRAFÍA}

Alba, V. 1975 Historia de la juventud (Barcelona: Plaza y Janés).

Bajoit, G. 2003 Todo cambia. Ánalisis sociologíco del cambio social y cultural en as sociedades contemporaneas (Santiago: LOM).

Casal, J. 2014 Pasado y futuro del estudio sobre la transición de los jóvenes (Buenos Aires: Flacso-Argentina).

Cascal, J. 2014 Pasado y futuro del estudio sobre la transición de los jóvenes (Buenos Aires: Flacso-Argentina).

Ceballo, J. 2010 Introducción a la sociología (Santiago de Chile: LOM Ediciones).

Consejo Nacional de Política Pública de la Persona Joven 2013 Segunda encuesta nacional de juventudes: informe de principales resultados (San José de Costa Rica: Consejo Nacional de la Política Pública de la Persona Joven).

Dávila, O. 2014 La Educación y la nueva condición juvenil (Buenos Aires: Flacso-Argentina). Davila, O., Ghiardo, F., \& Medrado, C. 2008 Los Desheredados. Trayectorias de vida y nuevas condiciones juveniles (Valparaíso, Chile: CIDPA).

Duarte, C. 2006 Discursos de resistencia juveniles en sociedades adultocentricas (San José de Costa Rica: DEI).

Duarte, C. 2013 “Acción Comunitaria con jóvenes. Desafíos generacionales" en Última

Década, 21(39), Diciembre, pp. 169-195.

Elizondo, S. 2005 Pesca y procesos de trabajo: el caso de los pescadores de Isla Caballo, el Golfo de Nicoya, Costa Rica (Ciudad Universitaria Rodrigo Facio: Universidad de Costa Rica). Tesis para optar por el grado de Licenciatura en sociología.

Infantino, J. 2013 "La cuestión generacional desde un abordaje etnográfico. Jóvenes artistas circenses en Buenos Aires" 21(39), Diciembre, pp. 87-113.

Lascarez, D. 2012 Pescadores Artesanales del Golfo de Nicoya: la disminución del recurso pesquero y la alteración socio ambiental como producto de la subsunción ideal del trabajo artesanal al capital. Tesis para optar por grado de Licenciatura en Sociología. . 
Ministerio de Educación Pública 2014 Memoria institucional 2006-2014. la educación subversiva: atreverse a cosntruir el pais que queremos (San José de Costa Rica: MEP).

Molina, I. 2008 Diálogos. Revista Electrónica de historia. Agosto 2007Febrero 2008

Recuperado el 3 de Febrero de 2014, de "Educación y sociedad en Costa Rica: 1821 al presente" (una historia no autorizada): http://historia. fcs.ucr.ac.cr/articulos/2007/vol2/7vol8n2imolina.pdf

Pérez Islas, J. A. 2014 La nueva valorización de la fuerza de trabajo juvenil (Buenos Aires: Flacso- Argentina).

Pérez, H. 2010 La población de Costa Rica 1750-2000: una historia experimental (Costa Rica: Universidad de Costa Rica).

Programa Estado de la Nación 2013 Cuarto Informe Estado de la Educación (San José: Programa Estado de la Nación).

Programa Estado de la Nación 2013 Cuarto Informe Estado de la Educación (San José: Programa Estado de la Nación).

Ruiz, J., \& Ispizua, M. 1989 La descodificación de la vida cotidiana. Métodos de investigación cualitativa (Bilbao: Universidad de Deusto).

Weber, M. 2006 Economía y sociedad (Madrid: Alianza Editorial). 



\title{
APUNTES TEÓRICOS PARA EL ANÁLISIS DE LA DESIGUALDAD SOCIAL EN AMÉRICA LATINA Y SU EFECTO EN LA JUVENTUD
}

\author{
Yannet López Verdecia*
}

“(...). Creo que hay que desnaturalizar a la juventud como algo dado para empezar a ver sus diversidades, que no siempre supone algo positivo porque también incluye las desigualdades". (Pablo Vommaro; 2015a)

\section{EL DESARROLLO TEÓRICO DE LA PERCEPCIÓN DE LA DESIGUALDAD SOCIAL}

La desigualdad social transita por un doble rasero entre las percepciones individuales de los sujetos implicados, las consideraciones de los decisores y tomadores e implementadores de políticas, investigadores y organizaciones sociales; así como el posicionamiento de los diversos grupos, capas y clases sociales. La percepción de la desigualdad transita por diversas esferas del desarrollo social y es expresión de procesos económicos, políticos y sociales mediatizados por determinadas situaciones y condiciones contextuales sentidas de forma grupal.

La desigualdad social fue una de las primeras temáticas trabajadas dentro de la ciencia sociológica. El tratamiento estuvo vinculado a los estudios sobre estructura social, al igual que la movilidad social, hechos y fenómenos sociales que producen desigualdades. Por tanto indicadores como el acceso al trabajo, a diversos servicios, recursos, posiciones sociales y a una situación socioeconómica representan expresiones objetivas de la desigualdad. La temática mantiene su vigencia en la actualidad con el desarrollo de temas como la pobreza, la mar-

* Centro Estudios Socioculturales. Universidad de Cienfuegos. Cienfuegos, Cuba. 
ginalidad y otros rasgos que marcan la desigualdad como la raza, el género, la edad, entre otros elementos.

La literatura de los clásicos de la sociología esboza los estudios del tema desde el análisis de la estructura socio clasista de las sociedades capitalistas. Un referente teórico que materializa las generalizaciones teóricas del tema es el sociólogo Talcott Parson (1937). El autor analiza que existen dos líneas fundamentales que generan estratificación: el estatus atribuido (condiciones naturales) y el estatus alcanzado (capacidad de aprovechamiento de oportunidades de cada individuo); descartando la apertura y/o barreras de las estructuras gobernantes en el aprovechamiento de oportunidades.

"El origen de la desigualdad" tiene su base en la percepción social según plantea Rousseau como obra, al plantear que el hombre no nace con la desigualdad sino después de que se compara con sus semejantes, ve sus diferencias por lo que pierde el sentido de igualdad del ser humano. En su obra se destaca otro eslabón esencial en el análisis de la misma: el acceso a las oportunidades y el desarrollo de la habilidad para acceder; donde el estado funciona como instrumento facilitador o no de dicho acceso a las oportunidades y por el otro el propio individuo capaz o no de desarrollar habilidades que le permitan el acceso.

Los estudios de la estructura ocupacional, poseen un posicionamiento pasivo para explicar la desigualdad social, asumen que siempre existirá promoción desigual del status ante la división funcional del trabajo y que no se puede erradicar. Es válido destacar los aportes que realizan los teóricos de este enfoque por la explicación que realizan en la generación desigual del individuo en su relación con el mercado. Esta estratificación social y su relación con el mercado en parte para Weber (1986) resulta "la clase económica" para explicar el desarrollo desigual.

Los teóricos europeos estudian el tema de la estructura social y la movilidad como expresiones producentes de desigualdades sociales desde dos vertientes esenciales: el enfoque gradacional y el relacional como argumenta Yannet López Verdecia y Teresa Muñoz Gutiérrez (enero 2013).

El primero estuvo representado por Glass (1954) con los estudios sobre Movilidad social en London, Inglaterra; por Dahrendorf (1957) Los estudios de las clases sociales y su conflicto en la sociedad industrial; por Miller, S. M. (1956). The Concept and Measurement of Mobility; Talcott Parsons (1937). La estructura de la acción; Stavenhagen, R. (s/f). La classes sociale et stratification. Lipset y Zetterberg (1956) y Lipset y Bendix (1963) con estudios sobre la movilidad social en las sociedades capitalistas industrializadas. El posicionamiento enfatiza en la desigualdad como proceso natural propiciado por el posterior desarrollo industrial de la sociedad. El primer posicionamiento teórico 
analiza la manipulación de los grupos en el poder y las restricciones generadas por las instituciones sociales; lo cual moldea el comportamiento humano.

Por otro lado el posicionamiento relacional puntea por la permanencia de una sociedad con una estructura social estable con escasa probabilidades de movilidad social. Por tanto enfocan los análisis de la producción desigual como condición natural humana y rechazan cualquier intento de cambio social; por tanto como plantea Kerbo, Harold R.; (2003) no creen posible una sociedad justa e igualitaria. El enfoque relacional estuvo representado por Pitirim Sorokin. (1927) con estudios sobre movilidad y estratificación social; Goldthorpe (1987). Social Mobility and Class Structure in Modern Britain. Kliksberg. (1989)."¿Cómo enfrentar la pobreza?" presenta un enfoque más moderno de análisis.

En los estudios sociales de la tradicional intelectualidad europea se destacan los aportes de Carlos Marx (1881) y Max Weber (1986)1. Los autores analizan, indistintamente, la capacidad que tiene el poder (político y económico) para legitimar las diferencias de clases. A pesar de provenir de supuestos teóricos diferentes: crítico y no crítico, respectivamente; comparten algunos supuestos paradigmáticos básicos sobre la naturaleza de la desigualdad social, y asumen que el conflicto y el poder son la clave del orden social; como refiere Kerbo, Harold R. (2003:83). Al interior del supuesto crítico se ubican los marxistas; quienes asumen que el sistema capitalista y sus características es el que moldea las condiciones presentes de explotación y desigualdad. Este presupuesto asume el cambio social como vía de obtener una sociedad más justa.

El análisis de la desigualdad social incluye la pobreza como indicador de medida dentro de la diferencia de clases. Por tanto el enfoque crítico hace énfasis en la desigualdad producida por las relaciones económicas o de propiedad de cada clase. El pensamiento marxista, además de la posibilidad de que la misma se reduce significativamente a través del cambio social. Esta idea no se materializa en el contexto latinoamericano hasta el triunfo de la Revolución Cubana en el año 1959.

Los representantes del paradigma crítico reaccionan ante la expansión de la desigualdad y pobreza que genera el sistema capitalista en la estructura de clases de la región latinoamericana. Se reconoce la existencia del conflicto de clases aunque se denomine de diversas maneras: antagonismo de clases (explotada y explotadora), o clase supra ordinaria y subordinada. Este aporte está basado en el pensamiento sociológico de Marx y Dahrendorf.

1 “(...) El resultado fue una centralización del poder en manos de unos pocos y finalmente de uno solo, situado en la cúspide del partido." (Weber, 1986) 
La acentuación de la discriminación fue tratada por Robert Merton "el efecto Mateo" citado por Atria; (2004). El autor hace énfasis en las condicionantes sociales como el prestigio social, la reproducción del poder ante las relaciones intergeneracionalidad; así mismo toma de Robert Merton la siguiente expresión como proceso de comprensión de la reproducción de la desigualdad social: "los procesos de auto-selección individual y de selección social institucionalizada, interactúan y afectan las probabilidades sucesivas de acceso a la estructura de oportunidades".

La reproducción de clases o de grupos y capas también se da en las diversas esferas de la vida social, no solo es expresión de la economía, o de la institucionalidad; sino también de las esferas de ciencia como refiere Merton citado por Arias cuando expresa: "los sistemas de recompensas, asignación de recursos y selección social operan para crear y mantener una estructura de clase por medio de la provisión de una distribución estratificada de oportunidades entre los científicos para incrementar su rol de investigadores.

Los teóricos del continente latinoamericano fueron reflejo de los estudios de la sociología norteamericana enfocada hacia la explicación de la reproducción social de las clases en las sociedades capitalistas. Teóricos del enfoque estructural funcionalista ${ }^{2}$, asumen las posturas funcionalistas del pensamiento sociológico burgués, sobre la evasión de la desigualdad social, en un sistema capitalista con una aparente igualdad de oportunidades, que no reconoce adecuadamente las diferencias de clases, desde el orden de económicos, sino desde la dimensión del status producido al interior de la estructura ocupacional; lo cual tiene su génesis en el pensamiento sociológico de Weber).

\section{EL COMPORTAMIENTO DE LA DESIGUALDAD SOCIAL EN AMÉRICA LATINA}

En el marco de la expansión del capitalismo hacia América Latina, se establece nexos de dependencia específicas, que polariza con mayor énfasis ambas posturas, aunque se produce una hibridación en el análisis de la estructura social y las desigualdades. Los estudios sobre estratificación social y descripciones de estructura social toman auge; sin embargo su limitante radica en la carencia de una visión más profunda en el análisis del antagonismo de clases. Los resultados de la época transitan hacia generalizaciones del proceso social y evaden el

2 Autores como Gino Germani (1962) de la Universidad de Buenos Aires, A. Solari y Labbens (1961) desde el Instituto de Ciencias Sociales de Montevideo, B. Hutchinson adscrito al Centro de Pesquisas de Río de Janeiro, G. Costa Pinto, y E. Hamuy en el Instituto de Sociología de la Universidad de Chile, según Filgueiras (2001). 
tema de la pobreza y el incremento de los grupos en desventaja social ante las barreras de movilidad vertical.

Las tendencias latinoamericanas sobre los estudios de estratificación poseen un desarrollo diferente a lo sucedido en el norte de América. Al respecto Germani; (1962) sostuvo que las mismas no se ajustaban plenamente al modelo de transición temprana al capitalismo que rigió en los países del norte. La situación de América Latina posee características que la tipifican. El propio desarrollo de factores que propician el desajuste de la economía de exportación de productos primarios con industrialización retrasada, conduce a caracterizar la región en su fase inicial "paleocapitalista". Germani analiza que estas condiciones producen un predominio de los propietarios latifundistas en la conformación de la clase alta, y a la sobreexpansión de los sectores de la clase media.

El desarrollo del capitalismo trasnacional complejiza las relaciones antagónicas de clase, a partir del incremento del nivel de desarrollo que alcanzan las fuerzas productivas sociales que se traduce en el incremento de la división social del trabajo. Los análisis de la sociología latinoamericana realizados por Ileana Rojas (1988) enfatizan el antagonismo de clases como el máximo exponente del aumento del grado de diferenciación entre clases en capas y pequeños grupos a su interior.

Los aportes más relevantes de la teoría latinoamericana tradicional al conocimiento universal es principalmente el modelo centroperiferia, que explica como los centros han retenido íntegramente el fruto de su progreso técnico e industrial sobre la explotación de los recursos de los países periféricos. Ver al respecto, entre otros, los trabajos de Raúl Prebish en el marco de la Comisión Económica para América Latina y el Caribe (CEPAL) en 1962 como refiere Portes y Hoffman (mayo 2003).

Desde las publicaciones de la CEPAL en la década del 60 se pone de manifiesto los fuertes nexos entre transición económica y movilidad estructural ocupacional; llaman la atención sobre este ámbito de la movilidad y su carácter complementario con relación al análisis de los desplazamientos individuales y las expresiones de desigualdad en el continente. Estos se consideran los aportes más notables de la región acerca de la transformación ocupacional y la crisis social en América Latina en la década de los años 80 . Durante la profundización de la crisis en los años 70 y 80 del pasado siglo XX, se potencian los estudios sobre desigualdades especialmente los de estratificación, orientados hacia problemas como el empleo, ocupación y pobreza.

Las dinámicas de cambio de las estructuras de desigualdad son expresiones de estatus de prestigio social dentro del esquema de jerarquías; aunque articula diferentes aristas y planos, como defiende 
Crompton (1994) "Esto es: parte de escalas ocupacionales deliberadamente construidas de acuerdo con el prestigio supuesto o la deseabilidad ocupacional" citado por Espina, M.; Nuñez, L.; Martin, L.; (2009:5). Asimismo los procesos de movilidad resultan expresión del reflejo de los cambios operados en la estructura de oportunidades generadas como refiere Atria, R.; (2004); quien asume el término de las oportunidades de vida por la literatura weberiana.

En general estos dos factores están positivamente relacionados con la movilidad social ascendente, pero actúan también como mecanismos de reproducción de las desigualdades en el perfil de la estratificación social. Por tanto las políticas públicas en función de estas esferas sociales precisan de un análisis contextual complejo para que su efecto no enfatice las desigualdades que generan dado los cambios sociales actuales.

Las condiciones socio históricos y contextuales de la sociedad actual conduce cada vez más a una estructura dinámica y compleja matizada por la situación de la estratificación social y la posición social objetiva y subjetiva de los individuos según la clase, grupo o capa social de la estructura que ocupa. Por tanto las tendencias al crecimiento económico, la mantención del poder y la lucha por la permanencia de las condiciones de vida de los diversos grupos, capas y clase mantiene vivo los trastornos, tensiones y luchas como expresión de las contradicciones que nombrara Norbert Elias; (1987) entre las necesidades o inclinaciones personales y los requerimientos de la existencia social para cada momento socio histórico.

En el tema de las desigualdades espaciales se analizan indicadores como la emigración y la marginalidad en un proceso encadena que está íntegramente relacionado con la búsqueda de oportunidades sociales ya sea en cuanto a territorio (regiones centralizadas y/o urbanizadas), posición sociales o categoría de empleo, por mencionar algunos. Estos fenómenos provocan los ya conocidos crecimientos de cinturones periféricos de pobreza urbana (favelas, cerros, callampas, cantegriles, entre otras nominaciones) como formas de exclusión de la sociedad.

La región latinoamericana reconocida como el continente más desigual según datos del Programa de las Naciones Unidas para el Desarrollo (PNUD); (2010) (ver gráfico 2) es expresión de una política de consumo, mercantilización y cultura de mercado que ha permeabilizado la existencia del campo como forma de vida y de producción. Se ha potencializado una industrialización bajo demandas transnacionales que propicia la fuga de capital, el crecimiento de los círculos de pobreza y la falta de identidad cultural en busca de "alternativas de vida" que le garantice una reproducción sociocultural de la imagen de la clase burguesa occidentalizada; promovidos por estrategias premonopolista, monopolista y transnacionalizado. 
Las condiciones estructurales de la región condiciona las expectativas colectivas e individuales, las cuales se expresan en la obra de Filgueira, C.; (2001). El mismo profundiza en temas referentes a la desigualdad vista desde la movilidad social. Aporta al análisis la existencia de tres grandes núcleos; primero referido a la movilidad estructural, segundo a la movilidad de reemplazo o individual y tercero a la marginalidad. Por tanto la coexistencia de un macro proceso de urbanización con el creciente grado de "salarización", la expansión del sistema educativo en todos sus niveles y la falta de capacidades gubernamentales para potenciar cada una de estas "estrategias" conduce a una contracción social vigente hasta tiempos actuales.

La dependencia económica produce el despliegue de procesos de movilidad en muy bajos grados y por lo general descendentes. En primer orden influye la distorsión de la economía en la región, debido a que los beneficios y los empleos que genera el desarrollo industrial, no repercuten en los países periféricos y se pierde la cadena de actividad económica como refiere Kerbo, Harold R.; (2003).

En segundo lugar se produce un conflicto en el sector económico tradicional: la agricultura, ante el desarrollo del llamado sector moderno o capitalista. El proceso industrial del sector produce mayor desempleo, encarecimiento de los productos por la intermediación de un mercado, entre otras causas. En tercer lugar se encuentran los conflictos de clases, pues se crea un conflicto de intereses entre la élite en el poder (nacional e internacional) con las clases desfavorecida, quienes reciben doble explotación. En este orden, existe un cuarto problema que son los mercados libres que genera mayor empobrecimiento sobre el capital nacional y la cultura de la región.

El desarrollo del capitalismo aumenta las diferencias de clases, desarrolla un proletariado sumamente dependiente y a su vez la estructura de oportunidades se adapta a las características socioeconómicas de las regiones de acuerdo a cada sociedad. Al respecto, Filgueira Carlos; (2001) bajo el posicionamiento crítico, argumenta que el esquema relacional, alcanza niveles descriptivos, centrados en aspectos particulares de la estructura social. ${ }^{3}$ Se realizan valoraciones acerca del desarrollo socioeconómico y un acercamiento a las aspiraciones de la población.

Este posicionamiento responde al planteamiento de Kerbo; (2003:140): “(..), dentro de la estructura ocupacional las personas es-

3 Filguiera y Geneletti desarrollaron un esquema clasificatorio para categorías ocupacionales que permite distinguir un conjunto de estrato, a partir de datos obtenidos de registros. (...) Rubén Kaztman abordó en la década de los años ochenta de manera específica, las transformaciones del empleo en la región. (Atria, R. 2004; p.18) 
tán ordenadas en términos de cualificación, y cuanta más cualificación tienen, mayores recompensas tienden a recibir (por ejemplo, ingresos)". El nivel educacional es identificado como cualidad e indicador determinante en los desplazamientos de la estructura ocupacional, para los estudios de este corte.

La interpretación de las desigualdades ha estado estrechamente ligada a las formas de articulación entre las economías dependientes y el mercado mundial, desbordando los contextos en los que habían sido enmarcados, aplicándolas fuera del estado nación y vistas en su encadenamiento global, donde también se distinguen desigualdades y articulaciones clasistas extranacionales.

La expresión de perdurabilidad de la desigualdad como expresión natural el desarrollo se mantuvo dentro de los temas relevantes de la sociología estructural por su posibilidad de legitimar el orden social capitalista y fomentar la formación de una clase con estabilidad. Así lo enfatiza Kerbo, Harold R. (2003:113) al plantear que la estructura de status (basado en el pensamiento de Weber), es la que proporciona el orden social.

Los estudios sobre movilidad son referentes de los procesos de desigualdad en cuanto a las trayectorias y/o rutas de movilidades individuales y grupales que asumen las sociedades. Como refiere Atria, R.; (2004) la sociedad equitativa es aquella que asegura la igualdad de oportunidades de las personas ante la ley, es capaz de suprimir las barreras económicas y sociales; o de compensar las desigualdades que ella misma genera impidiendo la realización del potencial individual.

Los estudios sobre las desigualdades sociales debe comprender la situación contextual de la sociedad en la que se convive, generar proyecciones hacia el acceso al ingreso, al consumo de bienes y servicios y al patrimonio. Asimismo tener en cuenta la incorporación de la población a la ciudadanía social y política con posibilidades de participación social y plena que posibilite la retroalimentación entre los diversos grupos, capas y clases sociales para asegurar un bienestar social, económico y político.

Las expresiones de concentración y dilatación de los centros de poder y de pobreza, así como la distribución del ingreso, entre otros indicadores distingue el desarrollo en diversos países de la región. Al respecto Modesto Gayo, María Luisa Méndez, Rosario Radakovich y Ana Wortman; (2011): "Argentina, Chile y Uruguay representan tres realidades-que aunque similares- tienen diferenciadas en términos de su concentración ydistribución del ingreso y patrones de desigualdad".

Los autores destacan el papel que debe jugar el Estado en el desarrollo de las políticas públicas. Además refieren que el modelo de desarrollo que se implementa afecta el desarrollo de dichas políticas 
encaminadas al ajuste estructural lo cual se expresa de forma diferente en cada contexto como se expone a continuación:

“(...), en Uruguay existe una distribución del ingreso relativamente igualitaria, mientras que Chile es -junto a Brasil y México- uno de los países latinoamericanos con mayor nivel de desigualdadde ingresos. Por su parte, Argentina ha vivido una crisis profunda durante la última década que se ha traducido en el empobrecimiento de la clase media y los sectores populares".

En este sentido se destaca el valor que poseen los estudios sobre pobreza. La dictaminación de políticas públicas y estrategias de acceso al consumo y a los ingresos, entre otros no logran alcanzar dicha equidad social por la limitada percepción de las desigualdades y por ende de la pobreza. La estructura de oportunidades amplia y /o estrecha debe tener su mirada hacia los grupos sociales que excluyen las propias políticas. Cabe preguntarse si los llamados NiNi o SinSin o quizás otros grupos sociales con expresiones socioeconómicas y culturales específicas como los Maras, pandillas callejeras no son también expresión de aquellos grupos sociales que se redescubrieron sin alternativas y capacidades desarrollas ante una estructura de oportunidades que los invisibilizó.

La implementación de oportunidades gubernamentales carece de una transversalidad adecuada hacia todos los grupos sociales, así como de retroalimentación y un sistema de evaluación adecuada. La herencia generacional otorga una garantía de estabilidad socioeconómica y política que conduce a una ratificación de los círculos de poder y las capas y grupos más desfavorecidos. Es en este orden en el que el acceso a la educación y la salud se convierten más en generadores de desigualdades cuando son objetos de políticas aisladas, no acordes a un programa de oportunidades en los diversos niveles de la sociedad.

Refieren Yannet López Verdecia, Teresa Múñoz Gutiérrez; (2013) que la apertura de oportunidades sociales integradas a políticas económicas, jurídicas producen desplazamientos ascendentes y favorece una situación y posicionamiento social a los grupos sociales y etarios, especialmente a los más vulnerables como las mujeres, adolescentes y los jóvenes. El resultado se materializa en procesos concretos de mayor equidad social especialmente en regiones rurales y montañosas. Sin embargo el estudio demuestra que la apertura de oportunidades sociales aisladas de un proceso económico, productivo, jurídico tiende a generar mayores brechas de desigualdad social afectando a los grupos antes mencionados.

En ese espacio temporal y contextual Cuba es expresión de consolidación de las transformaciones generadas; lo cual favorece la generación de estudios sociológicos por parte del Equipo de Estructura 
Social; (1988) que analizan los procesos de movilidad social de la clase obrera como grupo, su estructura interna, la transformación del campesinado, la dualidad campo-ciudad bajo los preceptos de la sociología Marxista- Leninista. Favorecida la apertura de la estructura de oportunidades sociales y el desarrollo de capacidades condujo al país en los primeros 30 años de revolución a una expresión de equidad social, ejemplo en Latinoamérica.

El desarrollo de la Revolución cubana responde al proceso sociohistórico de cambio social basado en los principios marxistas. Esta visión conduce a la formación de un cuadro estructural socio-clasista distribuido en tres grupos sociales según la propiedad:

La propiedad estatal (trabajadores con predominio de gastos intelectuales (dirigentes, especialistas y técnicos.), empleados y trabajadores con predominio de gastos físicos y trabajo manual (clase obrera, incluyendo la categoría ocupacional de obreros y trabajadores de los servicios), la propiedad cooperativa que comprende a las Cooperativas de Producción Agropecuaria (CPA) y la propiedad privada con los Pequeños Agricultores Individuales y los trabajadores por cuenta propia como refiere Espina; (2002).

Los estudios sobre la temática en Cuba atiende la distribución de la estructura social que posee equidad de oportunidades por la posición que ocupa el individuo ante la ley, al acceso a bienes y servicios o al consumo. También se tiene en cuenta las posibilidades de participar e incidir en las decisiones políticas; mientras que en América Latina se gestionaba un proceso de maduración de los movimientos de liberación nacional.

La experiencia cubana muestra la posibilidad de transformación social y promueve la efectividad de la teoría marxista en condiciones socio-históricas similares. Según Ileana Rojas y Jorge Hernández; (1987:8). El desarrollo teórico de los estudios en Cuba posee énfasis en la disminución de la desigualdad a través de proyectos sociales. Las estrategias propicien equidad de oportunidades sociales para contribuir a la eliminación de diferencias de clases; y promueve desplazamientos sociales al interior de la estructura ocupacional de la sociedad cubana.

En Cuba se asume la visión sociológica marxista- leninista para analizar la estructura social como objeto de estudio. El grupo de Estructura social del departamento de Sociología en el año 1988 enfoca los análisis hacia el proceso de eliminación de diferencias entre los sectores, capas y grupos que conforman la estructura social cubana contemporánea. Posteriormente le da continuidad el grupo de estructura y desigualdad social del Centro de Investigaciones Psicológicas y Sociológicas, adscrito al Ministerio de Ciencia, Tecnología y Medio Ambiente (CITMA). La producción científica del mismo enfatiza en los 
estudios sobre el tema específicamente en la década del 80 con el impacto del proyecto social cubano en la estructura social y en los años 90 se profundiza en los efectos de la crisis económica.

El contexto latinoamericano es muestra del desarrollo de diversos enfoques. El enfoque desarrollista tuvo opositores que se apoyaron en los principios de la corriente marxista, como la teoría de la dependencia, que se enfrenta e incrementa su estereotipo, como argumenta Rojas y Hernández; (1987) cuando refiere que la época del 60 fue escenario de procesos sociales contemporáneos. En este ámbito también se une el desarrollo del movimiento crítico en la sociología latinoamericana; por lo que permite centrarse en estudios de la vida política de la sociedad. Entre los que se destaca el caso de la dualidad estructural; para explicar las causas que influyen en el incremento del subdesarrollo.

El efecto de dichos procesos conduce a la pérdida de la identidad cultural, desmotivación individual y grupal por el medio social, su desarrollo socioeconómico y marcados movimientos de descenso en cuanto a la estructura ocupacional y social o ascenso para la minoría según sus capacidades y posibilidades de inclusión y/o asumen un proceso de emigración a otras regiones.

La concepción de pobreza y de desigualdad esta vista desde un enfoque superficial y/o vertical, donde se le atribuye al grupo o grupos en desventajas carencia de valores, de capacidades para aprovechar las oportunidades, se le enmarca en carencias económicas, por ende en de acceso al consumo, entre otras externas; sin embargo la construcción social delas propias estructuras sociales conducen a la reproducción social de estos grupos, capas y clases sociales a los cuales no llega de la misma forma las oportunidades, creando barreras de contracción que produce la pobreza, la marginalidad y la desigualdad social. En este sentido estas subestructuras sociales se convierten en la fuente de sobrevivencia a través de expresiones laborales informales e ilícitas, no recogidas en las principales cadenas de recogida, análisis y socialización de lainformación a nivel global.

El panorama en América latina posee diversidad de posicionamientos políticos que incide en la toma de decisiones y la proyección de políticas públicas. Al respecto Ernesto Rodríguez (2015). Enfatiza en que la expresión de la desigualdad también tiene su basamento en la desigualdad de cultural, género, de raza, además de económica y jurídica.

Los estudios sobre el tema en América Latina se han convertido en centro de atención por diversos centros, organizaciones y programas generadores de ciencias y políticas de desarrollo como CEPAL, el Fondo de Población de las Naciones Unidas (UNFPA), PNUD, UNESCO, CLACSO OIJ. El enfoque inter e intrageneracional en cuanto a transmisión de la desigualdad, es hoy centro de análisis. Daniela Trucco 
(2015), anuncia el posicionamiento que posee el PNUD sobre Desarrollo Humano para América Latina desde el 2010 al convocar a pensar en políticas públicas, capaces de romper la transmisión intergeneracional de la desigualdad.

La CEPAL está enfocada hacia la propuesta que los diversos centros de desarrollo de políticas y grupos de investigación generan espacios donde se pueda reflexionar sobre las problemáticas de la desigualdad y se produzcan tanto conocimientos como propuestas de políticas públicas e intervención social como centraliza el desarrollo de la Escuela Juventud y Desigualdades social en América latina y el Caribe en Honduras del 21-26 de junio de 2015.

Las propuestas de análisis de la CEPAL están enfocadas hacia las problemáticas de la desigualdad. Los centros de desarrollo de políticas y grupos de investigación generan espacios de producción de conocimientos como propuestas de políticas públicas e intervención social. El tema de la desigualdad social transita también por el diálogo política-ciencia. La relación de ambas esferas resulta contradictorio, dinámico y complejo En este ámbito estas instituciones sociales asumen la concepción más amplia del término incluyendo indicadores de género, sexualidad, territorio, etnia, cultura, nivel educativo y migraciones desde una perspectiva multisectorial y multiactoral.

El centro de atención respecto a las desigualdades en la agenda actual de las Ciencias Sociales en América Latina enfoca a la juventud como centro de atención, dado que es uno de los grupos sociales de mayor expresión de las vulnerabilidades sociales. Pensar en la juventud como centro de análisis ya implica una concepción más dinamizadora de la realidad Latinoamérica capaz de comprender las contradicciones de la sociedad actual y con una mirada no solo al presente sino también a las futuras generaciones.

\section{EL COMPORTAMIENTO DE LA JUVENTUD COMO GRUPO VULNERABLE DENTRO DE LA DESIGUALDAD SOCIAL EN LATINOAMÉRICA}

La juventud resulta expresión de vulnerabilidad por sus rasgos sociodemográficos, como psicosociales; pero su condición de fuerza laboral de remplazo en el proceso socioeconómico complejiza su condición en el desarrollo de habilidades para aprovechar o no las oportunidades sociales. En este sentido el trabajo asume la conceptualización de la Dra. Domínguez (2008) quien plantea que la juventud es una:

"categoría histórico- concreta que designa un grupo socio-demográfico internamente diferenciado según su pertenencia a la estructura social de la sociedad. Fundamentalmente a las 
distintas clases, capas y grupos que la componen, constituyendo su elemento más dinámico y móvil."

Las investigaciones y percepciones sobre el término juventud han detonado un sinnúmero de definiciones del período etario que debe comprenderla. El manejo de la edad es flexible y se dan diferencias entre los países. Por ejemplo, en el marco de la Organización Iberoamericana de Juventud (OIJ; 2005) se aceptó por consenso el rango de 14 a 30 años, distinguiendo como joven adolescente a las personas de 14 a 18 años, joven a las que transitan de 19 a 24 años y adulto joven a los de 25 a 30 años. En el 2005, la Convención Iberoamericana de Derechos de los Jóvenes, refrendó como joven a las personas entre 15 y 24 años. Tomado de López, Y.; Muñoz, T.; (2013).

En América Latina, algunos países asumen este intervalo, mientras que otros, incluyendo a Cuba, definen juventud, la que se extiende hasta los 29 años. El enfoque etario puede ser polémico y depende del criterio que se tome para adoptar una posición

Estudiosos sobre la juventud en Cuba debaten hoy cuál debe ser el límite superior; el cual llevan a pensar en su extensión hasta 35 años teniendo en cuenta factores como el envejecimiento poblacional, la postergación de la maternidad, la extensión del período de preparación en postgrado, la posibilidad real de obtener cierta independencia, la proyección de las políticas juveniles, ladependencia económica y habitacional con respecto a los padres, entre otras.

El tema ocupa un lugar central en las ciencias sociales por su posibilidad de pluri-enfoques que oscilan entre diversas perspectivas como refiere Luis Luis, M. (2009), la perspectiva biopsicosocial, demográfica y sociológica, entre otras. Sin embargo es preciso concebir las subjetividades y los procesos sociales a los que se enfrentan la juventud y a partir de ello comprender los diversos significados que le confieren a su inserción laboral y social.

La categoría juventud constituye una construcción social que parte de la práctica cultural acumulada. Históricamente las sociedades han elaborado su visión acerca de los jóvenes; durante la transición de la Comunidad primitiva a la sociedad de clases se estableció una subordinación a sus mayores que trasciende a la actualidad.

En los años cincuenta y sesenta los análisis sobre lo juvenil en la región desde la perspectiva sociológica, se realizaron bajo la influencia del enfoque estructural-funcionalista norteamericano, que veía a la juventud como problema. El período juvenil se concibió como una forma de socialización y moratoria. Las décadas del sesenta y setenta, marcan una ampliación de los estudios sobre juventud vinculados a la CEPAL; de ahí que estuvieran focalizados en los procesos de integración y de- 
sarrollo social de los jóvenes, intentando sumar dichas situaciones a proyectos modernizadores

La nueva generación latinoamericana de científicos sociales dedicados a la cuestión juvenil muestra un consenso respecto a la diversidad actual de la juventud. Es muy común que no se hable de juventud, sino de juventudes, cuyas diferencias están determinadas por elementos sociales y culturales, estrechamente relacionados con las transformaciones ocurridas en la organización económica. El proceso de segmentación social que se produce en América Latina genera tendencias de vinculación de las juventudes a los procesos de educación escolar. Las definiciones del término deben incluir nuevas variables que la escuela, el ámbito laboral, las instituciones religiosas, partidos políticos, asociaciones, y todos aquellos donde se desenvuelvan los jóvenes.

El indicador Educación es uno de los tradicionalmente más analizados por la CEPAL respecto al tema de la desigualdad social y está presente en cada uno de los países como políticas públicas priorizadas (Trucco, 2015) (Ver Gráfico 3). En el mismo se toman en cuenta el aporte positivo que han ganado los indicadores de desarrollo de las políticas educacionales en el incremento de inserción y culminación de estudios en los diferentes niveles escolares con respecto a años anteriores al 2012.

Es válido destacar que la mirada no debe estar enfocada a un análisis centralizado en estos indicadores; sino que se precisa del contraste estadístico de múltiples indicadores para reconocer que las políticas continúan sesgando a aquellos grupos en desventajas sociales. La falta de articulación de políticas invisibilizan a los grupos sociales que quedan fuera de este indicador analizado. Aunque existe un incremento desde 1990 al 2012 en la continuidad de estudios; es relevante el porcentaje de jóvenes que culminan la educación primaria con respecto a los otros niveles de enseñanza y cabe preguntarse qué cabida tienen en el sector laboral, de salud; en el acceso a los servicios económicos y sociales en sentido general en una sociedad altamente sesgada y estratificada.

Datos ofrecidos por la CEPAL muestran las desigualdades que atraviesan hoy la juventud latinoamericana las cifras muestran que los jóvenes están relativamente más desempleados y con trabajos de peor calidad -más precarios- que los adultos, situación que se agrava entre las mujeres jóvenes como informa Trucco, Daniela; (2015) al analizar el informe de CLACSO-UNESCO; (2013).

El análisis de las políticas gubernamentales en la actualidad conduce a profundizar el análisis de los indicadores como gasto en salud, gastos públicos, la inversión social, dado que dichos indicadores muestran que existen una atención priorizada hacia los grupos más adultos de la sociedad y los porcentajes de atención o gastos a la juventud se expresan en números más bajos, otros preguntas a colación incitan la 
mirada hacia en qué consisten los gastos. Según los datos de la CEPAL los tipos de inversión social en juventud se desglosan en directos, ampliados, indirectos y genera o territorial; lo cual deja brechas internas que invisibilizan la exclusión social al interior de los grupos juveniles y en su relación intrageneracional.

La generación de Políticas Públicas, de inclusión social en América Latina, así como la inversión social o el desarrollo de estrategias para la transformación colocan a la juventud como protagonistas del desarrollo y son eje de análisis por organizaciones regionales como CLACSO, FLACSO, la CELAJU, entre otros.

Los estudios contemporáneos sobre la juventud están internamente relacionados con otros grupos también vulnerables. El objetivo de analizar los referentes teóricos y prácticos sobre el desarrollo científico de la juventud en América Latina y Cuba contribuye a la comprensión de la construcción científica de esta categoría y su reconocimiento social.

La juventud se abre paso al interior de un mundo de organizaciones, movimientos, principios relacionados con la equidad, la participación y el protagonismo para la toma de decisiones. La existencia de una toma de autonomía y conciencia generacional conduce actualmente a visualizar esta categoría social, con grados de evolución en cuanto a responsabilidades con sus coetáneos y su tiempo. Los estudios actuales sobre el término conducen al llamado de sobreponerse a la concepción simbólica de la juventud y no perder de vista su condición históricocontextual.

Margulis y Urresti (2013), enfatizan que los grupos juveniles están matizados por las condicionantes y características de la estructura social de determinadas sociedades. Dentro de la concepción generacional del mismo, los autores hacen referencia a la experiencia social vivida por el individuo y a su vez la construida en colectivo. Dentro de esta concepción incorpora la distinción de la edad, el género y las clases sociales en un momento histórico dado.

El análisis sobre las investigaciones de juventud reclama la capacidad de generar visiones integradas, más que parciales. En este caso se encuentran temas sumamente tratados como los referidos a políticas de juventud en América Latina. El discurso internacional abre espacios de interacción y participación, diálogo abierto y confluencias de diversos actores como el Estado, en la construcción de una nueva sociedad. Así lo estableció el Congreso de Investigadores sobre Juventud celebrado en Cuba en marzo de 2013.

En el marco latinoamericano cobra auge escuelas, redes sociales, y estudios centralizados a niveles de la enseñanza superior como es el caso del Observatorio Javeriano de Juventud y el Programa de Jóvenes Investigadores del Instituto Pensar de la Pontificia Universidad 
Javeriana en Bogotá D.C, Colombia. Las políticas científicas exponen la necesidad de fortalecer las investigaciones sobre jóvenes y potencialmente realizado por investigadores juveniles. Entre sus principales pautas se encuentra, dinamizar, generar conocimiento y fortalecer el trabajo existente con la socialización de los resultados para futuros estudios sobre la temática

En los últimos diez años también ha tomado auge los estudios sobre juventud asociados a términos como la marginalidad, la pobreza y la desigualdad, acompasados con los estudios de las ciencias sociales en el continente con una mirada hacia el micro-espacio social. En este ámbito se insertan otros indicadores como la educación en valores, la globalización, las trasnacionales el desarrollo científico tecnológico, y los estudios sobre consumo e identidad cultural.

Los medios de comunicación masiva son reflejo de la toma de conciencia del tema de las desigualdades sociales y la emergencia de los grupos vulnerables como la juventud en el contexto actual. Espacios alternativos como Telesur muestran la incapacidad de las políticas públicas actuales en el diseño de estrategias más eficaces para generar la equidad social.

El estudio de la juventud reclama y a la vez posee una visión de integración social desde la percepción social de los propios jóvenes y sus subjetividades. El análisis sobre la sexualidad, la adicción y los grupos en desventaja social se integran a los estudios actuales, sin embargo carecen de profundización para el enfrentamiento y disminución de la vulnerabilidad en ámbito de percepción de riesgo y salud. Autores como Ernesto Rodríguez (2002) y Lorena Natalia Plesnicar (2015) identifican la necesidad del análisis sobre políticas educacionales, de inserción laboral, así como la percepción desde la equidad de género y promover y fortalecer la equidad y el acceso a las oportunidades en grupos sociales vulnerables como la mujer y los jóvenes.

La formulación de un programa de investigaciones sobre la juventud forma parte de la concepción de ampliar y profundizar los estudios sobre el tema a finales del siglo XX, como resultado de lo acontecido en el contexto regional. Una búsqueda de actualización de las distintas corrientes de pensamiento vigentes en el ámbito mundial, latinoamericano y caribeño, en vinculación con instituciones de América del Norte y Europa favorece desarrollar investigaciones con especial énfasis en dos disciplinas: la sociología y la antropología social.

Otros indicadores que visibilizan a la juventud en el contexto de desigualdad en América Latina hacen referencia a las desventajas sociales: la sobreviolencia ${ }^{4}$, la inclusión social relacionada con los registros

4 Los indicadores sobreviolencia juvenil en Honduras son muestra de la vulnerabilidad 
oficiales $^{5}$, el suicidio juvenil ${ }^{6}$ (ver grafico 1). La condición y situación social del género, la raza y la cultura son expresiones de desigualdad social.

Entre las causas de criminalidad y violencia en América Latina se encuentra la debilidad institucional y de los sistemas de seguridad ciudadana, la falta de reflejo de determinadas desigualdades sociales que no se reflejan en los indicadores y mediciones sociales, el carácter transnacional de la violencia, la falta de políticas con visión multiactoral y multisectorial lo cual se refleja a escasas proyecciones de empleo , y en otras caso de reconocimiento de empleo, la falta de espacios de recreación, la falta de proyección hacia la abstención; así como los que produce los fenómenos antes analizados como la emigración/ inmigración, empleo, acceso al ingreso, a la salud, a la educación, entre otros.

Las políticas públicas en América Latina favorecen sectores como la educación, la salud y el bienestar, el empleo, la participación política y cívica según reconoce y analiza Rodríguez, Ernesto (2015). Resulta interesante el enfoque de las mismas hacia los gastos en educación, fundamentalmente en los primeros niveles de educacionales. Aunque posee la particularidad de generar capacidades sin tener en cuenta la integración con otras esfera de la vida social y el contexto; después se encuentran los gastos en cuanto a salud y bienestar, y empleo con las mismas particularidades que la anterior; y en menor medida se encuentran los gastos públicos respecto a participación política y participación cívica, donde se desarrollan las expresiones de exclusión y vulnerabilidad social con mayor énfasis al reconocer a los implicados como objetos y no sujetos de políticas.

La contradicción esta en los efectos que producen las políticas públicas al vislumbrar datos estadísticos como los que ofrece Monzón, (2015) al mostrar los datos ofrecidos por el Informe Nacional sobre Desarrollo Humano PNUD que analiza que el 17.5\% del total de la po-

de los jóvenes que viven en desventaja social desde los diversos indicadores: territorio, región, raza, cultura, género, procedencia social, nivel educacional. Como refleja Núñez, (2015) la datos de muerte por homicidio de estudiantes según nivel educativo por años (2010-2014) en Honduras reflejan la trayectoria de violencia juvenil. El grupo etario más vulnerable resulta el que se encuentra entre 14 a 18 años ubicado en edad de secundarias. Son los grupos etarios más susceptibles a los empleos ilícitos y su comportamiento ha sufrido un aumento en el último año con tendencia al aumento.

5 Diversos grupos sociales no se registran en los datos oficiales del país, sobre todo en el sector educacional y aparecen como estudiantes sin determinar: el cúmulo de jóvenes no reflejado en las estadísticas oficiales de una sociedad es una forma de exclusión social. (Ver gráfico I).

6 Ver estudio de Ana Silvia Monzón (2015) titulado La dinámica de las juventudes hoy: perspectiva de género y etnia y presentado en la Escuela Juventud y Desigualdades, CLACSO. 
blación juvenil en Nicaragua no estudia ni trabaja. (Nicaragua, 2011) en consonancia con el elevado por ciento que posee el empleo informal tanto a nivel urbano para un 54\% y a nivel rural para un $76 \%$. Lo que conduce al análisis de que el $40 \%$ de los jóvenes nicaragüenses en edad de trabajar está desempleado o trabaja de manera irregular e informal.

En este sentido Vommaro, Pablo; (junio 2015) expresa la necesidad que poseen hoy las políticas públicas enfocadas hacia la juventud de repensarse desde políticas de los jóvenes y para los jóvenes donde se supere la visión adultocéntrica, con una ampliación hacia lo público.

La región hoy necesita una articulación, integración y aprovechamiento de las políticas existente desde una visión holística, multi actoral y factorial. El replanteamiento del ser joven y el lugar que ocupa en la toma de decisiones como sujeto activo generador de políticas (no solo sujeto de derechos). Entre estas también reconoce el lugar que ocupan las Nuevas Tecnologías de la Información y las Comunicaciones (NTICs) y los medios de comunicación. Para ello se debe gestionar un dialogo recíproco entre las proyección del Estado, los procesos y resultados de investigación generados por la academia y las acciones de las organizaciones y colectivos sociales.

La juventud dentro del marco de las desigualdades sociales transitan por la estigmatización y estereotipos promovidos por la estructura de clases, los círculos de poder, los grupos en ventaja social lo cual genera la resiliencia social y conduce a una reconstrucción colectiva de la participación social frente a la emergencia de exclusión cultural, de territorialidad. En este orden se encuentra la diversidad de expresiones que utilizan hoy los jóvenes para hacerse sentir desde un posicionamiento socio-político, ideológico, cultural.

El tema de la desigualdad desde la juventud transita por el proceso de deconstrucción de la juventud y juventudes; lo cual se ha materializado históricamente desde la visión del Estado, de sus políticas públicas y desde la academia. Por tanto la categoría juventud precisa una re conceptualización que implique la concepción integral de la construcción teórica desde el reconocimiento de saberes tradicionales, populares y prácticos como conocimiento más allá de los medidores de educación formal establecidos.

El análisis de juventud dentro de las desigualdades sociales precisan de un enfoque integral de política- academia, metodologías descriptivas, explicativas con acción participativa, análisis estadísticos tradicionales con mecanismos de análisis cualitativos, proyección de acciones con carácter inter e intrageneracional y un sistema de relaciones y proyecciones multiactoral y multisectorial capaz de transversalizar las políticas y enfocar integralmente el proceso, resultados y socialización de la academia también. 
El continente Latinoamericano y Caribeño asume hoy un posicionamiento que expresa un trabajo colectivo, y colaborativo entre diversas instituciones y convergen diversas comunidades (decisores, investigadores, decisores, hay ONG, instituciones) como refiere Vommaro (2015). Resulta un desafió para las Ciencias Sociales y la temática de la desigualdad social y de Juventud al hacer coincidir estos actores y sectores en un mismo espacio buscando alternativas para encontrar nuevos caminos. La integración multiactoral y sectorial debe "Pensar políticas para la igualdad, no homogenizante, sino una igualdad que reconozca la diversidad en la construcción de lo común". (Vommaro, 2015).

La profundidad de análisis sobre la juventud gana espacio en la medida que la desnaturalicemos de los conceptos tradicionales, la visualicemos como grupo social con intereses propios y en el marco de su sistema de relaciones inter e intrageneracional con marcado énfasis en el reconocimiento de su diversidad.

\section{CONCLUSIONES:}

La desigualdad social resulta expresión de la diversidad social que vive hoy las contracciones de la sociedad actual. Sentida desde la desigualdad racial, de género, territorial; además de económicas, políticas y sociales. Se ha expresado como la apertura o estrechez de las barreras sociales respecto al acceso a la oportunidad y el desarrollo de las habilidades de los sujetos para aprovecharlas.

Tradicionalmente los teóricos del tema centran la atención en los estudios sobre la estructura social y la movilidad como expresiones producentes de desigualdades sociales desde dos vertientes esenciales: el enfoque gradacional y el relacional. El posicionamiento no crítico puntea por la permanencia de una sociedad con una estructura social estable confiriéndole una explicación como condición natural humana. El otro posicionamiento teórico concibe que la desigualdad sea expresión de la manipulación de los grupos en el poder y las restricciones generadas por las instituciones sociales.

La situación socioeconómica de la región latinoamericana es muestra de la dependencia económica y su distorsión; lo cual produce un conflicto en el sector económico tradicional y genera conflictos de clases entre los intereses de la élite en el poder y las clases desfavorecidas. Su máxima expresión social se concentra en la fuga de capital, el crecimiento de los círculos de pobreza y la falta de identidad cultural en busca de una reproducción sociocultural del modo de vida elitista.

Los estudios sobre el tema en América Latina se han convertido en centro de atención por diversos centros, organizaciones y programas generadores de ciencias y políticas de desarrollo como CEPAL, UNFPA, PNUD, UNESCO, CLACSO OIJ, entre otras. El enfoque inter e intrage- 
neracional en cuanto a transmisión de la desigualdad, es hoy centro de análisis; así como el diálogo entre Política y Ciencia. El tema de la desigualdad social asume una perspectiva multisectorial y multiactoral.

El centro de atención respecto a las desigualdades en la agenda actual de las Ciencias Sociales en América Latina resulta la juventud como grupo social dinámico, contextual y a su vez vulnerable ante las estrategias adultocéntricas de la sociedad. La situación actual de la juventud en Latinoamérica hoy se encuentra en un re despertar de movilizaciones políticas y sociales en función de un proceso de reconocimiento categorial, social y práctico. El asumirse también como sujetos de acción y estar posicionando en diálogos de saber y de comunicación como actores de políticas públicas y sujetos de academia les permite asumir nuevos retos en el continente.

La juventud genera hoy un análisis articulado entre gobierno, políticas públicas, academia e instituciones u organizaciones sociales que potencien proyecciones generadas por los jóvenes lejos de una visión adultocéntrica y para los jóvenes con carácter inter e intrageneracional. La generación de políticas públicas debe romper su carácter homogéneo y atender a los grupos, capas y clases sociales tomando en cuenta las diversidades culturales, territoriales de género, raza, estructurales y de aspiraciones no solo colectiva, también individuales ante la generación actual y para las futuras generaciones.La categoría se reconcepctualiza desde lo objetivo- subjetivo teniendo en cuenta su sistema de relaciones, contexto social inmediato, las formas de expresión del sistema educacional, de empleo y de participación social desde la diversidad.

\section{BIBLIOGRAFÍA}

Atria, R.; 2004 Estructura ocupacional, estructura social y clases sociales (Santiago de Chile: . División de Desarrollo Social).

Centro de Estudio de la Juventud (CESJ) 2008 Revista Estudios sobre juventud, Enero- junio (Cuba: UNFPA).

CEPAL (Comisión Económica para América Latina y el Caribe) 2000 Panorama social de América Latina,1999-2000, (LC/G.2068-P), Santiago de Chile. Publicación de las Naciones Unidas.

Domínguez, M. I. 2008 Pasado, presente y futuro de las investigacionessobre juventud en VVAA Experiencias de investigación social en Cuba. Cuadernos del CIPS (La Habana: Editorial Caminos).

Durkheim, E. (s/f) El suicido (Cienfuegos: Universidad de La Habana)..

Equipo de Estructura Social 1988 Anuario Estudio de la sociedad cuabana 
contemporánea (La Habana: Editorial Academia).

Espina, Prieto, Mayra P. 2002 "Reajuste y movilidad social en Cuba". Presentación al XXII Congreso de Latin American Studies Asociation (LASA).

Filgueira, Carlos 2001 La Actualidad de Viejas Temáticas: sobrelos estudios de clase, estratificación y movilidad social en América Latina (Santiago de Chile: CEPAL).

Gayo, M.; Méndez, M. L.; Radakovich, R.; Wortman, A. 2011 Consumo cultural y desigualdad de clase, género y edad: un estudio comparado en Argentina, Chile y Uruguay. Serie Avances de Investigación n ${ }^{\circ} 62$ (Madrid).

López Verdecia, Y.; Muñoz Gutiérrez, T.; 2013 "Rutas de movilidad estructural ocupacional en jóvenes del la región montañosa de Cienfuegos". Informe de maestría en Sociología. Universidad de La Habana.

Luis, M. J. 2009 Análisis de la desvinculación laboral de los jóvenes en Cuba durante el período del 2000 al 2008. La Habana: Tesis de Maestría. Universidad de La Habana.

MARX, C.; 1881 Proyecto de respuesta a la carta de V. I. ZASULICH [1]. Archivos digitales maestría en Sociología. Universidad de la Habana. Cuba

Monzón, A. S. 2015 "La dinámica de las juventudes hoy: perspectiva de género y etnia". Trabajo presentado en la Escuela Internacional del Programa de Estudios sobre la Pobreza y las Desigualdades (Honduras: CLACSO).

Muñoz Gutiérrez, T. 2012 "Inicios de los estudios sobre la sociologia de la estrucura social en Cuba" (L. Y. Verdecia, Interviewer)

Elias, N. 1987 La sociedad de los individuos (Barcelona: Ed. Península).

Núñez, C. 2015 “Juventudes, participación política y desigualdades en América Latina". Trabajo presentado en la Escuela Internacional del Programa de Estudios sobre la Pobreza y las Desigualdades. CLACSO. Universidad Nacional Autónoma de Honduras (UNAH). Honduras.

Parsons, T. 1937 La estructura de la acción (s/d: Fondo de biblografía de la Maestría en Sociología).

Portes, A.; Hoffman, K. 2003 “Las estructuras de clase en América Latina: 
composición y cambios durante la época neoliberal”. Serie Políticas Sociales. Santiago de Chile.

Posada, Lucy Martin; Togores, Viviana \& Espina Prieto, Mayra P. 2009 El análisis de la movilidad social. Propuesta de una perspectiva metodológica integrada a la caracterización del caso cubano (La Habana: Centro de Investigaciones Psicológicas y Sociológicas.).

Plesnicar, Lorena Natalia 2015 “Políticas públicas para jóvenes y mujeres en América Latina. El caso de Bolivia desde la perspectiva de Ivonne Farah" (entrevistadora). Revista latinoamericana de Ciencias Sociales, Niñez y Juventud. Manizales, Colombia - Vol. $13 \mathrm{~N}^{\circ}$ 1, Centro de Estudios Avanzados en Niñez y Juventud, del Centro Internacional de Educación y Desarrollo Humano-Cinde- y la Universidad de Manizales.

Rodríguez, Ernesto 2014 "Limitaciones de las experiencias desplegadas hasta el Momento y Principales Desafíos a Encarar en el Futuro". CELAJU. II Foro de Políticas Públicas para la Igualdad, la Inclusión y la Protección Social. Quito, Ecuador.

Rodríguez, Ernesto 2002 "Políticas públicas de juventud en América Latina: de la construcción de espacios específicos, al desarrollo de una perspectiva generacional". Disponible en http://www.scielo.org. $\mathrm{co} / \mathrm{pdf} / \mathrm{rlcs} / \mathrm{v} 1 \mathrm{n} 2 / \mathrm{v} 1 \mathrm{n} 2 \mathrm{a} 02 . \mathrm{pdf}$

Rojas, I. 1988 “Intervención de Ileana Rojas en mesa redonda sobre Estructura social" en E. d. Sociología, Anuario Estudio de la socieda cubana contemporánea. Investigación sociológica sobre estructura social cubana (La Habana: Academia de Ciencias de Cuba/Instituto de Sociología y Psicología).

Rojas, I., \& Hernández, J. 1987 “La cuestión del Estado en la Sociología latinoamericana y los procesos sociales contemporáneos" en I. Rojas, \& J. Hernández Balance Crítico en la Sociología Latinoamericana Actual (La Habana: Ciencias Sociales).

Rousseau, J. 2002 "Origen de la Desigualdad entre los hombres". Tomado de wikipedia. com el 30 de julio de 2015.

Trucco, Daniela 2015 "Juventud: realidades y retos para un desarrollo con igualdad”. División de Desarrollo Social, CEPAL. Escuela Internacional del Programa de Estudios sobre la Pobreza y las Desigualdades. CLACSO. Honduras.

Vommaro, Pablo 2015 “Juventudes y políticas en la América Latina: participación política, políticas públicas y disputas por lo público". 
Escuela Internacional del Programa de Estudios sobre la Pobreza y las Desigualdades. CLACSO. Honduras.

Vommaro, Pablo 2015 Entrevista en el Suplemento Ni a palos,

DarioTiempo Argentino. http://www.niapalos.org/?p=20100

Margulis, Mario; Urresti, Marcelo 2013 "La juventud es más que una palabra”. Disponible en http://perio.unlp.edu.ar/teorias/index_ archivos/margulis_la_juventud.pdf

Weber, M. 1986 El Político y El Científico (Buenos Aires: UNSAM).

\section{ANEXOS}

\section{Gráfico 1}

Muerte por homicidio de estudiantes según nivel educativo por años (2010-2014)

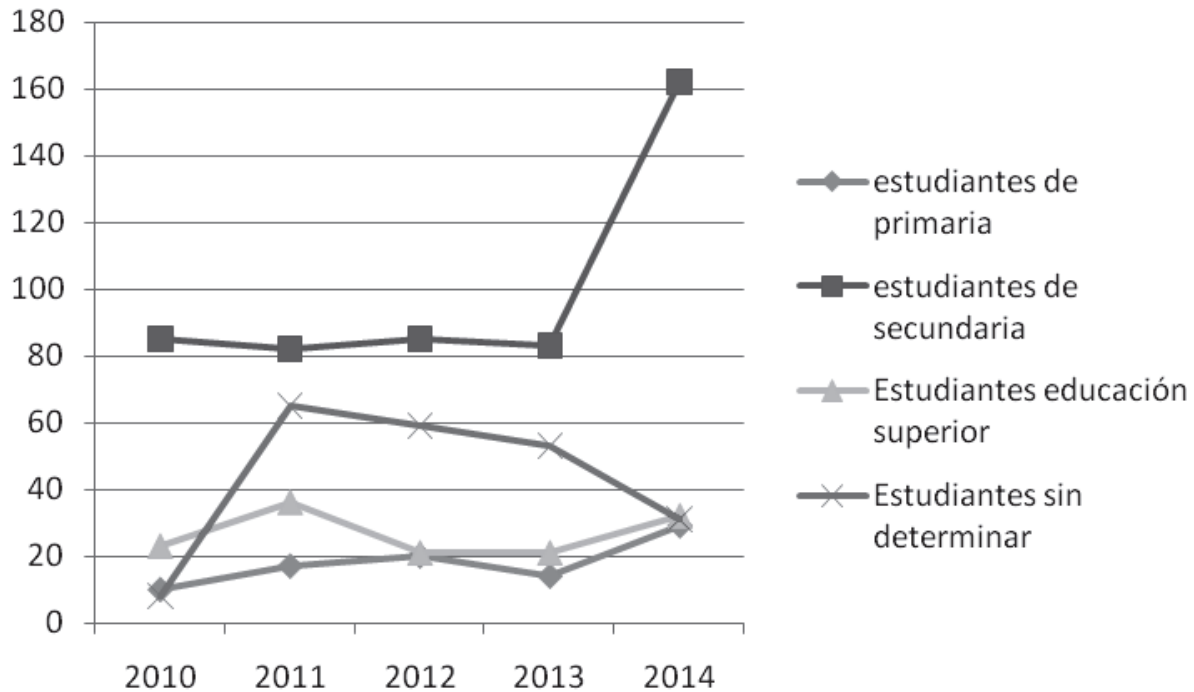

Elaborado por la autora. Datos tomados de Conferencia Clarissa Núñez. Foro “Juventudes, participación política y desigualdades en América Latina. Actualidad y Perspectivas. Escuela sobre Juventud y desigualdad social. CLACSO. 2015. 
Gráfico 2

World_Map_Gini_coefficient_with_legend_2

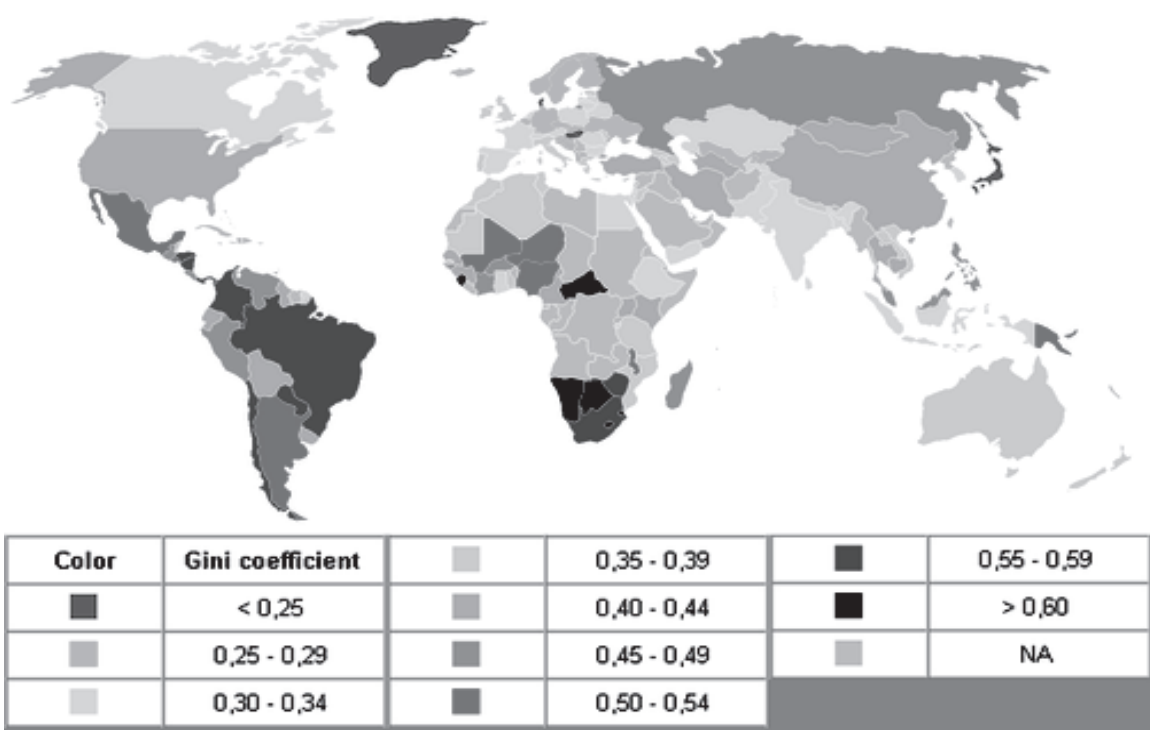

Tomado de www.wikipedia.com 
Gráfico 3

Porcentaje de jóvenes en la culminación de los diferentes niveles escolares entre el 1990 al 2012

\section{5 millones de jóvenes más escolarizados que dnies}

\section{América Latina (18 países)}

Jóvenes de 15 a 29 años que concluye la educación primaria, secundaria y terciaria, según grupo etario, 1990- 2012

(En porcentajes)

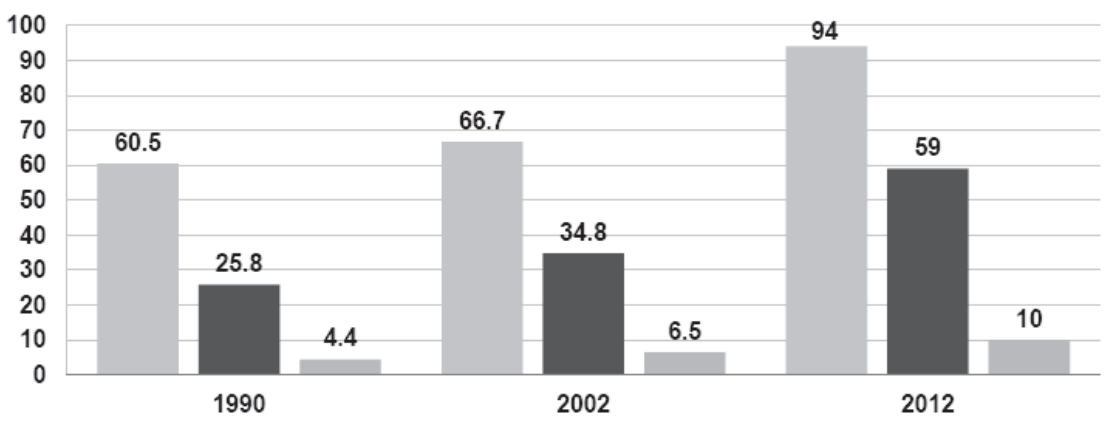

Porcentaje de jóvenes de 15 a 19 años que concluyeron la educación primaria - Porcentaje de jóvenes de 20 a 24 años que concluyeron la educación secundaria - Porcentaje de jóvenes de 25 a 29 años que concluyeron la educación terciaria

Fuente: Comisión Económica para América atina y el Caribe (CEPAL), sobre la base de tabulaciones especiales de las encuentas de hogares de los respectivos países. 



\title{
JÓVENES EN CREACCIÓN, APRENDIZAJES DESDE EL ACOMPAÑAMIENTO PSICOSOCIAL
}

\author{
Creación Colectiva* \\ Tejidos del Viento**
}

\begin{abstract}
APUNTES PARA REPENSAR NUESTRA RESPONSABILIDAD SOCIAL En la necesidad de tender un puente entre los escenarios académicos y las reflexiones que se suscitan a partir del trabajo en territorio, así como en reconocer el entramado de la realidad colombiana y latinoamericana desde dinámicas sociales, políticas, económicas y culturales disímiles
\end{abstract}

\footnotetext{
* En una apuesta por reconocer los aportes de todas las profesionales que hacen y han hecho parte de Tejidos del Viento, la autoría de este artículo es colectiva y carece de jerarquías respecto de la importancia de las investigadoras. Bogotá, Colombia. tejidosdelviento@gmail.com

** Tejidos del Viento es una OSC que realiza acompañamiento psicosocial a comunidades vulnerables y población victimizada por conflicto armado colombiano. En este proyecto participaron como investigadoras: Angélica Pineda-Silva, Magister en Psicoanálisis, Subjetividad y Cultura de la Universidad Nacional de Colombia, Psicóloga de la misma universidad. Marcela Porras Urrego, estudiante de Terapia Gestalt Integrativa de la Escuela de Transformación Humana, Psicóloga de la Pontificia Universidad Javeriana. Juliana Ospitia Rozo, Especialista en Psicología Social, Cooperación y Gestión Comunitaria de la Universidad del Bosque, Psicóloga de la Pontificia Universidad Javeriana. Ángela Ruíz López, Magister en Desarrollo Educativo y Social de la Universidad Pedagógica Nacional en asocio con el CINDE, Psicóloga de la Pontificia Universidad Javeriana. Tatiana Sarmiento Grillo, candidata a Magister en Intervención en Sistemas Humanos de la Universidad Central, Psicóloga de la Pontificia Universidad Javeriana. Alexa Rivera Taboada, estudiante de último semestre de la Licenciatura en Educación Artística de la Universidad Distrital Francisco José de Caldas, Actriz y Bailarina. Kellyn Duarte Pérez, candidata a Magister en Estudios de Género de la Universidad Nacional de Colombia, Psicóloga de la Pontificia Universidad Javeriana.
} 
y diversas, en 2011 varias profesionales de distintas áreas decidimos encarar desde nuestra praxis un contexto social que reconocemos como desigual, inequitativo y excluyente; por ello, conformamos una Organización de la Sociedad Civil que llamamos Tejidos del Viento. El nombre es una metáfora sobre el vínculo social, algo que no puedes ver pero sí sentir, como el viento.

Es importante mencionar que llamamos acompañamiento psicosocial a una atención que se realiza teniendo en cuenta que tanto lo psicológico como lo social pertenecen a un continuum, como lo señalo hace varias décadas Freud: "en la vida anímica del individuo, el otro cuenta, con total regularidad, como modelo, como objeto, como auxiliar y como enemigo, y por eso desde el comienzo mismo la psicología individual es simultáneamente psicología social en este sentido más lato, pero enteramente legítimo" (Freud, 1991: 67). A su vez, al hablar de acompañamiento psicosocial, queremos poner de presente que

no se puede desvincular el impacto individual de una perspectiva social dado el carácter político de las violaciones de derechos humanos, la importancia del contexto y las respuestas institucionales tanto en la forma en cómo se manifiestan las consecuencias y el sufrimiento, como en las circunstancias que ayudan o no a la recuperación" (Beristain, 2012: 9).

Nuestra apuesta es entonces la reconstrucción del tejido social desde acciones enmarcadas en lo cotidiano, el afecto y la colaboración. "Desde esta mirada lo relacional nos permite reconocer la complejidad de los fenómenos de violencia política y sus diferentes niveles de afectación, así como el mundo emocional, experiencial y explicativo, que son constituyentes de las realidades que se viven y al mismo tiempo lo que es susceptible de transformación" (Rodríguez, 2011: 2). Así, propiciamos espacios de encuentro que posibiliten el agenciamiento y reparación de quienes fueron vulnerados por distintas violencias.

En esta vía, y para dar cumplimiento a la política gubernamental formulada desde la Presidencia de la República de Colombia ${ }^{1}$, en febrero de 2013 la Gobernación de Cundinamarca en el marco del Plan de Desarrollo Departamental 2012-2016, Cundinamarca Calidad de Vida,

\footnotetext{
1 En el marco del Plan Nacional de Desarrollo 2010-2014 Prosperidad Para Todos, como medida de atención integral a las víctimas del conflicto armado, el Estado colombiano promulgo en 2011 la ley 1448, la cual se conoce como la ley de víctimas y restitución de tierras y que tiene como propósito "establecer un conjunto de medidas judiciales, administrativas, sociales y económicas, individuales y colectivas que beneficien a las víctimas del conflicto armado, en un marco de justicia transicional, que posibiliten hacer efectivo el goce de sus derechos a la verdad, la justicia y la reparación con garantía de no repetición" (Gobierno de Colombia, 2013).
} 
en cabeza de la Secretaría de Cooperación y Enlace Institucional, comenzó una estrategia de intervención psicosocial que priorizó a la comunidad víctima del conflicto sociopolítico de los municipios de Viotá y La Palma, los cuales a su vez fueron priorizados por la sentencia T025 de la Corte Constitucional debido a las secuelas e impactos causados por la guerra ${ }^{2}$ (Corte Constitucional, 2004 ). Con apoyo de las alcaldías municipales de los mencionados municipios, Tejidos del Viento diseñó, planificó y llevó a cabo el proyecto de acompañamiento psicosocial Telares de vida: construcciones itinerantes. La propuesta se proyectó en cuatro fases con diferentes grupos poblacionales; en el presente documento nos centraremos en la primera fase, así como el trabajo desarrollado con jóvenes rurales.

\section{TENSIONES, DESENCUENTROS Y CONTRADICCIONES}

Como menciona el Informe general Basta Ya Colombia: memorias de guerra y dignidad, realizado por el Grupo de Memoria Histórica, el conflicto armado interno en Colombia ha dejado un saldo de aproximadamente 220.000 muertos entre 1958 y 2012; de esta escalofriante cifra es preciso mencionar que el $81,5 \%$ corresponde a la muerte de civiles y el porcentaje restante a la muerte de combatientes, de donde se desprende que son las personas no combatientes quienes has sido los más perjudicados por una confrontación bélica que aún cobra vidas humanas (2013: 31). Esto sumado a los daños colaterales que ha causado y sigue causando la guerra, convierten al conflicto colombiano en uno de los más brutales de la historia reciente de la región latinoamericana.

Pese a que Colombia se reconoce como un país con una historia democrática, ajeno a dictaduras militares, como sí ocurrió en ciertas naciones centroamericanas o del cono sur, las víctimas del conflicto armado colombiano superan por mucho a las víctimas de las guerras civiles y/o dictaduras ocurridas en El Salvador, Argentina o Chile, por nombrar algunas ${ }^{3}$. Así pues, tenemos en Colombia una democracia que

2 En este punto es necesario mencionar que en la sentencia T025 de2004 proferida por la Corte Constitucional, las víctimas de desplazamiento forzado piden ayuda a diferentes entidades para recibir seguridad y acceso a diferentes derechos fundamentales tales como salud y vida digna debido a la ineficaz acción del Estado para brindar protección a dichos derechos; también es preciso mencionar que esta sentencia se emitió a dos años del primer gobierno de Álvaro Uribe Vélez.

3 Con respecto de la guerra civil salvadoreña se puede revisar el informe del año 2000 del International Committee of the Red Cross; sobre la Guerra Sucia en Argentina se puede revisar la información de la Comisión Nacional para la Investigación sobre la Desaparición de Personas (CONADEP, 1984); para el caso de la dictadura militar chilena entre 1973 y 1990 se puede consultar el Segundo Informe de la Comisión Valech. Por supuesto, entre otros documentos oficiales, así como realizados por diferentes investigadores y organizaciones. 
parece estable pero que convive con el conflicto armado de mayor duración en América Latina; en esta vía, el escenario colombiano es harto complejo y problemático pues confluyen múltiples causas y factores que perpetúan el conflicto armado interno, por lo cual establecer el impacto de la violencia en sus más de cinco décadas de duración es una tarea bastante complicada.

En la historia reciente del país ${ }^{4}$, hemos pasado de una Política de Seguridad Democrática que tenía como propósito combatir el terrorismo (Política de Defensa y Seguridad Democrática, 2003), representado en una lucha sin cuartel contra las guerrillas de las Fuerzas Armadas y Revolucionarias de Colombia (en adelante FARC) y el Ejército de Liberación Nacional (en adelante ELN), a una Política de Prosperidad Para Todos impulsada por el gobierno actual, el cual busca una salida negociada al conflicto armado por medio de la mesa de diálogos de paz instaurada en 2012 en La Habana, Cuba 5 .

Aun así, tanto el gobierno del expresidente Álvaro Uribe Vélez como el gobierno del presidente actual Juan Manuel Santos, se insertan en un marco político neoliberal. En este punto es preciso señalar que la correlación democracia capitalismo en el siglo XX ocasionó que el término democracia se haya alineado de manera paulatina con el afianzamiento del sistema capitalista. A lo largo del siglo precedente, a la par que Estados Unidos consolidaba su poder económico mediante la imposición del sistema capitalista, se introdujeron modificaciones jurídicas en las legislaciones de varios países latinoamericanos y se impulsó desde la Casa Blanca la firma de acuerdos y tratados a nivel internacional que tenían como propósito la adhesión diremos, obligatoria, al sistema democrático, produciendo lo que Soltonovich llama régimen democrático de dominación "[que] no es sino una apariencia de igualdad política que protege ideológicamente un régimen de dominación sostenedor del statu quo de asimetrías estructurales" (2010: 52).

Régimen democrático de dominación es entonces un oxímoron porque la idea de democracia excluye a la de dominación; ambos términos se contraponen generándose un contrasentido. Recordemos que desde principios de la década de los 80 se inició en Latinoamérica una serie de reformas jurídicas con el favor del Fondo Monetario Internacional, El Banco Mundial, el respaldo del gobierno estadounidense y la Reserva Federal. Bolivia, Chile y México fueron los primeros, a finales de los 80 llegó el turno para Costa Rica, Ecuador, Jamaica, Trinidad

4 Nos referimos a los cuatro últimos gobiernos 2002-2006 y 2006-2010 donde el presidente fue Álvaro Uribe Vélez y 2010-2014 y 2014-2018 donde el presidente fue y es Juan Manuel Santos.

5 Es necesario mencionar que los diálogos de paz liderados por el gobierno de Juan Manuel Santos no son el primer intento por terminar con el conflicto armado colombiano. 
y Tobago y Uruguay; en los 90 vendrían las reformas para Argentina, Brasil, Colombia, El Salvador, Guatemala, Guyana, Honduras, Nicaragua, Panamá, Paraguay, Perú y Venezuela. Asimismo, a principios de la década de los 90 el Consenso de Washington dictaría las políticas económicas para Latinoamérica lo que se evidencia entre otras cosas por las reformas constitucionales. En palabras de Atilio Borón (2004):

"Bástenos con decir que en realidad las políticas llevadas a cabo en nuestra región, lejos de haberintroducido "reformas"-estoes, cambios graduales en una dirección tendiente hacia una mayor igualdad, bienestar social, y libertad para el conjunto de la población, tal como lo indicaría la palabra "reforma" en la tradición de la filosofía política-, lo que hicieron fue potenciar una serie de transformaciones que recortaron antiguos derechos ciudadanos, redujeron dramáticamente las prestaciones sociales delestado y consolidaron una sociedad mucho más injusta y desigual que la que existía al comienzo de la etapa "reformista" (p. 19).

En Colombia por ejemplo, la reformada constitución de 1991 en su artículo primero expresa que:

Colombia es un Estado social de derecho, organizado en forma de República unitaria, descentralizada, con autonomía de sus entidades territoriales, democrática, participativa y pluralista, fundada en el respeto de la dignidad humana, en el trabajo y la solidaridad de las personas que la integran y en la prevalencia del interés general". (Sombreado propio).

Por Estado social de derecho se entiende que uno de los principales objetivos del Estado es combatir la desigualdad económica, social y en general, proteger a la población civil más vulnerable prestándole asistencia y protección; implica a su vez mejorar el nivel de vida el cual incluye la alimentación, la vivienda y la seguridad social (salud y educación). Sin embargo, un análisis un poco más detallado de la Carta Constitucional dejará ver que aquello que entendemos por derechos, están regulados como servicios; es decir, mercancías que se pueden negociar y que por ende son susceptibles de ser privatizadas. Es importante recordar que décadas antes del Consenso de Washington (1989), la UNESCO y la OMS eran los entes internacionales que regulaban las políticas públicas; actualmente y desde los 80 estas son reguladas por el FMI, el Banco Mundial, y sus filiales vía el crédito y la deuda. En esta vía, el Estado colombiano se ha caracterizado históricamente por ser un gobierno conservador que adopta las políticas neoliberales internacionales, de hecho, la inversión social que se realiza en el país es 
de 0.36 mientras que para el promedio latinoamericano es 0.58 , lo que evidencia, por un lado, que la inversión social en Latinoamérica no es muy alta y que además, Colombia se encuentra por debajo del promedio (Rodríguez, 2015).

\section{VIOTÁ Y LA PALMA, HEREDEROS DE UNA GUERRA SIN TREGUA}

Al volver sobre la pista del conflicto armado colombiano, es preciso mencionar que el mismo se ha configurado de manera particular en las diferentes regiones del país, sin embargo en los municipios de Viotá y La Palma donde Tejidos del Viento llevó a cabo su intervención, este presentó dinámicas similares como: desplazamientos forzados hacia las cabeceras municipales, municipios aledaños y Bogotá; amenazas, torturas, asesinatos selectivos, masacres, violencia sexual hacia las mujeres, señalamientos, desapariciones forzadas, montajes judiciales y reclutamiento forzado.

En la década de los 50 la violencia bipartidista golpeó a ambos municipios. En Viotá, Chulavitas y Chusmeros se enfrentaron por el control territorial; los primeros tenían la venia del partido conservador $^{6}$, los otros contaban con el apoyo de los liberales ${ }^{7}$. En La Palma, los enfrentamientos bipartidistas exacerbaron la intolerancia del partido coloreado de azul', lo que abrió paso a la incursión contra los comunistas, en su mayoría asentados en el municipio vecino de Yacopí. A finales de la década de los ochenta y principios de los noventa, el Frente 42 de las FARC toma el control territorial del municipio de Viotá; en La Palma hacia 1974 el Frente 22 de la misma organización hace lo propio, ocupando de manera progresiva gran parte del territorio; valga mencionar que a diferencia de Viotá, La Palma se configuró para esta guerrilla como un corredor estratégico más que de operaciones; en esta vía y debido a que el narcotraficante Gonzalo Rodríguez Gacha, alias "El mexicano" tenía intereses económicos y políticos en la Provincia del Rionegro 9 , a partir de los ochenta se da apertura a una guerra antiguerrilla (Tejidos del Viento, 2013).

Hacia el 2000 el conflicto se recrudeció con un nuevo actor armado, los paramilitares. A Viotá llegaron las Autodefensas Campesinas del

6 Partido político tradicional de Colombia que tiene una ideología conservadora.

7 El Partido Liberal Colombiano se ha identificado de manera tradicional con el color rojo y se adscribe a una ideología política de corte liberal.

8 Hacemos referencia al Partido Conservador Colombiano, el cual tradicionalmente se ha identificado con el color azul.

9 La Provincia de Rionegro se encuentra situada en el extremo noroccidental del departamento de Cundinamarca y es conformada por los municipios: El Peñon, La Palma, Pacho, Paime, San Cayetano, Topaipí, Villagómez y Yacopí. 
Casanare (ACC) al mando de alias "Martín Llanos" en complicidad con algunos miembros de la fuerza pública -el Batallón 28 Colombia con sede en La Mesa Cundinamarca- ${ }^{10}$ (Verdad abierta, 2012). El objetivo era acabar con la guerrilla en el marco de la Política de Seguridad Democrática del expresidente Álvaro Uribe Vélez. En un hecho sin precedentes, el 29 de marzo del año 2003 gran parte de la población rural fue desplazada de manera forzosa hacia el casco urbano (Casas, 2012). Algunos campesinos volvieron tiempo después, otros no lo hicieron jamás.

En el caso de La Palma, los enfrentamientos se dieron entre el Frente 22 de las FARC, el Frente Policarpa Salavarrieta, las Autodefensas Unidas de Cundinamarca al mando de alias "El Águila" y alias "Tumaco" y la Fuerza Pública con las operaciones Libertad 1 y 2 en los años 2002 y 2003 (Sentencia 001: proceso de restitución y formalización de tierras abandonadas forzosamente, 2014). A mediados del 2001 se agrava la guerra por la disputa del territorio entre guerrilla y paramilitares, lo que provocó varios desplazamientos forzados entre los que cabe destacar el ocurrido el 2 de agosto de 2002 cuando un grupo de paramilitares al mando de alias "Tumaco" entró a la vereda Hoya de Tudela, reunió a sus pobladores y los amenazó con asesinarlos si no salían del pueblo, pues según dijeron, se iban a enfrentar con la guerrilla. Otro desplazamiento masivo ocurrió el 15 de septiembre de ese mismo año. Los campesinos que habitaban las veredas de Murca, Rio Arriba, Ático, Alpujarra, Hortigal, Talanquera, Tabacal, el Potrero, La Hermosa, Hinche, Rio Negro y Acuaparal desalojaron en un lapso de 24 horas sus propiedades por temor a la orden de bombardeo y asesinato en el marco de dichos enfrentamientos. El 2 de octubre de 2002 otro desplazamiento se presentó cuando paramilitares llegaron en horas de la mañana a las veredas El Hoyo y Garrapatal y causaron el desplazamiento de 41 personas. En este caso también amenazaron a los pobladores para que salieran de su tierra y asesinaron a algunos campesinos a quienes acusaban de ser colaboradores de la guerrilla (Verdad abierta, 2013).

En el año 2002 más de 200 familias desplazadas retornaron al territorio con el acompañamiento de la Red de Solidaridad, la Gobernación de Cundinamarca, autoridades locales y la Cruz Roja. Sin embargo, este acompañamiento no fue continuo y la población civil palmera y viotuna quedó de nuevo a merced de grupos armados reorganizados que impidieron que estas familias llevaran una vida tranquila.

10 Alias “El Diablo' (lugarteniente de alias "Martín Llanos") relató cómo se manejaron las relaciones con algunos miembros del Batallón Colombia de Infantería 28 del ejército, con sede en la Mesa, Cundinamarca. 


\section{METODOLOGÍA, INTERACCIÓN E INTERVENCIÓN}

En el marco del contexto de violencia sociopolítica que aqueja a Colombia, a lo largo del 2013 realizamos un proceso de acompañamiento psicosocial a jóvenes rurales de los municipios de La Palma y Viotá, víctimas y herederos del conflicto armado colombiano. El trabajo se realizó bajo la convicción de que para poder entrelazar y unir los hilos desfragmentados por el conflicto sociopolítico del país, es necesario reconocer el poder del cuidado, del estar juntos y juntas, así como la eficacia de las prácticas de bienestar y solidaridad; por ello, a lo largo del proceso se promovió el compartir la palabra, las experiencias de vida y los saberes en espacios de respeto y reflexión colectiva. En este sentido "la invitación a la palabra o la obligación al silencio, el apoyo afectivo o el desprecio, la ayuda social o el abandono cargan la misma herida de una significación diferente según el modo en que las culturas estructuren sus relatos, haciendo que un mismo acontecimiento pase de la vergüenza al orgullo, de la sombra a la luz" (Cyrulnik, 2009: 23).

$\mathrm{Al}$ inicio de nuestra intervención y con el respaldo y la colaboración de las alcaldías municipales, identificamos a líderes y lideresas comunales a quienes llamamos actores faro ${ }^{11}$, en clara resonancia con los aportes provenientes de la etnografía ${ }^{12}$ y la Investigación Acción Participación (IAP) ${ }^{13}$. Con dichos actores generamos varios encuentros y junto con ellos llegamos a la conclusión de que era urgente priorizar la atención psicosocial en los jóvenes. Esto por varias razones entre las que cabe destacar el hecho de que este grupo poblacional no había recibido hasta el momento ningún tipo de atención, la necesidad de generar una apropiación del campo en los nuevas generaciones y la importancia de tramitar diferentes traumas y dolores que habían sido invisibilizados o dejados de lado.

Así pues, nos acercamos a las instituciones educativas veredales, y le compartimos a docentes, directivos y estudiantes la iniciativa de realizar un acompañamiento psicosocial cargado de sentido a partir de las necesidades particulares de cada territorio. De la mano creativa y

11 Llamamos actor faro a una persona que conoce las dinámicas sociales, económicas, culturales y/o políticas de la comunidad a la que pertenece, y a la vez, se encuentra interesado en apalancar los procesos de intervención que se pretendan llevar a cabo en su territorio.

12 "Como enfoque la etnografía es una concepción y práctica de conocimiento que busca comprender los fenómenos sociales desde la perspectiva de sus miembros -entendidos como actores, agentes o sujetos sociales- (Guber, 2001, p. 13).

13 "En la investigación-acción es fundamental conocer y apreciar el papel que juega la sabiduría popular, el sentido común y la cultura del pueblo, para obtener y crear conocimientos científicos, por una parte; y reconocer el papel de los partidos y otros organismos políticos o gremiales, como contralores y receptores del trabajo investigativo y como protagonistas históricos, por otra"(Fals Borda, 2015, p. 279) 
propositiva de los jóvenes, promovimos encuentros en los colegios veredales para pensar de manera colectiva estrategias que nos permitieran solucionar los conflictos por vías no violentas; entonces, comenzamos a encontrarnos cada quince días en un espacio que decidimos llamar Jóvenes en CreAcción. Tanto los objetivos del mismo como las temáticas a trabajar fueron co-construidas con los adolescentes a partir de sus problemáticas locales y cotidianas. Cabe mencionar que entendemos la cotidianidad "como [una] unidad fundamental de análisis social, [que] encuentra su expresión concreta en las comunidades a las que pertenecen los individuos en cuestión" (Ortega, 2008: 24). Es importante destacar que los aportes de los jóvenes siempre fueron tenidos en cuenta para jalonar las reflexiones; a partir de las expectativas y miedos individuales y el compartir los mismos en un espacio de confianza, respeto y empatía, los aprendizajes tuvieron lugar desde adentro, es decir, desde el día a día de quienes participamos en este espacio.

En este punto resulta necesario señalar que desde Tejidos del Viento trabajamos bajo cuatro ejes transversales de acción: conversacional, artístico, experiencial y participativo. El primer eje se traduce en el reconocimiento y la importancia de la palabra, el encuentro entre personas en un marco de respeto, escucha atenta y perceptiva, en disposición de cambio frente a las necesidades particulares tanto de contexto como subjetivas pues "la existencia, en tanto humana, no puede ser muda, silenciosa, ni tampoco nutrirse de falsas palabras sino de palaras verdaderas con las cuales los hombres transforman el mundo" (Freire, 2005: 106). El diálogo entendido entonces como un acuerdo y una necesidad de reivindicar la confianza y la fuerza de aquello que decimos, cómo, cuándo, donde, por qué y a quién se lo decimos, a partir de la premisa de que la experiencia narrativa construye realidades las cuales dotan de sentido y significado aquello que vivimos.

El componente artístico articula la capacidad creadora de todo sujeto humano. La posibilidad de reconectarnos con el goce que supone el encuentro con diferentes materiales, texturas, colores, formas y técnicas, nos permite recordar y reflexionar sobre la construcción y deconstrucción de las percepciones que fabricamos y bajo las cuales vivimos nuestras vidas. Lo estético es, entonces, aquello que nos permite movilizar diferentes afectos, sentimientos, emociones y percepciones. En este sentido, "la educación artística desempeña una función cultural. El principal aporte que hace la educación artística en el desarrollo cultural de nuestras comunidades radica en que es un actividad que propicia un modo de conocimiento particular por el cual se desarrolla la dimensión valorativa del ser humano" (Magisterio de Educación, 2000: 83). En otras palabras, el arte nos permite dar cuenta de la existencia de diferentes maneras de comunicar el sentirnos vivos, encontrando en la 
multiplicidad de las expresiones artísticas, así como en sus contrastes, el reconocimiento de una diferencia que nos enriquece.

El eje experiencial, donde vislumbramos que cada persona es producto de una historia, y que esa historia es el resultado del día a día que moldea lo que somos en el presente, y lo que podemos y queremos llegar a ser en el futuro. La vivencia cotidiana como el espacio donde emergen aprendizajes fundamentales, las victorias diarias como fuente de reconocimiento frente a lo que somos. Si logramos entender que nuestras experiencias personales son fundamentales para comprender nuestra sociedad, pues hacen parte de la misma, podríamos aventurarnos a decir que cada persona es una hebra del tejido tan importante como cualquier otra y que sólo por este hecho, su experiencia es digna de ser contada, escuchada, valorada y reconocida, pues como en un ejercicio de microhistoria, a partir de las vivencias de cada uno, podríamos reconstruir toda una percepción del mundo (Ginzburg, 1999).

Y finalmente el eje participativo, en el cual reconocemos la importancia de que los sujetos y las comunidades se apropien de las iniciativas para que a partir de una construcción colectiva, los proyectos estén aterrizados en las particularidades de cada colectivo y sea justo desde allí, desde donde las problemáticas al ser intervenidas se conviertan en posibilidades de cambio y mejora (Martín-Baró, 1998).

Tabla 1

Análisis cuantitativo del programa Jóvenes en CreAcción en los municipios de Viotá y La Palma

\begin{tabular}{|c|c|c|c|c|c|}
\hline Municipio & Vereda & $\begin{array}{l}\text { Grado de } \\
\text { escolarización }\end{array}$ & $\begin{array}{l}\text { Rango de } \\
\text { edad (años) }\end{array}$ & $\begin{array}{l}\text { \# de } \\
\text { participantes }\end{array}$ & $\begin{array}{l}\text { \# de } \\
\text { encuentros }\end{array}$ \\
\hline \multirow[t]{5}{*}{ Viotá } & Liberia & $\begin{array}{l}\text { Sexto, Séptimo y } \\
\text { Octavo }\end{array}$ & $11-16$ & 27 & 6 \\
\hline & Liberia & $\begin{array}{l}\text { Noveno, Décimo } \\
\text { y Undécimo }\end{array}$ & $13-19$ & 27 & 6 \\
\hline & Bajo Palmar & Sexto & $11-14$ & 35 & 4 \\
\hline & Bajo Palmar & Séptimo & $12-14$ & 40 & 4 \\
\hline & Bajo Palmar & Noveno & $14-16$ & 20 & 4 \\
\hline \multirow[t]{4}{*}{ La Palma } & Hortigal & Octavo y Noveno & $12-15$ & 30 & 10 \\
\hline & Hortigal & $\begin{array}{l}\text { Décimo y } \\
\text { Undécimo }\end{array}$ & $14-18$ & 15 & 10 \\
\hline & $\begin{array}{l}\text { Minipí de } \\
\text { Quijano }\end{array}$ & Octavo & $12-20$ & 36 & 7 \\
\hline & $\begin{array}{l}\text { Minipí de } \\
\text { Quijano }\end{array}$ & Noveno & $13-19$ & 22 & 7 \\
\hline
\end{tabular}


Como se puede observar en la tabla 1, en el municipio de Viotá trabajamos con 149 personas entre los 11 y los 19 años provenientes de las veredas de Bajo Palmar y Palestina y en el municipio de La Palma contamos con la participación de 103 jóvenes con edades entre los 12 y los 20 años habitantes de las veredas Hortigal y Minipí de Quijano. En total se conformaron 9 grupos, cinco de Viotá y cuatro de La Palma divididos en edades y nivel de escolarización.

La sistematización de la experiencia de los espacios de encuentro permitió concluir que en cuanto a las expectativas de los jóvenes para su futuro a mediano y largo plazo, se aspira con estudiar una profesión para lograr reconocimiento social y mejores condiciones económicas. En muchos casos la opción resulta ser una carrera militar por ser vista como una opción más estable y accesible; también se desea transformar ciertos aspectos de las instituciones educativas, las cuales, si bien, son percibidas como espacios de seguridad y protección, también son consideradas como instituciones autoritarias, por lo que los jóvenes reclaman la creación de espacios de integración y esparcimiento que mejoren la convivencia; en general se manifiesta una necesidad de transformar las condiciones sociales, económicas, políticas y culturales de los territorios locales con lo cual se apunta a una transformación del país. De otro lado, existe un miedo constante de perder a la familia o algún miembro de ella, así como a expresar los puntos de vista u opiniones personales. Basándonos en los testimonios de varios jóvenes, analizamos que dicho temor tiene que ver de manera directa con secuelas del conflicto armado, pues en las dinámicas de la guerra, de un lado, la amenaza de perder a alguien cercano es real e inminente, y de otro, el silencio se vuelve un mecanismo de defensa para proteger la vida.

A pesar de que en los encuentros los jóvenes se mostraron participativos y abiertos, fue necesario co-construir con ellos una serie de acuerdos y compromisos como: no burlarse, ni "boletear"14 al otro, reconocer las capacidades propias y de los demás, respetar al que sea o piense diferente, y escuchar de manera atenta. Estos acuerdos resaltan el compromiso y la búsqueda que tienen los estudiantes por desarrollar una capacidad crítica y de transformación, respecto a su ciclo vital y a lo que significa ser joven en un país como Colombia, especialmente en un contexto rural que ha sufrido la violencia.

Mediante la construcción colectiva se promovió la autonomía y el agenciamiento de los jóvenes, además de que al identificar y visibilizar el impacto del conflicto armado y de otras violencias, también se despertó en el grupo la consciencia de sus necesidades, fortalezas, estrategias de organización y comunicación asertiva para conseguir lo

14 Modismo que refiere a no hacer quedar mal a otra persona delante de los demás. 
que se desea; no solo de manera específica en el marco del desarrollo del proyecto, sino de manera general, en la adquisición de herramientas, que se espera, se extrapolen a otros contextos. En el marco de los diálogos propiciados, los jóvenes manifestaron sus preocupaciones respecto a la falta de oportunidades, el hacinamiento en las aulas escolares, la deficiencia del sistema de salud y el acceso precario de las vías, por lo que muchos manifiestan el deseo de migrar desde las zonas rurales hacia las cabeceras municipales y en gran medida, hacia la capital.

Cabe mencionar que la construcción de confianza fue un proceso al que se debió prestar especial atención, pues los jóvenes de los sectores rurales con los cuales interactuamos se mostraron en un principio callados, recelosos de conversar sobre su vida, ensimismados y con dificultades para posicionar su voz ante los demás y pedir aquello que necesitan. Esto motivó que se generaran metodologías artísticas que les permitieran expresarse por medio de lenguajes más allá de la palabra, en el sentido que "la educación artística retorna, justamente, a las fuentes originales de la memoria" (Monsalve, 2013: 37). A medida que se desarrollaron las sesiones y se dio plena legitimidad a las demandas y propuestas de los jóvenes, se logró reconocer la importancia de la comunicación, de la asertividad y del posicionamiento de sus voces desde el respeto y el cuidado.

Respecto al territorio, los jóvenes identificaron lugares que perciben como peligrosos, pues estos están asociados con la ocurrencia de diferentes prácticas victimizantes (tortura, reclutamiento forzado, secuestro, entre otros) por parte de los diferentes actores armados legales e ilegales; por esta razón, los estudiantes centraron gran parte del trabajo realizado en la necesidad de transformar dichos espacios cargados de un imaginario negativo. Asimismo, identificaron ciertos derechos que no les han sido reconocidos o que son vulnerados, como por ejemplo: la falta de oportunidades para una buena educación profesional, la mala atención en salud, el derecho a un trabajo digno, la poca posibilidad para la libre expresión, entre otros. Las discusiones suscitadas llevaron a que en el interior del grupo se repensaran los derechos y los deberes, así como los mejores medios para agenciarlos. Así, se construyeron campañas comunicativas para toda la comunidad académica, en donde primero se expresó la situación conflictiva, para luego proponer acciones que generaran cambios. Poder expresarse y ser escuchados fue percibido por los jóvenes como el ejercicio más importante de la intervención de Tejidos del Viento, pues son pocos los espacios en los que se sienten reconocidos y en la que su voz es potente y tenida en cuenta. 


\section{REFLEXIONES, RETOS Y DESAFÍOS}

Desde el proyecto Telares de Vida: construcciones itinerantes la Fundación Tejidos del Viento evidenció, en términos psicosociales, que la presencia de los grupos armados legales e ilegales han legitimado el uso de la violencia y la autodefensa, lo cual ha conllevado a naturalizar la impunidad. Si bien en el marco de las políticas públicas tanto de juventud como de atención integral a víctimas del conflicto armado colombiano se ha buscado generar acciones para reivindicar los derechos de los jóvenes, al no haber una política integral las acciones muchas veces resultan descoordinadas. Además, es preocupante cómo se construyen significados sobre lo ocurrido que naturalizan, legitiman o justifican las violaciones de Derechos Humanos poniendo en muchos casos la responsabilidad sobre las víctimas.

En el caso de los jóvenes rurales, los miedos y secuelas se expresan en la dificultad de expresarse, de exigir sus derechos, en la fragmentación de los vínculos y en el deseo de abandonar el campo para intentar buscar mejores posibilidades en las grandes urbes; estos adolescentes, hijos de la violencia sociopolítica, en particular la vivida desde comienzos de la década del dos mil, provienen en su mayoría de familias que fueron afectadas de una u otra manera con diferentes tipos de victimizaciones por los actores armados legales e ilegales. En el momento de la arremetida paramilitar en los territorios rurales, quienes ahora son la población joven de Viotá y La Palma, eran niños que resintieron crecer en medio de un conflicto armado que rebasaba sus posibilidades de comprensión. En este sentido, resulta urgente "examinar las prácticas políticas, las formas de asociación, las maneras de relacionarse con el entorno y con la naturaleza, las prácticas productivas y en fin, todos aquellos planos en los cuales la constitución de un ser joven reproduce los elementos dominantes en el conjunto de la sociedad, o por el contrario, idea prácticas de resistencia" (Useche, 2009: 34).

Asimismo, el impacto psicosocial se ha profundizado por la revictimización de la que han sido objeto los familiares y las víctimas de los municipios antes mencionados, quienes de manera constante afirman que la respuesta estatal ha sido débil y que inclusive, se han sentido maltratadas, violentadas o ignoradas por algunas de las instituciones que debían protegerlos o acompañarlos. Estos dos municipios han estado marcados por diferentes tipos de violencias, que han fragmentado el tejido social, dejando esteras de desconfianza, miedo, y en donde los habitantes se reconocen como víctimas directas e indirectas del conflicto armado, y también del abandono de la institucionalidad; así mismo, reclaman sus derechos y hacen saber sus denuncias y quejas a diferentes niveles. Por lo anterior, es importante hacer un reconocimiento de los contextos y de las historias violentas allí enmarcadas, que 
permitan evidenciar bajo qué intereses se dieron los enfrentamientos y cómo se han redefinido los espacios que habitan las personas afectadas por el conflicto armado colombiano.

Aún son imprecisas las cifras sobre el número de víctimas que ha dejado la violencia sociopolítica del país y se desconoce en profundidad la verdad acerca de los hechos que ocurrieron en tantos años de terror, miedo y silenciamiento; los jóvenes en sus relatos revelan un dolor y un sufrimiento que es necesario reparar de manera integral. La confrontación armada afectó todas las esferas de la vida, por lo que los jóvenes han experimentado incertidumbre, angustia, confusión, tristeza, culpa, rabia, ansiedad, miedo, deseos de venganza, impotencia, desesperanza y frustración. En este sentido, "la negligencia institucional que no prevé la ayuda médica, psicológica o financiera, o la negligencia cultural de una sociedad que deja de lado a sus lisiados porque ya no tienen valor, todas esas maneras de distanciarse paralizan el proceso de emprender una trayectoria resiliente y encierran a una parte de la población en una especie de campo de refugiados psíquicos que ya no podrán participar en la aventura social" (Cyrulnik, 2009: 52)

La mayoría de los jóvenes con quienes trabajamos presenta, además, una gran dificultad para identificar las propias capacidades, recursos y posibilidades, por lo cual definir su proyecto de vida ha sido un gran reto. De esta manera, se evidencia cómo el conflicto armado y las múltiples violaciones a los DD HH y al DIH que han ocurrido en estos dos municipios han alterado la dignidad y el desarrollo personal, social y político de las personas. Lo anterior se ha profundizado porque las exigencias de verdad, justicia y reparación integral no han sido atendidas de forma adecuada lo que evidencia un gran límite de la política pública de atención a población víctima del conflicto armado.

Si bien, existe un registro aproximado del número de víctimas producto del conflicto sociopolítico en Colombia ¿Qué nos dicen las cifras? ¿Podemos siquiera imaginarnos tales números? ¿Dónde queda la dimensión subjetiva en medio del mar de estadísticas? ¿Acaso podemos medir la dimensión del desgarrón traumático? En medio de una realidad devastadora, resulta legítimo preguntarnos por el papel de cada uno de nosotros, testigos de nuestro tiempo; interrogarnos sobre cómo fue que ocurrió todo esto, qué fue lo que determinó que nuestra realidad pasara de ser irrepresentable por el horror que la deshacía, a convertirse en un show mediático indiferente y atiborrado de imágenes que nos ceban y adormilan. De allí que la apuesta de Tejidos del Viento sea en pro de reintroducir la dimensión subjetiva, aquella que no pasa por los datos y que configura un imaginario social; reconociendo en la diferencia una oportunidad de crecimiento, y no una amenaza. Entonces, desde estos marcos de referencia, nuestra apuesta se juega en la 
construcción de paz desde abajo, es decir, desde los procesos de base cargados de significado por los jóvenes y para los jóvenes, en pro de contribuir a la construcción de paz desde la noviolencia, pues "la paz se entiende como una tarea permanente, una posibilidad de construcción, un principio ético sobre el cual se establecen reglas del juego colectivas, que son posibles gracias a la cultura y la creatividad humanas" (Vela, G, Rodríguez, J, Rodríguez, A \& García, L, 2011: 27)

De otro lado, es necesario reconocer que el acompañamiento psicosocial a población víctima del conflicto armado es un proceso que debe pensarse a largo plazo, pues la intervención además de otros componentes, debe contemplar un tiempo impredecible en el cual es fundamental el establecimiento de vínculos de confianza que en muchos casos resultan bastante difíciles justamente por las secuelas de la guerra. En esta vía, muchas veces es bastante complejo dar continuidad a los procesos ya que por lo general este tipo de proyectos dependen de la financiación de agentes externos para llevarse a cabo. Aunque las personas participantes son conscientes de los cambios y dificultades en este tipo de proyectos, pues en una dinámica de respeto y horizontalidad con los participantes se exponen las limitaciones del mismo, existe una alta expectativa y demanda de acompañamiento psicosocial. La ejecución del proyecto evidenció que en todas las instituciones educativas en las que se hizo presencia durante el año 2013, es urgente que se garanticen servicios de atención psicosocial y formación en derechos humanos, lo cual supone la facilitación de recursos y profesionales que asuman esta labor. Sin embargo, este punto nos encontramos de nuevo con la dificultad de los recursos económicos, pese a que esta atención está contemplada en diferentes puntos tanto de la política pública de atención a población víctima del conflicto armado, como en la política pública de infancia y adolescencia.

En cuanto a la situación de los jóvenes, se ha evidenciado la necesidad de diseñar e implementar políticas públicas de juventud en ambos municipios que reconozcan a los mismos como sujetos de derechos que pueden liderar procesos de transformación en sus comunidades. Para ello es importante que se construya una caracterización sobre la situación de la juventud, en la que se indague sobre sus expectativas académicas y laborales para diseñar estrategias que favorezcan el arraigo y la construcción de proyectos de vida en los municipios. Adicionalmente, es importante que se fortalezcan alianzas con las instituciones de educación superior para facilitar el acceso a programas técnicos en las veredas. También es importante que se apoyen las iniciativas productivas de los jóvenes incentivando el desarrollo de los proyectos productivos que se diseñan en los colegios. Esta política también debe incluir programas de ocio y esparcimiento que permitan a los jóvenes 
distanciarse del consumo de alcohol y de sustancias psicoactivas que se está posicionando en los municipios.

Adicionalmente la política pública debería incluir formación en derechos sexuales y reproductivos para prevenir los embarazos adolescentes y garantizar el uso de métodos anticonceptivos, aunque por supuesto una política sobre el cuidado y autocuidado rebasa lo concerniente al uso de métodos de planificación. Asimismo, es importante que se promueva la participación y organización juvenil, así como el fortalecimiento de liderazgos en cada una de las veredas. Paralelamente, es urgente que en ambos municipios se difunda y defienda el derecho de los jóvenes a declararse como objetores de conciencia al servicio militar obligatorio, tal como lo establece la sentencia C- 728 de 2009 de la Corte constitucional que reconoce la objeción como un derecho fundamental.

\section{BIBLIOGRAFÍA}

Beristain, C. 2012 Acompañar los procesos con las víctimas (Fondo de Justicia Transicional: Programas Promoción de la Convivencia y Fortalecimiento a la Justicia. PNUD: Programa Fortalecimiento a la Justicia. Disponible en http://www.psicosocial.net/grupo-accioncomunitaria/centro-de-documentacion-gac/trabajo-psicosocial-ycomunitario/herramientas-investigacion-accion-participante/833acompanar-los-procesos-con-las-victimas/file Recuperado en enero de 2016

Boron, A. 2004 Estado, capitalismo y democracia en América Latina (Buenos Aires: CLACSO).

Casas, L. 2012 Fe, militancia y memoria: tres vidas en Viotá (Bogotá: Universidad Nacional de Colombia. Facultad de Ciencias Humanas, Departamento de Antropología).

Cyrulnik, B. 2009 Autobiografía de un espantapájaros. Testimonios de resiliencia: el retorno a la vida (Barcelona: Gedisa).

Fals Borda, O. 2015 Una sociología sentipensante para América Latina (México: Siglo XXI/CLACSO).

Freire, P. 2005 Pedagogía del oprimido (México: Siglo XXI Editores).

Freud, S. 1991 Psicología de las masas y análisis del yo en Obras Completas vol. 18. (Buenos Aires: Amorrortu).

Ginzburg, C. 1999 Mitos, emblemas, indicios (Barcelona: Gedisa).

Gobernación de Cundinamarca 2006 División provincial de Cundinamarca edición 2006, 1:1000000. Disponible en http://cundinet. cundinamarca.gov.co:8080/Aplicaciones\%5CGobernacion\%5CM 
apasPla.nsf/0/34F584E1C8DD5DE405257C36001F5C31/\$FILE/ provincias-2006.pdf Recuperado en febrero de 2014.

Gobierno de Colombia 2010 Plan Nacional de Desarrollo 2010-2014: Prosperidad para Todos. Disponible en https://www.dnp.gov.co/PlanNacional-de-Desarrollo/PND-2010-2014/Paginas/Plan-NacionalDe-2010-2014.aspx Recuperado en enero de 2015.

Gobierno de Colombia 2013 "Urna de cristal, Portal de Participación ciudadana" en Abecé de la ley de víctimas. Disponible en http:// www.urnadecristal.gov.co/gestion-gobierno/abece-ley-de-victimas. Recuperado en agosto de 2015.

Gobierno de Colombia. Ministerio del Interior y de Justicia 2011. Ley de víctimas y restitución de tierras. Disponible en http://www. unidadvictimas.gov.co/normatividad/LEY+DE+VICTIMAS.pdf Recuperado en junio de 2015.

Gobierno de Colombia. Departamento Nacional de planeación 2014. Política Pública de Infancia y Adolescencia. Disponible en https:// www.dnp.gov.co/programas/desarrollo-social/pol\%C3\%ADticassociales-transversales/Paginas/infancia-y-adolescencia.aspx Recuperado en julio de 2015.

Grupo de Memoria Histórica de la Comisión Nacional de Reparación y Reconciliación 2013 ¡Basta ya! Colombia; Memorias de guerra y dignidad (Bogotá: Imprenta Nacional).

Guber, R. 2001 La Etnografía. Método, Campo y Reflexividad (Bogotá: Grupo Editorial Norma).

Martín Baró, I. 1998 Psicología de la Liberación (Madrid: Trotta).

Ministerio de Educación Nacional 2010 Orientaciones pedagógicas para la educación artística en básica y media. Disponible en http:// www.mineducacion.gov.co/1621/articles-340033_archivo_pdf_ Orientaciones_Edu_Artistica_Basica_Media.pdf Recuperado en enero de 2016.

Monsalve, J. 2013 Plan de estudios educación artística (Bogotá: Ediciones Sem).

Ortega, F. 2008 "Rehabitar la cotidianidad” en Veena Das: sujetos del dolor, agentes de dignidad (Bogotá: Universidad Nacional de Colombia. Facultad de Ciencias Humanas/Pontificia Universidad Javeriana/ Instituto Pensar).

Presidencia de la República, Ministerio de Defensa Nacional 2003 Política 
de Defensa y Seguridad Democrática. Disponible en http://www.oas. org/csh/spanish/documentos/Colombia.pdf . Recuperado en agosto de 2015 .

República de Colombia, Corte Constitucional 2004 Sentencia T025 de 2004. Disponible en http://www.corteconstitucional.gov.co/ relatoria/2004/t-025-04.htm Recuperado en mayo de 2013.

República de Colombia, Rama Judicial del Poder Público 2014 Sentencia 001: proceso de restitución y formalización de tierras abandonadas forzosamente. Disponible en http://www.legismovil.com/ BancoMedios/Archivos/sent-850013121001201400001-14.pdf Recuperado en enero de 2015.

República de Colombia, Corte Constitucional 2009 Sentencia C-728 de 2009. Disponible en http://www.corteconstitucional.gov.co/ relatoria/2009/C-728-09.htm Recuperada en mayo de 2013.

Rodríguez, M. 2011 Lo psicosocial: miradas posibles, diálogos fértiles. Conversaciones para seguir imaginando el presente" (Bogotá: Impresol Ediciones).

Rodríguez, E. 2015 Tipos de Gobierno y Politicas Públicas de Juventud en América Latina: ¿Existe algún tipo de correlación? Conferencia inaugural de la Escuela Internacional Juventud y desigualdad en América Latina y el Caribe (Tegucigalpa: CLACSO/UNAH).

Soltonovich, A. 2010 "La democracia y su oxímoron: notas sobre el concepto de régimen democrático de dominación” en Restrepo Domínguez, M. (Comp.) Teoría crítica y derechos Humanos (Bogotá: Universidad Pedagógica y Tecnológica de Colombia).

Tejidos del Viento 2013 Informe Final Proyecto Telares de Vida:

Construcciones Itinerantes. Disponible en www.tejidosdelviento.org Recuperado en enero de 2016.

Useche, O. 2009 Jóvenes produciendo sociedad. Subjetividades, derechos sociales y productividad juvenil (Bogotá: Corporación Universitaria Minuto de Dios UNIMINUTO, Facultad de Ciencias Humanas y Sociales /Centro de Estudios e Investigaciones Humanas y Sociales).

Vela, G., Rodríguez, J., Rodríguez, A. \& García, L. 2011 Acción sin daño como aporte a la construcción de paz: Propuesta para la práctica.

Disponible en: http://www.pnud.org.co/img_uplo ad/61626461626434343535373737353535/2011/accion_sin_dano. pdf Recuperado en enero de 2016. 
Verdad Abierta 2012 El Diablo "Martín Llanos" en Cundinamarca.

Disponible en http://www.verdadabierta.com/justicia-y-paz/ versiones/525-autodefensas-campesinas-de-casanare/4063-el-diablode-martin-llanos-en-cundinamarca Recuperado en enero de 2015

Verdad Abierta 2013 El terror que los paramilitares sembraron el la Palma, Cundinamarca. Disponible en http://www.verdadabierta. com/justicia-y-paz/imputaciones/5070-el-terror-que-losparamilitares-sembraron-en-la-palma-cundinamarca Recuperado en enero de 2015. 



\title{
AMPLIAÇÃO NO CAMPO DE POSSIBILIDADES DE JOVENS EM VULNERABILIDADE SOCIAL: A EXPERIÊNCIA DA CASA DAS JUVENTUDES
}

\author{
Bruna Rossi Koerich*
}

\section{INTRODUÇÃO}

A problemática da segurança pública obteve lugar de destaque no Brasil desde o processo de urbanização vivenciado no país. Contudo, a partir da década de 1980 o debate cresce em importância e em investimento público, sendo entendido como uma das prioridades nacionais. Apesar dos altos investimentos em políticas de repressão e controle da criminalidade, o país continuou apresentando elevados índices de violência urbana, em comparação com outros países.

Essa permanência, associada com os indicadores de superpopulação carcerária suscitaram a perspectiva de que entender a segurança pública apenas a partir da lógica de repressão não é suficiente para atenuar os efeitos de um fenômeno social tão massivo e complexo como a violência urbana. Dessa forma, ganham força, na última década, planos de ação voltados à prevenção da criminalidade e da letalidade, especialmente a de públicos mais atingidos por esse fenômeno, como a juventude moradora das periferias urbanas.

\footnotetext{
* Socióloga por Universidade Federal do Rio Grande do Sul; Coordenadora da Casa das Juventudes Mathias Velho e Harmonia - Secretaria Municipal de Segurança Pública e Cidadania/FundaçãoLa Salle, Canoas, Brasil. koerich.bruna@gmail.com
} 
Em que pese o significativo número de projetos voltados à prevenção da criminalidade, há, no Brasil, poucos estudos que investiguem a forma como esses projetos influenciam nas trajetórias juvenis.

Esse artigo é, em síntese, uma reflexão acerca da implementação de uma das recentes políticas públicas que surge como proposta de intervenção nesse campo, objetivando diminuir a incidência da violência na população jovem, à luz da concepção teórica de campo de possibilidades.

As reflexões constantes nesse documento foram possíveis a partir do trabalho cotidiano de implementação dessa política; pela escuta da percepção dos jovens que dela participam, realizada em momentos coletivos e individuais de avaliações sistemáticas; e pelas reflexões suscitadas na Escola Internacional de Pós Graduação "Juventudes y Desigualdades em la América Latina y el Caribe", realizada pelo C $L A$ CSO - Consejo Latinoamericano de Ciencias Sociales, em parceria com a UNAH - Universidad Nacional Autónoma de Honduras.

Visando contextualizar o cenário em que essa reflexão foi proporcionada, inicialmente trago um olhar possível sobre os (des)caminhos das políticas públicas de juventude no Brasil. A seguir, esboço uma discussão sobre o conceito de campo de possibilidades e sua implicação para os estudos sobre juventude.

Nas seções que seguem, apresento as Casa das Juventudes do Município de Canoas, objeto dessa reflexão, onde atuo diariamente como coordenadora nesse complexo papel de executar uma política, sempre tendo em mente a necessidade de reflexão e pesquisa constante. Analiso, em seguida, as ampliações no campo de possibilidades que as trajetórias de vida desses adolescentes e jovens se permitem a partir da participação no projeto. Como forma de tornar a análise mais palatável, divido essa análise a partir das dimensões profissional, social, cultural e política, mesmo entendendo que essa divisão é arbitrária e baseada na forma de organização das atividades do projeto. Sei que, concretamente, no surgimento de novas possibilidades de futuro, essas categorias se entrelaçam e se misturam de forma dialética.

Por fim, traço algumas considerações acerca da análise pretendida nesse artigo, que muito mais do que expor resultados estanques, pretende sistematizar impressões que a prática cotidiana levanta.

\section{JUVENTUDES, VULNERABILIDADES E POLÍTICAS PÚBLICAS: UM PERCURSO SOBRE A TEMÁTICA NO CENÁRIO BRASILEIRO}

O conceito juventude tem orientado um grande número de estudos e políticas públicas, mesmo que a sua conceituação seja motivo para grandes divergências teóricas permeada por alguns consensos. 
Inicialmente, é necessário compreender que utilizar a palavra juventude no singular é uma afronta à multiplicidade e diversidade de contextos e formas de experenciar essa fase da vida, marcadas por recortes de gênero, raça, classe, escolaridade, cultura e tantas outras variáveis que tornam obrigatório o uso desse conceito no plural.

A forma como a temática foi abordada no país depende muito do momento histórico analisado. Entender essas mudanças é fundamental para compreender o fenômeno atual da juventude. Dessa forma, pretendo nessa seção apresentar o caminho dessa temática no cenário brasileiro1.

Os primeiros textos legais que falam sobre essa parcela da população utilizam o termo menor como forma generalizante de abordar todos os sujeitos menores de 18 anos. Durante as primeiras décadas do século XX, a preocupação com esse público se restringia ao controle dos sujeitos menores de idade que se envolviam em atividades infracionais ou que de alguma forma fugiam à norma geral de conduta moral da época. Dessa forma, em 1923 cria-se no país o primeiro juizado de menores da América Latina, visando a disciplinarização da vida juvenil. Ainda na década de 20 consolida-se também o principal marco jurídico sobre essa população, que vai nortear o debate sobre a temática durante as próximas três décadas: o Código de Menores, decretado em 12 de outubro de 1927.

Conforme salienta Kreher (2012), o início do século XX pode ser caracterizado como o momento de consolidação do aparato jurídico para juventude e infância no Brasil:

Pelo impacto social, consideramos que o Brasil inventa no início do século XX o seu modus operandi, a sua forma de olhar, pensar, falar e investir, do ponto de vista da política pública e/ou social, à infância e juventude. Assume que as questões relativas a esta população são em primeiro lugar matéria de lei, processo e sentença; investe os juízes de um poder quase sobrenatural capaz de fabricar saberes/poderes sobre quem são estas pessoas e como administrá-las. (Kherer. p.3)

Data desse período, também, a consolidação de parcerias entre o Poder Público e o setor privado para o desenho das políticas de infância e juventude, que serão executadas especialmente por entidades beneficentes e religiosas. Essa mescla de competências de interesses e responsabilidades marcará as políticas de infância e juventude no Brasil até hodiernamente.

\footnotetext{
1 Apesar de o foco desse artigo ser o caso brasileiro, a realidade aqui retratada não se inscreve apenas em limites nancionais, mas ganha contornos de um processo global de preocupação com essa população específica.
} 
No ano de 1964, o cenário brasileiro é alterado pela instauração de uma ditadura civil-militar que perdurou no país por 25 anos. Esse período caracterizou-se por um avanço dos setores mais conservadores da sociedade, uma forte repressão aos opositores e um grande alinhamento com a política estadunidense.

Já nos primeiros anos do governo ditatorial foi decretada a criação da Fundação Nacional do Bem-Estar do Menor (FUNABEM). Esse é considerado um marco do deslocamento da problemática sobre infância e adolescência que deixa de ser exclusividade do poder judiciário e passa a figurar também com uma questão para o poder executivo. Com a consolidação da Política Nacional do Bem Estar do Menor é gestado o Novo Código de Menores, dirigido aos menores em situação irregular. (Batista, 2003).

A concepção que embasou esse debate no cenário acima descrito caracterizou-se por uma culpabilização das famílias pobres que por 'não possuírem competência' para a tutela adequada dos 'menores', eram as responsáveis pelo seu ingresso em trajetórias desviantes. Sobre a chamada Doutrina do Menor em Situação Irregular, Cecília M.B. Coimbra e Lygia S.M. Ayres alegam que:

Por situação de/em risco, definiu-se no novo Código, dentre outras, a incompetência da família pobre, expressa na falta ou carência de recursos financeiros para a manutenção de seus filhos, entendida pelos formuladores da Política Nacional do Bem Estar do Menor (PNBEM), então em vigor, como condição particular de grande parte da população brasileira. Ou seja, como problema meramente individual e não cabia ao Estado responsabilidade sobre o quadro social. A ele, cabia, apenas, a tutela dessas crianças e jovens pobres, à medida que deles as famílias apresentavam-se, segundo o modelo proposto no Código, como incompetentes e desestruturadas para tal função social. (Coimbra; Ayres, 2009, p.62)

Podemos entender a visão acerca da adolescência e juventude nesse período como uma das dimensões da Doutrina de Segurança Nacional, uma vez que o jovem pobre (tendencialmente um jovem infrator) era entendido como um risco à segurança, ganhando status de inimigo público social.

Dessa forma, um dos indicadores emblemáticos desse período foi o grande crescimento das internações compulsórias que Coimbra e Ayres (2009) caracterizaram como galopante. Segundo as autoras, podemos observar durante a década de 1970 "a abertura de inúmeros estabelecimentos para abrigar, em condições desumanas, os filhos da 
pobreza" (p.62). Essa medida além de estigmatizar e rotular as crianças e adolescentes pobres acabava por apartá-los de seus vínculos afetivos, ao gerar um afastamento compulsório de suas famílias.

Durante todo o período compreendido como ditadura civil-militar brasileira (1964-1985), ocorreram mobilizações sociais em defesa dos direitos humanos, que foram fortemente repreendidas. Durante os anos 80 , contudo, podemos observar uma ascensão dos movimentos pró- democracia, que garantiram a essa década um clima de efervescência social e cultural no país.

As mobilizações que envolveram diversos setores da sociedade brasileira tensionaram o cenário político nacional garantindo em 1985 o início do processo que ficou conhecido como redemocratização.

Essa conjuntura oportunizou a ascensão de temas vinculados à noção de cidadania, incentivando a participação popular em variados processos importantes da época, como é o caso da formulação e promulgação de uma Nova Constituição, em 1988, que não por acaso ficou conhecida como Constituição Cidadã.

Dois anos depois, muito influenciada por esse contexto de mobilização social, é promulgada a lei que é considerada, até hoje, o principal marco jurídico sobre a população menor de 18 anos: o Estatuto da Criança e do Adolescente.

A promulgação do ECA (como é largamente conhecido no país) é um marco da ruptura de paradigmas em relação a essa faixa da população. Se até os anos 90 os textos legais e políticas públicas eram orientados à "questão do menor", agora há uma mudança discursiva, e política com a substituição do termo "menor" para "criança e adolescente" (Coimbra e Ayres, 2009).

No decorrer do Estatuto da Criança e do Adolescente, podemos encontrar o reconhecimento de que crianças, adolescentes e jovens como sujeitos em condição peculiar de desenvolvimento. Apesar da noção de "desenvolvimento" ser passível de diversas críticas, por sugerir que esse sujeito ainda não está completo, o reconhecimento de direitos específicos para crianças, adolescentes e jovens pode ser considerado um grande avanço em termos de construção de uma vida mais digna para esses setores.

O ECA é fundamentado pela Doutrina da Proteção Integral, consagrada na Declaração Universal dos Direitos da Criança (1959), que idealiza crianças e adolescentes como cidadãos plenos, porém sujeitos à proteção prioritária devido à seu processo de desenvolvimento. O ECA considera crianças as pessoas de 0 a 12 anos e adolescentes as pessoas de 12 a 18 anos.

Apesar de já no ECA haver o reconhecimento de jovens como sujeitos prioritários, é somente no ano de 2010 que temos o termo "ju- 
ventude" incorporado expressamente na Constituição Federal, por meio da Emenda Constitucional $n^{\circ}$ 65, que define, também, o Estatuto da Juventude como instrumento capaz de regular os direitos dos jovens e articular as diferentes esferas do poder público na execução de políticas à juventude.

Se compreendermos, como já dissemos anteriormente, que a juventude (assim como a adolescência e até a infância) não é um momento estanque que se manifesta da mesma forma e no mesmo período etário para todas as pessoas, e sim fruto de intersecção entre contextos sociais e trajetórias individuais, devemos observar que a separação do público-alvo das políticas voltadas à adolescentes e à jovens é bastante arbitrária e obedece, em síntese, as delimitações etárias fixadas nos dispositivos legais. Dessa forma, hoje se considera jovem a população inscrita entre os 18 e os 29 anos.

Apesar de carecermos de mapeamentos e sistematizações das políticas e programas orientados à população jovem e/ou adolescente no Brasil - especialmente as de âmbito estaduais e municipais - podemos afirmar que apesar dos avanços, grande parte delas possui em sua origem a lógica do enfrentamento dos chamados 'problemas da juventude', como já observavam Marília P. Sposito e Paulo César R. Carrano no início dos anos 2000:

Problemas reais, identificados principalmente na área da saúde, da segurança pública, do trabalho e do emprego, dão a materialidade imediata para se pensar as políticas de juventude sob a égide dos problemas sociais a serem combatidos. Nesse processo é possível reconhecer que, em muitas formulações, a própria condição juvenil se apresenta como um elemento problemático em si mesmo, requerendo, portanto, estratégias de enfrentamento dos "problemas da juventude". Isso se expressa, por exemplo, na criação de programas esportivos, culturais e de trabalho orientados para o controle social do tempo livre dos jovens, destinados especialmente aos moradores dos bairros periféricos das grandes cidades brasileiras.(Sposito e Carrano, 2003. p. 6)

Assim, conforme aponta Camarano (2006), as questões associadas à temática juvenil atendem à uma ótica pessimista, marcado pelo conceito de instabilidade. Sposito e Corrochano (2005) argumetam que nem mesmo mesmo depois dos anos 90 quando a temática do desemprego passou a ser a principal preocupação das ações públicas voltadas à população juvenil, a vinculação com a violência passou a ser menos presente. Dessa forma, o desemprego juvenil é visto como um problema 
ainda maior que o desemprego presente em outras categorias etárias, pois o ócio e o tempo livre, aliados à situação instável e volátil da juventude dariam margem para a vinculação desses jovens em atividades ilícitas e violentas.

A origem da preocupação com adolescentes e jovens no Brasil está marcada pelo olhar da segurança pública. De certa forma, ao manter a preocupação nos problemas relacionados à juventude, e, principalmente, no foco do controle social do tempo dos jovens, as políticas para juventude de hoje guardam resquícios de sua orientação para a manutenção da ordem social.

Como destaca Kreher ao discutir as políticas voltadas para jovens no Brasil:

Independente de que políticas sejam essas e de quais setores elas partem - Assistência, Cultura, Educação, Saúde - que se desdobrem sobre a juventude os efeitos de uma política de segurança: a neutralização do perigo(so!) (Kreher, 2012, p.9)

A permanência desse viés de segurança nas políticas voltadas à juventude é, em parte, corroborada pelos dados estatísticos nacionais: $53,4 \%$ dos homicídios registrados no país em 2012 eram de jovens entre 15 e 29 anos. O Estudo “Os Jovens no Brasil”, publicado em 2014, demonstra que os homicídios são hoje a principal causa de morte de jovens de no Brasil, sugerindo que mesmo com a implementação de políticas públicas voltadas a esse público, a violência juvenil está longe de ser um problema superado.

Na tensão existente nas concepções de políticas orientadas à juventude entre os enfoques de risco e de sujeitos de direitos, podemos observar no cenário atual brasileiro a intersecção dessas duas concepções na formulação e implementação das políticas voltadas à população jovens no país.

Essa tensão pode ser compreendida como um dos paradoxos que permeiam as políticas de juventude no cenário latino-americano, conforme aponta Rodríguez (2015):

[...] La reflexión sobre las notorias contradicciones existentes entre la lógica con la que funcionan las principales políticas sectoriales de juventud (influenciadas claramente por los enfoques de riesgo) y los intentos por construir políticas integradas de juventud (procurando trabajar prioritariamente con enfoque de derechos) evidenciando - en todo caso - apenas una de las principales "tensiones y paradojas" que afectan estas particulares dinámicas en el campo de las políticas públicas, prácticamente en todos los países de la región. (Rodríguez, 2015, p. 27) 
Nesse sentido, o conceito de vulnerabilidade social aparece como uma interface dessas duas concepções nas políticas que visam a superação dessa condição por meio da garantia de direitos à jovens que por diversas razões tiveram o acesso a eles dificultados ou negados.

Assim, utilizando referenciais como Pizarro, Filgueiras e informes do CELADE - Centro Latinoamericano y de Caribe de Demografía - as autoras Maria Isabel Domínguez García, Idania Rego Espinosa e Clauda Castilla García propõe um enfoque multidimensional da vulnerabilidade, que envolva:

Una dimensión relacional, como El riesgo de acumular desventajas en el ámbito económico, social, político y cultural; Una dimensión dinámica, por su naturaleza de proceso en el que interactúan de forma simultánea situaciones de inclusión-exclusión y de transmisión generacional; Una dimensión relativa y contextual, que considere el significado de las particularidades locales[...] (Domínguez García; Espinosa y Castilla García, 2015, p. 143)

Por jovens em vulnerabilidade social entendemos aqui adolescentes e jovens com pouco ou nenhum acesso à condições dignas de vida, envolvendo os mais diferentes âmbitos de exposição ao chamado risco social. $\mathrm{O}$ termo vulnerabilidade social é, assim, entendido para além de fatores meramente econômicos. Ser vulnerável é, em síntese, estar exposto à condições que podem levar à uma trajetória mais disposta a violência e menos permeada por oportunidades.

Assim, mesmo sabendo o uso de termos como vulnerabilidade produz efeitos, alterando e reconstruindo identidades juvenis, sua necessidade de uso está na objetividade e na subjetividade das desigualdades sociais que oferecem diferentes limites para as construções de sonhos e projetos pra jovens expostos à contextos sociais e trajetórias biográficas distintas.

\section{JUVENTUDES E CAMPO DE POSSIBILIDADES}

Já é lugar comum nas ciências sociais o entendimento de que a desigualdade social é uma das grandes causas do comportamento violento, enfaticamente em jovens. No Brasil, trabalhos como o de Castro e Abramovay (2002) são importantes expoentes nessa tese

[...] sobre o papel, se não determinante, pelo menos de forte condicionamento, das desigualdades sociais para o crescimento da violência e do desencanto, sobre o futuro, em particular dos jovens em situações de pobreza (p.31). 
Dessa forma, acreditamos que as políticas públicas que visam diminuir a incidência da violência sobre jovens objetivam, no fundo, possibilitar outros projetos de futuro que esses jovens possam almejar, que não aqueles já 'prescritos' de acordo com a sua origem social.

Operacionalizar uma política pública voltada a jovens em vulnerabilidade social é, assim, entender o projeto de futuro que esses jovens foram constituindo ao longo dessa ainda breve trajetória, e possibilitar mudanças e novas construções desses projetos.

Usamos como referencial A. Shutz, para quem projeto pode ser entendido como "conduta organizada para atingir finalidades específicas". Dessa forma, projeto de futuro poderia ser entendido como um "planejamento de ações para o tempo que há de vir, marcado pelos desejos e trajetórias individuais (Costa, 2009).

É importante, contudo, salientar que os projetos não são baseados apenas em expectativas, e sim, são construídos a partir de uma relação com a realidade, com o possível. É nesse sentido que Velho (1999) utiliza a noção de projeto inscrita entre possibilidades concretas e expectativas individuais "evitando um voluntarismo individualista agonístico ou um determinismo sociocultural rígido" (p.40).

Inspirando-se na concepção de campo de Pierre Bourdieu (1996), como sendo as estruturas constitutivas do mundo social e das práticas tendo regras e tensões específicas, podemos dizer que esse leque de caminhos possíveis a serem seguidos por um indivíduo é compreendido como um campo de possibilidades

Dessa forma, campo de possibilidades pode ser descrito como o conjunto de possibilidades e referências que um indivíduo pode mobilizar, a partir de suas expectativas individuais, na construção de sua trajetória. É uma moldura constituída sócio-historicamente, mas que será preenchida pelas escolhas e singularidades biográficas. (Koerich, 2013).

Nessa relação complexa entre as possibilidades e as vontades é que vão sendo tecidas as trajetórias de vida, permitindo espaços para constantes mudanças. Conforme Souza (2004):

se as condições de desigualdade entre os indivíduos limitam o campo de possibilidades e de escolhas, sempre deixam margens de manobra, através das quais os homens podem se movimentar socialmente e promover mudanças, mesmo que pequenas, em seu meio (p.34)

Analisando essas tensões, Tavares (2009) afirma que as trajetórias juvenis se conformam a partir de duas hipóteses.

Os jovens, no anseio por conhecer o mundo e conquistar autonomia podem expandir as margens ou ocupar os interstícios 
dos lugares sociais onde vivem e, com isto, reinventar trajetórias dissonantes de seu grupo social. Ou, por outro lado, podem ficar ancorados no lugar social de origem, confirmando os limites que cerceiam a vida das gerações mais velhas. (p.2)

Apesar de os projetos guiarem ações e marcarem as trajetórias individuais à todo o momento, há períodos da vida em que a construção de projetos aparece com maior ênfase. Para Almeida (2010), a construção de projetos de vida encontra-se particularmente presente no processo de transição da juventude para a vida adulta. É nesse momento que as expectativas em relação às esferas profissionais e pessoais são analisadas visando uma conciliação entre elas.

Assim, a construção/reorientação dos projetos de vida e de futuro estão presentes com maior importância a adolescência e a juventude, uma vez que - em geral - é nessa fase de vida que escolhas importantes são tomadas orientadas pela construção de um futuro imaginado e sonhado.

Em parte, esse processo de construção de utopias e negociações com as possibilidades concretas, muito típicas dessa fase da vida, pode ser marcado por grandes processos de rupturas e tensões, propiciando, assim, consolidações de vulnerabilidades.

Conforme aponta Camarano sobre a relação entre juventude e processos de escolhas, dando margem para processos de construção de vulnerabilidades:

Por um lado, a juventude constitui-se em uma fase da vida vulnerável per se, pois é quando muitas das características dos indivíduos são delineadas, o que ocorre, muitas vezes, em situações de conflitos e rupturas. Isso pode aumentar ou diminuir a vulnerabilidade dos jovens, mas não deixa de ser um momento de buscas e definições. A obrigatoriedade das escolhas nessa fase, no entanto, não é necessariamente acompanhada pelo amadurecimento psicossocial dos jovens, os quais, na maior parte das situações, não dispõem de informações e experiência suficientes para fazer opções que repercutirão em seu futuro" (Camarano, 2006, p. 15)

A análise do campo de possibilidades aparece como uma oportunidade, inclusive, de observar esses aspectos de tensão entre vontades e possibilidades apreendidas pelo jovem de acordo com o seu contexto social.

Nesse sentido, buscamos refletir sobre as possíveis alterações no campo de possibilidades de jovens e adolescentes que frequentam o projeto "Casa das Juventudes" 


\section{CASA DAS JUVENTUDES: UMA DAS FERRAMENTAS DA SEGURANÇA PÚBLICA CIDADÃ}

Os esforços de defesa de um novo paradigma para a segurança pública brasileira, trazendo novo destaque para as políticas de prevenção, culminaram na elaboração e implementação do Programa Nacional de Segurança Pública com Cidadania (PRONASCI), desenvolvido pelo Ministério da Justiça.

A Lei que institui o Programa, afirma que o seu principal objetivo é "articular ações de segurança pública para a prevenção, controle e repressão da criminalidade, estabelecendo políticas sociais e ações de proteção às vítimas" (Brasil, 2007). Instituído para atender as ações até o ano de 2012, o PRONASCI teve como foco de atuação as regiões metropolitanas do país.

Situado na Região Metropolitana de Porto Alegre (RS), o Município de Canoas foi um dos municípios participantes do Programa, ganhando, inclusive, destaques de repercussão nacional devido à seus projetos locais. O município, localizado a $14 \mathrm{~km}$ da capital Porto Alegre, com uma população média de 320 mil habitantes, apresenta o $3^{\circ}$ maior PIB do Estado do Rio Grande do Sul. Apesar de sua situação economicamente favorável, o município historicamente figurou entre as localidades mais violentas do Estado, mas seus índices de criminalidade sofreram considerável decréscimo a partir da consolidação do PRONASCI no município.

Uma das ações previstas no Programa Nacional de Segurança Pública com Cidadania foi o Projeto Proteção de Jovens em Território Vulnerável - PROTEJO. De acordo com as suas diretrizes nacionais, essa iniciativa tem como proposta atender jovens que apresentem os chamados fatores de risco para a violência:

O projeto tem como objetivo geral identificar, acolher e acompanhar jovens entre 15 e 24 anos, em situação de risco, vulnerabilidade social ou exposição a violências, como egressos do sistema prisional, cumpridores de medidas socioeducativas, em situação de rua, ou moradores de aglomerados urbanos com altos índices de homicídios e crimes violentos, por meio de um percurso sócio formativo, com vistas à reconfiguração de suas trajetórias de vida. (Diretrizes Nacionais Projetos Mulheres da Paz e Proteção de Jovens em Território Vulnerável.)

No município de Canoas, o primeiro território a receber ação prioritária do PRONASCI, tornando-se um Território de Paz em 2009, foi o bairro Guajuviras, conhecido pelo seu alto índice de criminalidade. Várias das iniciativas de segurança pública cidadã foram realizadas no 
território, incluindo a execução do PROTEJO desde 2010. O espaço físico em que o projeto PROTEJO foi implementado no Bairro Guajuviras ficou conhecido como "Casa das Juventudes" que além da execução do projeto oferecia serviços para a população jovem do bairro Guajuviras.

A instituição do Território de Paz Guajuviras gerou uma significativa redução dos índices de violência local e municipal, observadas, por exemplo, com a redução de 39,2\% dos homicídios no bairro de 2009 para 2010 e de 18\% no município como um todo, segundo dados do Observatório Municipal de Segurança Pública.

Devido ao grande êxito dos projetos implementados no bairro Guajuviras, constatado pelos indicadores de segurança pública, a região mais populosa do município de Canoas, formada pelos bairros Mathias Velho e Harmonia transformou-se em Território de Paz em 2011. Envolvendo recursos municipais, estaduais e federais, a consolidação do Território de Paz da Grande Mathias, previa entre as suas ações a criação de um Centro de Referência para as Juventudes.

O Centro de Referência para as Juventudes está aberto ao público desde 2012 e para a sua execução foi criada a Casa das Juventudes Mathias Velho e Harmonia. Apesar das especificidades constantes nos projetos do Protejo e do Centro de Referência, as Casas das Juventudes do bairro Guajuviras e do bairro Mathias Velho hoje atuam como único projeto com sede em dois territórios, respeitando as diferenças de demandas decorrentes das diversidades locais. Cada uma das Casas atende, em média, 80 jovens e realiza cerca de 1000 atendimentos por mês. As Casas das Juventudes possuem equipes multidisciplinares, compostas por educadores sociais, estagiários, sociólogos, assistentes sociais e psicólogos.

O Público-alvo prioritário das Casas das Juventudes são os adolescentes e jovens expostos aos chamados Fatores de Risco à violência, como já demonstrado anteriormente. Assim, a Casa das Juventudes recebe encaminhamentos de vários serviços e equipamentos da Rede Socioassistencial do município de Canoas, relacionados às secretarias de educação, saúde, e desenvolvimento social.

Os jovens em cumprimento de medida socioeducativa (MSE) são encaminhados pelos Centros de Referência Especializados de Assistência Social. A participação nas atividades da Casa das Juventudes é entendida, também, como prestação de serviços à comunidade, não sendo, então, diferenciada a atuação desses jovens dos demais. Esse entendimento de prestação de serviço diferenciasse bastante de grande parte das unidades de prestação de serviço, que envolvem esses adolescentes em atividades de trabalhos repetitivos e com poucos espaços de reflexão sobre o seu trabalho, sobre o ato infracional cometido e sobre a organização da sociedade como um todo. A equipe da Casa 
das Juventudes entende que a MSE possui como principal objetivo a construção de uma nova socialização do adolescente 'em conflito com a lei', oportunizando novas possibilidades em suas trajetórias, e acesso a novos valores sociais.

A comunidade local também atua como um 'mobilizador' do projeto, identificando jovens que estejam expostos à diferentes formas de vulnerabilidades e encaminhando-os para a Casa das Juventudes ou então alertando a equipe para que entrem em contato com a família ou responsável. Na realidade, como a Casa das Juventudes se pretende um espaço de acolhida aos jovens de bairros marcados por altos índices de violência e vulnerabilidade, todos os jovens provindos das periferias do município, que estejam dentro da faixa etária prevista, são atendidos nas diferentes atividades. Dessa forma, observamos que uma grande rede de participação na Casa é construída pelos próprios jovens, que identificam e mobilizam amigos e conhecidos que vem na Casa das Juventudes uma forma de acesso á serviços diferente dos oferecidos em outros espaços da Rede Socioassistencial.

As principais atividades que já foram ou ainda hoje são oferecidas aos jovens e adolescentes na Casa das Juventudes são: Oficinas de Cidadania (envolvendo dinâmicas e discussões sobre temas transversais à questão da prevenção e da violência urbana); Oficinas de Arte e Cultura (oficinas de percussão, violão, teatro, desenho, canto e dança); Cursos profissionalizantes (oficinas de informática, jornalismo cidadão, DJ, customização e manicure); Encaminhamentos para demais serviços da rede Socioassistencial (Mediação com escolas, vagas de estágio, Centros de atendimentos especializados, etc); Atendimentos Psicossociais (Acompanhamentos sistemáticos, a familiares, visitas domiciliares, distribuição de cestas de alimentos, construção dos Planos de Desenvolvimento Individuais); Espaços de práticas de cidadania (Assembleias de jovens e incentivos à espaços formais de participação); Telecentro com acesso à internet aberto a toda a comunidade local; Oficinas de práticas esportivas (Hapikido e Capoeira)

\section{AMPLIAÇÕES DO CAMPO DE POSSIBILIDADES NO CONTEXTO DA CASA DAS JUVENTUDES}

Se compreendermos que na construção de seus projetos de vida e de futuro, os atores individuais se movem dentro de campo de possibilidades, onde estão inscritos suas alternativas e opções, o acesso a novas redes e oportunidades amplia esse campo, alargando as possibilidades das escolhas individuais.

Por meio da sistematização da experiência cotidiana nos projeto Casa das Juventudes da Grande Mathias Velho, buscamos aqui realizar 
uma reflexão que indique de que forma as atividades oferecidas aos jovens e adolescentes contribui para o alargamento dessas possibilidades.

\section{DIMENSÃO PROFISSIONAL}

A inserção no mundo do trabalho é uma das grandes preocupações da juventude, uma vez que a autonomia financeira é um dos grandes indicadores de passagem para vida adulta (Camarano, 2006).

Por esse motivo, algumas das ações desenvolvidas na Casa das Juventudes buscam a qualificação do jovem para o mercado de trabalho. É o caso, por exemplo, das capacitações em cultura digital, dos cursos profissionalizantes de jornalismo cidadão, de customização, de DJ, de manicure e pedicure e de juventude empreendedora.

Contudo, as trajetórias de trabalho dos jovens que ingressaram no mercado de trabalho ainda durante seu tempo de participação no projeto são marcadas por trabalho instáveis e com pouca relação com as atividades de qualificação profissional.

Em muitos dos casos, inclusive, o ingresso no mercado de trabalho afastou o jovem do sistema escolar e da participação na Casa das Juventudes. Há, inclusive, casos de jovens que abandonaram o cumprimento de medida socioeducativa ou mudaram o seu cumprimento para uma unidade de prestação de serviço que funcionasse nos finais de semana para poder continuar trabalhando.

Além da importância devido à conquista da subsistência, o discurso sobre a necessidade do trabalho aparece, em muitos jovens, marcado por uma dimensão subjetiva, como que atendendo aos interesses dos pais ao reproduzir uma noção que dicotomiza o jovem que trabalha daquele que é desinteressado ou incompetente, reforçando uma lógica de culpabilização daqueles que não conseguem um trabalho formal.

A abrangência dessa lógica de individualização e de responsabilização do jovem em relação à sua empregabilidade, amplamente difundida na sociedade, é um limite claro a efetivação de uma qualificação profissional conduzida de forma a incentivar o trabalho coletivo e demonstrar que a inserção no mercado de trabalho não é apenas uma questão de vontade, mas de aproveitar as oportunidades, que variam de acordo com a origem social do indivíduo. Se tomarmos o caso do curso de juventude empreendedora, observamos que freqüentemente o seu conteúdo acabava por reproduzir a concepção do jovem 'empreendedor de si mesmo', responsável pelo seu sucesso ou fracasso profissional.

Outra dificuldade encontrada na dimensão profissional diz respeito ao dilema entre garantir uma formação mais orientada a profissões mais acessíveis à população 'vulnerável' (por exemplo, o curso de manicure) e oferecer qualificação para uma profissão mais próxima da vontade dos jovens, porém com maiores dificuldades de inserção 
efetiva no mercado de trabalho (como os cursos de DJ, customização e jornalismo cidadão). Se as primeiras acabam por estigmatizar o jovem morador de periferia, limitando o seu campo de possibilidades às ocupações que encontram respaldo em suas trajetórias familiares de trabalho e emprego; As segundas podem cair no erro de acreditar que apenas a formação é necessária, ocultando que existe um investimento financeiro (alto, muitas vezes) necessário para a efetivação dessa atuação como forma de trabalho.

Dessa forma, podemos demarcar que a participação dos adolescentes e jovens na Casa das Juventudes, especialmente nessa modalidade de cursos e oficinas, contribui mais para a existência de uma qualificação profissional do que pela efetivação dessa atividade como prática profissional.

A qualificação aparece, assim, como um ponto positivo a ser colocado no currículo, independente da proximidade entre a qualificação e as vagas procuradas. De forma similar, a participação nas oficinas de inclusão digital contribuem na ampliação do campo de possibilidades desses jovens ao proporcionar a busca por trabalhos e estágios que necessitam de conhecimentos em informática.

É importante salientar, contudo, que essa ampliação é bastante limitada, principalmente porque em uma sociedade marcada por desigualdades sociais tão gritantes, os jovens acabam por 'competir' com jovens com conhecimentos muito mais avançados em informática e mesmo com acesso a um número maior de cursos de qualificação profissional.

Outra característica importante que limita essa ampliação é o fato de muitas vezes os pais desses jovens por desconhecimento ou descrença na capacidade de ascensão social que outras ocupações podem trazer, acabam pressionando o jovem para inserir-se em ocupações que figuram nas trajetórias familiares de trabalho, como o trabalho doméstico e a construção civil.

\section{DIMENSÃO SOCIAL}

Uma das preocupações constante da equipe é a garantia do acesso a todos os serviços da rede socioassistencial do município. Assim, sempre que se avalia necessário, a equipe de referência atua na mediação entre os jovens e/ou suas famílias e serviços específicos que são disponibilizados para a população.

De todos os serviços em que a mediação é realizada que vai desde o acesso a outros projetos sociais como o Núcleo de Justiça Comunitária ou o Centro de Referência para Mulheres Vítimas de Violência, até o encaminhamento para vagas e oportunidades de estágio e trabalho, o que demanda um acompanhamento mais sistemático é a relação com a escola. 
Pesquisas realizadas na Região Metropolitana de Porto Alegre têm demonstrado que a grande maioria dos jovens da região que estão no sistema carcerário não concluiu o ensino básico. Esses dados sugerem que a evasão do sistema formal de ensino é um dos fatores de risco em relação à violência. Sendo assim, além do auxílio na matrícula, do contato constante com a Secretaria Municipal de Educação visando à garantia e possíveis remanejamentos de vagas de acordo com a realidade específica de cada jovem, a Casa das Juventudes também funciona como um espaço para os jovens realizarem seus temas de casa, contando com uma biblioteca equipada com livros didáticos das mais diferentes áreas, com o auxílio dos colegas e de um telecentro com acesso às ferramentas virtuais de ensino e de realização de trabalhos. Mais recentemente, a CJ passou a ofertar oficinas de Acompanhamento Pedagógico, com uma profissional para atender especificamente os adolescentes com mais dificuldades de aprendizagem.

Nesses casos, a ampliação do campo de possibilidades dos adolescentes e jovens dá-se por meio de atividades que buscam a frequência e o sucesso escolar, entendendo que essas características contribuem para uma trajetória de vida mais distante da violência urbana.

Os jovens contam, também com sistemáticos atendimentos psicossociais que visam à garantia de sua saúde mental e sua relação com familiares, amigos ou colegas. Nos casos em que se avalia necessário, acontece o acompanhamento de familiares, envolvendo também visitas domiciliares por parte da equipe.

Apesar de a participação na Casa das Juventudes possibilitar um aumento de possibilidades de escolha na dimensão social, não são poucos os limitantes dessas ampliações. O baixo hábito de leitura e de realização dos temas escolares faz com que, muitas vezes, a biblioteca seja usada mais como local de convivência do que como espaço de estudo. Além disso, a vontade de permanecer na Casa o maior tempo possível, faz com que alguns adolescentes decaiam no seu rendimento escolar, ao dedicarem menos tempo aos estudos.

Quando o adolescente ou jovem encontra-se em grande defasagem na relação idade-série, os empecilhos para sua permanência no sistema escolar não são poucos, mesmo com a criação das modalidades EJA (Ensino de Jovens e Adultos) na educação formal, muitas vezes o espaço escolar mostra-se hostil para essa parcela da população. Visando atuar nessa questão, objetivando ampliar de forma efetiva suas possibilidades de futuro por meio da educação, as Casas das Juventudes iniciaram um processo de viabilizar a criação de um EJA dentro de suas dependências. Acredita-se, assim, que proporcionar uma educação formal em espaços não escolares e com bastante vínculo com esses adolescentes pode contribuir na diminuição dos índices de evasão. 
Acreditando na importância da construção de projetos de futuro durante a adolescência e a juventude, a equipe da Casa das Juventudes está se preparando para desenvolver os Planos de Desenvolvimento Individuais - PDI - nos quais, depois de falarem sobre as suas trajetórias biográficas, os jovens são convidados a mapearem suas redes de contato, suas referências e a construírem propostas de projetos de futuro. Nesse processo, o técnico da equipe que acompanha construção desses mapeamentos e projetos atua como um mediador auxiliando o jovem a compreender o seu campo de possibilidades e oportunidade de novas trajetórias.

O mapeamento de suas redes de contatos e de projeção em relação aos seus projetos de futuro possibilitam uma ampliação efetiva do campo de possibilidades desses jovens, apesar de a participação na Casa não ser o suficiente para concretizar partes significativas desses projetos. Para que essa efetivação fosse possível, seria necessária uma atuação pública orientada à integralidade, buscando uma prática intersetorial e em rede.

\section{DIMENSÃO CULTURAL}

Entendendo o acesso à cultura como um aspecto importante para a construção de projetos de futuro, a Casa das Juventudes proporciona aos jovens beneficiários oficinas das mais variadas formas de arte e cultura.

Além de conhecer um largo espectro cultural, os jovens podem desenvolver suas habilidades nas oficinas que mais lhe interessarem. Já passaram pelo projeto oficinas de dança, hip-hop, funk, música, violão, percussão, teatro, desenho, e canto.

Sempre que possível, os educadores abordam em suas oficinas as temáticas transversais escolhidas por toda a equipe como prioritárias em cada período. Assim, os jovens podem observar diferentes dimensões de uma mesma temática e conviver com a construção interdisciplinar do conhecimento.

Mais do que apenas participarem das oficinas, os jovens são convidados a montar coreografias, peças e apresentações que demonstrem para o público da cidade as atividades realizadas no projeto. Também são desenvolvidas oficinas de práticas esportivas, que mesclam atividade física e elementos culturais, como a capoeira e o Hapikido.

Apresentar aos jovens uma nova forma de socialização, de identificação com a juventude e mesmo de diversão contribui para o afastamento das práticas violentas como principal forma de socialização e de relação com o seu território.

Pudemos observar durante os momentos em que os jovens apresentam os resultados das oficinas uma quebra de estereótipo do jovem 
violento proveniente dos bairros que compõem hoje o Território de Paz da Grande Mathias.

A convivência com educadores sociais também se mostrou-se como um ponto importante na ampliação das possibilidades de escolhas sobre o futuro desses jovens. A construção de referência em jovens que garantem sua subsistência, ou parte importante dela, através da arte ou da difusão de elementos culturais contribui para a alimentação do sonho de muitos jovens e adolescentes da Casa.

Mesmo para os jovens que não demonstram interesse em encontrar na arte sua independência financeira, observamos uma ampliação nas possibilidades de construção de relações e rede de contatos. Assim, a identidade criada por adolescentes e jovens em relação ao mundo cultural não necessariamente está relacionada com a busca pela subsistência, mas ajuda a pautar a sua relação com o mundo.

Um dos grandes limites encontrados, no entanto, em relação a dimensão cultural refere-se à complexidade de se abordar a cultura popular, enfaticamente à cultura popular mais presente no cotidiano desses jovens sem manter a estigmatização que algumas manifestações dessa cultura impõe. Dessa forma, um importante desafio dos educadores é, por exemplo, abordar a cultura do funk, problematizando a sua forte relação com a hipersexualização e com a apologia à violência.

Além disso, em uma sociedade que prega o pragmatismo, muitas vezes as atividades culturais são vistas com preconceito por estarem "roubando tempo" de atividades laborais e de inserção no mercado de trabalho. Apesar dos esforços da equipe multiprofissional, essa visão é bastante difundida, mesmo entre os jovens que freqüentam o projeto.

\section{DIMENSÃO POLÍTICA E CIDADÃ}

Como nos adverte José Murilo de Carvalho (2008), cidadania é um termo complexo, e engloba diversas dimensões. Ao falar de cidadania precisaríamos, ao mínimo, falar de três ordens de direitos fundamentais: os civis, os sociais e os políticos. Há, contudo, vastas bibliografias apontando que na América Latina existem indícios de uma incompletude desses três aspectos, ao menos para parcelas da população.

Em um cenário de tanta desigualdade civil, social e política, podemos falar em cidadania? Essa é uma das perguntas discutidas freqüentemente com os jovens participantes da Casa das Juventudes, visando estimular sua criticidade.

Durante as oficinas, os jovens são convidados a formular opiniões, argumentar e debater seus pontos de vista sobre assuntos que cercam o seu cotidiano como desigualdade social, identidade racial, identidades de gênero, novos arranjos familiares, violência urbana, opressões geracionais, entre outros. As oficinas são desenvolvidas pela 
equipe de referência e apresentam desde sua elaboração um caráter interdisciplinar, uma vez que são planejadas e coordenadas por profissionais das ciências sociais, serviço social, psicologia e educação.

Como forma de estimular o protagonismo juvenil, os jovens também participam de processos de avaliação e de sugestão em relação ao funcionamento do projeto. No início do ano, todos os jovens puderam participar da confecção das Regras Coletivas da Casa das Juventudes.

Recentemente, o projeto foi questionado acerca de espaços de participação e decisão organizados pelos próprios jovens, onde eles pudessem desenvolver suas ideias para o andamento do projeto. A equipe deparou-se, então, com um limite a ser superado.

Mesmo com receio das demandas que apareceriam, já que em outras oportunidades observou-se a difusão de discursos conservadores por parte de alguns dos jovens que freqüentam o projeto, optou-se pela realização de uma assembleia semanal de cada uma das turmas ${ }^{2}$ da Casa.

Nos espaços de assembléia, os jovens são convidados a construírem projetos coletivos da turma. A assembléia é acompanhada por uma pessoa da equipe de referencia que auxilia na sistematização dos encaminhamentos e, posteriormente, na execução desses em conjunto com os jovens.

Até o momento, os encaminhamentos giraram em torno da organização cotidiana ou de atividades assistenciais no seu território, sugerindo, assim, que a atuação como sujeitos ativos de cidadania colocou-se como possibilidade para esses jovens e adolescentes, mesmo que reforçando um viés assistencialista.

A participação cidadã extrapola os muros da Casa das Juventudes, envolvendo os jovens e adolescentes também nos espaços formais de participação e cidadania no cenário político municipal e estadual, como a Conferência Municipal dos Direitos da Criança e do Adolescente, por exemplo, que contou com uma participação ativa dos adolescentes da Casa, sendo dois deles, inclusive eleitos delegados e participantes de reuniões de organização da Conferência Estadual.

$\mathrm{O}$ incentivo ao protagonismo dos jovens e adolescentes na Casa das Juventudes amplia o seu campo de possibilidades na medida em que derruba um discurso bastante difundido socialmente de que adolescentes e jovens são muito imaturos para pensar e tomar decisões sozinhos e de que não se interessam por nada que tenha relação com a coletivi-

2 As turmas são formadas de acordo com o turno de participação do jovem nas atividades da Casa, esperando que o outro turno seja preenchido com a frequência escolar. Os jovens e adolescentes que não estão estudando ou o fazem no turno da noite podem optar por qual das assembleias participar, podendo, inclusive, participar das duas. 
dade. A prática de cidadania permanente na Casa das Juventudes vem estimulando que esses jovens e adolescentes busquem seus espaços de autoafirmação e construam novos canais de diálogo e escolhas.

Contudo, como ainda carecem de espaços que possibilitem uma participação efetiva da juventude, essa ampliação de possibilidades é limitada estruturalmente pela descriminação e pelo "adultocentrismo".

\section{CONSIDERAÇÕES FINAIS}

Esse artigo buscou refletir sobre possíveis alterações que a participação em um projeto de prevenção às violências pode gerar no campo de possibilidades de adolescentes e jovens considerados em vulnerabilidade social.

Em relação à alteração do campo de possibilidades nas escolhas e construção de projetos de futuro dos adolescentes e jovens acompanhados, podemos afirmar que, de forma geral, a participação no projeto lhes possibilitou novas oportunidades de futuro, mesmo que não exatamente da forma como as diretrizes ou mesmo a equipe do projeto imaginavam.

Ao contrário do que se poderia acreditar inicialmente, as estratégias de inserção imediata no mercado de trabalho se mostraram as pouco efetivas em relação à ampliação do campo de possibilidades, um vez que a estrutura social leva os adolescentes a seguirem as trajetórias familiares de trabalho. Em raras exceções, podemos encontrar casos de ruptura com essas tarjetórias, para um investimento em inserções ocupacionais mais ancoradas na realização e nas possibilidades de progressão. A necessidade de retorno financeiro imediato pode ser considerada o grande limitador dessa ruptura.

Nesse sentido, a conclusão do ensino básico, mesmo que não assegure de forma incontestável uma melhor inserção no mercado de trabalho, aparece ao menos como um estímulo à novas tentativas de empregabilidades menos dissociadas de suas demandas e interesses. A ampliação da escolaridade, então, aparece não apenas com um meio de garantia de ampliações no campo de possibilidades, mas também como um meio de superação e autosuperação de suas possibilidades.

Por outro lado, o contato com a Casa das Juventudes representou grande ampliação nas dimensões sociais, culturais e políticas que prorporcionaram ao jovem, principalmente, uma ampliação nas formas de se relacionar com o mundo, nas perspectivas de compreesão sobre a sociedade e, mais do que isso, no seu posicionamento nela de forma atuante.

Por fim, apesar de funcionar em certa medida como uma política de controle social do tempo, lógica muito reproduzida no discurso da família desses jovens, marcados por por frases como "Agora meu filho 
não fica na rua", a Casa das Juventudes demonstrou-se um espaço de acolhida das demandas jovens e de construção de novos projetos de futuro, ancoradas em novas possibilidades de trajetórias biográficas.

Secundariamente, podemos afirmar que apesar dos limites encontrados na operacionalização de um projeto com uma visão de atedimento integral à juventude, decorrentes das dificuldades do diálogo inter-setorial e das tensões existentes nas discussões sobre competências, a Casa das Juventudes caminha em direção à integralidade, um vez que suas atividades possuem elementos de cinco das seis tipologias de políticas para as juventudes apontadas por Núñez, Vászquez e Vommaro (2015) ${ }^{3}$

Em que pese haja resquícios do enfoque de risco na política selecionada, inslusive no recorte de público-alvo de jovens expostos aos fatores de risco ou em vulnerabilidade social, há uma forte orientação da concepção de jovens como sujeitos de direitos, principalmente observada nos momentos de incentivo do protagonismo juvenil e de práticas de cidadania ativa.

\section{BIBLIOGRAFIA}

Almeida, Rachel de Castro 2010 "O valor do trabalho para a juventude contemporânea na elaboração de projetos de vida". Tese (doutorado). PUC - Minas. Programa de Pós-Graduação de Ciências Sociais. Belo Horizonte, 2010.

Batista, Vera Malaguti 2003 Difíceis ganhos fáceis: drogas e juventude pobre no Rio de Janeiro (Rio de Janeiro: Revan).

Bourdieu, Pierre 1996 Razões Práticas: sobre a teoria da ação (Campinas: Papirus).

Brasil. Lei $\mathrm{N}^{\circ} 11.530$, de 24 de outubro de 2007. Institui o Programa Nacional de Segurança Pública com Cidadania - PRONASCI e dá outras providências. Diário Oficial [da] República Federativa do Brasil, Brasília, DF, 25 out. 2007.

Carvalho, José Murilo de Carvalho 2008 Cidadania no Brasil: O longo caminho (Rio de Janeiro: Civilização Brasileira).

\footnotetext{
3 Ao analisar as políticas públicas de juventude existentes na Argentina, os autores identificaram seis orientações diferentes: Políticas de participação política e construção de cidadania; Políticas de inclusão social; Políticas de atividades e práticas culturais; Políticas de acesso à direitos; Políticas de inclusão e conclusão do ensino; e Políticas de apoio ao desenvolvimento econômico e aos empreendimentos produtivos. No caso da Casa das Juventudes, não observamos elementos apenas da última tipologia
} 
Camarano, Ana Amélia (Org) 2006 Transição para a vida adulta ou vida adulta em transição? (Rio de Janeiro: IPEA).

Castro, Mary Garcia; Abramovay, Miriam 2014 “Juventudes”. Ponencia da Congresso da Associação Latino Americana de População, ALAP, I, 2004, Caxambú, Minas Gerais.

Coimbra, Cecília Maria Bouças 2009 Pivetes: encontros entre a psicologia e o judiciário (Curitiba: Juruá)

Domínguez G., Maria Isabel; Espinosa, Idania Rego; García, Claudia Castilla. Rodríguez, Ernesto 2015 "Revertir la vulnerabilidad. Experiencias de transformación social con jóvenes cubanos" Rodríguez, E... [et.al.] Juventudes Latinoamericanas: prácticas socioculturales, politicas y políticas públicas (Buenos Aires: CLACSO).

Guimarães, Nadya Araujo 2006 “Trajetórias inseguras, autonomização incerta: os jovens e o trabalho em mercados sob intensa transições ocupacionais" en Camarano, A. A. (Org) Transição para a vida adulta ou vida adulta em transição? (Rio de Janeiro: IPEA).

Koerich, Bruna Rossi 2013 “De mãe para filha: rupturas e continuidades de trajetórias familiares em trabalho doméstico”. [Trabalho de Conclusão de curso]. Porto Alegre: Universidade Federal do Rio Grande do Sul, Curso de Ciências Sociais, Departamento de Sociologia; 2013.

Kreher, Rodrigo 2012 "Entre a juventude e a segurança, pode uma Guajuvira?” [Trabalho de conclusão de curso]. Porto Alegre: Pontifícia Universidade Católica do Rio Grande do Sul, Curso de Direito.

Menandro, M. C. S.; Trindade, Z. A.; Almeida, A. M. O. 2003

"Representações sociais da adolescência/juventude a partir de textos jornalísticos (1968-1974 e 1996-2002)” em Arquivos Brasileiros de Psicologia, v. 55, $\mathrm{N}^{\circ} 1$, p. 42-55.

Núñez, Pedro; Vázquez, Melina; Vommaro, Pablo 2015” Entre la inclusión y la participación. Una revisión de las políticas públicas de juventud en la Argentina actual" en Rodríguez, E. [et.al.]. Juventudes Latinoamericanas: prácticas socioculturales, politicas y políticas públicas (Buenos Aires: CLACSO).

Rodríguez, Ernesto 2015 “A modo de prólogo: estudios sobre juventudes en América Latina: Un mosaico de realidades diversas pero convergentes, a caracterizar más y mejor" em Rodríguez, E. [et.al.] 
Juventudes Latinoamericanas: prácticas socioculturales, políticas y políticas públicas (Buenos Aires: CLACSO).

Souza, Adriana Barreto de 2007 "Biografia e escrita da História: reflexões preliminares sobre relações sociais e de poder" em Revista Universitária Rural: Série Ciências Humanas. Seropédica Nº1, v.29, pp.27-36, jan-jul (Rio de Janeiro).

Sposito, Marília Pontes; Carrano, Paulo César Rodrigues 2003 “Juventude e políticas públicas no Brasil”. Artigo apresentado em: Reunião Anual do ANPEd - Associação Nacional de Pós-graduação e Pesquisa em Educação.26a' 5 a 8 de outubro; Poços de Caldas (MG).

Sposito, Marília Pontes; Corrochano, Maria Carla 2005 “A face oculta da transferência de renda para jovens no Brasil” em Tempo Social $\mathrm{N}^{\circ} 2$ - Revista de Sociologia da USP (São Paulo), v.17, pp.141-172, novembro.

Tavares, Maurício Antunes 2009 “Entrelaçamento entre campo de possibilidades e trajetórias de vida: a questão da escolarização dos jovens no interior de Pernambuco" em Simpósio Internacional Processo Civilizador ,XII, Recife.

Velho, Gilberto 1999 Projeto e metamorfose: antropologia das sociedades complexas (Rio de Janeiro: Jorge Zahar).

Waiselfisz, Júlio Jacobo 2014 Mapa da violência: os jovens no brasil (Brasília: Secretaria Nacional da Juventude). 



\title{
SEGMENTACIÓN ESCOLAR: POSICIONES DE PROFESORES DE ESCUELAS SECUNDARIAS EN CHILE
}

\author{
Cecilia Millán La Rivera*
}

MARCO DE ANTECEDENTES

La desigualdad es un fenómeno multidimensional que incluye las diferencias entre las personas hasta las grandes asimetrías globales. Es un problema que envuelve aspectos estructurales como también las interacciones cotidianas que crean y recrean las desigualdades. De igual forma se producen prácticas de resistencia que deslegitiman las culturas de elite.

Los mecanismos de las desigualdades pueden ser explicados por "la apropiación del valor excedente producido por el trabajo ajeno (explotación) y la obtención de un beneficio mediante el control del acceso a un recurso o ventaja (acaparamiento de oportunidades-exclusión)" (Reygadas, 2008: 43).

Las desigualdades se manifiestan a través de distintas estructuras: 1) Estructuras económicas: apropiaciones diferenciales de riqueza; 2) Estructuras políticas: disparidades de poder; 3) Estructuras socia-

\footnotetext{
* Doctora en Ciencias Antropológicas de la Universidad Autónoma Metropolitana, investigadora del Programa Alternativas Pedagógicas y Prospectiva Educativa en América Latina (APPEAL), en la Facultad de Filosofía y Letras de la Universidad Nacional Autónoma de México (UNAM), ceciliapazmlarivera@gmail.com.
} 
les: diferencias de estatus y prestigio y 4) Estructuras culturales: que legitiman la desigualdad y producen distribución inequitativa de los recursos simbólicos. Asimismo también tienen expresión en distintos niveles: 1) Macrosocial: estructuras inequitativas en agregados sociales amplios; 2) Mesosocial: pautas asimétricas de relaciones entre distintas instituciones que se expresa en la interacción entre géneros, etnias, culturas y clases sociales e 3) Individual: desigualdad de capacidades y recursos (Reygadas, 2008).

En cuanto a las desigualdades en el mundo, América Latina es el continente más desigual no así el más pobre. En el caso de Chile, que es uno de los países más desiguales a nivel mundial se suma la segmentación escolar que en un contexto de desigualdad estructural agudiza las diferencias, desventajas y oportunidades de los sujetos en la sociedad.

La segregación escolar se define como una "distribución desequilibrada de alumnos de un mismo perfil (socioeconómico, cultural, procedencia...), entre distintas escuelas" (Alegre, 2010:1167). La segregación es un proceso de separación entre grupos con diferencias culturales, religiosas, tradiciones étnicas, económicas, que afecta las probabilidades de interacción, es decir de compartir experiencias o ser afectados por condiciones compartidas. Es una problemática que reproduce y mantiene las desigualdades sociales, lo que genera distintos tipos de exclusión que limitan las posibilidades de los sujetos de ocupar posiciones que les permitan una subsistencia autónoma y digna.

La segregación escolar puede expresarse en cuatro dimensiones. Una de ellas es por sexo, a esta división entre hombres y mujeres, muchas veces, se suma una enseñanza que se nutre de estereotipos sexuales que fomentan las diferencias y desigualdades de género. Otro tipo, es la segregación étnica que se da cuando se separa en colegios a poblaciones inmigrantes o grupos étnicos en determinadas escuelas. Existe también la segregación académica que es separar a los estudiantes según su rendimiento académico. Esto puede suceder al interior de las escuelas o entre éstas. Debido a la importancia que se le ha dado a las pruebas estandarizadas y sus resultados cada vez se acentúa este tipo de segregación a través de la elección que hacen los establecimientos públicos y privados de sus estudiantes. Por último, la segregación social, que es una de los más estudiadas junto a la étnica, separa a sus estudiantes según su origen socioeconómico (Andrés, 2013). Cada una de estos tipos de segregación suelen articularse y al sumarse acentúan las diferencias entre los estudiantes.

En cuanto a las causas de la segregación escolar, son múltiples variando sus consecuencias entre los países. Su origen se explica por factores internos como externos que se agrupan en tres dimensiones: factores contextuales, factores institucionales y factores socio-culturales (Bellei, s.f.). 
Con respecto a los factores contextuales, la segregación residencial es la más importante siendo la base territorial un factor fundamental. En áreas urbanas segregadas, los espacios de interacción serán menores lo que incluye el comercio, las plazas, escuelas, entre otros, generándose procesos de aislamiento (Cruz, 2013). En cuanto a los factores institucionales, puede haber escuelas separadas por raza. Los factores socioculturales se expresan a través de las preferencias familiares o tipos de escuelas comunitarias, que se distinguen por credo religioso, colonias, o grupos de elite, como también por la selección de los alumnos por los colegios (Bellei, s.f).

La segregación escolar afecta no solo el proceso de aprendizaje como se ha demostrado a través del efecto "pares", que muestra que una diversidad de estudiantes beneficia el aprendizaje de quien tiene una condición de desventaja, sino también expresa una modalidad de exclusión social que tiene implicaciones socio-culturales y políticas que son relevantes de considerar si lo que se busca es una sociedad más integrada y una democracia más sana. Las sociedades más democráticas e igualitarias requieren espacios en el que puedan convivir grupos de distinto nivel socioeconómico, etnias,sexo, nacionalidad, con distintas capacidades, compartiendo la diversidad cultural existente (Torres, 2007).

En suma, la segregación afecta tres supuestos de lo educativo. Primero, la educación históricamente se ha concebido como un espacio de socialización complementario al de la familia, lugar en el que se espera que los estudiantes compartan con personas diferentes en términos económicos y culturales. Segundo, el efecto "pares" demuestra que una diversidad de estudiantes beneficia el aprendizaje de quien tiene una condición de desventaja y tercero, en términos de políticas sociales, la inclusión siempre favorecerá a los grupos más desfavorecidos y vulnerables de la sociedad (Valenzuela, 2006).

En el caso de Chile, el estudio realizado por Juan Pablo Valenzuela (2006) muestra una elevada segregación socioeconómica en el sistema escolar, tanto en la educación básica como media e indistintamente en los sectores de mayor y menor nivel socioeconómico. Asimismo, entre colegios, los particulares subvencionados ${ }^{1}$ muestran mayor segregación que los colegios públicos, lo que no significa que tal fenómeno no exista en estos últimos.

También existe una importante segregación tanto al interior de las escuelas como entre las escuelas, lo que está fuertemente influenciado

1 Con respecto a los tipos de colegios que existen en Chile, existen tres modalidades financiados por el Estado: colegios municipales (público), particular subvencionado y los que siguen siendo públicos pero son administrados por corporaciones empresariales. Y están también los colegios privados pagados, que no tienen financiamiento del Estado y se sostienen con los aranceles que se les cobra a las familias de los estudiantes (Maldonado, 2003). 
por la segregación residencial (Bellei, s.f.). Al interior de las escuelas la segregación es menor ( 0.15 y 0.30 del índice Duncan $\left.{ }^{2}\right)$ en comparación a la segregación entre escuelas ( 0.45 y 0.53 del índice de ordenamiento escolar $^{3}$ ). La segregación al interior de la escuela es mayor en la enseñanza media, donde ocurre en un $45 \%$ de los establecimientos, mientras que en la educación básica se da en un 30\% de las escuelas. El ordenamiento y segregación al interior del colegio se realiza por razones académicas más que socioeconómicas (Treviño, Valenzuela y Villalobos, 2014).

También existe una estratificación educacional por tipo de sostenedor: los estudiantes más vulnerables asisten, 70\% de ellos, a establecimientos municipales (públicos) mientras que los niños y niñas de nivel socioeconómico alto asisten mayoritariamente a establecimientos particulares pagados (Valenzuela, 2006).

La segmentación socioeconómica en Chile se explica por cuatro fenómenos; 1) la segregación residencial de las comunas; 2) la presencia de escuelas privadas en las comunas, 3) la presencia y relevancia de escuelas privadas subvencionadas en las comunas y 4) el financiamiento compartido (Bellei, s.f.)

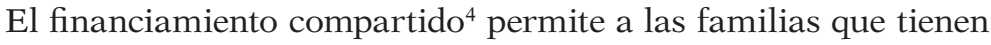
más recursos optar por colegios, que ha tenido como consecuencia que en las escuelas se eduquen estudiantes de condiciones económicas y cul-

2 "Índice de Duncan o disimilitud por establecimiento. Se trata de un índice que establece un continuo entre 0 y 1 , donde valores bajos se asocian a niveles bajos de segregación y altos a altos niveles de segregación" (Walsemann \& Bell, 2010 citado en Treviño et al., 2014, p.4).

3 "Índice de ordenamiento escolar. Es un índice utilizado para estudiar el nivel de segregación al interior de la escuela (Collins \& Gan, 2013). Valores altos del índice revelan poca variación relativa en el curso respecto de la variación promedio en la escuela, lo que sugiere que el aula está homogéneamente ordenada, mientras que valores bajos del índice muestran que hay más variación entre aulas, y que los alumnos se distribuyen heterogéneamente" (Treviño et al., 2014, p.4).

4 En 1988 se incorporó a la subvención escolar el sistema de financiamiento compartido. Esa nueva modalidad les permite a los colegios cobrar un monto a los estudiantes, sin perder la totalidad de la subvención estatal (Vial, 1998). Antes frente al aporte el establecimiento automáticamente perdía la subvención escolar estatal (Aedo y Sapelli, 2001). El financiamiento mixto que empezó a operar en 1993 en democracia, era sólo para establecimientos privados, incluyéndose a partir de ese año los colegios públicos, pero con varias restricciones que han hecho que su aplicación sea mínima. En 1996 el financiamiento compartido en los colegios públicos corresponde apenas a un 3\% (Vial, 1998). Los colegios particulares subvencionados, en cambio, han aceptado de manera masiva esa modalidad. Con esta nueva forma se buscó aumentar los recursos de los establecimientos y una disminución del gasto fiscal. Tal situación ha hecho que los establecimientos privados subvencionados por el Estado reciban más recursos que los públicos (Vial, 1998). Esto supondría una mejor calidad en esos establecimientos, situación que no sucede. Con el Proyecto de Inclusión que se aprobó en enero del 2015, se termina con el copago llamado también financiamiento compartido, esta ley prohíbe en las escuelas que reciban subvención del Estado cobrar a los padres. Tampoco las donaciones o aportes voluntarios podrán ser considerados como requisitos de ingreso o permanencia del estudiante. 
turales similares (Valenzuela, 2006). El sistema educativo también genera segregación al fomentar la selección de estudiantes, privilegiando a los de un nivel socioeconómico medio y alto (Sapelli y Gallego, 2007).

Con respecto a la estructura educacional en Chile, ésta se divide en colegios públicos (municipalizados), privados subvencionados y privados. El primero no cobra aranceles, ni hace selección de sus estudiantes, a diferencias de las otras dos categorías de escuelas secundarias. Con respecto a los aranceles los colegios privados subvencionados cobran mucho menos que los colegios privados pagados (Ministerio de Educación, 2010).

Como consecuencia de esa estructura, los colegios municipalizados reciben a los estudiantes de escasos recursos, de sectores más vulnerables y con un capital distinto al de la escuela; en cambio, los colegios privados pagados educan a los estudiantes con mejores niveles socioeconómicos y con un mejor ambiente de aprendizaje, mientras que los privados subvencionados se centran, mayoritariamente, en las familias de clase media. Es así que las tres categorías de escuelas son un fiel reflejo de las diferencias socioeconómicas existentes en nuestra sociedad, que se expresan en lo económico y también en el capital cultural, personal y familiar (Redondo, Descouvieres y Rojas, 2001).

En suma, hoy las escuelas privadas congregan a los estudiantes de clase alta, en oposición a los establecimientos públicos que reciben a la clase baja. La clase media por su parte elige un establecimiento $\mathrm{u}$ otro, dependiendo de sus intereses y recursos.

Frente a esta situación, las clases medias se han visto más afectadas que las clases privilegiadas, ya que históricamente han estudiado en instituciones privadas o en establecimientos públicos de mucho prestigio. En la situación actual la clase media ha tenido que "elegir" entre los establecimientos públicos y privados, a veces apostando a la educación privada, con un gran esfuerzo económico, ya sea para consolidar su posición, por creer que es mejor la educación entregada en ese establecimiento o para evitar que sus hijos se relacionen con estudiantes de un nivel socioeconómico distinto y más bajo, que suelen ser estigmatizados de manera negativa.

La elección del establecimiento educacional (entre otros factores) y los beneficios que trae eso a las clases privilegiadas, ha provocado una segmentación que legitima la desigualdad social y genera en esas clases una cierta seguridad laboral y de privilegios que los mantiene como clases acomodadas. Esa situación sucede debido a las redes que establecen en las escuelas y la valoración social que tienen los establecimientos de los que egresan que les asegura una buena fuente laboral, debido entre otras razones, a los valores que suelen entregarse en esos establecimientos los cuales coinciden con las necesidades laborales, siendo por ello más viable su contratación (Torres, 2007). 
Por otra parte, los sectores más vulnerables que tienen menos recursos económicos y un capital cultural distinto, terminan asistiendo a establecimientos con bajos resultados de aprendizaje y con un estigma negativo por parte de la sociedad. De tal forma, la dinámica entre los colegios privados y públicos polariza a la población, entregando distintas habilidades a los estudiantes lo cual no surge de las capacidades de cada uno, sino del lugar de origen.

Frente a los fenómenos de desigualdad y segmentación descrita resulta interesante resumir algunas de las reflexiones de Francois Dubet (2005). Este autor cuestiona la tan defendida igualdad de oportunidades y de méritos en el ámbito educativo. Sostiene que el mérito, solo es viable y real en condiciones de igualdades sociales, sexuales, étnicas y de otra índole, lo que no sucede en la realidad. También problematiza la idea de igualdad de oportunidades, ya que a pesar de que en principio los individuos son libres e iguales están distribuidos en posiciones desiguales en la sociedad. Siendo así, lo que prevalece son los privilegios de nacimiento o inteligencia que reproducen las desigualdades. Frente a esta reflexión crítica del autor, resulta pertinente preguntarse cuánto puede hacer la escuela en sociedades tan desiguales como las de Latinoamérica. Si asumimos que la desigualdad y la segmentación son fenómenos multidimensionales y sobredeterminados, es posible pensar que la escuela pueda mitigar, en parte, las diferencias de origen no de manera "única" pero sí en articulación con cambios económicos, políticos y socioculturales.

Como han señalado muchos autores, entre ellos, Paul Willis, Henry Giroux, Jean Anyon y Michael Apple, además de los procesos de reproducción que se dan en la escuela, también existe conflicto, lucha y resistencias que muestra comportamientos de oposición a las lógicas de dominación (Giroux, 1985) dando espacios al cambio.

Como ya se mencionó al inicio de este documento, las desigualdades y las segmentaciones son fenómenos que se recrean a través de mecanismos materiales y simbólicos, que producen distribuciones asimétricas entre los sujetos. Estos procesos son construcciones sociales que involucra a los individuos como a las instituciones y aspectos estructurales que se articulan conformando una red compleja de posiciones.

Para efectos de este trabajo nos interesa centrar el análisis en el aspecto cultural y simbólico como factor de producción o no de las inequidades educativas. Para eso se opta por un nivel micro, centrándonos en la posición de los docentes de tres escuelas de secundarias en Chile.

\section{METODOLOGÍA}

\section{ENFOQUE}

Esta investigación opta por un enfoque etnográfico, entendido como "una concepción y práctica del conocimiento que busca comprender 
los fenómenos sociales desde la perspectiva de sus miembros" (Guber, 2001, p.12). Esta perspectiva resulta pertinente para el estudio ya que permite acceder a dimensiones que no pueden ser reveladas sin un diálogo flexible que permita comprender los significados dados por los sujetos. Desde esta perspectiva se rescata la reflexividad de los sujetos, es decir, la capacidad que tiene el individuo de reflexión en torno a su situación, con sus propias expectativas, motivaciones e intereses, inserto en una estructura social que lo condiciona, pero no lo determina (Guber, 2004).

\section{SUJETOS DE ESTUDIO}

Durante la investigación se entrevistó a treinta y dos profesores de tres escuelas de secundaria en Chile. Se entrevistó a 11 profesores de un colegio público, 10 del colegio particular subvencionado y 11 del colegio público que opera como privado ya que se mantiene a través del cobro a las familias de los estudiantes. Los tres colegios se encuentran en la ciudad de Santiago, capital de Chile.

Las características de los profesores entrevistados se puede observar en las siguientes tablas.

Tabla 1

Antecedentes del docente en la escuela pública

\begin{tabular}{|c|c|c|c|c|}
\hline & Edad & $\begin{array}{l}\text { Años en la } \\
\text { escuela }\end{array}$ & $\begin{array}{l}\text { Años como } \\
\text { docente }\end{array}$ & $\begin{array}{l}\text { Tipos de colegios que han } \\
\text { trabajado }\end{array}$ \\
\hline 1 Juan & 55 aprox & 34 años & 34 años & Colegio público \\
\hline 2 Marina & 55 aprox & 25 años & 30 años & $\begin{array}{l}\text { Colegio particular } \\
\text { subvencionado }\end{array}$ \\
\hline 3 Daniel & 48 años & 18 años & 18 años & Colegio público \\
\hline 4 Ernesto & 52 años & 13 años & 14 años & Colegio público \\
\hline 5 Patricia & 60 años & 36 años & 36 años & $\begin{array}{l}\text { Colegio público } \\
\text { y particular subvencionado }\end{array}$ \\
\hline 6 Jaime & 53 años & 30 años & 31 años & $\begin{array}{l}\text { Colegio particular } \\
\text { subvencionado }\end{array}$ \\
\hline 7 Fernanda & 23 años & 2 años & 2 años & Sólo colegio Darío Salas \\
\hline 8 Gloria & 30 aprox & 6 meses & 5 años aprox & $\begin{array}{l}\text { Colegio particular } \\
\text { subvencionado }\end{array}$ \\
\hline 9 Paola & 35 aprox & 7 años & 10 años & Colegio privado \\
\hline 10 Oscar & 31 años & 6 años & 8 años & $\begin{array}{l}\text { Colegio privado } \\
\text { y particular subvencionado }\end{array}$ \\
\hline 11 Carlos & 45 aprox & 1 año & 6 años & $\begin{array}{l}\text { Colegio particular } \\
\text { subvencionado }\end{array}$ \\
\hline
\end{tabular}


Tabla 2

Antecedentes del docente en la escuela particular subvencionada

\begin{tabular}{|c|c|c|c|c|}
\hline & Edad & $\begin{array}{l}\text { Años en la } \\
\text { escuela }\end{array}$ & $\begin{array}{l}\text { Años como } \\
\text { docente }\end{array}$ & Tipos de colegios que han trabajado \\
\hline 1. Alejandro & 49 años & 21 años & 21 años & Solo colegio Excelsior \\
\hline 2. Héctor & 47 años & 23 años & 23 años & Solo colegio Excelsior \\
\hline 3. Andrea & $\begin{array}{l}35 \text { años } \\
\text { aprox }\end{array}$ & 8 años & 8 años & Solo colegio Excelsior \\
\hline 4. Mariella & 33 años & 2 años & 10 años & $\begin{array}{l}\text { Colegio particular subvencionado } \\
\text { y público }\end{array}$ \\
\hline 5. Sergio & 52 años & 2 años & 27 años & $\begin{array}{l}\text { Colegio particular subv. } \\
\text { y particular pagado }\end{array}$ \\
\hline $\begin{array}{l}\text { 5. Juan } \\
\text { Carlos }\end{array}$ & 47 años & 1 año & 18 años & $\begin{array}{l}\text { Colegio particular subvencionado } \\
\text { y público }\end{array}$ \\
\hline 6. Grisella & 40 años & 6 meses & 8 años & Sólo Particular subvencionado \\
\hline 7. Violeta & 32 años & 7 años & 7 años & Sólo colegio Excelsior \\
\hline 9. Susana & 31 años & 5 años & 7 años & Sólo particular subvencionado \\
\hline 10. Víctor & $\begin{array}{l}40 \text { años } \\
\text { aprox }\end{array}$ & & & \\
\hline
\end{tabular}

Tabla 3

Antecedentes del docente de la escuela pública-privada

\begin{tabular}{|c|c|c|c|c|}
\hline & Edad & $\begin{array}{l}\text { Años } \\
\text { en la } \\
\text { escuela }\end{array}$ & $\begin{array}{l}\text { Años como } \\
\text { docente }\end{array}$ & Tipos de colegios que han trabajado \\
\hline 1 Pablo & 27 años & 2 años & 2 años & Sólo colegio Manuel de Salas \\
\hline $\begin{array}{l}2 \text { María } \\
\text { Angélica }\end{array}$ & 39 años & 11 años & 11 años & Colegio particular subvencionado \\
\hline 3 Eduardo & 32 años & 40 años & 40 años & Colegio particular subvencionado \\
\hline 4 Enrique & 33 años & 5 años & 5 años & Sólo colegio Manuel de Salas \\
\hline $\begin{array}{l}5 \text { Miguel } \\
\text { Ángel }\end{array}$ & 60 años & 33 años & 33 años & Sólo colegio Manuel de Salas \\
\hline 6 Alejandra & 42 años & 16 años & 16 años & Sólo colegio Manuel de Salas \\
\hline 7 Luis R. & 35 años & 5 años & 5 años & $\begin{array}{l}\text { En colegios públicos y part } \\
\text { subvencionado }\end{array}$ \\
\hline 8 Marcia & 40 años & 15 años & 15 & Colegio privado \\
\hline 9 Luis B. & 65 años & 40 años & 40 & $\begin{array}{l}\text { En colegios públicos y part } \\
\text { subvencionado }\end{array}$ \\
\hline 10 Natalia & 35 aprox & 6 años & 6 años & En colegios particular subvencionado \\
\hline 11 Cristian & 43 años & 18 años & 18 & Sólo colegio Manuel de Salas \\
\hline
\end{tabular}




\section{CONSTRUCCIÓN DEL INSTRUMENTO Y PROCESAMIENTO DE LOS DATOS}

Se diseñó una pauta de entrevista con preguntas semi-estructuradas. En relación a la fase de análisis, se transcribieron los audios de los relatos en su totalidad en documentos Word. Luego se prosiguió a una lectura atenta de los textos para codificar párrafos de las transcripciones en base al objetivo. Las codificaciones de los párrafos permitieron identificar fragmentos de importancia que se ordenó en otro documento, realizando dicho proceso con cada establecimiento educacional y profesor, permitiendo comprender y analizar los distintos significados y sentidos que emergieron a través de los relatos de los maestros, iniciando el proceso de interpretación, para proceder finalmente a las conclusiones y reflexiones finales.

\section{RESULTADOS}

Como se explicó, Chile es uno de los países más desiguales a nivel mundial lo que se replica en el espacio educativo siendo el segundo país del mundo en segregación escolar (PISA 2009, en Educación 2020). Esta segmentación se explica, en gran parte, por la estructura y división de los colegios, siendo un fiel reflejo de las diferencias socioeconómicas existentes en nuestra sociedad.

Frente al problema de la segmentación escolar, los profesores entrevistados han construido las siguientes posiciones: 1) Quienes cuestionan la segmentación explicándola como resultado de la desigualdad de la sociedad chilena; 2) quienes están de acuerdo con ella porque deben haber diferencias en las sociedades; 3) quienes valorizan el aprendizaje y la convivencia en la diversidad, situación que no existe en las escuelas de Chile y 4) finalmente quienes cuestionan la diversidad por las dificultades pedagógicas y sociales que conlleva.

\section{EN DESACUERDO CON LA SEGMENTACIÓN: REFLEJO DE LA SOCIEDAD}

La mayoría de los profesores cuestionan la segmentación actual siendo para ellos un reflejo de la desigualdad que existe en la sociedad chilena. Así lo señalan Juan, Oscar, Daniel y Patricia, todos del colegio público. "Es un reflejo de la sociedad en la cual vivimos no más y la educación no podría ser ajena a eso, vivimos en una sociedad totalmente segmentada y por lo tanto, las personas se educan de acuerdo a eso". "Para mí es reflejo de la sociedad, tenemos Isapre, tenemos Fonasa, la Isapre más cara y la más barata pal' perraje, el sistema educativo es reflejo de eso". "Es que la separación no sólo es en la educación esta es una separación que se ha hecho a nivel de vivienda, de barrio, de todo [...] si a ti te aislaron a vivir en un barrio muy periférico, lejos de todo y te construyeron la escuela al lado, dónde vas a mandar a tu hijo, quedan segregados por una cuestión de barrio”. 
En el colegio particular subvencionado, también Susana y Mariela concuerdan con lo señalado, "es un reflejo de la sociedad nada más, se hace los mismo que pasa en la sociedad, nosotros no nos mezclamos con los ricos y los más perjudicados son los de menores recursos, están al último". "Es horroroso, es determinismo, es lo más triste de la literatura naturalista, niñito pobre va a ser pobre toda su vida, porque qué opción tiene, sale de un colegio entre comillas pobre, va a ir a la universidad, va a surgir, ni siquiera tiene el mundo, por último una polola que le permita ascender socialmente [...] o sea nada de nada, pobre, mueres pobre, y tus hijos, y los hijos de tus hijos por el resto de tu vida, por el simple pecado de haber pertenecido a esta raza, sí es determinismo".

Entre los profesores del colegio público-privado, Pablo se suma y condensa lo descrito, "esa diferencia yo sostengo que es implacable, que no es trivial encontrar un modelo donde no se reproduzca la sociedad en sí [...] hay hartos estudios de que la educación es un aparato de reproducción lamentablemente".

Las narraciones de estos profesores muestran, en su mayoría, un análisis realista de las problemáticas de desigualdad de la sociedad chilena, pero también refleja, en algunos casos, una resignación de lo que acontece en la sociedad y en la escuela. La reproducción del sistema y la relación de la cultura dominante con la escuela han sido explicadas por la sociología de la educación marxista y neo marxista que crítica el enfoque funcionalista y aquellas teorías que consideran que la educación es casi la única dimensión que permite la movilidad y el cambio social.

Dentro de esta perspectiva existen dos enfoques: la teoría de la reproducción social y teorías de la reproducción cultural. En el primer grupo están los autores marxistas como Samuel Bowles y Herbert Gintis, Louis Althusser, Charles Baudelot y Roger Establet, tienen en común la herencia de Marx centrándose en cómo la educación contribuye a la reproducción de la estructura social por medio de la reproducción de las condiciones de producción y de la estructura de las clases sociales. En el segundo grupo, quienes no son solo marxista sino con una perspectiva más plural, están Pierre Bourdieu y Basil Bernstein, ellos centran su análisis en cómo la cultura actúa en la escuela y media en el proceso de la reproducción social.

Efectivamente en Chile los datos muestran que los estudiantes de nivel socioeconómico más bajos y de colegios públicos ingresan menos a la universidad, y quienes lo hacen ingresan a las universidades privadas que exigen menos puntaje para su ingreso y son paradojalmente las que cobran más dinero.

Si bien la mayoría de los profesores sobrevaloran la estructura por sobre lo que puedan hacer los sujetos, María Angélica del colegio público 
privado advierte que es importante no perpetuar las desigualdades en la creencia de que la realidad es difícil de cambiar. "Muchos nos estamos escudando en eso, en que nuestro colegio es pobre, no puedo aprender y los chiquillos se están quedando en eso, [...] yo creo que sí falta mucho empeño, mucho trabajo, obviamente que si un cabro ve que no va a pasar nada después de que salga de cuarto medio le va a dar lo mismo terminar [...], yo creo que eso es un espejo de lo que somos, ahora para que se cambie eso debe haber un cambio desde otros aspectos también, o sea debe cambiar todo, porque estamos segmentados todos segmentados".

Esa mirada permite pensar en las contradicciones y resistencias que existen en todo proceso hegemónico. Mirada que defienden autores como Paul Willis y Henry Giroux, Jean Anyon y Michael Apple, quienes rescatan la resistencia de los propios sujetos en el sistema educativo y por tanto dan espacio al cambio. Esta perspectiva surge como respuesta al enfoque reproduccionista que sobrevalora la estructura por sobre lo que puedan hacer los sujetos. El enfoque reproduccionista "ignora" las contradicciones y resistencias que existen en todo proceso hegemónico, siendo necesario no sólo conocer cómo funciona el proceso de dominación unidireccional, sino también las resistencias existentes que permitan caminos distintos a los hegemónicos. Esto se refleja de manera clara con los movimientos estudiantiles que ha habido en Chile y que generan fisuras al sistema de reproducción existente y a la ideología que sostiene el modelo educativo actual.

Es interesante mencionar, que los profesores, hacen referencia a que hubo una época en que las diferencias no eran tan marcadas, siendo el golpe militar un hito fundamental de los cambios de la sociedad chilena. Juan y Daniel, profesores del colegio público, hacen referencia a su propia historia como ejemplo de la integración en las escuelas públicas,
"yo estudié en el liceo de aplicación, yo tenía compañeros que sus papás eran abogados, médicos, mi papá era obrero, ahora eso no se da, los pobres con los pobres, los ricos con los ri- cos”. "En los años '50 y “60 en los colegios [públicos] de mucho prestigio, [...] llegaban gente de mucho dinero porque eran considerados mejores que cualquier otro colegio pagado, la diferencia no era tan marcada porque precisamente había una real posibilidad, la movilidad social era total, hoy en día no".

Lo dicho lo reafirman maestras del colegio público y público privado, quienes reconocen que hubo un momento histórico en que se agudiza la segmentación, como también la descalificación de quienes asisten a los colegios públicos. "Antiguamente no era tan notoria la separación, 
la mayoría de extracto medio y bajo se iban a colegios fiscales, [...] no se sentían como discriminados, (hoy) como que la pobreza significa delincuencia, ahora es difícil que haya mezcla" (Gloria). "No era tan abismante como ahora la diferencia cultural, el niño de una población o un niño que vivía en el barrio alto tenía un nivel semejante de conocimiento, de lenguaje oral, era bastante parecido, hoy día evidentemente que esta segmentación amplía cada vez más la brecha" (Marcia).

Sergio del colegio particular subvencionado condensa muy bien la idea de que la segmentación actual es producto de contextos históricos particulares y de una planificación que se llevó a cabo en dictadura. "La segmentación no es una casualidad, a inicios de los '80 se estudia el modelo económico de este país, para implementarlo había que hacer varias modificaciones partiendo de cómo te educas, cómo sanas tus enfermedades, cómo te jubilas, [...] hay una intencionalidad de separar".

En cuanto al proceso de mayor integración que existió antes, efectivamente previo a la dictadura hubo un proceso democratizador en la sociedad y en la educación. Fue la época del modelo desarrollista. En ese contexto el gobierno de Eduardo Frei (1964-1970) propone un proyecto educativo desarrollista y luego en el gobierno de Salvador Allende (1970-1973) se defiende un proyecto revolucionario y socialista en el ámbito educativo.

En el gobierno de Frei $^{5}$ se sostiene que la educación es fundamental para el progreso económico y la movilidad social. En ese período se considera que el Estado debe ser responsable de la educación, siendo su función velar y garantizar el derecho a su acceso, como también su gratuidad (Ruiz, 2010). El principio orientador de la reforma educativa fue la igualdad de oportunidades, que debía materializarse en la cobertura, pero también en una igualdad educacional que se expresara en la permanencia y calidad a todos los educandos y en una mayor integración social.

Posterior al gobierno de Frei, asume en la presidencia el socialista Salvador Allende ${ }^{6}$ (1970-1973). En su gobierno se apuesta por una

5 Durante el gobierno de Frei se alcanzan avances importantes en educación. El gasto público aumentó de un $15 \%$ a un $20 \%$, se construyeron 3.000 nuevos colegios, se alcanzó una cobertura del 95\% en educación primaria, la tasa de los alumnos de enseñanza secundaria creció en un $20 \%$, al igual que la educación técnica-profesional que creció de un $25 \%$ en 1964 , a un $30 \%$ en 1970 . También se coordinó desde el Estado diversos procesos de alfabetización (Soto, 2004). Fue un período en el que se avanzó principalmente en la cobertura educacional y se buscó la integración social, metas acordes a las propuestas que se estaban realizando en el contexto internacional.

6 Durante el gobierno socialista se aseguró una matrícula del 100\% en educación primaria, con desayuno y almuerzo, además de la atención médica gratuita. Aumentó la matrícula en educación secundaria. Se potenció la capacitación de adultos y alfabetización, aumentando de 126.776 en 1970 a 593.698 en 1973. En la educación superior se 
educación inclusiva y democrática. Educación que debe ir acompañada de mejores condiciones de vida, siendo ambos elementos fundamentales para el proceso de un proyecto social que buscaba llegar al socialismo. Es una etapa en que se aumenta el presupuesto en educación y se amplía la cobertura, incorporando la participación de todos los actores sociales en la búsqueda de un real proceso de democratización de la sociedad chilena (Ruiz, 2010).

El 11 de septiembre de 1973 se da un Golpe de Estado que reconfiguró a la sociedad chilena. Este nuevo orden partió del supuesto que el crecimiento económico resuelve los problemas sociales y económicos de la sociedad, dependiendo del mercado y de los sectores privados y que el Estado debe cumplir un rol mínimo y sólo subsidiario (Chonchol, 1996). Esto se expresó en todos los ámbitos, siendo lo educativo fuertemente mermado a partir de 1979. Entre múltiples cambios, la educación se traspasa al sector privado y el Estado restringe su rol sólo a funciones normativas y de fiscalización, restringiéndose cada vez su responsabilidad en la educación.

\section{DE ACUERDO CON LA SEGMENTACIÓN: DEBEN EXISTIR DIFERENCIAS}

De los profesores entrevistados un profesor apoya la segmentación y las desigualdades como procesos naturales, habiendo otra profesora que si bien no apoya esta idea no se imagina que pudiese ser de forma distinta. Ambos trabajan en el colegio particular subvencionado.

Alejandro así lo expresa:

Lamentablemente nuestra sociedad requiere de distintos tipos de personas, no todos pueden ser abogados, médicos, también necesitamos secretarias, también apunta a lo que el medio requiere hoy, vemos un exceso de profesionales que están trabajando en los supermercados, el mercado es muy chico está saturado de algunos profesionales, lamentablemente se tienen que dar esas diferencia, por una cuestión natural.

La posición de Alejandro, coincide con las argumentaciones que dan los funcionalistas de la sociología para explicar las diferencias sociales en la sociedad. Este enfoque considera que la educación es un subsis-

\footnotetext{
duplicó el número de estudiantes matriculados, siendo muy importante la inclusión de otros sectores, lo que modificó la condición elitista y clasista de la universidad. Ejemplo de ello es el caso de la Universidad de Concepción que en 1973 logra que el 48\% de los estudiantes corresponda a familias de bajos recursos económicos. Existió participación en las universidades y escuelas en todos los estamentos, teniendo todos espacios de participación en el Ministerio de Educación y en las políticas que se estaban definiendo (Palma, 2002). También se desarrollan diversas experiencias educativas, como los programas de alfabetización (Gajardo, 2004).
} 
tema que debe cumplir dos funciones, la socialización que transmite normas a través de la escuela y la selección y diferenciación de los individuos para las distintas ocupaciones y prestigio (Guerrero, 2003).

Para este enfoque, la estratificación es importante ya que es un rasgo fundamental para el buen desarrollo de la sociedad. Davies y Moore en 1945 desarrollan las bases de esta teoría. Sus planteamientos son un pilar para la visión funcionalista de la educación, ya que pone de relieve el principio de la meritocracia, que nutre la función del subsistema educativo hacia el subsistema económico y estratificacional (Guerrero, 2003).

A pesar de los argumentos planteados con anterioridad la realidad actual de las sociedades demuestra que las desigualdades y reproducciones son procesos históricos que responden más bien a fenómenos de explotación y de exclusión.

En el caso de Grisella, ella muestra una posición que naturaliza la realidad social, a tal punto de ser muy difícil imaginarse una sociedad distinta a la actual. Así lo expresa, "no po' no estoy de acuerdo, pero de qué otra forma esto puede ser cambiado".

\section{ASPECTOS PEDAGÓGICOS DE LA SEGMENTACIÓN: VALORACIÓN Y COSTOS DE LA DIVERSIDAD}

Las otras posiciones de los profesores se centran en aspectos pedagógicos de la segmentación escolar. Un grupo de profesores, se centró en la importancia de la diversidad en el aula y otros, en las dificultades que conlleva la integración de distintos tipos de estudiantes.

Los profesores Carlos, Patricia y Ernesto, del colegio público, valoran la diversidad en la escuela como parte del proceso de formación del joven, quien debe aprender a respetar la diferencia y a vivir en un mundo diverso y distinto. Así lo expresan, "debería existir una heterogeneidad ya que se crean menos resquemores, vivir en un ambiente educativo donde exista respeto y se pueda superar las diferencias, [...] ponerse en el lado del otro, sobre todo si eres alguien que tiene plata, que tenemos las mismas posibilidades". "Es muy difícil que las personas se superen si no tienen a quien imitar y cuando la convivencia social está mal, existen referentes y tu aprendes de otro, [...] no tiene que segregarse al pobre, si lo segregas y le das poca educación y mala, qué va a aprender socialmente hablando, sólo reafirma su conducta entre sus pares". "Esta estructura debe ser cambiada de manera radical, por eso se plantea que la escuela en Chile y las universidades sean gratuitas ahí van a converger diferentes niveles socio económicos".

Oscar, de manera muy sincera reconoce, que frente a lo que sucede no le gustaría colocar a su hijo en un colegio donde vayan jóvenes de un nivel más bajo que el de su hijo. "No quiero estar con 
una familia que tiene cierta carga socio cultural de más bajo nivel, yo si pudiera pagarle a mi hijo un colegio, se lo pagaría, más que por la calidad de enseñanza porque los profes somos casi los mismos [...] por los pares, es otro nivel cultural".

La postura de Oscar refleja muy bien la posición de las diversas familias chilenas, que optan por colocar a sus hijos en colegios particulares subvencionados para evitar que se relacionen con jóvenes de nivel socioeconómico más bajo, ya que consideran que eso afectará de manera negativa a sus hijos. Esta posición muestra una de las consecuencias de la segmentación, que profundiza la discriminación y el prejuicio hacia "otro" que es distinto. Las diferencias suelen verse como algo negativo y perjudicial.

En el colegio público-privado los profesores defienden la diversidad como parte fundamental del proceso de formación. Enrique plantea, "yo creo que la diversidad dentro de un colegio es importante, enriquece mucho la relación o la visión que un chico pude tener con respecto al mundo". Luis por su parte, señala: "no es bueno (la segmentación) porque la idea es que todos convivamos con alumnos de diferentes niveles socioeconómicos". Natalia dice: "yo creo que lo ideal sería integración [...], o sea es de aprendizaje mutuo para la vida al final estar estudiando con gente que es súper diferente, el aprender que somos diferentes y que podemos compartir si somos diferentes".

Sólo parte de los profesores del colegio particular subvencionado centran su posición en las dificultades de la diversidad en el aula, sin por eso estar de acuerdo con la segmentación.

Héctor cuenta como en la escuela se experimentó separando a los estudiantes por habilidades y luego como se los mezcló porque los jóvenes se sentían mal al estar en el curso de los "malos estudiantes". Para él, la mejor manera de trabajar con los estudiantes es que sean de un mismo nivel, y así no quedan rezagados los de un nivel más bajo y no pierden los estudiantes que van más adelantados, "yo nunca estuve de acuerdo, llegaba a la sala y me encontré con uno del A, otro del curso E, para mí no era cómodo, porque no sabía a qué nivel trabajar, porque en cualquier nivel había damnificados, qué hace uno, elige el medio y los más altos pierden porque no se les puede explotar y los más bajos siguen mirado el techo, no entienden nada, y quiénes son los que andaban menos perdidos, los términos medios".

Además de los problemas pedagógicos existen problemas sociales de discriminación, así lo explica Andrea:

Imagínate yo lo viví un poco, yo estaba en un colegio donde todos mis compañeros eran el hijo del alcalde, el director del hospital, hijo de diputado y mi papá era carpintero, ya vamos 
a hacer una fiesta y yo no podía ir, también es un proceso que uno tiene que aceptar y estar seguro y decir no tengo plata pero no importa. Para mí no fue tan terrible, lo pude llevar a cabo todo bien, porque teníamos buenas notas entonces todos los otros compañeros querían estudiar contigo, pero qué pasa con los alumnos que son del montón, ahí sería más difícil.

La preocupación de discriminación que expresa Andrea se constata en la misma escuela en que trabaja, así lo confirma Mariela quien comenta cómo reaccionan los estudiantes cuando ingresan a la escuela jóvenes de nivel socioeconómico más bajo, a los que se les llama despectivamente "flaites" y que pueden ser discriminados incluso por los mismos profesores. Ella considera que el ingreso de los estudiantes de un nivel socioeconómico más bajo puede afectar negativamente al grupo. "No quiero ser peyorativa, [...] la gente humilde de antes no son igual a los de ahora, [...] a veces logran ser la manzana podrida, si tienen tierra fértil logran echar a perder al resto, los desordenan, algunos los admiran y los siguen y los tratan de imitar, no sé cuál será el equilibrio para integrar".

La narración de Mariela refleja los estereotipos que existen con respecto a los jóvenes de sectores bajos, a quienes se les estigmatiza de "manzanas podridas". Con las diferencias de estudiantes el razonamiento suele operar en contra de los "malos" estudiantes que influyen negativamente y no al revés de cómo los "buenos" estudiantes pueden influir de manera positiva en la conducta de los jóvenes. Estos relatos muestran las dificultades que se tienen para convivir con un otro distinto, a quien por desconocimiento o por las pocas herramientas pedagógicas que se tienen se les discrimina y desvaloriza a priori. También muestra las debilidades institucionales para cobijar y trabajar con estudiantes con necesidades y características distintas.

Las narraciones de los profesores enfocadas en lo pedagógico muestran dos posiciones. Una que defiende la integración, porque comprende que esta tiene un efecto positivo en el proceso de aprendizaje, valorando y reconociendo el efecto "pares", como estrategia para que estudiantes que están en una condición de desventaja, se beneficien de aquellos que tienen una condición destacada en dichos procesos. Comprenden además, que la exclusión social, tiene implicaciones socio-culturales y políticas que son relevantes de considerar si lo que se busca es una sociedad más integrada y una democracia más sana. Las sociedades más democráticas e igualitarias requieren espacios en el que puedan convivir grupos de distinto nivel socioeconómico, etnias, sexo, nacionalidad, con distintas capacidades, compartiendo la diversidad cultural existente (Torres, 2007). 
La otra postura, da cuenta de las dificultades que se presentan al plantear procesos de integración en la escuela en una sociedad tan desigual como la chilena, enfatizando los problemas de enseñanza y los problemas sociales de discriminación. Estos aspectos requieren ser atendidos y reflexionados por la comunidad escolar, por las instituciones responsables de la educación y la sociedad en su conjunto.

\section{CONCLUSIONES}

En suma, se construyen cuatro posiciones con respecto a la segmentación escolar. Un grupo se centra en el cuestionamiento, explicación sobre todo determinista de las condiciones estructurales de la sociedad. Solo un profesor justifica las diferencias de la sociedad. Otro grupo se centra en el aspecto pedagógico de la segregación, y se divide entre quienes valoran la importancia de la integración y la diversidad en la escuela como parte de la formación pedagógica, y quienes lo cuestionan centrándose en los problemas que puede generar dicha integración.

Del primer grupo sobresale que quienes sostienen que la segmentación escolar es expresión de lo que sucede en la sociedad, no pudiendo ser distinto, le conceden a la estructura una totalidad que no da espacio a la capacidad de ellos como maestro y del sujeto de modificar sus propias condiciones. Solo una maestra entendiendo los condicionamientos (y no determinismo) reconoce la importancia del rol del profesor en poder cambiar, en parte, los determinismos de clase. Este punto, es fundamental en sociedades tan desiguales y segmentadas como la chilena. Si bien las estructuras no determinan, es cierto que condicionan, pero aun así existen espacios de reflexividad y de acción que permiten modificar las hegemonías existentes. Como ya lo señalaba Gramsci y los enfoques de resistencia de la educación, los profesores al igual que los estudiantes pueden ser agentes fundamentales en los procesos de cambio.

El movimiento estudiantil que emergió en democracia así lo ha demostrado, primero con la revolución pingüino el 2006 momento en que los estudiantes secundarios sorprendieron por su organización y capacidad crítica al sistema educativo y político, en un momento en que la sociedad chilena estigmatizaba a los jóvenes de apáticos. Lo mismo ha sucedido con el movimiento estudiantil universitario que comenzó el 2011 y ha continuado. Estos movimientos desplazan las lógicas hegemónicas que han predominado y corroen el modelo imperante abriendo una fisura de posibilidades para pensar en condiciones y sentidos de sociedad distintos.

En cuanto a la postura del otro grupo que se centra en las consecuencias pedagógicas de la segmentación existe una preocupación por el tipo de formación que se le da a un joven que no convive con 
otro distinto ni en la escuela ni en su barrio por la segregación residencial existente. En ese sentido reconocen la mayoría de los profesores en que es necesario contribuir a un proceso de integración que permita una formación ética y política de convivencia con sujetos distintos. No obstante, también se reconoce las dificultades que existen ya sea por los problemas de discriminación que implica la convivencia con otros diferentes y por las dificultades pedagógicas que eso conlleva. La postura de estos profesores se sostiene en una visión realista de las problemáticas que han vivido ellos mismos, pero vuelve a predominar aquello por sobre las diversas estrategias pedagógicas, expectativas y deseos de lo que debiese ser la educación. Por otra parte, lo que señalan está develando las dificultades que está teniendo la sociedad chilena para convivir en un mismo espacio con otros distintos. En el caso de los profesores no cuentan con las herramientas necesarias para acoger una diversidad de estudiantes heterogéneos en sus prácticas pedagógicas, pero más aun no existe una institucionalidad que respalde y acompañe estos procesos.

Está problemática nos lleva a preguntarnos cómo se están concibiendo las relaciones sociales y las diferencias al interior de la sociedad chilena. Lo anterior es relevante por distintos aspectos.

Lo más evidente -no siempre ha sido reconocido así- es señalar que en ninguna sociedad existe una sola cultura sino las culturas, lo que implica además aceptar que no existen culturas superiores e inferiores, lógica que ha predominado por siglos y que ha sustentado y justificado las conquistas y dominaciones y que dio lugar a diversas discriminaciones étnicas, sexuales, clasistas, entre otras (Fornet-Betancourt, 2007).

Asimismo los procesos culturales llevan en sí mismo la fragilidad de lo humano que se expresa en ser al mismo tiempo homo sapiens $y$ homo demens, siendo necesario una constante reflexión y práctica de la convivencia entre las colectividades. No hay que olvidar que la globalización ha posibilitado tanto la confrontación como la negación de las tradiciones culturales (Fornet-Betancourt, 2007).

Por otra parte, la importancia de la integración social a través del reconocimiento y el diálogo entre los diferentes sujetos se articula también con la educación cívica. Las democracias requieren de experiencias en común que trasciendan los espacios de individuación ${ }_{7} \mathrm{y}$ de consumo que ha permeado a la sociedad chilena, fragilizándola . La

$7 \mathrm{La}$ realidad chilena se construye en base a un modelo económico impuesto a la fuerza durante la dictadura y que se perpetúa en democracia y que ha tenido diversas expresiones de inconformidad por parte de la ciudadanía, la más importante han sido los movimientos estudiantiles, primero la del 2006 y luego la del 2011. Es una democracia que hace política desde las cúpulas de poder, al margen y sin participación ciudadana, lo que se ha ido modificando paulatinamente a partir de los movimientos 
escuela debiese potenciar un espacio de comunidad que habilite una cohesión social que trascienda al proceso de individuación que se expresa, muchas veces, en el repliegue familiar. De tal modo, el desafío de la escuela es fortalecer una identidad colectiva, pero al mismo tiempo generar un espacio de diálogo y negociación de las pluralidades presentes en las sociedades, ampliando el sentido actual de lo educativo que se reduce a destrezas cognitivas y laborales (Peña, 2007).

En suma, la problemática de la segregación escolar tiene grados de complejidad que se reflejan en las diversas posiciones que tienen los profesores. También se develan las tensiones y limitaciones institucionales que tiene la escuela y las dificultades de los profesores para enfrentar la diversidad que se exige hoy considerar en el aula. Si bien la mayoría de los profesores considera necesario la diversidad como parte del proceso de formación, también se reconocen las dificultades pedagógicas y de convivencia que conlleva y que devela los problemas que se tiene como sociedad no solo en el espacio pedagógico. Por otra parte, se resignifica el rol de la escuela a partir de una posición "realista y pragmática" sobre la educación, ya no siendo un referente de movilidad social e integración como sí lo fue en otra época y que invita a reflexionar sobre el lugar que hoy ocupa la escuela y en cuánto los profesores contribuyen -o no- a los procesos desiguales estructurales que sufren las sociedades latinoamericana y en especial en el caso de Chile.

Para finalizar, solo afirmar como dice Cornelius Castoriadis el ser humano se caracteriza por su capacidad de creación, poder que da forma al caos que no es otra cosa que la cultura, siendo así, aún es posible construir realidades distintas a pesar de los condicionamientos estructurales que permean cuerpos y subjetividades.

\section{BIBLIOGRAFÍA}

Alegre, M. 2010 "Casi-mercados. Segregación escolar y desigualdad educativa. Una trilogía con final abierto" en Revista Campinas, V.31, $\mathrm{N}^{\circ} 113$, pp. 1157-1178.

Andrés, F. 2013 "La segregación escolar en nuestro sistema" en Revista Fórum Aragón, Nº10, pp. 47-52.

Bellei, C. (s.f.) Segregación socioeconómica y académica de la educación chilena: magnitud, causas y consecuencias (Chile: Centro de Investigación Avanzada en Educación).

sociales. Como diría Lechner, Chile vive "un déficit de política en relación a la modernización económica" (1998:233). 
Chonchol, J. 1996 "Reflexiones sobre Chile: ¿hay alternativas al modelo neoliberal?” En: Revista Estudios Avanzados. Vol 10, N²7, San Pablo, mayo-agosto.

Cruz, J. 2013 “Las bases territoriales de la segmentación educativa”, En: Revista del departamento de Geografía, año 1, Nº1

Dubet, F. 2005 La escuela de las oportunidades ¿qué es una escuela justa? (Barcelona: Gedisa).

Fornet-Betancourt, R. 2007 Sobre el concepto de interculturalidad (México: Consorcio intercultural).

Giroux, H. 1985 Teorías de la reproducción y la resistencia en la nueva sociología de la educación: un análisis crítico en Revista Cuadernos Políticos, pp. 36-55.

Guber, R. 2001 La etnografía: método, campo y reflexividad (Buenos Aires: Norma). Guber, R. 2004 El salvaje metropolitano. Reconstrucción del conocimiento social en el trabajo de campo (Buenos Aires: Paidós).

Guerrero, A. 2003 Enseñanza y sociedad. El conocimiento sociológico de la educación (Madrid: Siglo XXI).

Ministerio de educación 2010 Ministerio de educación. Cuenta pública 2006-2010. Calidad para todos (Santiago de Chile: Gobierno de Chile).

Peña, C. 2007 "Educación y ciudadanía: Los problemas subyacentes" en Revista Pensamiento Educativo, Vol. 40, N¹ 2007, Chile.

Redondo, J., Descouvieres, C., y Rojas, K. 2001 Equidad y Calidad de la Educación en Chile. Reflexiones e Investigaciones. (Santiago de Chile: Universidad de Chile).

Reygadas, L. 2008 La apropiación. Destejiendo las redes de la desigualdad (México: Anthropos / UAMI).

Ritzer, G. 1993 Teoría Sociología Contemporánea (México: Mc Graw-Hill).

Ruiz, C. 2010 De la república al mercado (Santiago de Chile: Chile.)

Sapelli, C. y Gallegos, F. 2007 El financiamiento de la educación en Chile: una evaluación. Revista pensamiento educativo, Vol 40 N¹, pp. 263-284.

Torres, J. 2007 Educación en tiempos de neoliberalismo (España: Morata). 
Treviño, E., Valenzuela, J. y Villalobos, C. 2014 ¿Se agrupa o segrega al interior de los establecimientos escolares chilenos? Segregación académica y socioeconómica al interior de la escuela. Análisis de su magnitud, principales factores explicativos y efectos (Santiago de Chile: Centro de Investigación Avanzada de Educación/Universidad de Chile).

Valenzuela, J 2006 Evolución de la Segregación Socioeconómica de los Estudiantes Chilenos y su Relación con el Financiamiento Compartido (Santiago de Chile: Ministerio de Educación). 



\title{
JOVENS NO BRASIL: A INTERFACE VÍDEO, JUVENTUDE E PROJETOS SOCIAS
}

\author{
Gianne Neves Oliveira*
}

\section{INTRODUÇÃO}

O Brasil tem atualmente uma população jovem-adulta, das periferias, que teve em sua trajetória de vida a específica experiência de participar de projetos sociais em diferentes áreas, o que se transformou em mais um critério que pode fazer ou não diferença na vida desses jovens. Nesse sentido, este artigo, produzido a partir da minha dissertação de mestrado Jovens egressos de projetos sociais: experiências para entrada na vida adulta, tem como objetivo promover uma reflexão sobre as formas como jovens egressos de projetos sociais de comunicação, da área de produção audiovisual, estão ingressando na vida adulta, enquanto sujeitos sociais e políticos.

Através da análise de projetos sociais, com jovens, desenvolvidos pela ONG Centro de Criação de Imagem Popular (CECIP) e

1 Organização da sociedade civil, sem fins lucrativos, fundada em 1986, no Rio de Janeiro. Sua atividade abrange a produção de materiais educativos, impressos e au-

\footnotetext{
* Mestre em Ciências Sociais pela Pontifícia Universidade Católica de São Paulo, coordena projetos com jovens no CECIP - Centro de Criação de Imagem Popular - Rio de Janeiro, Brasil. gianeves@yahoo.com.br
} 
do relato de vida dos jovens egressos desses projetos, este artigo trás dados que contribuem para a reflexão sobre os limites e possibilidades da ação de ONGs junto aos jovens, visto que, em sua maioria, são organizações financiadas pelo setor privado e que, portanto, seus projetos sociais têm limitações como duração, abrangência e possibilidade de continuidade.

Este estudo tem como base o depoimentos de três jovens que participaram de dois projetos sociais coordenados pelo CECIP, o Botando a Mão na Mídia - Oficina com alunos e educadores, realizado entre os anos 2000 e 2002, e Essa Tvé Nossa, realizado nos anos de 2002 e 2003, período em que os exparticipantes tinham idades entre 15 e 20 anos e no início da pesquisa, em 2011, eles tinham idades entre 25 e 29 anos, faixa-etária considerada jovem-adulto.

Esses jovens descreveram os projetos nos quais participaram no passado e suas experiências pós-projeto até àquele momento, o que possibilita uma reflexão sobre o perfil dos projetos e ações voltadas para a juventude, ultrapassando a ideia do jovem como ameaça ou ameaçador. Além de fornecer algumas indicações, à exemplo, o papel de projetos sociais com jovens, na influência sobre políticas públicas para a juventude moradora de periferias, que, em sua maioria, são descontinuadas, setorizadas e de cunho assistencialista.

A Baixada Fluminense, região metropolitana do Rio de Janeiro, local onde os projetos socias foram realizados, é uma periferia que, como muitas outras, apresenta contrastes sociais. A infraestrutura é precária, os índices de violência são altos, o acesso à educação e a aparelhos culturais é restrito e a juventude, em sua maioria, é estigmatizada. Em um contexto mais geral, é recente o olhar para a juventude brasileira de forma mais plural, considerando as juventudes, incluindo os jovens de periferia. Eles passaram a "existir", mas geralmente associados a problemas sociais.

Para esse grupo de jovens, principalmente na década de 1990, foram desenvolvidas ações de controle social e de "preparação" para o mercado de trabalho. Nesse contexto, eles se tornaram um dos principais públicos-alvo de projetos e programas sociais de diferentes naturezas. Essas iniciativas envolviam organismos internacionais, ONGs, organizações empresariais, entre outros. Somente no final dos anos

diovisuais, e também a capacitação de agentes sociais para atuarem na transformação de suas realidades.

2 Adota-se aqui o recorte etário trabalhado pela Secretaria Nacional de Juventude (SNJ) e o Conselho Nacional de Juventude (Conjuve), que consideram: Jovem de 15 a 29 anos, com os subgrupos de 15 a 17 (jovem-adolescente), de 18 a 24 anos (jovem-jovem) e de 25 a 29 anos (jovem-adulto). 
1990, a juventude passa a ser uma questão social com mais relevância. Dessa forma, o jovem passou a ser visto como sujeito de direitos, ou seja, sujeito a políticas públicas que atendam as suas especificidades.

Nos anos 2000, principalmente com o governo do Presidente Lula, houve uma ampliação do diálogo entre o governo e a sociedade civil, por meio dos movimentos sociais, contribuindo para que o debate sobre a juventude brasileira fosse ampliado.

Essas ideias ganharam maior densidade no país a partir de 2004, quando se iniciou, em nível federal, amplo diálogo sobre a necessidade de se instaurar uma política nacional voltada para esse público. No início de 2005, foram criados a Secretaria Nacional de Juventude, ${ }^{3}$ o Conselho Nacional de Juventude e um "programa de emergência" voltado para jovens entre 18 e 24 anos que estavam fora da escola e do mercado de trabalho. (SILVA e ANDRADE, 2009, p. 36)

Faz-se importante destacar outras iniciativas de abertura ao diálogo que foram colocadas em prática, como por exemplo, a Conferência Nacional de Juventude ${ }^{4}$ e a aprovação do Projeto de Lei sobre o Estatuto da Juventude. ${ }^{5}$ Porém, é fundamental, diante dessa ampliação refletir se tais iniciativas estão considerando e atendendo de fato as demandas e necessidades da juventude brasileira e ainda, se essas políticas estão suficientemente articuladas de forma a possibilitar o desenvolvimento integral dos jovens e consequentemente, a sua inserção social múltipla.

Para a implementação das políticas nacionais para a juventude, o diálogo entre poder público, setor privado e o chamado terceiro setor, entre outros atores, tem se ampliado, mostrando certa mescla nas ações desenvolvidas por esses setores, o que pode ser avaliado positivamente, visto que a sociedade civil tem melhores condições de demonstrar a diversidade da juventude brasileira. Porém, tal cenário apresenta a dificuldade em delimitar qual é o papel de cada ator no desenvolvimento dessas políticas juvenis, assim, faz-se necessário produzir informações acerca dos processos de implementação e resultados

3 A Secretaria Nacional de Juventude foi criada em 2005, órgão executivo ligado à Secretaria-Geral da Presidência da República.

4 Foram realizadas duas Conferências Nacionais de Juventude, a primeira em 2008 e a segunda em 2011. A terceira está prevista para 2015. A realização dessas conferências inclui o processo de mobilização anterior da juventude em âmbito municipal e estadual para escuta de suas demandas e prioridades.

5 O Projeto de Lei foi criado em 2007, aprovado em outubro de 2011. 
dessas iniciativas, visto que ainda existe um vazio na elaboração e realização de políticas públicas específicas para os jovens, que propiciem benefícios sociais efetivos e sustentáveis.

O impacto desses projetos sociais são considerados aqui de acordo com Roche (2002), ou seja, atentando-se para as mudanças provocadas pelos resultados da intervenção, dando ênfase aos resultados intangíveis indicados pelos jovens, mas sem perder a perspectiva das possíveis limitações dessas ações. Pois, logo que os projetos são finalizados, parece que se instaura um cenário de descontinuidade na formação, desenvolvimento e inserção desses jovens.

Neste estudo, os jovens são considerados como sujeitos de direitos, protagonistas de suas trajetórias e com potencial para utilizarem os meios de comunicação para a produção de informações sobre si e sobre suas realidades. Assim, a categoria básica dessa análise é a juventude, considerando esta uma categoria em construção, cheia de dúvidas e incertezas. Sabendo que, diferentes estudos sobre esse grupo específico focam nas singularidades juvenis, o que é algo indiscutível, propõe-se aqui considerar também as características universais, inerentes a esse grupo de jovens da periferia.

A singularidade da juventude está aqui, visto que os sujeitos deste estudo são jovens moradores da periferia carioca, egressos de projetos sociais de comunicação. Porém, fez-se necessário enriquecer esta discussão colocando o desafio de encontrar o que essa juventude tem em comum com qualquer outro grupo de jovens, independentemente de sua origem ou grupo social. Essa intenção surgiu ao refletir sobre o que representou, no início dos anos 2000, jovens moradores da Baixada Fluminense, dominando equipamentos e a linguagem audiovisual e produzindo seus próprios programas de TV.

Considerando conceitos utilizados por Pais (1990), buscar a unidade entre os jovens não está relacionado à ideia de aparente unidade, fazendo referência somente a uma fase da vida e tão pouco a ideia de diversidade, considerando somente as diferenças sociais. Juventude não é socialmente homogenia e não se pretende fazer aqui uma mera generalização que desconsidere toda a produção acerca das especificidades da juventude brasileira. A proposta é sair da polarização das correntes geracional e classista e refletir sob a ótica da diversidade da condição social e o caráter universal do ser jovem, considerando parâmetros menos rígidos. Tendo em vista a relação e a inter-relação entre diversidade e unidade, esta pesquisa considera as ideias de Morin:

Trata-se, ao mesmo tempo de reconhecer a unidade dentro da diversidade, o diverso dentro da unidade; de reconhecer, por exemplo, a unidade humana em meio às diversidades indivi- 
duais e culturais, as diversidades individuais e culturais em meio à unidade humana. (MORIN, 2011, p. 25)

A proposta é considerar juventude enquanto parte de uma unidade humana, com igual potencial de aprendizado e competência criativa na utilização da tecnologia, que coloca todos os jovens confrontados com problemas e soluções de ordens muito iguais, direcionados para a sua condição humana. Para compreender a ideia de condição humana, consideram-se as contribuições de Morin:

A compreensão humana nos chega quando sentimos e concebemos os humanos como sujeitos; ela nos torna abertos a seus sofrimentos e suas alegrias. Permite- nos reconhecer no outro os mecanismos egocêntricos de autojustificação, que estão em nós, bem como as retroações positivas. (MORIN, 2011, p. 51)

Nesse sentido, o reconhecimento do igual potencial de aprendizado e de criatividade dos jovens faz parte de uma unidade, o todo. Onde o todo e as partes são recíprocos, faces de uma mesma moeda, em que tanto um quanto o outro podem ser causadas e causadoras de acordo com Morin. Assim, compreender a juventude somente sob a perspectiva da diversidade pode ser uma das causas para a produção de estereótipos que orientam a formulação de políticas e projetos equivocados para esses sujeitos.

Para compreender a entrada desses jovens na vida adulta, foram consideradas as dimensões do trabalho, da educação e da família. A intenção foi identificar, dentro dessas dimensões, as diversas situações em que a transição para a vida adulta pode ocorrer e a diversidade de caminhos percorridos por esses jovens, considerando os possíveis imprevistos e que os caminhos não são lineares, como aponta Camarano:

Muitas possibilidades de transições para as várias fases da vida parecem abrir-se na atualidade, embora o modelo tradicional ainda predomine. O curso da vida tem se colocado como um espaço para novas e inovadoras experiências, em oposição à ideia de que ele se constituía de passagens ritualizadas de uma etapa para outra. (CAMARANO, 2006, p. 58)

A diversidade de caminhos para vida adulta inclui, também, os problemas e as incertezas que são partes integrantes do processo de transição dos jovens para a vida adulta. $\mathrm{O}$ "ser jovem" não está sendo considerado somente sob a ótica da transitoriedade, mas como sujeitos de direitos, com suas experiências, decisões e vivências, assim como a vida adulta não é considerada como algo estável e final. 
O tema transição para a vida adulta se relaciona com iniciativas de projeto social de comunicação com jovens, considerando que esses projetos tem a intenção de que a experiência com a produção de vídeo seja um suporte para o futuro, assim como um exercício de análise crítica do mundo, que pode contribuir para que os jovens enriqueçam seus repertórios e ampliem seus leques de escolhas, a partir da confirmação ou criação de valores.

A par das mudanças que ocorrem em vários níveis na sociedade contemporânea, também os processos de entrada na vida adulta sofrem importantes transformações. À medida que o acesso à informação e a todo um conjunto vasto de recursos se dissemina em escala global e está disponível às populações, permeando e moldando os seus cotidianos, encontram-se cada vez mais pontos de semelhanças, em diferentes sociedades, entre as formas de ser jovem e ser adulto.

O tema das tecnologias, também abordado neste estudo, está baseada no entendimento de Martín-Barbero (2004), como uma expansão do corpo humano. O autor utiliza o conceito de tecnicidade do mundo, a técnica como dimensão constituinte do ser humano. Assim, essa técnica não é um instrumento, mas uma nova organização perceptiva, uma forma de apropriação dessa técnica.

Para o autor, o papel chave das novas tecnologias de comunicação está na formulação de novas demandas sociais, elas tornam possível a emergência de uma nova linguagem e de um novo discurso social, o discurso popular maciço. As novas tecnologias têm um caráter transversal, a forma em que se inscrevem na cotidianidade afeta a sociedade civil. Não afetam só em um ponto específico, mas a todos - trabalho, escola, lazer, saúde, relações, criando um novo tecido que supre as velhas formas de associação social.

Este artigo, por meio da fala dos jovens, busca apresentar o sentido mais amplo da realização de projetos sociais com jovem, como uma possibilidade de ampliação de oportunidades e de inserção social, com ações que vão além do controle e da mera preparação, com cunho estritamente técnico e profissional, para inserção no mercado de trabalho.

\section{ABORDAGENS JUVENIS}

Juventude é a categoria básica de análise, embora esta seja uma categoria que apresenta um número significativo de produção em diferentes áreas e sob diferentes enfoques, ainda se tem muito a descobrir sobre a juventude no Brasil. O retrato da juventude brasileira ainda está em construção. Há uma busca pelo sentido de sua identidade, assim como a busca por desmistificar os variados estereótipos e rótulos associados aos jovens. 
No Brasil, são aproximadamente 50 milhões de pessoas com idades entre 15 e 29 anos, o que representa mais de $25 \%$ da população total (2013). Os estudos e a produção de conhecimento no campo da juventude são cada vez mais crescentes e diversos. Em uma breve contextualização, apresenta-se algumas abordagens relacionadas à condição juvenil e a implementação de políticas para este seguimento.

Estudos da década de 1960 tendiam a ver os jovens como segmento de forte participação nas práticas da vida cotidiana, fazendo uma associação entre a noção de juventude e a condição de estudante, eram referência na realização ações culturais e considerados como um segmento crítico, ativo e organizado. Já na década de 70, muitos estudos consideraram que a juventude estava vivendo um vazio político e cultural, como consequência da ditadura militar.

Em 1980, algumas pesquisas buscavam as razões pelas quais a juventude não tinha mais a mesma participação identificada na década de sessenta. Neste período o sentido da prática juvenil, assim como a participação política, começavam a ser repensados. Importante destacar que, nessa mesma década, com a constituição de 1988, foram instauradas algumas políticas voltadas para a juventude, quando alguns direitos foram assegurados para crianças e adolescentes até 18 anos.

Nos anos 90 buscou-se, entre tantas outras condições, identificar comportamentos e estilos juvenis, entender as resistências, valorizar as micropolíticas e considerar a juventude no plural. Em se falando de juventude, não se pode deixar de citar a criação do ECA - Estatuto da Criança e do Adolescente -, em 1990, que pode ser considerado um marco jurídico importante na garantia dos direitos de crianças e adolescentes até os 18 anos. Porém os jovens dos 19 aos 29 anos continuaram não sendo foco de políticas específicas.

Nos anos 2000, muitos trabalhos se concentraram nas novas redes sociais, atuação cultural e micropolíticas cotidianas (Borelli, Rocha, Oliveira, Rangel e Lara 2010). Os anos 2000, considerando as reverberações dos anos anteriores, a juventude estava diretamente ligada à expansão da tecnologia, onde a relação tempo e espaço se dava de forma diferente, assim como a tecnologia passava a ser um bem.

É relevante considerar que foi no ano de 2005, com a criação da Secretaria Nacional de Juventude, que o seguimento juvenil de 15 a 29 anos começa a ser considerado, na elaboração de projetos e programas no âmbito das políticas públicas. Essa criação marca também o fortalecimento do reconhecimento da noção de jovens enquanto sujeitos de direitos. Reconhecer a juventude, em termos políticos e sociais, enquanto detentores de direitos, uma concepção recente que ainda é um desafio, visto que a condição juvenil é pautada por estereótipos e contradições, concepções que orientam ações controladoras e tutelares. Os jovens, 
enquanto sujeitos direitos, pressupõem-se como atores sociais, que devem ter a sua autonomia, formas de agir e pensar, respeitadas e ainda sua identidade e suas formas de expressão valorizadas.

Importante considerar que ao longo das diferentes décadas, a associação da juventude aos atos de violência era constate. A ideia de jovens associados à violência está relacionada principalmente aos jovens pobres, moradores de periferia. Relação que permanece até os dias atuais, quando os jovens são vistos como os promotores da violência ou quando são as vítimas, em potencial, dos diferentes tipos de violências. Projetos e programas, criados nesse contexto, consideram os jovens como criminalizados, como ameaçados ou ameaçadores e ou como objetos, públicos-alvo de políticas puramente assistencialistas, que não consideram o desenvolvimento e a formação juvenil. São essas visões que ainda orientam muitas políticas para a juventude no Brasil.

Hoje a busca pelas singularidades da juventude brasileira está cada vez mais presente nos estudos realizados por diversas áreas do conhecimento, assim como o tema da participação política e diferentes formas de organização, da promoção de políticas públicas de, com e para os jovens e bem como temas relacionados a interface juventude e tecnologias, onde seus usos e apropriações são algumas das reflexões mais contemporâneas de pesquisa. Neste contexto seguem os depoimentos de 3 jovens que tiveram em suas trajetórias experiências de participação em projetos sociais de comunicação.

Esses jovens participaram, no início dos anos 2000, dos projetos Botando a Mão na Mídia e Essa Tv é Nossa, quando aprenderam a produzir seus próprios vídeos e, ainda, compartilhar com suas comunidades. No período em que participaram das atividades tinham idades entre 16 e 19 anos, eram moradores de bairros periféricos do Rio de Janeiro, localizados nos municípios de Belford Roxo, Nova Iguaçu e Queimados, cidades da Baixada Fluminense.

Em sua maioria, eram estudante de escola pública, somente um dos jovens estudava em escola privada. Moravam com suas famílias formadas, geralmente, por pai/padrasto e/ou mãe, irmãos e irmãs. Suas famílias tinham renda entre dois e três salários mínimos na época. A bolsa- auxílio que esses jovens ganhavam do projeto, cerca de $\mathrm{R} \$$ 50,00 (cinqüenta reais), na maioria dos casos, era para consumo pessoal. Nenhum desses jovens estava em situação de conflito com a lei. 


\title{
JOVENS DA BAIXADA FLUMINENSE EM FOCO: 3 HISTÓRIAS EDITADAS \\ CARLA E SUA BUSCA POR SEUS OBJETIVOS PROFISSIONAIS
}

\begin{abstract}
Eu sempre fui muito pesquisadora de tudo, sempre gostei de fazer tudo e minha mãe trabalhava no colégio, onde tinha o projeto. Ai ela conseguiu uma vaga para mim no projeto e eu participei, foi por intermédio da minha mãe total.

Depois do projeto eu trabalhei, eu tive alguns empregos, mas não foram de carteira assinada, nunca trabalhei com o que eu aprendi (no projeto), nunca empreguei o que eu aprendi, nem hoje, mas eu trabalhei numa empresa de logística de móveis, depois eu saí e entrei na faculdade e fazia gestão de recursos humanos, é o que eu gosto, mas infelizmente não deu para eu prosseguir e hoje eu trabalho numa empresa de logística farmacêutica.
\end{abstract}

Carla se define assim, como alguém que busca as oportunidades, uma pessoa com iniciativa e que acredita que é importante fazer aquilo que gostamos, mas que, para isso, é preciso correr atrás, como ela mesma disse. Em seus depoimentos, falou dos aprendizados adquiridos a partir da técnica do vídeo, mas destaca que a produção audiovisual não foi a sua opção profissional. Faz-se importante compreender o conjunto de motivos pelos quais Carla não ingressou na área de produção audiovisual.

Na verdade eu trabalhei mais com telemarketing, que era o que dava mais oportunidade para a minha idade. Os empregos que dão hoje para os jovens é para telemarketing, eu trabalhei na Claro, que foi uma experiência árdua, foi a mais difícil para mim, foi duro, você ser xingado é complicado.

A entrada de Carla no mercado de trabalho não se difere da grande maioria dos jovens, que se depara com a total falta de possibilidade de escolha. O telemarketing, atendimento telefônico, nos chamados callcenters, é um dos postos de trabalho que mais tem crescido no país e que mais emprega jovens. Na sua maioria, não exige experiência profissional e tem uma certa flexibilidade nos horários. Carla aponta para o possível aspecto positivo dessa função.

O telemarketing ele não é muito bem visto, mas é um trabatho bem dinâmico, que te dá a chance de estudar, porque hoje em dia conseguir um trabalho que te dê chance de você estudar é complicado, às vezes da para conciliar dois empregos, dá uma mobilidade maior para você. 
Carla aponta as dificuldades em ser uma operadora de teleatendimento, mas ainda assim reproduz a ideia de que é uma oportunidade para, ao mesmo tempo, trabalhar e buscar meios para se desenvolver, na busca pela realização dos projetos individuais. Novaes (2006) aponta o teleatendimento como um trabalho simplificado, que não exige criatividade e não estimula a autonomia.

\title{
Ao ser perguntada sobre como o projeto contribuiu
}

\section{para as suas experiências profissionais e sobre os vários cursos que já fez, Carla faz as suas considerações:}

\begin{abstract}
Eu acho que o que eu trouxe para a minha vida hojeéisso, que na hora certa eu consegui ver que estudando é que a gente consegue alguma coisa, é que correndo atrás dos nossos objetivos que a gente consegue realmente alguma coisa e se você almeja alguma coisa, você tem que fazer com que aquela coisa aconteça, não adianta ficar: 'eu poderia ter feito uma faculdade'.
\end{abstract}

Eu quero conseguir terminar o inglês e a faculdade porque hoje em dia, antigamente era: eu tenho faculdade, isso te levava a algum lugar, hoje em dia não, eu tenho faculdade e pós-graduação, isso já te leva em algum lugar, se você tem faculdade, pós-graduação e o inglês isso já te dá um diferencial a mais e é isso que eu quero ter um diferencial sempre.

A entrevistada dá ênfase aos aprendizados adquiridos, ao longo do projeto, que estão relacionados à melhora da relação interpessoal, do contato e valorização do ser humano. Ela ainda destaca a habilidade para a troca de saberes, no sentido de que todos têm o que aprender e todos têm o que ensinar, indicando uma ressignificação do lugar do saber, pois reconhece em si e no outro o poder de ensinar algo e aprender algo.

O que eu posso tirar paraleloé isso que (no projeto) sempre a gente foi voltado pra ensinar e sempre ter o cuidado com as pessoas, ter aquela coisa de conseguir realmente passar alguma coisa, ter sempre felling de saber o que a pessoa tem pra passar e o que você tem pra aprender, que a gente não só aprendeu, mas conseguiu ensinar e tem sempre esse retorno, tem sempre um retorno, porque tudo o que você é na vida você já aprendeu com alguém e você nunca ta isento de aprender, ta sempre aprendendo a vida é um aprendizado, eu aprendo com você, como eu aprendi, eu aprendo com quemeu vou conhecerna rua, no ponto de ônibus, quem eu vou sentar do lado no ônibus, a gente está sempre em 
contato com coisas novas, a gente nunca ta pronto pra tudo, a gente tem sempre uma coisa nova pra aprender.

Carla demonstra dinamismo e sensibilidade na busca por seus objetivos e segue destacando a educação como um passaporte para conseguir alguma coisa, que pode ser traduzido como acesso a melhor inserção no mercado de trabalho. Novaes (2006) chama essa ideia de mito da escolaridade, considerando que essa relação entre escola e emprego não é uma garantia. Visto que existe uma lacuna entre as possibilidades de inserção no mercado de trabalho e os anos de estudo. A entrevistada transita entre o ideal do aumento da escolaridade e a consciência em relação à escassez de oportunidades.

A correlação entre presente e passado, na elaboração de planos futuros, aparece nas falas de Carla, ela projeta para si e para sua família condições de vida melhores, na busca pela realização profissional, afirmando não ter interesse em constituir uma família e querer continuar vivendo com os pais. Ela não demonstra medo das imprevisibilidades e incertezas que o futuro apresenta. Ao longo de sua trajetória, ela agregou valores - "eu aprendi isso a perseverança, busca pelos ideais e não desistir dos sonhos, a vontade de crescer" - que estão contribuindo para esse posicionamento positivo diante da vida.

Carla Modesto, 25 anos, participou do projeto Essa Tvé Nossa, é auxiliar de Tecnologia da Informação. Mora com os pais, duas irmãs e dois sobrinhos, em Belford Roxo - Baixada Fluminense, mesma casa da época do projeto. Não é casada, não tem filhos e pretende morar sempre com os pais. Teve vários trabalhos na área de telemarketing, trabalhou de manicure e de vendedora de roupas. Faz curso de inglês e iniciou faculdade de Gestão de Recursos Humanos, mas teve de interromper por falta de recursos financeiros. Pretendia voltar à faculdade em 2012.

\section{CARLOS ANDRÉ E O SEU OLHAR ATRAVÉS DA CÂMERA}

Eu? É até curioso isso aí, porque quando eu comecei a fazer o projeto eu sempre via como uma coisa mais profissional também, eu nunca consegui muito ver só como ali, então assim eu me comportava, desde muito novo, eu pensava que aquilo ali poderia ser um trabalho, nunca fui de me iludir com as coisas, não é meu perfil, mas eu ficava sempre no meu íntimo pensando que aquilo ali podia ser um trabalho e acabou virando um trabalho porque logo depois do projeto eu fui contratado pelo CECIP, tô até hoje aqui, to muito feliz aqui a princípio, não tenho o que reclamar. 
Carlos André teve a sua entrada no mercado de trabalho de uma maneira bastante particular, pois, após o encerramento do projeto, foi contratado para fazer parte da equipe do CECIP. Fica clara a sua preocupação em ocupar um espaço no mercado de trabalho e essa preocupação parece ter orientado a sua participação no projeto, que logo foi entendido como uma possibilidade de escolha profissional. Mas de qual escolha profissional se está falando?

A primeira experiência de trabalho do Carlos André foi anterior ao projeto, quando tinha idade entre 14 e 15 anos. Ele foi garçom, no turno da noite, em um restaurante que servia refeições. Anteriormente, o jovem já havia feito outros trabalhinhos, como disse ele, para definir os trabalhos que fazia para o pai e para mãe, em troca de pouco dinheiro. Essa experiência está de acordo com a realidade dos jovens brasileiros, que acessam o mercado de trabalho cada vez mais cedo por diferentes razões, e vale ressaltar que o trabalho não fez com que ele abandonasse os estudos.

Ao saber do projeto, Carlos André precisou fazer uma escolha entre o trabalho e o projeto, optou pelo projeto, opção esta que, segundo ele, não foi tão difícil, visto que o fato de trabalhar não era uma obrigação imposta pela família. Essa experiência de trabalho deu ao jovem condições de fazer certas comparações, de acordo com a fala a seguir.

\begin{abstract}
Eu acho que isso também é uma diferença que se tem né você vê que eu estava saindo, por exemplo, de um trabalho, que eu tinha um patrão, para vir trabalhar com coordenadores, com educadores, uma coisa totalmente diferente, claro não era um trabalho pesado em si e tal, mas eu pelo menos, já via como um compromisso e eu acho que isso mostrou para mim onde eu queria estar, com que tipo de relação que eu queria estar [...] porque você descobre com que tipo de pessoa você quer se relacionar, você aprende a valorizar as pessoas, podia cobrar nesse sentido, mas não cobra, cobra em outro, cobra de outra forma.
\end{abstract}

Ao entrar no projeto, Carlos André teve a possibilidade de comparar as diferenças entre estar no mercado de trabalho e estar num processo de formação, e também de ser um trabalhador e de ser um estudante, abrindo, assim, um diferente leque de opções sobre como, onde e com quem gostaria de se inserir no mundo do trabalho, o que certamente deu a ele acesso diferenciado às oportunidades de trabalho. Essa foi uma alternativa profissional que ultrapassa a aptidão para o uso das tecnologias, mas que valoriza a relação humana. Carlos André descreve como foi o processo de trabalho no CECIP. 
No início eu lembro que eu fazia mais lanche né, lanche para os jovens né, e uma vez ou outra que eu assumia algum compromisso até porque eu tinha uma série de dificuldades, uma grande dificuldade de falar no meio deles, mas eu fotografava, a parte de fotografia e de câmera eu sempre gostava de fazer e sempre fiz, eu até uma vez me surpreendi quanto tem de registro daquele projeto na rede do CECIP, foto, vídeo, muita coisa, acho que eu só fotografava no projeto Jovens em Ação, mas ai fazia o lanche.

[...] hoje por exemplo eu tenho carteira assinada, eu fiquei um ano, dois anos nesse projeto né e depois apareceu um curso para fazer edição de vídeo, na Darcy, ${ }^{6}$ eu fiz a edição e aí o CECIP resolveu me contratar como editor, depois do curso fui contratado como editor, to até hoje, trabalho na edição aqui, fazendo assistência também de alguns projetos que às vezes vem para ser editado aqui

O jovem experimentou o desenvolvimento do gosto e da habilidade técnica para trabalhar na área de produção audiovisual, o que possibilitou a abertura de novas alternativas, campos de trabalho, visto que mantém trabalhos fora do CECIP.

Eu tenho filmado casamento para uma pessoa especifica, que tem uma casa de festa em Santa Tereza então ela está sempre contando comigo, vira e mexe final de semana, então sábado e domingo. Sábado agora eu vou filmar um outro, mas é lá na Barra, para uma outra pessoa, até tem alguns vídeos na Internet assim, dos que eu fiz, tem um site lá que vocêvai, dá para ver isso. E também faço muito trabalho de edição também, esse ano está mais fraco edição, mas os últimos quatro anos eu sempre tenho pegado edição fora, enfim faço, ai converso aqui com o CECIP, o pessoal sempre libera, ou chego mais tarde ou vou mais cedo para lá ou venho mais cedo para cá e aí faço esse trabalho.

[...] Eu gosto de filmar assim também, além da edição eu gosto de filmar, então quando eu vou fazer o casamento é legal, eu trabalho sempre com um câmera, a gente combina os planos, fazemos os enquadramentos, depois a gente vê a edição e fica legal, então eu gosto disso assim.

6 Escola de Cinema Darcy Ribeiro, localizada no Rio de Janeiro, é referência na formação de profissionais na área de produção audiovisual/cinema. O CECIP tinha uma parceria com a escola que concedia bolsas de estudos aos jovens dos projetos sociais e para a equipe técnica da ONG. 
Os depoimentos dele contribuem para a reflexão acerca das diferentes formas como os projetos sociais podem influenciar na inserção social dos jovens. De acordo com Novaes (2006), as possibilidades de inclusão e exclusão social de um jovem, atualmente, são mensuradas, considerando o gênero, local onde vive, sua etnia, entre outros, incluindo a participação ou não desse jovem em projetos sociais. Carlos André faz um longo relato sobre uma experiência que teve e as suas reflexões sobre o que ele chama de uma coisa social, como resultado do projeto social.

[...] é historinha eu não sei se te interessa, mas eu vou contar. Quando eu era criança eu estudei no colégio que é em frente a um Salão (de festas), láé um salão muito bonito, depois vocêvê na Internet, é gramadinho, uma piscina, é uma casa muito bonita e a gente quando era criança, a gente jogava bola em frente o muro desse lugar, dessa área e aí assim, eles abriam às vezes o portão e a gente queria ficar vendo o que tinha ali, é um salão muito antigo, a gente ficava tentando ver, mas fechava muito rápido o portão, jogava a bola e às vezes caía lá e a gente não podia pedir, porque era um lugar muito, era um muro mesmo que você não tinha contato com nada entendeu [...] aí assim eu ficava pensando que deve ser dificílimo entrar aí, uma coisa absurda você entrar aí, a gente sempre via com aquela cara assim meio estranha eu e meus colegas também, nisso eu tinha, eu estava na quarta série, eu estudei lá até a quarta série, então eu era muito criança e dai depois desse tempo todo eu fui surpreendido para gravar lá, ai entrei e tal aí falei pros meus colegas, até encontrei alguns e ai eles "ah você conseguiu entrar lá, ah eu consegui, ah legal, pô danado, o que tem lá, sabe", assim alguns ainda se perguntam, ah é um lugar normal, mas isso assim eu achei muito interessante porque querendo ou não ai tem uma coisa do projeto social, porque ali é uma família de classe média alta e que a gente pô de colégio público tem uma barreira, uma dificuldade imensa de entrar em contato com esse tipo de sociedade né e você que depois disso tudo, muitos anos depois eu voltei lá, entrei e fui aceito é uma coisa, é estranho mesmo. Ai tem uma coisa da coisa social é porque eu imagino que se não fosse o meu trabalho de produção de vídeo, nem que agora adulto quisesse entrar, talvez eu não me interessasse mais em entrar, mas é um racha da sociedade né, você jamais entraria, então dai você vê que mesmo que em longo prazo as coisas acontecem entendeu, porque o único interesse que eles tiveram para que eu entrasse lá, foi porque eu tenho uma formação em câmera né já de tempos e consegui na primeira vez que eu fui, ela quis me testar, quis saber se eu era capaz, eu fiz a filmagem e fui chamado, hoje já fiz várias filmagens, então sabe isso 
foi o CECIP, foi a ação do CECIP que me colocou ali indiretamente ou não, entendeu? [...]

A fala do Carlos André resgata a discussão sobre as relações e fronteiras existentes entre as diferentes classes sociais. A experiência vivida pelo Carlos André serviu como uma espécie de intersecção entre essas fronteiras, estabelecida pela relação de trabalho. A câmera de vídeo fez o que ele chama de racha, que lhe deu a oportunidade de negociar com as realidades, a dos seus amigos de infância e a do que ele chama de classe média alta. Para Novaes (2006), o acesso aos projetos sociais pode eliminar certas marcas de exclusão através, por exemplo, da capacitação profissional.

Os projetos sociais tornam-se pontes para um determinado tipo de inclusão social de jovens moradores de certas áreas marcadas pela pobreza e pela violência das cidades. Com eles, uma parcela dos jovens pode inventar novas maneiras de sociabilidade e integração societária que resultem em determinadas modalidades de inclusão. (Ibid., p. 114)

A ideia de criação de novas/diferentes maneiras de se integrar socialmente faz parte da trajetória de Carlos André, que reconhece ter um percurso de vida diferenciado, o que está expresso no relato a seguir.

Não é todo mundo que passa pelos ensinamentos que eu passei, eu me sinto um privilegiado e tal, mas também me sinto com uma responsabilidade de correr mais atrás, eu me cobro, eu fico pensando caramba não posso parar aqui.

O que Carlos André chama de privilégio são as oportunidades de escolha e formação, que deveria ser oferecida a todo e qualquer jovem, as quais ele teve acesso. Ele encarou o projeto social como uma possibilidade profissional, ao se identificar com a técnica audiovisual, encontrou caminhos para dar continuidade a sua formação na área, assim, ele pode se inserir no mercado de trabalho de maneira mais cuidada, visto que, segundo o relatório anual Tendências Mundiais de Emprego 2012, da Organização Internacional do Trabalho (OIT), é elevada a taxa de jovens fora do mercado de trabalho. Sobre os jovens empregados, está o desafio em relação à qualidade nos postos de trabalho ocupados por eles ainda, o que é bastante variada.

Carlos André Holanda, 25 anos, participou do projeto Essa Tv é Nossa e de outro projeto do CECIP, é editor de vídeo e assistente de editor no CECIP e faz trabalhos de cameraman e editor como freelancer. Mora com uma irmã, em Nova Iguaçu, Baixada Fluminense, no 
mesmo bairro em que morava na época do projeto. Não é casado e não tem filhos. Fez curso de cinema na Escola de Cinema Darcy Ribeiro, no Rio de Janeiro. Tem a intenção de fazer faculdade de cinema ou de história. No momento, está priorizando o trabalho.

\section{DIEGO BION, TECENDO REDES E RELAÇÕES}

[...] teve uma época que eu fiquei assim meio pulando de galho em galho, tem um projeto aqui eu vou nesse, ta acabando ai eu vou num outro, então, eu estudei assim em muitos lugares essa coisa da linguagem audiovisual, estudei em várias instituições assim, várias ONGs.

[...] eu nunca me senti refém ou sendo devedor de algum lugar ou de alguma pessoa eu sempre me senti livre, pra a partir daquela experiência tocar a minha vida, a partir de outros processos também.

Diego descreve sua trajetória com bastante clareza no que se refere às suas escolhas de vida. Para dar continuidade ao seu desenvolvimento pessoal e profissional, optou por uma educação não formal de acordo com o seu relato.

[...] aí acabei não concluindo o ensino médio e aí fiquei muito tempo assim, aí a minha conclusão do meu ensino médio foi uma dessas provas que abrem assim, acho que todo ano, fui lá fiz a prova, passei e aí só pra dizer assim que isso não me faz a menor falta assim, porque eu fui lá abri o "lance", não estudei nada, fui lá fiz a prova, passei e nem peguei o diploma até agora também, sim isso realmente é uma coisa que não faz falta. Eu dou muito mais valor pra essa educação não formal assim, as pessoas com quem eu tive contato, foi meu professor tal [...]

Diego descreve as suas impressões sobre a época em que estudou na $\mathrm{Fa}$ etec, ${ }^{7}$ no curso de produção audiovisual, indicando que sua experiência com o ensino formal não foi de sucesso. A análise feita por ele tem como referência para comparação os projetos sociais dos quais fez parte, considerando a metodologia de ensino e os equipamentos os quais teve acesso. A experiência em projetos sociais deu ao Diego condições e repertório para fazer essa análise, assim como para fazer a escolha por uma formação informal.

7 Fundação de Apoio à Escola Técnica do Estado do Rio de Janeiro. 
[...] a Faetec tava defasada nesse sentido, assim tecnologicamente e na verdade em outros sentidos assim. Tinha um estúdio lá no último andar do prédio que não era usado porque tinha um monte de pombo dentro do duto do ar condicionado, com pombos mortos assim, então não tinha condições de usar o estúdio e tal enfimé uma época bem "trash" do governo do Rio.

\section{[...] então teve um dado momento que eu senti que ali não aten- dia mais as minhas necessidades e ai eu larguei a Faetec e fui pra Kabum que era uma escola que dava um super suporte técnico e tecnológico.}

Essa vivência do Diego indica para um dos grandes desafios da juventude brasileira que é o abandono escolar. Tal situação se dá por diferentes motivos e motivações, e a desestrutura dessas instituições de ensino é, também, uma das razões para essa evasão, para além das razões socioeconômicas. A análise do Diego não faz uma relação direta entre escola e inserção no mercado, considerando o que Novaes (2006) chama de "mito da escolaridade". A análise dele se refere à necessidade de se ter uma estrutura adequada para acesso e produção de conhecimento.

Diego conta a sua trajetória de forma bastante madura e consciente, e descreve claramente como a experiência no projeto possibilitou a ampliação das suas possibilidades de vida. Ele compreende a produção audiovisual enquanto uma ferramenta poderosa de expressão, mas também como forma de garantir seu sustento, de acordo com o relato a seguir.

Nesse período que tive contato com o fazer audiovisual, que além de durante muito tempo ter vivido mesmo assim de grana de oficina de audiovisual em outros projetos e tal eu também me sirvo muito dessa linguagem, não só no Buraco ${ }^{8}$, mas também para realizar os meus filmes. Os meus poucos filmes são geralmente, o audiovisual me ajuda como válvula de escape assim mesmo, tem alguma coisa que está assimali me incomodando, tem gente que escreve tal, eu penso muito sobre aquilo e vez.

\footnotetext{
8 Diego faz referência ao cineclube Buraco do Getúlio, fundando por ele e mais três amigos, em 2006. O cineclube funciona em Nova Iguaçu. Exibe, semanalmente, filmes nacionais, no Centro Cultural Sílvio Monteiro, único espaço cultural da cidade e mensalmente realiza sessões seguidas de apresentações de teatro, poesia e música, em um bar. O nome do cineclube faz referência ao nome de uma rua famosa de Nova Iguaçu, Rua Getúlio Vargas e a um túnel da estação de trem, popularmente chamado pelos usuários de "buraco da estação".
} 
ou outra rola um curta e tal, talvez essas sejam as coisas mais básicas assim e mais importantes ao mesmo tempo, porque a linguagem me deu sustento durante muito tempo.

Ele descreve que a consciência de si e a ampliação de possibilidades de vida foram alguns dos aprendizados importantes adquiridos com o projeto e, em seu relato de vida, descreve como vem colocando em prática esses saberes. A entrada de Diego no mercado de trabalho se deu através do CECIP, que o contratou ao término do projeto do qual fazia parte.

[...] uma coisa que sem dúvida marcou, que eu vou levar para o resto da vida éque assim, dentro desse periodo que eu passei láe tal eu vi que eu podia ser e fazer da minha vida o que eu quisesse e não só aquilo que talvez as pessoas digam que determinadas pessoas possam fazer, foi nesse contato que eu descobri que eu podia fazer, ser da minha vida o que eu quisesse [...]

[...] o primeiro trabalho que eu tive foi no próprio CECIP [...] aí enfim continuei no CECIP durante um tempo e tal e aí teve um dia que eu falei pô não quero mais, quero conhecer outras pessoas também, outras maneiras de trabalhar, trabalhar em outros lugares e tal ai eu recebi uma proposta para trabalhar aqui em Nova Iguaçu e aí foi muito legal essa época.

O CECIP, como local do primeiro emprego, é uma característica semelhante nas trajetórias do Diego e do Carlos André, o que indica uma forma bastante específica de acessar o mundo do trabalho. Além disso, os dois jovens indicam o CECIP como um lugar de relações de trabalho bastante respeitosas. No caso do Diego, os aprendizados que obteve com o projeto o impulsionaram a buscar outras experiências profissionais.

Conscientemente eu percebi que existiam outras possibilidades no mundo pra mim e que o CECIP não era a única, apesar de ser um lugar maravilhoso enfim, pessoas super queridas trabalhando lá, eu decidi ir pra outros lugares também viver outras coisas, com outras pessoas, conhecer outras maneiras de trabalho e eu acho também que foi bacana porque, uma coisa que talvez eu tenha aprendido lá, talvez eu tenha aprendido lá não, que com certeza me ajudou muito lá no início, foi essa coisa de lidar com a pessoa mesmo, então eu soube sair do CECIP de uma maneira muito tranquila, saí de lá de uma maneira muito tranquila. 
Diego descreve um grande exercício de liberdade e autonomia ao fazer escolhas ao longo do projeto e depois de sua finalização. Ele coloca em prática a negociação entre a dependência e a independência, uma das características que contribui para a compreensão dessa transição para a vida adulta. Essa liberdade e autonomia possibilitaram que ele, em sua trajetória, circulasse por diferentes espaços e relações, assim, Diego indica que a sua habilidade para tecer redes foi também um ganho vindo do projeto.

Eu faço parte de muitas redes assim e eu acho que é uma coisa que eu aprendi lá. Conseguir identificar as redes e valorizar isso enfim, essas redes que a gente vai formando ao longo da nossa trajetória assim, então eu passei por muitas instituições e tenho redes de cada uma dessas instituições que eu participei assim e isso trazendo um pouco pro Buraco que é a coisa que eu mais gosto de fazer é assim, todo mundo trabalha de graça desde a banda que vai lá se apresentar ao cara que coloca o some tal, então essa questão colaborativa da rede foi uma coisa que eu acho que tem dentro de mim e tem origem nesse período do Credicard.

As suas experiências, em diferentes organizações, participando de projetos e/ou trabalhando, deu a ele condições de refletir criticamente sobre a relação entre os jovens participantes dos projetos e as organizações realizadoras.

[...] eu acho que assim pra minha trajetória eu acho que tiveram algumas coisas que foram fundamentais principalmente pela quantidade de coisas que eu fiz ao longo do tempo assim eu acho que uma coisa, que outras pessoas egressas de projetos sociais, talvez tenham uma dificuldade que eu nunca tive, e eu falo isso a partir de relatos de amigos, é porque pra gente que saiu, que fez parte ali de um processo e às vezes pra instituição que ofereceu de alguma maneira, existe uma sensação assim de como se fosse uma divida assim porque geralmente. (Autora pergunta: Você acha que das duas partes?) Não, acho que das duas partes, mas de maneiras diferentes, porque tem pessoas que passam por esses processos e que modificam as suas vidas de alguma maneira tal, mas existem outras pessoas, e eu acho que eu sou uma dessas pessoas, que a passagem por uma situação como essa modifica radicalmente a trajetória da vida, eu acho que eu faço parte desse grupo, que foi modificado e se modificou a partir desse encontro, com as pessoas, com a linguagem, com a experiência enfim com uma série de coisas, eu faço parte dessas pessoas que a vida mudou radicalmente, que eu também modifiquei a vida radicalmente a partir disso. Então, pra essas pessoas que tem a vida modificada a partir de uma experiência 
como essa às vezes fica uma sensação de divida entre quem passou por esse processo e quem ofereceu de alguma maneira esse processo e aí isso acaba gerando em alguns casos de você não conseguir se desvencilhar daquela instituição, você ter uma "vibe" de ser eternamente grato de ta só pra li, às vezes dá as costas para um mundo que te oferece uma série de outros processos bacanas também, com instituições, com grupos de pessoas, enfim de outras maneiras. Eu nunca me senti dessa maneira ou na verdade quando talvez eu estivesse começando a me sentir, eu decidi que esse não era um caminho bom.

Essa fala de Diego indica sua habilidade de fazer uma análise crítica entre os objetivos a que se propõem os projetos sociais e as possibilidades reais de impacto dessas ações na vida dos jovens. Indica ainda que os projetos sociais são capazes de estimular transformações, no caso do Diego, uma transformação individual, seguindo um modelo criado e recriado por ele, com autonomia, independência e criticidade. Nesse discurso, está colocada a reflexão sobre a ideia de gratidão, fidelidade e compensação que podem ser inerentes nessas relações entre beneficiador e beneficiário, ofuscando a ideia de que ações de formação e desenvolvimento juvenis são de direito do jovem e não um favor que recebem.

Diego Bion, 26 anos, participou do projeto Essa Tvé Nossa e de outro projeto do CECIP, é assistente de articulação de rede no Programa Cine Mais Cultura, do Ministério da Cultura. Mora com sua esposa e seu filho de um ano, em Nova Iguaçu, Baixada Fluminense, em um bairro diferente do que morava na época do projeto. Trabalhou nos projetos com jovens do CECIP, durante dois anos. Participou de projetos na área de comunicação e trabalhou como educador em diferentes ONGs. Iniciou o curso de Audiovisual, de nível médio na Faetec, deu aula para crianças e adultos na Escola Livre de Cinema de Nova Iguaçu, fez trabalhos para a Fundação Roberto Marinho e iniciou na Oi Kabum! Escola de Arte e Tecnologia. Terminou o ensino médioá distância e pretendia iniciar a faculdade em 2012.

\section{CONSIDERAÇÕES FINAIS}

Este estudo é o resultado do exercício de estabelecer um diálogo entre o campo prático dos projetos sociais com jovens e o campo da teoria. O objetivo foi produzir algum conhecimento que possa contribuir para o aperfeiçoamento e reflexão para essas duas vertentes e que essas possam se potencializar uma através da outra. Nesse contexto, seguem algumas considerações finais, com observações que se fizeram importantes nesse processo de reflexão.

O trabalho de organizações não governamentais segue sendo realizado na tentativa de eliminar as desigualdades e instaurar cidadania. 
Tais iniciativas, apesar de suas limitações, têm produzido resultados sociais que devem ser considerados, principalmente no âmbito do estímulo ao desenvolvimento da capacidade humana.

Ao analisar as entrevistas dos jovens egressos, percebe-se grande satisfação em terem participado dos dois projetos. De maneira geral, os entrevistados expressam valores morais aprendidos, assim como grande capacidade intelectual. Expressaram eficiente habilidade para se relacionarem com o outro, compreensão do sentido da solidariedade e também explicitaram grande capacidade pessoal para gerir e administrar suas vidas. Ao relatarem a busca por seus objetivos, não se apresentou de forma nítida o desejo dos jovens de conquistarem seus objetivos coletivos, ou conquistarem seus objetivos de maneira coletiva e organizada. Parece que os projetos não fortaleceram a organização juvenil e também a participação nos espaços formais de decisão e debate político.

Os aprendizados destacados pelos jovens estão ancorados na aquisição de valores, reconhecimento da identidade, vivência da sociabilidade e ampliação de projetos pessoais de vida.

O desenvolvimento da formação moral. A participação nos projetos, possibilitaram o desenvolvimento de habilidades emancipatórias, fazendo com que criassem alternativas de inserção social, que contribuíram para que se colocassem em um lugar de menor vulnerabilidade.

Os jovens entrevistados demonstram ter objetivos de vida muito claros, objetivos estes que passam por escolhas profissionais, maneira de se relacionar com as pessoas, formação de família, assim como consciência sobre o lugar que querem ocupar na sociedade. A dimensão da formação do ser humano é o principal efeito dos projetos na vida dos jovens, o que possibilitou que estes criassem projetos de vida e, de maneira autônoma, criassem diferentes estratégias para realizá-los e se inserirem socialmente, indicando uma diferença no modelo da trajetória de vida de seus pais e gerações anteriores.

Apesar desse crescimento pessoal, assim como grande parcela dos jovens moradores de periferia urbana, esses jovens egressos, também seguem encontrando dificuldades no acesso à formação educacional de qualidade, na permanência em instituições de ensino e no mercado de trabalho, ocupando cargos com melhor remuneração. De fato, a inserção no mercado de trabalho, por exemplo, não era um dos objetivos dos projetos, mas essa realidade aponta para o vazio de políticas públicas que garantam a inserção juvenil.

No caso deste estudo, entendemos que o CECIP tem contribuições positivas para os necessários processos de criação de modelos de políticas públicas para a juventude, que devem ser produzidas valorizando o jovem como cidadão, numa linha emancipatória, que almeja um indivíduo protagonista de sua trajetória. 
Essa análise contribui para a ideia de que, apesar de projetos sociais com grupos de jovens com identidades individuais, produzirem resultados satisfatórios, faz-se necessária uma análise estrutural, apontando a potencialidade da ação combinada entre governo, mercado e sociedade civil, na garantia dos direitos juvenis, fundamentalmente, nas ações que possibilitem aos jovens serem atores de mudanças nas suas realidades.

\section{BIBLIOGRAFIA}

Borelli, S. H. S.; Lara, M. R.; Oliveira, R. A.; Rangel, L. H. V.; Rocha, R. M. 2010 "Jovens urbanos, ações estético-culturais e novas práticas políticas: estado da arte (1960-2000)" en Sara Victoria Alvarado y Pablo A. Vommaro (org.) Jóvenes, cultura y política en América Latina: algunos trayectos de sus relaciones, experiencias y lecturas (1960-2000) (Buenos Aires: Homo Sapiens/CLACSO).

Camarano, Ana Amélia (Org.) 2006 Transição para a vida adulta ou vida adulta em transição? (Rio de Janeiro: Ipea).

Martín-Barbero, Jesús 2004 "Tecnologias: inovações culturais e usos sociais" en Ofício do Cartógrafo. Travessias latino-americanas da comunicação na cultura (São Paulo: Loyola).

Morin, Edgar 2011 A cabeça bem-feita: repensar a reforma, reformar o pensamento (Rio de Janeiro: Bertrand Brasil).

Novaes, Regina Reys 2006 "Prefácio" en Almeida, Maria Isabel Mendes de; Eugênio, Fernanda (Orgs.) Culturas Jovens: novos mapas do afeto (Rio de Janeiro: Zahar).

Pais, José Machado 1990 “A construção sociológica da juventude - alguns contributos" en Análise Social, v. XXV (105-106), pp. 139-165, 1990.

Roche, Chris 2002 Avaliação de impacto dos trabalhos de ONGs: aprendendo a valorizar as mudanças (São Paulo: Cortez).

Silva, Enid Rocha; Andrade, Carla Coelho de 2009 "A política nacional de juventude: avanços e dificuldades" en Castro, Jorge Abrahão de; Aquino, Luseni Maria C. de; Andrade, Carla Coelho de (Org.) Juventude e políticas sociais no Brasil (Brasília: Ipea). 


\title{
TRANSICIÓN HACIA EL ESTADO COMUNAL Y POLÍTICAS PÚBLICAS DE JUVENTUD EN LA VENEZUELA DEL SIGLO XXI: APUNTES CRÍTICOS DESDE LA FILOSOFÍA POLÍTICA DE SIMÓN RODRÍGUEZ
}

\author{
Arquímides Romero*
}

\section{TRANSICIÓN SISTÉMICA AYER Y HOY}

América Latina en general, y Venezuela en particular, en estos momentos vive una época transicional: Nuestras sociedades son espacios de tensiones entre fuerzas progresistas de carácter popular, algunas con radicales proyectos de ruptura, (Venezuela, Bolivia, Ecuador) otros con proyectos de reforma social (Brasil, Argentina, Uruguay, Nicaragua, El Salvador). Pero sean radicales, o sean moderados, todos estos procesos en marcha pueden verse frenados por el peso de las circunstancias. Siguiendo constantes históricas, fuerzas conservadoras constituidas por elites socioeconómicas locales entregadas al capital trasnacional, se han opuesto a tales intentos de cambio, que, de acuerdo con sus visiones, sólo ofrecen caos, lesionan la cohesión social, se basan en modelos teóricos obsoletos o falsos, y están condenados al fracaso, entre otros elementos; en contraste, los grupos conservadores ofrecen ante la opinión pública apariencias de respeto a las formalidades democráticas,

\footnotetext{
* Abogado. Ex juez penal, y de Protección de Niños, Niñas y Adolescentes. Especialista en prevención de riesgos psicosociales y Diplomado en economía ecológica. Militante del movimiento social: Escuela Social Rodrigueana Latinoamericana y del Caribe (ESRLC). Asesor en el diseño y ejecución de proyectos de desarrollo comunitario, medios alternativos de solución de conflictos, y educación en derechos humanos. Correo: arquimedesromero@hotmail.com
} 
orden y estabilidad económica, en aplicación de teorías presuntamente eficaces. Con las diferencias propias de cada momento, hoy se están reproduciendo las lógicas transicionales que vivió y sufrió la generación de independencia de comienzos del siglo XIX. La confrontación que vivió Bolívar, Artigas, San Martín y demás gigantes de la independencia, respondió a los mismos patrones. Primero estuvieron confrontados al colonialismo español y toda su carga supersticiosa y sus prácticas sanguinarias, luego de derrotado éste, el nuevo enemigo pasó a ser el aldeanismo y los mezquinos intereses de mediocres oligarquías locales, herederas del modelo cultural feudal de la colonia, quienes rápidamente se aliaron con el naciente imperialismo capitalista en condiciones leoninas para nuestros pueblos. Se logró así lo que los españoles no pudieron: Derrotar el proyecto de emancipación continental. Las fuerzas conservadoras de hoy son las naturales continuadoras de aquellas. La sinonimia entre ambos momentos históricos es completa.

Pero hoy una nueva generación ha retomado las banderas del inconcluso proyecto Bolivariano: La generación Bicentenaria. Venezuela, con el Comandante Hugo Chávez a la cabeza, fue el país que en América Latina encendió la chispa de estos procesos de cambio (al igual que en el siglo XIX). Venezuela se ha constituido así en un país-símbolo, debido a su rol histórico pasado y actual, y a la vez en un país-músculo, debido a la fortaleza de su industria petrolera y su poder generador de renta puesta al servicio de las causas sociales. Las políticas de juventud que hoy se ejecutan y planifican en nuestro país no pueden entenderse sino ubicándolas en el contexto del momento histórico, que comporta un drama transicional sistémico, con todas sus oportunidades y amenazas. Entender esas dimensiones es vital para abordar los procesos de creación de políticas públicas con perspectiva a ser aplicada y asumida por y para la población joven, y a tales efectos, Venezuela cuenta con un teórico que abordó magistralmente todas esas categorías: SIMON RODRIGUEZ, una de las tres raíces del movimiento Bolivariano que está abriendo la brecha a la generación Bicentenaria en este siglo XXI.

\section{CONTEXTOS HISTÓRICOS Y DINÁMICAS TRANSICIONALES EN VENEZUELA}

De acuerdo con el analista marxista Vladimir Acosta, la Revolución Bolivariana que conquistó el poder político formal en Venezuela en 1999, estrictamente hablando, no es una Revolución, porque no se ha planteado una ruptura radical de los modos de producción capitalistas. Es un proyecto reformista de alto impacto social que crea condiciones pre-revolucionarias únicas, nunca antes vividas ni en este país ni en ningún otro, (Acosta, 2013) para preparar posteriores transustanciaciones auténticamente revolucionarias (transustanciaciones en el sen- 
tido que le da Calvo Bacca al término, citado por el Presidente Chávez: Cambiar la sustancia, más allá de transformar ó cambiar las formas). En ese contexto, la Revolución Bolivariana se caracterizaría por los siguientes elementos:

Composición política
Heterogeneidad sectorial

Pluralidad ideológica
Militares, sindicalistas, estudiantes, intelectuales, campesinos, empresarios, entre otros.

Clase Obrera, campesina, sectores medios urbanos, burguesía nacionalista.

Bolivarianismo, marxismo-leninismo, indigenismo, desarrollismo nacionalista.

Fuente: Elaboración propia.

La diversidad de corrientes en el campo revolucionario contrasta con cierta homogeneidad programática en el campo opositor al gobierno del entonces Presidente Chávez, pues esta se mostraba mucho más uniforme en su composición, y nucleada en torno a una meta común: La salida de Chávez del poder y de su proyecto de emancipación social. Alrededor de esa corriente se aglutinan los viejos partidos políticos desplazados del poder (Acción Democrática y COPEI), los nuevos partidos políticos nacidos de las divisiones internas de los aquellos (Un Nuevo Tiempo, Primero Justicia); los gremios empresariales, grandes latifundistas, las cúpulas sindicales asociadas a la política tradicional, las cúpulas religiosas, y sobre todo, los dueños de los medios de comunicación. Estos sectores han recibido apoyo masivo de las clases medias urbanas, (muy influidas por la cosmovisión del "American way of Life"), bajo la premisa de que el gobierno de Chávez constituye una amenaza a sus derechos, intereses y estilo de vida.

La pluralidad de corrientes a lo interno del movimiento Bolivariano y la agresividad de la oposición, les supuso a los revolucionarios la necesidad de unificación de objetivos y acciones en torno a metas mínimas comunes, lo que facilitó la concreción del proyecto Bolivariano en su fase inicial. La Revolución Bolivariana se planteó cumplir con dos objetivos urgentes: a) La refundación Republicana a través del proceso 
Constituyente; b) El pago de la deuda social dejada por el modelo de sociedad atrasada y neo-colonial heredada de la era de la democracia representativa que gobernó Venezuela desde 1959 a 1999, y por la fase neoliberal vivida al final de dicho período, que aceleró las desigualdades sociales y el deterioro en la calidad de vida de las mayorías.

Los asfixiantes niveles de pobreza de las mayorías nacionales reclamaban una respuesta urgente de un gobierno nacional que asumió para sí las reivindicaciones populares. Para ello el gobierno del Presidente Chávez se valió de una estrategia: La defensa del precio del petróleo y el fortalecimiento de la industria petrolera, principal (y prácticamente única) fuente de divisas del país, para la posterior redistribución de la renta petrolera, priorizando las históricamente desatendidas necesidades de las mayorías nacionales.

Tal hecho supuso una trampa: (Lander, 2014) Por un lado, Venezuela logró importantes avances en materia de inclusión social, sustancial disminución de la pobreza y aumento de indicadores de desarrollo humano, tales como eliminación del analfabetismo, incremento acelerado de matrícula escolar en todos sus niveles, disminución de la desnutrición, acceso a servicios públicos, entre otros, (UNICEF, 2015), así como importantes cambios positivos en el ámbito de la cultura política y el estimulo a la participación ciudadana, innovando estrategias de organización socio-comunitaria directamente relacionadas con mejoras de la calidad de vida en la cotidianidad de las comunidades, (misiones sociales, mesas técnicas de agua y/o energía, entre otros) por otra parte, se fortalece el modelo rentista-petrolero heredado del pasado democrático-representativo-burgués, desestimulando la actividad productiva no-petrolera, poco competitiva ante productos y servicios importados con divisas abundantes y baratas generadas por dicha renta, a su vez, la no superación del modelo rentista fortalece el modelo cultural que alimenta a la sociedad burguesa: Consumismo, hedonismo, despilfarro, que a su vez inciden en el fortalecimiento de subjetividades que el modelo de inclusión social aspira superar: Individualismo, competencia, egoísmo, frivolidad, elementos que mantienen "sano" un patrón cultural más o menos extendido en Venezuela de estimulo a conductas anómicas, (corrupción, tráfico de influencias, delincuencia común y organizada, burocratismo) circunstancia que tiene una data histórica, pues viene siendo arrastrada desde tiempos coloniales, generándose así fuertes contradicciones a lo interno de los objetivos y estrategias del proyecto Bolivariano. (Lander, op cit: Chacón, 2012)

El modelo de gestión de gobierno revolucionario viene disputando con la burguesía tradicional la hegemonía política y social, logrando hasta ahora constituirse en nuevo referente hegemónico gracias a sus innovaciones político-jurídicas y a la efectividad de sus novedosos 
planes y programas sociales, pero en cuanto a la hegemonía económica y cultural, esta sigue siendo controlada por la burguesía tradicional, que parece consolidada en esos ámbitos, al no estar en duda la legitimidad del modelo petrolero-rentista en sí sino su administración, siendo dicha burguesía beneficiaria indirecta de los procesos de redistribución de renta, ya que al aumentar el poder adquisitivo de las clases populares, producto de políticas redistributivas, termina beneficiándose al sector privado que controla la casi totalidad de medios de producción y distribución, así como el sector financiero que controla el crédito al consumo, generándose un fuerte proceso de acumulación de capital a favor de la burguesía, en medio de un discurso de enfrentamiento con esta. (Lander, op cit) Se plantea así una disputa entre fuerzas políticas antagónicas luchando por aumentar el poder de influencia en la formación de subjetividades individuales y sociales. Las fuerzas conservadoras pro-burguesas pasan de un discurso de "recuperación" de la democracia y las libertades contra un gobierno presuntamente despótico, a otro de administración tecnocrática del proyecto de inclusión social, (triunfo de la hegemonía política y social Bolivariana), entretanto, la Revolución Bolivariana, más coherente consigo misma a nivel discursivo, se plantea claras rupturas con el modelo burgués, sin embargo, se perciben incoherencias entre discurso y praxis, avances y retrocesos, principalmente en la ejecución de políticas públicas, respuestas institucionales, y comportamiento de amplios sectores sociales en abierta contradicción con las lógicas discursivas gubernamentales (triunfo de la hegemonía cultural y económica burguesa). (Chacón, op cit)

A partir del 2007, en un intento de aprovechar los saldos positivos de las experiencias acumuladas, aprendizaje de los errores, profundización en las innovaciones sistémicas, uso práctico de referentes teóricos propios, con miras a romper a un tiempo con las lógicas relacionales propias del capitalismo-dependiente y de lo que fue el socialismo burocrático del siglo XX, el Presidente Chávez propone la creación y consolidación del ESTADO COMUNAL como instrumento al servicio del proyecto de construcción de socialismo Bolivariano ó socialismo del Siglo XXI. Propuesta nacida de la necesidad de plantearse como meta revolucionaria la definitiva superación del Estado Burgués que pervive en tiempos de Revolución Bolivariana, pero ahora administrado por un gobierno revolucionario que detenta el poder formal, lo que constituye una peligrosa contradicción en sí misma.

\section{TRANSICIÓN HACIA EL SOCIALISMO DEL SIGLO XXI,} EPISTEMOLOGÍA RODRIGUEANA, MARXISMO Y ESTADO COMUNAL Refiriéndose a la transición sistémica pos-independentista, Simón Rodríguez advirtió: Ni somos aún Repúblicas ni hemos dejado de ser colo- 
nias, (Rodríguez, 2010) es decir, los Estados-Naciones nacidos al calor de la guerra de independencia se habían convertido en espacios de lucha hegemónica entre la vieja cultura monárquico-colonial (aparentemente derrotada) y la nueva cultura republicana-decolonial (aparentemente triunfante). En medio de aquella transición, la vieja cultura se mimetizó adoptando ropajes nuevos, generando Republicas bastardas y caricaturas sociales.(Rodríguez, op cit) El colonialismo español fue sustituido por la subordinación al naciente imperialismo inglés, (luego Estadounidense), y las estructuras de clase desiguales y atrasadas del sistema colonial se mantuvieron virtualmente intactas, de tal manera que el viejo colonialismo se mantuvo bajo nuevas formas: Mediante el voluntario auto-sometimiento de las recién nacidas Repúblicas Latinoamericanas al imperialismo capitalista. Más adelante sentenció Rodríguez: No lo llamen Repúblicas porque no lo son, y no lo son porque no hay pueblo. (Rodríguez, op cit) El entendía por pueblo (republicano), al total de la población formada para el ejercicio de ciudadanía, la autonomía productiva y el auto-gobierno local, lo contrario a pueblo es populacho, masa de pueblo ignorante, explotada y/o excluida por la negligencia de la sociedad, pero sobre todo por la indiferencia e inoperancia de sistemas de gobierno controlados por sectores oligárquicos entregados a interese foráneos y confrontados con sus propios conciudadanos.

En la actual transición, Venezuela vive circunstancias parecidas: Ni somos aún Repúblicas socialistas-autosustentables ni hemos dejado de ser Repúblicas burguesas-dependientes, ambos modelos se disputan la hegemonía, manteniendo hasta el momento una relativamente equilibrada correlación de fuerzas, pero hay elementos que hacen de la actual coyuntura un hecho más complejo que en el pasado. Por ahora, la burguesía acepta el triunfo de la hegemonía político-social del modelo de inclusión Bolivariano, de tal manera que no ataca al modelo, entre otras cosas, porque le supondría un costo político muy elevado, sino que ofrece corregir sus fallas desde visiones corporativistas, bajo la premisa de que el modelo puede ser más eficiente, por su parte, la burguesía sabe que su hegemonía en el ámbito económico, y en menor medida en el ámbito cultural, ofrece posibilidades para revertir el proyecto de Revolución Bolivariana y hacer que el viejo modelo representativo regrese bajo nuevas formas. Por ello, la oposición le apuesta al fracaso de las iniciativas de construcción de alternativas económicas, a la burocratización y estancamiento en la ejecución de políticas públicas, y a la ineficacia y corrupción del aparato estatal, (hecho evidenciado en el divorcio que suele percibirse entre discurso y praxis oficial), lo que incidiría en la conformación de subjetividades ambivalentes, combinación de éxitos y fracasos revolucionarios, y críticas opositoras legitimas e ilegítimas. Una vez más Simón Rodríguez 
nos aporta un referente teórico indispensable para la comprensión del actual momento político: El estudio de los hábitos y costumbres, es decir, el estudio de las conductas, de la (auto) conciencia de estas, y los intereses materiales de las que se nutren, elemento esencial en el pensamiento filosófico Rodrigueano. Los hábitos y costumbres propios del modelo representativo presuntamente derrotado, muestran su vigencia y fortaleza en plena Revolución, como consecuencia de la no resolución transicional a favor de las lógicas revolucionarias.

Adaptando el modelo de análisis Rodrigueana la actual realidad transicional venezolana (tanto coyuntural como estructural), podemos decir que estamos en presencia de un cambio de proyecto civilizatorio que implica una compleja TRANSICION POLITICA. El método Rodrigueano, junto con el método marxiano, (ambos dialécticos) constituyen insumos epistémicos invalorables, marcos teóricos que permiten alcanzar las más completas conclusiones sobre contextos complejos, porque parten de visiones de totalidad. Dicho esto, el drama transicional de la Venezuela actual, plantea diversas tensiones y espacios en disputa no resueltos, de su resolución depende que la revolución avance, caiga atrapada en las lógicas que quiere superar, ó se revierta y permita el retorno al poder de las elites tradicionales. La soberbia, torpeza, y arrogancia de los sectores conservadores venezolanos, hicieron que perdieran el poder político en beneficio de las fuerzas revolucionarias, pero la fuerza de las viejas prácticas del pasado, aún vigentes, hacen que la revolución no detente el poder de manera efectiva, diluyendo su modelo de justicia social a favor de fuerzas conservadoras que se insertan en el movimiento Bolivariano y lo derechizan. La revolución necesita entonces pasar definitivamente de....

\begin{tabular}{|c|c|c|c|}
\hline Estado Burgues & & Estado Comunal & \\
\hline Economía Rentista & A & Economia Productiva & $\begin{array}{l}\text { Para ello es menester } \\
\text { profundas reformas } \\
\text { en los hábitos }\end{array}$ \\
\hline Cultura Aristocratica & & Cultura Popular & y costumbres sociales. \\
\hline Sociedad Neocolonial & & Socialismo & \\
\hline
\end{tabular}

Fuente: Elaboración propia. 
Se parte de una premisa simple: No se pueden lograr verdaderos cambios haciendo siempre lo mismo. Si queremos resultados distintos necesitamos procesos, métodos, enfoques distintos. La revolución Bolivariana ha logrado importantes avances en tales procesos de cambio, pero no suficientes, y lo que es peor, hoy luce estancada, se muestra a la defensiva, y la burguesía, en clara alianza con el imperialismo, muestra hoy toda su fuerza en medio de una contraofensiva brutal que ha desatado un terrible crisis a partir del 2013, crisis que se agudiza con el pasar de los días y amenaza revertir los logros alcanzados hasta la fecha referidos al pago de la deuda social y disminución de la pobreza.

Luego del contundente triunfo de las fuerzas progresistas en el referéndum presidencial del 15 de agosto de 2004, la participación popular, ese gran motor que venía impulsando el avance revolucionario, muestra señales de estancamiento, y la iniciativa es tomada entonces por instituciones clásicas de mediación propias de la modernidad: Partidos políticos, Instituciones Estatales, y en menor medida, gremios y sindicatos. Se desacelera el proceso de creación del poder popular y este pasa por períodos de burocratización (Acosta, op cit). No es la intención de este trabajo valorar negativamente la necesidad de institucionalizar relaciones de poder, y encausarlas hacia objetivos comunes, conforme a planes, políticas y programas diseñados a tales efectos, pero si ello se hace conforme a métodos de cooptación y sometimiento de las iniciativas del poder popular al poder formal, se están reforzando lógicas relacionales propias del Estado burgués: clientelismo; subordinación del poder constituyente al poder constituido; burocratización estatal, entre otros elementos previamente abordados. Semejante contradicción es suicida. Los hábitos y costumbres del pasado se mantendrían sólidos en su esencia, solo se habrían cambiado sus formas más epidérmicas.

El Estado Comunal surge entonces como un punto de equilibrio entre la iniciativa popular y la necesidad de encausarla institucionalmente, pero a partir de un nuevo tipo de institucionalidad, que no frene o anule tales iniciativas, sino que las potencie: Es el autogobierno local en articulación con el poder formal para la progresiva transferencia de competencias al primero, dejando al segundo solo roles básicos de diseño de macro-políticas públicas, supervisión, control, y administración de recursos. Es la negación del neoliberalismo y más allá, la concreción revolucionaria: La reducción del Estado para hacerlo más fuerte, en beneficio de una sociedad organizada en contra del capital.

El Estado Comunal (sin desmeritar el aporte de la Comuna de París, los Soviéts o Las Comunas Chinas, entre otras experiencias revolucionarias anti-capitalistas) se constituye así en una innovación propia, auténticamente venezolana. Se hace carne el "inventamos ó erramos" de Simón Rodríguez, preludio de la sentencia de Mariátegui: Nuestro 
socialismo no puede ser calco ni copia, sino creación heroica. Las comunas, comunidades organizadas para la autonomía productiva y política, coinciden con las toparquías Rodrigueanas, la forma más perfecta de gobierno que pueda imaginar la mejor política; (Rodríguez). La concepción de gobierno fuerte y a la vez democrático, articulado con las comunidades organizadas en redes, es un concepto completamente Bolivariano (visión coincidente con el leninismo, pero nacida en Latinoamérica un siglo antes), y mejor aún, es un tipo de Estado que es enemigo implacable del burocratismo y la corrupción propias del Estado Burgués; la unión cívico-militar, como medio-instrumento para lograr los dos objetivos anteriores, está presente en el pensamiento de Rodríguez y Bolívar, y es ampliado por Ezequiel Zamora, pero a condición de que ese ejército sea pueblo en armas, y ese pueblo sea pueblo en revolución. En Hugo Chávez se sintetizan estas corrientes y nace entonces El Estado Comunal. No se trata acá de caer en los postulados epistémicos idealistas propios del academicismo burgués, expertos en una suerte de fetichismo individualista que simplifica los procesos históricos al accionar de individuos geniales. Se reconoce, admira y divulga el legado de estos genios, pero su obra es producto de sus circunstancias, de su tiempo histórico. La genialidad de tales gigantes, su merito, consiste en su capacidad de síntesis y su compromiso de lucha y dirección con las causas populares, y esa genialidad jamás habría aparecido sin un pueblo movilizado y combativo que nutra tales acciones e ideas. Es la simbiosis perfecta pueblo-líder-pueblo, relación dialéctica propia de las revoluciones verdaderas.

Pero tal definición estaría incompleta sin el aporte del marxismo: El proceso de acumulación originaria, la consolidación del capitalismo como sistema universal homogeneizante, del imperialismo como fuerza que destruye a todo lo largo del planeta cualquier modo de producción no-capitalista, y del neoliberalismo como fase capitalista que fortalece el monopolismo imperial, definen al enemigo de clase del Estado Comunal venezolano: La burguesía trasnacional y sus socios, las oligarquías locales. (Porque no llegan a la categoría de burguesías, es decir no cumplen ningún rol modernizador en estas tierras). ${ }^{1} \mathrm{El}$ neocolonialismo dependiente propio del imperialismo que nos ha sido impuesto, es incapaz de desarrollar nuestras fuerzas productivas, porque si se desarrollasen se vería limitado el proceso de acumulación de capital (entendiendo al capitalismo como un sistema-mundo según las lógicas metrópoli-periferia, que poco tiene que ver con el capital que

1 El cantautor marxista y bolivariano, Alí Primera, con impresionante lucidez dice en una de sus canciones al referirse a las oligarquías locales: "Somos esclavos de esclavos, nuestros amos tienen amo." 
obtienen el puñado de familias oligarcas venezolanas, que son sus simples intermediarios), de tal manera que el capital se acumula a partir de la limitación (cuando no anulación) de nuestras fuerzas productivas, en una suerte de acumulación originaria continuada.

La súper-explotación de nuestras clases trabajadoras a que se refiere Ruy Mauro Marini en su brillante dialéctica de la dependencia, genera así un aporte marginal al proceso de generación de plusvalía que a su vez crea capital. En América Latina, el capital se nutre con mucho más fuerza de la marginación de millones de seres humanos, a quienes se les roban sus capacidades productivas para después ni siquiera darles la opción de poder vender su fuerza de trabajo en un débil mercado capitalista dependiente, solo les queda la mera y desesperada supervivencia en la marginalidad y la precariedad en medio de una sociedad inhumanamente hostil. Si esos millones de excluidos que pululan en los países neocoloniales fuesen absorbidos formalmente por el capitalismo, es decir, fuesen explotados o súper-explotados, habría un importante proceso de generación de plusvalía a favor de las oligarquías locales, pero se reduciría significativamente el proceso de acumulación originaria continuada para el capitalismo imperialista como sistema, porque la inclusión de millones de marginados y marginadas al proceso de desarrollo productivo (incluso de tipo capitalista-dependiente), que no sea ordenado por el imperialismo de manera directa para su beneficio, termina afectando la transferencia de recursos periferia-centro, debido a la necesidad de mayor circulación monetaria a lo interno de la propia periferia, circulación que nacería con ocasión de la incorporación de toda esa masa trabajadora ociosa a los procesos productivos locales. Desde ese punto de vista, abordar las categorías inclusión-exclusión desde las ópticas tradicionales de las ciencias sociales influidas por el positivismo, tiende a ser un abordaje chocante para el marxismo.

Se plantea entonces la siguiente hipótesis: El estado comunal busca quebrar el espinazo de ese proceso de acumulación originaria continuada a partir de las siguientes premisas: a) Siendo que en Venezuela, y el resto de América Latina, el capital crece de la exclusión de millones de hombres y mujeres expropiados de sus capacidades productivas para después ni siquiera ser explotados por el capitalismo sino simplemente ser sometidos a la más vil abyección, y siendo que los explotados y súper.-explotados por el capitalismo contribuyen a generar plusvalía, no así acumulación originaria continuada, tenemos entonces que son los excluidos y excluidas de Venezuela y Latinoamérica el sujeto social que contribuye con mayor fuerza a la creación de capital, por tanto, son el verdadero sujeto revolucionario transustancial, y los explotados y súperexplotados directamente por el capitalismo son creadores de plusvalía, más que capital en sí mismo, de modo que son el complemento de los 
excluidos y excluidas. Juntos constituyen el proletariado latinoamericano moderno. b) Las contradicciones entre capital y trabajo en Venezuela, en lo esencial, no nacen de manera directa de las contradicciones entre fuerzas productivas y modos de producción, sino de manera indirecta, es decir, de las contradicciones en las formas de acumulación de capital, que ni siquiera alcanzan a desarrollar autenticas fuerzas productivas. De manera que un modelo socio-productivo que impida que ese proceso de acumulación originaria continuada se siga dando, es un modelo que va en contra de la principal fuente de crecimiento del capital.

El incluir a millones de seres humanos en un Estado Comunal tan autárquico como sea posible, a través de un sistema de economía social combativo, que no sea complemento del capitalismo (como ha sucedido históricamente) sino su mortal enemigo, en un país donde el imperialismo no desarrollará jamás las fuerzas productivas a plenitud, luce entonces como la vía más idónea para hacer la revolución. Se ataca al capitalismo en la raíz, arrebatándole al sujeto social del que obtiene mayores dividendos: Los excluidos y las excluidas de siempre.

\section{EL ROL DE LAS JUVENTUDES EN LA ACTUAL TRANSICIÓN POLÍTICA Y LA LUCHA POR LA HEGEMONÍA}

Lo hecho hasta ahora por la revolución Bolivariana, tanto por sus logros como por sus fallas, crea las bases para lo que se puede y debe hacer en lo sucesivo, y un correcto enfoque generacional que priorice a las juventudes como sujeto transustancial protagónico es vital, pues las juventudes (junto con otros sujetos: obreros, campesinos, mujeres, pobladores y pobladoras, entre otros y otras) se convierten en sujeto estratégico en la lucha por la consolidación de la hegemonía disputada entre las fuerzas revolucionarias y burguesas.

La situación coyuntural y estructural favorece el ensayo de políticas públicas que resuelvan el drama transicional a favor de la causa revolucionaria, desde un enfoque juvenil. De acuerdo con el censo poblacional de 2011 llevado por el Instituto Nacional de Estadísticas, por primera vez en su historia Venezuela cuenta con un "bono demográfico", es decir, más de la mitad de su población se encuentra en edades económicamente activas, de entre 15 a 45 años de edad. El rango específico de entre 15 a 30 años constituye el $27.7 \%$ del total de la población del país, es decir, cerca del 30\% de nuestra sociedad está en estos momentos iniciando o por iniciar sus proyectos de vida familiares y profesionales. ¿Qué sistema económico será capaz de darles oportunidades significativas de desarrollo de metas personales en sintonía con un proyecto de país justo? Se evidencia que el país necesita de su juventud, y la juventud necesita de su país. Cualquier modelo económico que aspire a ser hegemónico debe saber entender las necesidades objetivas y 
subjetivas de la población juvenil, darles respuestas adecuadas y canalizarla según sus propios objetivos y estrategias. Un modelo "mercadocéntrico" explotará a las juventudes en beneficio del capital; un modelo "estato-céntrico" las usará para su propio beneficio político; un modelo "socio-céntrico" debe conjugar necesidades individuales-grupales y sociales para direccionarlas de modo armónico.

Para las instituciones del actual Estado venezolano, se hace prioritario unificar y centralizar esfuerzos en el diseño y ejecución de políticas públicas, con miras a asegurar los mayores niveles de eficacia y eficiencia posibles, y obtener los mejores resultados con pérdida mínima de recursos, pero más importante aún, las políticas públicas con perspectiva juvenil deben orientarse hacia la concreción de metas, y definición de acciones concretas que contribuyan a consolidar al Estado Comunal, y esto a su vez supone un radical cambio en la correlación de fuerzas en el ámbito económico.

En el mes de octubre de 2013 el gobierno venezolano realizó la segunda encuesta nacional de juventudes, realizada a 10.000 jóvenes (mitad hombres, mitad mujeres) de entre 15 a 30 años, en todo el territorio nacional y con representaciones proporcionales por clases sociales. Las instituciones públicas en Venezuela categorizan la pertenencia social de la población de la siguiente forma: 1) Clase Alta y Clase Media Alta =Clase AB; 2) Clase Media = Clase C; Clase Media Baja= Clase D; Clase obrera y/o en precariedad = Clase E. Más allá de las observaciones que se le pudieran hacer a esta categorización (debido a su alta carga ideológica de derecha), este es el referente oficial venezolano y en consecuencia es el que debe tenerse en cuenta para análisis de datos oficiales. A efectos de la encuesta señalada, el 3\% de los encuestados son de clase AB, el 17\% Clase C, el 40\% Clase D, y el $40 \%$ Clase E, coincidiendo dicho muestreo con las proporciones poblacionales del Instituto Nacional de Estadísticas.

De los resultados de la encuesta se pueden analizar resultados muy interesantes, que demuestran con datos empíricos las disputas hegemónicas en curso. En el ámbito político y social, el 73\% de los encuestados valora positivamente el modelo de democracia participativa promovida por el gobierno revolucionario, contra un 6\% que prefiere la democracia representativa y un $6 \%$ que prefiere los sistemas dictatoriales; Un $60 \%$ de los encuestados manifiesta ser favorable al socialismo, frente a un $21 \%$ que favorece al capitalismo y un $19 \%$ que no sabe/no responde; En cuanto a las instituciones que más contribuyen al desarrollo del país, un 30\% señaló a los Consejos Comunales, Comunas y Misiones Sociales (todas creadas por el gobierno revolucionario), frente a un $18 \%$ que optó por las Universidades. (llama la atención que no figuran en las opciones de respuesta ni El Gobierno, ni las Fuerzas Ar- 
mas, ni la Iglesia, ni los medios de comunicación. No queda claro si es porque no formaban parte de la pregunta ó por no ser señalados como respuestas) Hasta acá se podría decir que hay una situación de ventaja para el proyecto político Bolivariano.

En los ámbitos económicos y culturales el panorama es distinto. El 41\% de los encuestados trabaja y/o estudia a la vez, frente a un 30\% que se dedica a estudiar exclusivamente, y un 29\% ni trabaja ni estudia. (Acá se presenta otra categoría en discusión, ya que un 14\% del total de encuestados manifestó que se dedicaba exclusivamente a labores de cuidado del hogar, siendo incluidos en la categoría "ni trabaja ni estudia", según la visión economicista que le niega a las labores de cuidado valor económico, por no generar ingresos directos. Si se incluyese dicha categoría al área de trabajo, la población joven que ni trabaja ni estudia quedaría en 15\%). De la población que trabaja en actividades generadoras de remuneración, el $89 \%$ lo hace en el sector servicios, el $7 \%$ en el sector manufacturero, y el 3\% en el sector agrícola. Llama la atención que un $64 \%$ de los encuestados que laboran dice sentirse insatisfechos con su actual trabajo y le gustaría cambiarlo. De estos datos, se puede concluir que el modelo rentista, focalizado en el sector servicios, tiene en la juventud una fuente abundante de mano de obra que lo fortalece, mientras que las actividades productivas, dada su debilidad estructural, se muestran incapaces de convertirse en alternativa para las mayorías juveniles. Por otra parte, la insatisfacción laboral es una constante, (realidad propia del capitalismo como sistema). El modelo se muestra así hostil con la juventud (y con la sociedad toda), tanto cualitativa como cuantitativamente, una prueba más de la necesidad de un cambio de modelo, hacia otro que sea capaz de desarrollar y potenciar nuestras capacidades productivas. De los anteriores datos, es lógico inferir que de allí se desprenden un cúmulo de necesidades insatisfechas. El 48\% de los encuestados considera que los principales problemas del país son de tipo económico: Inflación, desabastecimiento y desempleo (Nótese que la encuesta fue realizada en el 2013, y entre los años 2014 y 2015 se ha agravado la situación económica). El 23\% de los encuestados considera que la inseguridad es el otro gran problema del país. Es importante destacar que un 53\% de los encuestados manifiesta tener al menos dos hijos, lo que aumenta el cuadro de necesidades. Por otra parte, el siguiente dato es también ilustrativo sobre la forma de pensar y sentir de nuestras juventudes: Las principales motivaciones de la juventud para la toma de decisiones en cuanto a opciones educativas-laborales poseen un carácter individualista-aspiracional: Un 68\% elige sus estudios y/o trabajo para la concreción de proyectos de desarrollo propios (obtención de título universitario, empleo, adquisición de vivienda y vehículo, constituir familia); un $11 \%$ lo hace en función de goce hedo- 
nista (Fiestas, acumular dinero, viajes) y sólo un 2\% manifiesta elegir sus estudios ó profesión para ayudar al progreso del país.

La consolidación del modelo rentista ha impedido que se desarrolle un modelo económico alterno que ofrezca oportunidades sólidas para canalizar las expectativas personales de las juventudes venezolanas desde lógicas anti-capitalistas, forzando a las juventudes a buscar en el mercado de trabajo capitalista tradicional opciones de empleo para la satisfacción de sus necesidades (lo que incluye el Estado Burgués en su rol de empleador). Tal circunstancia es aprovechada por la burguesía local para consolidar su hegemonía cultural sobre el grueso de la población y seguir transmitiendo y reforzando las subjetividades que le son propias.

En cuanto a los aportes que debe hacer El Estado para contribuir a dar oportunidades a las juventudes, el 73\% de los encuestados señala que El Estado debe priorizar la facilitación de oportunidades de empleo y estudios, seguido por acceso a vivienda ( $8 \%$ ), programas recreacionales $(6 \%)$, programas de salud (4\%), todas las anteriores $(9 \%)$. De modo que, para nuestras juventudes, la educación y el trabajo son las categorías que deben ocupar la mente y los corazones de los decisores de políticas públicas, al mismo tiempo, las juventudes, mayoritariamente ganadas a la idea de la democracia participativa y la construcción del socialismo, han de constituirse en fuerza organizada, poder popular activo, que empuje hacia la concreción de políticas públicas para sí, elevando el nivel de calidad política del modelo democrático, sólo posible mediante profundos aportes por la consolidación del Estado Comunal. Se puede concluir entonces que existe un formidable reto para crear situaciones que permitan equilibrar las legítimas aspiraciones y necesidades individuales, con las necesidades sociales y las metas nacionales, convirtiéndolas en una sola energía que logre la definitiva superación del modelo rentista. Atender estos ámbitos debe ser un objetivo estratégico del Estado Comunal en nacimiento. Y una vez más Simón Rodríguez nos da luces para ello.

\section{EL INVALORABLE APORTE RODRIGUEANO}

Uno de los elementos que más asombra del proyecto civilizatorio de Simón Rodríguez es la vibrante actualidad de sus principales preceptos, que trascienden el momento histórico en el que nacieron. La perspicacia de su pensamiento le hizo concluir (muy acertadamente) que para la construcción de nuevo modelo de sociedad se necesita un nuevo tipo de sociabilidad, y esta nueva sociabilidad no podría surgir nunca de la generación que ya está "gobernada" por la sociabilidad vieja: nacería de las nuevas generaciones. Estas nuevas generaciones serían educadas por el nuevo Estado Republicano nacido al calor de la revolución. Se 
fomentaría en las juventudes nuevos hábitos y costumbres, radicalmente distintos a los de la generación de sus padres y abuelos, y ello pasa por una novedosa y ambiciosa revolución educativa, pero esta revolución educativa, a su vez, es tan sólo el medio para lograr la necesaria revolución socio-económica. Esta visión abarcadora, totalizadora de la realidad social lleva a Rodríguez a dar con poderosísimas innovaciones pedagógicas: La originalidad y brillantez en el método pedagógico Rodrigueano nace de la combinación entre procesos educativos y procesos productivos, fusionados a partir de Rodríguez en un solo proceso. Es la unión de fuerzas entre los dos principales motores sociales: EDUCACION Y TRABAJO, pero no de cualquier tipo, sino de educación y trabajo liberadores, (en oposición a las lógicas del capital) que cambiarían a las sociedades desde sus raíces. Se trataba de una ruptura radical con el pasado y una innovación no vista en ninguna parte del mundo hasta el momento, ni siquiera en Europa ó Estados Unidos, considerados fuentes de todo saber e innovación, desde la perspectiva de las colonizadas mentes de la nueva clase política que nacía en las Repúblicas Latinoamericanas. La meta de Rodríguez era pasar de un tipo de sociabilidad negativa, propio de un modelo de sociedad opresor, a un tipo de sociabilidad positiva, propio de un modelo de sociedad en transición hacia la liberación nacional.

Pero la historia nos ha enseñado que el prometedor proyecto Rodrigueano falleció prematuramente junto con Bolívar, el genial discípulo. La transición revolucionaria nunca se concretó, y la actual generación de comienzos del siglo XXI, heredera de aquellas inconcreciones, está batallando por saldar esa deuda, no solo por compromiso histórico-romántico con nuestros héroes de la independencia, (aunque algo de eso hay) sino porque de no hacerlo estaremos condenando a nuestra propia generación y a las generaciones futuras a seguir con el peso de la pobreza y la opresión con el que tuvieron que cargar nuestros ancestros. No terminar lo que la generación de independencia empezó, en la actual coyuntura histórica, adquiere dimensiones de crimen.

Aplicando los anteriores preceptos a la sociedad venezolana transicional actual, podemos afirmar que el Estado Comunal en nacimiento necesita construir su propia sociabilidad, en oposición a la sociabilidad del Estado Burgués que aún pervive, y esta sociabilidad difícilmente surgirá de la actual generación adulta, formada en hábitos y costumbres aburguesados, y de sus actuales modos de producir y consumir. Como expresó lucidamente Ernesto "Che" Guevara: La construcción del hombre (y la mujer nuevos) no nacerá de la actual generación, estamos demasiado contaminados de los vicios del capitalismo. Con tener conciencia de esos vicios y detener su proceso corruptor en nosotros, 
habremos hechos nuestro trabajo. Debemos formar a las nuevas generaciones para que estén libres de nuestros vicios, para que piensen pos sí mismas y aprendan de nuestros errores. El hombre (y la mujer) nuevos es un proyecto de largo plazo. (Guevara, 2009).

Así, la sociabilidad propia del Estado Burgués puede ser caracterizada en una poderosa palabra: ALIENACIÓN, en su sentido marxista y Rodrigueano. El ser humano no se pertenece a sí mismo, tiene una falsa conciencia de sí y de lo que debe ser la vida en sociedad, se alimenta de prejuicios que luego se hace idelogía inamovible y desata inncesarios conflictos. La competencia, el individualismo, el egoísmo, la codicia, la usurpación, el engaño, es decir, el triunfo de la NO-ÉTICA, es la garantía de éxito individual en esa sociedad hiper-hostil al ser humano que es la sociedad burguesa. Alienación y anomia son las consecuencias lógicas de este sistema relacional.

La sociabilidad positiva, debe entederse diferenciada de los postulados de corrientes sociológicas funcionalistas,que solo buscan hacer que el modelo de opresión capitalista funciones más eficientemente(Damiani, 2013). Desde esa perspectiva, el funcionalismo busca convencer a los oprimidos de lo "natural" de su condición, de las bondades de la opresión, y de las consecuenas negativas de no aceptar esa verdad. No, la sociabilidad positiva nace de la transustanciación social completa, pasa por la Revolución política para hacer nacer la sociedad igualitaria.

Rodríguez posee un enfoque de optimismo generacional, complementado con un enfoque de clases y étnico, pues de entre la infancia y la juventud, su prioridad son los más pobres, los hijos e hijas de los esclavizados y esclavizadas originarios de Africa, los hijos e hijas de los indígenas en estado de servidumbre, de los mestizos y mestizas desempleados, de los inmigrantes europeos pobres. Busca acabar con el absurdo que significa el que existan decenas de miles de miserables sin trabajo, apiñados en grandes ciudades al borde de la inanición, mientras decenas de millones de hectareas de tierra virgen permanecen improductivas en un continente escasamente poblado, y ese otro absurdo que significa tener sistemas económicos sin diversificar, dependientes de metropolis europeas, cuando tenemos abundancia de recursos naturales que, combinados con un pueblo educado para la producción, podría hacer que nosotros mismos satisfagamos equilibrada, frugal y holgadamente nuestras propias necesidades, dependiendo cada vez menos del mercado internacional. De modo que Rodríguez abarca categorías etnicas, sociales, culturales y espacio-territoriales. Su prioridad es convertir en sujetos productivos autonomos a los hijos e hijas de los excluidos, es decir, a los que más contribuyen a la acumulación originaria continuada de capital, y a los 
hijos e hijas de los superexplotados y explotados por las clases opresoras, los generadores de plusvalía. No excluye a los hijos e hijas de los ricos, pero no son su prioridad, en todo caso, quiere unirlos a todos en un solo proyecto de liberación nacional, quiere consolidar la nueva hegemonía. De las nuevas generaciones deben surgir las personas libres de alienación (que él llamaba preocupaciones ó prejuicios). Pero no es posible lograr ese objetivo si subsiste la base material que crea a la alienación, esa base debe ser destruida. Por eso, la educación no puede ser liberadora sin antes haber sido liberada por fuerzas revolucionarias. Intentos de hacer cambios sociales sólo desde la educación es heroica resistencia, ó perdida de tiempo y energía.

En Rodríguez se niega por completo la idea de utopismo educativo, tal idea es una falacia, (Ponce, 2010),y así lo debemos entender hoy día. Su proyecto educativo es un medio para avanzar en la fase económica de la revolución emancipatoria ya iniciada, para continuar su movimiento, para transustanciar radicalmente la base material de la sociedad, pero ese cambio material no se consolidará sin proyecto de revolución educativa que abarque el ambito de las conciencias, de las subjetividades, porque la revolución se estancará, y hasta fracasará, si mantiene viva a la educación de tipo burguesa. Es una cuestión dialéctica. En el manifiesto del partido comunista, publicado en Europa en 1848, los jóvenes Marx y Engels plantean como uno de los puntos del programa mínimo revolucionario, la puesta en marcha de un sistema educativo que le diera instrucción gratuita a todos los niños y jóvenes, poniendo las escuelas al servicio de la producción, eliminando la división entre trabajo manual e intelectual, también proponen la creación de sistemas de producción que industrializaran el campo y eliminaran las contradicciones campo-ciudad. El viejo Simón Rodríguez, en América Latina, decía exactamante lo mismo.... 20 años antes.

\section{SOBRE LA EDUCACIÓN}

Por razones de espacio se hará hincapié en el elemento educativo, (entendiendo su conexión con el elemento económico), desde un enfoque para y con las juventudes, de acuerdo con la dinámica transicional en estudio. En cuanto a la educación como sistema, tenemos que en los Estados Modernos, la educación se divide en las siguientes categorías: 


\section{SISTEMA EDUCATIVO}

\begin{tabular}{l|l} 
Informal & $\begin{array}{l}\text { Formación en oficios, me } \\
\text { joramiento profesional }\end{array}$ \\
& $\begin{array}{l}\text { Familia, comunidad, } \\
\text { Centros de Trabajo, Medios } \\
\text { de Comunicación, Grupos } \\
\text { sociales. }\end{array}$
\end{tabular}

Formal

No-formal

Jardines de Infancia, Escuela primaria y secundaria, Universidades.

Fuente: Elaboración propia

En el mundo occidental, (del cual hace parte América Latina de manera forzada) la educación ha sido objeto de estudio, debates, análisis, y pugnas entre fuerzas en oposición desde al menos hace dos siglos. La revolución francesa (la más radical de las revoluciones burguesas), se hizo de los más avanzado de la filosofía progresista de su tiempo y levantó las banderas de la instrucción pública, gratuita y laica para todo el pueblo, donde antes había instrucción privada elitesca para los hijos (que no las hijas) de la nobleza, e instrucción caritativa y filantrópica para algún reducido grupo de pobres muy "afortunados", que eran instruidos en ciertos oficios, necesarios para servir bien a sus señores, y estarles eternamente agradecidos por su generosidad. Previo a la revolución, la religión tenía el control de los procesos educativos. La revolución burguesa le disputó la hegemonía del hecho educativo a los sectores monárquicos, aristocráticos y eclesiásticos, y terminó ganando. Hoy se ve como algo natural que tales fuerzas retrogradas hayan sido desplazadas por el empuje de las fuerzas modernizadoras, pero en su momento la revolución burguesa tuvo que vencer prejuicios que parecían indestructibles, vertiendo mucha sangre en el camino. Desde el triunfo burgués en Francia se ha universalizado su modelo educativo, en la misma medida que se ha universalizado su capitalismo, y lo que en su momento fue una gran conquista popular, hoy es un instrumento al servicio de la opresión, la mecanización social, la promoción del conformismo, y la ideologización más acabada, hipócritamente disfrazada de neutralidad instrumental. La instrucción 
pública de hoy en día es un traje a la medida para la burguesía y su modelo explotador.

Hoy, la burguesía juega el mismo papel retrógrado que en el pasado jugaron la aristocracia y la iglesia. Hoy las nuevas fuerzas revolucionarias, el proletariado (que en América Latina lo constituyen en primer lugar los excluidos y excluidas) deberán barrer con las fuerzas retrógradas burguesas y sus modelos educativos, y eso sólo ocurrirá en el marco de procesos revolucionarios. Los intentos de reforma educativa progresistas en contextos conservadores son vitales espacios de lucha, pero insuficientes por sí solos de producir cambios reales.

Desde la llamada corriente de la pedagogía crítica ó pedagogía emancipadora latinoamericana se ha escrito y pensado mucho al respecto, partiendo de nuestra especificidad. Simón Rodríguez es considerado por muchos analistas del tema como el padre de estas pedagogías, y son sus continuadores, José Martí, Gabriela Mistral, José Vasconcelos, Paulo Freire, Iván Ilich, entre otros y otras. Tenemos también experiencias concretas como la escuela indigenal Warisata en Bolivia, la escuela rural mexicana en México posrevolucionario, las escuelas populares del MST en Brasil, entre otros. La mordaz crítica a la educación y sociedad conservadora es el punto de inicio de todos estos pensadores y de los movimientos sociales, y desde esa crítica nacen sus propuestas, algunas reformistas, otras revolucionarias. Basados en sus preceptos, se ha elaborado el siguiente cuadro a modo de síntesis (síntesis un tanto arbitraria quizás) de todas esas corrientes:

\begin{tabular}{|c|c|c|}
\hline $\begin{array}{l}\text { Modelos educativos } \\
\text { / Modelos sociales: }\end{array}$ & $\begin{array}{l}\text { Educación } \\
\text { conservadora-burguesa }\end{array}$ & $\begin{array}{l}\text { Educación } \\
\text { liberadora-revolucionaria }\end{array}$ \\
\hline SUJETO & $\begin{array}{l}\text { La sociedad en su conjunto. } \\
\text { (Se promueve un tipo de } \\
\text { homogeneidad que invisibiliza } \\
\text { las diferencias sociales, para } \\
\text { agudizarlas). }\end{array}$ & $\begin{array}{l}\text { Toda la sociedad, priorizando } \\
\text { a las infancias y juventudes } \\
\text { de las clases populares, dada } \\
\text { su condición de sujeto social } \\
\text { transustancial. }\end{array}$ \\
\hline OBJETO & $\begin{array}{l}\text { Constituir y/o consolidar } \\
\text { subjetividades, relaciones } \\
\text { sociales y conductas afines a } \\
\text { los procesos de acumulación } \\
\text { de capital y a la visión } \\
\text { ideológica burguesa. (Se } \\
\text { estimula la alienación, el } \\
\text { hedonismo, el acriticismo, el } \\
\text { conformismo, la anomia, entre } \\
\text { otros elementos). }\end{array}$ & $\begin{array}{l}\text {--Crear nuevas subjetividades } \\
\text { y relaciones sociales que } \\
\text { prioricen el bien común. La } \\
\text { individualidad se desarrolla } \\
\text { desde el impacto social } \\
\text { positivo. Se estimulan procesos } \\
\text { cognitivos que conecten } \\
\text { empáticamente a los individuos } \\
\text { unos con otros. Se potencia el } \\
\text { punto de vista del proletariado. }\end{array}$ \\
\hline
\end{tabular}




\begin{tabular}{|c|c|c|}
\hline $\begin{array}{l}\text { Modelos educativos } \\
\text { / Modelos sociales: }\end{array}$ & $\begin{array}{l}\text { Educación } \\
\text { conservadora-burguesa }\end{array}$ & $\begin{array}{l}\text { Educación } \\
\text { liberadora-revolucionaria }\end{array}$ \\
\hline FINALIDAD & $\begin{array}{l}\text { Fortalecer la hegemonía de las } \\
\text { lógicas capitalistas y valores } \\
\text { (egoísmo, competencia, } \\
\text { codicia, vanidad, insensibilidad) } \\
\text { en perjuicio de las lógicas del } \\
\text { trabajo liberador. (Solidaridad, } \\
\text { cooperación, frugalidad, } \\
\text { dialogo, creatividad). }\end{array}$ & $\begin{array}{l}\text { Contribuir a la construcción } \\
\text { de la nueva hegemonía } \\
\text { democrática-popular. Educar } \\
\text { para el trabajo liberador y la } \\
\text { democracia directa. Se trata } \\
\text { de ir haciendo la sociedad } \\
\text { libre de explotación de clases } \\
\text { y prejuicios, desde una } \\
\text { perspectiva generacional. }\end{array}$ \\
\hline MÉTODO & $\begin{array}{l}\text {-- Sistema educativo formal } \\
\text { y no- formal: Procesos de } \\
\text { enseñanza-aprendizaje } \\
\text { mecánicos, repetitivos, } \\
\text { aburridos, autoritarios, } \\
\text { abstractos, desvinculados } \\
\text { de la realidad individual y } \\
\text { social de los y las estudiantes. } \\
\text { Los docentes cumplen roles } \\
\text { burocratizados. Se forma mano } \\
\text { de obra para las necesidades } \\
\text { del sistema capitalista. } \\
\text { (Educación Bancaria, simple } \\
\text { instrucción formal) } \\
\text {-- Sistema educativo informal: } \\
\text { Carente de estrategia y } \\
\text { planificación, socialmente } \\
\text { fragmentado (desvinculado } \\
\text { de la educación formal y } \\
\text { no-formal), la improvisación } \\
\text { domina este sistema, al propio } \\
\text { tiempo que se promueve un } \\
\text { discurso que idealiza a los } \\
\text { sujetos (principalmente a la } \\
\text { familia). Se exceptúa a los } \\
\text { medios de comunicación, cuyo } \\
\text { accionar es estratégicamente } \\
\text { definido por los intereses } \\
\text { económicos de sus } \\
\text { propietarios. }\end{array}$ & $\begin{array}{l}\text { - Desaparece la división entre } \\
\text { sistema educativo formal, } \\
\text { no-formal e informal. Se } \\
\text { constituye un único sistema } \\
\text { con roles diferenciados: } \\
\text { Las relaciones pedagógicas } \\
\text { se hacen dinámicas, } \\
\text { estimulantes, dialógicas, } \\
\text { científicas, conectadas con } \\
\text { necesidades humanas. Se } \\
\text { suprime progresivamente la } \\
\text { división entre trabajo manual } \\
\text { e intelectual, haciendo de la } \\
\text { enseñanza y la producción de } \\
\text { bienes y servicios, un único } \\
\text { proceso. Los docentes se hacen } \\
\text { agentes de transustanciación } \\
\text { (Educación Social Rodrigueana.) } \\
\text { Se articulan escuela-familia y } \\
\text { comunidad de manera activa } \\
\text { desde la puesta en práctica } \\
\text { de emprendimientos socio- } \\
\text { productivos. La escuela se } \\
\text { vuelve centro de producción } \\
\text { para la economía social y } \\
\text { solidaria, así como de ejercicio } \\
\text { de ciudadanía. Se aprende } \\
\text { haciendo, a diferencia de la } \\
\text { memorización del conocimiento } \\
\text { parcelado. }\end{array}$ \\
\hline
\end{tabular}




\begin{tabular}{|c|c|c|}
\hline $\begin{array}{l}\text { Modelos educativos } \\
\text { / Modelos sociales: }\end{array}$ & $\begin{array}{l}\text { Educación } \\
\text { conservadora-burguesa }\end{array}$ & $\begin{array}{l}\text { Educación } \\
\text { liberadora-revolucionaria }\end{array}$ \\
\hline PROPAGACIÓN & $\begin{array}{l}\text { - Sistema educativo formal y } \\
\text { no formal: Mediante centros } \\
\text { educativos públicos y privados, } \\
\text { su cantidad, distribución } \\
\text { territorial, dotación, y } \\
\text { capacitación docente. } \\
\text {-- Sistema educativo } \\
\text { informal: A través de } \\
\text { relaciones familiares, de } \\
\text { trabajo, amistades, grupos } \\
\text { con afinidades subjetivas } \\
\text { (políticas, culturales, } \\
\text { religiosas, deportivas, etc.). La } \\
\text { socialización transmite valores } \\
\text { ideológicos de las clases } \\
\text { dominantes. }\end{array}$ & $\begin{array}{l}\text { - Vinculación escuela- } \\
\text { sociedad: Conexión entre } \\
\text { centros educativos formales } \\
\text { y emprendimientos socio- } \\
\text { comunitarios que se vinculen } \\
\text { con los procesos pedagógicos. } \\
\text {-- Acompañamiento permanente } \\
\text { a las familias en su rol } \\
\text { socializador de la infancia y } \\
\text { juventud. (Postura crítica ante el } \\
\text { patriarcado). } \\
\text {-- Problematización del rol de } \\
\text { los medios de comunicación. } \\
\text { Creación y divulgación de } \\
\text { producción comunicacional } \\
\text { propia. }\end{array}$ \\
\hline RESULTADOS & $\begin{array}{l}\text {-- Individuales conservadoras, } \\
\text { se tiene instrucción sin } \\
\text { educación, en su sentido } \\
\text { social. } \\
\text {-- Mínima armonía social, vidas } \\
\text { atomizadas, se vive sin sentir } \\
\text { afinidad por el semejante. } \\
\text {-- Supremacía del capital sobre } \\
\text { el trabajo. } \\
\text {-- La vida es angustiosa y } \\
\text { estresante. Se masifican las } \\
\text { conductas escapistas, fuentes } \\
\text { de vicios e insatisfacción. }\end{array}$ & $\begin{array}{l}\text { - Tanta autonomía productiva y } \\
\text { política como sea posible a nivel } \\
\text { local, regional y nacional. } \\
\text { - Creación de una nueva } \\
\text { cultura de convivencia y respeto } \\
\text { a los derechos humanos, así } \\
\text { como de valoración del trabajo } \\
\text { y la creatividad. } \\
\text {-- Individuos críticos y } \\
\text { participativos. } \\
\text {-- La vida se hace más } \\
\text { placentera, porque las } \\
\text { necesidades se satisfacen } \\
\text { equilibradamente. }\end{array}$ \\
\hline MODELO POLÍTICO & $\begin{array}{l}\text { Democracia liberal-burguesa, } \\
\text { representativa, parlamentaria/ } \\
\text { Dictaduras militares / Sistemas } \\
\text { monárquicos-constitucionales. }\end{array}$ & $\begin{array}{l}\text { Democracia popular } \\
\text { revolucionaria/ Estados- } \\
\text { Naciones en procesos de } \\
\text { transición pos-capitalista hacia } \\
\text { el socialismo. }\end{array}$ \\
\hline
\end{tabular}

Fuente: Elaboración propia.

Desde las pedagogías emancipadoras se ataca de manera inclemente a la educación burguesa y su pernicioso poder de influencia sobre las juventudes con miras a facilitar la explotación humana. En el cuadro anterior han quedado resumidas las principales características del modelo educativo burgués existente, y en oposición a este, el modelo educa- 
tivo emancipador que responde a principios e intereses absolutamente distintos. La educación burguesa no puede entenderse sino en sociedades donde la burguesía es el sujeto social hegemónico indiscutible, de manera que mantener el modelo de educación burguesa en sociedades con proyectos revolucionarios en marcha, no tiene sentido. Las infancias y las juventudes venezolanas que hacen vida en el sistema educativo serán las víctimas de semejantes indefiniciones y contradicciones, colocándolas en innecesarias situaciones de vulnerabilidad en el ejercicio de sus derechos. Por eso, para la revolución es urgente definir su modelo educativo y actuar en consecuencia, en lugar de seguir haciendo de la educación un espacio tácito de lucha entre fuerzas antagónicas, sin precisar cuál es el modelo concreto.

\section{PUGNACIDAD EN EL ÁMBITO EDUCATIVO}

La revolución Bolivariana, al momento de conquistar el poder formal en 1999, se consigue con un sistema de instrucción pública destruido, al igual que el resto de la infraestructura pública, legado del neoliberalismo implementado en la fase final del modelo pseudo-democrático, liberal, burgués, neo-colonizado y subordinado al imperialismo mundial. En aplicación de sus políticas de pago de deuda social (y reforzamiento del modelo petrolero rentista como medio para lograrlo), la revolución se plantea como objetivo revertir los indicadores de exclusión social específicos del sistema educativo. En ese sentido, se incrementó aceleradamente el acceso a la matrícula escolar, se mejoró la infraestructura educativa, se crearon nuevas escuelas, se otorgaron importantes beneficios socio-económicos a los gremios docentes, es decir, se lograron mejoras importantes en el modelo educacional en sus aspectos cuantitativos. (UNICEF, opcit: PNUD, 2014). Pero en cuanto a los elementos cualitativos del sistema, los cambios no son tan profundos. Se crean las escuelas bolivarianas y los "Simoncitos", instituciones educativos ubicadas principalmente en sectores populares, caracterizados, entre otras cosas, por el hecho de que la jornada escolar abarca el día completo, de 8:0o am a $4 \mathrm{pm}$, se le facilitan a las y los estudiantes tres comidas diarias, aliviando presiones en economías familiares, debido a la atención institucional de necesidades alimenticias y de cuidado de sus hijos e hijas en edad escolar, (UNICEF, opcit) pero más allá de esos avances que aseguraban mayor inclusión y justicia social, el resto de las instituciones escolares ya existentes seguían funcionando igual que siempre respecto a los modelos de enseñanza-aprendizaje. La esencia del modelo educativo, su cualidad, seguía respondiendo a lógicas burguesas. Se trata de la educación que recibió la niñez que hoy son adultos jóvenes.

La educación para el trabajo, o la instrucción en artes y oficios (capacitación profesional ó educación no-formal) es otro ámbito digno 
de análisis. El modelo educativo burgués históricamente ha dividido la educación tradicional (abstracta), de la educación laboral (práctica), como reforzamiento a su sistema de opresión de clases y su necesaria división del trabajo. Así, la educación tradicional es vista como la educación para adquirir conocimientos que permitan el ingreso a la universidad, obtener un título que de licencia para ejercer una profesión, tener una buena calificación para ingresar con ventajas al mercado de trabajo, obtener un buen empleo con un buen sueldo ó ejercer profesiones liberales con autonomía, y ascender socialmente. La educación laboral es para los que fracasan en la educación tradicional, y el destino de sus estudiantes y egresados es ser mano de obra calificada para ser explotada ó súper-explotada por el sistema económico capitalista. Ambas formas educativas combinadas, aparentemente distintas (y hasta antagónicas) en realidad constituyen el complemento ideal de la educación burguesa: Educación para la apropiación del trabajo por parte de la burguesía.

Vale la pena hacer una breve reflexión sobre la llamada educación no-formal. A mediados del siglo XX, el educador y político socialdemócrata venezolano Luis Beltrán Prieto Figueroa, considerado el más grande pedagogo venezolano de dicho siglo, creó el Instituto Nacional de Capacitación y Educación (INCE), para formar a las juventudes populares venezolanas en oficios prácticos. Era el año 1959, acababa de caer la dictadura derechista del General Marcos Pérez Jiménez, y empezada la era social-demócrata. Ambos sistemas de gobierno aparentemente opuestos, coincidían en su actitud pro-imperialista. La dictadura había iniciado con fuerza un proceso desarrollista y modernizador (al modo cepalino) que fue continuado por la socialdemocracia, pero había escasez de mano de obra calificada y estaba en peligro el impulso de ese proceso, a su vez, el fenómeno migratorio campo-ciudad (iniciado décadas antes) se aceleraba, aumentando las desigualdades sociales. El INCE nace en respuesta a atacar ambos fenómenos: Se capacita la mano de obra que necesita la industria capitalista-dependiente (entonces en plena expansión), y se le dan alternativas de empleo a parte importante de la población excluida. Fue un intento de implementar elementos de educación Rodrigueana a la Venezuela de mediados del siglo XX, no sin antes pasar los preceptos Rodrigueanos por el filtro de la burguesía, con el debido cuidado de eliminar todo elemento revolucionario en el nuevo modelo educativo. Junto con el INCE se crearon las escuelas técnicas industriales, las escuelas prácticas de agricultura, y otras experiencias educativas "Rodrigueanas", todas ellas diseñadas en función de las necesidades de la clase capitalista de la Venezuela de entonces.

Es necesario hacer algunas aclaratorias que ponen en evidencia la colonialidad de nuestros decisores y la invisibilización de nuestros 
referentes. Simón Rodríguez planteó un modelo de EDUCACION POPULAR (instrucción general, para todos, pero enfocada en los sectores populares y sus intereses de clase), a través de lo que llamó ESCUELA SOCIAL (escuela para la sociabilidad positiva), en donde se daría a los y las estudiantes cuatro tipos de instrucción: Científica (para hacer al pueblo pensante); Práctica (para hacer al pueblo productivo); Corporal (para hacer al pueblo sano); y Social (para hacer al pueblo sociable). Todo ello con miras a crear desde la escuela latinoamericana las condiciones para que surja un sistema de producción de bienes y servicios hasta entonces inexistente, que satisfaga necesidades materiales concretas, en una relación dialéctica Sociedad-Estado-Sociedad que de movimiento a la revolución económica por hacerse, en medio de la transición política post-independentista. A todo ese sistema lo llamó EDUCACIÓN SOCIAL, y sus egresados ejercerían oficios prácticos dentro de un macro sistema de intercambios solidarios llamado ECONOMÍA SOCIAL, por otra parte, los egresados de la escuela social serían CIUDADANOS, capaces de organizarse en comunidades con sistemas de autogobierno, para VIVIR SIN REYES NI CONGRESOS, es decir, sin las clásicas figuras de autoridad de las monarquías y las repúblicas. (Rodríguez, op cit)

La realidad latinoamericana del siglo XIX y sus formas de hacer la revolución, difieren sustancialmente de la realidad europea. Mientras los revolucionarios europeos plantean que la clase revolucionaria, la clase obrera, debe hacer la revolución apropiándose de los modernos medios de producción previamente creados por la burguesía, modificando las relaciones de producción que destruirían las contradicciones entre capital y trabajo, en América Latina la burguesía no había creado medios de producción modernos, porque no existe burguesía modernizadora a la europea, sino oligarquías locales pseudo-feudales (feudales a lo interno de las haciendas y minas, capitalista-mercantilistas al momento de relacionarse con el mercado internacional). Luego de la muerte de Bolívar, e incluso desde antes, Simón Rodríguez lucidamente intuye que las oligarquías locales no tienen ni la voluntad ni la capacidad de dirigir a la sociedad toda para hacer una revolución burguesa modernizadora (como continuación de la revolución de independencia), por lo concluye que el desarrollo de autenticas fuerzas productivas modernizadoras en estas tierras sólo será obra del proletariado latinoamericano.

La función de su modelo escolar es la de desatar las potencias contenidas en el pueblo, la fuerza material, facilitando la conexión a nivel de la autoconciencia con sus propias capacidades creadoras, con su fuerza moral, y así hacer sentir al pueblo amor propio, convirtiéndole en pueblo innovador, y desterrando para siempre los prejuicios (aliena- 
ción) coloniales. De entre el pueblo, la niñez y la juventud de origen popular serían los protagonistas de tales procesos, pues de ellos se puede esperar que se conduzcan con un nuevo tipo de hábitos y costumbres. Las escuelas sociales serían centros de producción y de enseñanzaaprendizaje a un mismo tiempo, autónomas, y si bien serían instituciones públicas, contarían con un presupuesto propio, lo que facilitaría la conexión con las necesidades de las comunidades circunvecinas, con importantes márgenes de autonomía administrativa que no habrían permitido mayores espacios a prácticas burocratizadas. El problema es que su sistema escolar necesitaba de un Estado revolucionario en el poder para ser impulsado, y las Repúblicas Latinoamericanas tempranamente dejaron de ser revolucionarias, para entregarse en brazos del capitalismo imperialista en nacimiento.

El propio Rodríguez advertía que muchos filósofos antes que él habían hecho tratados sobre educación, sobre sus métodos, sus prácticas, sus alcances y beneficios, pero nadie había pensado en un modelo escolar diseñado para que hiciera parte vital de una revolución decolonial en marcha, compleja y difícil. Era Simón Rodríguez el primero en hacerlo, y él tan sólo pidió ese reconocimiento para sí, pero hasta eso le fue negado. Su proyecto había recibido completo apoyo de su excepcional discípulo, Simón Bolívar, y su sistema estaba llamado a ser el tipo de educación a ser aplicada en la recién fundada República de Bolivia en 1825, donde fue designado Director de Instrucción Pública por el Libertador a finales de ese año, para después ser políticamente derrotado por la oligarquía Boliviana a mediados de 1826, que presionó al entonces Presidente de Bolivia, Antonio José de Sucre, para expulsar al peligroso filosofo revolucionario y su amenazante proyecto anti-oligárquico y anti-imperialista. La transición post-independista y las luchas por la hegemonía entre modelos en pugna, se mostraron en todo su dramatismo contradictorio con esa decisión. Simón Rodríguez terminaría de perder toda esperanza para la consecución de sus ideas con la prematura muerte de Bolívar en 1830.

Mientras tanto en Europa, las ideas pedagógicas respondían a otras dinámicas. Marx y Engels hablarán de educación social, pero sin profundizar en el tema. La educación europea se caracterizará por la masificación de la instrucción pública burguesa. Para finales del siglo XIX y comienzos del siglo XX, en Alemania, un grupo de pedagogos, encabezados por Natorp y Kerschensteiner, entre otros, pasarán a la historia oficial certificada por la academia, como los creadores de la "pedagogía social", sistema educativo continuador del legado de Pestallozzi, Frebel, y Don Bosco. La pedagogía social alemana, resultado de la combinación de filantropía con pragmatismo y olfato político, se plantea como objetivo instruir a los hijos de los obreros alemanes más 
empobrecidos, en oficios requeridos por la gran industria alemana (entonces la de más acelerado crecimiento en el mundo), para que dichos niños (no tanto las niñas) tenga una alternativa de vida como obreros de la gran industria, en lugar del mundo de la delincuencia y la marginalidad que seguramente les esperaba y que amenazaba con crear inmanejables problemas sociales. (Pérez, 2002) Cualquier investigación sobre educación social apuntará a ubicar a Natorp y Kerschenteiner como sus "creadores", sin embargo, ese modelo ya había tenía un padre en tierras latinoamericanas un siglo antes, sin que la academia le dé créditos a su creador. A mediados del siglo XX, Venezuela terminará adoptando el modelo alemán, no el Rodrigueano.

En cuanto a la educación informal, que en realidad se refiere a procesos de socialización extra-escolares de la vida cotidiana, tenemos que mucho antes que Gramsci, Althusseró Foucault, Simón Rodríguez abarcó el tema cultural desde una óptica sistémica, demostrando que la socialización mediada a través de los centros de trabajo, la familia, los grupos religiosos, las comunidades, los medios de comunicación, entre otros, por intermedio del lenguaje, son parte vital en la constitución de subjetividades individuales y colectivas, de interrelaciones sociales, que a su vez crean hábitos y costumbres que terminan legitimando el accionar social. Una sociedad en revolución debe abordar este difícil espacio, en donde las fuerzas conservadoras tienen amplias ventajas, al plantear en términos dicotómicos las categorías publico-privado. No contradecir ese paradigma burgués pone en riesgo éxito de cualquier intento de cambio social.

Sólo se abundara en la familia, por el peso de esta institución social: Acido crítico del modelo de familia colonial-patriarcal, Simón Rodríguez consideraba que el influjo que las familias ejercen sobre sus hijos e hijas es pernicioso, transmitiéndoles prejuicios a los más jóvenes (alienación), enseñándoles a simular sus emociones, a ocultar lo que sienten, a hacer de la hipocresía un ejercicio diario de convivencia, debido a la tendencia a ejercer la autoridad paterna de manera arbitraria y en perjuicio de los derechos de la infancia. La crianza familiar, vista como una potestad de los padres, se convierte así en una "viruela social" (que cuando no mata al enfermo lo deforma de por vida), y hace de las nuevas generaciones personas inútiles, formadas en la sociabilidad negativa, incapaces de ejercer correcta ciudadanía, por lo tanto enemigas tácitas de cualquier proyecto de cambio. (Rodríguez, op cit) Hoy día, las dinámicas y estructuras familiares han cambiado radicalmente con respecto al siglo XIX, pero la esencia de las lógicas relacionales parece darle la razón a Rodríguez. De acuerdo con UNICEF y el PNUD, en concordancia con estudios del CINDE, en América Latina, entre el 70\% y el 90\% de las familias violan sistemáticamente los derechos de sus propias 
hijos e hijas, violaciones que van desde el lamentablemente común maltrato verbal-psicológico, hasta hechos más graves como abusos sexuales, uso de niños, niñas y jóvenes para delinquir, lesiones y homicidios. Semejante realidad, hace de las familias los espacios de mayor riesgo para la infancia y la juventud, (Alvarado, 2012) en contraste, la derecha tradicional (sobre todo religiosa) sostiene un discurso idealizado de la familia, como espacio privilegiado de convivencia, amor y transmisión de valores. Como diría Marx, las especulaciones idealistas y metafísicas propias de la burguesía chocan con la realidad concreta. El abordaje de la socialización intra-familiar para la sociabilidad positiva, desde la superación de la falsa dicotomía público-privado, debe ser otro objetivo estratégico del Estado Comunal.

La educación no cambiará a la sociedad, lo harán las revoluciones, pero el impulso revolucionario se detendrá si no se cambia radicalmente con el modelo educativo y productivo. Las juventudes por sí solas tampoco lo harán, lo hará la sociedad toda, pero las juventudes tienen un papel protagónico que cumplir para que la revolución avance, se detenga ó se revierta. Una vez más las lógicas de la dialéctica se muestran con todo su vigor. El Estado Comunal necesita convertirse en Estado Comunal Docente si aspira ser el nuevo referente hegemónico. No hay recetas para ello, el presente trabajo es apenas una invitación para empezar a problematizar el tema.

\section{EPÍLOGO}

La transición Estado Burgués-Estado Comunal, economía rentista-economía-productiva, democracia representativa-democracia protagónica, poder constituido (formal)-poder constituyente (popular), se muestra como un proceso difícil y plagado de contradicciones. La lucha por la consolidación de una nueva hegemonía popular-revolucionaria que desplace a la vieja hegemonía burguesa-conservadora será un continuo indefinido, planteador de desafíos formidables.

Las políticas públicas que tienen como sujeto a las juventudes, pasan por la necesidad de definición del Tipo de Estado del que nacen dichas políticas y el tipo de sociedad que debe ser beneficiaria de las mismas, pues de ello depende el tipo de relaciones sociales que han de nacer. Las categorías EDUCACION y TRABAJO, entendidas como procesos que impulsan cambios radicales, o que por el contrario los frenan, deben ser asumidas desde perspectivas problematizadas que visibilicen todas sus ricas dimensiones. Las necesidades de la juventud no pueden entenderse sino como formando parte de las necesidades sociales en su conjunto. Plantear disyuntivas inter-generacionales, inter-étnicas, de género, o espacio-territoriales, en una sociedad en vía hacia el socialismo es un falso dilema. Es cierto que la diferenciación de realidades 
y circunstancias es vital para hacer lecturas correctas del mundo y actuar en consecuencia, pero partiendo de que la dicotomía realmente válida es la lucha de clases, que en el caso Venezolano supone la lucha contra el imperialismo.

Como diría Aníbal Nazoa, El Estado Comunal tiene la necesidad de desplegar todo el poder creador del pueblo para buscar la manera de superar las dificultades que impiden su propia concreción, y acelerar la progresiva superación de la actual etapa transicional. La revolución debe conectarse con el sentir y el pensar de las juventudes, para que las juventudes se conecten desde su sentir y pensar con la Revolución, y no hay mejor manera de hacerlo que desde la vida cotidiana. La fuerza de las necesidades es más poderosa que la voluntad.

Es difícil precisar por cuánto tiempo convivirán capitalismo y socialismo, sobre todo porque estos sistemas no se pueden entender a lo interno de un país sino como sistemas-mundo. Pero lo que sí está claro es que esa convivencia será inexorable por un buen tiempo, de la misma forma en que feudalismo y capitalismo convivieron por más de 300 años, hasta el definitivo triunfo de este último. De allí la importancia del estudio y construcción de una nueva hegemonía revolucionaria, que debe nacer de la exitosa atención de necesidades básicas: alimentación, vestido, vivienda, salud, recreación, y ser capaz de proveer a las juventudes los medios para atender dichas necesidades fuera de las lógicas del capitalismo. La actual coyuntura visibiliza la necesidad de cambios drásticos. Tenemos en Simón Rodríguez una de las mentes más esclarecidas para entender las dimensiones de dramas transicionales como el actual, desde ópticas revolucionarias. Venezuela es un símbolo, representa la esperanza de millones de excluidos y excluidas de todo el mundo. Es tiempo de ser creativos, es tiempo de INVENTAR y ACERTAR.

\section{BIBLIOGRAFÍA}

Acosta, Vladimir 2013 Ensayos radiales del programa "Temas sobre el tapete" Tomo II (Caracas: Monte Ávila Editores).

Alvarado, Ospina, Quintero, Luna y Patiño 2012 La escuela como territorio de paz.Construcción social del niño y la niña como sujetos políticos en contextos de conflicto armado (Buenos Aires: CLACSO/CINDE).

BID, CORPOVISIONARIOS 2012 Antípodas de la violencia, desafíos de cultura ciudadana para la crisis de (in)seguridad en América Latina (Washington: s/d).

Chávez, Hugo 2012 II Plan de la Patria 2013-2019 (Caracas: Minci). 
Chacón, Jesse 2013 “Las políticas públicas y el problema de su gestión”. Disponible en: www.gisxxi.org

Damiani, Luis 2014 El Método dialéctico en la investigación social (Caracas: Editorial Trinchera).

Freire, Paulo 1972 Pedagogía del oprimido (Santiago de Chile: Editorial Tierra Nueva).

Guevara, Ernesto 2010 El socialismo y el hombre en Cuba (Caracas: Cuadernos de formación ideológica del PSUV, $\mathrm{N}^{\circ}$ 02).

Imen, Pablo 2012 Una educación Rodrigueana para el socialismo del siglo XXI. (Maracay: Redes socioculturales).

Lander, Edgardo 2014 Venezuela: Crisis terminal del modelo petrolero rentista. Disponible en: www.tni.org.

Marini, Ruy Mauro 1972 Dialéctica de la dependencia. (Santiago de Chile: Facultad de Ciencias Económicas de la Universidad de Chile).

Marx, Karl 2010 El Capital, Tomo I (Santiago de Chile: Centro de Estudios Miguel Enríquez).

Marx, Karl; Engels, Friedrich 2010 El Manifiesto del Partido Comunista (Caracas, Cuadernos de formación ideológica del PSUV, $\mathrm{N}^{\circ}$ 02).

Ministerio del Poder Popular para la Juventud 2014. $2^{\circ}$ Encuesta Nacional de Juventudes. Disponible en: www.minju.gob.ve

Paideia- ULA 2007 El Estado venezolano y la posibilidad de Ciencia (Caracas, FONACIT).

Pérez Serrano, Gloria 2002 Origen y evolución de la pedagogía social. Cátedra de Pedagogía social de la UNED, España. Revista Interuniversitaria, $\mathrm{N}^{\circ}$ 09, pp 193-231.

PNUD, 2013 Seguridad ciudadana con rostro humano: diagnóstico y propuestas para América Latina (NewYork: PNUD)

Ponce, Aníbal 2010 Educación y lucha de clases (Madrid: Partido Comunista Obrero Español).

Rodríguez, Simón 1916 El Libertador del Mediodía de América y sus compañeros de armas, defendidos por un amigo de la causa social (Caracas: El perro y la rana). 2010 Inventamos ó erramos (Caracas: El perro y la rana). 1990 Sociedades Americanas. Caracas, Biblioteca Ayacucho. 
JUVENTUD Y DESIGUALDADES EN AMÉRICA LATINA Y EL CARIBE

Rojas, Armando 2008 Simbiosis de Los Simones. Socialismo desde el $A L B A$ (Maracay: Fundación Aldeas).

Sojo, Mirna 2011 Educación, pedagogía y escuela. Aportes teóricos (Maracay: Escuela

Social Rodrigueana Latinoamericana y del Caribe).

UNICEF Gobierno de la República Bolivariana de Venezuela, 2015 Plan de Acción

Unicef-Venezuela, 2015-2019. Disponible en: www.unicef.gob.ve. 


\title{
JÓVENES Y CLASES SOCIALES EN EL POST-NEOLIBERALISMO \\ DESIGUALDAD Y MERCADO DE TRABAJO \\ EN ARGENTINA DESDE UNA PERSPECTIVA \\ MULTIDIMENSIONAL*
}

\author{
Gonzalo Assusa**
}

\section{INTRODUCCIÓN}

En este artículo presentaremos los resultados de un primer momento estructuralista de análisis sobre la desigual distribución de los recursos de poder social entre jóvenes. Abordamos este problema desde un análisis de familias de distintas clases sociales y la inserción de sus miembros jóvenes en el mercado de trabajo en el conglomerado de Gran Córdoba, Argentina ${ }^{1}$.

$1 \mathrm{El}$ texto que presento aquí surge de un trabajo colectivo, llevado adelante en el proyecto "Estrategias de reproducción social en familias cordobesas: dinámicas recientes",

* El escrito es un análisis de material generado en el marco de la investigación en proceso para la tesis del Doctorado en Ciencias Antropológicas en la Universidad Nacional de Córdoba, denominada "La cultura del trabajo en jóvenes de sectores populares en el contexto de posconvertibilidad". Dicha investigación se realiza en el marco de una Beca Interna de Posgrado de CONICET, con inicio en el año 2012 y que está aún en curso. Agradezco los las lecturas, comentarios y correcciones del Dr. Gabriel Kessler sobre la versión original del texto.

** Licenciado en Sociología (Universidad Nacional de Villa María). Doctorando en ciencias Antropológicas (Universidad Nacional de Córdoba). Docente de Sociología de nivel medio en la Escuela Superior de Comercio Manuel Belgrano. Email: gon_assusa@hotmail.com. 
Para ello explicitaremos las herramientas teórico-metodológicas que, desde la perspectiva relacional de Pierre Bourdieu, nos sirvieron para construir el espacio social de las clases contemporáneo. Fundamentalmente desarrollaremos las categorías de espacio social, capitales, clases sociales y estrategias de reproducción social. Esta propuesta implica una forma concreta de operativizar la adopción de las perspectivas intergeneracional y del ciclo de vida (Rodríguez, 2010: 49) en la construcción de la juventud como objeto de indagación e intervención.

Describiremos las propiedades que trazan las principales relaciones de desigualdad en el espacio de las clases sociales en Córdoba y las características y modalidades asociadas a cada una de las posiciones de clase. De esta manera, podremos mostrar problemáticas estructuralmente asociadas y definitorias de las condiciones objetivas para el desarrollo de estrategias de reproducción social en las familias de las distintas clases del espacio, en lo referente a recursos monetarios, educativos, a configuraciones familiares, etc.

Finalmente, reconstruiremos la dinámica del mercado de trabajo en la Argentina post-neoliberal y analizaremos más en detalle las desiguales condiciones laborales de los jóvenes en el espacio social cordobés, poniendo en diálogo los datos estadísticos surgidos de nuestro procesamiento de la Encuesta Permanente de Hogares (EPH) de INDEC de los años 2003 y 2013 con diversas investigaciones contemporáneas que toman como referente el mercado de trabajo argentino y latinoamericano y, más específicamente, la inserción laboral de los jóvenes, la informalidad y la segmentación del mercado de trabajo.

Consideramos que pensar las problemáticas juveniles desde la perspectiva de las desigualdades de clase en América Latina y el Caribe resulta vital para poner en diálogo nuestros resultados con otras perspectivas, como así también para complejizar las metodologías, clasificaciones, cruce de variables, etc., en la producción de datos para las políticas de juventud (Rodríguez, 2015).

Nuestra propuesta se centra, en el presente texto, en una metodología cuantitativa, aunque habilita un programa de investigación más general, articulado con distintos métodos y técnicas cualitativas. Desde este punto de partida, plantearemos algunas reflexiones sobre las transformaciones en las condiciones laborales de los jóvenes entre la crisis del neoliberalismo y la década post-neoliberal en Argentina, en un esfuerzo

dirigido por la Dra. Alicia B. Gutiérrez y el Mgter. Héctor O. Mansilla. Todo lo relativo a la interpretación y procesamiento de datos estadísticos de la EPH-INDEC surge de las discusiones colectivas con los compañeros de dicho proyecto. 
por pensar las inserciones laborales en el marco de los sistemas de prácticas familiares articulados desde distintas posiciones de clase ${ }^{2}$.

\section{LAS CLASES SOCIALES Y LAS CATEGORÍAS DE EDAD COMO SISTEMA DE RELACIONES}

Bourdieu parte de la necesidad de tres rupturas epistemológicas para la construcción de un concepto de clases sociales que habilite su incorporación como elemento explicativo fundamental en su sistema de herramientas teóricas: las rupturas con el sustancialismo, el economicismo y el intelectualismo (Bourdieu, 1990a). Este autor comprende a las clases sociológicamente construidas como clases "teóricas" o "en el papel", mientras que reserva el carácter de clase "movilizada" para momentos específicos en que los grupos son constituidos como actores colectivos y organizados para la acción por portavoces y representantes con el poder simbólico para realizarlo. Martín Criado (1998), con un gesto conceptual homólogo, sostiene que la sociología de la juventud debe, antes que suponer la categoría etaria como grupo social efectivamente existente y actuante como agente colectivo, analizar las condiciones sociales de su producción: pensarla como una clase-de edad-en el papel (Bourdieu, 1990b) ${ }^{3}$.

Las clases sociales se conforman por un conjunto de relaciones pluridimensionales. Esto implica que las propiedades definotorias de las clases son relativas y, por lo tanto, signadas por la desigualdad. De esta manera, la propuesta teórica de Bourdieu pretende rearticular la noción de clase social en una economía general de las prácticas sociales (Bourdieu, 1997; Baranger, 2000: 50; Gutiérrez, 2011: 12), es decir, reenviando las relaciones de clase a la totalidad del flujo de la vida social, al sistema multidimensional de los recursos sociales. El conjunto de herramientas teóricas aquí recuperadas implica una resolución parcial a una generalizada declamatoria acerca de la necesidad de pensar mul-

2 Volviendo sobre lo señalado por informes sobre la juventud latinoamericana, en donde se señala la necesidad de pensar el peso de la familia como agente mediador para desentrañar las principales desigualdades laborales entre los jóvenes (CEPAL-OIJ, 2014: 46).

3 En línea con estas distinciones, Vommaro sostiene que "Una generación, entonces, puede ser comprendida a partir de la identificación de un conjunto de sujetos que comparten la experiencia de lo que perciben como un conflicto, un problema. Así, el vínculo generacional aparece y se constituye como efecto de un proceso de subjetivación, ligado a una vivencia común en torno a una experiencia de ruptura, a partir de la cual se crean mecanismos de identificación y reconocimiento [...]" (Vommaro, 2014: 23). Nuestro trabajo se centrará, más bien, en las condiciones sociales en las que dichos procesos de subjetivación y dichas experiencias de ruptura se construyen y, por lo tanto, más en las posiciones sociales de los jóvenes que en las generaciones constituidas como tales. En otras palabras, intentaremos dar cuenta del estado de las relaciones de fuerza de la lucha social y generacional por la "transmisión de poderes y privilegios" (Vommaro, 2014: 17). 
tidimensionalmente la desigualdad, pero en demasiadas ocasiones sin un correlato en el que se viabilice esta opción teórica en producciones concretas de datos empíricos.

Es así que la analítica bourdieusiana parte de un primer abordaje comprendido como una topología sociológica, construyendo un espacio social en varias dimensiones en base a la desigual distribución de las propiedades actuantes como poder y fuerza en el universo en cuestión, es decir, un campo de fuerzas objetivas irreductible a su manifestación en interacciones concretas (Bourdieu, 1990a: 282).

Así, el espacio social precede ontológica y epistemológicamente a las clases (Baranger, 2004), dado que, para esta perspectiva, son las relaciones las que "efectivamente" existen, constituyendo a las posiciones como relativas y definidas estructuralmente en un sistema ${ }^{4}$. Lo mismo podemos afirmar acerca de las "clases de edad": su construcción situada, histórica, social y culturalmente (Vommaro, 2014), implica que la juventud sólo cobra sentido y valor en el marco de sistemas de relaciones (generacionales) concretos.

El espacio social se configura en tres dimensiones (Bourdieu, 1990a; 2006; Gutiérrez, 2005; 2012): 1) el volumen global de capital (económico, cultural, social y simbólico), que permite identificar los principales principios de jerarquización y dominación en el espacio; 2) la estructura patrimonial del mismo, es decir, la forma en la que el capital se distribuye entre sus distintas especies. Esto contribuye a identificar fracciones y principios de oposición hacia el interior de regiones del espacio, distanciando estrategias más centradas en el capital cultural o articuladas en torno al capital económico -aun cuando todas puedan situarse en la región dominante del espacio-, y por consiguiente, identificar modos de reproducción diferenciales (Bourdieu, 2006); y 3) la trayectoria individual, de clase y de la estructura de clase, es decir, la dimensión histórica o temporal (Bourdieu, 2006: 113).

Reeién entonees construimos las clases -en sentido lógico- como conjunto de agentes que comparten posiciones semejantes, punto a partir del cual se vincularán condiciones productoras de habitus y prácticas homogéneas y homólogas (Bourdieu, 1990a: 284). Las clases son, para Bourdieu, un conjunto de agentes

[...] que se encuentran situados en unas condiciones de existencia homogéneas, que imponen unos condicionamientos

\footnotetext{
4 En este espacio de relaciones, los desplazamientos -aquello que otras corrientes llamarían "movilidad social" (Kessler y Espinoza, 2003)- son pagados con tiempo y trabajo, dado que su estructura se construye fundamentalmente en base al capital económico y al capital cultural (Bourdieu, 1990a: 285), a partir del registro de distintos indicadores, variables, manifestaciones y tipologías.
} 
homogéneos y producen unos sistemas de disposiciones homogéneas, apropiadas para engendrar unas prácticas semejantes, y que poseen un conjunto de propiedades comunes, propiedades objetivadas, a veces garantizadas jurídicamente (como la posesión de bienes o de poderes) o incorporadas, como los habitus de clase (y, en particular, los sistemas de esquemas clasificadores) (Bourdieu, 2006: 100).

Las posiciones de clase, así, son definidas como coordenadas que entrecortan múltiples factores de diferenciación, no solamente por una posición en las relaciones de producción (en la estructura de empleo o en la condición socio-ocupacional), como lo era en las corrientes teóricas de influencia marxista y weberiana, sino por distribuciones etarias, geográficas y de sexo determinadas y por un conjunto de características auxiliares (principios de selección o exclusión no necesariamente formales, sino reales, prácticos), es decir, por la estructura de relaciones entre todas las propiedades pertinentes que confiere su propio valor a cada una de ellas y a los efectos que ejercen sobre las prácticas (Bourdieu, 2006: 104).

El esquema se completa con la categoría de estrategias de reproducción social. Dado que el espacio se constituye como resultado de una estructura de distribución de capitales y, a su vez, estos son el resultado de trabajo, esfuerzo y tiempo sedimentado ${ }^{5}$, los agentes tienden a mantener o mejorar sus posiciones (y en este mismo acto, a reproducir la totalidad de la estructura social) a través de un conjunto de prácticas fenomenalmente muy diferentes -estrategias laborales, culturales, domésticas, de natalidad, etc.- (Bourdieu, 2011) que tienden a funcionar como sistema -con sus reemplazos funcionales y sus mecanismos compensatorios- (Bourdieu, 2011: 38), presuntamente, por ser producto de un mismo principio unificador y generador: el habitus (Bourdieu, 2006: 122; 2011: 131). Las condiciones y límites en las que estas estrategias podrán desarrollarse dependerán, simultánea y relacionalmente, de la posición de clase y de edad de los agentes, del estado de desarrollo de los instrumentos de reproducción (mercado de trabajo, mercado escolar,

5 Para Bourdieu, como para Marx, el capital es trabajo (esfuerzo, tiempo) acumulado, reificado o sedimentado (Bourdieu, 2000: 132). Esto significa que no cualquier bien [material o intangible] en cualquier situación puede ser considerado capital: el conocido ejemplo marxiano indica que los medios de producción se configuran como capital en el capitalismo (y bajo relaciones de producción capitalistas, puesto en funcionamiento por trabajo asalariado), y no en cualquier época bajo cualquier modo de producción. El capital (para Marx y para Bourdieu) es producto de trabajo en condiciones de producción históricamente situadas, en el marco de relaciones de producción, distribución y consumo específicas signadas por desigualdades y estructuras de poder concretas. 
mercado de las políticas sociales, mercado matrimonial), y del estado de relación de fuerzas entre las clases y las generaciones (Bourdieu, 2006: 128; Gutiérrez, 2005; 2012).

La configuración de las estrategias de reproducción social en tanto sistema permite desplazarnos de actores individuales hacia el agente colectivo familiar, nivel en el cual pueden observarse efectivamente los mecanismos de reemplazo funcional y compensación entre las prácticas fenomenalmente diferentes pero necesarias para la reproducción social. Esta configuración permite también visualizar algunas características fundamentales de la trama de relaciones intergeneracionales que condicionan los horizontes de posibilidad para la producción, el desarrollo y la experiencia de diversas y desiguales juventudes latinoamericanas.

\section{TEORÍA RELACIONAL Y TÉCNICA RELACIONAL: EL ANÁLISIS DE CORRESPONDENCIAS MÚLTIPLES}

Las técnicas de producción de datos, en tanto tales, implican siempre una filosofía social subyacente (Baranger, 2004), es decir, supuestos lógicos acerca de las maneras que adopta la causalidad y supuestos ontológicos, acerca de lo efectivamente existente y actuante en la sociedad. Por ello es que adoptamos el Análisis de Correspondencias Múltiples (ACM) como una combinatoria de técnicas que funciona en tanto herramienta para pensar estructuralmente. En otras palabras, técnicas que contribuyen a pensar las clases sociales (Bourdieu, 1990a) y los grupos de edad (Bourdieu, 1990b; Vommaro, 2014) ya no como sustancias, sino como construcciones socioculturales y como red de relaciones.

Dentro del conjunto de técnicas multivariadas que pretenden analizar relaciones de interdependencia, el ACM forma parte de los análisis factoriales que permiten clasificar unidades de análisis y variables (Assusa y Freyre, 2014). Se concibe como una técnica exploratoria, herramienta que, ordenando y clasificando datos, sirve para crear tipologías (López-Roldán, 1996), plantear hipótesis y construir interpretaciones, que sólo podrán avanzar por medio de la complementariedad con otras técnicas (Gutiérrez y Mansilla, 2015; Baranger, 2004).

En segundo lugar, desarrollado por la Escuela Francesa de datos (Moscoloni, 2005; Crivisqui, 1993), el ACM permite efectivamente observar la desigualdad en términos de los efectos estructurales del sistema de relaciones entre las variables y sus respectivas modalidades ${ }^{6}$.

6 Esto implica una crítica metodológica y epistemológica al tipo de análisis bivariado de la estadística, pero también al análisis factorial más sofisticado que resume variables en factores, operando aún unidmensionalmente, pero de manera más compleja. El ACM, en cambio, hace actuar simultáneamente un conjunto de variables activas -es decir, aquellas que participarán en la conformación de una nube de coordenadas que refleje 
El procesamiento se complementa con una técnica de Clasificación Jerárquica Ascendente (CJA), la cual permite distinguir, en el espacio multidimensional construido en base al sistema relacional, diferentes clases sociales sobre la base de clases construidas (en el papel), "recortadas" en base a la diferenciación surgida de estos métodos.

De lo que se trata es de volver sobre la multiplicidad de coordenadas originales para, a través de la aplicación de algoritmos de clasificación, formar clases de hogares en tanto posiciones próximas en aquel espacio social original (multidimensional). Una de las características más importantes de este método es que realiza los cálculos a partir de las coordenadas que los agentes poseen en los ejes factoriales que conforman el espacio social, y no sobre los valores de las variables originales: de allí la complementariedad de los métodos factoriales y de clasificación (Gutiérrez y Mansilla, 2013).

\section{EL ESPACIO DE LAS CLASES SOCIALES EN CÓRDOBA, 2013}

Las transformaciones durante la última década en nuestro país resultaron complejas de juzgar, pero también sumamente disputadas, dadas las implicancias políticas que traían aparejados los distintos diagnósticos (Kessler, 2014). Es claro, de igual manera, que el período de la postconvertibilidad constituyó una etapa de fuertes transformaciones de toda la estructura social (Battistini, 2012), ya sea que las mismas hayan tendido a definirse como reconfiguraciones o como cambios estructurales. El procesamiento que encaramos apunta a desentramar algunos de estos problemas en un contexto ya con cierta acumulación de discusiones empíricas y conceptuales sobre la efectiva caracterización de la estructura social contemporánea en el país y a reconocer en la misma una serie de tendencias contrapuestas (Kessler, 2014).

El Diagrama 1 que presentamos proyecta en un plano factorial el resultado de las técnicas convinadas de $\mathrm{ACM} \mathrm{y} \mathrm{CJA}^{7}$, resumiendo visual-

las desigualdades en el espacio social- e identifica sus múltiples relaciones (los factores principales), contemplando el peso específico de cada una de ellas en términos de la desigualdad que adquiere su distribución en un conjunto de unidades de análisis determinadas. La técnica funciona, así, como una generalización del análisis de componentes principales, adaptado al procesamiento de datos cualitativos (Baranger, 2004). El resto de las variables relevantes se proyectan sobre el mismo espacio multidimensional como variables "ilustrativas", es decir, que no participan de la conformación de la "deformidad" de la nube de puntos, aunque sí manifiestan su desigual distribución sobre dicho espacio (algunas veces, no como "posiciones objetivas", tal como las hemos definido, sino más bien como "tomas de posición", resultado de las estrategias desarrollad as desde dichas posiciones) (Bourdieu, 2006).

7 Los resultados que presentamos en el este capítulo surgen de un procesamiento y aná- 
mente una de las perspectivas posibles (la que mayor inercia refleja) del conjunto multidimensional de coordenadas, es decir, de la forma que adquiere la desigualdad en este espacio ${ }^{8}$.

Así, resultó un dendograma (Diagrama 2) con un corte óptimo en cuatro clases, en correspondencia con las regiones descriptas del espacio social, de $10,72 \%, 42,45 \%, 38,95 \%$ y $7,88 \%$ respectivamente.

\section{LAS REGIONES DEL ESPACIO SOCIAL: LAS POSICIONES DE CLASE DE LOS JÓVENES CORDOBESES}

Denominaremos al conjunto de familias enclasadas en la región de bajo volumen de capital (en el cuadrante inferior izquierdo) como clase dominada (con un $10,72 \%$ del total de los hogares, tal como lo muestra la Tabla 1). Estas familias estarían caracterizadas por los ingresos más bajos, tanto los de origen laboral (del referente) como los familiares. De igual manera, presentan asociación con una baja acumulación de capital escolar. Sus referentes aparecen asociadas fundamentalmente a la rama y el carácter del servicio doméstico y su situación conyugal está signada por la modalidad "separado o viudo", y por la modalidad "mujer" de la variable "sexo". Esto provocaría un mayor peso de las estrategias familiares de reproducción social sobre el referente (y también, probablemente, sobre algunos de sus hijos o hijas), tanto a nivel de recursos monetarios como de tareas de reproducción doméstica.

En cuanto a lo laboral estas familias aparecen fundamentalmente vinculadas a la jerarquía o categoría de empleados o asalariados, no calificados, sin uso de maquinaria en la actividad laboral. Presentan cierta antigüedad de los referentes en sus puestos, aunque sin cobertura

lisis de las bases correspondientes al tercer trimestre del año 2003 y 2013 de la Encuesta Permanente de hogares (EPH) de INDEC para Gran Córdoba. El detalle sobre el trabajo de procesamiento y recategorización operado sobre la base original de datos puede encontrarse en Gutiérrez y Mansilla (2013; 2015).

8 Así, del resultante del ACM aplicado a la base de 2013, el primero de los factores, con una inercia propia de $9,51 \%$, opone a las familias con mayor y menor volumen total de capital, conformado principalmente por las variables de ingresos, nivel educativo, calificación y carácter laboral. El segundo factor, con una inercia de 6,94\%, opondría accesos diferenciales a espacios de valorización de los recursos y estructuras patrimoniales con distintas orientaciones, y es conformado principalmente por las variables situación conyugal, edad y sexo del referente de hogar, jerarquía y carácter ocupacional. Si bien todos los factores reflejan, de alguna manera, volumen y estructura de capital, esta oposición muestra más claramente estrategias y modos de reproducción con dominantes patrimoniales diferenciales (más orientadas al capital económico o al capital cultural). Para el CJA, tomamos los tres primeros factores (dado que a partir del tercero, los mismos presentan un decrecimiento irregular de la inercia), conformando una nube de tres direcciones de alargamiento. Estas tres dimensiones, desde nuestra perspectiva (que acumulan en conjunto el $22,75 \%$ de la inercia total) expresan claras diferencias entre las familias, mientras que el resto respondería a diferencias más específicas sobre aspectos puntuales. 
médica de ningún tipo por parte del mismo.

Mientras tanto, en la región de alto volumen de capital del espacio social (cuadrante superior derecho), encontramos lo que denominamos como clase dominante, (con un 7,88\% de las familias, tal como lo muestra la Tabla 2). Su estructura patrimonial aparece asociada al máximo nivel de ingresos, a puestos laborales de dirección, con calificación técnica o profesional, así como también a la propiedad de empresas pequeñas, medianas y grandes. Por su parte, sus referentes se asocian a la cobertura médica de tipo privada.

En la región media del espacio social se concentran la mayor cantidad de familias. La masividad de esta región la caracteriza por una fuerte heterogeneidad. Clasificamos a este grupo en dos clases: la primera, que hemos denominado clase media dominada (con un 42,45\% de los casos, tal como lo muestra la Tabla 3), se ubica en el cuadrante inferior derecho ${ }^{9}$. Esta posición de clase, comparte con la primera posición los bajos ingresos (que van del tercer decil en los ingresos totales del referente, hasta el sexto en el caso del ingreso total familiar). La variabilidad de los deciles indica la presencia de otros activos además del referente en la familia.

La condición laboral de sus referentes se ubica en la calificación operativa, en tareas de construcción, industria y trasporte o logística, con operación de maquinaria y equipos electromecánicos, con una asociación al cuentapropismo o a la condición de autónomos propietarios, a establecimientos de hasta 5 personas y al ámbito laboral privado.

Las modalidades que caracterizan al referente son las de sexo "varón", situación conyugal "unido o casado" (que contribuye a diferenciar esta configuración familiar de la asociada a la clase dominada, anteriormente descrita), y el tipo de hogares con 4 o más miembros. El capital escolar es también bajo (el nivel educativo va de primario incompleto a secundario incompleto).

Finalmente, en el cuadrante superior izquierdo, denominamos a esta posición clase media dominante, con más de un 38\% de los hogares para 2013 (tal como lo muestra la Tabla 4). Estas unidades domésticas presentan una asociación a ingresos medios y altos, incluso siendo caracterizados por el décimo decil en ingresos totales del referente y familiares. Sus referentes presentan una caracterización vinculada a edades jóvenes (hasta 34 años), situación conyugal de "solteros", sexo "mujeres” e insertos en hogares unipersonales. También se caracterizan

9 Sandra Fachelli (2012), construye una tipología a partir de la combinación de ACM y CJA en donde agrupa estos sectores en el "estrato medio laboral activo", con un peso relativo en Argentina (alrededor del 45\%) cercano al que definimos para esta posición en el espacio social cordobés. 
como inquilinos, cuya condición de vivienda aparece vinculada a la modalidad de departamento.

Sus referentes se asocian a ocupaciones técnicas o de asalariados profesionales, en la condición de empleados, trabajadores asalariados y, en menor medida, jefes. Su alta calificación (aunque sin un necesario correlato en el control del proceso productivo), se condice con una fuerte acumulación de capital cultural institucionalizado (universitario completo y, en menor medida, incompleto).

Relacionados al ámbito de ocupación estatal, en establecimientos medianos (de 6 a 40 personas o de más de 40), presentan cobertura médica de obra social (descuento vía laboral), lo cual abonaría a la hipótesis de condiciones de registro laboral en términos de legalidad. Estos referentes aparecen vinculados a las ramas de la educación, la salud y los puestos de gestión jurídico-administrativa, con operación de sistemas y equipos informáticos.

\section{LA DIMENSIÓN HISTÓRICA. DEL ESPACIO SOCIAL 2003 AL ESPACIO SOCIAL 2013.}

Para comprender la configuración de la distribución de recursos en el período de la post-convertibilidad, incluimos en el análisis la construcción del espacio social de las clases 2003, bajo los mismos preceptos analíticos y tomando idénticas variables activas y factores para la producción del dendograma (con los tres primeros factores se da cuenta de un 23,63\% de la inercia total). Algunas de las transformaciones que reseñaremos tanto aquí como en el apartado acerca de las condiciones laborales de los jóvenes, servirán para interpretar la manera en la que las mutaciones estructurales generaron condiciones de posibilidad bastante diferentes para la producción de problemas sociales (fundamentalmente, para la producción del problema de la "empleabilidad juvenil"), como así también, horizontes de posibilidad también diferentes para las estrategias laborales que podrían desarrollar en este período los jóvenes y sus familias.

Si bien las clases construidas, en tanto regiones "recortadas" en un sistema de relaciones, sostienen cierta continuidad en cuanto a las principales modalidades caracterizantes, en primera instancia cambian sus pesos relativos. En el espacio social de las clases en Córdoba construido para 2003, encontramos una posición dominada en la que se enclasan mayor cantidad de hogares (19\%), y unas posiciones intermedias (dominada, 42\%, y dominante, 32\%) que disminuyen su participación proporcional, además de una región dominante $(6 \%)$ con una relativa estabilidad. En nuestro esquema de interpretación, estas transformaciones no implican necesariamente movilidades "ascendentes" o "mejoras" en el período, aunque sí transformaciones del sistema de relaciones. 
Por otra parte, para 2003 en la clase dominada aparecen asociaciones significativas con la recepción de mercadería y ayuda en alimento como estrategias de consumo del hogar. Algo similar sucede en la clase media-dominada, en donde aparece también la estrategia de venta de pertenencias para la resolución de necesidades económicas cotidianas. Muchas investigaciones identificaron el crecimiento de los ingresos laborales en los hogares pobres como un signo característico de la primera década del siglo XXI en América Latina y el Caribe (Vommaro, Alvarado y Rodríguez, 2013). Hay también una mayor diferenciación de los niveles educativos de estas posiciones, cuya asociación en la clase dominada llega sólo hasta el nivel primario completo. En el caso de la clase media-dominada se vislumbra una vinculación a condiciones laborales de mayor informalidad en 2003 (asociación a la no-cobertura de salud) y al ámbito del comercio como actividad característica ${ }^{10}$.

Gran parte de la bibliografía ha analizado estas transformaciones como una apertura de nuevas brechas de desigualdad en la post-convertibilidad: por ejemplo, entre quienes se insertan en el mundo laboral y los beneficiarios de planes sociales (González Bombal, Kessler y Svampa, 2010), o entre empleados "protegidos" y "precarizados" (Kessler y Merklen, 2013), como así también una mayor diferenciación salarial (Basualdo, 2006), en detrimento de la díada "empleados" / "desempleados", más cercana al binomio "inclusión" / "exclusión" en boga en la década de 1990 (Grassi, 2003). Estas recomposiciones y reacomodamientos estructurales tienen lugar en un contexto en el que existe cierto acuerdo acerca de la fuerte recomposición de los niveles de empleo (Neffa, Oliveri y Persia, 2010; Pérez, 2010; Donza, 2011; Waisgrais, 2006).

\section{LOS JÓVENES EN EL MERCADO DE TRABAJO CORDOBÉS DE LA POST-CONVERTIBILIDAD}

De esta manera, en base a la construcción del espacio social de las clases para Gran Córdoba con las bases de datos de 2013 y de 2003, mostraremos, a partir de las asociaciones de distintas dimensiones del mundo laboral con datos relevados en la EPH a las posiciones de clase

10 Como hipótesis de interpretación, esto último respondía a una estrategia típica del período de crisis en la creación de empleo durante la década de 1990. Muchos ex-asalariados formales invirtieron sus indemnizaciones, tras las pérdidas de sus empleos durante el período, en pequeños emprendimientos comerciales o de servicios. Las teorías estructuralistas latinoamericanas señalan comúnmente que el Sector Informal, y fundamentalmente, los trabajadores "autónomos" en el mismo, funcionan a modo de refugio contracíclico (Vera, 2013: 17). Por otra parte, el crecimiento del sector industrial (Basualdo, 2009), en términos de salarios así como también de plantel laboral y de calificaciones (Español y Herrera, 2010), contribuyen a la modificación de la estructura patrimonial de esta región del espacio. 
construidas, las condiciones diferenciales para el desarrollo de estrategias laborales de los jóvenes y sus familias.

Tomaremos, para la presentación de los datos, por separado, jóvenes (individuos entre 15 y 24 años) y adultos (individuos entre 25 y 64 años), sin perder de vista la arbitrariedad de los recortes ${ }^{11}$. Esto permitirá cotejar los datos con ciertos parámetros de comparabilidad internacional.

\section{A - ACTIVIDAD E INACTIVIDAD ECONÓMICA DE LOS JÓVENES}

Un primer punto para considerar las condiciones laborales de los jóvenes en el espacio social cordobés actual está vinculado a la evolución de la tasa de participación ${ }^{12}$. Entre 2003 y 2013 los porcentajes (ver Tabla 5) aumentaron fundamentalmente para los jóvenes de la región dominante del espacio social, mientras que se mantuvieron o descendieron levemente para los de la región dominada. En la población adulta el proceso es similar, aunque con un aumento generalizado, siempre más marcado para las clases dominantes, y con una distribución más escalonada.

En un contexto de recuperación de la actividad y el empleo en general, como fue en el país en el período post-2001, quienes primero habrían logrado insertarse habrían sido aquellos individuos con algún tipo de calificación o credencial y, con mayor probabilidad, aquellos con experiencias acumuladas, trayectorias laborales más amplias y "obligaciones familiares" (fundamentalmente "adultos").

Algunos investigadores explican estas diferencias en las tasas de actividad por lo que llaman el "efecto desaliento" (Pérez y Barrera, 2012: 234; Pérez y Brown, 2014: 149): que las tasas bajas de actividad estén asociadas a los hogares con jefes sin calificación laboral hace pensar en procesos discriminatorios de los empleadores hacia los trabajadores sin credenciales educativas (particularmente hacia los jóvenes ingresantes a la actividad laboral), quienes progresivamente abandonarían la búsqueda de empleo. Por esto, algunas investigaciones los cuantifican como parte del "desempleo oculto".

Por otra parte, al observar sus diferentes categorías (Ver Tabla 6) encontramos que en todo el período analizado la inactividad vinculada a las tareas de reproducción doméstica ("ama de casa") se asocia a los jóvenes (fundamentalmente mujeres) de familias posicionadas

11 Esta separación implicó que, por el tamaño relativamente pequeño de la clase dominante, sumado a una composición de edad más bien "envejecida", el grupo de jóvenes de ese sector fuese demasiado pequeño en número absoluto de casos como para sostener hipótesis. Si bien en las tablas este grupo seguirá apareciendo, quedará excluido de muchos de los análisis por esta razón.

12 Proporción de activos sobre la población total. 
en la región dominada del espacio cordobés (sobre todo en la clase media-dominada). En 2013 esta tendencia se profundiza aún más ${ }^{13}$. Esta observación sólo puede sopesarse en relación a las asociaciones de determinadas posiciones de clase (fundamentalmente la dominada y media-dominada) a configuraciones familiares numerosas, con mayor presencia de menores en el mismo ${ }^{14}$ : lo que Pérez y Brown denominan "problemas estructurales limitantes de la inserción laboral de los jóvenes", entre los cuales resaltan el bajo nivel de ingreso per-cápita de los hogares, por la cantidad de miembros, y el peso de las tareas de cuidado y reproducción en los mismos (Pérez y Brown, 2014: 160-161).

En relación al crecimiento de la categoría "ama de casa" entre los jóvenes inactivos para la región dominada del espacio social, entendemos que existió también en el período cierto viraje en la orientación de las políticas sociales que, tendiente a proteger los derechos de infancia y niñez, reforzó imágenes culturales que atan a las mujeres al espacio y las tareas domésticas. Si los programas emergentes en la crisis 2001-2003 desencadenaron la activación de mujeres provenientes de la inactividad (a raíz de lo que en este contexto se denominó "contraprestaciones laborales"), las nuevas políticas sin contraprestaciones, atadas a cumplimientos de derechos escolares y sanitarios de los menores de las familias, habrían significado una "vuelta al hogar" de las mujeres de familias pobres (Calvi y Zibecchi, 2006) ${ }^{15}$.

13 Mientras que ama de casa posee para el año 2013 porcentajes de 9\% y 16\% para los jóvenes en general de la clase dominada y media-dominada respectivamente, la proporción llega a $23 \%$ y $36 \%$ respectivamente para las jóvenes mujeres de dichas posiciones. Otras investigaciones sostienen también que dos tercios de los denominados "ni-ni" en Latinoamérica son mujeres (Vommaro, Alvarado, Rodríguez, 2013). Esto coincide con tendencias señaladas por los demógrafos: un repunte de la conyugalidad, generalizado, pero que se concentra particularmente en la clase media-dominada, en donde las modalidad unido/ casado crece de $11 \%$ a $21 \%$ para los jóvenes.

14 Para 2013 el porcentaje hogares con 2 o más menores de 10 años superaba el 20\% para la clase media-dominada, mientras que oscilaba entre $9 \%$ y $12 \%$ para el resto de las posiciones. Los hogares con 4 o más miembros también superaban el 51\% para esa clase, mientras que variaba entre $22 \%$ y $29 \%$ para el resto de las regiones del espacio social.

15 Esto aparece como sumamente relevante, en orden a discutir algunas nociones hoy en boga, como la de "jóvenes NI-NI", con un fuerte poder de performatividad política, aunque también afectada tendencia homogeneizante. Reforzando la interpretación que antes enunciábamos, los datos de la CEPAL (comunicación de Daniela Trucco en el marco de la Escuela CLACSO-UNAH "Juventud y Desigualdad"), indican que más de la mitad de los denominados "NI-NI", son personas dedicadas a las tareas de reproducción doméstica ("amas de casa"). En este sentido, los datos indican que sería necesario rever la perspectiva de algunas políticas de empleo para jóvenes orientadas hacia la "activación económica", dado que este abordaje pierde de vista algo que los datos de CEPAL, de otras investigaciones y el procesamiento propio para Gran Córdoba están mostrando: las condiciones desiguales, expresadas en tramas de relaciones intergeneracionales, de los jóvenes para su inserción laboral, en relación a sus configuraciones familiares y su asociación a 


\section{B - DESOCUPACIÓN Y SUBEMPLEO}

La bibliografía sobre la evolución del desempleo indica que los jóvenes son uno de los núcleos más críticos en cuanto a niveles de desempleo en todo el mundo, desde hace varias décadas (Rodríguez, 2015; Núñez, Vázquez y Vommaro, 2015; Pérez 2010; Salvia, 2008; Jacinto, 2008; Martín Criado, 1999). El caso argentino no parece ser la excepción, aunque la manera en la que este fenómeno afecta a distintas posiciones del espacio social es diferencial. La tasa de desempleo de jóvenes (Ver Tabla 7) desciende de niveles entre el 29\% y el 33\% en 2003 para la clase dominada y media (dominada y dominante), a porcentajes entre el $23 \%$ y el $26 \%$ para las mismas posiciones en 2013. Las tasas de desempleo de adultos (siempre más bajas que las de jóvenes), en cambio, se distribuyen de manera mucho más desigual entre las distintas posiciones de clase $^{16}$, y el descenso de sus niveles durante el mismo período es mucho más marcado (Neffa, Oliveri y Persia, 2010). Algunos autores, reconociendo la recuperación del empleo en este período en el contexto latinoamericano, plantean que la relación de desempleo de jóvenes / desempleo de adultos se deterioró al menos desde 2007 a la actualidad (Vommaro, Alvarado, Rodríguez, 2013). Ante la fuerte reactivación del empleo durante la década (González, 2011; Neffa, Oliveri y Persia, 2010), fueron los adultos (proporcionalmente más afectados como Jefes de Hogar) quienes mayormente lograron insertarse y llegar a los puestos laborales mejor posicionados, también a raíz de efectos de acumulación en trayectorias laborales más prolongadas. Desde una perspectiva intergeneracional, podemos leer este proceso como una disminución de la presión sobre los más jóvenes en hogares de las clases más desposeídas para su inserción temprana en la actividad laboral y para su contribución en la provisión de recursos monetarios para el hogar.

La relativa igualación entre las tasas de desempleo de jóvenes de distintas posiciones confirma lo que algunas investigaciones que realizan estudios de panel plantean acerca de su condición global de vulnerabilidad: con menor acumulación de experiencia y más expuestos a prácticas discriminatorias, existe una mayor tendencia entre los jóvenes hacia la movilidad laboral (rotación) y hacia la precariedad, una mayor vulnerabilidad a entrar en el desempleo y una mayor dificultad, tanto para entrar a la actividad como para salir del desempleo (Pérez, 2010; Núñez, Vázquez y Vommaro, 2015) ${ }^{17}$.

hogares de diversas posiciones de clase.

16 Desde otro esquema teórico (neomarxista), Pérez y Barrera (2012) proponen conclusiones homólogas sobre esta evolución.

17 Algo distinto sucede con la subocupación horaria demandante (Ver Tabla 8), que disminuye para los jóvenes de todas las clases, salvo para los de la clase dominada, entre 


\section{C - CARACTERÍSTICAS DE LOS PUESTOS DE TRABAJO DE LOS JÓVENES OCUPADOS}

Entre los jóvenes ocupados, hay una distribución relativamente constante durante el período en términos de carácter laboral y rama de actividad ${ }^{18}$. Globalmente, el comercio es el carácter con mayor asociación a los trabajadores jóvenes, mientras que el servicio doméstico y la construcción aparecen particularmente vinculados a la región dominada del espacio social. Lo mismo sucede entre las actividades de gestión administrativo-jurídica y las clases media-dominante y dominante.

En cuanto a la jerarquía laboral (indicador, entre otras cuestiones, de la posición en las relaciones de producción, así como en las formas contractuales que adquieren las mismas) aparece como constante una asociación a la condición de trabajador asalariado por parte de los jóvenes ocupados (Ver Tabla 9) ${ }^{19}$. Sin embargo, vale hacer la salvedad para aquellos jóvenes de familias de clase dominada, quienes durante este mismo período realizan un pasaje importante hacia la condición de cuentapropistas (con un 24\% de los ocupados jóvenes).

En relación a la cobertura de obra social por medio de descuentos en los puestos laborales de los jóvenes ocupados como indicador de empleo formal (Ver Tabla 10), encontramos que aquellos que no perciben descuentos por obra social en el marco de sus ocupaciones disminuyen en el período para todas las clases del espacio (Narodowski, Panigo y Dvoskin, 2010), aunque más marcadamente para la región dominada. Así, las condiciones de no-registro y falta cobertura médica por medio de sus trabajos ascienden a más del 50\% para los jóvenes de esta región y superan en todas las posiciones de clase las cifras de informalidad de adultos. Esta tendencia es general para los países de América Latina y el Caribe (Vommaro, Alvarado, Rodríguez, 2013) ${ }^{20}$.

quienes aumenta considerablemente. En adultos sucede lo mismo, aunque el aumento en la posición más desfavorecida es menos marcado entre 2003 y 2013. Son categorizados como subocupados demandantes aquellos que, pretendiendo trabajar más horas, buscan hacerlo activamente. La tasa se calcula tomando como base la PEA

18 Ambas variables poseen un número elevado de modalidades, sumado a que su nomenclatura se ha modificado entre las puntas del período analizado. El primero describe más específicamente las características de la tarea laboral propiamente dicho, mientras que el segundo refiere al sector de la economía en la que la misma se desarrolla.

19 Existió en el período 2003-2013 un proceso general de asalarización en Argentina, que autores como Palomino y Dalle (2012) o González (2011) rescatan como alentador, dadas sus asociaciones a mejores condiciones registro y cobertura social en el trabajo que en la condición de "cuentapropia".

20 Estos datos coinciden con los que muestran las estadísticas del Ministerio de Trabajo, Empleo y Seguridad Social de la Nación Argentina para todo el país en el mismo período 
Tomando otra de las variables para el mismo grupo de edad (la de cobertura médica), observamos que la no-protección en salud de los jóvenes disminuye para todas las posiciones de clase (Ver Tabla 11), pero fundamentalmente para la región media del espacio (clase media-dominada y clase media-dominante). Esto indicaría que, incluso cuando los jóvenes en general estén expuestos a peores condiciones de registro laboral, resulta determinante la mediación de las familias (CEPALOIJ, 2014) para la distribución y el acceso a los beneficios laborales de seguridad social complementarios al puramente monetario (como la cobertura médica). Aquí, vuelve a resultar fundamental la adopción de la perspectiva inter-generacional para comprender cabalmente la multidimensionalidad y la complejidad de las estructuras de desigualdad, no sólo laboral, sino también social y sanitaria.

En este sentido, los adultos y, fundamentalmente, los referentes de hogar, accederían a condiciones menos precarias de inserción al mercado de trabajo que las de los jóvenes, entre las familias de clase media-dominada. Esto no sucedería con la misma intensidad para las familias de clase dominada ${ }^{21}$.

\section{D - LOS INGRESOS Y SU DISTRIBUCIÓN}

Para el análisis de la dimensión de los ingresos, construimos un índice tomando como base la mediana del ingreso total y laboral ${ }^{22}$ de los jóvenes, y observando su relación con la mediana del ingreso (total y laboral) de los jóvenes de cada una de las clases ${ }^{23}$.

(de 73\% en 2003 a 62\% en 2013 entre los menores de 24 años). Para los mayores a 25 años, en cambio, los porcentajes oscilan entre 40\% y 50\% para 2003 y 27\% y 32\% para 2013.

21 En esta línea, un informe del CELS (2012) reconoce que el aumento de la sindicalización en el período 2005-2008 contribuyó positivamente a la disminución del trabajo no-registrado, fundamentalmente en empresas grandes del sector privado. Otros, como Waisgrais, han señalado que la posibilidad de caer en empleos informales se relaciona positivamente con ingresos familiares bajos, y negativamente con niveles educativos altos (Waisgrais, 2005), lo cual confirmaría la idea de las mejores condiciones laborales de los individuos de familias de clase media-dominante.

22 Tomamos ambos montos para observar si presentaban comportamientos diferentes. En el análisis, sin embargo, hablaremos de ingresos en un sentido genérico, pues si bien la distribución de los ingresos laborales se muestra levemente menos desigual, ambos presentan una dinámica muy similar.

23 Por la necesidad de construir el espacio social a partir de variables categorizadas y no continuas, hemos trabajado hasta aquí con la datos de ingreso agrupados por deciles del aglomerado. No obstante, su distribución genera algunos problemas para el análisis, fundamentalmente por la fuerte dispersión que presentan modalidades como el décimo decil de ingresos (el más alto). En el caso de la base del tercer trimestre de 2013, los valores correspondientes al decil de ingresos de la ocupación principal más altos oscilan entre 8000 y 50000 pesos argentinos, con una media ubicada en los 12500. Mientras que en el 
De esta manera, pudimos observar que las distancias entre las medianas de ingresos totales de cada clase tendieron a achicarse (tomando como referencia la mediana de ingreso general) en la década que va de 2003 a 2013. Por su parte, al observar la distribución del mismo índice para los ingresos de los referentes de hogar, identificamos una disminución paralela de las distancias, aunque con una matriz estructural que perdura durante la década, más escalonada y desigual que la de jóvenes, ubicando las máximas medianas de ingresos individuales en la clase dominante ${ }^{24}$.

Otros estudios han señalado, incluso sosteniendo una crítica hacia los límites estructurales del modelo de desarrollo de la post-convertibilidad, la reducción en la desigualdad de ingresos individuales, hacia el interior de la clase trabajadora, entre sus estratos más y menos calificados (Féliz, López y Fernández, 2012), como así también entre las clases en general (Pérez y Barrera, 2012). Se ha resaltado la importancia de esta observación, también, dado que un fuerte aumento de los ingresos se produce para los hogares pobres, mientras que proporcionalmente crece el origen laboral de estos recursos monetarios y decrece el proveniente de transferencias de ingresos (Vommaro, Alvarado y Rodríguez, 2013).

Otro factor fundamental en este sentido es la re-regulación de las relaciones laborales (González, 2011; Donza, 2011), al menos desde el dictado de una nueva Ley de Contratos de Trabajo en el año 2004, a partir de la recomposición de las paritarias regulares y colectivas, así como también por la recuperación del Salario Mínimo, Vital y Móvil (Biaffore y Berasueta, 2010). Estas variaciones en conjunto pueden indicar una fuerte transformación en el modo de reproducción asociado a la clase dominada y a las clases populares en general.

Esta dinámica se inserta en un proceso vivido en toda América Latina y el Caribe: una progresiva disminución del Coeficiente de Gini y, por consiguiente, de la desigualdad de ingresos individuales, más aún si se considera el Gini post-impuestos y políticas redistribuctivas y de sostenimiento de ingresos (Kessler, 2014; 2015). Distintas conclusiones han señalado quienes analizaron la denominada distribución "primaria" o "funcional" del ingreso, es decir, los procesos diferenciales de apropiación del excedente por parte del trabajo y del capital, aunque esta es una perspectiva que, por cuestión de espacio, dejamos fuera de nuestro texto.

resto de los deciles la desviación estándar no supera el valor de 400, en este decil la cifra llega a 6639 pesos. A raíz de esto.

24 Esto coincide con los datos generales para América Latina y el Caribe señalados por el informe de CEPAL-OIJ (2014). 


\section{REFLEXIONES FINALES: HIPÓTESIS DE TRABAJO SOBRE LA DESIGUAL DISTRIBUCIÓN DE RECURSOS PARA LAS ESTRATEGIAS LABORALES DE LOS JÓVENES}

En torno a lo expuesto, planteamos una serie de hipótesis de trabajo e interpretación que seguimos explorando en nuestro proceso de investigación, a partir de metodologías complementarias que permiten dar cuenta del efectivo devenir de las estrategias de reproducción social de jóvenes en el marco de familias de distintas clases sociales.

Una primera hipótesis surge de la observación sobre la evolución de la inactividad entre los jóvenes de la región dominada del espacio social (su relativo estancamiento en un contexto de crecimiento de los niveles de empleo y el crecimiento de la categoría de "ama de casa" entre los inactivos de esta región del espacio), que indica la necesidad de explorar la articulación entre las tareas de reproducción doméstica y las estrategias laborales, para desanudar uno de los ejes centrales de la producción de la problemática del empleo para los jóvenes de clases populares.

Contribuyendo a la identificación de este eje de tensión, un viraje en ciertas políticas sociales de sostenimiento de ingresos en los últimos años $^{25}$ habría reforzado imaginarios de las mujeres con un fuerte anclaje en las tareas y responsabilidades de la reproducción doméstica. Por su parte, como hemos mostrado en la descripción de las clases en el espacio social cordobés, las distintas configuraciones familiares (tamaño del hogar, presencia de menores, situación conyugal) imponen cuotas diferenciales de trabajo invertido en el hogar, particularmente importantes en el caso de las clases populares.

A la inactividad y a las configuraciones familiares se suman, en las clases populares, volúmenes bajos de capital económico y, en el caso de la clase dominada, condiciones de informalidad laboral y no-cobertura médica. El efecto estructural que puede vislumbrarse en este caso reafirma la posición de subalternidad de estas familias y particularmente de sus jóvenes, dada su imposibilidad para resolver las problemáticas de reproducción doméstica por medio del mercado (contratando servicios médicos privados, trabajo de cuidado para los menores, etc.).

Estas reflexiones parciales plantean desafíos en dos direcciones. En relación a los datos ya citados de CEPAL, resulta central considerar

25 Que en Argentina podría identificarse con el pasaje desde el Plan Jefes y Jefas de Hogar Desocupados, de corte más cercano a la política de empleo y que tuvo una gran repercusión entre mujeres de sectores populares en el país, al Plan Familia, y luego a la Asignación Universal por Hijo, más vinculados a las políticas de infancia y niñez. Tendencias como estas en las políticas sociales podrían encontrarse en muchos de los países de América Latina y el Caribe durante el período post-neoliberal. 
el peso específico del trabajo y la inversión de tiempo en el ámbito doméstico para proponer nociones críticas y alternativas a la de "jóvenes NI-NI". Categorías como "inactividad" o "no estudia ni trabaja", mal describen el peso específico de tareas y el esfuerzo realizado por jóvenes, fundamentalmente mujeres y de clases populares, que organizan, coordinan y realizan la economía de los cuidados en sus hogares. Por otra parte, comenzar a mirar las estrategias de reproducción social, en tanto productoras y resultado de entramados de condiciones de vida desiguales, se adapta mejor a la construcción de los jóvenes -tanto en la política pública como en la investigación- en tanto sujetos activos de derecho antes que como meros receptores de dispositivos políticos.

Analizar las problemáticas "juveniles" de empleo desde una perspectiva relacional invita a pasar desde la observación de la transmisión inter-generacional de la pobreza (Rossel y López Cariboli, 2012) al análisis de la reproducción inter-generacional de las desigualdades sociales. Este salto, a su vez, obliga a pensar el lugar de la familia como sistema relacional, como agente colectivo ${ }^{26}$ y como mediador central del acceso a los recursos y oportunidades en el mercado de trabajo, es decir, como configurador fundamental de las desigualdades entre los jóvenes en materia de inserción laboral (CEPAL-OIJ, 2014).

Por otra parte, la visualización de estas distribuciones en la situación laboral y doméstica de los jóvenes entre las distintas posiciones del espacio social plantea la necesidad cabal de intervenciones transversales (Rodríguez, 2010; 2015), que rearticulen las separaciones artificiales entre políticas de "familia" para jóvenes (en la órbita del "desarrollo social") y políticas de "empleo" para jóvenes (en la órbita del ministerio de "trabajo"), en orden a producir políticas públicas que desanuden los núcleos de la desigualdad de manera compleja, en relación a problemáticas también complejas.

Por último, el desempleo y su centralidad en las preocupaciones públicas respecto de la juventud mutaron de manera fundamental en el período que va de 2003 a 2013. Si sus dimensiones caen abruptamente para los adultos (aun cuando la tasa de desempleo para la clase dominada supere el $10 \%$ ), jóvenes de prácticamente todas las posiciones de clase presentan niveles muy importantes de desocupación. Siendo así, ¿por qué los diagnósticos y las políticas públicas siguen definiendo el

26 En este sentido, la noción aquí trabajada de estrategias de reproducción social aporta en vistas a operativizar articulaciones colectivas de prácticas fenoménicamente muy diversas, pero que funcionan como sistema (prácticas de provisión económica, de inversión cultural, de aprendizaje laboral, de cuidado, de fecundidad, etc.). Como ya sostuvimos, la adopción de la perspectiva inter-generacional y transversal debe traducirse, desde nuestro punto de vista, en herramientas conceptuales y metodológicas concretas que permitan producir conocimiento útil para estas formas políticas de intervención. 
problema del empleo juvenil en relación a los "jóvenes vulnerables"? No se trata simplemente de un deterioro de las relaciones entre grupos de edad, sino de que los jóvenes siguen apareciendo como los más vulnerables a caer en el desempleo y la informalidad (Pérez, 2010). Pero también, los jóvenes aparecen expuestos como objeto de prácticas de vulnerabilización y estigmatización en el marco de las luchas sociales y generacionales por los recursos (Vommaro, 2014). En nuestro trabajo de campo cualitativo hemos podido observar los múltiples prejuicios, pánicos morales, desconfianzas y acusaciones que pesan sobre los jóvenes de clases populares, sobre su cultura, su estilo, sus hábitos morales y sobre su capacidad como ciudadanos y trabajadores. Este juego de múltiples disputas categoriales y clasificaciones político-culturales sólo puede ser entendida en profundidad en el marco de la reconstrucción de sus estructuras sociales de posibilidad: la estructura de relaciones de clase (social y de edad) y las configuraciones familiares en ella; el mercado de trabajo, sus segmentos y la desigual inserción laboral de los jóvenes.

\section{BIBLIOGRAFÍA}

Assusa, G. y Freyre, M. L. 2014 "Clases sociales y prácticas laborales desde la perspectiva de las estrategias de reproducción social" en Desenvolvimento em Questão, Vol. 12, N ${ }^{\circ}$ 27, julio-septiembre, pp. $5-41$.

Baranger, D. 2000 “Sobre estructuras y capitales: Bourdieu, el análisis de redes y la noción de capital social" en Revista de Antropología Avá, $\mathrm{N}^{\circ}$ 2, pp. 41-63.

Baranger, D. 2004 Epistemología y metodología en la obra de Pierre Bourdieu (Buenos Aires: Prometeo).

Basualdo, E. 2006 “La reestructuración de la economía argentina durante las últimas décadas: de la sustitución de importaciones a la valorización financiera" en Basualdo, E. y Arceo, E. (comps.) Neoliberalismo y sectores dominantes. Tendencias globales y experiencias nacionales (Buenos Aires: CLACSO).

Basualdo, E. 2009 “Evolución de la economía argentina en el marco de las transformaciones de la economía internacional de las últimas décadas" en Basualdo, E. y Arceo, E. (comp.) Los condicionantes de la crisis en América Latina (Buenos Aires: CLACSO).

Battistini, O. 2012 "Los sectores populares en Argentina. Su organización y estructura desde el neoliberalismo hasta la actualidad" en 
Battistini O. y Mauger, G. (comps.), La difícil inserción e los jóvenes de clases populares en Argentina y Francia (Buenos Aires: Prometeo).

Biaffore E. y Berasueta, A. 2010 "Principales reformas normativas en el ámbito laboral. Período 2002/2009” en Neffa, J. C., Panigo, D. y Pérez, P. E. Transformaciones del empleo en Argentina: Estructura, dinámica e instituciones (Buenos Aires: CICCUS).

Bourdieu, P. “2000 "Las formas del capital. Capital económico, capital cultural y capital social. En Poder, derecho y clases sociales (Bilbao: Editorial Descleé de Boruwer).

Bourdieu, P. 1990 “Espacio social y génesis de las clases” en Sociología y cultura (México D.F.: Grijalbo/Fondo Nacional para la Cultura y las Artes).

Bourdieu, P. 2006 La distinción: criterios y bases sociales del gusto (Madrid: Taurus).

Bourdieu, P. 2011 "Estrategias de reproducción y modos de dominación" en Las estrategias de reproducción social (Siglo XXI: Buenos Aires).

Calvi, G. y Zibechi, C. 2006 “El epitafio del Plan Jefes de Hogar o una nueva orientación de la política social? Evaluando algunos de los escenarios sociolaborales posibles ante la consolidación del Plan Familia” en Lavboratorio, Año 8, № 19, otoño/invierno, pp. 37 a 46.

CELS 2012 Derechos humanos en Argentina, Informe 2012 (Buenos Aires: Siglo XXI Editores).

CEPAL-OIJ 2014 Invertir para transformar: la juventud como protagonista del desarrollo. (Madrid: CAF/OIT/AECID).

Crivisqui, E. 1993 Análisis factorial de correspondencias: Un instrumento de investigación en ciencias sociales (Asunción: Centro de Publicaciones Universidad Católica de Asunción).

Donza, E. 2011 “Calidad del empleo durante los ciclos de expansión y retracción en el área urbana de la Argentina, 2004-2009” en Salvia, A. (comp.), Deudas Sociales en la Argentina post-reformas. Algo más que una pobreza de ingresos (Buenos Aires: UCA/Biblos).

Español, P. y Herrera, G. 2010 "Empleo industrial en la postconvertibilidad. Una aproximación del período 2003-2008 bajo una mirada de largo plazo" en Neffa, J. C., Panigo, D. y Pérez, P. E. (comps.) Transformaciones del empleo en Argentina. Estructura, dinámica e instituciones (Buenos Aires: CICCUS). 
Fachelli S. 2012 "Desigualdad y estratificación social en la argentina" en Fachelli, S., López, N., López-Roldán, P. y Sourrouille, F. Desigualdad y diversidad en América Latina: hacia un análisis tipológico comparado (Buenos Aires: IIPE/UNESCO).

Féliz, M., López E. y Fernández, L. 2012 “Estructura de clase, distribución del ingreso y políticas públicas. Una aproximación al caso argentino en la etapa post-neoliberal” en Féliz, M. et. al. Más allá del individuo. Clases sociales, transformaciones económicas y políticas estatales en la Argentina contemporánea (Buenos Aires: Editorial El Colectivo).

González Bombal, I., Kessler, G., Svampa, M. 2010 “Introducción: las reconfiguraciones del mundo popular" en González Bombal, I., Kessler, G., Svampa, M. (coord.). Reconfiguraciones del mundo popular: el conurbano bonaerense en la posconvertibilidad (Buenos Aires: Prometeo/UNGS).

González, M. 2011 "El mercado de trabajo en la post-convertibilidad. Pintos de continuidad y ruptura con el patrón de crecimiento anterior" en AAVV, Desarrollo económico, clase trabajadora y luchas sociales en la Argentina Contemporánea (Buenos Aires: IEC/ CONADU).

Grassi, E. 2003 Politicas y problemas sociales en la sociedad neoliberal. La otra década infame [I] (Buenos Aires: Espacio Editorial).

Gutiérrez, A. 2005 Pobre como siempre. Estrategias de reproducción social en la pobreza (Córdoba: Ferreyra Editor).

Gutiérrez, A. 2011 “La producción y reproducción de la pobreza. Claves de un análisis relacional” en Salgado, Jorge Arzate; Gutiérrez, Alicia B. y Huamán, Josefina (coords.) Reproducción de la pobreza en América Latina. Relaciones sociales, poder y estructuras económicas (Buenos Aires: CLACSO).

Gutiérrez, A. 2012 Las prácticas sociales. Una introducción a Pierre Bourdieu (Villa María: EDUVIM).

Gutiérrez, A. y Mansilla, H. 2013 “El espacio social y su reproducción: aspectos teórico metodológicos y fuentes secundarias”. Ponencia presentada en el XXIX Congreso ALAS, Santiago de Chile.

Gutiérrez, A. y Mansilla, H. 2015 “Clases y reproducción social: el espacio social cordobés en la primera década del siglo XXI" en Política y Sociedad. Vol. 52. N 2, pp. 409-442. 
Jacinto, C. 2008 "Los dispositivos recientes de empleo juvenil: institucionalidades, articulaciones con la educación formal y socialización laboral" en Revista del Trabajo - Nueva Época. Año 4, $\mathrm{N}^{\circ} 6$.

Kessler G. y Espinoza, V. 2003 “Movilidad social y trayectorias ocupacionales en Buenos Aires. Continuidades, rupturas y paradojas" en Estratificación y movilidad social en América Latina: transformaciones estructurales de un cuarto de siglo (Santiago de Chile: UN/CEPAL/LOM)

Kessler, G. 2014 Controversias sobre la desigualdad. Argentina 2003-2013 (Buenos Aires: Fondo de Cultura Económica).

Kessler, G. 2015 “Desigualdad en América Latina ¿un cambio de rumbo?” en Carta mensual INTAL. $\mathrm{N}^{\circ} 221$. BID.

Kessler, G. y Merlken, D. 2013 "Una introducción cruzando el Atlántico" en Castel, R., Kessler, G., Merklen, D. y Murard, N., Individuación, precariedad, inseguridad ¿Desinstitucionalización del presente?

(Buenos Aires: Paidós).

López-Roldán, P. 1996 "La construcción de una tipologia de segmentación del mercado de trabajo" en Papers. $\mathrm{N}^{\circ} 48$, pp. 41-58.

Martín Criado, E. 1998 Producir la juventud: crítica de la sociología de la juventud (Madrid: AKAL).

Martín Criado, E. 1999 "El paro juvenil no es el problema, la formación no es la solución” en Cachón Rodríguez, Lorenzo (coord.) Juventudes, mercados de trabajo y políticas de empleo (Valencia: 7imig).

Moscoloni, N. 2005 Las nubes de datos: Métodos para analizar la complejidad (Rosario: UNR Editora).

Narodowski, P., Panigo, D. y Dvoskin, N. 2010 “Aspectos teóricos relevantes para el análisis empírico de la informalidad en la Argentina" en Neffa, J. C., Panigo, D. y Pérez, P. E. Transformaciones del empleo en Argentina: Estructura, dinámica e instituciones (Buenos Aires: CICCUS).

Neffa, J. C., Oliveri, M. L., Persia, J. 2010 “Transformaciones del mercado de trabajo en la Argentina: 1974-2009” en Neffa, J. C., Panigo, D. y Pérez, P. E. Transformaciones del empleo en Argentina. Estructura, dinámica e instituciones (Buenos Aires: CICCUS).

Núñez, P., Vázquez, M. y Vommaro, P. 2015 “Entre la inlclusión y la participación. Una revisión de las políticas públicas de juventud en 
la Argentina actual" en Cubides, H.; Borelli, S.; Unda, R.; Vázquez, M. (eds.). Juventudes latinoamericanas: prácticas socioculturales, políticas y políticas públicas (Buenos Aires: CLACSO).

Palomino, H. y Dalle, P. 2012 "El impacto de los cambios ocupacionales en la estructura social de la Argentina: 2003-2011" en Revista de Trabajo, 8, 10, julio-septiembre, pp. 205-224.

Pérez, P. 2010 “¿Por qué difieren las tasas de empleo de jóvenes y adultos? Un análisis de transiciones laborales en Argentina post-Convertibilidad" en Neffa, J. C., Panigo, D. y Pérez, P. E. Transformaciones del empleo en Argentina. Estructura, dinámica e instituciones (Buenos Aires: CICCUS, Buenos Aires).

Perez, P. y Barrera, F. 2012 "Estructura de clases, inserción laboral y desigualdad en la post-convertibilidad" en Feliz, M. et. al. Más allá del individuo: Clases sociales, transformaciones económicas y políticas estatales en la Argentina contemporánea (Buenos Aires: Editorial El Colectivo).

Pérez, P. y Brown, B. 2014 "Políticas de empleo para jóvenes: el 'Programa Jóvenes con Más y Mejor Trabajo"' en Pérez, P. y Busso, M. (coords.). Tiempos contingentes: inserción laboral de los jóvenes en la Argentina Posneoliberal (Buenos Aires: Miño y Dávila).

Quartulli, D. y Salvia, A. 2012 "La movilidad y la estratificación socioocupacional en la Argentina. Un análisis de las desigualdades de origen" en Entramados y perspectivas, $\mathrm{N}^{\circ} 2$, vol. 2, pp. 15-42.

Rodríguez, E. 2010 Políticas públicas de juventud en América Latina: avances concretados y desafíos a encarar en el marco de Año Internacional de la Juventud (s/d: UNESCO).

Rodríguez, E. 2015 “A modo de prólogo: estudios sobre juventudes en América Latina: Un mosaico de realidades diversas pero convergentes, a caracterizar más y mejor" en Cubides, H.; Borelli, S.; Unda, R.; Vázquez, M. (eds.) Juventudes latinoamericanas: prácticas socioculturales, políticas y políticas públicas (Buenos Aires: CLACSO).

Rossel, C. y López Cariboli, S. 2012 Edad, desigualdad y distribución: hacia la orientación etaria de los Estados de Bienestar (Madrid: CeALCI/ Fundación Carolina).

Salvia, A. 2008 "Introducción. La cuestión juvenil bajo sospecha" en Salvia, A. (comp.). Jóvenes promesas. Trabajo, educación y exclusión 
social de jóvenes pobres en la Argentina (Buenos Aires: Miño y Dávila).

Vera, J. 2013 “Informalidad y segmentación laboral desde la perspectiva estructuralista: una aplicación para la Argentina (1992-2010)” en Revista Lavboratorio $\mathrm{N}^{\circ} 225$. Año 14, pp. 11-35.

Vommaro, P. 2014 “Juventudes, políticas y generaciones en América Latina: cercamientos teórico conceptuales para su abordaje” en Alvarado, S. V. y Vommaro P. (comps.) En busca de las condiciones juveniles latinoamericanas (Ciudad Autónoma de Buenos Aires: CLACSO/El Colegio de la Frontera Norte/ El COLEF/Universidad de Manizales/Cinde).

Vommaro, P., Alvarado S. V., y Rodríguez, E. 2013 "Políticas de inclusión social de jóvenes de América Latina y el Caribe: situación, desafíos y recomendaciones para la acción”. IX Reunión del Foro de Ministros de Desarrollo Social de América Latina y el Caribe (Buenos Aires, 16-18 de septiembre). UNESCO.

Waisgrais, S. 2005 “Segmentación del mercado de trabajo en Argentina. Una aproximación a través de la economía informal”. Trabajo presentado en el Séptimo Congreso Nacional de Estudios sobre el Trabajo. Buenos Aires: ASET.

Waisgrais, S. 2006 "Características del empleo asalariado registrado: un análisis multivariante" en Serie Trabajo, Ocupación y Empleo. Los retos laborales en un proceso de crecimiento sostenido. 7. Pp. 109-143. 
JUVENTUD Y DESIGUALDADES EN AMÉRICA LATINA Y EL CARIBE

\section{ANEXOS}

Diagrama 1. Espacio social de las clases en Córdoba. 2013.

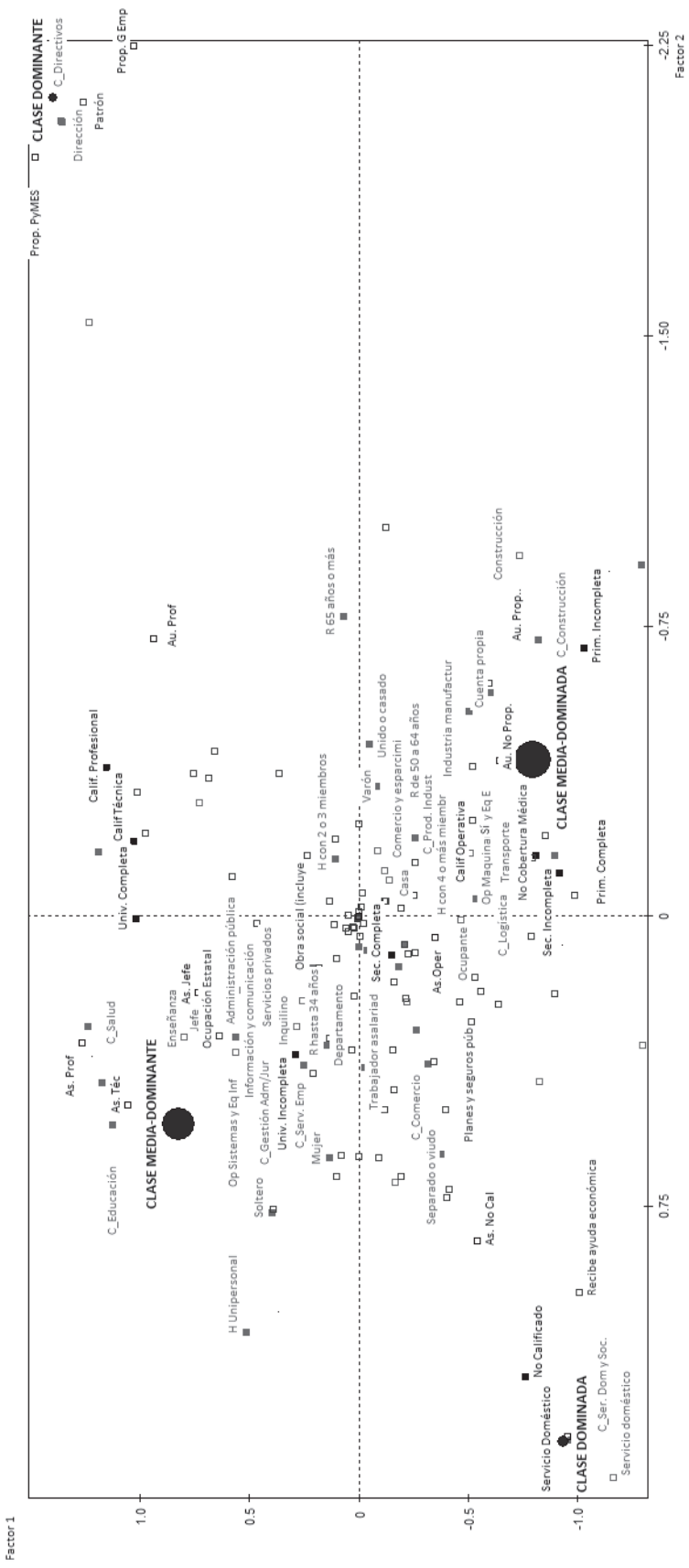


Diagrama 2. Dendograma resultado de la CJA. Gran Córdoba. 2013.

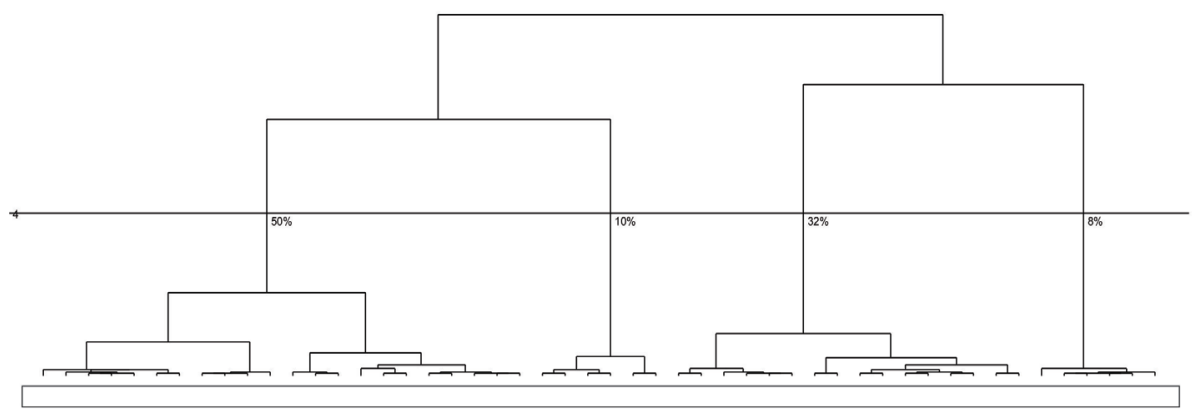

Tabla 1. Descripción de asociaciones a la Clase Dominada

\begin{tabular}{|c|c|c|c|c|c|c|c|}
\hline \multicolumn{8}{|c|}{$\begin{array}{l}\text { CLASE: CLASE DOMINADA } \\
\text { (efectivos: } 66 \text { - porcentaje: 10.72) }\end{array}$} \\
\hline Variables & $\begin{array}{l}\text { modalidades } \\
\text { características }\end{array}$ & $\begin{array}{l}\% \text { de la } \\
\text { modalidad } \\
\text { en la } \\
\text { CLASE }\end{array}$ & $\begin{array}{l}\% \text { de la } \\
\text { modalidad } \\
\text { en la } \\
\text { muestra }\end{array}$ & $\begin{array}{l}\% \text { de la } \\
\text { CLASE } \\
\text { en la } \\
\text { modalidad }\end{array}$ & $\begin{array}{l}\text { Valor- } \\
\text { Test }\end{array}$ & Probabilidad & Peso \\
\hline $\begin{array}{l}\text { Caracter } \\
\text { Ocupacional } \\
\text { del RH }\end{array}$ & $\begin{array}{l}\text { C_Ser. Dom y } \\
\text { Soc. }\end{array}$ & 79,25 & 9,39 & 90,47 & 15,62 & 0,000 & 58 \\
\hline $\begin{array}{l}\text { Condición Socio } \\
\text { Ocupacional } \\
\text { del RH }\end{array}$ & Serv Dom & 79,25 & 9,39 & 90,47 & 15,62 & 0,000 & 58 \\
\hline $\begin{array}{l}\text { Calificación } \\
\text { ocupacional del } \\
\text { RH }\end{array}$ & No Calificado & 89,90 & 13,97 & 69,01 & 15,26 & 0,000 & 86 \\
\hline $\begin{array}{l}\text { Rama de } \\
\text { Actividad CAES } \\
\text { codificada } 1\end{array}$ & $\begin{array}{l}\text { Servicio } \\
\text { doméstico }\end{array}$ & 48,93 & 5,25 & 100,00 & 12,36 & 0,000 & 32 \\
\hline Sexo del RH & Mujer & 86,24 & 36,50 & 25,33 & 8,76 & 0,000 & 225 \\
\hline $\begin{array}{l}\text { Tamaño del } \\
\text { establecimiento } \\
\text { del RH_rec }\end{array}$ & Ns./Nr. & 51,96 & 12,63 & 44,10 & 8,23 & 0,000 & 78 \\
\hline $\begin{array}{l}\text { Tecnología } \\
\text { ocupacional RH }\end{array}$ & $\begin{array}{l}\text { Sin operación } \\
\text { de máq }\end{array}$ & 100,00 & 61,46 & 17,44 & 7,96 & 0,000 & 379 \\
\hline
\end{tabular}




\begin{tabular}{|c|c|c|c|c|c|c|c|}
\hline \multicolumn{8}{|c|}{$\begin{array}{l}\text { CLASE: CLASE DOMINADA } \\
\text { (efectivos: } 66 \text { - porcentaje: 10.72) }\end{array}$} \\
\hline Variables & $\begin{array}{l}\text { modalidades } \\
\text { características }\end{array}$ & $\begin{array}{l}\% \text { de la } \\
\text { modalidad } \\
\text { en la } \\
\text { CLASE }\end{array}$ & $\begin{array}{l}\% \text { de la } \\
\text { modalidad } \\
\text { en la } \\
\text { muestra }\end{array}$ & $\begin{array}{l}\% \text { de la } \\
\text { CLASE } \\
\text { en la } \\
\text { modalidad }\end{array}$ & $\begin{array}{l}\text { Valor- } \\
\text { Test }\end{array}$ & Probabilidad & Peso \\
\hline $\begin{array}{l}\text { Situación } \\
\text { conyugal } \\
\text { reagrupada SPAD }\end{array}$ & $\begin{array}{l}\text { Separado } 0 \\
\text { viudo }\end{array}$ & 49,56 & 17,68 & 30,04 & 6,34 & 0,000 & 109 \\
\hline $\begin{array}{l}\text { Grupo decílico } \\
\text { IPCF SPAD }\end{array}$ & ingresos bajos & 59,83 & 31,31 & 20,49 & 5,09 & 0,000 & 193 \\
\hline $\begin{array}{l}\text { Grupo decílico } \\
\text { p47t SPAD }\end{array}$ & ingresos bajos & 38,52 & 14,38 & 28,72 & 4,95 & 0,000 & 89 \\
\hline $\begin{array}{l}\text { Jerarquía } \\
\text { ocupacional del } \\
\text { RH }\end{array}$ & $\begin{array}{l}\text { Trabajador } \\
\text { asalariad }\end{array}$ & 93,31 & 71,04 & 14,08 & 4,70 & 0,000 & 438 \\
\hline $\begin{array}{l}\text { Antigüedad } \\
\text { Laboral RH Todos }\end{array}$ & $\begin{array}{l}\text { Más de } 1 \text { a } 5 \\
\text { años }\end{array}$ & 46,01 & 22,92 & 21,52 & 4,20 & 0,000 & 141 \\
\hline $\begin{array}{l}\text { Categoria de } \\
\text { actividad/ } \\
\text { inactividad del } \\
\text { RH }\end{array}$ & $\begin{array}{l}\text { Obrero } 0 \\
\text { empleado }\end{array}$ & 94,33 & 75,23 & 13,44 & 3,98 & 0,000 & 464 \\
\hline $\begin{array}{l}\text { Grupo decílico } \\
\text { de P21 del } \\
\text { AGLOMERADO }\end{array}$ & P21_2 Decil & 23,18 & 8,99 & 27,65 & 3,50 & 0,000 & 55 \\
\hline $\begin{array}{l}\text { Condición Socio } \\
\text { Ocupacional } \\
\text { del RH }\end{array}$ & As. No Cal & 18,83 & 6,12 & 32,98 & 3,49 & 0,000 & 38 \\
\hline $\begin{array}{l}\text { Grupo decílico } \\
\text { de ITF del } \\
\text { AGLOMERADO }\end{array}$ & ITF $1^{\circ}$ decil & 17,79 & 6,11 & 31,19 & 3,49 & 0,000 & 38 \\
\hline $\begin{array}{l}\text { Tipo de } \\
\text { Cobertura } \\
\text { Medica RH }\end{array}$ & $\begin{array}{l}\text { No paga ni le } \\
\text { descue }\end{array}$ & 42,21 & 23,65 & 19,13 & 3,46 & 0,000 & 146 \\
\hline $\begin{array}{l}\text {...de subsidio } \\
\text { o ayuda social } \\
\text { (en dinero) del } \\
\text { gobierno, igle }\end{array}$ & Sí & 24,78 & 10,80 & 24,60 & 3,17 & 0,001 & 67 \\
\hline $\begin{array}{l}\text { Grupo decílico } \\
\text { de P21 del } \\
\text { AGLOMERADO }\end{array}$ & P21_1 Decil & 18,71 & 7,79 & 25,76 & 2,80 & 0,003 & 48 \\
\hline
\end{tabular}




\begin{tabular}{|c|c|c|c|c|c|c|c|}
\hline \multicolumn{8}{|c|}{$\begin{array}{l}\text { CLASE: CLASE DOMINADA } \\
\text { (efectivos: } 66 \text { - porcentaje: 10.72) }\end{array}$} \\
\hline Variables & $\begin{array}{l}\text { modalidades } \\
\text { características }\end{array}$ & $\begin{array}{l}\% \text { de la } \\
\text { modalidad } \\
\text { en la } \\
\text { CLASE }\end{array}$ & $\begin{array}{l}\% \text { de la } \\
\text { modalidad } \\
\text { en la } \\
\text { muestra }\end{array}$ & $\begin{array}{l}\% \text { de la } \\
\text { CLASE } \\
\text { en la } \\
\text { modalidad }\end{array}$ & $\begin{array}{l}\text { Valor- } \\
\text { Test }\end{array}$ & Probabilidad & Peso \\
\hline $\begin{array}{l}\text { Nivel educativo } \\
\text { del Referente del } \\
\text { Hogar }\end{array}$ & $\begin{array}{l}\text { Prim. } \\
\text { Completa }\end{array}$ & 24,82 & 12,42 & 21,43 & 2,67 & 0,004 & 77 \\
\hline $\begin{array}{l}\text { Nivel educativo } \\
\text { del Referente del } \\
\text { Hogar }\end{array}$ & $\begin{array}{l}\text { Sec. } \\
\text { Incompleta }\end{array}$ & 30,22 & 17,26 & 18,76 & 2,63 & 0,004 & 107 \\
\hline $\begin{array}{l}\text { ¿Compran en } \\
\text { cuotas } 0 \text { al fiado } \\
\text { con tarjeta de } \\
\text { crédito o libre }\end{array}$ & No & 53,16 & 38,37 & 14,85 & 2,42 & 0,008 & 237 \\
\hline $\begin{array}{l}\text {...de cuotas de } \\
\text { alimentos o } \\
\text { ayuda (en dinero) } \\
\text { de personas qu }\end{array}$ & Sí & 20,55 & 11,03 & 19,97 & 2,42 & 0,008 & 68 \\
\hline
\end{tabular}


Tabla 2. Descripción de asociaciones a la Clase Dominante

\section{CLASE: CLASE DOMINANTE}

(efectivos: 49 - porcentaje: 7.88)

Variables

características

Tecnología

ocupacional RH

Jerarquía

ocupacional del

RH

\begin{tabular}{l|l} 
Caracter & Ocupacional del
\end{tabular}

RH

Categoría de

actividad/

inactividad del

RH

Condición Socio

Ocupacional del

RH

Condición Socio

Ocupacional del

RH

Antigüedad
Laboral RH Todos

Calificación

ocupacional del

RH

Tipo de Cobertura

Medica RH

Calificación

ocupacional del

RH

Grupo decílico

de P21 del

AGLOMERADO

Cantidad de

miembros del H

SPAD

S/D

Dirección

C_Directivos

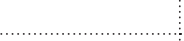

Patrón

Prop. PyMES

Prop. G Emp

Ns./Nr.

Calif Técnica

:

Mutual/

Prepaga/Servi

Calif.

Profesional

P21_9 ${ }^{\circ}$ Decil

$\mathrm{H}$ con 203 $\begin{array}{llllll}\% \text { de la } & \% \text { de la } & \text { \% de la } & \text { Valor- } & \text { Probabilidad Peso }\end{array}$

modalidad modalidad CLASE Test

en la en la en la

CLASE muestra modalidad

100,00

10,53

74,87

$99,99 \quad 0,000$

65

100,00

7,88

100,00

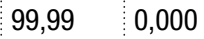

49

7,75

100,00

99,99

0,000

48

79,90

6,39

98,60

$\begin{array}{ll}99,99 & 0,000\end{array}$

39

40,12

3,25

97,26

$10,16 \quad 0,000$

20

39,78

3,14

100,00

9,87

0,000

19

$\begin{array}{l:l}82,72 & 24,41\end{array}$

26,70

$8,72 \quad 0,000$

151

64,38

21,11

24,04

$6,59 \quad 0,000$

130

30,50

9,42

25,52

4,29

0,000

58

\begin{tabular}{l|l}
32,72 & 11,78
\end{tabular}

21,89

3,93

0,000

73

29,84

11,58

20,30

3,65

0,000

71

68,38

43,86

12,29

3,29

0,001

271 


\begin{tabular}{|c|c|c|c|c|c|c|c|}
\hline \multicolumn{8}{|c|}{$\begin{array}{l}\text { CLASE: CLASE DOMINANTE } \\
\text { (efectivos: } 49 \text { - porcentaje: } 7.88 \text { ) }\end{array}$} \\
\hline Variables & $\begin{array}{l}\text { modalidades } \\
\text { características }\end{array}$ & $\begin{array}{l}\% \text { de la } \\
\text { modalidad } \\
\text { en la } \\
\text { CLASE }\end{array}$ & $\begin{array}{l}\% \text { de la } \\
\text { modalidad } \\
\text { en la } \\
\text { muestra }\end{array}$ & $\begin{array}{l}\% \text { de la } \\
\text { CLASE } \\
\text { en la } \\
\text { modalidad }\end{array}$ & $\begin{array}{l}\text { Valor- } \\
\text { Test }\end{array}$ & Probabilidad & Peso \\
\hline $\begin{array}{l}\text { Situación } \\
\text { conyugal } \\
\text { reagrupada SPAD }\end{array}$ & Unido o casado & 82,16 & 59,64 & 10,86 & 3,25 & 0,001 & 368 \\
\hline $\begin{array}{l}\text { Grupo decílico } \\
\text { IPCF SPAD }\end{array}$ & $\begin{array}{l}\text { ingresos } \\
\text { medios alto }\end{array}$ & 52,70 & 31,52 & 13,18 & 3,13 & 0,001 & 194 \\
\hline Edad del RH & $\begin{array}{l}R \text { de } 50 \text { a } 64 \\
\text { años }\end{array}$ & 47,25 & 27,73 & 13,43 & 2,85 & 0,002 & 171 \\
\hline $\begin{array}{l}\text { Grupo decílico } \\
\text { p47t SPAD }\end{array}$ & $\begin{array}{l}\text { ingresos muy } \\
\text { altos }\end{array}$ & 33,59 & 16,20 & 16,35 & 2,84 & 0,002 & 100 \\
\hline $\begin{array}{l}\text { Grupo decílico } \\
\text { de P21 del } \\
\text { AGLOMERADO }\end{array}$ & P21_10 Decil & 26,12 & 12,22 & 16,84 & 2,73 & 0,003 & 75 \\
\hline $\begin{array}{l}\text {...de pedir } \\
\text { préstamos a } \\
\text { familiares/ } \\
\text { amigos? }\end{array}$ & No & 96,59 & 82,42 & 9,24 & 2,68 & 0,004 & 508 \\
\hline $\begin{array}{l}\text { Cantidad de } \\
\text { miembros por } \\
\text { ambiente de } \\
\text { uso exclusivo } \\
\text { codificad }\end{array}$ & $\begin{array}{l}\text { Entre } 1 \text { a } 2 \\
\text { personas }\end{array}$ & 42,91 & 25,33 & 13,35 & 2,66 & 0,004 & 156 \\
\hline Edad del RH & $\begin{array}{l}\mathrm{R} 65 \text { años } 0 \\
\text { más }\end{array}$ & 11,43 & 3,74 & 24,07 & 2,48 & 0,007 & 23 \\
\hline $\begin{array}{l}\text { Tamaño del } \\
\text { establecimiento } \\
\text { del } \mathbf{R H} \text { rec }\end{array}$ & De 6 a 40 & 37,59 & 21,23 & 13,95 & 2,46 & 0,007 & 131 \\
\hline $\begin{array}{l}\text { Nivel educativo } \\
\text { del Referente del } \\
\text { Hogar }\end{array}$ & Univ. Completa & 42,58 & 26,69 & 12,58 & 2,40 & 0,008 & 165 \\
\hline $\begin{array}{l}\text { Grupo decílico } \\
\text { de ITF del } \\
\text { AGLOMERADO }\end{array}$ & ITF $10^{\circ}$ decil & 24,66 & 12,03 & 16,16 & 2,39 & 0,008 & 74 \\
\hline
\end{tabular}


Tabla 3. Descripción de asociaciones a la Clase Media-Dominada

\section{CLASE: CLASE MEDIA DOMINADA}

(efectivos: 262 - porcentaje: 42.45)

\begin{tabular}{|c|c|c|c|c|c|c|c|}
\hline Variables & $\begin{array}{l}\text { modalidades } \\
\text { características }\end{array}$ & $\begin{array}{l}\% \text { de la } \\
\text { modalidad } \\
\text { en la } \\
\text { CLASE }\end{array}$ & $\begin{array}{l}\% \text { de la } \\
\text { modalidad } \\
\text { en la } \\
\text { muestra }\end{array}$ & $\begin{array}{l}\% \text { de la } \\
\text { CLASE } \\
\text { en la } \\
\text { modalidad }\end{array}$ & $\begin{array}{l}\text { Valor- } \\
\text { Test }\end{array}$ & Probabilidad & Peso \\
\hline $\begin{array}{l}\text { Calificación } \\
\text { ocupacional } \\
\text { del RH }\end{array}$ & Calif Operativa & 89,80 & 53,14 & 71,73 & 16,35 & 0,000 & 328 \\
\hline Sexo del RH & Varón & 85,17 & 63,50 & 56,94 & 9,79 & 0,000 & 392 \\
\hline $\begin{array}{l}\text { Tamaño del } \\
\text { establecimiento } \\
\text { del RH_rec }\end{array}$ & Hasta 5 & 58,84 & 36,66 & 68,13 & 9,79 & 0,000 & 226 \\
\hline $\begin{array}{l}\text { Grupo decílico } \\
\text { IPCF SPAD }\end{array}$ & ingresos bajos & 51,80 & 31,31 & 70,23 & 9,45 & 0,000 & 193 \\
\hline $\begin{array}{l}\text { Condición Socio } \\
\text { Ocupacional } \\
\text { del RH }\end{array}$ & As.Oper & 58,16 & 36,69 & 67,29 & 9,44 & 0,000 & 226 \\
\hline $\begin{array}{l}\text { Caracter } \\
\text { Ocupacional } \\
\text { del RH }\end{array}$ & C_Construcción & 24,75 & 11,98 & 87,69 & 8,52 & 0,000 & 74 \\
\hline $\begin{array}{l}\text { Condición Socio } \\
\text { Ocupacional } \\
\text { del RH }\end{array}$ & Au. Prop.. & 26,04 & 12,95 & 85,35 & 8,29 & 0,000 & 80 \\
\hline $\begin{array}{l}\text { Tecnología } \\
\text { ocupacional RH }\end{array}$ & $\begin{array}{l}\text { Op Maquinaria } \\
\text { y Eq } E\end{array}$ & 26,64 & 13,80 & 81,96 & 8,01 & 0,000 & 85 \\
\hline $\begin{array}{l}\text { Jerarquía } \\
\text { ocupacional } \\
\text { del RH }\end{array}$ & Cuenta propia & 32,57 & 18,33 & 75,44 & 7,72 & 0,000 & 113 \\
\hline $\begin{array}{l}\text { Rama de } \\
\text { Actividad CAES } \\
\text { codificada } 1\end{array}$ & Construcción & 22,30 & 11,06 & 85,61 & 7,60 & 0,000 & 68 \\
\hline $\begin{array}{l}\text { Categoría de } \\
\text { actividad/ } \\
\text { inactividad del } \\
\text { RH }\end{array}$ & Cuenta Propia & 32,24 & 18,38 & 74,44 & 7,50 & 0,000 & 113 \\
\hline $\begin{array}{l}\text { Situación } \\
\text { conyugal } \\
\text { reagrupada } \\
\text { SPAD }\end{array}$ & Unido o casado & 75,95 & 59,64 & 54,06 & 7,12 & 0,000 & 368 \\
\hline
\end{tabular}




\begin{tabular}{|c|c|c|c|c|c|c|c|}
\hline \multicolumn{8}{|c|}{$\begin{array}{l}\text { CLASE: CLASE MEDIA DOMINADA } \\
\text { (efectivos: } 262 \text { - porcentaje: } 42.45 \text { ) }\end{array}$} \\
\hline Variables & $\begin{array}{l}\text { modalidades } \\
\text { características }\end{array}$ & $\begin{array}{l}\% \text { de la } \\
\text { modalidad } \\
\text { en la } \\
\text { CLASE }\end{array}$ & $\begin{array}{l}\% \text { de la } \\
\text { modalidad } \\
\text { en la } \\
\text { muestra }\end{array}$ & $\begin{array}{l}\% \text { de la } \\
\text { CLASE } \\
\text { en la } \\
\text { modalidad }\end{array}$ & $\begin{array}{l}\text { Valor- } \\
\text { Test }\end{array}$ & Probabilidad & Peso \\
\hline $\begin{array}{l}\text { Nivel educativo } \\
\text { del Referente } \\
\text { del Hogar }\end{array}$ & Sec. Incompleta & 29,66 & 17,26 & 72,93 & 6,91 & 0,000 & 107 \\
\hline $\begin{array}{l}\text { Caracter } \\
\text { Ocupacional } \\
\text { del RH }\end{array}$ & C_Logística & 15,93 & 8,02 & 84,37 & 6,36 & 0,000 & 49 \\
\hline $\begin{array}{l}\text { Caracter } \\
\text { Ocupacional } \\
\text { del RH }\end{array}$ & C_Prod. Indust & 28,43 & 17,19 & 70,20 & 6,14 & 0,000 & 106 \\
\hline $\begin{array}{l}\text { Grupo decílico } \\
\text { p47t SPAD }\end{array}$ & $\begin{array}{l}\text { ingresos medios } \\
\text { bajo }\end{array}$ & 40,45 & 27,57 & 62,29 & 6,06 & 0,000 & 170 \\
\hline $\begin{array}{l}\text { Cantidad de } \\
\text { miembros del H } \\
\text { SPAD }\end{array}$ & $\begin{array}{l}\text { H con } 4 \text { o más } \\
\text { miembr }\end{array}$ & 56,32 & 42,06 & 56,84 & 6,04 & 0,000 & 259 \\
\hline $\begin{array}{l}\text { Tipo de } \\
\text { Cobertura } \\
\text { Medica RH }\end{array}$ & $\begin{array}{l}\text { No paga ni le } \\
\text { descue }\end{array}$ & 35,74 & 23,65 & 64,15 & 6,02 & 0,000 & 146 \\
\hline $\begin{array}{l}\text { Nivel educativo } \\
\text { del Referente } \\
\text { del Hogar }\end{array}$ & Prim. Completa & 21,31 & 12,42 & 72,84 & 5,62 & 0,000 & 77 \\
\hline $\begin{array}{l}\text { Cantidad de } \\
\text { miembros por } \\
\text { ambiente de } \\
\text { uso exclusivo } \\
\text { codificad }\end{array}$ & $\begin{array}{l}\text { Menos de } 1 \\
\text { persona p }\end{array}$ & 81,36 & 69,57 & 49,65 & 5,46 & 0,000 & 429 \\
\hline $\begin{array}{l}\text { Ambito laboral } \\
\text { del RH }\end{array}$ & $\begin{array}{l}\text { Ocupación } \\
\text { Privada }\end{array}$ & 93,37 & 84,45 & 46,93 & 5,20 & 0,000 & 521 \\
\hline $\begin{array}{l}\text { Rama de } \\
\text { Actividad CAES } \\
\text { codificada } 1\end{array}$ & $\begin{array}{l}\text { Industria } \\
\text { manufactur }\end{array}$ & 22,51 & 14,14 & 67,57 & 5,03 & 0,000 & 87 \\
\hline $\begin{array}{l}\text { Tipo de } \\
\text { vivienda } \mathbf{R}\end{array}$ & Casa & 76,07 & 65,43 & 49,35 & 4,67 & 0,000 & 404 \\
\hline
\end{tabular}




\begin{tabular}{|c|c|c|c|c|c|c|c|}
\hline \multicolumn{8}{|c|}{$\begin{array}{l}\text { CLASE: CLASE MEDIA DOMINADA } \\
\text { (efectivos: } 262 \text { - porcentaje: 42.45) }\end{array}$} \\
\hline Variables & $\begin{array}{l}\text { modalidades } \\
\text { características }\end{array}$ & $\begin{array}{l}\% \text { de la } \\
\text { modalidad } \\
\text { en la } \\
\text { CLASE }\end{array}$ & $\begin{array}{l}\% \text { de la } \\
\text { modalidad } \\
\text { en la } \\
\text { muestra }\end{array}$ & $\begin{array}{l}\% \text { de la } \\
\text { CLASE } \\
\text { en la } \\
\text { modalidad }\end{array}$ & $\begin{array}{l}\text { Valor- } \\
\text { Test }\end{array}$ & Probabilidad & Peso \\
\hline $\begin{array}{l}\text {...de subsidio } \\
\text { o ayuda social } \\
\text { (en dinero) del } \\
\text { gobierno, igle }\end{array}$ & Sí & 17,06 & 10,80 & 67,05 & 4,19 & 0,000 & 67 \\
\hline $\begin{array}{l}\text { Rama de } \\
\text { Actividad CAES } \\
\text { codificada } 1\end{array}$ & $\begin{array}{l}\text { Transporte y } \\
\text { almacen }\end{array}$ & 11,22 & 6,32 & 75,41 & 4,00 & 0,000 & 39 \\
\hline $\begin{array}{l}\text { Grupo decílico } \\
\text { de P21 del } \\
\text { AGLOMERADO }\end{array}$ & P21_3 Decil & 12,49 & 7,83 & 67,75 & 3,67 & 0,000 & 48 \\
\hline $\begin{array}{l}\text { Grupo decílico } \\
\text { de P21 del } \\
\text { AGLOMERADO }\end{array}$ & P21_4 $4^{\circ}$ Decil & 13,03 & 8,18 & 67,57 & 3,65 & 0,000 & 50 \\
\hline $\begin{array}{l}\text { ¿La vivienda } \\
\text { está ubicada } \\
\text { cerca de } \\
\text { basural/es ( } 3 \\
\text { cuadras o m }\end{array}$ & Sí & 14,08 & 9,10 & 65,65 & 3,59 & 0,000 & 56 \\
\hline $\begin{array}{l}\text {...de cuotas } \\
\text { de alimentos } \\
\text { o ayuda (en } \\
\text { dinero) de } \\
\text { personas qu }\end{array}$ & No & 94,45 & 88,97 & 45,06 & 3,59 & 0,000 & 549 \\
\hline $\begin{array}{l}\text { Nivel educativo } \\
\text { del Referente } \\
\text { del Hogar }\end{array}$ & $\begin{array}{l}\text { Prim. } \\
\text { Incompleta }\end{array}$ & 8,34 & 4,68 & 75,62 & 3,54 & 0,000 & 29 \\
\hline $\begin{array}{l}\text { Antigüedad } \\
\text { Laboral RH } \\
\text { Todos }\end{array}$ & Ns./Nr. & 31,86 & 24,41 & 55,40 & 3,47 & 0,000 & 151 \\
\hline $\begin{array}{l}\text { Regimen de } \\
\text { tenencia recod }\end{array}$ & Propietario & 58,21 & 50,30 & 49,13 & 3,24 & 0,001 & 310 \\
\hline $\begin{array}{l}\text { Condición Socio } \\
\text { Ocupacional } \\
\text { del RH }\end{array}$ & Au. No Prop. & 4,01 & 2,19 & 77,83 & 2,50 & 0,006 & 14 \\
\hline
\end{tabular}




\begin{tabular}{|c|c|c|c|c|c|c|c|}
\hline \multicolumn{8}{|c|}{$\begin{array}{l}\text { CLASE: CLASE MEDIA DOMINADA } \\
\text { (efectivos: } 262 \text { - porcentaje: } 42.45 \text { ) }\end{array}$} \\
\hline Variables & $\begin{array}{l}\text { modalidades } \\
\text { características }\end{array}$ & $\begin{array}{l}\% \text { de la } \\
\text { modalidad } \\
\text { en la } \\
\text { CLASE }\end{array}$ & $\begin{array}{l}\% \text { de la } \\
\text { modalidad } \\
\text { en la } \\
\text { muestra }\end{array}$ & $\begin{array}{l}\% \text { de la } \\
\text { CLASE } \\
\text { en la } \\
\text { modalidad }\end{array}$ & $\begin{array}{l}\text { Valor- } \\
\text { Test }\end{array}$ & Probabilidad & Peso \\
\hline $\begin{array}{l}\text { Cantidad de } \\
\text { ambientes/ } \\
\text { abitaciones de } \\
\text { la vivienda }\end{array}$ & $\begin{array}{l}\text { Vivienda de tres } \\
\text { amb }\end{array}$ & 41,44 & 35,84 & 49,07 & 2,49 & 0,006 & 221 \\
\hline $\begin{array}{l}\text { Grupo decílico } \\
\text { de ITF del } \\
\text { AGLOMERADO }\end{array}$ & ITF $6^{\circ}$ decil & 14,40 & 10,70 & 57,16 & 2,48 & 0,007 & 66 \\
\hline $\begin{array}{l}\text { Grupo decílico } \\
\text { p47t SPAD }\end{array}$ & ingresos bajos & 18,70 & 14,38 & 55,20 & 2,47 & 0,007 & 89 \\
\hline $\begin{array}{l}\text {...con } \\
\text { mercaderías, } \\
\text { ropa, alimentos } \\
\text { de familiares, } \\
\text { vecinos u }\end{array}$ & No & 97,22 & 94,59 & 43,63 & 2,43 & 0,008 & 584 \\
\hline $\begin{array}{l}\text { Rama de } \\
\text { Actividad CAES } \\
\text { codificada } 1\end{array}$ & $\begin{array}{l}\text { Comercio y } \\
\text { esparcimi }\end{array}$ & 21,03 & 16,64 & 53,62 & 2,34 & 0,010 & 103 \\
\hline
\end{tabular}


Tabla 4. Descripción de asociaciones a la Clase Media-Dominante

CLASE: CLASE MEDIA DOMINANTE

(efectivos: 240 - porcentaje: 38.95)

\begin{tabular}{|c|c|c|c|c|c|c|c|}
\hline Variables & $\begin{array}{l}\text { modalidades } \\
\text { características }\end{array}$ & $\begin{array}{l}\% \text { de la } \\
\text { modalidad } \\
\text { en la } \\
\text { CLASE }\end{array}$ & $\begin{array}{l}\% \text { de la } \\
\text { modalidad } \\
\text { en la } \\
\text { muestra }\end{array}$ & $\begin{array}{l}\% \text { de la } \\
\text { CLASE } \\
\text { en la } \\
\text { modalidad }\end{array}$ & $\begin{array}{l}\text { Valor- } \\
\text { Test }\end{array}$ & Probabilidad & Peso \\
\hline $\begin{array}{l}\text { Nivel educativo } \\
\text { del Referente } \\
\text { del Hogar }\end{array}$ & Univ. Completa & 53,72 & 26,69 & 78,41 & 12,05 & 0,000 & 165 \\
\hline $\begin{array}{l}\text { Condición Socio } \\
\text { Ocupacional } \\
\text { del RH }\end{array}$ & As. Téc & 34,72 & 14,03 & 96,41 & 12,01 & 0,000 & 87 \\
\hline $\begin{array}{l}\text { Rama de } \\
\text { Actividad CAES } \\
\text { codificada } 1\end{array}$ & Enseñanza & 37,00 & 18,60 & 77,49 & 9,26 & 0,000 & 115 \\
\hline $\begin{array}{l}\text { Tecnología } \\
\text { ocupacional RH }\end{array}$ & $\begin{array}{l}\text { Op Sistemas y } \\
\text { Eq Inf }\end{array}$ & 29,11 & 14,21 & 79,80 & 8,31 & 0,000 & 88 \\
\hline $\begin{array}{l}\text { Calificación } \\
\text { ocupacional } \\
\text { del RH }\end{array}$ & Calif Técnica & 38,32 & 21,11 & 70,70 & 8,23 & 0,000 & 130 \\
\hline $\begin{array}{l}\text { Caracter } \\
\text { Ocupacional } \\
\text { del RH }\end{array}$ & C_Salud & 15,24 & 5,93 & 100,00 & 8,21 & 0,000 & 37 \\
\hline $\begin{array}{l}\text { Condición Socio } \\
\text { Ocupacional } \\
\text { del RH }\end{array}$ & As. Prof & 14,79 & 5,76 & 100,00 & 8,09 & 0,000 & 36 \\
\hline $\begin{array}{l}\text { Tamaño del } \\
\text { establecimiento } \\
\text { del RH_rec }\end{array}$ & Más de 40 & 48,48 & 29,48 & 64,07 & 8,05 & 0,000 & 182 \\
\hline $\begin{array}{l}\text { Grupo decílico } \\
\text { p47t SPAD }\end{array}$ & $\begin{array}{l}\text { ingresos muy } \\
\text { altos }\end{array}$ & 30,98 & 16,20 & 74,50 & 7,70 & 0,000 & 100 \\
\hline $\begin{array}{l}\text { Caracter } \\
\text { Ocupacional } \\
\text { del RH }\end{array}$ & $\begin{array}{l}\text { C_Gestión Adm/ } \\
\text { Jur }\end{array}$ & 26,80 & 13,52 & 77,21 & 7,51 & 0,000 & 83 \\
\hline $\begin{array}{l}\text { Grupo decílico } \\
\text { IPCF SPAD }\end{array}$ & $\begin{array}{l}\text { ingresos muy } \\
\text { altos }\end{array}$ & 23,36 & 11,11 & 81,92 & 7,50 & 0,000 & 69 \\
\hline $\begin{array}{l}\text { Cantidad de } \\
\text { miembros del H } \\
\text { SPAD }\end{array}$ & H Unipersonal & 27,55 & 14,08 & 76,19 & 7,46 & 0,000 & 87 \\
\hline
\end{tabular}




\begin{tabular}{|c|c|c|c|c|c|c|c|}
\hline \multicolumn{8}{|c|}{$\begin{array}{l}\text { CLASE: CLASE MEDIA DOMINANTE } \\
\text { (efectivos: } \mathbf{2 4 0} \text { - porcentaje: } \mathbf{3 8 . 9 5} \text { ) }\end{array}$} \\
\hline Variables & $\begin{array}{l}\text { modalidades } \\
\text { características }\end{array}$ & $\begin{array}{l}\% \text { de la } \\
\text { modalidad } \\
\text { en la } \\
\text { CLASE }\end{array}$ & $\begin{array}{l}\% \text { de la } \\
\text { modalidad } \\
\text { en la } \\
\text { muestra }\end{array}$ & $\begin{array}{l}\% \text { de la } \\
\text { CLASE } \\
\text { en la } \\
\text { modalidad }\end{array}$ & $\begin{array}{l}\text { Valor- } \\
\text { Test }\end{array}$ & Probabilidad & Peso \\
\hline $\begin{array}{l}\text { Grupo decílico } \\
\text { IPCF SPAD }\end{array}$ & $\begin{array}{l}\text { ingresos medios } \\
\text { alto }\end{array}$ & 49,13 & 31,52 & 60,72 & 7,44 & 0,000 & 194 \\
\hline $\begin{array}{l}\text { Caracter } \\
\text { Ocupacional } \\
\text { del RH }\end{array}$ & C_Educación & 12,41 & 4,83 & 100,00 & 7,29 & 0,000 & 30 \\
\hline $\begin{array}{l}\text { Situación } \\
\text { conyugal } \\
\text { reagrupada } \\
\text { SPAD }\end{array}$ & Soltero & 38,48 & 22,67 & 66,10 & 7,24 & 0,000 & 140 \\
\hline $\begin{array}{l}\text { Categoría de } \\
\text { actividad/ } \\
\text { inactividad del } \\
\text { RH }\end{array}$ & $\begin{array}{l}\text { Obrero } 0 \\
\text { empleado }\end{array}$ & 90,06 & 75,23 & 46,63 & 7,01 & 0,000 & 464 \\
\hline $\begin{array}{l}\text { Tipo de } \\
\text { Cobertura } \\
\text { Medica RH }\end{array}$ & $\begin{array}{l}\text { Obra social } \\
\text { (incluye }\end{array}$ & 82,91 & 66,58 & 48,51 & 6,95 & 0,000 & 411 \\
\hline $\begin{array}{l}\text { Ambito laboral } \\
\text { del RH }\end{array}$ & $\begin{array}{l}\text { Ocupación } \\
\text { Estatal }\end{array}$ & 25,86 & 14,15 & 71,18 & 6,50 & 0,000 & 87 \\
\hline $\begin{array}{l}\text { Regimen de } \\
\text { tenencia recod }\end{array}$ & Inquilino & 50,90 & 35,25 & 56,25 & 6,39 & 0,000 & 217 \\
\hline $\begin{array}{l}\text { Jerarquía } \\
\text { ocupacional } \\
\text { del RH }\end{array}$ & $\begin{array}{l}\text { Trabajador } \\
\text { asalariad }\end{array}$ & 84,40 & 71,04 & 46,28 & 6,01 & 0,000 & 438 \\
\hline $\begin{array}{l}\text {...de subsidio } \\
\text { o ayuda social } \\
\text { (en dinero) del } \\
\text { gobierno, igle }\end{array}$ & No & 97,92 & 89,20 & 42,76 & 6,00 & 0,000 & 550 \\
\hline $\begin{array}{l}\text { Calificación } \\
\text { ocupacional } \\
\text { del RH }\end{array}$ & $\begin{array}{l}\text { Calif. } \\
\text { Profesional }\end{array}$ & 21,65 & 11,78 & 71,57 & 5,84 & 0,000 & 73 \\
\hline
\end{tabular}




\begin{tabular}{|c|c|c|c|c|c|c|c|}
\hline \multicolumn{8}{|c|}{$\begin{array}{l}\text { CLASE: CLASE MEDIA DOMINANTE } \\
\text { (efectivos: } 240 \text { - porcentaje: } 38.95 \text { ) }\end{array}$} \\
\hline Variables & $\begin{array}{l}\text { modalidades } \\
\text { características }\end{array}$ & $\begin{array}{l}\% \text { de la } \\
\text { modalidad } \\
\text { en la } \\
\text { CLASE }\end{array}$ & $\begin{array}{l}\% \text { de la } \\
\text { modalidad } \\
\text { en la } \\
\text { muestra }\end{array}$ & $\begin{array}{l}\% \text { de la } \\
\text { CLASE } \\
\text { en la } \\
\text { modalidad }\end{array}$ & $\begin{array}{l}\text { Valor- } \\
\text { Test }\end{array}$ & Probabilidad & Peso \\
\hline $\begin{array}{l}\text { Cantidad de } \\
\text { miembros por } \\
\text { ambiente de } \\
\text { uso exclusivo } \\
\text { codificad }\end{array}$ & $\begin{array}{l}\text { Entre } 1 \text { a } 2 \\
\text { personas }\end{array}$ & 36,55 & 25,33 & 56,21 & 5,05 & 0,000 & 156 \\
\hline Sexo del RH & Mujer & 48,49 & 36,50 & 51,74 & 4,95 & 0,000 & 225 \\
\hline $\begin{array}{l}\text { Grupo decílico } \\
\text { de P21 del } \\
\text { AGLOMERADO }\end{array}$ & P21_10 Decil & 20,55 & 12,22 & 65,49 & 4,82 & 0,000 & 75 \\
\hline $\begin{array}{l}\text { Antigüedad } \\
\text { Laboral RH } \\
\text { Todos }\end{array}$ & Más de 5 años & 53,32 & 41,80 & 49,69 & 4,54 & 0,000 & 258 \\
\hline $\begin{array}{l}\text { Grupo decílico } \\
\text { de ITF del } \\
\text { AGLOMERADO }\end{array}$ & ITF $10^{\circ}$ decil & 19,76 & 12,03 & 64,01 & 4,44 & 0,000 & 74 \\
\hline $\begin{array}{l}\text { Nivel educativo } \\
\text { del Referente } \\
\text { del Hogar }\end{array}$ & Univ. Incompleta & 26,87 & 18,17 & 57,59 & 4,43 & 0,000 & 112 \\
\hline Edad del RH & R hasta 34 años & 40,26 & 30,34 & 51,69 & 4,24 & 0,000 & 187 \\
\hline $\begin{array}{l}\text { Tipo de } \\
\text { vivienda } R\end{array}$ & Departamento & 44,40 & 34,37 & 50,31 & 4,16 & 0,000 & 212 \\
\hline $\begin{array}{l}\text { Grupo decílico } \\
\text { p47t SPAD }\end{array}$ & $\begin{array}{l}\text { ingresos medios } \\
\text { alto }\end{array}$ & 49,25 & 39,86 & 48,13 & 3,67 & 0,000 & 246 \\
\hline $\begin{array}{l}\text { Grupo decílico } \\
\text { de P21 del } \\
\text { AGLOMERADO }\end{array}$ & P21_8 ${ }^{\circ}$ Decil & 15,33 & 9,78 & 61,01 & 3,62 & 0,000 & 60 \\
\hline $\begin{array}{l}\text { Grupo decílico } \\
\text { de ITF del } \\
\text { AGLOMERADO }\end{array}$ & ITF $9^{\circ}$ decil & 17,65 & 11,73 & 58,60 & 3,43 & 0,000 & 72 \\
\hline $\begin{array}{l}\text { Tamaño del } \\
\text { establecimiento } \\
\text { del } \text { RH_rec }\end{array}$ & De 6 a 40 & 28,50 & 21,23 & 52,28 & 3,31 & 0,000 & 131 \\
\hline $\begin{array}{l}\text { Condición Socio } \\
\text { Ocupacional } \\
\text { del RH }\end{array}$ & As. Jefe & 5,61 & 2,65 & 82,58 & 3,24 & 0,001 & 16 \\
\hline
\end{tabular}




\begin{tabular}{|c|c|c|c|c|c|c|c|}
\hline \multicolumn{8}{|c|}{$\begin{array}{l}\text { CLASE: CLASE MEDIA DOMINANTE } \\
\text { (efectivos: } 240 \text { - porcentaje: } 38.95 \text { ) }\end{array}$} \\
\hline Variables & $\begin{array}{l}\text { modalidades } \\
\text { características }\end{array}$ & $\begin{array}{l}\% \text { de la } \\
\text { modalidad } \\
\text { en la } \\
\text { CLASE }\end{array}$ & $\begin{array}{l}\% \text { de la } \\
\text { modalidad } \\
\text { en la } \\
\text { muestra }\end{array}$ & $\begin{array}{l}\% \text { de la } \\
\text { CLASE } \\
\text { en la } \\
\text { modalidad }\end{array}$ & $\begin{array}{l}\text { Valor- } \\
\text { Test }\end{array}$ & Probabilidad & Peso \\
\hline $\begin{array}{l}\text { Rama de } \\
\text { Actividad CAES } \\
\text { codificada } 1\end{array}$ & $\begin{array}{l}\text { Administración } \\
\text { públi }\end{array}$ & 11,02 & 6,73 & 63,81 & 3,12 & 0,001 & 41 \\
\hline $\begin{array}{l}\text { ¿Compran } \\
\text { en cuotas o } \\
\text { al fiado con } \\
\text { tarjeta de } \\
\text { crédito o libre }\end{array}$ & Sí & 68,89 & 61,63 & 43,54 & 3,02 & 0,001 & 380 \\
\hline $\begin{array}{l}\text { Jerarquía } \\
\text { ocupacional } \\
\text { del RH }\end{array}$ & Jefe & 5,61 & 2,76 & 79,29 & 2,94 & 0,002 & 17 \\
\hline $\begin{array}{l}\text {...de alguna } \\
\text { jubilación } 0 \\
\text { pensión? }\end{array}$ & No & 86,02 & 80,36 & 41,69 & 2,87 & 0,002 & 496 \\
\hline $\begin{array}{l}\text { Grupo decílico } \\
\text { de P21 del } \\
\text { AGLOMERADO }\end{array}$ & P21_9 ${ }^{\circ}$ Decil & 16,38 & 11,58 & 55,07 & 2,78 & 0,003 & 71 \\
\hline $\begin{array}{l}\text { Caracter } \\
\text { Ocupacional } \\
\text { del RH }\end{array}$ & C_Serv. Emp & 10,60 & 6,79 & 60,78 & 2,64 & 0,004 & 42 \\
\hline $\begin{array}{l}\text { Rama de } \\
\text { Actividad CAES } \\
\text { codificada } 1\end{array}$ & $\begin{array}{l}\text { Servicios } \\
\text { privados }\end{array}$ & 15,62 & 11,43 & 53,22 & 2,53 & 0,006 & 71 \\
\hline $\begin{array}{l}\text { Rama de } \\
\text { Actividad CAES } \\
\text { codificada } 1\end{array}$ & $\begin{array}{l}\text { Información y } \\
\text { comuni }\end{array}$ & 6,01 & 3,40 & 68,76 & 2,40 & 0,008 & 21 \\
\hline $\begin{array}{l}\text {...de cuotas } \\
\text { de alimentos } \\
\text { o ayuda (en } \\
\text { dinero) de } \\
\text { personas qu }\end{array}$ & Sí & 14,98 & 11,03 & 52,90 & 2,36 & 0,009 & 68 \\
\hline
\end{tabular}


Tabla 5. Tasa de participación según clase y edad. Gran Córdoba. 2003-2013

\begin{tabular}{|c|c|c|c|c|c|c|c|c|}
\hline & \multicolumn{2}{|c|}{$\begin{array}{l}\text { Clase } \\
\text { dominada }\end{array}$} & \multicolumn{2}{|c|}{$\begin{array}{l}\text { Clase media } \\
\text { dominada }\end{array}$} & \multicolumn{2}{|c|}{$\begin{array}{l}\text { Clase media } \\
\text { dominante }\end{array}$} & \multicolumn{2}{|c|}{$\begin{array}{l}\text { Clase } \\
\text { dominante }\end{array}$} \\
\hline & 2003 & 2013 & 2003 & 2013 & 2003 & 2013 & 2003 & 2013 \\
\hline Jóvenes (15-24 años) & $43 \%$ & $44 \%$ & $52 \%$ & $45 \%$ & $34 \%$ & $44 \%$ & $44 \%$ & $59 \%$ \\
\hline Adultos (25-64 años) & $65 \%$ & $72 \%$ & $76 \%$ & $75 \%$ & $84 \%$ & $92 \%$ & $80 \%$ & $83 \%$ \\
\hline
\end{tabular}

Tabla 6. Categoría de inactividad de jóvenes según clase social. Gran Córdoba. 2003-2013

\begin{tabular}{|c|c|c|c|c|c|c|c|c|}
\hline & \multicolumn{2}{|c|}{ Clase dominada } & \multicolumn{2}{|c|}{$\begin{array}{l}\text { Clase media } \\
\text { dominada }\end{array}$} & \multicolumn{2}{|c|}{$\begin{array}{l}\text { Clase media } \\
\text { dominante }\end{array}$} & \multicolumn{2}{|c|}{ Clase dominante } \\
\hline & 2003 & 2013 & 2003 & 2013 & 2003 & 2013 & 2003 & 2013 \\
\hline Estudiante & $80,3 \%$ & $65,3 \%$ & $68,2 \%$ & $63,5 \%$ & $93,4 \%$ & $95,0 \%$ & $90,7 \%$ & $85,7 \%$ \\
\hline Ama de casa & $9,2 \%$ & $16,3 \%$ & $13,6 \%$ & $23,0 \%$ & $5,3 \%$ & $5,0 \%$ & $1,9 \%$ & $0,0 \%$ \\
\hline Otros & $11 \%$ & $18 \%$ & $18 \%$ & $14 \%$ & $1 \%$ & $0 \%$ & $7 \%$ & $14 \%$ \\
\hline
\end{tabular}

Tabla 7. Desempleo según clase social y edad. Gran Córdoba. 2003-2013

\begin{tabular}{|c|c|c|c|c|c|c|c|c|}
\hline & \multicolumn{2}{|c|}{ Clase dominada } & \multicolumn{2}{|c|}{$\begin{array}{l}\text { Clase media } \\
\text { dominada }\end{array}$} & \multicolumn{2}{|c|}{$\begin{array}{l}\text { Clase media } \\
\text { dominante }\end{array}$} & \multicolumn{2}{|c|}{$\begin{array}{l}\text { Clase } \\
\text { dominante }\end{array}$} \\
\hline & 2003 & 2013 & 2003 & 2013 & 2003 & 2013 & 2003 & 2013 \\
\hline Jóvenes (15-24 años) & $31,0 \%$ & $23,7 \%$ & $29,1 \%$ & $24,0 \%$ & $32,5 \%$ & $25,6 \%$ & $12,5 \%$ & $0,0 \%$ \\
\hline Adultos (25-64 años) & $19,5 \%$ & $13,7 \%$ & $12,4 \%$ & $8,4 \%$ & $7,7 \%$ & $3,5 \%$ & $1,4 \%$ & $1,7 \%$ \\
\hline
\end{tabular}

Tabla 8. Subocupados demandantes según clase social y edad. Gran Córdoba. 2003-2013

\begin{tabular}{|c|c|c|c|c|c|c|c|c|c|c|}
\hline & \multicolumn{2}{|c|}{ Clase dominada } & \multicolumn{2}{|c|}{$\begin{array}{l}\text { Clase media } \\
\text { dominada }\end{array}$} & \multicolumn{2}{|c|}{$\begin{array}{l}\text { Clase media } \\
\text { dominante }\end{array}$} & \multicolumn{2}{|c|}{$\begin{array}{l}\text { Clase } \\
\text { dominante }\end{array}$} & \multicolumn{2}{|l|}{ Total } \\
\hline & 2003 & 2013 & 2003 & 2013 & 2003 & 2013 & 2003 & 2013 & 2003 & 2013 \\
\hline $\begin{array}{l}\text { Jóvenes } \\
\text { (15-24 } \\
\text { años) }\end{array}$ & $12,1 \%$ & $28,9 \%$ & $12,0 \%$ & $8,0 \%$ & $5,0 \%$ & $4,7 \%$ & & & $10,0 \%$ & $10,6 \%$ \\
\hline $\begin{array}{l}\text { Adultos } \\
\text { (25-64 } \\
\text { años) }\end{array}$ & $10,9 \%$ & $15,7 \%$ & $14,8 \%$ & $6,9 \%$ & $5,7 \%$ & $4,7 \%$ & $2,8 \%$ & $1,7 \%$ & $10,4 \%$ & $6,8 \%$ \\
\hline
\end{tabular}


Tabla 9. Jerarquía laboral de jóvenes ocupados según clase social. Gran Córdoba. 2003-2013.

\begin{tabular}{|c|c|c|c|c|c|c|c|c|}
\hline & \multicolumn{2}{|c|}{ Clase dominada } & \multicolumn{2}{|c|}{$\begin{array}{l}\text { Clase media } \\
\text { dominada }\end{array}$} & \multicolumn{2}{|c|}{$\begin{array}{l}\text { Clase media } \\
\text { dominante }\end{array}$} & \multicolumn{2}{|c|}{$\begin{array}{l}\text { Clase } \\
\text { dominante }\end{array}$} \\
\hline & 2003 & 2013 & 2003 & 2013 & 2003 & 2013 & 2003 & 2013 \\
\hline Cuenta Propia & $7,5 \%$ & $24,1 \%$ & $13,3 \%$ & $10,5 \%$ & $7,4 \%$ & $6,3 \%$ & $0,0 \%$ & $10,0 \%$ \\
\hline Trabajador asalariado & $92,5 \%$ & $75,9 \%$ & $85,5 \%$ & $89,5 \%$ & $92,6 \%$ & $90,6 \%$ & $71,4 \%$ & $80,0 \%$ \\
\hline
\end{tabular}

Tabla 10. Percepción de descuentos por obra social de jóvenes ocupados según clase social. Gran Córdoba. 2003-2013.

\begin{tabular}{|c|c|c|c|c|c|c|c|c|}
\hline & \multicolumn{2}{|c|}{ Clase dominada } & \multicolumn{2}{|c|}{$\begin{array}{l}\text { Clase media } \\
\text { dominada }\end{array}$} & \multicolumn{2}{|c|}{$\begin{array}{l}\text { Clase media } \\
\text { dominante }\end{array}$} & \multicolumn{2}{|c|}{ Clase dominante } \\
\hline & 2003 & 2013 & 2003 & 2013 & 2003 & 2013 & 2003 & 2013 \\
\hline Sí & $17 \%$ & $35 \%$ & $17 \%$ & $39 \%$ & $57 \%$ & $66 \%$ & $22 \%$ & $25 \%$ \\
\hline No & $83 \%$ & $65 \%$ & $83 \%$ & $61 \%$ & $43 \%$ & $34 \%$ & $78 \%$ & $75 \%$ \\
\hline
\end{tabular}

Tabla 11. Jóvenes sin ningún tipo de cobertura médica según clase social. Gran Córdoba. 2003-2013.

\begin{tabular}{l|lll:l}
\hline & $\begin{array}{l}\text { Clase } \\
\text { dominada }\end{array}$ & $\begin{array}{l}\text { Clase media } \\
\text { dominada }\end{array}$ & $\begin{array}{l}\text { Clase media } \\
\text { dominante }\end{array}$ & $\begin{array}{l}\text { Clase } \\
\text { dominante }\end{array}$ \\
2003 & $57,5 \%$ & $76,7 \%$ & $14,7 \%$ & $27,8 \%$ \\
2013 & $52,9 \%$ & $45,8 \%$ & $6,2 \%$ & $41,2 \%$ \\
\hline
\end{tabular}

Tabla 12. Relación entre la mediana de ingresos laborales individuales por clase social y la mediana de ingreso laboral para jóvenes y referentes de hogar. Gran Córdoba. 2003-2013.

\begin{tabular}{|c|c|c|c|c|}
\hline & \multicolumn{2}{|c|}{ Referentes de hogar } & \multicolumn{2}{|c|}{ Jóvenes (15-24 años) } \\
\hline & 2003 & 2013 & 2003 & 2013 \\
\hline Clase dominada & 0,14 & 0,35 & 0,94 & 0,80 \\
\hline Clase media-dominada & 0,81 & 0,75 & 1,00 & 1,00 \\
\hline Clase media-dominante & 1,89 & 1,50 & 2,25 & 1,46 \\
\hline Clase dominante & 2,68 & 1,75 & 1,09 & 0,80 \\
\hline
\end{tabular}


